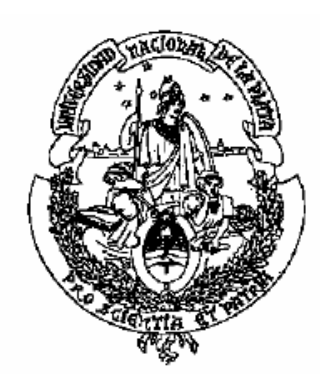

UNIVERSIDAD NACIONAL DE LA PLATA

FACULTAD DE CIENCIAS EXACTAS

DEPARTAMENTO DE QUIMICA

Trabajo de Tesis Doctoral

\title{
ALUMINOSILICATOS NATURALES Y MODIFICADOS COMO ADSORBENTES PARA LA ELIMINACION DE CONTAMINANTES AMBIENTALES
}

María José González

Director Dra. Irma Lía Botto

Codirector Dr. Isidoro Bernardo Schalamuk 
El presente trabajo para optar al grado de Doctor de la Facultad de Ciencias Exactas, de la Universidad Nacional de La Plata (UNLP), fue realizado en el "Centro de Química Inorgánica" y en el "Instituto de Recursos Minerales" (CEQUINOR e INREMI), Departamento de Química, Facultad de Ciencias Exactas, bajo la dirección de la Dra. Irma Lía Botto y la Codirección del Dr. Isidoro Bernardo Schalamuk. 
Este trabajo de Tesis fue realizado con el apoyo de:

\author{
- ANPCyT. PICTs 2494 y 2186 \\ - Comisión de Investigaciones Científicas de la Provincia de Buenos Aires \\ - Universidad Nacional de La Plata
}


A Germán, Lautaro y Salvador por su apoyo incondicional.

A mis padres $y$ hermanos por su confianza. 


\section{AGRADECIMIENTOS}

Este trabajo de Tesis presenta los resultados de un largo proceso de investigación que se inició varios años atrás. La realización de esta tarea a lo largo de estos años no hubiera sido posible sin el apoyo y la colaboración de muchas personas e instituciones que directa o indirectamente han aportado al desarrollo de la misma. En estas breves palabras espero resumir mi profundo agradecimiento a todos los que hicieron posible que diera este gran paso.

En primer lugar, deseo expresar mi sincero agradecimiento a los Dres. Prof. Lía Botto y Abel Schalamuk, no solo por los aportes que han realizado para mi formación profesional sino mucho más importante, por posibilitar mi crecimiento personal. A ambos, les agradezco la confianza que han depositado en mí al incluirme en su grupo interdisciplinario de investigación. Asimismo, les agradezco el haberme dirigido en la realización de este trabajo de Tesis, con infinita paciencia y dedicación, que muchas veces fue más allá de sus deberes. Les agradezco profundamente el aliento que me dieron para que siga mis convicciones, orientándome durante el desarrollo de esta investigación. Sus sugerencias y correcciones fueron un aporte indispensable para la culminación de este trabajo.

También, debo agradecer al Dr. Horacio Thomas y a su equipo de colaboradores de la PlaPiMu, especialmente a Toto y Mario, por su valiosa colaboración en la realización de los ensayos a nivel planta piloto.

Asimismo, agradezco a los Dres. Graciela Giaccio y Raúl Zerbino del LEMIT, por su aporte en los ensayos mecánicos, gracias por su predisposición y consejos, los que han sido de gran importancia en el desarrollo del capítulo 10 de este trabajo.

No debo olvidar dar las gracias a mis compañeros y amigos del INREMI, especialmente a Mario, Cecilia y Nelson, que junto con Abel me acompañaron y soportaron mi ayuno en el viaje de campo. También les agradezco a Raúl de Barrio, Florencia y Joaquín por la bibliografía que me facilitaron. Le agradezco particularmente a mi amiga Adriana por su infinita paciencia para la realización de los dibujos y gráficos, gracias por interpretar siempre tan bien lo que necesitaba. Asimismo, la agradezco a Marcela por su gran aporte a nivel administrativo. A mis amigas y compañeras de trabajo Marcela, Mabel, Ma. José y Ceci por escucharme a lo largo de todos estos años, sin entender exactamente todo, pero apoyándome siempre.

También tengo un agradecimiento especial para mis compañeros del equipo de investigación del CEQUINOR, en particular a María Elena y Enzo, quienes siempre han estado a mi lado y me han incentivado a no bajar los brazos. No quiero dejar de dar las gracias al Ing. Edgardo Soto, "Toto", por sus medidas BET y por haber encontrado en él una excelente persona y compañero de trabajo.

También debo agradecer a la Dra. Delia Gazzoli, de la Università di Roma "La Sapienza", Italia, cuyo aporte fue de suma importancia para la realización de esta Tesis.

No quiero dejar de agradecerles también, a mis compañeros de la cátedra de Introducción a la Química correlación para Ciencias Naturales, por la paciencia y el afecto que me brindaron en todos estos años. Especialmente a los JTP, Enzo, Cari, Andrea y Raúl, gracias por su comprensión, apoyo y compañerismo.

También es fundamental agradecer a las instituciones que financiaron el desarrollo de esta investigación, sin cuyo aporte hubiera sido imposible la realización de este trabajo, a la 
ANPCyT proyectos PICTs 2494 y 2186, a la Comisión de Investigaciones Científicas de la $P B A$, a la UNLP y a los Institutos CEQUINOR e INREMI.

Finalmente, un agradecimiento especial lo debo dedicar a mis seres queridos. A lo largo de estos años, a la par del desarrollo de esta investigación fue transcurriendo mi vida. La concreción de este trabajo no hubiera sido posible sin el apoyo incondicional de mi esposo Germán y mis hijos, Lautaro y Salvador, este último nació y creció junto con la tesis. Los tres siempre han estado a mi lado, guiándome y sobretodo soportándome en los momentos más difíciles, cuando algo no me cerraba y veía todo negro. Su aliento durante todos estos años me ha permitido tener la fuerza y motivación suficiente para seguir esforzándome y llegar a completar esta meta.

Por último, también debo agradecer a mis padres, Isabel y Edgardo, a mis hermanos, Marita, Cintia y Esteban, y a mi abuela Luchi, quienes desde la distancia siempre estuvieron a mi lado y me impulsaron para que concluyera mis estudios universitarios, muchas veces confiando en mi más de lo que yo lo hacía.

A todos los que han estado de distintas formas a mi lado en estos años de trabajo y han hecho posible la culminación de este trabajo 
Si el hombre es un gesto

El agua es la historia

Si el hombre es un pueblo

El agua es el mundo

Si el hombre está vivo

El agua es la vida

Joan Manuel Serrat - El hombre y el agua 


\section{ÍNDICE}

\section{CAPITULO 1}

Introducción y objetivos

CAPÍTULO 2

2.1. Problemática de las aguas subterráneas conteniendo As 5

2.2. Distribución de acuíferos contaminados a nivel mundial 6

2.3. Situación en el país 9

2.4. Efectos nocivos del As $\quad 15$

2.5. Legislación 18

2.6. Reseña de las técnicas de remoción de As comúnmente empleadas 20

CAPÍTULO 3

3.1. Algunos aspectos de la química del arsénico 26

3.2. Algunas consideraciones hidrogeológicas $\quad 29$

3.3. Afinidad del As hacia los sistemas oxídicos conteniendo metales de 32 moderado potencial iónico

3.4. La química de los óxidos de hierro 36

\section{CAPÍTULO 4}

4.1. Características generales de los minerales de arcilla 52

4.2. Arcillas como adsorbentes naturales $\quad 57$

4.3. Especies minerales empleadas en la eliminación de As 60

4.4. Aspectos geológicos de minerales de depósitos nacionales 65 seleccionados para su eventual uso como adsorbentes en el tratamiento de remoción de As

4.4.1. Arcillas ferruginosas de la provincia de Buenos Aires 68

4.4.2. Yacimientos Oolíticos de Hierro. Provincias de Salta y Jujuy 72

4.4.3. Especies minerales con bajo contenido de hierro 75

CAPITULO 5: Parte experimental

5.1. Técnicas fisicoquímicas de análisis 81

5.1.1. Análisis químico por ICP-AES e ICP-MS 82

5.1.2. Difracción por rayos $X \quad 84$

5.1.3. Microscopía electrónica (SEM-EDS) 86

5.1.4. Parámetros texturales y medidas de superficie mediante BET 88

5.1.5. Espectroscopia de Infrarrojo 90

5.1.6. Espectroscopia Raman 91

5.1.7. Análisis térmicos $\quad 94$

5.1.7.1. Análisis termogravimétrico (TGA) 94

5.1.7.2. Reducción a temperatura programada (TPR) 95

5.1.8. Análisis granulométrico 96

5.2. Muestras de aguas empleadas en los ensayos de adsorción $\quad 97$

5.3. Ensayos de determinación de As en muestras líquidas 98

5.3.1. Método colorimétrico del dietilditiocarbamato de plata (SDDC) 99 
5.3.2. Medidas por Absorción atómica-generación de hidruros (AAS-HG)

5.3.3. Medidas por Absorción atómica con horno de grafito (AAS-GF) 102

5.3.4. Método colorimétrico semicuantitativo con tiras de ensayo 103

5.4. Otras determinaciones en muestras líquidas $\quad 105$

5.5. Ensayos de laboratorio de modificación química de arcillas 106

CAPITULO 6: Arcillas ferruginosas de la PBA como adsorbentes del As

$\begin{array}{ll}\text { 6.1. Caracterización fisicoquímica } & 107\end{array}$

6.1.1. Caracterización mediante análisis químico (ICP AES-MS), por DRX y 108 SEM-EDS

6.1.2. Aplicación de otras técnicas de caracterización fisicoquímica 128

6.2. Ensayos de adsorción a nivel laboratorio $\quad 134$

6.2.1. Pruebas preliminares $\quad 135$

6.2.2. Optimización de condiciones de tratamiento 136

$\begin{array}{ll}\text { 6.2.2.1. Experimentos realizados } & 136\end{array}$

$\begin{array}{ll}\text { 6.2.2.2 Resultados y conclusiones del ajuste } & 140\end{array}$

6.2.3. Isoterma de adsorción 143

6.2.4. Estudio de la etapa de coagulación 148

$\begin{array}{ll}\text { 6.2.5. Efectividad del adsorbente } & 157\end{array}$

6.2.6 Estudio complementario mediante espectroscopia Raman "microprobe" 159

para visualizar la presencia del contaminante en la arcilla ferruginosa

6.3. Escalado a nivel planta piloto

162

CAPITULO 7: Potencialidad de otros geomateriales naturales $y$ químicamente modificados en el proceso de adsorción de arsénico

7.1. Potencialidad en el proceso de adsorción de As de geomateriales químicamente modificados

7.1.1. Algunos aspectos relacionados a la adsorción de As con minerales activados

7.1.2. Activación de las muestras

7.1.3. Caracterización de las muestras originales y activadas químicamente $\quad 170$

7.1.4. Evaluación de la remoción de As a nivel laboratorio 183

7.1.5. Estudio complementario para visualizar la presencia del contaminante 193 en el adsorbente

7.2. Potencialidad de las muestras del yacimiento Unchimé en el proceso de 196 adsorción de As

7.2.1. Caracterización fisicoquímica de las muestras 196

7.2.2. Evaluación de la remoción de As a nivel laboratorio 201

CAPITULO 8: Activación de las arcillas ferruginosas

8.1. Activación de la muestra de arcilla ferruginosa 206

8.2. Caracterización de las muestras activadas $\quad 207$

8.3. Evaluación de la remoción de As a nivel laboratorio 211

CAPITULO 9: Preparación de coagulantes a partir de especies minerales

9.1. Algunas consideraciones sobre el empleo de coagulantes 214

$\begin{array}{ll}\text { 9.2. Obtención de coagulantes de } \mathrm{Al}(\mathrm{III}) \text { a partir de caolinita } & 219\end{array}$ 
9.2.1. Preparación del coagulante $\quad 219$

$\begin{array}{ll}\text { 9.2.2 Determinaciones y resultados } & 221\end{array}$

9.3. Obtención de coagulantes de Fe(III) a partir de arcilla ferruginosa 224

9.3.1. Preparación del coagulante 224

9.3.2. Resultados obtenidos en la preparación del coagulante 226

$\begin{array}{ll}\text { 9.3.3. Ensayos de coagulación/sedimentación } & 228\end{array}$

9.4. Activación del residuo del tratamiento extractivo de la metacaolinita con 231 sales de $\mathrm{Fe}$ (III)

9.4.1. Activación del sólido $\quad 231$

9.4.2. Caracterización de la muestra activada 231

9.4.3. Evaluación de la remoción de As a nivel laboratorio 234

CAPITULO 10: Inmovilización del residuo del proceso de remoción de As. Tratamiento de la arcilla agotada

10.1. Generalidades sobre la disposición de residuos generados en el 236 tratamiento de aguas conteniendo As

10.1.1. Algunos aspectos del proceso de inmovilización por cementación 240

10.1.2. Algunos aspectos de la lixiviación de los residuos 241

10.1.3. Características físicas de las piezas elaboradas $\quad 250$

10.2. Experimental 253

10.2.1. Preparación de las piezas 253

10.2.1.1. Materiales empleados en la preparación $\quad 254$

10.2.1.2. Mezclas elaboradas $\quad 254$

10.2.1.3. Elaboración de las piezas 255

10.2.2. Evaluación mecánica de las piezas 256

10.2.2.1. Exposición a temperatura 256

$\begin{array}{ll}\text { 10.2.2.2. Ensayos mecánicos } & 257\end{array}$

10.2.3. Caracterización fisicoquímica 257

10.2.4. Ensayos de lixiviación $\quad 257$

10.2.4.1. Ensayos preliminares para determinar la estabilidad de hormigones 257

en condiciones extremas (ácidos fuertes)

10.2.4.2. Test de lixiviación EPA 1311 (TCLP) 258

10.2.4.3. Test monolítico NEN $7345 \quad 259$

10.3. Resultados y discusión $\quad 259$

10.3.1. Caracterización fisicoquímica 259

10.3.2. Propiedades físicas y mecánicas 263

$\begin{array}{ll}\text { 10.3.3 Ensayos de lixiviación } & 267\end{array}$

CAPITULO 11: Conclusiones generales 273

REFERENCIAS BIBLIOGRÁFICAS $\quad 280$

ANEXO 12296

$\begin{array}{ll}\text { ANEXO 2 } & 298\end{array}$ 


\section{CAPITULO 1}

\section{Introducción y objetivos}

Este trabajo de Tesis se ha realizado en el marco de una investigación interdisciplinaria, dirigida al aprovechamiento de algunos de nuestros vastos recursos minerales para el desarrollo de tecnologías alternativas para el tratamiento de aguas subterráneas con contenidos anómalos de arsénico.

El trabajo se ha desarrollado en dos Centros de Investigación de la UNLP, el Centro de Química Inorgánica (CEQUINOR-CCT La Plata, FCE) y el Instituto de Recursos Minerales (INREMI, CICPBA-FCNyM), bajo la Dirección de la Dra. Irma Lía Botto y la Codirección del Dr. Isidoro Bernardo Schalamuk. La actividad fue realizada a través de Proyectos de Investigación ANPCyT (PICTs 2494 y 2186), CICPBA y UNLP.

El objetivo específico del trabajo está dirigido a la utilización de aluminosilicatos naturales, de amplia distribución en nuestro país, para su empleo, en su forma natural y/o modificada, en procesos de importancia en el control del medio ambiente, en particular los relacionados al tratamiento de aguas subterráneas conteniendo arsénico.

Bajo la premisa de desarrollar un procedimiento que evite el riesgo sociosanitario asociado al consumo de agua con contenidos anómalos de As en zonas sin acceso al agua de red, se aborda en particular la problemática planteada en algunas localidades del interior de la provincia de Buenos Aires, evaluando materiales naturales de amplios recursos en las Sierras Septentrionales que puedan ser empleados en una estrategia tecnológica de fácil implementación y simplicidad operativa.

La abundancia en el país de minerales del grupo de los aluminosilicatos, la versatilidad química y estructural de dichas especies así como las innovativas estrategias de tratamiento de algunas de ellas, ameritan la exploración y profundización del tema, tanto en lo referente a la geología, tipología, mineralogía, composición química, propiedades de superficie, estructurales y espectroscópicas, como en su funcionalidad en la adsorción y eliminación de contaminantes. El conocimiento de estos aspectos no sólo facilita el proceso de transformación, que se desarrolla en el campo de la química inorgánica experimental sino que es de utilidad para su aplicación, resultando así de interés no sólo científico sino también tecnológico.

Dentro del grupo de los aluminosilicatos cabe destacar, en primer lugar, a los minerales de arcilla, cuyos depósitos se encuentran ampliamente distribuidos en el 
ámbito de la provincia de Buenos Aires. En general, la geoquímica de los depósitos cuya mineralogía resulta claramente asociada a una amplia gama de eventos geológicos, permite identificar los procesos naturales que han sucedido a través de alguna reacción que ha dado lugar a la formación de especies de arcilla de diferente estructura laminar. Dichos procesos han representado también una fuente de fases oxídicas de hierro que, segregadas y precipitadas "in situ", permiten la identificación de arcillas ferruginosas o ricas en hierro. Las características de depositación, morfología, composición, textura, tamaño de partícula de estas últimas determinan su potencialidad, sin modificación ulterior, como materiales adsorbentes de contaminantes inorgánicos aniónicos, como por ejemplo el arseniato (V), del que se conoce claramente su afinidad por el hierro. Estos hechos no solo representan una alternativa de solución a graves problemas ambientales sino que también incrementan el valor agregado de especies cuyo aprovechamiento queda, de otro modo, limitado a la fabricación de materiales cerámicos y de construcción.

Por otra parte, materiales laminares y tridimensionales con bajo contenido de hierro (inferior al $5 \%$ como $\mathrm{Fe}_{2} \mathrm{O}_{3}$ ) pueden ser objeto de modificaciones químicas que permitan transformarlos en aptos para el proceso de adsorción de As.

El trabajo se inicia en los Capítulos 2 y 3 haciendo referencia a la problemática de la contaminación de aguas subterráneas con As y a la química del elemento. Especialmente se hace referencia a la distribución de acuíferos contaminados a nivel mundial y a nivel nacional, prestando especial atención a la situación de la provincia de Buenos Aires. Asimismo, se exponen los efectos nocivos del As en la salud, se resumen los aspectos relacionados a la legislación vigente y se presenta una breve reseña de las técnicas de remoción de As comúnmente empleadas. Finalmente, se hace mención a la afinidad del As hacia los sistemas oxídicos conteniendo hierro.

En el Capítulo 4 se hace mención a las propiedades generales, particularmente estructurales de los minerales de arcilla, que facilitan su empleo en procesos de adsorción de importancia ambiental. Asimismo, se exponen los principales aspectos geológicos de los minerales procedentes de depósitos nacionales que fueran seleccionados para su eventual uso como adsorbentes en el tratamiento de remoción de As, los que han sido divididos en tres grupos según su procedencia, características estructurales y composicionales:

_ Arcillas ferruginosas de las Sierras Septentrionales de la provincia de Buenos Aires.

_ Yacimientos oolíticos de hierro de Unchimé provincia de Salta. 
_ Especies minerales con bajo contenido de hierro posibles de ser modificadas químicamente para transformarlas en aptas para el proceso de adsorción de As.

En el Capítulo 5 se describen detalladamente los aspectos metodológicos llevados a cabo en la investigación. En primer lugar se hace referencia a las técnicas fisicoquímicas de análisis empleadas en la caracterización de los materiales seleccionados: análisis químico por ICP-AES e ICP-MS, difracción por Rayos X (DRX), microscopía electrónica SEM-EDS, medidas de superficie BET, espectroscopía vibracional (FTIR y Raman), análisis termogravimétrico (DTG-TG), reducción a temperatura programada (TPR). En segundo lugar se presenta el procedimiento seguido en el laboratorio para la preparación de las muestras de agua empleadas en los ensayos de adsorción, así como las técnicas empleadas para evaluar la calidad fisicoquímica de las mismas. Asimismo, se detallan los métodos empleados en la determinación de As en muestras líquidas y el procedimiento seguido en la determinación de otros parámetros que fueron analizados para evaluar la calidad del agua después del tratamiento de adsorción.

En el Capítulo 6 se analiza el empleo de las arcillas ferruginosas de la provincia de Buenos Aires como adsorbentes del As. En primer término se presentan en forma detallada los resultados de la caracterización fisicoquímica de todas las muestras seleccionadas. En particular los datos mineralógicos y químicos, permitieron la selección de algunos minerales de arcilla, que, en una etapa posterior, fueron evaluados en el laboratorio como adsorbentes. Se optimizaron a nivel laboratorio y banco las principales variables que afectan el proceso de adsorción. Estos parámetros fueron tenidos en cuenta para el escalado a nivel de planta piloto, que fue realizado en la Planta Piloto Multipropósito (PLAPIMU, CICPBA).

Posteriormente, tal como se expone en el Capítulo 7, se procedió a la modificación química de las especie minerales con bajos contenidos de hierro para activar su capacidad adsorbente. Esta etapa comprendió la obtención de geomateriales activados mediante el empleo de soluciones de sales de Fe(III), la caracterización de las muestras originales y activadas y su posterior utilización en el tratamiento de remoción de As optimizado para las arcillas ferruginosas. Finalmente, en el mismo capítulo, se analizó el empleo de otros minerales ricos en hierro (yacimiento Unchimé, Salta).

En el Capítulo 8 se evaluó el efecto de la modificación química de la arcilla ferruginosa con sales de hierro, a fin de analizar la posibilidad de prolongación de la vida útil del adsorbente. El trabajo comprendió la activación de la arcilla ferruginosa, la 
caracterización fisicoquímica de las muestras activadas y la evaluación de las mismas en el procedimiento de remoción de As, empleando las variables optimizadas para la arcilla sin activar.

Considerando que en la tecnología de remoción de As propuesta, se requiere de un coagulante para acelerar el proceso de sedimentación y asegurar la calidad del agua a partir de la obtención de valores adecuados de turbidez, en el Capítulo 9 se analizó la posibilidad de obtención de coagulantes a partir de materias primas de bajo costo, accesibles y que estructuralmente permitan la extracción de Al y/o Fe en sus formas activas.

Para lograr que el tratamiento propuesto resulte sustentable y compatible con el medio ambiente, en el Capítulo 10 se estudian las posibilidades de inmovilización del As procedente de la adsorción del contaminante en el material de arcilla, evaluando la utilización de la arcilla ferruginosa empleada en el tratamiento de As para la fabricación de morteros y hormigones. Se analiza el proceso desde el punto de vista del impacto ambiental (minimizando o eliminando los efectos de lixiviación) y desde su aplicación en el área de la construcción en las zonas de instalación de los equipos de tratamiento.

Finalmente, en el Capítulo 11 se resumen las conclusiones obtenidas del estudio. 


\section{CAPÍTULO 2}

\subsection{Problemática de las aguas subterráneas conteniendo As}

En una parte considerable del Planeta el agua subterránea es la única fuente del vital elemento revistiendo así gran importancia para el desarrollo humano. Sin embargo, la presencia de diferentes contaminantes impacta negativamente en la salud y en el crecimiento de vastas regiones. En este contexto, la contaminación natural con los elementos arsénico y flúor, es uno de los principales problemas del agua subterránea de la región central de la República Argentina, por lo que es indispensable su tratamiento antes de destinarla a consumo humano.

El arsénico desde la antigüedad es reconocido como uno de los venenos tradicionales, sin embargo, no es una sustancia extraña, sino que es un elemento natural que se encuentra ampliamente distribuido en la corteza terrestre (abundancia relativa 1,5 a $2 \mathrm{mg} \mathrm{kg}^{-1}$ ). Por otra parte, a bajos niveles de concentración es altamente tóxico (Jones, 2007). Se combina con oxígeno, cloro y azufre para formar compuestos inorgánicos de arsénico dependiendo de las condiciones del medio. En su mayor estado de oxidación se encuentra como oxoanión debido a su elevado potencial iónico, en tanto que en un medio de características reductoras es común formando parte de sulfuros y sulfosales. En animales y en plantas se combina con carbono e hidrógeno para formar compuestos orgánicos. Los compuestos de As se encuentran preferentemente en minerales (sulfuros $u$ óxidos), y en cantidades traza en tierra, agua, aire, así como en plantas y tejidos animales.

El As puede llegar al agua tanto por vía natural como por vía antropogénica (Fernández Turiel et al., 2005). Por vía natural puede ingresar a través del ascenso de fluidos magmáticos e hidrotermales, desorción y disolución de minerales conteniendo As durante la meteorización, etc. La vía antropogénica se encuentra representada por la actividad minera, procesos metalúrgicos, particularmente asociados a la obtención de cobre así como por el uso de plaguicidas y preservantes de la madera (Fernández Turiel et al., 2005; Jones, 2007).

El arsénico es una de las 10 sustancias químicas que la Organización Mundial de la Salud (OMS) considera más preocupantes para la salud pública. Excepto en las personas expuestas al arsénico por motivos laborales, la vía de exposición más importante es la vía oral, por el consumo de agua y alimentos. La mayor amenaza para la salud reside en la necesidad de utilizar este tipo de agua para bebida, preparación de alimentos, actividades agropecuarias (riego de cultivos, actividad ganadera y producción de animales de granja, etc.). 
El impacto negativo en la sociedad, se revela a través del deterioro en la salud de los pobladores de regiones afectadas. En nuestro país, el Hidroarsenicismo Crónico Regional Endémico, conocido como HACRE, se define por el Ministerio de Salud de la Nación (CONAPRIS, 2006), como la enfermedad producida por el consumo de arsénico a través del agua y los alimentos. Se caracteriza por presentar lesiones en la piel y alteraciones sistémicas cancerosas y no cancerosas luego de un periodo variable de exposición a concentraciones mayores a las permitidas en agua de consumo diario. La presencia de As en el agua tiene también importantes consecuencias en el desarrollo socioeconómico y el crecimiento de las regiones afectadas.

Por lo expuesto, el problema del agua con contenidos anómalos de As se considera de alta prioridad y en tal sentido, mundialmente se desarrollan y evalúan distintas opciones para disminuir los riesgos asociados al consumo de agua conteniendo As. A continuación se mencionan algunas de las estrategias dirigidas a la mitigación del problema:

- Búsqueda de alternativas de sustitución del agua subterránea con contenidos altos de As, por ejemplo proveer agua de otras fuentes (ríos, lagos).

- En caso de existencia de perforaciones con concentraciones bajas del elemento, proceder a la mezcla de agua de alto contenido con la de bajo contenido para obtener valores más adecuados.

- En aquellas localidades donde las aguas subterráneas constituyan la única fuente del vital compuesto se requiere la instalación de un sistema seguro de abastecimiento de agua que haga uso de algún método de remoción de As tendiente a disminuir la exposición prolongada de la población.

Además, es fundamental informar a la población respecto a los riesgos de beber agua sin tratamiento y promover la participación de la comunidad. Como se expondrá brevemente en el punto 2.6, existen distintas técnicas y metodologías para la remoción de arsénico del agua, sin embargo, la tecnología apropiada será la que la comunidad entienda, acepte y esté dispuesta a mantener en el tiempo.

\subsection{Distribución de acuíferos contaminados a nivel mundial}

La presencia de arsénico en el agua subterránea puede considerarse en la actualidad como una problemática mundial. La presencia de As en el agua subterránea se ha detectado en diversas áreas del planeta. Las áreas más afectadas representadas en la Figura 2.1 se encuentran en Argentina, Bangladesh, Chile, China, Hungría, India, México, Rumania, Vietnam y EEUU (Smedley and Kinninburgh, 2002). 
En el mapa se marcan las áreas afectadas con As de origen natural, así como el As asociado con aguas termales (Argentina, Japón, Nueva Zelanda, Chile, Kamchatka, Islandia, Francia, República Dominicana y EEUU) y el relacionado con la actividad minera principalmente el relacionado a la liberación a partir de los minerales de sulfuro (Ghana, Grecia, Tailandia y EEUU).

En términos de población afectada, el problema mas serio se localiza en Bangladesh e India (West Bengal), sin embargo, en relación al territorio afectado, la región más extensamente afectada se encuentra en la llanura Chaco-pampeana argentina. Es de destacar que si bien en ambos casos la presencia de As en el agua subterránea es de origen geogénico, las características hidrogeológicas de estas zonas son diferentes: en la primera predominan acuíferos en ambientes reductores, mientras que en la segunda los acuíferos presentan condiciones predominantemente oxidantes (Smedley and Kinninburgh, 2002).

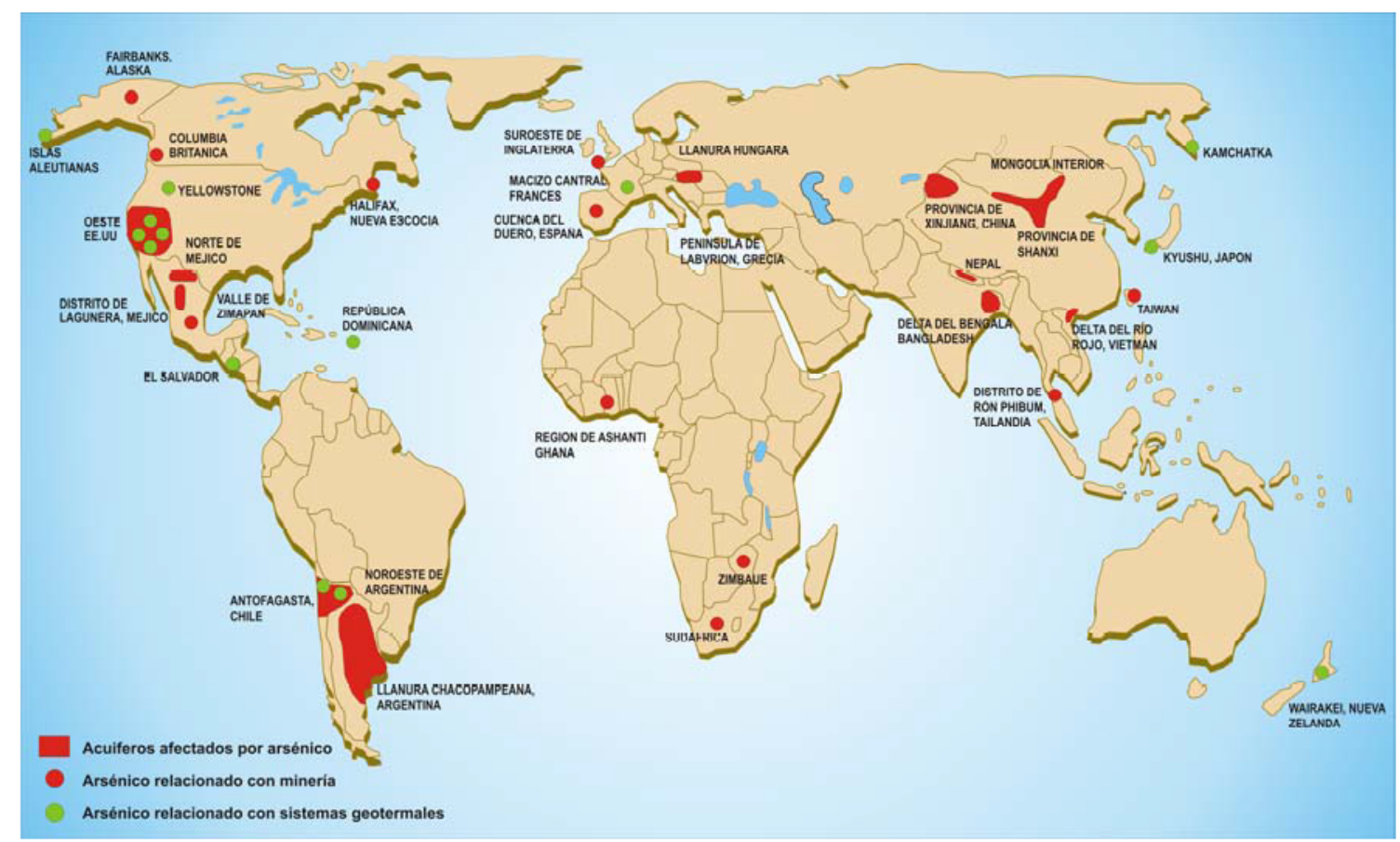

Figura 2.1. Distribución mundial de los principales acuíferos con altos contenidos de As tomando como límite permitido $50 \mathrm{\mu g} \mathrm{L}^{-1}$ (simplificado de Smedley and Kinninburgh, 2002).

La OMS en las Guías de Calidad para el Agua Potable (1993) reduce el valor guía de arsénico en agua de $50 \mu \mathrm{g} \mathrm{L}^{-1}$ a un valor provisional de $10 \mu \mathrm{g} \mathrm{L}^{-1}$, basándose en un estudio realizado por el Foro de Evaluación de Riesgo de la Agencia de Protección Ambiental de los Estados Unidos (EPA) en 1986 sobre evaluación de riesgo. La EPA estima el peligro de contraer cáncer de piel a partir de un estudio epidemiológico realizado en Taiwán donde se observaron más de 40.000 personas 
que consumían agua proveniente de pozos artesianos con altos contenidos de As, en un rango de 10 a $1.820 \mu \mathrm{g} \mathrm{L}^{-1}$ (valores más frecuentes entre 400 a $600 \mathrm{\mu g} \mathrm{L}^{-1}$ ).

La EPA clasifica al arsénico como cancerígeno en el grupo A debido a la evidencia de sus efectos adversos sobre la salud. La exposición a $50 \mathrm{\mu g} \mathrm{L}^{-1}$ puede causar 31,33 casos de cáncer de piel por cada 1.000 habitantes. El límite mínimo de aceptación fue entonces disminuido de $50 \mu \mathrm{g} \mathrm{L}^{-1}$ a $10-20 \mu \mathrm{g} \mathrm{L}^{-1}$. El Centro Internacional de Investigaciones sobre Cáncer ha clasificado al As en el grupo I porque tienen pruebas suficientes de la carcinogenicidad para seres humanos, razón por la cual en los últimos años se advierte una tendencia general en países industrializados a reducir los límites mínimos permitidos de arsénico en agua de bebida.

La OMS ha calificado la situación en Bangladesh como "la peor intoxicación masiva en la historia", no solo por los niveles encontrados de As en las aguas sino porque es uno de los países más pobres y más densamente poblados del planeta. En la Nota No 372 (OMS, 2012), señala que desde que se descubrió la presencia del elemento en los años 90 se han realizado grandes avances para disminuir su concentración en el agua logrando que la población afectada disminuya en alrededor de un $40 \%$. Sin embargo, la cantidad de personas que beben agua con contenidos de As que superan la legislación de ese país $\left(50 \mu \mathrm{g} \mathrm{L}^{-1}\right)$ es de 20 millones de personas, y esa cifra aumenta a 50 millones si se considera el límite impuesto por la OMS. Debido a la magnitud de la problemática hay una gran cantidad de estudios realizados durante las últimas décadas para mitigar el problema en esa región.

En muchos países de América Latina la presencia de As en el agua subterránea se ha detectado en los últimos 10-15 años. En la actualidad, los problemas de la contaminación con As se han descrito en 94 regiones de 14 países que comprenden en orden alfabético: Argentina, Bolivia, Brasil, Chile, Colombia, Cuba, Ecuador, El Salvador, Guatemala, Honduras, México, Nicaragua, Perú y Uruguay (Bundschuh et al., 2012). Argentina fue el primer país en el que se reportó As en las aguas subterráneas, hecho ocurrido a principios del siglo XX, mas precisamente en 1913 en la localidad de Bell Ville (Córdoba). Con posterioridad, a fines de la década del $50 \mathrm{y}$ principios de los 60, se detectó en México y Chile. Asimismo, en la década del 70 fue detectado en Perú. En el resto de los países señalados previamente el hallazgo ocurrió a principios del siglo XXI.

Si bien se han registrado en muchas zonas de América Latina manifestaciones tóxicas y efectos en la salud humana debido a la exposición al arsénico, en la actualidad no es posible evaluar con precisión el número de personas que podrían 
estar afectadas. En 2009 se estimaba que en América Latina por lo menos 4,5 millones de personas estaban expuestas al agua potable con más de $50 \mu \mathrm{g} \mathrm{L}^{-1}$ de As, sin embargo, al tomar en cuenta el límite de $10 \mu \mathrm{g} \mathrm{L}^{-1}$, adoptado por la mayoría de los países de América Latina, el número de personas expuestas podría alcanzar los 14 millones (Bundschuh et al., 2012).

En la mayoría de las áreas urbanas con suministro centralizado de agua, el problema del arsénico se ha visto mitigado por la instalación de plantas de tratamiento de agua o por aprovechamiento de recursos hídricos alternativos. Prácticamente no se proporcionaron soluciones para la mitigación del arsénico en zonas rurales y poblaciones periurbanas aisladas (no conectadas a un sistema centralizado de suministro de agua) en el ámbito de América Latina (Bundschuh et al., 2012).

\subsection{Situación en el país}

En nuestro país, el área afectada por contenidos anómalos de As en las aguas subterráneas, comprende gran parte de la planicie Chaco-pampeana, representando aproximadamente $10^{6} \mathrm{~km}^{2}$ (Smedley and Kinninburgh, 2002). En muchas regiones localizadas en 16 de las 23 provincias argentinas se han encontrado acuíferos con concentraciones de As elevadas (Bundschuh et al., 2012). En la Figura 2.2 se observan datos oficiales (Ministerio de Educación, 2011) de la distribución del contenido de As en Argentina en función del límite de referencia para el agua potable de $50 \mu \mathrm{g} \mathrm{L}^{-1}$, establecido por el Código Alimentario Argentino (CAA) hasta el año 2007.

Se ha estimado que entre 1,2 y 2 millones de personas están expuestas al elemento teniendo en cuenta el límite de seguridad de $50 \mu \mathrm{g} \mathrm{L}^{-1}$ en el agua potable. Sin embargo, si se considera el límite de $10 \mu \mathrm{g} \mathrm{L}^{-1}$ introducido en Argentina en 2007, y que aun no se ha puesto en vigencia, el número de habitantes expuestos crónicamente aumentaría entre 3 y 8 millones (Bundschuh et al., 2012).

La zona afectada abarca una gran faja noroeste-sureste que tiene como límite meridional a los cursos de los ríos Desaguadero y Colorado. Como límite septentrional se ha fijado provisionalmente el borde norte del altiplano en la zona cordillerana y el río Bermejo, en la llanura Chaco-pampeana. El río Paraná es el límite nororiental de esta faja. En toda la zona, salvo en casos muy puntuales (explotaciones mineras, fundiciones), no existen actividades antrópicas que puedan generar las anomalías de As observadas (Fernández Turiel et al., 2005).

El As contenido en el agua subterránea de nuestro país es de origen natural, producto de la disolución de minerales de arsénico vinculados a las erupciones volcánicas y a la actividad hidrotermal, principalmente en la Cordillera de los Andes, 
en los últimos 5 millones de años. El principal agente de transporte desde la Cordillera hacia el Este, hasta alcanzar la Ilanura Chaco-pampeana fue el viento, que produjo la acumulación del loess pampeano, que contiene cenizas y/o vidrio volcánico que aparecen como los principales generadores del As en el agua subterránea (Auge et al., 2013).

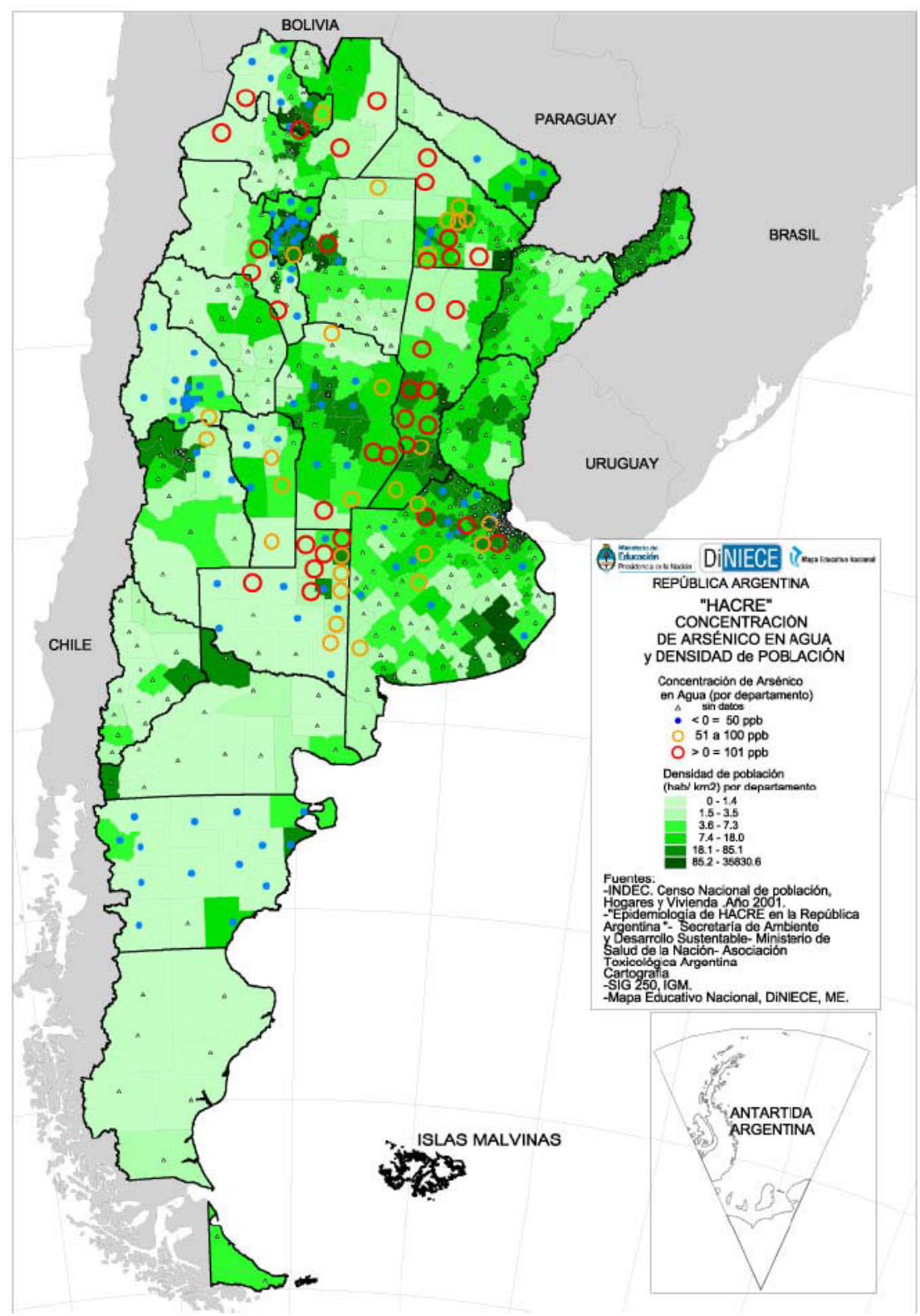

Figura 2.2. Zonas de concentración de As en Argentina (Ministerio de Educación, 2011).

Nicolli et al. (2012), distinguen las siguientes regiones según el contenido de As en el agua subterránea:

_ Llanura Chaco-Salteña: los acuíferos se alojan en secuencias superpuestas de sedimentos eólicos y fluviales de la Edad Terciaria y Cuaternaria. Las concentraciones de arsénico en el agua subterránea varían de 10 a $800 \mu \mathrm{g} \mathrm{L}^{-1}$ afectando a la población 
peri-urbana y rural en la parte centro-occidental de la provincia de Chaco (unos 311.500 habitantes). El arsénico se correlaciona positivamente con el flúor.

_ Llanura oriental Tucumana (cuencas hidrogeológicas Burruyacu y Río Salí): la calidad del agua subterránea varía mucho dependiendo de las concentraciones de elementos traza. La evaporación cerca de la superficie de la tierra da lugar a una alta salinidad en las capas superficiales. En Los Pereyra los acuíferos de profundidad $<15$ m muestran la más alta concentración de As en las aguas subterráneas $\left(1.660 \mu \mathrm{g} \mathrm{L}^{-1}\right)$. Las concentraciones disminuyen significativamente a mayor profundidad $(60-180 \mathrm{~m})$ con un valor medio de $33,7 \mathrm{\mu g} \mathrm{L}^{-1}$ y un rango de 11,4 a $107 \mu \mathrm{g} \mathrm{L}^{-1}$. Las aguas subterráneas poco profundas son del tipo $\mathrm{NaHCO}_{3}$, tienen un $\mathrm{pH}$ comprendido entre $6,28-8,72$ y su ambiente es oxidante. Las aguas subterráneas profundas tienen un $\mathrm{pH}$ promedio un poco más alto $(6,72-9,24)$ y muestran una disminución significativa en las concentraciones de $\mathrm{Na}$ y bicarbonato.

_ Santiago del Estero (cuenca del Río Dulce): la calidad del agua subterránea está condicionada por la baja pendiente regional, los sedimentos de textura fina, una alta evaporación y lluvias estacionales, dando lugar a un aumento de la salinidad en verano. La cuenca del Río Dulce presenta sedimentos de loess eólicos, incluyendo minerales de origen volcánico cubiertos por sedimentos aluviales y eólicos alternados. En varias áreas se identifica una capa de ceniza volcánica (0,53 a 1,35 m de espesor). El contenido de As en el sedimento es de $6 \mathrm{mg} \mathrm{kg}^{-1}$. La composición de las aguas subterráneas es predominantemente de tipo bicarbonato sódico, el pH oscila entre 6,88,8 , mientras que el contenido de As varía entre $2-4.780 \mu \mathrm{g} \mathrm{L}^{-1}$, asociado a $\mathrm{F}, \mathrm{V}$ y U.

_ Sur de la provincia de Córdoba: las concentraciones de As determinadas se encuentran en el rango de $40-300 \mu \mathrm{g} \mathrm{L}^{-1}$ (media $70 \mu \mathrm{g} \mathrm{L}^{-1}$ ) y las de $\mathrm{F}$ entre 100-11.500 $\mu \mathrm{g} \mathrm{L}^{-1}$ (media $3.900 \mu \mathrm{g} \mathrm{L}^{-1}$ ). Estos valores se encuentran en los acuíferos con bajas velocidades de circulación, alto $\mathrm{pH}(7,70-8,50)$, condiciones oxidantes y agua tipo $\mathrm{Na}$ bicarbonato.

_ Sureste de la provincia de Córdoba: los acuíferos poco profundos $(2-22 \mathrm{~m})$ se desarrollan en los sedimentos de loess limo arcillosos. La composición de las aguas subterráneas es altamente heterogénea. La concentración de As varía entre $<10$ y $3.810 \mu \mathrm{g} \mathrm{L}^{-1}$. Las concentraciones más altas de oligoelementos (As, V, U, Mo, F) se asociaron a las aguas subterráneas alcalinas del tipo Na-bicarbonato. Los sedimentos del loess y el vidrio volcánico son las principales fuentes de arsénico y oligoelementos asociados. Los contenidos de As están en el rango 5,81 a $37,3 \mathrm{mg} \mathrm{kg}^{-1}$ en el loess y 6,83 a $10,4 \mathrm{mg} \mathrm{kg}^{-1}$ en el vidrio volcánico. 
_ Centro-norte de la provincia de Santa Fe: el sistema acuífero comprende, en su base, una secuencia de sedimentos marinos (aguas subterráneas tipo $\mathrm{Na}$ sulfatocloruro) constituido por arcillas verdes, arena gris (acuífero confinado) y hacia abajo capas de arena (acuífero semi-confinado aluvial). El último se conoce como "arenas Puelches", por lo general recibe aguas subterráneas de buena calidad (tipo Nabicarbonato) y es la principal fuente de abastecimiento de agua para la población. Hacia arriba, la columna estratigráfica continúa con sedimentos lacustres y depósitos cuaternarios eólicos (loess de la Formación Pampeana) que incluyen un acuífero superficial (3-15 m de espesor) de baja producción y calidad de agua variable. Una fuerte variabilidad de la química del agua subterránea se produce a partir de la zona centro (ciudad Esperanza) a las zonas centro-norte de la provincia de Santa Fe. Las concentraciones de As aumentan de 19,5-53,6 $\mathrm{g} \mathrm{L}^{-1}$ (mediana: 37,2 $\mathrm{g} \mathrm{L} \mathrm{L}^{-1}$ ) a 15,0 a $780 \mu \mathrm{g} \mathrm{L}^{-1}$ (mediana: 70,6 $\mathrm{g} \mathrm{L} \mathrm{L}^{-1}$ ). La composición química de los sedimentos también muestra diferencias significativas en las concentraciones de As: relativamente bajas en el área central y alta en la zona norte. Otras diferencias principales son la aparición de fases minerales sobresaturadas con grandes cantidades de arcillas, óxidos e hidróxidos de $\mathrm{Fe} \mathrm{y} \mathrm{Al}$ en el área central con respecto a la zona centro-oeste. La evaporación producida por el clima semiárido que afecta esta región contribuye al aumento de arsénico y oligoelementos asociados, sobre todo en las zonas del norte y el oeste. Con la excepción de F, se encontraron incrementos positivos para As (178\%), $\mathrm{V}, \mathrm{U}$ y B en las zonas centro-norte.

_ Provincia de Buenos Aires: se distinguen los siguientes acuíferos: post-Pampeano (baja profundidad: 2-10 m), Pampeano (freática/acuitardo, profundidad 20-30 m) y Puelches (semi-confinado/confinado, profundidad 20-50 m). El acuífero Pampeano, se recarga por la lluvia, cubre una amplia zona de la región del sur, mientras que el acuífero Puelches se extiende sobre todo el centro hacia las zonas del norte. Se recarga por la lluvia y por el agua subterránea que se filtra del acuitardo Pampeano, por otro lado, el acuífero Puelches puede suministrar el acuífero Pampeano a través de bombeo. El agua fluye en sentido SO-NE y descarga en el río Paraná, río de La Plata y pequeñas cuencas hidrográficas. La contaminación por As y $\mathrm{F}$ ha sido bien documentada en las aguas subterráneas de las zonas centro-sur de la provincia de Buenos Aires. Allí, las áreas planas restringen la circulación del agua y favorecen la evaporación, aumentando la salinidad y la vulnerabilidad. Las concentraciones de As pueden llegar a $100-1.300 \mu \mathrm{g} \mathrm{L}^{-1}$.

_ Zona norte de la provincia de La Pampa: las aguas subterráneas de tipo bicarbonato sódico, oxidantes, $\mathrm{pH}$ neutro a alcalino $(7,0$ a 8,7$)$, con alta salinidad y altas 
concentraciones de As, F, B, Mo, Se y $\mathrm{U}$ se alojan en un loess superior TerciarioCuaternario y sedimentos limosos eólicos. La distribución espacial del As es heterogénea y la composición de las aguas subterráneas presenta una alta variabilidad: rangos de As entre $<4$ a $5.300 \mu \mathrm{g} \mathrm{L}^{-1}$ en coexistencia con $\mathrm{F}$ (30 a $2.900 \mu \mathrm{g}$ $\left.\mathrm{L}^{-1}\right), \mathrm{B}\left(500\right.$ a $\left.14.000 \mu \mathrm{g} \mathrm{L}^{-1}\right), \mathrm{V}\left(20\right.$ a $\left.5.400 \mu \mathrm{g} \mathrm{L}^{-1}\right)$, Mo $\left(2,7\right.$ a $\left.990 \mu \mathrm{g} \mathrm{L}^{-1}\right)$ y U $(6,2$ a 250 $\left.\mu \mathrm{L}^{-1}\right)$.

En este trabajo de tesis se presta especial atención a la situación de la provincia de Buenos Aires (PBA) debido a que los minerales empleados en el tratamiento de eliminación de As provienen de las Sierras Septentrionales de la PBA. De esta forma, la cercanía a los lugares afectados permitiría el desarrollo de una tecnología económicamente rentable. Las localidades de la PBA pertenecen hidrogeológicamente a la llanura Chaco-pampeana (Auge, 2004).

Los contenidos de As en la PBA han sido estudiados por diversos autores en los últimos años. Auge (2009) reportó que en la PBA la distribución areal del agua freática con menos de $100 \mu \mathrm{g} \mathrm{L}^{-1}$ de As disuelto abarca alrededor del $62 \%\left(190.000 \mathrm{~km}^{2}\right)$ de la superficie total. Agua con menos de $50 \mu \mathrm{g} \mathrm{L}^{-1}$ de As en solución (límite hasta el 2007 establecido por el CAA) se encuentra solo en el $20 \%$ del territorio $\left(61.000 \mathrm{~km}^{2}\right)$, destacándose los ámbitos NE y centro. Este último es el más extenso y abarca los partidos de Tandil, Balcarce, Olavarría, Tapalqué, Gral. Alvear, Bolívar, Daireaux, Gral. La Madrid, Cnel. Suárez, Saavedra y Tornquist. También coincide la región con las dunas que bordean la Costa Atlántica Bonaerense.

Navoni et al. (2012) analizaron la concentración de arsénico en agua recolectada durante el período 2003-2008 en 52 localidades de la PBA. Encontraron un amplio rango de concentraciones del elemento en las muestras estudiadas con un valor promedio de $49,9 \mu \mathrm{g} \mathrm{L}^{-1}$, y en algunas localidades la concentración alcanzó valores cercanos a los $200 \mu \mathrm{g} \mathrm{L}^{-1}$. Del total de muestras (152), cerca del $40 \%$ superaron el valor máximo de $50 \mu \mathrm{g} \mathrm{L}^{-1}$ y $80 \%$ el de $10 \mu \mathrm{g} \mathrm{L}^{-1}$. Los niveles de As más elevados se distribuyeron en departamentos con preponderancia de población rural, sin embargo, se detectaron valores intermedios en departamentos con alto número de habitantes urbanos (por ej., Junín, 9 de Julio, Chacabuco). Asimismo, destacan que tanto las muestras de agua de red como las obtenidas de perforaciones presentaron niveles de arsénico similares, lo que indica una ausencia de tratamiento del agua, al menos para este elemento.

Recientemente, Auge et al. (2013) sobre la base de 640 análisis de As total, en muestras tomadas en 159 puntos de los acuíferos someros de la PBA, elaboraron una 
cartografía de carácter orientativo a escala regional (1:3.000.000) (Figura 2.3).

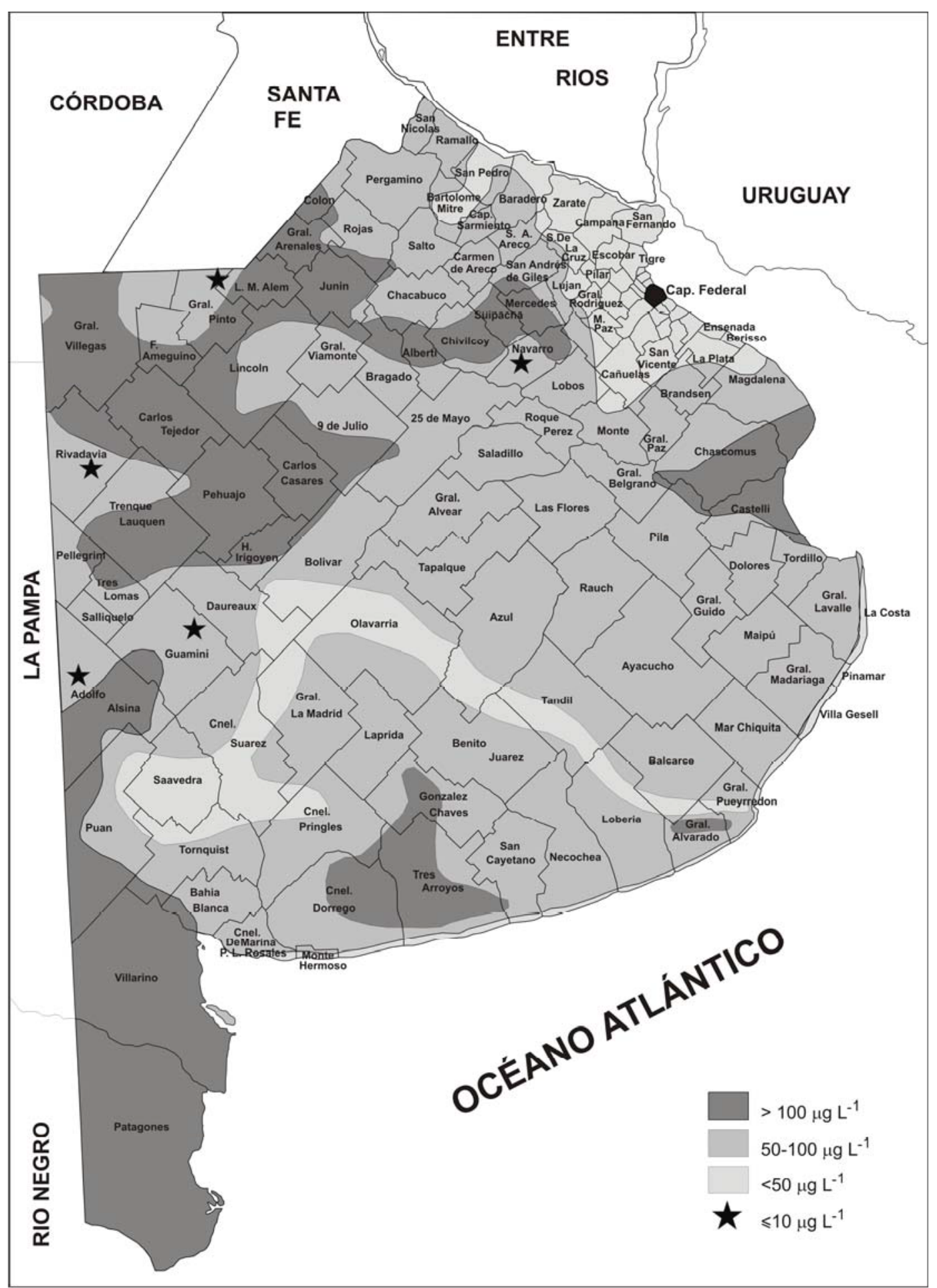

Figura 2.3. Distribución de arsénico en la provincia de Buenos Aires (simplificado de Auge et al., 2013).

Los resultados indicaron que el $87 \%$ del territorio provincial $(267.000$ $\mathrm{km}^{2}$ ) tiene agua subterránea que supera la norma provincial vigente $\left(50 \mu \mathrm{g} \mathrm{L}^{-1}\right) \mathrm{y}$ sólo el $13 \%\left(40.000 \mathrm{~km}^{2}\right)$ de su superficie total $\left(307.000 \mathrm{~km}^{2}\right)$ presenta contenidos menores. Cumplen con esta última condición las regiones NE y centro-Sur, en esta 
última, fundamentalmente los ámbitos inter y peri-serranos. También resalta la región que coincide con las dunas que bordean la costa Atlántica Bonaerense. Las regiones que registran los tenores más elevados (mayores a $\left.100 \mu \mathrm{g} \mathrm{L}^{-1}\right)$ ocupan el $29 \%$ (89.000 $\mathrm{km}^{2}$ ) de la superficie de la provincia y coinciden con zonas vecinas a la Bahía Samborombón, gran parte de la Pampa Arenosa y la totalidad de la región en forma de bastón, al Sur de Bahía Blanca (Figura 2.3). Es de destacar que, en este trabajo se reporta que sólo el $9 \%$ de la población de la PBA se encuentra potencialmente afectada, esto es debido a que la mayor concentración poblacional (14,2 millones de habitantes equivalente a $91 \%$ ) se ubican dentro de ámbitos con tenores menores a 50 $\mu \mathrm{L} \mathrm{L}^{-1}$. Sin embargo, habría que tener en cuenta que este número se vería aumentado si se toma como límite permisible el valor fijado en el CAA a partir del año 2007.

\subsection{Efectos nocivos del As}

Si bien todos los compuestos del arsénico son tóxicos, los compuestos orgánicos se consideran menos tóxicos que las formas inorgánicas. Estas últimas prevalecen en aguas naturales como arsenito o arseniato, destacando que los compuestos de As(III) suelen ser varias veces más tóxicos que los compuestos de $\mathrm{As}(\mathrm{V})$ (Jones, 2007).

Las posibles vías de exposición al As son: la digestiva, la cutánea y la pulmonar (inhalación). Las dos últimas son más frecuentes en intoxicaciones de origen ocupacional, si bien, es de destacar que la absorción dérmica es generalmente considerada insignificante. La vía digestiva es la más frecuente y puede producirse de forma aguda (consumo accidental, envenenamiento, suicida) o crónica (consumo prolongado de agua y alimentos con contenidos anómalos del elemento).

La mayoría de las personas afectadas en el mundo están expuestas de manera crónica y natural, por beber agua contaminada o por exponerse a suelo o polvo con niveles elevados de As (Gonsebatt, 2012). Como las características organolépticas de las aguas arsenicales no son desagradables, no presenta olor, color o sabor, es consumida por un período prolongado hasta que los efectos tóxicos puedan observarse. El comienzo de los síntomas puede ocurrir entre los 5 y 10 años de exposición y las lesiones malignizarse décadas después (CONAPRIS, 2006).

Después de la absorción, la mayoría del As inorgánico se elimina rápidamente de la sangre. Aunque algunos compuestos de arsénico son convertidos en los testículos, riñón y pulmón, el hígado es el sitio principal de metabolismo del arsénico en los mamíferos. El arsénico se elimina del cuerpo principalmente por los riñones a través de la orina, otras rutas menos importantes de eliminación incluyen las heces, el sudor, descamación de la piel y la incorporación en el cabello y las uñas (Jones, 
2007). En los seres humanos, entre el 40 al $70 \%$ del arsénico absorbido se metaboliza y excreta dentro de las $48 \mathrm{hs}$. La presencia de As en orina es un buen indicador de exposición reciente, mientras que cuando la exposición ha ocurrido en el pasado (meses), podría detectarse en pelo y uñas (Gonsebatt, 2012).

El As absorbido una vez dentro de las células es biotransformado a través de procesos de metilación, que solo pueden ocurrir en el estado de oxidación +3 , por lo que es necesario reducir las formas oxidadas del elemento. En el proceso de biotransformación del arsénico intervienen reacciones de óxido-reducción por las que se generan moléculas o especies reactivas de oxígeno y se consumen agentes reductores celulares. Estas moléculas reductoras que se "distraen" en metabolizar As son las encargadas de evitar la oxidación que sufren los lípidos, proteínas y ADN de los organismos que respiramos oxígeno (Gonsebatt, 2012).

En relación al mecanismo de toxicidad, en el estado de oxidación +3 (arsenito), el $\mathrm{As}$, al igual que muchos metales pesados $(\mathrm{Cd}, \mathrm{Pb}, \mathrm{Hg})$ tiene afinidad por los grupos sulfhidrilo $(\mathrm{SH})$ que están en los aminoácidos cisteína y metionina de algunas proteínas, es por ello que se acumula en tejidos ricos en queratina como piel, pelo y uñas (Gonsebatt, 2012). De esta forma pueden alterar la estructura de las proteínas dando lugar a interrupciones de procesos metabólicos e influir en una amplia gama de actividades metabólicas incluyendo la captación celular de glucosa, la gluconeogénesis, la oxidación de ácidos grasos, entre otras. Esta toxicidad metabólica amplia puede producir una gran variedad de síntomas (Jones, 2007). Por otra parte, por su ubicación en la tabla periódica, el As comparte similitudes químicas con el $P$, elemento esencial para los organismos vivos. Así, en su forma pentavalente puede remplazar al fosfato que tiene igual valencia, sustituyéndolo en compuestos y/o reacciones vitales, así, actúa bloqueando la formación de ATP en las mitocondrias (Gonsebatt, 2012).

El mecanismo carcinogénico del As se desconoce, no existe un modelo animal en el que se hayan podido reproducir claramente los efectos que causa en el ser humano y de ahí la dificultad de entender cómo es que no tiene un órgano blanco y es capaz de inducir no uno sino varios tipos de cáncer (Gonsebatt, 2012). Se ha demostrado que el arsénico no interactúa directamente con el $A D N$, sino que los efectos del arsénico se producen a través de la alteración indirecta de la expresión génica a través de la interrupción de la metilación del $A D N$, la inhibición de la reparación del ADN o el estrés oxidativo (Jones, 2007). Ni el As(III) ni el As(V) son mutágenos, sólo en combinación con otros agentes que dañan el ADN como la luz ultravioleta, la radiación ionizante, los agentes alquilantes, deficiencias nutricias, etc., 
el As es capaz, incluso a bajas dosis, de potenciar el daño genotóxico de estos agentes, por ello se piensa que el As tiene un papel de promotor en el desarrollo de cáncer (Gonsebatt, 2012).

Como se comentara en ítems anteriores, Argentina fue el primer país de América Latina donde la ocurrencia de arsénico en el agua subterránea ha sido reportada. En el año 1913 el Dr. Goyenechea relacionó las patologías observadas en la localidad cordobesa de Bell Ville con el consumo de agua con elevados contenidos de As, debido a los numerosos casos diagnosticados en dicha ciudad se la denominó "enfermedad de Bell Ville" (Goyenechea, 1917). Con posterioridad esta patología fue denominada "arsenicismo crónico regional endémico" por el Dr. Ayerza, quien describió en detalle las manifestaciones cutáneas y extracutáneas (Ayerza, 1917). En 1951 Tello, introdujo la denominación actual "hidroarsenicismo crónico regional endémico o HACRE" (Tello, 1951).

EI HACRE es la enfermedad producida por la ingesta de arsénico en el agua de bebida que se caracteriza por ciertas lesiones en la piel y alteraciones sistémicas cancerosas y no cancerosas luego de varios años de exposición. Para producir estos efectos son necesarias dosis que están casi seis órdenes de magnitud por debajo de las que producen la muerte inminente, unos pocos microgramos que se ingieran todos los días durante algunos años pueden ser suficientes para que los trastornos se hagan evidentes (García, 2012).

Los efectos adversos del arsénico dependen en gran medida de la dosis y la duración de la exposición (Rahman et al., 2009). Si bien los efectos tóxicos del elemento afectan a personas de todas las edades, la sensibilidad humana a dichos efectos varía, probablemente debido a factores genéticos, metabólicos, de la dieta, del estado de salud, del sexo y de la edad, entre otros. La situación de pobreza puede incrementar la susceptibilidad de la población a enfermar por exposiciones a uno o más tóxicos ambientales. Además, el menor acceso a la atención médica oportuna hace que el estado de pobreza sea un factor de vulnerabilidad (Navoni et al., 2012).

Las manifestaciones clínicas de toxicidad por arsénico son muchas, pero los síntomas más comúnmente observados en las personas que sufren de intoxicación crónica son las lesiones cutáneas. La enfermedad se manifiesta en nuestro país con características propias que la diferencian de las enfermedades similares de otras zonas endémicas del mundo como México, Chile o Taiwán. Se observa un predominio neto de la queratodermia palmo-plantar (lesiones en la piel) y melanodermia (cambio de pigmentación) (Ryczel, 2011). 
Gonsebatt (2012) describe las siguientes etapas durante la exposición crónica: la preclínica, en donde la persona no muestra efectos pero el As puede ser detectado en muestras de pelo, uñas y orina. La etapa denominada como hidroarsenicismo o arsenicismo crónico transcurre con oscurecimiento o melanosis en la piel, generalmente en las palmas de las manos, en pecho y espalda, acompañada de hipopigmentación punteada e hiperqueratosis en las palmas de las manos o en las plantas de los pies que pueden tomar la forma de callos o verrugas. La OMS estima que esta etapa requiere de un tiempo de exposición de entre 5 y 10 años, dependiendo de la dosis. Estas lesiones de piel se pueden considerar como precancerosas. Asimismo, pueden presentarse síntomas clínicos más pronunciados como dilatación del hígado, riñones y bazo, así como conjuntivitis, bronquitis y diabetes. En la etapa de malignidad aparecen los tumores en la piel, vejiga y pulmón y ocasionalmente gangrena en las extremidades. Cuando la exposición es a bajas dosis $(0,005-0,0006 \mathrm{mg} / \mathrm{kg} / \mathrm{día})$ no existen los signos claros de arsenicismo descritos arriba, sin embargo se han documentado efectos neurológicos como problemas de memoria y aprendizaje en la población infantil.

Como los efectos adversos del arsénico para la salud dependen de la dosis y la duración de la exposición las acciones de salud están dirigidas a evitar o discontinuar la exposición. En las etapas preclínicas y clínicas del HACRE la recuperación puede ser completa si se reemplaza el agua arsenical por agua segura. En la última etapa las manifestaciones no cancerosas pueden ser reversibles, pero cuando aparecen neoplasias malignas, la única medida es el tratamiento oportuno para reducir las secuelas (Navoni et al., 2012).

\subsection{Legislación}

Desde la primera versión de la Normativa Internacional para el Agua Potable de 1958, la OMS incluye al arsénico en la categoría de elemento tóxico, estableciendo entonces una concentración máxima admisible de $200 \mu \mathrm{g} \mathrm{L}^{-1}$ (OMS, 1958). En 1963 redujo este valor a $50 \mu \mathrm{g} \mathrm{L}^{-1}$, el cual se mantuvo como límite de concentración superior y provisional en las Normas Internacionales de 1971 (OMS, 1971). Posteriormente y como se mencionara en puntos anteriores, en 1993, la OMS estableció $10 \mu \mathrm{g} \mathrm{L}^{-1}$ como un valor de referencia en el agua potable, tomando en consideración el hecho de que los compuestos inorgánicos del As hayan sido clasificados por la International Agency for Research on Cancer (IARC, 1987) en el grupo I (cancerígenos para humanos) (OMS, 1993). Este valor permanece como provisional desde la Normativa de 2003 a la actualidad (OMS, 2003). Es de destacar, que este valor límite está indicado como provisional debido a un balance de aspectos relativos a la evaluación de riesgos y 
capacidad cancerígena del arsénico, el límite práctico de cuantificación (del orden de 1-10 $\mu \mathrm{g} \mathrm{L}^{-1}$ ) y las dificultades prácticas para atender la eliminación del arsénico del agua de consumo en regiones muy amplias del planeta.

Es también de señalar, que los límites establecidos por la OMS no son valores obligatorios, sino que tienen la intención de ser usados como base para el desarrollo de normativas nacionales que se ajusten a cada país. En un cierto número de países el límite de $10 \mu \mathrm{g} \mathrm{L}^{-1}$ ha sido ya adoptado, como por ejemplo la Unión Europea desde 1998 y EEUU desde 2002. Sin embargo, muchos otros países han conservado el valor previo de la OMS de $50 \mu \mathrm{g} \mathrm{L}^{-1}$, particularmente debido a consideraciones técnicas y económicas asociadas a la disminución del As del agua. Sin embargo las pruebas acerca de la carcinogenicidad del As para seres humanos son cada día más concluyentes, razón por la cual en los últimos años se advierte una tendencia general a reducir los límites mínimos permitidos de arsénico en agua de bebida.

En la Argentina, el contenido de As en el agua para consumo se encuentra regulado por el Código Alimentario Argentino (Ley Nacional 18.284). Hasta el año 2007, dicho código permitía una concentración máxima de arsénico en el agua de bebida de $50 \mu \mathrm{g} \mathrm{L}^{-1}$. En ese año, a través de la Resolución Conjunta No 68/2007 de la Secretaría de Políticas, Regulación y Relaciones Sanitarias y $N^{\circ} 196 / 2007$ de la Secretaría de Agricultura, Ganadería, Pesca y Alimentos, se estableció que dicho límite descendía a $10 \mu \mathrm{g} \mathrm{L}^{-1}$, estableciendo un plazo de hasta 5 años para adecuarse a dicho valor. Sin embargo, al cumplirse dicho plazo en el año 2012 no se había podido cumplir con esta reducción en vastas zonas del país, por lo que se ha establecido una prórroga (Resolución Conjunta 34/2012 de la Secretaría de Políticas, Regulación e Institutos y 50/2012 de la Secretaría de Agricultura, Ganadería y Pesca), habiendo puesto como condición la conclusión de un estudio epidemiológico al respecto (CAA, 2012).

García (2012) destaca que la reducción a $10 \mu \mathrm{g} \mathrm{L}^{-1}$ no elimina por completo el riesgo pero lo reduce hasta 6 casos de cáncer de piel cada 10.000 habitantes que consumen esa agua durante toda su vida, y que podrían atribuirse a la ingesta de arsénico en el agua de bebida. De esta forma, no habiéndose realizado un estudio que permita cuantificar riesgos, costos y beneficios para las poblaciones afectadas, el retorno al estándar de $50 \mu \mathrm{g} \mathrm{L}^{-1}$ hace suponer un incremento en el número de personas afectadas, estimando que 10 a 20 casos de cáncer de piel cada 10.000 habitantes que consumen agua con esa concentración durante toda su vida podrían atribuirse a la problemática del arsénico. Es decir, el riesgo se incrementa entre dos y tres veces respecto al observado haciendo cumplir el estándar de $10 \mu \mathrm{g} \mathrm{L}^{-1}$. 
Es de señalar que dada la organización federal del país, las normas son potestad de cada provincia, que puede tener su legislación particular salvo una adhesión expresa a leyes nacionales marco como el CAA. Surge así la paradoja de que pobladores de una misma región, separados por escasos kilómetros beban agua con distintos contenidos permitidos de As (Hernández et al., 2005). De esta forma, provincias limítrofes tienen normativas distintas, por ejemplo, para Buenos Aires el valor máximo permitido de As es de $50 \mu \mathrm{g} \mathrm{L}^{-1}$, mientras que para La Pampa es $150 \mu \mathrm{g}$ $\mathrm{L}^{-1}$, para Santa Fe $100 \mu \mathrm{g} \mathrm{L}^{-1}$, mientras que para Córdoba y Entre Ríos este valor es de $50 \mu \mathrm{g} \mathrm{L}^{-1}$. Sin embargo es de destacar que en ninguna de estas provincias existen estudios toxicológicos basados en una cantidad representativa de habitantes y a lo largo de un lapso de tiempo que también resulte representativo, para establecer con mayor certeza el límite de potabilidad respecto al As (Auge et al., 2013).

En relación a la PBA, la Ley 11.820 establece un límite tolerable de As de $50 \mu \mathrm{g}$ $\mathrm{L}^{-1}$ (Senado y Cámara de Diputados PBA, 2012). Esta Ley se encuentra vigente en la actualidad, sin embargo, hay que destacar que en el año 2004 la PBA adhirió al CAA (Ley Provincial 13.280), por lo que deberá adecuarse para llegar al límite de $10 \mu \mathrm{g} \mathrm{L}^{-1}$ establecido en dicho código.

Finalmente, cabe una reflexión sobre los criterios para fijar los niveles adoptados como límites. Hernández et al. (2005) plantean que los niveles de las normas de la OMS tienden a proteger la salud. Por consiguiente es esperable que los umbrales de aptitud sean cada vez más bajos, aunque han planteado el interrogante de si deben seguirse estrictamente esas pautas en distintas regiones en vez de utilizar cada jurisdicción criterios propios, teniendo en cuenta las recomendaciones, pero avalados por estudios de base científica acerca de la tolerancia real a la ingesta de agua con contenidos de arsénico. Por otra parte, García (2012) destaca que el As es un agente cancerígeno que no tiene un valor umbral de efecto conocido, y por ende la concentración tolerable en el agua para consumo humano debería resultar necesariamente de la evaluación de riesgos para la salud, del análisis de las mejores tecnologías disponibles para el abatimiento, de los costos de su implementación, del nivel de percepción que cada comunidad tiene de ese riesgo, de las decisiones gubernamentales respecto de la asignación de los recursos públicos y de la capacidad de gestión de los funcionarios responsables de ejecutar las políticas.

\subsection{Reseña de las técnicas de remoción de As comúnmente empleadas}

Como se discutió en los puntos anteriores, las aguas subterráneas de la planicie Chaco-pampeana presentan contenidos de As superiores a los recomendados, 
impactando en la calidad de vida de un gran número de poblaciones así como en las posibilidades de desarrollo económico productivo de la región, aspectos que se encuentran estrechamente vinculados a los esfuerzos que se dirijan hacia la solución del problema. La bibliografía señala diferentes tecnologías para la remoción de As de aguas. Bundschuh et al. (2005) reportan los principales métodos de remoción, que se indican a continuación:

1) Procesos de adsorción

2) Procesos de intercambio iónico

3) Procesos de membrana

4) Procesos de coagulación-precipitación

Por lo general los tratamientos de remoción de arsénico tienen una etapa previa de oxidación, porque resulta más fácil de remover el $\mathrm{As}(\mathrm{V})$ que el $\mathrm{As}(\mathrm{III})$. La oxidación no es un tratamiento en sí mismo, sino que constituye un paso inicial que aumenta la performance del tratamiento seleccionado. Puede realizarse de diversas maneras (D’Ambrosio, 2005): a) por simple aireación, b) empleando agentes oxidantes diversos como cloro, hipoclorito, ozono, peróxido de hidrógeno o c) mediante radiación. Debe tenerse en cuenta al momento de evaluar el uso de un agente oxidante la disponibilidad y el costo del mismo.

A continuación se realiza una breve descripción de las tecnologías de remoción de As disponibles.

Procesos de adsorción: la adsorción es un proceso de transferencia de masa. Una sustancia es transferida desde la fase líquida donde está disuelta a la superficie de un sólido donde queda atrapada por fuerzas físicas o químicas. Como es un fenómeno superficial cuanto mayor es la superficie del sólido mayor es la capacidad de acumular material ( $D^{\prime}$ Ambrosio, 2005). Es uno de los métodos más eficientes en la eliminación de $\mathrm{As}(\mathrm{V})$ del agua. La capacidad de un adsorbente depende de factores tales como, el $\mathrm{pH}$, la temperatura, las propiedades texturales y fisicoquímicas del adsorbente, estado de oxidación del As, presencia de iones competitivos (Leyva Ramos, 2010).

En la remoción de As pueden usarse como adsorbentes óxidos de aluminio (alúmina activada), óxidos/hidróxidos de hierro, dióxido de titanio, oxido de cerio o metales reducidos (Höll y Litter, 2010). Si bien el carbono activado es un adsorbente ampliamente empleado en el tratamiento de aguas, su capacidad para adsorber aniones es muy baja, debido a que no posee suficientes sitios activos. Por este motivo el carbón activado debe ser modificado o impregnado con algún metal para incrementar su capacidad (Leyva Ramos, 2010). La alúmina activada $\left(\mathrm{Al}_{2} \mathrm{O}_{3} / \mathrm{Al}(\mathrm{OH})_{3}\right)$ 
es un adsorbente frecuentemente empleado en la remoción del $\mathrm{As}(\mathrm{V})$. Posee una superficie del orden de $200-300 \mathrm{~m}^{2} \mathrm{~g}^{-1}$, la máxima capacidad de adsorción se logra a $\mathrm{pH}$ cercanos a 6 . Solo los fosfatos compiten con los iones arseniato por los sitios de adsorción y se puede regenerar con $\mathrm{NaOH}$ (Höll y Litter, 2010).

En la remoción de As también se emplean oxi/hidróxidos metálicos hidratados. Pueden ser sintéticos o naturales. Entre ellos se pueden citar el óxido de hierro granular y el hidróxido de hierro granular (GFH®). Este último es un material sintético tipo akaganeíta, que retiene fuertemente aniones arseniato y también es efectivo para las especies de $\mathrm{As}(\mathrm{III})$, probablemente debido a la oxidación a $\mathrm{As}(\mathrm{V})$ en la superficie. Se ha empleado en plantas y filtros domésticos en distintas partes del mundo. Otros óxidos empleados con éxito en la remoción de arsénico son: el óxido férrico granular (Bayoxide ${ }^{\circledR}$, GFO), el dióxido de titanio granular (Adsorbsia®), el óxido de cerio y el dióxido de manganeso. En contraste con la alúmina activada estos materiales no se regeneran sino que deben ser enterrados (Höll y Litter, 2010).

La adsorción empleando óxidos/hidróxidos metálicos se basa en la alta afinidad de las especies de As presentes en el agua por las superficies de los mismos, de manera de formar complejos superficiales estables (quimisorción). La aplicación de adsorbentes oxídicos naturales, que regulan el comportamiento químico del elemento en los sedimentos mediante mecanismos de adsorción y desorción, constituyen la base para el desarrollo de tecnologías de bajo costo y fácil implementación. En este sentido, los minerales de hierro son abundantes en la naturaleza y relativamente baratos por lo que son una alternativa atractiva para su uso como adsorbentes en el tratamiento de aguas con As (Aredes et al., 2012). Se presenta como una alternativa promisoria a nivel domiciliario o en comunidades pequeñas, ya que no requieren agentes de desorción peligrosos y el equipamiento empleado es de fácil mantenimiento (Jeong et al., 2007). En los Capítulos 3 y 4 se amplía la información sobre el empleo de minerales de hierro en la remoción de arsénico en agua.

Se han reportado otros adsorbentes naturales empleados en la eliminación de As, algunos son minerales tales como zeolitas y siderita y otros son residuos de actividades agroindustriales (cascarón de huevos, biomasa de sorgo) (Leyva Ramos, 2010). También se han ensayado materiales basados en el empleo de arena y cuarzo cubiertos con óxidos metálicos (arena recubierta con óxido férrico o con dióxido de manganeso) (Höll y Litter, 2010).

Procesos de intercambio iónico: En este procedimiento el contaminante se intercambia con otros iones presentes en una resina de intercambio iónico. Las resinas 
consisten en una matriz polimérica de enlace cruzado a la cual se le unen grupos funcionales cargados a través de enlace covalente (D’Ambrosio, 2005). Para la remoción de As existen resinas de intercambio iónico fuertemente básicas en forma de cloruro (Höll y Litter, 2010), resinas sulfato selectivas para la remoción principalmente de arseniato y resinas nitrato selectivas que también remueven arsenito (D’Ambrosio, 2005).

La solución a purificar se pasa a través del lecho hasta que se satura y comienza la fuga del contaminante. En ese momento la resina se reactiva con una solución de regenerante (generalmente $\mathrm{NaCl}$ ) que generará un efluente líquido conteniendo As (D’Ambrosio, 2005). La capacidad de las resinas depende principalmente de la calidad del agua de partida, como por ejemplo de los sólidos disueltos. El Fe y el Mn pueden obstruir el lecho y la presencia de otros aniones (sulfatos, nitratos) pueden competir con las especies de As.

La remoción del arseniato es relativamente independiente del $\mathrm{pH}$ y de la concentración de $\mathrm{As}(\mathrm{V})$ del agua a tratar (Höll y Litter, 2010). Las ventajas de las resinas de intercambio iónico son su fácil regeneración y su amplio rango de $\mathrm{pH}$. Este método es relativamente costoso y la regeneración de la resina produce efluentes ricos en arsénico (Castro de Esparza, 2006).

Procesos de membrana: estos procesos de separación física utilizan membranas semipermeables que permiten el paso de agua y separan ciertos solutos. Existen distintos tipos de membranas de acuerdo al tamaño de poro de los elementos filtrantes: microfiltración $\left(10^{3}-10^{4} \AA\right)$, ultrafiltración (30-100 $\AA$ ), nanofiltración (10-100 $\AA$ ) y osmosis inversa (5-20 A) (Tarquini, 2010).

Para la remoción de As en agua se usa la ósmosis inversa, proceso que se basa en la utilización de una bomba de alta presión para forzar el pasaje del agua a tratar a través de una membrana semipermeable. De esta forma los iones quedan retenidos en la membrana. La presión a aplicar debe ser mayor que la presión osmótica natural del agua a tratar. La presión de operación promedio es de 10-20 bars (D’Ambrosio, 2005). El rechazo salino logrado con las membranas de ósmosis inversa es superior al $99 \%$, no solo se retienen iones, sino que también es posible eliminar virus y bacterias (Tarquini, 2010).

Entre las ventajas del proceso de ósmosis inversa pueden nombrarse: reducción del contenido de As mayor al 99\%, reducción y/o eliminación de otras especies químicas presentes en al agua. Es de destacar que la remoción del arsénico es independiente del $\mathrm{pH}$ y de la presencia de otros solutos. Además, el sistema puede 
diseñarse para abastecimientos domiciliarios o para redes públicas, no requiriendo de regeneradores químicos (Tarquini, 2010). Sin embargo, las membranas demandan que el agua a tratar no contenga cantidades excesivas de material coloidal, en especial materia orgánica. Los costos de operación son altos, requieren de operadores calificados y el agua tratada tiene muy bajos niveles salinos, que como micronutrientes resultan importantes para la salud humana.

Procesos de coagulación-precipitación: en el proceso de coagulación el agregado de un agente químico (coagulante) desestabiliza los coloides del agua, permitiendo que las partículas coloidales se aglomeren formando flóculos pequeños que se van juntando hasta formar aglomerados mayores capaces de sedimentar (Sancha, 2010). La coagulación convierte el As soluble en un producto insoluble permitiendo su separación por sedimentación y/o filtración. Esta ha sido la tecnología más utilizada en el mundo (D’Ambrosio, 2005).

Los coagulantes más comunes son las sales de $\mathrm{Al}$ y de $\mathrm{Fe}$, entre ellas: sulfato de aluminio, sulfato férrico y cloruro férrico. La remoción del As se basa en la formación de una especie coloidal a partir de la hidrólisis del coagulante (especies metálicas hidrolizadas con carga positiva) que puede atraer las especies de As cargadas negativamente (Sancha, 2010). Debido a que el As(III) no se encuentra cargado a los $\mathrm{pH}$ naturales de las aguas, se recomienda realizar una etapa previa de oxidación. La efectividad total del proceso de remoción de As dependerá del subsiguiente proceso de separación sólido-líquido final, por lo cual se requiere una alta eficiencia en el proceso de filtración (Sancha, 2010).

Esta tecnología ha sido ampliamente empleada para potabilización de aguas por sus bajos costos de operación y mantenimiento. La eficiencia del proceso para remover arsénico depende principalmente de factores tales como, especiación del As, $\mathrm{pH}$ del agua, dosis de coagulante, presencia de iones competidores (en particular fosfatos y fluoruro). La disposición de los lodos generados puede aumentar los costos. Esta tecnología es recomendable para condiciones de tratamiento centralizado donde se dispone de infraestructura y personal calificado (Sancha, 2010). También puede emplearse como coagulante cal o cal hidratada. Este proceso se conoce como ablandamiento con cal y es fuertemente dependiente del pH (D’Ambrosio, 2005).

Al momento de seleccionar una tecnología de remoción de As se deben evaluar las ventajas y desventajas de cada una de ellas y su factibilidad desde el punto de vista tecnológico, ambiental y económico. Algunas tecnologías resultan eficaces al disminuir la cantidad de arsénico en el agua de consumo, pero exigen complicados 
diseños de ingeniería y profesionales capacitados. Los métodos de coagulaciónfloculación y ablandamiento con cal, son los más usados en grandes sistemas. En pequeños sistemas puede aplicarse el intercambio iónico, alúmina activada, ósmosis inversa, nanofiltración y electrodiálisis inversa (Castro de Esparza, 2006).

Además de los aspectos económicos, desde el punto de vista técnico, las características fisicoquímicas y microbiológicas de las aguas así como los materiales disponibles en la región serán un factor importante a tener en cuenta en el momento de elegir una metodología. La selección del método dependerá de la especiación del As, del pH, la composición química del agua (concentración inicial de As, dureza, presencia de sílice, sulfatos, fosfatos, hierro y otras especies químicas), los volúmenes de agua a tratar, la infraestructura disponible y finalmente, se debe tener en cuenta la manipulación y disposición final de los residuos generados (Höll y Litter, 2010).

Los métodos convencionales a menudo no son económicamente viables en zonas de bajos recursos o en comunidades pequeñas con población rural o dispersa. En este sentido durante las últimas décadas se han realizado una gran cantidad de trabajos que apuntan al desarrollo de tecnologías económicas o emergentes (Bundschuh et al., 2011). Algunas de las tecnologías emergentes prometedoras citadas en la bibliografía son: remediación in situ (Cortina et al., 2010), tecnologías fotoquímicas (Morgada y Litter, 2010), adsorción empleando materiales geológicos como arcillas, lateritas, suelos (Bundschuh et al., 2011) y nanopartículas de Fe o método del hierro "zerovalente" ZVI (Morgada y Litter, 2010). 


\section{CAPÍTULO 3}

\subsection{Algunos aspectos de la química del arsénico}

$\mathrm{El}$ arsénico es un metaloide del grupo $\mathrm{V} A$ que ha sido muy estudiado por su conocida toxicidad. Sus propiedades químicas le permiten formar compuestos tanto con metales como con no metales. Si bien presenta propiedades intermedias entre metales y no metales, por su electronegatividad, energía de ionización y potencial iónico en sus mayores estados de oxidación, predominan las características de no metal formando más fácilmente aniones que cationes. Por su ubicación en la tabla periódica, presenta similitudes con el $\mathrm{P}$, entre ellas los posibles estados de oxidación: $+5,+3,0$ y -3 . Puede formar compuestos tanto inorgánicos como orgánicos. Se ha utilizado en la medicina y en diversos campos como, la agricultura, la ganadería, la electrónica, la industria y la metalurgia (Mandal and Suzuki, 2002).

Las formas químicas definen la disponibilidad biológica y los efectos fisiológicos y toxicológicos del arsénico. Las especies inorgánicas son más tóxicas que las orgánicas aunque es de destacar que estas últimas tienen la capacidad para acumularse y transformarse en inorgánicas. El As(III) inorgánico es mucho más tóxico, mas soluble y mas móvil que el As(V) inorgánico (Mandal and Suzuki, 2002). El grado de toxicidad disminuye de la siguiente forma: arsina $>\mathrm{As}(\mathrm{III})$ inorgánico $>\mathrm{As}(\mathrm{III})$ orgánico $>\mathrm{As}(\mathrm{V})$ inorgánico $>\mathrm{As}(\mathrm{V})$ orgánico $>$ arsénico elemental, siendo la toxicidad del As(III) 10 veces mayor que la del As(V) (Castro de Esparza y Wong de Medina, 1998; Mandal and Suzuki, 2002).

Es un elemento ubicuo que ocupa el lugar 20 en abundancia en la corteza terrestre (Mandal and Suzuki, 2002). Se moviliza a través de una combinación de procesos naturales tales como las reacciones de meteorización, la actividad biológica y las emisiones volcánicas, así como a través de una serie de actividades antropogénicas. Si bien, la mayoría de los problemas ambientales por la presencia de arsénico son el resultado de la movilización a partir de procesos naturales, el hombre ha tenido un importante impacto adicional a través de la actividad minera, el empleo de combustibles fósiles, el uso de pesticidas arsenicales, herbicidas y desecantes de cultivos y la utilización del arsénico como aditivo en alimentos para ganado. Aunque el empleo de productos arsenicales como pesticidas y herbicidas se ha reducido significativamente en las últimas décadas, sigue siendo común su uso para la conservación de la madera (Smedley and Kinninburgh, 2002).

La concentración de As en la mayoría de las rocas oscila entre 0,5 y $2,5 \mathrm{mg} \mathrm{kg}^{-1}$, con una concentración media en las rocas ígneas y sedimentarias de $2 \mathrm{mg} \mathrm{kg}^{-1}$. Se 
encontraron concentraciones más altas en sedimentos arcillosos de grano fino y en fosforitas. En la naturaleza hay más de 200 minerales que contienen arsénico, de los cuales aproximadamente el $60 \%$ son arseniatos, el $20 \%$ sulfuros y sulfosales y el $20 \%$ restante incluye arseniuros, arsenitos, óxidos y arsénico elemental, sin embargo, es de destacar que solo algunos de ellos son encontrados comúnmente en cantidades significativas (Mandal and Suzuki, 2002). Las mayores concentraciones del elemento aparecen en sulfuros como pirita, calcopirita, galena y marcasita, donde sustituye al azufre en la estructura. En estos minerales el contenido de As puede llegar a superar el $10 \%$. El mineral de As más abundante es la arsenopirita (FeAsS); otros arseniuros metálicos son los minerales $\mathrm{FeAs}_{2}$ (löllingita), NiAs (niccolita), CoAsS (cobalto brillante), NiAsS (gersdorfita) y $\mathrm{CoAs}_{2}$ (esmaltita). También son importantes los sulfuros AsS (realgar) y $\mathrm{As}_{2} \mathrm{~S}_{3}$ (oropimente). Otros minerales donde puede encontrarse arsénico son los óxidos e hidróxidos metálicos de $\mathrm{Fe}, \mathrm{Mn}$ y $\mathrm{Al}$ donde el As puede estar formando parte de la estructura o adsorbido a la superficie. El As también puede ser adsorbido en los bordes de los minerales de arcilla y sobre la superficie de la calcita y minerales comunes en los sedimentos. Los fosfatos también pueden presentar contenidos altos de As (Smedley and Kinninburgh, 2002).

Una característica importante que influye notoriamente en los niveles de As que pueden encontrarse en el ambiente, se relaciona con su alta movilidad y capacidad de transformación, puede adsorberse y desorberse de partículas, cambiar de estado de oxidación al reaccionar con oxígeno u otras moléculas del aire, agua o suelo, así como por acción de microorganismos (Mandal and Suzuki, 2002; Smedley and Kinninburgh, 2002).

Respecto al comportamiento ambiental en aguas cabe mencionar que en aguas superficiales y subterráneas el arsénico comúnmente se encuentra en estado de oxidación +5 (como anión arseniato) y +3 (como anión arsenito), ambas especies de gran movilidad. Bajo condiciones de reducción, generalmente en los sedimentos de los lagos y en algunas aguas subterráneas, predomina el arsénico trivalente 0 arsenito siendo altamente dependiente del $\mathrm{pH}$.

En lo que respecta a la movilidad y transporte en el agua subterránea, queda condicionada a efectos de flujo y dilución, que dependerá del régimen hidrogeológico y paleohidrogeológico del acuífero. El tiempo de residencia en el agua es un factor crítico que afecta la concentración del oxoanión: a menor tiempo de residencia, mayor tasa de renovación, y por tanto mayor tasa de pérdida de arsénico por flujo. La consecuencia directa es que, en general, en acuíferos profundos y "antiguos" será 
mucho más difícil encontrar altas concentraciones de As, requiriéndose en estos casos flujos muy lentos.

Desde el punto de vista geoquímico, el transporte en el agua está condicionado por la adsorción, ya que ésta produce un retardo en el movimiento del arsénico en comparación con el propio flujo del agua. Sin embargo es muy difícil que el arsénico sea completamente extraído de los acuíferos con el flujo del agua, bien a causa de su adsorción en el lecho o bien a causa de su elevada concentración. Puesto que el arsenito y el arseniato tienen diferentes comportamientos de adsorción, serán transportados en el agua con diferente velocidad. En condiciones oxidantes y ligeramente ácidas, el $\mathrm{As}(\mathrm{III})$ se mueve 5 ó 6 veces más rápido que el $\mathrm{As}(\mathrm{V})$, y este último se moverá más rápidamente en condiciones neutras (aunque siempre más lento que $\mathrm{As}(\mathrm{III})$ ); mientras que en condiciones reductoras y alcalinas, tanto $\mathrm{As}(\mathrm{III})$ como $\mathrm{As}(\mathrm{V})$ se mueven rápidamente. En forma general puede decirse que la desorción del arsénico adsorbido en la fase sólida de un acuífero está condicionada por los cambios de $\mathrm{pH}$, la ocurrencia de reacciones redox (reducción/oxidación), la presencia de iones competitivos y los cambios en la estructura cristalina de la fase sólida.

En lo referente a las especies covalentes involucradas con la movilidad del arsénico, los arseniatos tienen mayor capacidad de ionización debido a la presencia del doble enlace. La existencia de los varios aniones puede relacionarse con el potencial redox (Eh) y con el $\mathrm{pH}, \mathrm{y}$ en aguas con altos niveles de oxígeno, el $\mathrm{As}^{+5}$ (como $\mathrm{H}_{3} \mathrm{AsO}_{4}$ ) se vuelve estable, existiendo en un rango de $\mathrm{pH}$ de entre 2 a 13 como se indica en la Tabla 3.1.

Tabla 3.1. Predominio de las especies de As en relación a los rangos de pH en el medio acuoso.

\begin{tabular}{c|c|c|c|c}
\hline $\mathrm{pH}$ & $0-9$ & $10-12$ & 13 & 14 \\
\hline $\mathrm{As}(\mathrm{III})$ & $\mathrm{H}_{3} \mathrm{AsO}_{3}$ & $\mathrm{H}_{2} \mathrm{AsO}_{3}{ }^{-}$ & $\mathrm{HAsO}_{3}{ }^{{ }^{-}}$ & $\mathrm{AsO}_{3}{ }^{3-}$ \\
\hline $\mathrm{pH}$ & $0-2$ & $3-6$ & $7-11$ & $12-14$ \\
\hline $\mathrm{As}(\mathrm{V})$ & $\mathrm{H}_{3} \mathrm{AsO}_{4}$ & $\mathrm{H}_{2} \mathrm{AsO}_{4}{ }^{-}$ & $\mathrm{HAsO}_{4}{ }^{{ }^{-}}$ & $\mathrm{AsO}_{4}{ }^{-{ }^{-}}$ \\
\hline
\end{tabular}

El potencial redox y el $\mathrm{pH}$ son los factores más importantes que controlan la especiación del elemento (Figura 3.1). El potencial redox regula los estados de oxidación del As mientras que el $\mathrm{pH}$ afecta el grado de protonación de las formas ácidas de los oxoaniones del elemento en soluciones acuosas. El arseniato es estable en ambientes oxidantes y predomina sobre el arsenito. Para los valores de $\mathrm{pH}$ comúnmente encontrados en aguas naturales las especies dominantes de $\mathrm{As}(\mathrm{V})$ son $\mathrm{H}_{2} \mathrm{AsO}_{4}^{-}$cuando el $\mathrm{pH}$ se encuentra entre 2,2 y 6,9 y $\mathrm{HAsO}_{4}{ }^{2-}$ a valores de $\mathrm{pH}$ 
comprendidos entre 6,9 y 11,5. El ácido arsénico $\left(\mathrm{H}_{3} \mathrm{AsO}_{4}\right)$ y el arseniato $\left(\mathrm{AsO}_{4}{ }^{3-}\right)$ solo pueden estar presentes en condiciones extremadamente ácidas $(\mathrm{pH}<2,2)$ y alcalinas $(\mathrm{pH}>11,5)$, respectivamente. En condiciones reductoras es estable el arsenito, a $\mathrm{pH}$ inferior a aproximadamente 9,2 la especie no cargada $\mathrm{H}_{3} \mathrm{AsO}_{3}$ es la dominante. A valores de $\mathrm{pH}$ entre 9,2 y 12 predomina la especie $\mathrm{H}_{2} \mathrm{AsO}_{3}{ }^{-}$y solo cuando el $\mathrm{pH}$ excede 12 puede estar presente la especie $\mathrm{HAsO}_{3}{ }^{2-}$ (Smedley and Kinninburgh, 2002; Stollenwerk, 2003).

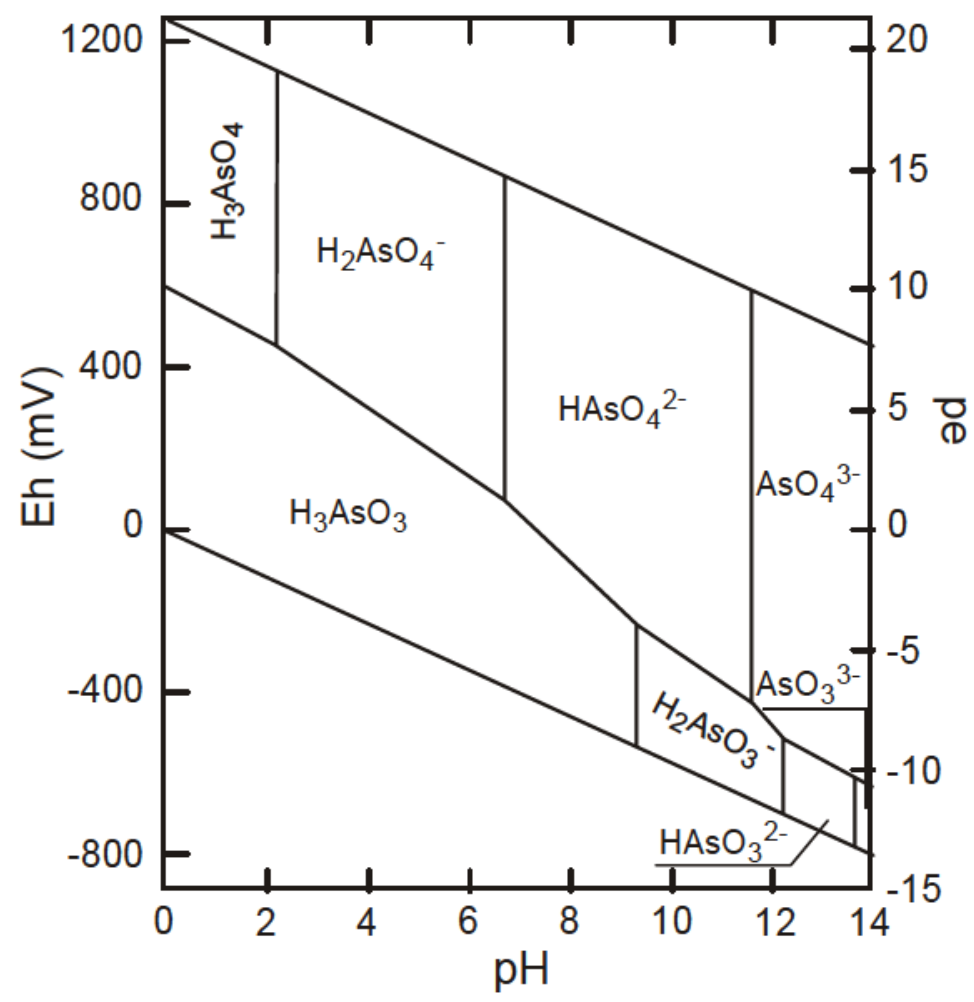

Figura 3.1. Diagrama Eh-pH para especies acuosas de arsénico en el sistema As- $\mathrm{O}_{2}-\mathrm{H}_{2} \mathrm{O}$ a $25^{\circ} \mathrm{C}$ y 1 bar de presión total (Smedley and Kinniburgh, 2002).

\subsection{Algunas consideraciones hidrogeológicas}

La presencia de elevados niveles de As en agua está directamente relacionada con su liberación desde la fase sólida, con fenómenos de transporte y de transferencia a otros medios y a procesos de dilución por mezcla. El arsénico es un elemento particular entre los elementos traza por su sensibilidad a movilizarse a los valores de $\mathrm{pH}$ que se encuentran típicamente en las aguas subterráneas $(6,5$ a 8,5$)$, tanto en condiciones oxidantes como reductoras (Smedley and Kinninburgh, 2002).

El arseniato, es la especie arsenical más difundida en el medio ambiente y es la mayoritaria en aguas y suelos (Smedley and Kinninburgh, 2002; Stollenwerk, 2003). La forma reducida, arsenito, se encuentra en forma minoritaria en aguas, suelos y seres vivos (Litter y Morgada, 2009). Las formas de arsénico orgánicas pueden ser producidas por la actividad biológica, sobre todo en las aguas superficiales, pero rara 
vez son cuantitativamente importantes (Smedley and Kinninburgh, 2002). Es de destacar que tienden a encontrarse concentraciones más altas de As en las aguas subterráneas que en las aguas superficiales (Stollenwerk, 2003).

En las Figuras 3.2 a y b se muestra la distribución de las especies de As(III) y $\mathrm{As}(\mathrm{V})$ en función del $\mathrm{pH}$. En general, en aguas superficiales predomina el $\mathrm{As}(\mathrm{V})$, mientras que en aguas subterráneas pueden encontrarse ambos estados de oxidación ya que las concentraciones de $\operatorname{As}(\mathrm{III})$ y $\mathrm{As}(\mathrm{V})$ dependen de la entrada de As al sistema, de las condiciones redox y de la actividad biológica. En aguas marinas predomina el As(V) inorgánico (Litter y Morgada, 2009).
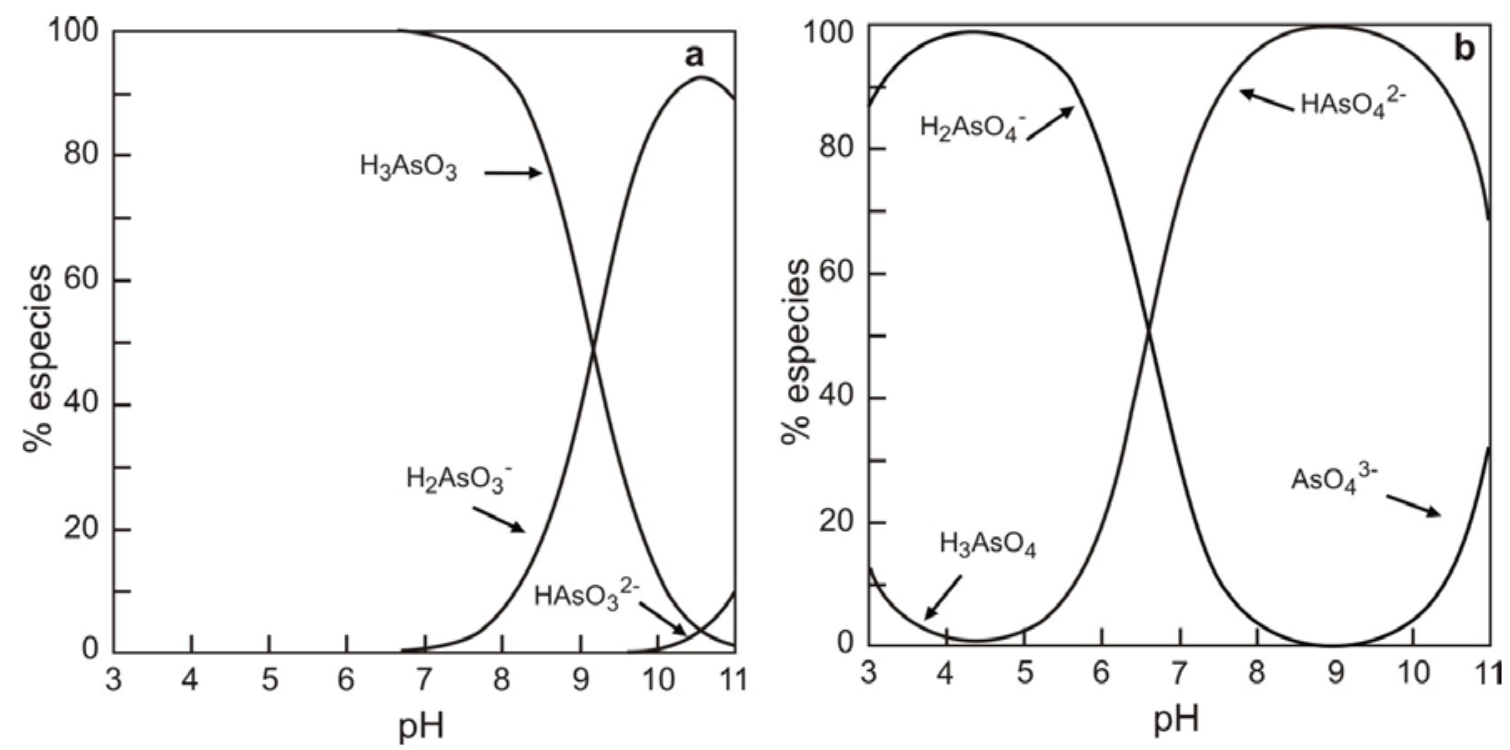

Figura 3.2. a) Especies de arsenito en función del pH. b) Especies de arseniato en función del $\mathrm{pH}$ (Smedley and Kinniburgh, 2002).

En lo que respecta a la adsorción-desorción, la Figura 3.3 muestra las curvas de adsorción de $\mathrm{As}(\mathrm{III})$ y $\mathrm{As}(\mathrm{V})$ en fases hidratadas de hierro (HFO), en función del pH, en la que el área sombreada representa el rango de $\mathrm{pH}$ para el cual se produce la máxima desorción de As.

Como se mencionara precedentemente, la especiación del As en el medio tiene un efecto significativo en la movilidad de las distintas especies en el agua. El As(III) es más móvil que el $\mathrm{As}(\mathrm{V})$. La adsorción de As, especialmente el pentavalente, sobre oxi/hidróxidos metálicos $y$ otros minerales puede restringir su movilidad $y$ disponibilidad. El As(III), como $\mathrm{H}_{3} \mathrm{AsO}_{3}$, forma dominante a $\mathrm{pH}<9,2$, es mucho menos fuertemente adsorbido, lo que contribuye a un aumento en la movilidad (Stollenwerk, 2003).

En el agua subterránea se encuentran elevadas concentraciones de arsénico geogénico en una amplia variedad de entornos y con distintas condiciones climáticas, 
incluyendo tanto ambientes oxidantes como reductores. Además, las aguas subterráneas de algunas áreas pueden contener As debido a la actividad geotermal, la minería y la industria (Mandal and Suzuki, 2002; Smedley and Kinniburgh, 2002). Smedley and Kinniburgh (2002) definen los siguientes ambientes naturales en los cuales se presentan contenidos de As elevados en las aguas subterráneas: ambientes reducidos (por ejemplo Bangladesh, India, Taiwán, Vietnam), ambientes oxidantes (por ejemplo México, Chile, Argentina) y ambientes mixtos (USA).

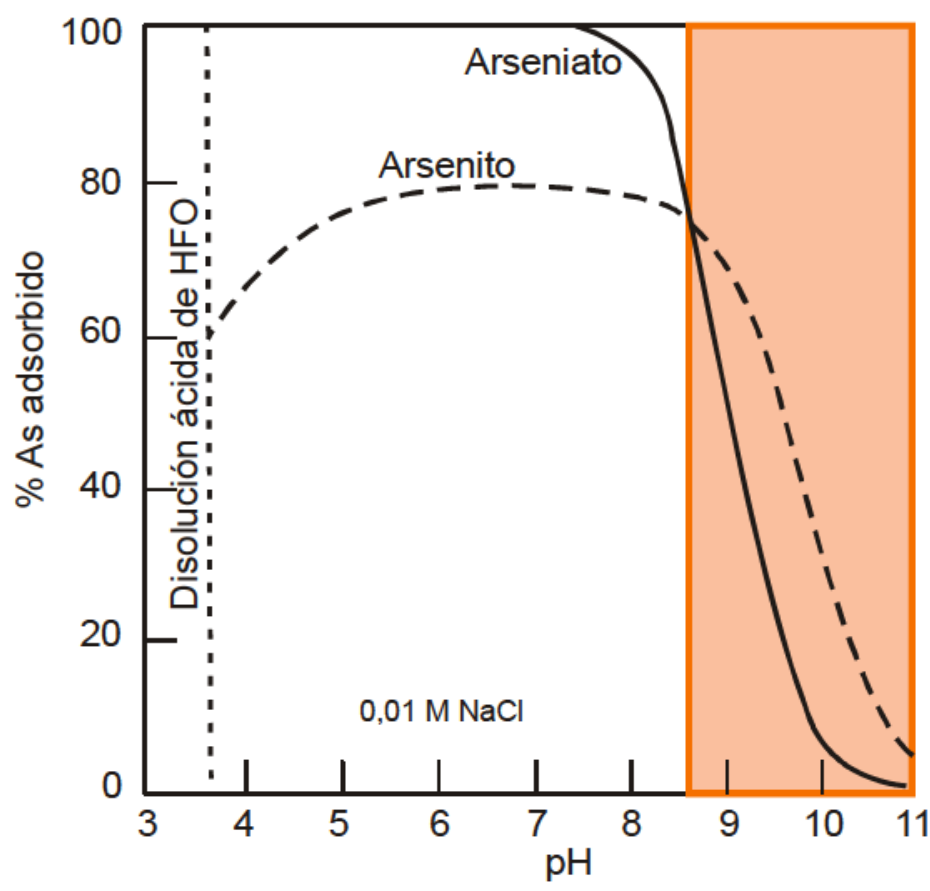

Figura 3.3. Curvas de adsorción de $\mathrm{As}(\mathrm{III})$ y $\mathrm{As}(\mathrm{V})$ en función del $\mathrm{pH}$. El área sombreada representa el rango de $\mathrm{pH}$ para el cual se produce la máxima desorción de As.

Como se comentó en el Capítulo 2, en las aguas subterráneas de nuestro país prevalecen las condiciones oxidantes, por ese motivo el arsénico está mayoritariamente disuelto en forma de especies de $\mathrm{As}(\mathrm{V})$ (Smedley and Kinniburgh, 2002; Fernández-Turiel et al., 2005; Bundschuh et al., 2012). Las aguas suelen tener alta salinidad y las concentraciones de As se correlacionan bien con la existencia de especies disueltas de B, F, V, Mo y Se. En este ambiente geoquímico, el Fe y el Mn tienden a formar especies minerales en forma de óxidos por lo que la concentración de estos elementos disueltos es baja (Smedley and Kinniburgh, 2002; Fernández-Turiel et al., 2005). El pH de las aguas es neutro o tiende a la alcalinidad predominando las especies $\mathrm{H}_{2} \mathrm{AsO}_{4}^{-}$y $\mathrm{HAsO}_{4}{ }^{2-}$ (Fernández-Turiel et al., 2005). Smedley et al. (2002) encontraron valores típicos de $\mathrm{pH}$ de 7,0 a 8,7; mientras que Nicolli et al. (2001) reportaron valores de $\mathrm{pH}$ comprendidos entre 6,3 y 9,2. Es de destacar, que las aguas subterráneas del tipo bicarbonato de sodio y $\mathrm{pH}$ alto $(>8)$ presentan mayores 
concentraciones de arsénico que las aguas subterráneas del tipo bicarbonato de calcio ( $\mathrm{pH}$ aproximadamente neutro) (Bundschuh et al., 2012).

La ceniza volcánica que se encuentra en una proporción de $5-25 \%$ en los sedimentos del loess chaco-pampeano es la principal fuente de As y otros elementos, tales como V, Mo, U, B y F. Esta ceniza volcánica, contiene más de $90 \%$ de vidrio de composición riolítica con concentraciones de arsénico entre 5 y $8 \mathrm{mg} \mathrm{kg}^{-1}$ y debido a su estructura amorfa, el elemento es muy soluble en agua. En períodos de tiempo geológicos, las condiciones fueron favorables para la adsorción en oxi/hidróxidos metálicos de $\mathrm{Fe}$, $\mathrm{Al}$ y $\mathrm{Mn}$ desde donde se ha podido producir la desorción, especialmente en condiciones de $\mathrm{pH}$ alto, situación que conduce a un aumento en la concentración de As disuelto (Smedley and Kinniburgh, 2002; Bundschuh et al., 2012).

La compleja geoquímica del As implica una suma de procesos que controlan la partición del elemento entre las fases sólida y la acuosa, incluyendo la precipitación/disolución de minerales, la adsorción/desorción, la oxidación/reducción y las transformaciones biológicas. De todas ellas, la adsorción/desorción es el proceso más importante que controla las concentraciones de As en aguas subterráneas (Stollenwerk, 2003). En el siguiente punto se presentan algunas particularidades de estos procesos de adsorción/desorción.

\subsection{Afinidad del As hacia los sistemas oxídicos conteniendo metales de moderado potencial iónico}

Las reacciones de adsorción entre el arsénico y las superficies minerales son generalmente el control más importante de la concentración de As disuelto en aguas subterráneas. La adsorción es una función compleja que relaciona las propiedades de la superficie sólida, el pH, la concentración y la especiación del arsénico así como la presencia de iones competitivos. La adsorción de As por oxi/hidróxidos metálicos y minerales de arcilla probablemente es el mayor control sobre el transporte de arsénico en el agua subterránea (Stollenwerk, 2003).

Los óxidos e hidróxidos de metales como hierro, aluminio y manganeso son las fuentes más importantes de sedimentos del acuífero en los que la presencia del contaminante es más generalizada. En dichas especies existen grupos funcionales superficiales $\mathrm{OH}_{2}{ }^{+}, \mathrm{OH}$ y $\mathrm{O}^{-}$, responsables de las propiedades de adsorción (Stollenwerk, 2003). Como se muestra en la Figura 3.4, tras la exposición al agua, los iones metálicos en la superficie de los oxi/hidróxidos completan sus esferas de coordinación con los grupos $\mathrm{OH}$ de las moléculas de agua. Dependiendo del $\mathrm{pH}$, se desarrolla una carga superficial en el sólido, debido a la protonación o disociación de los grupos $\mathrm{OH}$ funcionales según las siguientes ecuaciones: 


$$
\begin{aligned}
& \mathrm{XOH}(\mathrm{s})+\mathrm{H}^{+}(\mathrm{aq}) \leftrightarrow \mathrm{XOH}_{2}^{+}(\mathrm{s}) \\
& \mathrm{XOH}(\mathrm{s}) \leftrightarrow \mathrm{XO}^{-}(\mathrm{s})+\mathrm{H}^{+}(\mathrm{aq})
\end{aligned}
$$

Donde $\mathrm{XOH}$ representa un grupo hidroxilo superficial reactivo unido a un ión metálico $X(F e, A l o ́ ~ M n)$.

La carga superficial positiva se produce por transferencia directa de protones bajo condiciones ácidas (ecuación 3.1), mientras que la carga superficial negativa se genera por disociación de los grupos $\mathrm{OH}$ en soluciones alcalinas (ecuación 3.2). Este efecto del $\mathrm{pH}$ sobre la superficie de los oxi/hidróxidos se relaciona con el cambio en el punto de carga cero (PZC) del sólido (valor de $\mathrm{pH}$ donde la carga superficial neta es cero). Cuando el pH es mayor que el PZC se favorece la ecuación 3.2 por lo que la carga de la superficie es negativa, no presentado afinidad por los oxoaniones. Cuando el $\mathrm{pH}$ del medio es menor que el PZC se ve favorecida la ecuación 3.1 y la superficie del mineral adquiere carga positiva con afinidad por las especies cargadas negativamente. Por lo tanto, la adsorción de oxoaniones en estos minerales se ve favorecida a $\mathrm{pH}$ ácido, incrementando la movilidad del elemento al aumentar el $\mathrm{pH}$ del acuífero.

A

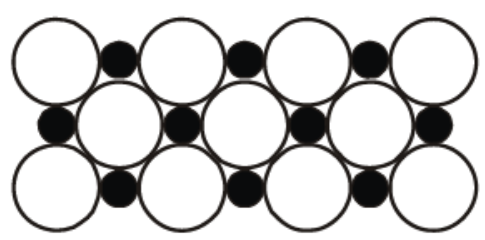

C

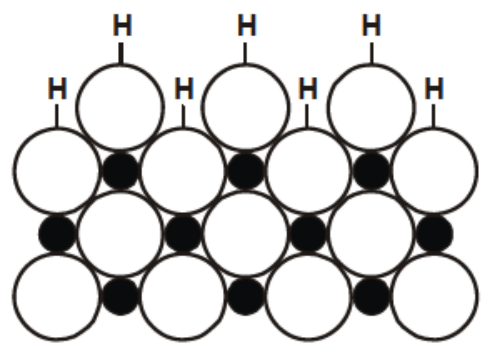

B

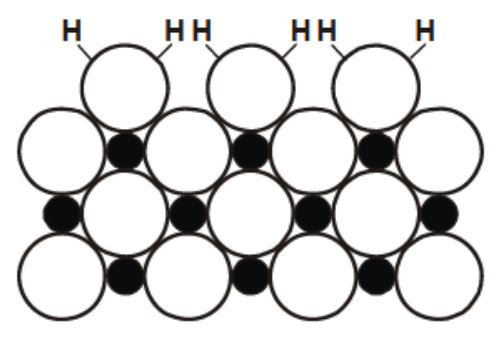

- Iones metálicos<smiles>c1ccccc1</smiles>

Figura 3.4. Sección transversal de la capa superficial de un óxido metálico. A: iones metálicos de la superficie insaturados. B: en presencia de agua los iones metálicos de la superficie pueden coordinar moléculas de agua. C: la quimisorción disociativa conduce a una superficie hidroxilada. (Stollenwerk, 2003).

Los sólidos de los acuíferos raramente se encuentran constituidos por fases minerales discretas. Además, en función del tiempo, las reacciones de meteorización producen mezclas más complejas de minerales (oxi/hidróxidos metálicos, aluminosilicatos, carbonatos, materia orgánica) con diferente grado de cristalinidad. El 
conjunto de fases contribuyen, en distintas proporciones, a la adsorción y desorción del arsénico. El PZC de cada componente de un acuífero presenta un valor característico y en la Figura 3.5 se muestran los valores de PZC de los principales componentes de los acuíferos. Los oxi/hidróxidos de Fe de diferente cristalinidad y composición son las fases más comunes asociadas a los sólidos del acuífero. Pueden estar presentes como partículas discretas o como revestimientos sobre otras superficies minerales. Estos oxi/hidróxidos tienen los valores más altos de PZC (superior a 7) los que los identifica como minerales propicios para la retención de aniones (Sadiq, 1997).

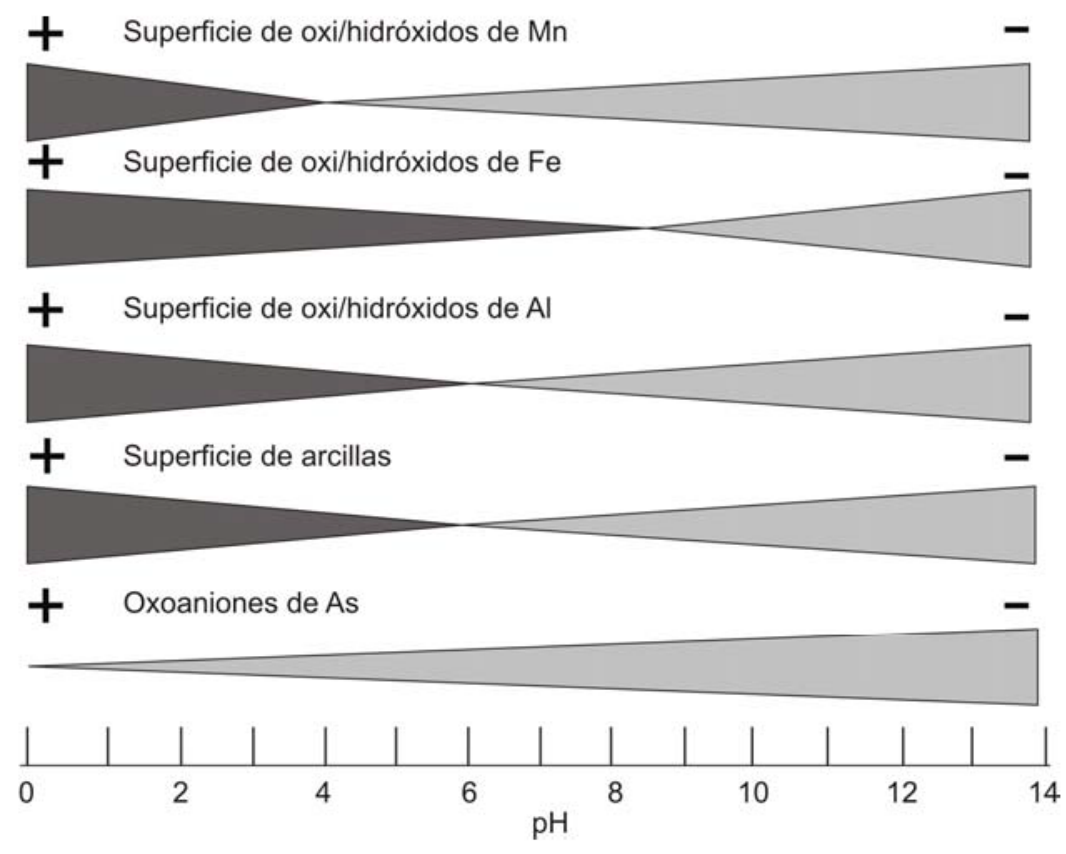

Figura 3.5. Distribución de cargas de los principales minerales de los acuíferos (modificado de Sadiq, 1997).

El grado de adsorción/desorción, controlado en gran medida por el $\mathrm{pH}$, es distinto para los dos oxoaniones de $\mathrm{As}(\mathrm{III})$ y $\mathrm{As}(\mathrm{V})$. El arseniato se adsorbe en el rango de $\mathrm{pH}$ que se encuentra en la mayoría de las aguas subterráneas, presentando una mayor adsorción a valores de $\mathrm{pH}$ más bajos. A medida que aumenta el pH por encima de aproximadamente 7 , aumenta la carga negativa de la superficie sólida, y disminuye significativamente la adsorción de las especies de $\mathrm{As}(\mathrm{V})$. El arsenito también se adsorbe sobre un rango amplio de $\mathrm{pH}$, pero en contraste con el $\mathrm{As}(\mathrm{V})$, la adsorción del $\mathrm{As}(\mathrm{III})$ aumenta con el $\mathrm{pH}$, alcanzando un máximo a pH aproximadamente entre 8 y 9. Como resultado de este comportamiento, el As(III) es generalmente más móvil que el $\mathrm{As}(\mathrm{V})$ en ambiente ácido y menos móvil en ambiente alcalino (Stollenwerk, 2003).

En relación al mecanismo de adsorción, en la Figura 3.6 se esquematizan los dos mecanismos que describen la adsorción de los solutos por una superficie sólida. 
La formación de complejos superficiales de esfera externa ("outer-sphere surface complexation"), o la adsorción no específica, implica la atracción electrostática entre una superficie cargada y un ión de carga opuesta en solución que permanece atraído a una cierta distancia de la superficie del mineral. La formación de complejos de esfera interna ("inner-sphere surface complexation"), también denominado adsorción específica, implica la formación de un complejo de coordinación con la superficie del mineral formando una unión fuerte con los iones de la solución. Las uniones de los complejos de esfera interna son más difíciles de romper que las uniones de los complejos de esfera externa (Stollenwerk, 2003).

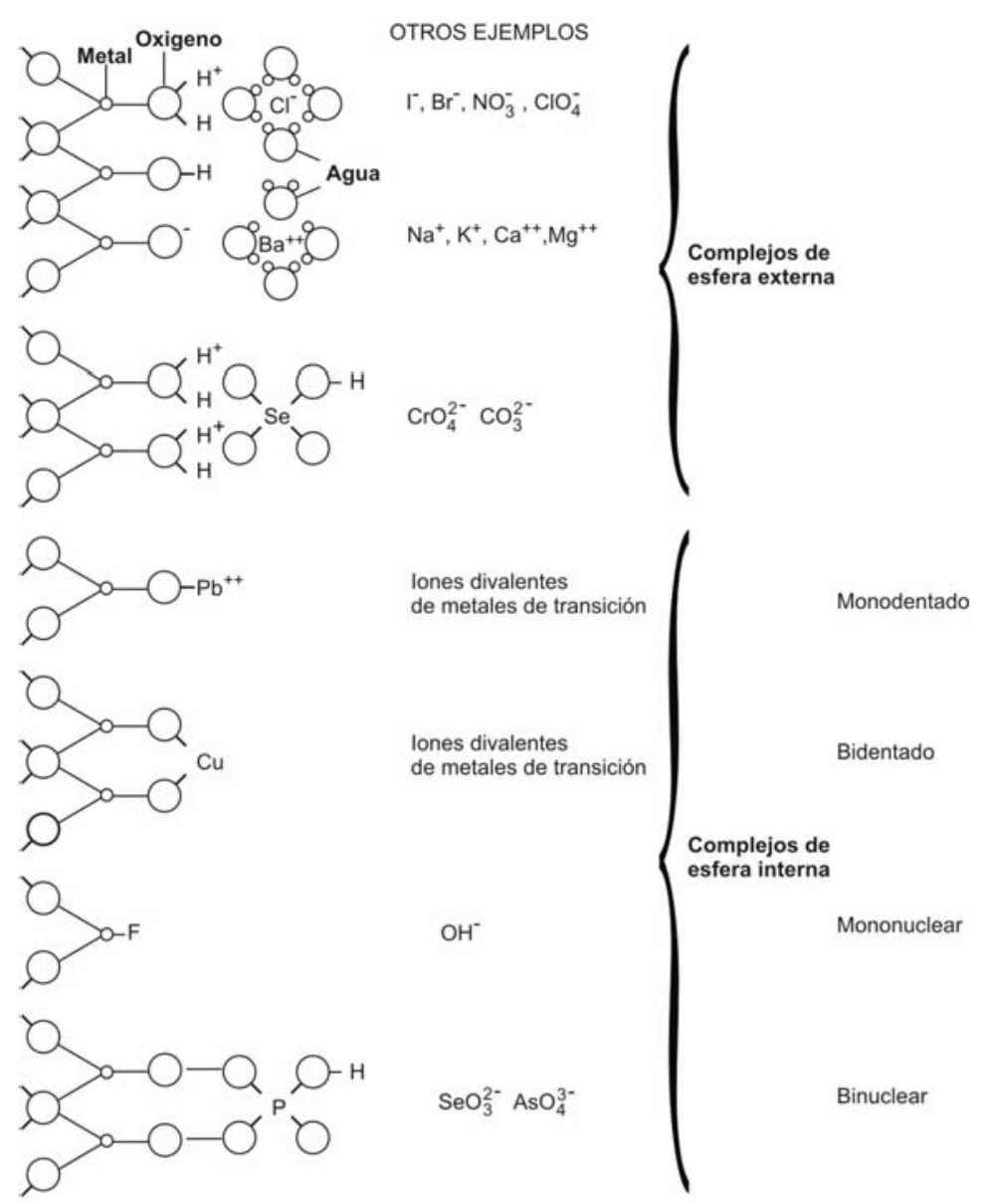

Figura 3.6. Representación esquemática de complejos de superficie formados entre algunos iones inorgánicos y los grupos hidroxilo de una superficie oxídica. (Stollenwerk, 2003).

En el caso del As, la adsorción se lleva a cabo por intercambio de los "ligandos arseniato" con grupos funcionales superficiales SupOH y $\mathrm{SupOH}_{2}{ }^{+}$, formando complejos de esfera interna. Este tipo de adsorción requiere que el oxoanión no se encuentre completamente disociado para aportar un protón para la complejación con el grupo de la superficie, formando $\mathrm{H}_{2} \mathrm{O}$ (Hingston et al., 1972). La formación de este tipo de complejos superficiales se puede representar por medio de las siguientes reacciones: 


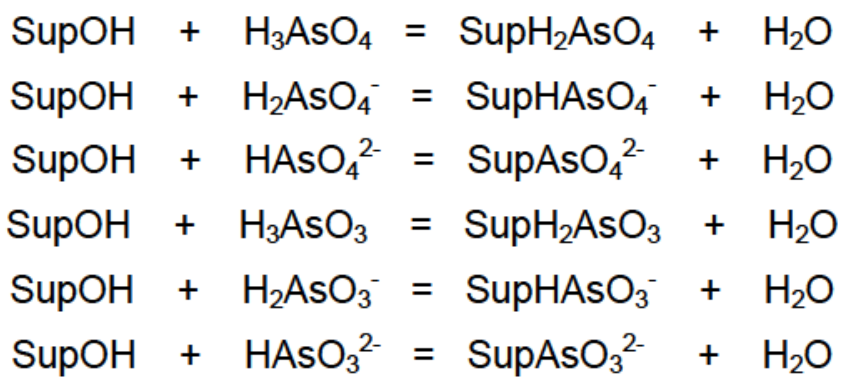

Donde SupOH representa la asociación entre el átomo metálico y el grupo funcional superficial OH (Stollenwerk, 2003). Mayores detalles sobre la formación de complejos superficiales sobre oxi/hidróxidos de Fe se darán en el Capítulo 4.

La cinética de la adsorción de As(III) y As(V) por los oxi/hidróxidos metálicos es rápida, más del $90 \%$ de la adsorción se produce en unas pocas horas. Sin embargo, pueden ser necesarios varios días para alcanzar el equilibrio completo. La etapa limitante para alcanzar el equilibrio es la transferencia de masa, la que es controlada por la difusión de las especies de As a los sitios de adsorción (Stollenwerk, 2003).

Muchos de los solutos comúnmente presentes en las aguas subterráneas pueden influir en la adsorción de As por parte de los oxi/hidróxidos metálicos. Los solutos pueden competir directamente con el arsénico por los sitios de unión superficial o pueden influir indirectamente en la adsorción por la alteración de la carga electrostática de la superficie sólida. Los aniones compiten directamente con el arsénico por los sitios de complejación superficial. Los fosfatos son los principales interferentes en la adsorción de $\mathrm{As}(\mathrm{V})$, debido a la similitud química entre ambos elementos, los complejos de superficie formados por el fosfato son idénticos a los formados por el arseniato, presentando similares afinidades por los sitios superficiales. Contrariamente, el sulfato tiene poco efecto sobre la adsorción de $\mathrm{As}(\mathrm{V})$, debido a que se adsorbe por atracción electrostática formando complejos de esfera externa. La adsorción de cationes sobre la superficie de los oxi/hidróxidos puede aumentar la adsorción de arsénico por el aumento de la carga de la superficie del sólido (Stollenwerk, 2003).

\subsection{La química de los óxidos de hierro}

La química del elemento hierro es sumamente interesante en lo que respecta a la presencia, distribución y formas que, en nuestro planeta, presenta uno de los elementos más abundantes $(\sim 5 \%)$, cuarto en orden relativo en la corteza después del O (45\%), Si (27\%) y $\mathrm{Al}(8,40 \%)$. En efecto, los tres estados de oxidación más comunes (elemental, di y trivalente) quedan fuertemente condicionados a las características del medio. Por otra parte, el comportamiento de las especies iónicas en solución acuosa 
es notablemente contrapuesto. El Fe(II) por sus características de tamaño y radio (menor potencial iónico que la especie trivalente) cumple un rol en parte similar al de otras especies divalentes, caracterizado por un entorno octaédrico de moléculas de agua y una gran movilidad geoquímica. Esas propiedades garantizan su participación en fenómenos de meteorización por los cuales el ión se puede lixiviar de las especies minerales que lo contienen. Sin embargo, la alteración con disolución, generalmente es acompañada por un proceso de oxidación que conduce a la especie trivalente, de menor estabilidad en un medio acuoso y de relativamente poca movilidad a los pHs comunes en sistemas naturales (entre 4-9). La razón de este comportamiento está asociada al elevado potencial iónico del Fe(III) y el proceso de hidrólisis asociado al mismo. La capacidad redox del sistema $\mathrm{Fe}-\mathrm{O}_{2}$-agua se asocia a la dependencia de los valores de los potenciales para las hemireacciones $E_{\mathrm{Fe}(\mathrm{III}) / \mathrm{Fe}(\mathrm{II})}^{0}=0,77 \mathrm{v}$ y $\mathrm{E}^{0}{ }_{\mathrm{O} / \mathrm{H} 2 \mathrm{O}}=1,23 \mathrm{v}$ con el pH del medio. La estabilidad para el par hematita/magnetita es dependiente de la $\mathrm{pO}_{2}$ y del agua. La hematita es la fase más estable a $640 \mathrm{~K} \mathrm{y} \mathrm{pO}=10^{-23} \mathrm{mbar}$, mientras que a una $\mathrm{pO}_{2}=1$ bar la estabilidad de ese óxido se extiende hasta $1690 \mathrm{~K}$. En sistemas acuosos la magnetita es la fase predominante en medio básico y condiciones reductoras, en tanto que la hematita es estable en un amplio rango de $\mathrm{pH}$ en condiciones oxidantes. Sin embargo, el dominio de la hematita puede ser reemplazado por otras fases como la goethita u otras fases metaestables polimórficas.

Las Figuras 3.7.a y b representan los diagramas típicos que relacionan potencial redox y $\mathrm{pH}$, indicando las zonas observables en medios naturales. Por otra parte, la Figura 3.7.c corresponde al diagrama $\mathrm{Eh} / \mathrm{pH}$ para las especies de hierro.

Existen 16 óxidos de hierro, en su mayor parte naturales, incluyendo óxidos propiamente dichos, hidróxidos y oxi/hidróxidos, cuyo nombre y composición se detallan en la Tabla 3.2. La mayor parte de ellos contiene al hierro en estado trivalente, en coincidencia con los conceptos de ácidos y bases de Pearson. En función del pH y del potencial las especies se encuentran en solución como iones $\mathrm{Fe}$ (III) ○ $\mathrm{Fe}$ (II) hidratados en rangos de $\mathrm{pH}$ muy ácido o intermedio respectivamente.

Las fases sólidas presentan estructuras que consisten en ordenamientos compactos de aniones (preferentemente hcp) en el que el hierro se encuentra en coordinación octaédrica $\mathrm{Fe}^{\prime \prime \prime}(\mathrm{O}, \mathrm{OH})_{6}$ si bien es posible la presencia de Fe tetraédrico $\mathrm{Fe}^{\text {III }} \mathrm{O}_{4}$. Las modificaciones estructurales se presentan en base a la forma en la que las unidades estructurales se dispongan en el espacio, existiendo 5 polimorfos de fórmula $\mathrm{FeOOH}$ y cuatro de estequiometría $\mathrm{Fe}_{2} \mathrm{O}_{3}$. En algunos casos aniones como cloruro, sulfato y carbonato pueden formar parte de la estructura cristalina. En contraste con las formas cristalinas, la ferrihidrita denominada "amorphous iron oxide o hydrous ferric 
oxide" se encuentra ampliamente distribuida en entornos superficiales, particularmente en forma de nanopartículas. Se transforma en el tiempo en las formas oxídicas mas estables de las que se considera fase precursora.
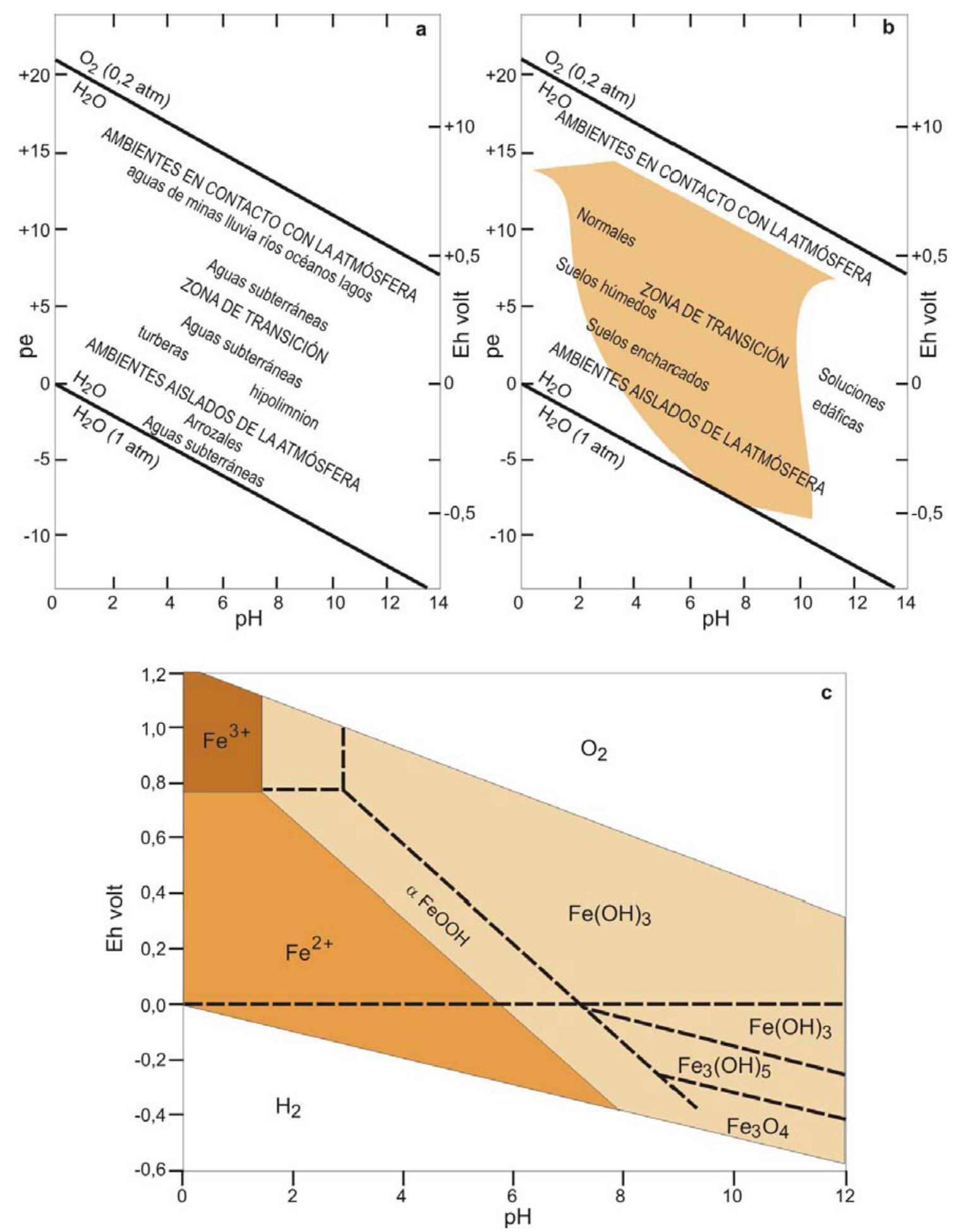

Figura 3.7. Diagramas potencial redox vs $\mathrm{pH}$ en distintos ambientes naturales ( $\mathrm{a}$ y b). Diagrama $\mathrm{Eh} / \mathrm{pH}$ para las especies de hierro. 
Tabla 3.2. Óxidos, hidróxidos y oxi/hidróxidos de hierro (Cornell and Schwertmann, 2003).

\begin{tabular}{|c|c|}
\hline hidróxidos y oxi/hidróxidos & óxidos \\
\hline 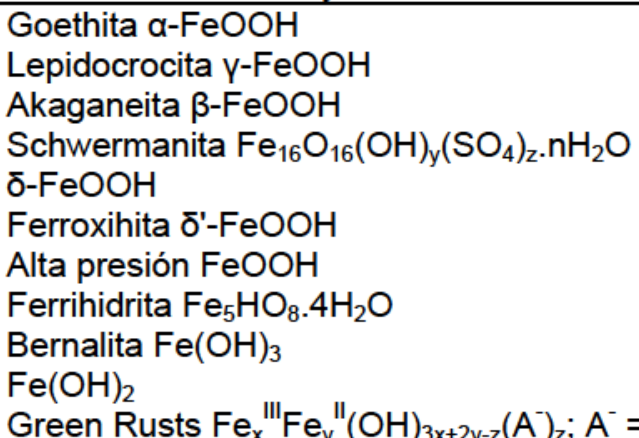 & $\begin{array}{l}\text { Hematita } \alpha-\mathrm{Fe}_{2} \mathrm{O}_{3} \\
\text { Magnetita } \mathrm{Fe}_{3} \mathrm{O}_{4}\left(\mathrm{Fe}^{\mathrm{II}} \mathrm{Fe}_{2}{ }^{\text {III }} \mathrm{O}_{4}\right) \\
\text { Maghemita } \mathrm{Y}-\mathrm{Fe}_{2} \mathrm{O}_{3} \\
\mathrm{\beta}-\mathrm{Fe}_{2} \mathrm{O}_{3} \\
\varepsilon-\mathrm{Fe}_{2} \mathrm{O}_{3} \\
\text { Wustita } \mathrm{FeO} \\
\mathrm{SO}_{4}^{2-}\end{array}$ \\
\hline
\end{tabular}

Por otra parte, algunas micas como la biotita, piroxenos y anfiboles como la augita y la hornblenda respectivamente, el olivino, la ilmenita, la magnetita, la pirita, etc., se pueden citar como minerales importantes en rocas primarias donde el hierro se presenta como constituyente mayoritario. Durante la meteorización, en presencia de $\mathrm{O}_{2}$ y $\mathrm{H}_{2} \mathrm{O}$ el hierro divalente es lixiviado de las especies primarias y posteriormente la forma oxidada es hidrolizada formando óxidos y oxi/hidróxidos de $\mathrm{Fe}$ (III) (minerales pedogénicos de hierro). Los más importantes son minerales de arcilla ricos en hierro así como óxidos de $\mathrm{Fe}$ (III) libres. Se rompen de este modo enlaces $\mathrm{Fe}$ (II)-O-Si y se forman grupos $\mathrm{Fe}(\mathrm{III})-\mathrm{OH}$ y Si-OH. Por ejemplo la goethita se forma por la oxidación e hidrólisis de olivina (fayalita) según:

$$
\mathrm{Fe}_{2} \mathrm{SiO}_{4}+1 / 2 \mathrm{O}_{2}+3 \mathrm{H}_{2} \mathrm{O} \rightarrow 2 \mathrm{FeOOH}+\mathrm{Si}(\mathrm{OH})_{4}
$$

Sin embargo, bajo condiciones reductoras se pueden formar carbonatos y sulfuros divalentes así como fosfatos di y trivalentes.

La goethita puede obtenerse también a partir de la pirita según la reacción:

$$
4 \mathrm{FeS}_{2}+15 \mathrm{O}_{2}+10 \mathrm{H}_{2} \mathrm{O} \rightarrow 4 \mathrm{FeOOH}+8 \mathrm{H}_{2} \mathrm{SO}_{4}
$$

En ambas reacciones el $\mathrm{O}_{2}$ actúa como aceptor de electrones.

La estabilidad de los minerales litogénicos de $\mathrm{Fe}$ (II) en el proceso hidrolíticooxidativo de meteorización depende de la estructura cristalina y del tamaño de partícula, siendo en general los silicatos mas estables que los sulfuros y éstos que los carbonatos. Asimismo, dentro de los silicatos conteniendo $\mathrm{Fe}$, los neso-silicatos (estructuras conteniendo grupos tetraédricos $\mathrm{SiO}_{4}$ aislados), son menos resistentes que los silicatos de cadenas y laminares y el color pardo rojizo que puede apreciarse en granitos alterados es atribuido a la presencia de goethita y ferrihidrita (primeras etapas de la alteración) (Nagano et al., 1999). Usualmente los mecanismos de transformación de rocas y minerales complejos en fases simples de Fe se suelen asociar a procesos topotácticos que facilitan el proceso de cambio. También es posible 
observar por este proceso la cristalización de un óxido de hierro en la superficie del mineral patrón, el que puede actuar como "template". Entre los procesos de alteración no debe descartarse el proceso común de "coating" no orientado sobre la superficie de la partícula del mineral original. Finalmente existen casos en los que no existe relación estructural entre el mineral original y la fase de hierro final. Ocurre cuando el proceso de oxidación e hidrólisis del Fe(II) lixiviado no ocurre "in situ": su presencia puede relacionarse con procesos adicionales de migración. En definitiva, las variaciones en las características del medio (espaciales y temporales) condicionan el contenido y tipo de especie oxídica.

La presencia de la asociación goethita/hematita se basa en la similar estabilidad termodinámica de ambas especies. Sin embargo, muchas veces las condiciones climáticas determinan la preponderancia de algunos de esos productos. Mientras la goethita es observada en mayor escala a elevadas latitudes, la hematita lo hace a bajas latitudes. Asimismo la formación de goethita prevalece en clima húmedo y/o lluvioso, en la parte inferior de una toposecuencia, a diferencia de la hematita que se observa en sabanas con períodos secos y en la parte superior de la toposecuencia. Por otra parte, la ferrihidrita, debido a su naturaleza metaestable, es observada en formaciones jóvenes. Su transformación a óxidos mas estables es rápida y solo se retrasa en presencia de ciertas impurezas que actúan como inhibidores.

En relación a la solubilidad de los óxidos, existe una región de mínima solubilidad entre $\mathrm{pH}$ 7-8 (en las proximidades del PZC). En función del carácter anfótero de los óxidos, se disuelven en medio ácido para formar hidroxo especies catiónicas y en medio básico para formar hidroxo especies aniónicas, si bien existen diferentes opiniones respecto al comportamiento en la región de $\mathrm{pH}$ entre 6 y 9. Las Figuras 3.8. a y b representan las curvas de solubilidad calculadas en función del pH para diferentes especies.

Es interesante mostrar la Figura 3.9 en la que se representa la diferencia entre los valores calculados y experimentales para la ferrihidrita, los cuales son mayores debido a la presencia de fase coloidal (tamaño de partícula $<5 \mathrm{~nm}$ ) que asegura un mayor ataque químico.

\section{Formación de sistemas $\mathrm{Fe}(\mathrm{III})-\mathrm{O}$}

En la naturaleza los sistemas cristalinos hierro trivalente-oxígeno se generan a partir de partículas monodispersas que, en solución acuosa, operan como precursores. Contrariamente, en el laboratorio existen diferentes formas de obtención de dichos sistemas a partir del hierro di y trivalente en solución. A continuación se hace 
referencia a las formas más comunes de formación de los sistemas $\mathrm{Fe}$ (III)-O, si bien todos ellos tienen en común el proceso de hidrólisis: a) hidrólisis forzada de iones metálicos, b) hidrólisis de alcóxidos metálicos y c) hidrólisis oxidativa (Cornell and Schwertman, 2003).
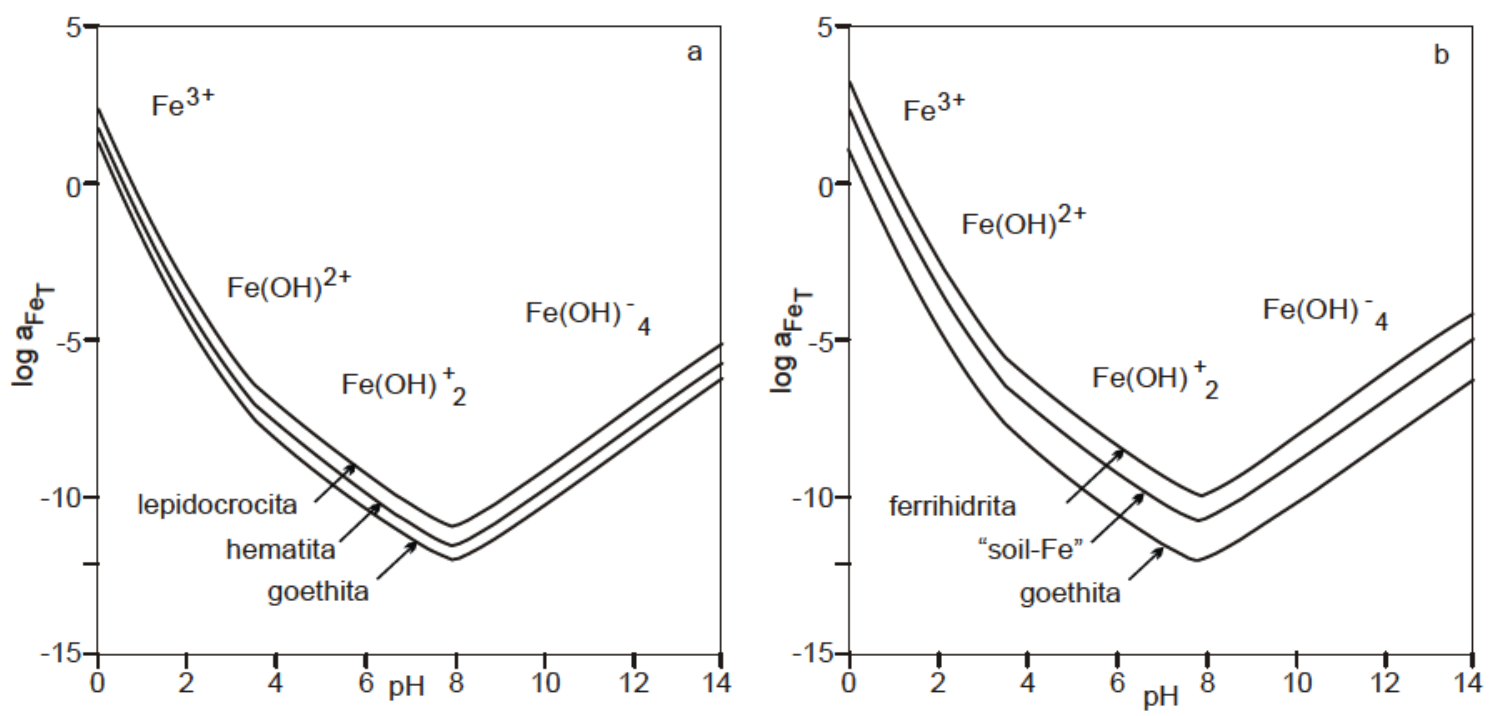

Figura 3.8. Curvas de solubilidad vs $\mathrm{pH}$ para distintas especies de hierro (Cornell and Schwertman, 2003).

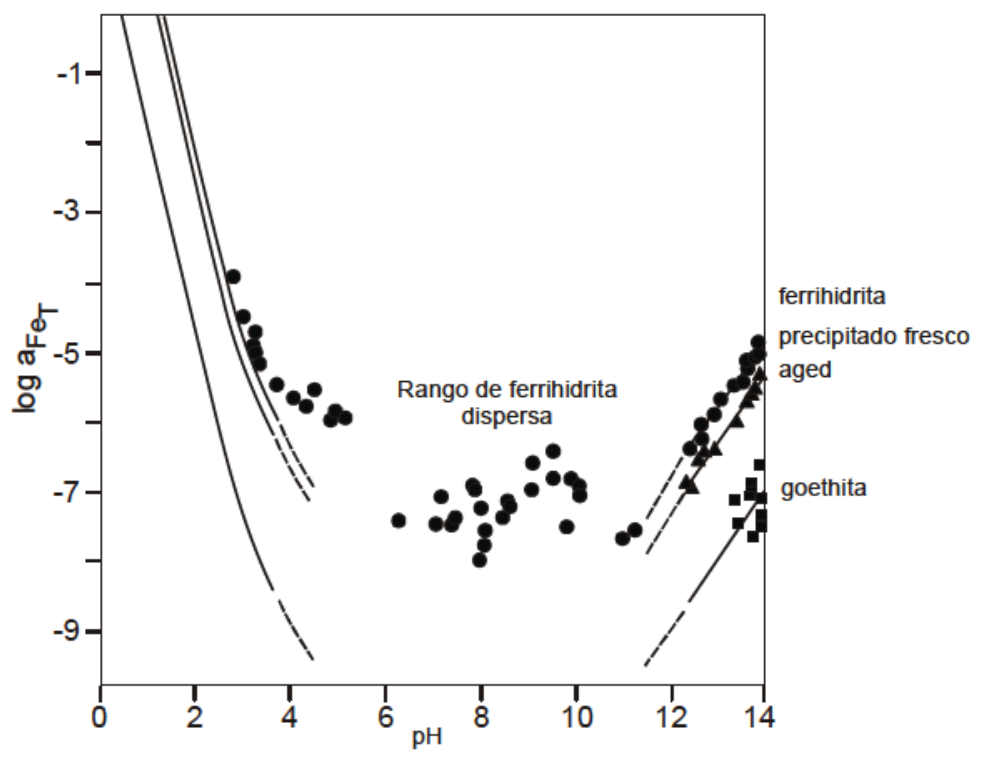

Figura 3.9. Solubilidad de ferrihidrita en función del pH (Cornell and Schwertman, 2003).

Reacción general de hidrólisis: Es bien conocido que en medio acuoso, las sales de $\mathrm{Fe}$ (III) se disocian para formar el complejo hexacuo hierro(III) según la reacción:

$$
\mathrm{FeCl}_{3}+6 \mathrm{H}_{2} \mathrm{O} \rightarrow\left[\mathrm{Fe}\left(\mathrm{H}_{2} \mathrm{O}\right)_{6}\right]^{3+}+3 \mathrm{Cl}^{-}
$$

Sin embargo, debido a las propiedades del catión se induce un proceso ácidobase de Lewis que conduce a una desprotonación y finalmente a óxidos $u$ oxi/hidróxidos cristalinos: 


$$
\begin{gathered}
{\left[\mathrm{Fe}\left(\mathrm{H}_{2} \mathrm{O}\right)_{6}\right]^{3+} \rightarrow \mathrm{FeOOH}+3 \mathrm{H}^{+}+4 \mathrm{H}_{2} \mathrm{O}} \\
2\left[\mathrm{Fe}\left(\mathrm{H}_{2} \mathrm{O}\right)_{6}\right]^{3+} \rightarrow \mathrm{Fe}_{2} \mathrm{O}_{3}+6 \mathrm{H}^{+}+9 \mathrm{H}_{2} \mathrm{O}
\end{gathered}
$$

Ese proceso general es facilitado por alguno de los métodos indicados precedentemente.

Hidrólisis de $\mathrm{Fe}(\mathrm{III})$ en medio ácido: Los equilibrios que conducen a productos de hidrólisis de bajo peso molecular $\mathrm{FeOH}^{2+}, \mathrm{Fe}(\mathrm{OH})_{2}{ }^{+}$y $\mathrm{Fe}_{2}(\mathrm{OH})_{2}{ }^{+4}$ son establecidos rápidamente. Las especies de menor peso molecular interaccionan entre si y generan las de mayor nuclearidad:

$$
\mathrm{Fe}_{2}(\mathrm{OH})_{2}^{4+}+\mathrm{FeOH}^{2+}+\mathrm{H}_{2} \mathrm{O} \rightarrow \mathrm{Fe}_{3}(\mathrm{OH})_{4}{ }^{5+}+\mathrm{H}^{+}
$$

El desarrollo de las especies polinucleares lleva a la continua caída del pH. El proceso gobierna la morfología del producto final.

La polimerización de las especies de hierro conduce a un sistema coloidal (3-5 $\mathrm{nm}$ ) consistente en especies polinucleares con un centro de Fe de nuclearidad p con grupos $\mathrm{OH}^{-}$y $\mathrm{O}^{=}$en posición puente, que puede ser representado como $\mathrm{Fe}_{\mathrm{p}} \mathrm{O}_{\mathrm{r}}(\mathrm{OH})_{\mathrm{s}}{ }^{3 p-}$ $(2 r+s)$. Dado que estas especies son polielectrolitos cargados positivamente, pueden coagular a través de aniones adsorbidos específicamente. Los iones Fe periféricos se encuentran coordinados al menos con una molécula de agua, y la desprotonación por incremento del $\mathrm{pH}$ conduce a la coagulación. Los núcleos críticos se encuentran constituidos por 16-32 átomos de Fe y a posteriori se da la etapa de crecimiento.

En lo que respecta a la hidrólisis forzada de iones metálicos cabe mencionar algunos factores como la hidrólisis térmica de soluciones de sales metálicas. En este procedimiento la hidrólisis se logra a partir de un simple calentamiento de las soluciones salinas a temperaturas cercanas a los $100^{\circ} \mathrm{C}$.

En segundo término la hidrólisis se consigue por el método de obtención in situ por efecto de un agente precipitante. El proceso implica la alcalinización controlada mediante un reactivo apropiado que aporte los iones $\mathrm{OH}^{-}$. Se prefiere carbonato acido de sodio al $\mathrm{NaOH}$ para evitar grandes gradientes de $\mathrm{pH}$. La utilización de urea se remonta al año 1937. Modernamente se ha retomado esta técnica para la obtención de nano-partículas monodispersas (Candall, 1995).

\section{Disolución de las fases oxídicas de hierro(III)}

De la misma forma que la formación de los óxidos de hierro representa un proceso natural de relevancia, también es importante la disolución. Es conocido que los óxidos de Fe son compuestos insolubles. El Fe(III) por su PI es una especie que tiende a la formación de especies oxídicas estables, propiedad asociada a la afinidad 
geoquímica de Pearson. El proceso global de movilización/inmovilización en un medio natural forma parte del ciclo del hierro incluyendo las posibilidades de empleo del elemento por los sistemas orgánicos e inorgánicos, atribuido, en cierta medida, a la formación de complejos (Cornell and Schwertman, 2003).

El comportamiento hacia la disolución ocurre básicamente a través de dos tipos de procesos: a) electroquímicos y b) dependientes particularmente del área superficial y morfología cristalina (aspecto de gran interés en un medio natural).

En la mayor parte de los sistemas naturales la disolución suele proceder en forma extremadamente lenta existiendo una serie de factores que afectan la velocidad del proceso (temperatura, luz UV, composición de la solución, pH, Eh, concentración de ácido y la presencia de agentes complejantes y/o reductores). También depende de las propiedades del óxido como área superficial, estequiometría, cristaloquímica, hábito cristalino, presencia de defectos extrínsecos e intrínsecos, iones como impurezas, dislocaciones, microfracturas, etc.. En lo que respecta al efecto del pH del medio, a $\mathrm{P}=1 \mathrm{~atm}$, la disolución de un óxido bien cristalizado de $\mathrm{Fe}(\mathrm{III})$ requiere de un $\mathrm{pH}<1$ aún a temperatura del orden de $\operatorname{los} 70^{\circ} \mathrm{C}$.

En lo que respecta al mecanismo, la disolución puede ocurrir a través de patrones de comportamiento que implican procesos de protonación, complejación y reducción así como fotoquímicos y biológicos.

La Figura 3.10 muestra esquemáticamente el proceso de disolución por protonación, el que se inicia con una etapa de adsorción de un protón en la superficie $\mathrm{Fe}-\mathrm{O}-\mathrm{H}$ transformando la estequiometría en $\mathrm{FeOHOH}_{2} \rightarrow \mathrm{Fe}(\mathrm{OH})^{2+}$. La posterior adsorción de dos nuevos protones por átomo de Fe debilitan el enlace $\mathrm{Fe}-\mathrm{O}$ en la red y facilitan la salida del ión Fe(III). La energía de activación de la etapa 3 de la figura es mucho mayor, sugiriendo la necesidad de un medio altamente ácido $(\mathrm{pH}$ del orden de 1). Los aniones que acompañan al protón también ejercen un importante rol, promoviendo algunos de ellos la disolución, (por ejemplo los $\mathrm{Cl}^{-}$), impidiendo el proceso $\left(\mathrm{ClO}_{4}^{-}\right)$y presentando un carácter intermedio (sulfato) (Cornell and Schwertman, 2003).

Por otra parte la presencia de bases de Lewis que actúan como ligandos o complejantes (cloruro), resulta importante en el proceso de complejación. mecanismo ocurre a través de la interacción de la especie con la superficie y su efecto sobre la fuerza del enlace Fe-O puede escribirse:

$$
\text { Sup-Fe-OH }+\mathrm{L}^{-}+\mathrm{H}^{+} \rightarrow \text { Sup-Fe-L }+\mathrm{H}_{2} \mathrm{O} \rightarrow \mathrm{FeL}(\mathrm{ac})+\mathrm{H}_{2} \mathrm{O}
$$




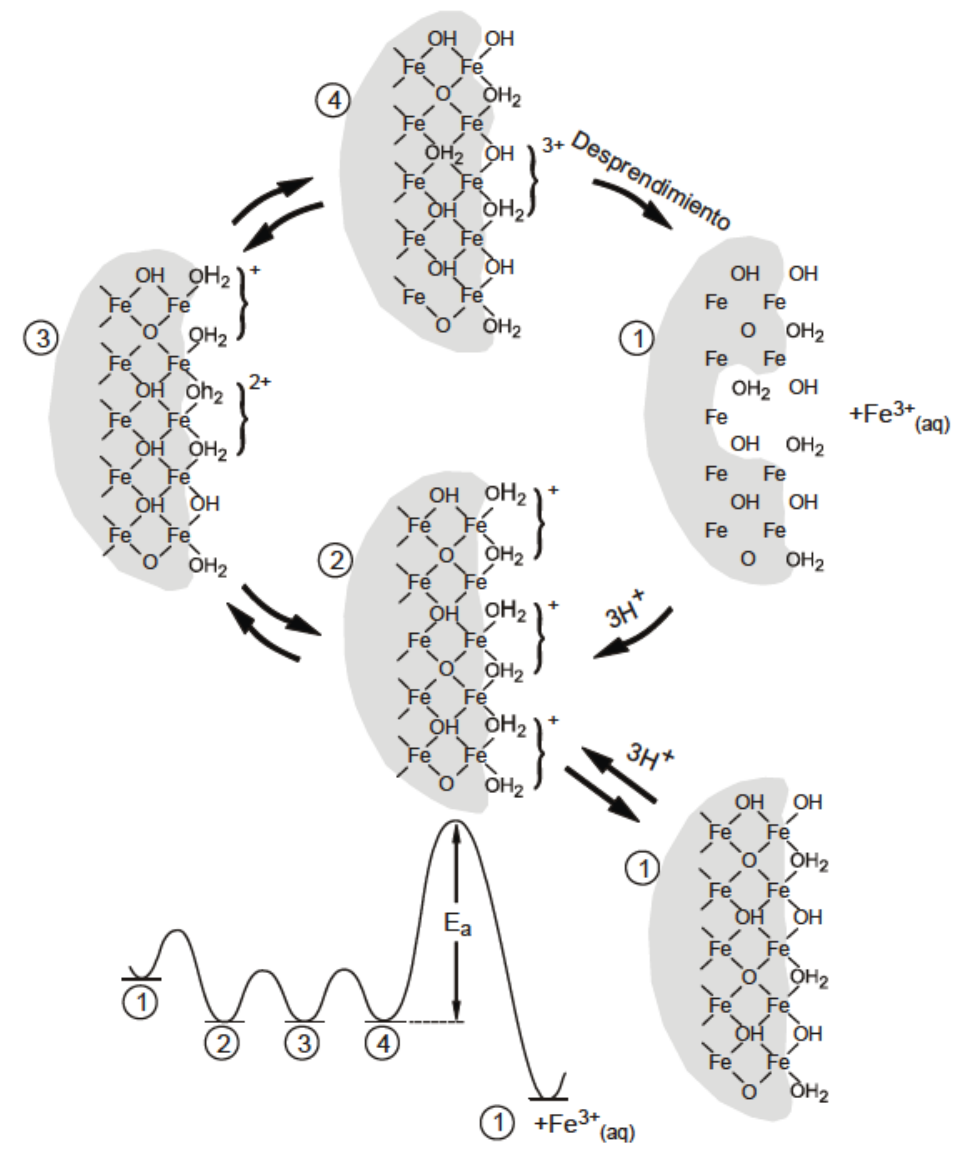

Figura 3.10. Representación esquemática de la disolución por protonación de un óxido de $\mathrm{Fe}$ (III) (Cornell and Schwertman, 2003).

Las curvas de la Figura 3.11 muestran el efecto en la disolución de la presencia de un complejante orgánico como el oxalato a pH 3 y 5.

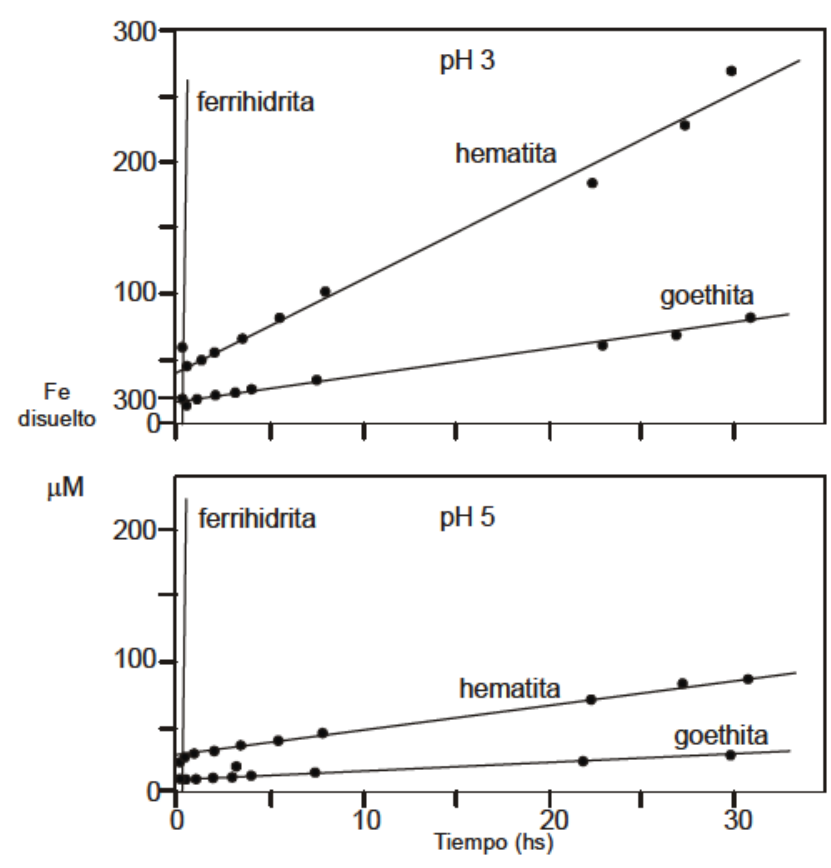

Figura 3.11. Disolución de hematita, goethita y ferrihidrita en presencia de oxalato (Cornell and Schwertman, 2003). 
Las etapas involucradas en el proceso de disolución mediante la presencia de un ligando orgánico se representan esquemáticamente en la Figura 3.12. El proceso comprende: a) la adsorción del ligando, b) el debilitamiento del enlace metálico que tiende a favorecer el desprendimiento y c) la adsorción del protón y restitución de la superficie para un nuevo ataque.

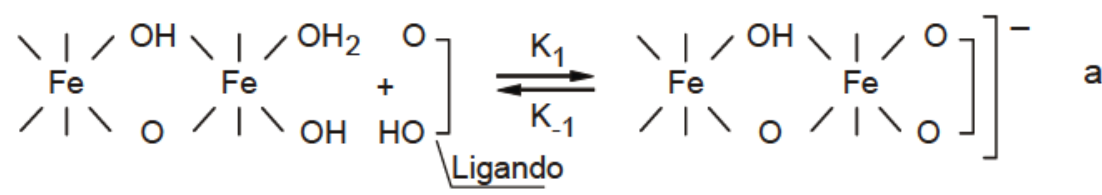

Adsorción de ligando
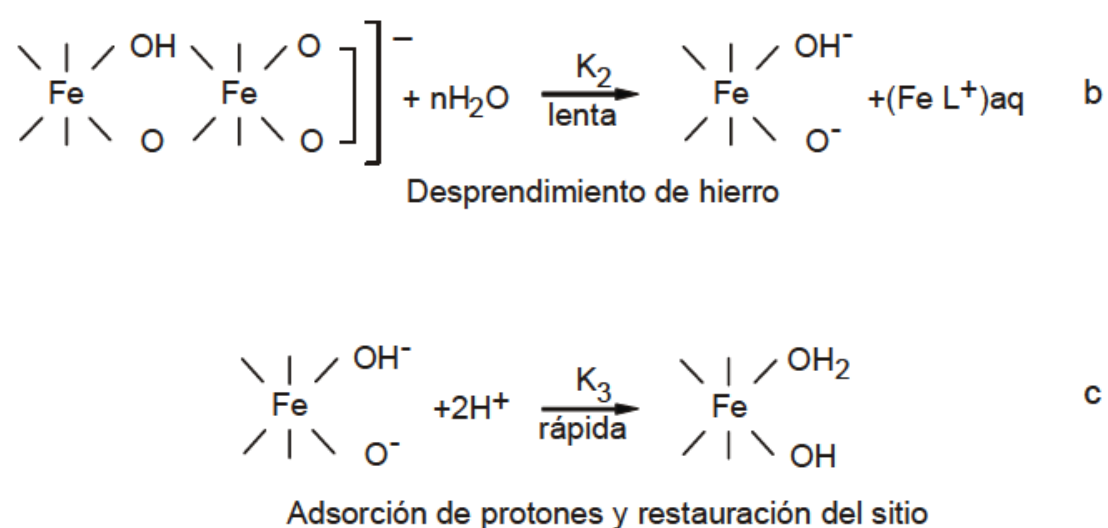

Figura 3.12. Etapas involucradas en la disolución de un óxido de $\mathrm{Fe}$ (III) por un ligando orgánico (Cornell and Schwertman, 2003).

\section{Algunos aspectos relacionados con la formación/disolución de óxidos comunes de hierro en sistemas naturales}

Dado que las especies minerales de hierro estudiadas en el marco del estudio de los materiales empleados en este trabajo de tesis son hematita, goethita y ferrihidrita, se hará una breve referencia a datos de bibliografía relacionados a dichas fases.

La goethita y hematita naturales suelen presentarse asociados y su separación del mineral anexo, usualmente silicatos minerales, ha sido realizada mediante tratamiento con ácidos. Las curvas de disolución en soluciones $2 \mathrm{M}$ de ácidos $\mathrm{HClO}_{4}$, $\mathrm{H}_{2} \mathrm{SO}_{4}$ y $\mathrm{HCl}$ muestran que la efectividad del proceso guarda una relación de 1:5:20, con energías de activación también crecientes.

Por otra parte, la velocidad de disolución de la ferrihidrita se ve afectado por el mecanismo por el cual se ha formado, observándose que se ve particularmente favorecida cuando la ferrihidrita se ha obtenido por hidrólisis de una sal de hierro en medio amoniacal. Asimismo, la presencia de silicato adsorbido reduce la capacidad de disolución por bloqueo superficial de los sitios de Fe. 
En lo que respecta a la formación de ferrihidrita, esta fase precipita rápidamente como especie ferrihidrita "2-line" (ver propiedades estructurales más adelante) a partir de la hidrólisis de una solución de $\mathrm{Fe}(\mathrm{III})$ a $\mathrm{pH}>3$, mientras que a menor $\mathrm{pH}$ y temperatura próxima a $100{ }^{\circ} \mathrm{C}$ precipita la forma ferrihidrita "6-line" (Cornell and Schwertman, 2003).

Por último, la disolución vs tiempo de hematitas sintéticas en $\mathrm{HCl}$ a $65^{\circ} \mathrm{C}$ (con un variado rango de morfologías) se asocia particularmente al área superficial de la especie original. Esas características se hallan relacionadas con el método de formación de hematita (Cornell and Schwertman, 2003).

Los comentarios realizados brevemente demuestran que existen una serie de factores que afectan tanto la formación como la velocidad de disolución de una fase del sistema $\mathrm{Fe}$ (III)-O. Para el último proceso (disolución) se ha comentado que en ácidos fuertes la ferrihidrita se disuelve más rápido que la goethita o la hematita.

Existen diferentes procedimientos que conducen a la formación de hematita. Puede obtenerse a partir de soluciones de Fe(III) a temperatura aproximada a los 100 ${ }^{\circ} \mathrm{C}$ (hidrólisis forzada), elevada concentración de hierro y bajo $\mathrm{pH}$. En condiciones hidrotérrnicas $\left(150{ }^{\circ} \mathrm{C}\right)$ la formación de hematita es muy rápida. También se puede obtener a partir de ferrihidrita "2-line" en medio acuoso y pH 7, por transformación en estado sólido de oxi/hidróxidos de hierro (deshidroxilación y re-organización interna) o por oxidación de magnetita. En la naturaleza una forma común de obtención de hematita es a través de la transformación de ferrihidrita. Sin embargo, esta forma termodinámicamente inestable pude transformar también hacia goethita, dado que ambas presentan energías libres de formación comparables. Los patrones alternativos para la transformación hacia una u otra fase se indican en el siguiente diagrama, resultando los mecanismos competitivos:

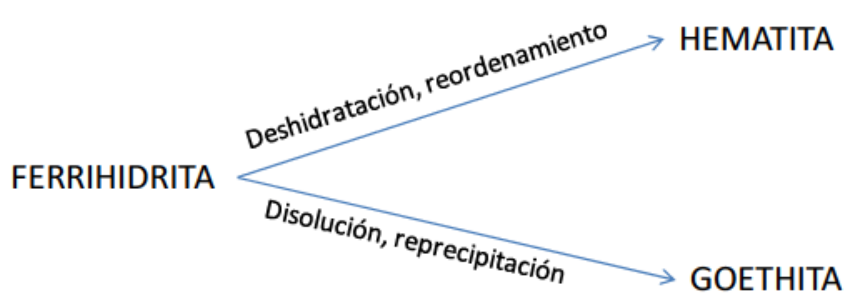

En sistemas naturales la presencia de un gran número de aditivos puede alterar la formación de los productos de transformación de ferrihidrita. El Al, los silicatos y la materia orgánica de suelos produce un efecto retardador, al igual que los fosfatos en 
lagos y los silicatos en sistemas bio-inorgánicos. Los aditivos pueden interferir según dos mecanismos:

a) por adsorción: estabilizando la ferrihidrita e impidiendo la etapa de reordenamiento interno para dar hematita o impidiendo la disolución para generar goethita. Los oxoaniones presentan la peculiaridad de formar complejos multi-nucleares en superficie (bloqueo superficial).

b) por interferencia en solución: cuando los ligandos no tienen un rol destacable sobre la superficie de las partículas se plantea una competencia entre los ligandos orgánicos y las especies $\left[\mathrm{Fe}(\mathrm{OH})_{4}\right]^{-}$por los sitios retrasando la formación de núcleos estables.

La Figura 3.13 resume esquemáticamente la formación y/o transformación de óxidos de hierro.



Figura 3.13. Formación y transformación de los óxidos de Fe (Cornell and Schwertman, 2003). 


\section{Aspectos relativos a la estructura y propiedades de la ferrihidrita}

Dentro de las fases oxídicas de hierro, la especie ferrihidrita es particularmente interesante dado que se localiza en ambientes naturales próximos a la superficie, donde se la puede encontrar en ambientes geológicos diversos ("pristine" suelos, sedimentos y áreas contaminadas por drenajes ácidos en minas). Su proporción es variable debido a su metaestabilidad. Por su elevada área superficial presenta gran reactividad y en tal sentido juega un importante rol en el secuestro de contaminantes en aguas subterráneas y cursos de agua a través de un proceso de adsorción y coprecipitación (Cornell and Schwertman, 2003).

Respecto a la fórmula de la ferrihidrita no se ha determinado aún con precisión debido al variable contenido de agua (entre 15-25\%).

Con respecto a su estructura se conocen comúnmente dos formas designadas como "2-line" y "6-line" en base al número de líneas de DRX que se presentan anchas y con una muy pobre resolución. Lo real es que no se encuentra en forma cristalina ni en la naturaleza ni en el laboratorio. Existen estudios referidos al orden a corto alcance con dominios de 2-6 nm en los que se identifica como una monofase. El trabajo estructural más reciente es atribuido a Michel et al. (2007) realizado en base a un modelo, correspondiente al mineral akdalaite $\mathrm{Al}_{10} \mathrm{O}_{14}(\mathrm{OH})_{2}$. El sistema cristalino establecido es el hexagonal con grupo espacial $\mathrm{P} 6_{3} m c$ y una celda unitaria de dimensiones a $\sim 5,95 \AA$ y c $\sim 9,06 \AA$. La representación poliédrica de la celda unitaria se muestra en la Figura 3.14.

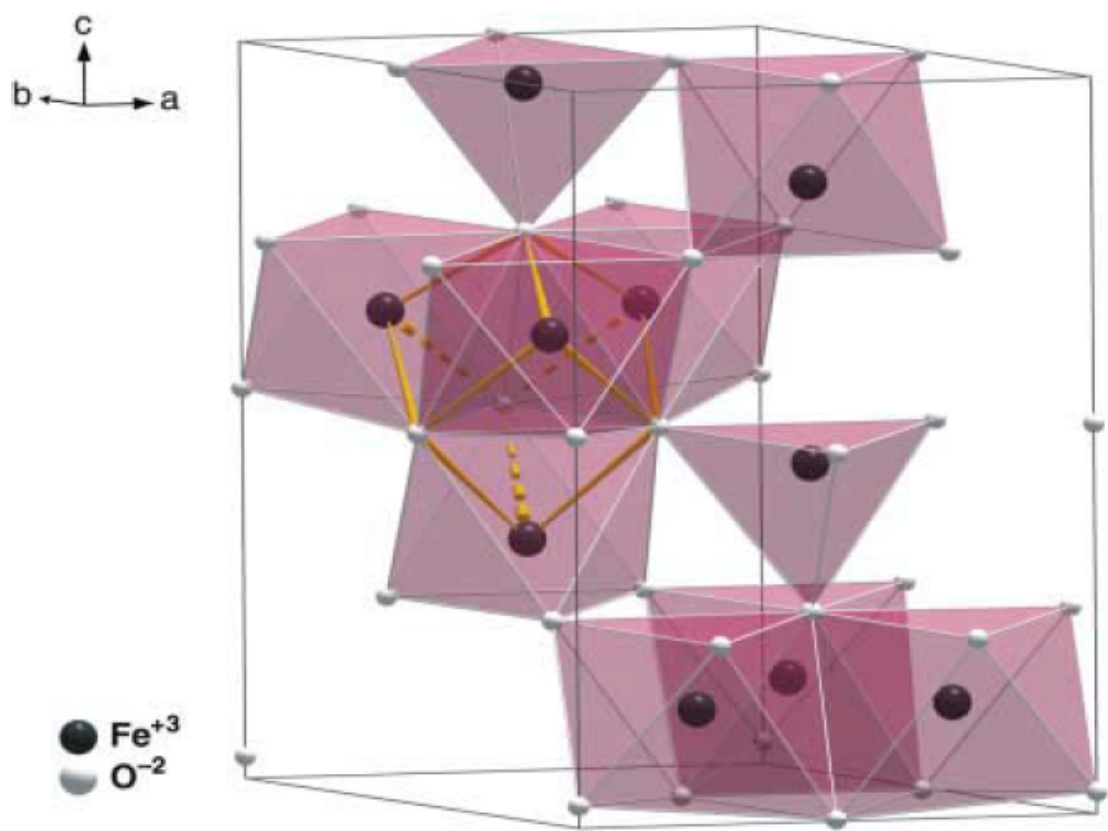

Figura 3.14. Representación ideal de la celda unidad hexagonal para ferrihidrita. Los átomos unidos en amarillo definen una unidad tipo cubana que conecta la estructura básica del modelo (Michel et al., 2007). 
Sobre la base de ésta estructura la fórmula química ideal es $\mathrm{Fe}_{10} \mathrm{O}_{14}(\mathrm{OH})_{2} \mathrm{O}$ $\left(\mathrm{Fe}_{5} \mathrm{HO}_{8}\right)$. Sin embargo, el análisis térmico sugiere fuertemente la presencia de agua enlazada a la superficie (Michel et al., 2007). El modelo también sugiere la presencia de tensiones estructurales, defectos de línea, vacancias, agregaciones y correlaciones interparticulares, muchas de ellas mostrando reminiscencias con la estructura de la gama alúmina en la que es posible establecer la presencia de nano-dominios y defectos "stacking fault" en la matriz (Paglia et al., 2006).

El motivo estructural básico del modelo se encuentra muy relacionado con el cluster tipo Baker-Figgis ó Keggin constituido por 13 átomos de Fe y 40 de oxígeno que se muestra en la Figura 3.15.

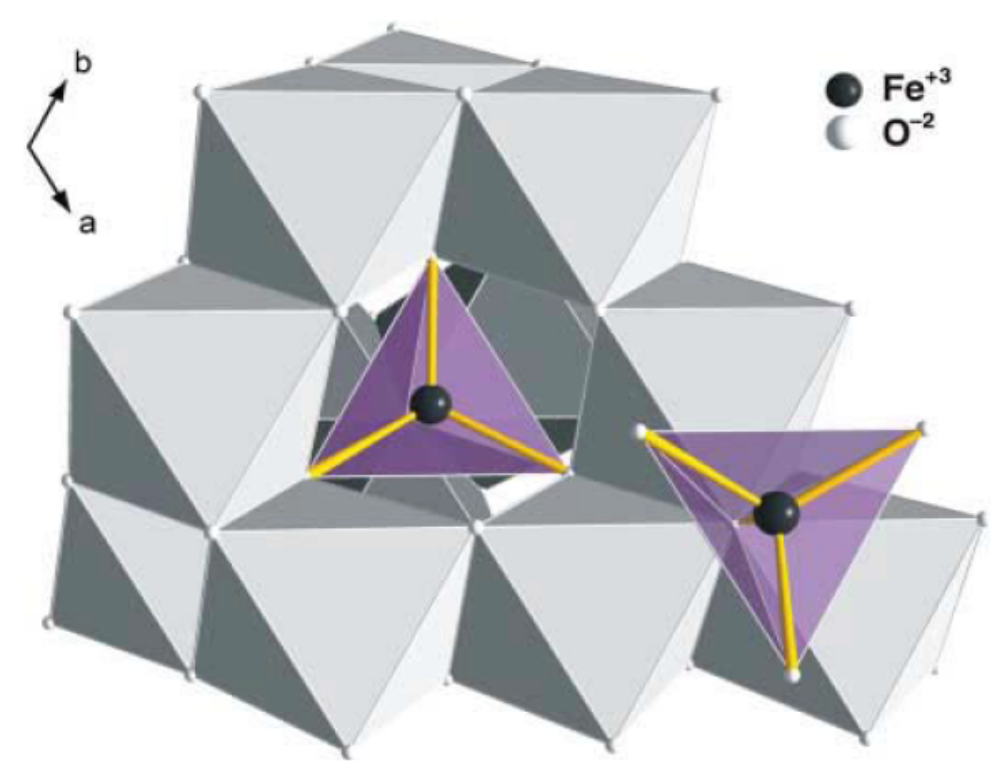

Figura 3.15. Vista parcial de la representación del cluster tipo Keggin con el tetraédro central (FeO4) rodeado por los 12 octaédros de hierro (FeO6) (Michel et al., 2007).

El tetraedro central $\mathrm{FeO} 4$ se encuentra conectado a 12 octaedros $\mathrm{FeO} 6$ periféricos mediante puentes $\mu 4-0 x 0$, ordenados según compartimento de aristas de grupos de 3. De esta forma la estructura de las nano-partículas de 2-6 nm pueden describirse como un empaquetamiento tridimensional de clusters conectados con cluster adyacentes a través de un par común de octaedros compartiendo aristas. Se forman puentes $\mu 4$-oxo a partir de tres grupos de puentes cis $\mu 2-\mathrm{OH}$ a cada uno de los puentes centrales $\mu 4-0 x 0$. El ordenamiento crea una unidad tipo cubana correspondiendo a 4 octaedros de Fe compartiendo una arista (Figura 3.14). La estructura de la forma ideal consiste de un $20 \%$ de Fe tetraédrico y $80 \%$ de $\mathrm{Fe}$ octaédrico aunque la ocupación de los sitios metálicos periféricos disminuye cuando el tamaño de la partícula se hace menor, reflejando un elevado grado de desorden y de valencias insaturadas. La presencia del poliedro $\mathrm{FeO} 4$ ha sido motivo de gran debate 
(Pankhurst and Pollard, 1992) sugiriendo en un primer momento una situación similar a la de la maghemita. Se ha sugerido la presencia de densidades de defectos elevadas que irrumpen en la continuidad estructural. Estos aspectos de la estructura conducen a un ensanchamiento de los picos de DRX. De ahí que la estequiometría cambia con el tamaño cristalino dado que la población de dos de los tres sitios del Fe disminuye con el tamaño de la partícula. En las condiciones de tamaño nanoscópico y ante la presencia de vacancias el rol estructural del agua se convierte en determinante en las partículas de menor dimensión. En coincidencia con estas apreciaciones, las medidas termodinámicas indican que la energía superficial de las nano-partículas es reducida por hidratación y que los oxihidróxidos tienen menor energía superficial que los óxidos (Nacrotsky et al., 2008).

Un modelo para la formación de ferrihidrita podría implicar la nucleación de clusters en solución, agrupamiento que no puede construirse coherentemente más allá de un cierto rango debido a los efectos de tensión. La agregación de nano-partículas de baja coherencia es la razón fundamental de la composición variable que suele presentar y que se encuentra estrechamente relacionada con las condiciones de síntesis.

La ferrihidrita (en forma de agregados de 2-5 nm de diámetro) presenta un área superficial entre 200-500 $\mathrm{m}^{2} \mathrm{~g}^{-1} \mathrm{y}$ es en un 90-100\% soluble en una solución de acido/oxalato de amonio en ausencia de luz.

Una característica de la ferrihidrita es la de ser precursora de la hematita. En general, las transformaciones de fase en los sistemas Fe-O son muy comunes. En principio, las transformaciones sin cambios químicos se denominan iso-químicas. Existen otras transformaciones que implican modificaciones químicas: entre estas se cuenta la deshidratación, la deshidroxilación y la oxidación/reducción. Estructuralmente los procesos de transformación pueden ser tanto topotácticos como reconstructivos (Cornell and Schwertman, 2003). El primero tiene lugar en la matriz sólida e implica reordenamienetos atómicos internos existiendo coincidencia en las tres dimensiones de la fase inicial y final. Puede suceder que exista una relación parametral entre la fase inicial y final por lo que la transformación se denomina pseudomórfica. El segundo tipo de transformación se denomina reconstructiva e implica disolución y reprecipitación. La fase inicial se rompe completamente por disolución y precipita una nueva fase que no guarda ninguna relación estructural con la original. Este es el proceso dominante en gran parte de los procesos que ocurren en un entorno natural. En presencia de agua la hematita se forma a partir de agregados nanoscópicos de ferrihidrita por un proceso de cristalización de corto rango. 
La transformación de hematita a partir de ferrihidrita (vía húmeda) implica la combinación de procesos de agregación-deshidratación y reordenamiento requiriendo agua, en tanto que la formación de goethita a partir de ferrihidrita comprende la disolución del precursor y la cristalización del producto final en el seno de la solución.

Una serie de pautas permiten establecer el rol del agua en el proceso: a) la agregación a partir de la solución es esencial y no se puede formar hematita a partir de un sol, b) el mínimo de agua adsorbida es de aproximadamente 100-150 g por kg de ferrihidrita, debajo del cual no existe transformación, c) la transformación es precedida por una etapa de nucleación, d) la hematita es razonablemente cristalina desde el comienzo, e) por estudios con agua dopada con el isótopo de ${ }^{18} \mathrm{O}$ se ha determinado que el mismo termina formando parte de la estructura de hematita.

La transformación de ferrihidrita-hematita por vía seca (efecto de la temperatura) implica una combinación de los procesos de deshidratación-deshidroxilaciónreordenamiento atómico conduciendo a un gradual ordenamiento estructural facilitado por las similitudes dado que la compartición de caras entre octaedros que se observa en la estructura de la hematita también se observan en la ferrihidrita "6-line". 


\section{CAPÍTULO 4}

\subsection{Características generales de los minerales de arcilla}

Las arcillas son conocidas y utilizadas por el hombre desde la antigüedad. Para la vida moderna se han convertido casi en indispensables dado que son el material de muchos tipos de cerámica, tales como porcelana, ladrillos, tejas y artículos sanitarios, así como componentes esenciales de plásticos, pinturas, papel, caucho y cosméticos. Asimismo, las arcillas no son contaminantes y se pueden emplear como agentes de descontaminación (Bergaya and Lagaly, 2006).

El término arcilla se usa habitualmente con diferentes significados dependiendo de la disciplina involucrada en la que encuentra aplicación. De esta forma, para la sedimentología, la palabra arcilla es un término netamente granulométrico, atribuido a los sedimentos con un tamaño de grano $<2 \mu \mathrm{m}$. Para la petrología, la arcilla es una roca sedimentaria, comúnmente de origen detrítico, con características bien definidas. En el área de la ciencia de los materiales cerámicos una arcilla es una especie natural que mezclada con agua presenta propiedades plásticas. Finalmente, desde el punto de vista mineralógico, el término arcilla engloba mayoritariamente a un grupo de filosilicatos, cuyas propiedades fisicoquímicas dependen de su estructura laminar y de su tamaño de grano muy fino $(<2 \mu \mathrm{m})$.

Las técnicas de rayos $\mathrm{X}$ han demostrado que las arcillas están constituidas predominantemente por un grupo de sustancias cristalinas denominadas genéricamente minerales de arcilla, y que son, en esencia, aluminosilicatos hidratados (Klein and Hurlbut, 1997). Aunque una arcilla puede estar formada por un único mineral de arcilla, por lo general se presentan como una mezcla de varios de ellos acompañada, a su vez, por otros minerales accesorios o asociados (silicatos y/o óxidos) tales como feldespatos, cuarzo, oxi/hidróxidos de hierro y aluminio, etc. (Klein and Hurlbut, 1997; Bergaya and Lagaly, 2006).

Los minerales de arcilla pertenecen al grupo de los filosilicatos (del griego phyllon que significa hoja) o silicatos laminares. Forman parte de la clase mineral de los silicatos cuya unidad estructural básica está representada por un tetraedro regular $\left(\mathrm{SiO}_{4}{ }^{-4}\right)$, donde 4 iones oxígeno se sitúan en los vértices rodeando al ión $\mathrm{Si}^{+4}$ con ángulos de enlace O-Si-O desviados ligeramente del valor teórico 109,5 (Figura 4.1 a). Estas unidades estructurales surgen del modelo covalente de enlace Si-O, por superposición de orbitales $\mathrm{s}$ y $\mathrm{p}$ (hibridación $\mathrm{sp}^{3}$ de geometría tetraédrica $\mathrm{T}_{\mathrm{d}}$ ). Dentro de la familia de los silicatos es posible la condensación de las unidades $T_{d}$ mediante la cual cada átomo de oxígeno puede unirse a otra unidad tetraédrica dando lugar a 
diferentes configuraciones espaciales. Un tetraedro puede compartir uno, dos, tres o cuatro oxígenos, dando origen a la gran variedad de estructuras de silicatos existentes (Klein and Hurlbut, 1997). En los filosilicatos se comparten tres vértices de cada tetraedro generando capas de composición $\left(\mathrm{Si}_{2} \mathrm{O}_{5}\right)_{n}{ }^{2 n-}$, finitas o infinitas, con una relación elemental O:Si del orden de 2,5 (Figura 4.1 b). Dentro de este grupo se encuentran la mayoría de los minerales estudiados en el presente trabajo.

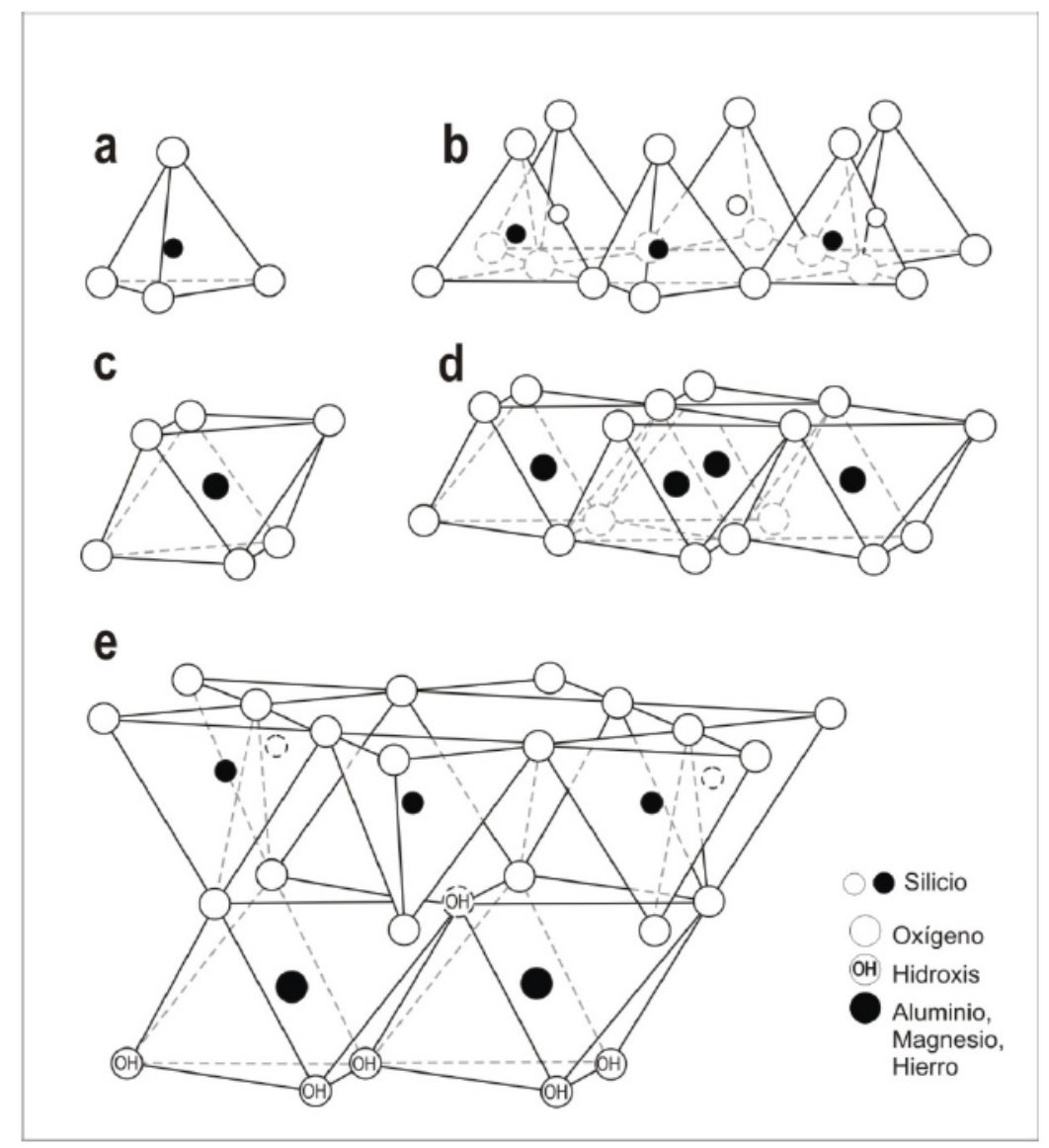

Figura 4.1. a) Tetraedro aislado de geometría $T_{d}$. b) Disposición de los tetraedros formando un retículo hexagonal (tetraedros unidos por tres vértices). c) Octaedro aislado: un átomo de aluminio, magnesio o hierro coordinado a 6 oxígenos u oxidrilos. d) Condensación de los octaedros generando una capa de disposición octaédrica. e) Unión entre capas tetraédricas y octaédricas generando láminas complejas de tipo Tetraédrica-Octaédrica.

Es posible que el Al se encuentre en las estructuras de los silicatos, tanto en posiciones tetraédricas sustituyendo al $\mathrm{Si}$, como en posiciones octaédricas. Presenta valores de potencial iónico que le permiten adoptar ambas coordinaciones, en base a la regla de la relación de radios $r_{\text {catión }} / r_{\text {anión }}$, teniendo en cuenta las posibles pequeñas variaciones de tamaño en ambos casos. La posibilidad de sustitución estructural Al por $\mathrm{Si}$ en coordinación tetraédrica se soporta por los tamaños de las especies, $\mathrm{Al}(\mathrm{III})_{\text {tetraédrico }}=0,39 \AA$ y Si(IV) tetraédrico $=0,26 \AA$ (Shannom, 1979), y consecuentemente por el carácter polarizante de las mismas en un entorno oxídico $\left(\rho=r_{\text {catión }} / r_{\text {anión }} 0,29\right.$ y 0,20 respectivamente) inferior a 0,41 correspondiente a dicha coordinación. La 
sustitución isomórfica mencionada es acompañada por un ajuste composicional con el fin de mantener la neutralidad eléctrica, incorporando iones positivos de pequeña carga y gran tamaño (bajo potencial iónico), fundamentalmente elementos alcalinos y alcalinotérreos ampliamente difundidos en la naturaleza.

Por otra parte el Al puede presentar coordinación octaédrica (Figura $4.1 \mathrm{c}$ ), situación que se basa en el valor del radio iónico del aluminio en esa coordinación $(0,535 \AA)$ que incrementa el valor de la relación $\rho(\sim 0,39)$ al límite de la región de estabilidad para un entorno oxídico en coordinación 6 . Cabe recordar que la regla de Goldschmidt establece valores de $\rho$ limitados a los rangos $0,22-0,41$ y $0,41-0,73$ para

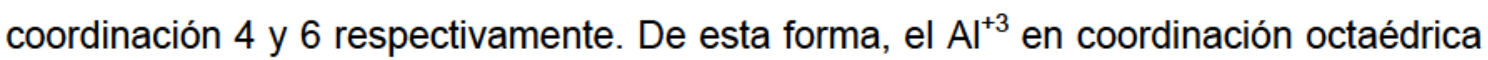
puede servir para ligar los grupos tetraédricos mediante simples enlaces iónicos mucho más débiles que los que unen los iones en los tetraedros.

Se pueden reconocer dos tipos básicos de bloques de construcción de los silicatos laminares, la capa de tetraedros $\mathrm{TO}_{4}$ compartiendo tres vértices donde $\mathrm{T}: \mathrm{Si}^{+4}$ o $\mathrm{Al}^{+3}$, y la capa de octaedros unidos por aristas (Figura $4.1 \mathrm{~d}$ ). La capa octaédrica está formada por átomos metálicos distintos del Si coordinados a átomos de oxígeno ó iones $\mathrm{OH}^{-}$. Las capas octaédricas, en las que todos los sitios se encuentran ocupados por cationes divalentes se denominan trioctaédricas. Cuando los cationes de la capa octaédrica ocupan solo dos tercios de los sitios octaédricos se llama dioctaédrica (se producen con cationes trivalentes como $\mathrm{Al}^{+3}$ ). Las capas tetraédricas $(\mathrm{T})$ y octaédricas (O) presentan simetría análoga y dimensiones casi idénticas, lo que permite la participación de los átomos de oxígeno entre ambas capas. El átomo de $\mathrm{O}$ de la capa tetraédrica es compartido por la capa octaédrica (Figura 4.1 e).

Cuando las láminas tetraédricas y octaédricas se unen la estructura resultante puede ser eléctricamente neutra o presentar carga negativa. Existe la neutralidad eléctrica si (i) la hoja octaédrica contiene cationes trivalentes (generalmente $\mathrm{Al}^{3+}$ y $\mathrm{Fe}^{3+}$ ) en dos sitios octaédricos con una vacancia en el tercer sitio, (ii) cuando la capa octaédrica contiene cationes divalentes (por lo general $\mathrm{Fe}^{2+}, \mathrm{Mg}^{2+}$ ) en todos los sitios octaédricos y (iii) la capa tetraédrica contiene $\mathrm{Si}^{4+}$ en todos los tetraedros. La carga negativa en las capas surge a partir de (i) la sustitución de $\mathrm{Si}^{4+}$ por $\mathrm{Al}^{3+}$ en sitios tetraédricos, (ii) la sustitución de $\mathrm{Al}^{3+}$ por cationes de menor carga en los sitios octaédricos y (iii) la presencia de vacancias. Esta variabilidad de carga es reconocida como una de las características más importantes de los filosilicatos del tipo 2:1 (capa formada por 2 láminas tetraédricas y 1 octaédrica) debido a que induce la ocupación del espacio interlaminar por cationes intercambiables. En filosilicatos del tipo 1:1 (capa 
formada por 1 lámina tetraédrica y 1 octaédrica) la carga de la capa es por lo general cercana a cero (Brigatti et al., 2006).

La clasificación de los filosilicatos puede analizarse desde la forma de apilamiento de las capas tetra y octaédricas así como de sus ubicaciones relativas. La repetición de láminas define el plano basal 001 de la celda unitaria y es ese espaciado el que se utiliza para identificar el tipo de especie laminar. Sobre la base del apilamiento es posible establecer la presencia de tres tipos de silicatos laminares que se esquematizan en la Figura 4.2.
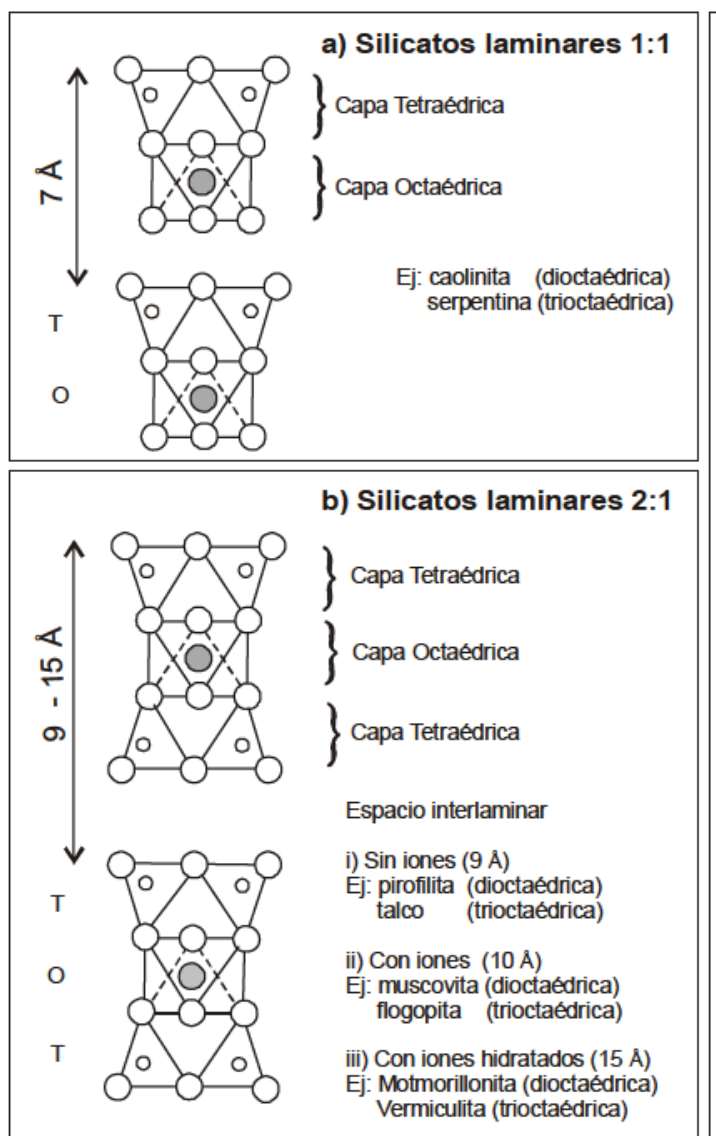

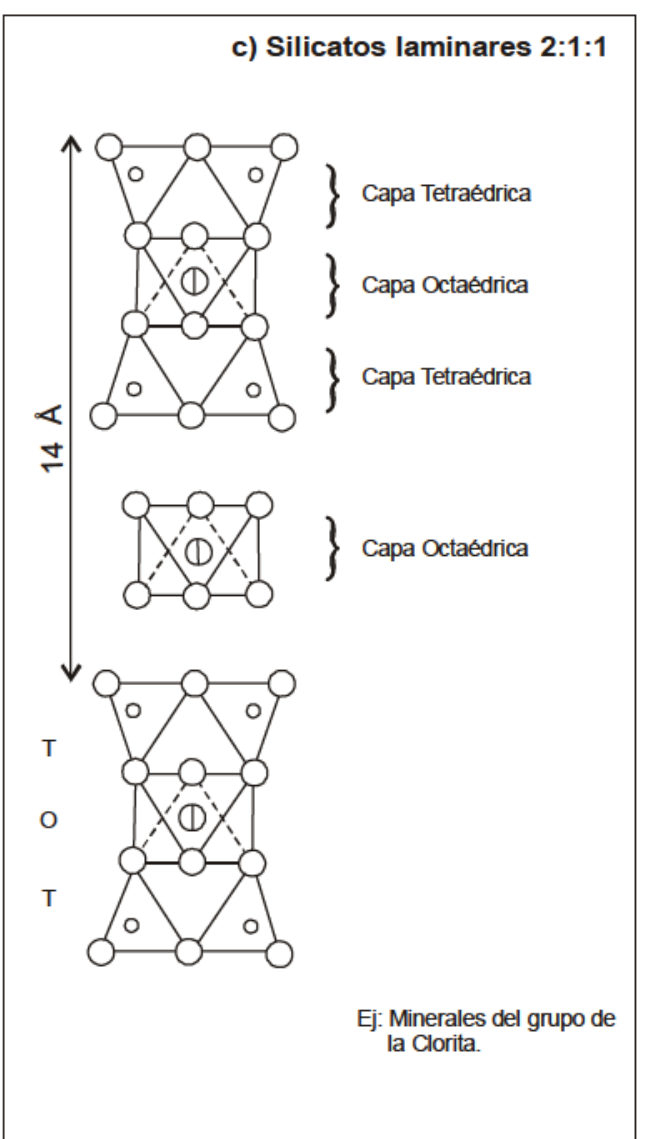

Figura 4.2. Representación esquemática de los diferentes tipos de silicatos laminares. a) Silicatos laminares 1:1. b) Silicatos laminares 2:1. c) Silicatos laminares 2:1:1.

_ Silicatos laminares 1:1: Surgen de la combinación de una lámina tetraédrica con una octaédrica (bloque T-O). El balance de carga es en este caso nulo. El mismo surge de la combinación de la capa de tetraedros $\left(\mathrm{Si}_{2} \mathrm{O}_{5}\right)_{3}{ }^{6-}$ con una de octaedros de $\mathrm{Al}(\mathrm{III})$ donde se ocupan 2/3 de los huecos octaédricos o la totalidad de los mismos en el caso de la incorporación de $\mathrm{Mg} \circ \mathrm{Fe}$ divalente. El mineral de arcilla más simple que representa a este grupo es la caolinita (dioctaédrica), donde, desde un punto de vista ideal, el Si queda confinado a los sitios tetraédricos y el Al a los octaédricos. La ocupación de los sitios octaédricos por especies divalentes (por ejemplo $\mathrm{Mg}(\mathrm{II})$ ) genera 
la especie trioctaédrica serpentina. Las fuerzas de atracción entre bloques neutros (TO) (T-O) son muy débiles (fuerzas de Van der Waals).

_ Silicatos laminares 2:1: surgen de la combinación de dos capas tetraédricas y una octaédrica a modo de sándwich (bloques T-O-T). La repetición de esta combinación, extendida en dos dimensiones, puede dar lugar a diferentes tipos de especies laminares, según se observe la ausencia de material entre las capas o se puedan albergar cationes grandes anhidros o hidratados. La incorporación de dichos cationes se produce para mantener la neutralidad eléctrica cuando las sustituciones, tanto en la capa tetraédrica como en la octaédrica así lo requieran. Las características mencionadas permiten la siguiente subdivisión:

- $\quad$ Sin material en el espacio interlaminar: los dos extremos de este tipo de silicato lo constituyen el talco $\mathrm{Mg}_{3}(\mathrm{OH})_{2} \mathrm{Si}_{4} \mathrm{O}_{10}$ (trioctaédrica) y la pirofilita $\mathrm{Al}_{2}(\mathrm{OH})_{2} \mathrm{Si}_{4} \mathrm{O}_{10}$ (dioctaédrica). Las capas (T-O-T) son eléctricamente neutras y sólo existen débiles fuerzas atractivas de Van der Waals entre capas vecinas.

- $\quad$ Con iones en el espacio interlaminar: la sustitución del Si por Al en posición tetraédrica (sustitución de 1/4 del silicio de las capas de talco o pirofilita) genera una carga negativa que debe ser compensada por la presencia de cationes grandes (comúnmente iones $\mathrm{K}^{+}$), como se observa en las micas flogopita $\mathrm{KMg}_{3}(\mathrm{OH})_{2} \mathrm{Si}_{3} \mathrm{AlO}_{10}$ (trioctaédrica) y muscovita $\mathrm{KAl}_{2} \mathrm{Si}_{3} \mathrm{AlO}_{10}(\mathrm{OH})_{2}$ (dioctaédrica). Si el desbalance eléctrico de la sustitución Al-Si se compensa con la presencia de cationes divalentes como el $\mathrm{Ca}^{2+}$, el mayor carácter polarizante del catión se traduce en una mayor fuerza del enlace, resultando más difícil la típica exfoliación observada en las micas del grupo de la muscovita y flogopita. La mayor resistencia a la separación de capas es consistente con la presencia de micas quebradizas.

- $\quad$ Con iones hidratados en el espacio interlaminar: la posibilidad de que algunos cationes se encuentren en forma hidratada, con una cantidad variable de moléculas de agua, da lugar a la existencia de las micas hidratadas. Las capas débilmente cargadas surgen del reemplazo de $\mathrm{Al}$ por $\mathrm{Mg}$ en capas di o trioctaédricas. La compensación se observa por la incorporación de iones alcalinos o Mg hidratados. La montmorillonita, puede derivarse de la pirofilita por reemplazo de $\mathrm{Al}_{\text {octaédrico }}$ por $\mathrm{Mg}$.

Las posibilidades de sustituciones isomórficas, ya comentadas, conducen a una deficiencia de carga positiva que usualmente se compensa por (i) reemplazo de $\mathrm{O}^{=}$por $\mathrm{OH}^{-}$, (ii) variación en el número de cationes en capa octaédrica (dioctaédrica $\rightarrow$ trioctaédrica) y (iii) por la adsorción de cationes en la superficie de las capas, efecto responsable de la elevada capacidad de intercambio catiónico (CIC). En 
párrafos anteriores se mencionó que la montmorillonita, puede derivarse de la pirofilita por reemplazo de $\mathrm{Al}_{\text {octaédrico }}$ por $\mathrm{Mg}$. En el caso de observarse una deficiencia de carga positiva, la unión de bloques queda compensada por la presencia de iones $\mathrm{K}$, así, por ejemplo, el comportamiento de la especie se aparta del de la montmorillonita y se genera la illita, cuya estructura resulta transicional a la de la muscovita, cuyo contenido en $\mathrm{K}$ es aún mayor. Según la representación mediante fórmulas ideales, puede establecerse básicamente la siguiente diferencia composicional entre montmorillonita, illita y muscovita:

$$
\mathrm{Al}_{4} \mathrm{Si}_{8} \mathrm{O}_{20}(\mathrm{OH})_{4} \quad \mathrm{~K}_{0-2} \mathrm{Al}_{4}\left(\mathrm{Si}_{8-6} \mathrm{Al}_{0-2}\right) \mathrm{O}_{20}(\mathrm{OH})_{4} \quad \mathrm{~K}_{2} \mathrm{Al}_{4}\left(\mathrm{Si}_{6} \mathrm{Al}_{2}\right) \mathrm{O}_{20}(\mathrm{OH})_{4}
$$

_ Silicatos laminares 2:1:1: se originan por la intercalación de capas octaédricas (tipo brucita $\mathrm{Mg}_{2}(\mathrm{OH})_{4}$ ) entre grupos laminares 2:1 (T-O-T), a modo de sándwich del tipo (T-OT) (O) (T-O-T), como es observado en las cloritas donde existe alternancia de capas tipo mica cargadas negativamente con capas cargadas positivamente (generadas por la sustitución de $\mathrm{Mg}$ por $\mathrm{Al}$ en la capa de brucita, con una composición tipo $\mathrm{Mg}_{2} \mathrm{Al}(\mathrm{OH})_{6}{ }^{+}$). Esto da lugar a la presencia de "iones bidimensionales infinitos" de cargas opuestas.

Desde el punto de vista económico las arcillas son un grupo de minerales industriales con diferentes características mineralógicas y genéticas y con distintas propiedades tecnológicas y aplicaciones. Esas aplicaciones industriales se basan en sus propiedades fisicoquímicas derivadas de su tamaño de partícula extremadamente pequeño, su morfología laminar y la posibilidad de sustituciones isomórficas que dan lugar a la presencia de cationes en el espacio interlaminar. Como consecuencia de estos factores, presentan una considerable área superficial.

Mundialmente el $90 \%$ de la producción de arcillas se destina preferentemente a la fabricación de materiales de construcción y agregados. Sólo un $10 \%$ se dedica a otras industrias (fabricación de papel, caucho, pinturas, adsorbentes, decolorantes, arenas de moldeo, productos químicos y farmacéuticos, entre otros). En la mayoría de las provincias de nuestro país se registra producción de arcillas, siendo la provincia de Buenos Aires la de mayor producción y oferta, tanto en volumen como en sus diferentes variedades y calidades. La principal actividad minera en la provincia se desarrolla en los distritos de Olavarría, Barker y Tandil.

\subsection{Arcillas como adsorbentes naturales}

Debido a sus propiedades estructurales, los silicatos laminares presentan gran capacidad para adsorber e inmovilizar especies extrañas y en tal sentido, las arcillas y los minerales de arcilla han sido utilizados como materiales para el control de la contaminación, como "carriers" de pesticidas y como barreras en la eliminación de 
residuos. Las propiedades superficiales relacionadas a su área, carga y posibilidad de incremento del espaciado interlaminar hacen que estos materiales sean beneficiosos para la salud humana y sean empleados en formulaciones farmacéuticas (protectores gastrointestinales, antiácidos, protectores dermatológicos, cosméticos) o en forma de excipientes (bases inertes, lubricantes, emulsionantes). Estos materiales son atractivos debido a su amplia distribución en la naturaleza, facilidad de extracción y costo relativamente bajo. Además, en general, no son tóxicos (Churchman et al., 2006).

Las propiedades de la superficie de los minerales de arcilla dependen de muchos factores, incluyendo la composición química, la naturaleza de los átomos superficiales $(\mathrm{O}, \mathrm{OH})$, la presencia y variedad de defectos estructurales, la carga neta de la capa y el tipo de cationes intercambiables (Schoonheydt and Johnston, 2006). En lo que se refiere a la carga eléctrica superficial, cada mineral de arcilla se caracteriza por un valor, generalmente negativo, cuyo origen se relaciona a:

_ Superficie basal (caras): una carga permanente negativa se introduce sobre la superficie de los minerales de arcilla como resultado de las sustituciones isomorfas en las capas tetraédricas u octaédricas. Es independiente de $\mathrm{pH}$. La carga negativa que resulta de la sustitución isomorfa se compensa con la presencia de cationes intercambiables de los cuales los iones $\mathrm{Ca}^{2+}, \mathrm{Mg}^{2+}, \mathrm{K}^{+}$y Na${ }^{+}$son los más comunes. La naturaleza química de estos cationes intercambiables (es decir, radio iónico efectivo, energía de hidratación, constante de hidrólisis) determina muchas de las propiedades químicas y físicas importantes de los minerales de arcilla (Schoonheydt and Johnston, 2006).

_ Superficie lateral (bordes): se genera por los grupos hidroxilo situados en los "broken edges" o bordes rotos con sitios $\mathrm{Al}-\mathrm{OH}$ y $\mathrm{Si}-\mathrm{OH}$ en contacto con el medio. Estos grupos $\mathrm{OH}$ terminales pueden tener carga positiva o negativa dependiendo del $\mathrm{pH}$ del medio. Como se comentó en el Capítulo 3, el valor de pH donde la carga superficial neta es cero se conoce como el punto de carga cero (PZC). Para valores de pH más altos que el PZC de un mineral, la superficie tendrá una carga neta negativa y tenderá a adsorber especies catiónicas. Del mismo modo, la superficie del borde tendrá carga neta positiva a pH menores al PZC (Schoonheydt and Johnston, 2006).

La presencia de estas cargas superficiales y la elevada superficie específica posibilita una interacción importante con las moléculas de agua y los compuestos disueltos en ella. Dado que la mayoría de los minerales de arcilla están cargados negativamente tienen afinidad por las especies positivas. De esta forma, se ha 
reportado ampliamente en la bibliografía el empleo de arcillas como adsorbentes de iones de metales pesados (Churchman et al., 2006; Wan Ngah and Hanafiah, 2008; Fu and Wang, 2011). La adsorción de metales pesados por las arcillas no solo depende de la capacidad de intercambio catiónico de los minerales de arcilla, sino que implica una variedad de procesos, incluyendo la complejación superficial directa ("innersphere") o indirecta ("outer-sphere"), el intercambio iónico simple y la precipitación superficial (Churchman et al., 2006).

La capacidad de adsorción de aniones es pequeña debido a la carga superficial predominantemente negativa, de modo que la posibilidad de complejar las especies aniónicas de arsénico solo pueden ser atribuidas a los grupos $\mathrm{OH}$ laterales asociados a los bordes rotos de las partículas de arcilla (Stollenwerk, 2003). Este intercambio aniónico es dependiente del $\mathrm{pH}$, pero su magnitud nunca es alta. Algunos aniones, en particular los fosfatos, se pueden adsorber, al menos parcialmente de forma irreversible. Sin embargo, es de destacar que las superficies de los aluminosilicatos pueden ser modificadas para dar materiales aptos para la adsorción de aniones (Churchman et al., 2006).

En relación a la adsorción de aniones de arsénico, Stollenwerk (2003) señala que los resultados de los experimentos que evalúan la adsorción de As por diferentes minerales arcillosos en general presentan semejanzas. En todos los casos, la adsorción por gramo de sólido, tanto de $\mathrm{As}(\mathrm{III})$ como de $\mathrm{As}(\mathrm{V})$, aumenta con la concentración inicial del elemento. La adsorción máxima de $\mathrm{As}(\mathrm{V})$ empleando caolinita, montmorillonita, illita, halloysita y clorita se produce hasta valores de $\mathrm{pH}$ cercanos a 7, luego disminuye al aumentar el pH. La adsorción de As(III) por estos mismos minerales de arcilla es mínima a pH bajo y aumenta con el incremento del $\mathrm{pH}$. En todos los minerales de arcilla el arseniato se adsorbe en mayor grado que el arsenito a $\mathrm{pH}<7$. A valores más altos de $\mathrm{pH}$, la adsorción de $\mathrm{As}(\mathrm{V})$ y $\mathrm{As}$ (III) son más comparables. La halloysita y la clorita presentan una mayor adsorción de $\mathrm{As}(\mathrm{V})$ que la caolinita, illita y montmorillonita. Este comportamiento puede atribuirse a la mayor superficie específica de la halloysita debido a su estructura altamente desordenada y a la mayor proporción de hierro en la clorita que podría proporcionar sitios superficiales $\mathrm{Fe}-\mathrm{OH}$ adicionales.

Goldberg (2002) estudió la adsorción de los oxoaniones de arsénico sobre illita, caolinita y montmorillionita en comparación con óxidos amorfos de $\mathrm{Fe}$ y $\mathrm{Al}$, demostrando que la afinidad de adsorción es menor en las arcillas que en los óxidos metálicos. La adsorción del arseniato a valores cercanos al $100 \%$ sólo se alcanzó en caolinita alrededor de $\mathrm{pH}$ 5. En todas las otras especies de arcilla, la adsorción fue 
significativamente inferior al $100 \%$. En relación al $\mathrm{pH}$, la adsorción de arseniato fue máxima a bajos $\mathrm{pH}$ y disminuyó al aumentar el $\mathrm{pH}$ por encima de 5 .

La superficie puede ser un factor importante en la adsorción de As por los minerales de arcilla. Estudios como los de Frost and Griffin (1977) muestran que la montmorillonita puede adsorber aproximadamente el doble de $\mathrm{As}(\mathrm{V})$ y $\mathrm{As}(\mathrm{III})$ que la caolinita, debido a su mayor área superficial (2,5 veces mayor que la de la caolinita). Sin embargo, los resultados de Manning and Goldberg (1996) muestran que el área superficial no siempre es un buen indicador de la adsorción de $\mathrm{As}(\mathrm{V})$ por minerales de arcilla. Ellos encontraron que la caolinita (área superficial $9,1 \mathrm{~m}^{2} \mathrm{~g}^{-1}$ ) adsorbe $30 \%$ más $\mathrm{As}(\mathrm{V})$ que la illita y un $50 \%$ más que la montmorillonita (área superficial 18,6 y $24,2 \mathrm{~m}^{2}$ $\mathrm{g}^{-1}$ respectivamente).

Zhang and Selim (2008) sugieren que las sustituciones isomórficas de Fe por Al en las arcillas pueden contribuir a la adsorción de As. Por su parte, Doušová et al. (2006), señalaron que las arcillas no son adsorbentes selectivos para los contaminantes aniónicos debido a su bajo valor de PZC (ver Figura 3.4). Por ello, proponen un tratamiento previo que modifica la carga superficial del mineral que, activada por la presencia de oxi/hidróxidos de $\mathrm{Fe}(\mathrm{III})$, aumenta significativamente la eficiencia de la adsorción de arseniato (desde 15 a más del 90\%).

\subsection{Especies minerales empleadas en la eliminación de As}

Como se comentó en el Capítulo 2, las técnicas convencionales de remoción de arsénico (coagulación-precipitación, adsorción, ósmosis inversa) pueden ser aplicadas a mediana o gran escala como así también a nivel domiciliario. Sin embargo, para comunidades pequeñas o poblaciones rurales dispersas suelen no ser rentables, razón por la cual las tecnologías de bajo costo como las basadas en el empleo de materiales geológicos como adsorbentes así como las técnicas fotoquímicas o el uso de materiales biológicos, están siendo ampliamente desarrolladas. En este sentido, en América Latina, en las últimas dos décadas se han obtenido experiencias empleando tecnologías emergentes tales como la coagulación-filtración con sales de Fe y Al y la adsorción utilizando adsorbentes de bajo costo como especies minerales (arcillas, lateritas, suelos), adsorbentes orgánicos originales y/o modificados (Bundschuh et al., 2011).

En este contexto, la adsorción utilizando adsorbentes naturales y/o sintéticos es el método más comúnmente usado y efectivo en la remoción de arsénico. El proceso de adsorción usualmente se complementa con el de coagulación-floculación a fin de acelerar el tratamiento y eliminar la turbidez y coloración que pueden ser asociadas al 
mismo. Es de destacar, que el costo del material es un parámetro importante a tener en cuenta al seleccionar un adsorbente. En general, un material puede decirse que es de "bajo costo" si requiere poco procesamiento, es abundante en la naturaleza o es un subproducto o residuo de la industria (Amiri et al., 2011).

Como se señaló en el Capítulo 3, entre los recursos que un medio natural posee para controlar la movilidad del arsénico y otros oxoaniones tóxicos se destacan los óxidos metálicos y los minerales de arcilla. Los oxi/hidróxidos metálicos conteniendo $\mathrm{Fe}, \mathrm{Al}$ y/o Mn resultan ser los adsorbentes naturales más eficientes, razón por la cual, estos sistemas constituyen la base de los procesos tecnológicos mas efectivos y económicos para la remoción de As (Jain et al., 1999; Bhattacharya et al., 2003; Dixit and Hering, 2003; Bundschuh et al., 2011; Giles et al., 2011, Aredes et al., 2012). Básicamente, el proceso resulta semejante al que regula el comportamiento químico del elemento en los acuíferos mediante mecanismos de adsorción y desorción. Las ventajas se encuentran asociadas a la abundancia de materiales naturales ricos en esos elementos tales como arcillas, zeolitas y diversos tipos de suelos que pueden destinarse al suministro de agua en poblaciones rurales o muy alejadas de centros urbanos.

Es de destacar que la mayoría de los estudios reportados se centran en la remoción de las especies oxídicas de $\mathrm{As}(\mathrm{V})$ porque el arseniato se une mas fuertemente a los óxidos metálicos que el arsenito. Sin embargo, el estado de oxidación no es una limitación para la técnica de adsorción debido a que se puede realizar una oxidación previa al tratamiento, tal como se explicó en el Capítulo 2. Además, la adsorción depende del pH y del potencial redox del ambiente (MamindyPajany et al., 2009).

Como se ha descrito anteriormente, entre los sistemas de óxidos conteniendo hierro son abundantes en la naturaleza y relativamente baratos por lo que son ampliamente utilizados. Los oxi/hidróxidos de Fe(III) sintéticos, como el oxido de hierro hidratado amorfo, la ferrihidrita y la goethita han demostrado una fuerte afinidad por las especies solubles de As debido a su alta carga superficial positiva, por lo que se han reportado como adsorbentes promisorios (Hsia et al., 1994; Wilkie and Hering, 1996; Raven et al., 1998; Sun and Doner, 1998). Sin embargo, la mayoría de estos materiales se comercializan como polvos de granulometría fina que resultan difíciles de separar del agua luego del tratamiento de adsorción. Comparados con estos materiales sintéticos, los minerales de hierro naturales, tales como hematita, ferrihidrita, goethita y lepidocrocita, se presentan como una alternativa más atractiva porque son más rentables y están disponibles en diferentes tamaños de partícula (Guo 
et al., 2007). El empleo de materiales geológicos para la remediación del agua subterránea conteniendo As, se ha reportado como una solución emergente prometedora, especialmente cuando los materiales se encuentran disponibles localmente, lo que disminuye el costo del procedimiento (Bundschuh et al., 2011).

En relación al efecto del $\mathrm{pH}$, se ha reportado en la literatura que la adsorción del arseniato sobre los oxi/hidróxidos de hierro es fuertemente dependiente del $\mathrm{pH}$, disminuyendo la adsorción al aumentar el pH (Pierce and Moore, 1982; Goldberg, 2002; Dixit and Hering, 2003; Stollenwerk, 2003; Guo et al., 2007; Mamindy-Pajany et al., 2009). Por el contrario, la adsorción de arsenito no depende del pH manteniéndose constante en un amplio rango (Goldberg, 2002; Dixit and Hering, 2003). Como se señaló en el Capítulo 3, este comportamiento puede ser explicado en términos de ionización del adsorbente y del adsorbato.

La carga superficial del adsorbente se produce por protonación o disociación de los grupos funcionales $\mathrm{XOH}$ de la superficie (X representa $\mathrm{Al}$ ó Fe en el oxi/hidróxido metálico o un grupo aluminol en los bordes de las partículas de arcilla) según las ecuaciones 3.1 y 3.2. Estas reacciones de ionización superficiales se llevan a cabo en función del pH de la solución en contacto con el sólido adsorbente. Este efecto del pH está relacionado con el cambio en el $\mathrm{PZC}$ de los minerales. Cuando $\mathrm{PZC}<\mathrm{pH}$ se ve favorecida la ecuación 3.2 por lo que la carga de la superficie es negativa. En estas condiciones la superficie no presenta afinidad por los oxoaniones. Cuando el PZC>pH se ve favorecida la ecuación 3.1 y la superficie del adsorbente adquiere carga positiva presentando afinidad por las especies cargadas negativamente. Por lo tanto, la adsorción de oxoaniones en estos minerales se ve favorecida a $\mathrm{pH}$ ácidos cuando la carga superficial es positiva. Es de destacar que el PZC de los oxi/hidróxidos de Fe se encuentra típicamente en el rango de 7,4-8,7 (Guo et al., 2007).

En relación al efecto del pH sobre el adsorbato, también comentado en el Capítulo 3, el arseniato se encuentra cargado negativamente en casi toda la escala de $\mathrm{pH}$, mientras que el arsenito, predomina como especie neutra a $\mathrm{pH}$ inferiores a 9,2 y sólo cuando el pH excede 12 puede estar presente la especie $\mathrm{HAsO}_{3}{ }^{2-}$. De lo expuesto surge que a los valores de $\mathrm{pH}$ en los cuales la superficie del mineral de hierro se encuentra cargada positivamente, el arseniato presenta carga negativa mientras que el arsenito es neutro. En estas condiciones se favorece la adsorción de las especies de $\mathrm{As}(\mathrm{V})$. A valores altos de $\mathrm{pH}$ la superficie del mineral se encontrará cargado negativamente y se produce una repulsión electrostática con los oxoaniones, es por esto que la adsorción de arseniato disminuye al aumentar el pH (Pierce and Moore, 1982; Goldberg, 2002; Dixit and Hering, 2003; Guo et al., 2007; Mamindy-Pajany et al., 
2009). Contrariamente, en estas condiciones el arsenito sigue siendo neutro por lo que no es afectado por el cambio de signo de la superficie (Goldberg, 2002; Dixit and Hering, 2003).

Guo et al. (2007) realizaron estudios de remoción de arseniato empleando como adsorbentes hematita y siderita naturales, demostrando que ambos materiales remueven el As con distintas eficiencias, si bien la siderita fue más eficiente en la remoción del arseniato respecto a las especies orgánicas y al arsenito. La hematita natural con una granulometría entre $0,25-0,5 \mathrm{~mm}$ presentó una capacidad de adsorción de arseniato de $202 \mu \mathrm{g} \mathrm{g}^{-1}$. En general el $\mathrm{pH}$ tuvo un gran impacto en la adsorción de arseniato, disminuyendo la remoción de $\mathrm{As}(\mathrm{V})$ al aumentar el $\mathrm{pH}$.

Mamindy-Pajany et al. (2009) ensayaron como adsorbentes goethita y hematita. Ambos óxidos resultaron buenos candidatos como adsorbentes del $\mathrm{As}(\mathrm{V})$ para ser empleados en tecnologías de remoción, particularmente por ser abundantes en la naturaleza y presentar relativo bajo costo. El estudio mostró que a los pH correspondientes a las aguas naturales (6-9) ambos minerales fueron capaces de adsorber mas del $80 \%$ del arsénico. Estudios complementarios evaluando hematita, goethita y magnetita (Mamindy-Pajany et al., 2011) demostraron que la hematita presenta porcentajes de remoción de arseniato de $100 \%$ en el rango de $\mathrm{pH}$ entre $2-11$, mientras que para los otros adsorbentes el rango de $\mathrm{pH}$ efectivo se reduce a 2-8.

Bundschuh et al. (2011) evaluaron el posible empleo de materiales geológicos nacionales como adsorbentes del arsénico de aguas subterráneas de la provincia de Santiago del Estero. Ensayaron suelos ricos en arcillas y cenizas volcánicas de Santiago del Estero y suelo laterítico de Misiones. Los ensayos en "batch" a nivel laboratorio (relación líquido/sólido 1:10) demostraron una mayor remoción de $\mathrm{As}(\mathrm{V})$ para la laterita (99\%) que para las muestras de Santiago del Estero (40-53\%). Si bien, la aplicación de la laterita misionera podría ser factible, el costo de transporte se presentó como una restricción económica importante a tener en cuenta. Maji et al. (2008) también reportaron ensayos en columna empleando laterita y agua subterránea natural, destacando la fácil separación del adsorbente del agua tratada y la buena calidad del agua con posterioridad al tratamiento. En efecto, el agua luego del tratamiento presentó una disminución significativa de los sólidos disueltos, mientras que el $\mathrm{Fe}$ y el $\mathrm{Al}$ del adsorbente no fueron lixiviados en el efluente y no se observaron cambios significativos en el valor del $\mathrm{pH}$ inicial del agua.

En relación al mecanismo de adsorción, Goldberg (2002) reportó que la comprensión de los mecanismo de adsorción de los oxoaniones de As pueden ser 
proporcionados por métodos experimentales macroscópicos (cambios en el PZC del adsorbente y efecto de la fuerza iónica), así como por métodos microscópicos (técnicas espectroscópicas). Los cambios en PZC pueden ser usados como evidencia de una fuerte adsorción específica y la formación de complejos superficiales de esfera interna. La formación de complejos de esfera interna de aniones aumentan la carga negativa de las superficies sólidas, disminuyendo de ese modo el PZC a valores más bajos de pH (Stollenwerk, 2003). Los cambios en la fuerza iónica influyen en las fuerzas electrostáticas cercanas a la superficie del mineral afectando la formación de complejos de esfera externa generando una disminución en la adsorción al incrementar la fuerza iónica de la solución. Los aniones que forman complejos de esfera interna coordinan directamente con la superficie de una manera que es relativamente independiente de la fuerza iónica (Stollenwerk, 2003).

Cambios en el PZC fueron encontrados en la adsorción sobre óxidos de $\mathrm{Fe}$ amorfos para arsenito (Pierce and Moore, 1980; Suarez et al., 1998) y arseniato (Hsia et al., 1994; Suarez et al., 1998; Goldberg and Johnston, 2001) sugiriendo la formación de complejos superficiales de esfera interna. La adsorción de arseniato en óxidos amorfos de Fe y Al (Hsia et al., 1994; Goldberg and Johnston, 2001) y en hematita y goethita (Mamindy-Pajany et al., 2009) mostró poca dependencia de la fuerza iónica sugiriendo también la formación de complejos superficiales de esfera interna, mientras que la adsorción de arsenito mostró una disminución al aumentar la fuerza iónica indicando la formación de complejos superficiales de esfera externa (Goldberg and Johnston, 2001).

Las técnicas espectroscópicas proporcionan observaciones experimentales directas de los mecanismos de adsorción de los iones (Goldberg, 2002). Estudios espectroscópicos (Myneni et al., 1998; Goldberg and Johnston, 2001; O'Really et al., 2001; Müller et al., 2010; Jia et al., 2006) y predicciones teóricas (Myneni et al., 1998; Goldberg and Johnston, 2001) han propuesto que la adsorción de arseniato sobre la superficie de los oxi/hidróxidos de Fe se produce por formación de complejos de esfera interna preferentemente por medio de la formación de un complejo bidentado.

O'Really et al. (2001) reportan que el modelo que interpreta el proceso de adsorción sobre los oxi/hidróxidos de Fe sugiere la presencia del anión arseniato como ligando mono o bidentado (Figura 4.3), según el grado de cobertura superficial. Los complejos monodentados predominan a coberturas superficiales bajas, los complejos bidentados mononucleares dominan a altos niveles de cobertura, mientras que predominan los complejos bidentados binucleares a coberturas superficiales cercanas 
a la capacidad de la monocapa. En relación al arsenito también se ha reportado la formación de complejos de esfera interna sobre óxidos de Fe (Goldberg, 2002).

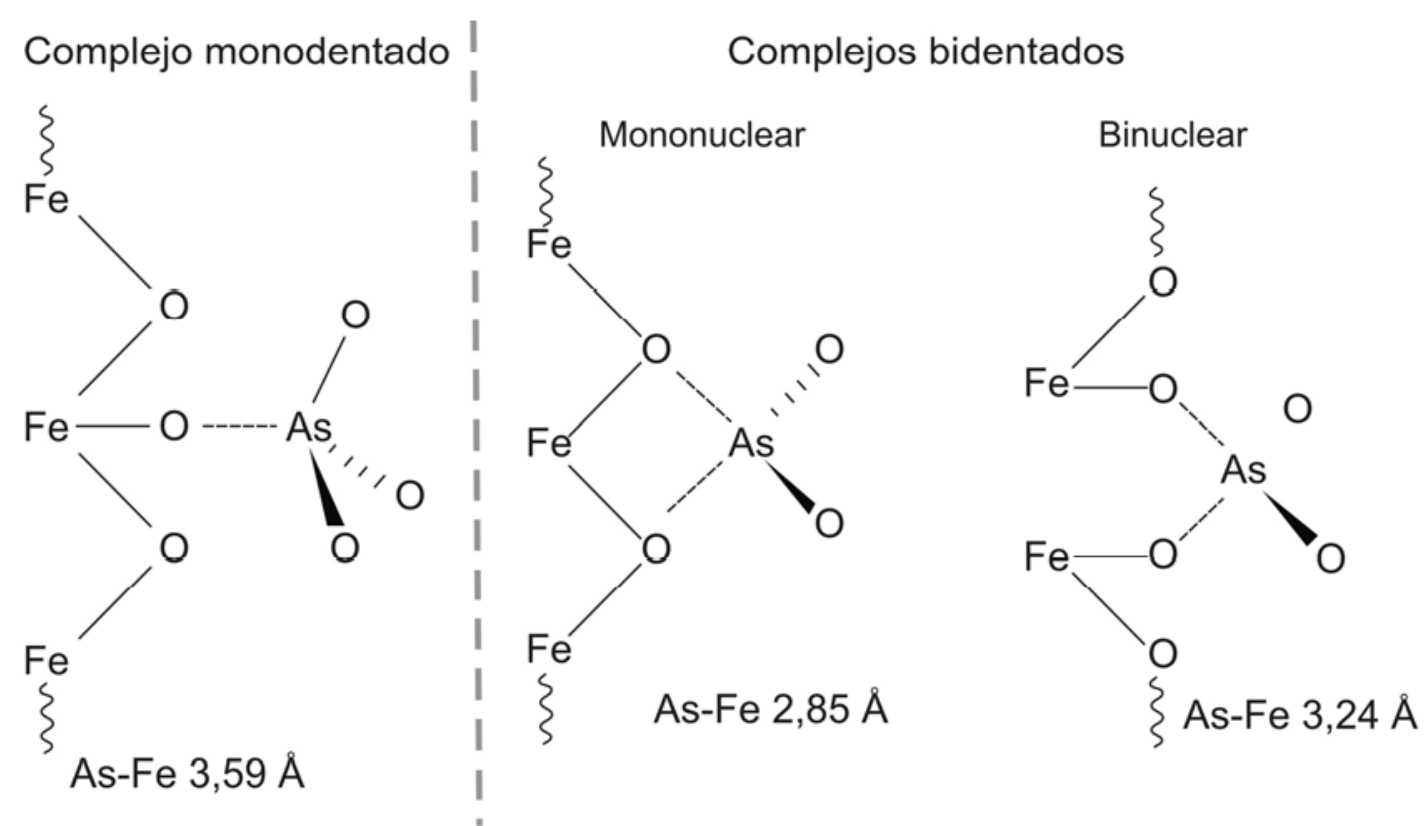

Figura 4.3. Ilustración esquemática de los mecanismos de adsorción propuestos de arseniato en goethita (O'Really et al., 2001).

En la remoción de As empleando minerales de hierro, es importante tener en cuenta la presencia en el agua de oxoaniones competitivos. En este sentido, el fosfato se reporta como el principal competidor (Goldberg, 2002; Guo et al., 2007; Giles et al., 2011), por lo que cuando está presente en el agua a tratar hay que agregar mayor cantidad de adsorbente para disminuir el As a niveles aceptables. En relación a otros aniones competidores, Guo et al. (2007) demostraron que el nitrato no tiene un efecto significativo a concentraciones por debajo de los $10 \mathrm{mg} \mathrm{N} \mathrm{L}^{-1}$, mientras que Goldberg (2002) reportó que el efecto del sulfato es menos importante que el fosfato y que el molibdato solo presenta efecto significativo a pH por debajo de 5. Estos resultados son esperables debido a las similitudes estructurales de las especies arseniato y fosfato.

\subsection{Aspectos geológicos de minerales de depósitos nacionales seleccionados para su eventual uso como adsorbentes en el tratamiento de remoción de As}

Debido a la abundancia de recursos minerales nacionales de potencialidad para ser empleados como adsorbentes del As, en la presente Tesis se propone el aprovechamiento de algunos de nuestros vastos recursos minerales para el desarrollo de tecnologías alternativas para el tratamiento de aguas subterráneas con contenidos anómalos del elemento. La selección se basó en las características estructurales y composicionales de las especies minerales que regulan los procesos de adsorcióndesorción en los acuíferos. 
En este sentido, se focalizó la atención en aluminosilicatos por su amplia distribución en el ámbito de la vasta región Chaco-pampeana afectada. Algunos aluminosilicatos como arcillas y zeolitas se han reportado como especies abundantes en la naturaleza representando fuentes de muy bajo costo para el tratamiento del problema (Elizalde González et al., 2001; Dixit and Hering, 2003; Jesen et al., 2005; Doušová et al., 2006; Guo et al., 2009; Bundschuh et al., 2011; Giles et al., 2011; Aredes et al., 2012).

Los minerales de arcilla se encuentran en muchos casos asociados a especies oxídicas de hierro, producto de procesos geoquímicos como la lixiviación, oxidación e hidrólisis natural que han conducido a la deposición de dichas fases. En medios propicios se facilita la condensación de "clusters" de hierro con formación de especies oxídicas amorfas y/o cristalinas, con diferente grado de hidratación según la secuencia geoquímica "clusters"-fase coloidal-fase oxídica amorfa-óxidos hidratados-óxidos anhidros (de diferente granulometría) (Cornell et al., 1987; Cornell et al., 1989; Thompson and Mitchell, 1993; Schwertmann and Cornell, 2000). Es así que en muchos casos se observan como materiales ferruginosos que representan una alternativa de estudio interesante para su aplicación como adsorbentes del As.

Por otra parte, materiales laminares y tridimensionales con bajo contenido de hierro son susceptibles de ser modificados químicamente para transformarlos en aptos para el proceso de adsorción. Entre ellos, las zeolitas, caracterizadas por su elevada capacidad de intercambio catiónico, presentan además la posibilidad de adsorción catiónica superficial, debido a su característica carga negativa. Es por ello que la interacción con sales de hierro puede tener lugar tanto a nivel superficial como eventualmente másico, conduciendo a la formación de óxidos e hidróxidos de hierro hidratados.

El trabajo de Tesis se ha centralizado en la aplicación de una estrategia tecnológica basada en la remoción del contaminante mediante el empleo de geomateriales, preferentemente localizados en las cercanías de las áreas afectadas para disminuir el costo del tratamiento. Se evaluaron materiales naturales de amplias reservas, que se localizan en la PBA, así como en otras regiones del país. En particular se aborda la problemática planteada en algunas localidades del interior de la PBA y eventualmente la tecnología podría ser adaptada a otras provincias cuyas aguas subterráneas registren altos contenidos del elemento.

Específicamente, se propone la utilización de los siguientes minerales procedentes de depósitos nacionales (Figura 4.4): 


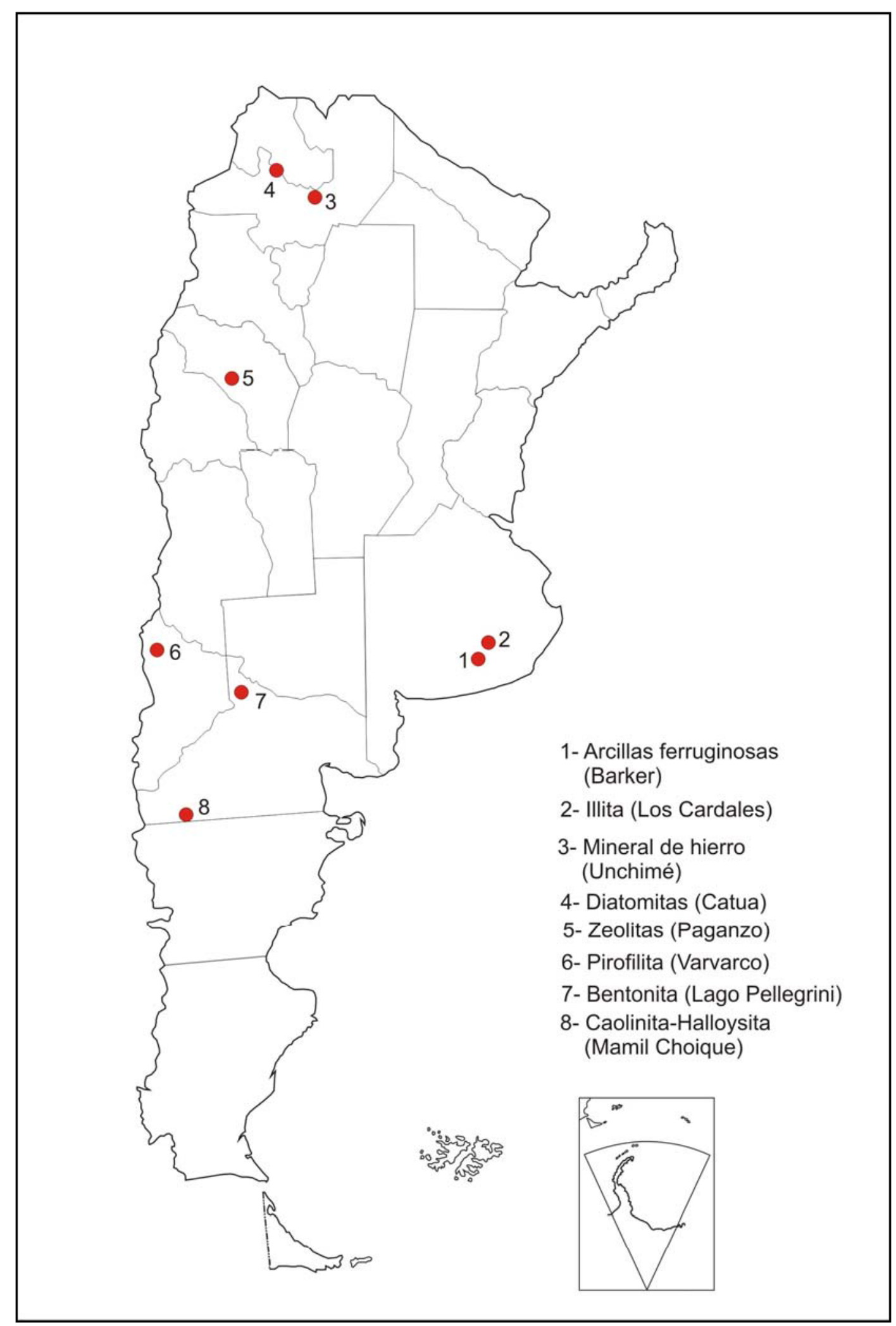

Figura 4.4. Ubicación de los depósitos de las muestras ensayadas.

_ Arcillas ferruginosas de la PBA: la PBA cuenta con abundantes y accesibles depósitos de minerales de arcillas ricas en hierro ( $40 \%$ expresado como $\mathrm{Fe}_{2} \mathrm{O}_{3}$ ), materias primas cuya eventual explotación y procesamiento para su empleo como 
adsorbentes constituyen una posibilidad de aprovechamiento de un material de bajo costo altamente promisorio para solucionar el grave problema en las zonas afectadas.

_ Yacimientos Oolíticos de Hierro de las Provincias de Salta y Jujuy: se analiza el empleo de otros minerales ricos en hierro fuera de la PBA. Se trata de depósitos de hierro oolítico con contenidos de hierro entre 34 y $65 \%$ de $\mathrm{Fe}_{2} \mathrm{O}_{3}$.

_ Especies minerales posibles de ser modificadas: se analiza la posibilidad de aprovechamiento de otras especies minerales con bajo contenido de hierro, como aluminosilicatos laminares y tridimensionales, susceptibles de ser modificados químicamente para transformarlos en aptos para el proceso de adsorción de As. La modificación química se realiza mediante tratamiento con sales de hierro (III).

A continuación se describen los principales aspectos geológicos de las especies estudiadas.

\subsubsection{Arcillas ferruginosas de la provincia de Buenos Aires}

La minería de minerales no metalíferos y rocas de aplicación de la PBA es una de las más importantes del país. Se centra principalmente en la extracción de rocas graníticas, calizas y minerales industriales, especialmente arcillas que se destinan a la industria cerámica. La actividad extractiva se ubica fundamentalmente en las Sierras Septentrionales, conformadas por cerros alineados en sentido noroeste-sureste a lo largo de unos $350 \mathrm{~km}$ desde Olavarría hasta Mar del Plata y un ancho máximo del orden de los $60 \mathrm{~km}$ en el área de Tandil. La producción anual de minerales y rocas industriales oscila entre 12.000 .000 y 15.000 .000 toneladas que se destina preferentemente a la industria de la construcción, de este volumen un $25 \%$ corresponde a materiales arcillosos que abastecen a la industria cerámica y cementera (Dirección de Minería de la Nación, 2012).

Las sierras presentan elevaciones de entre 200 a 300 metros sobre la llanura circundante; están integradas por un basamento precámbrico, sobre el que yacen sedimentitas precámbrico-paleozoicas y sedimentos cuaternarios. De acuerdo a Iñiguez et al. (1989) las sedimentitas que asientan sobre el basamento se desarrollaron en cinco ciclos de depositación, originados en un ambiente marino de plataforma epicontinental.

El material extraído y ensayado en el presente trabajo de tesis doctoral proviene de amplios depósitos arcillosos que se localizan en las proximidades de las localidades de Barker y Villa Cacique, Partido de Benito Juárez (Foto 4.1). 


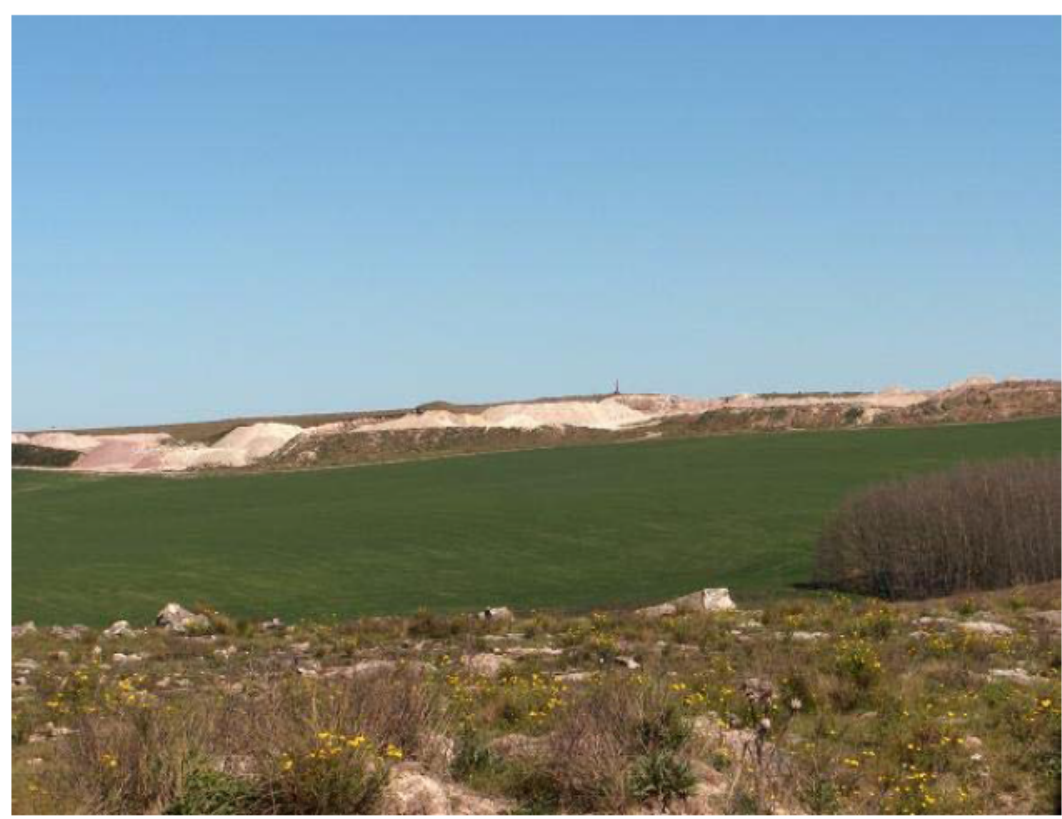

Foto 4.1. Vista panorámica de canteras en Barker, provincia de Buenos Aires.

Los depósitos se emplazan en la formación Las Águilas (Zalba et al., 1988), del grupo Sierras Bayas, unidad asignada al Neoproterozoico Superior y al cuarto ciclo sedimentario propuesto por Iñiguez et al. (1989). Esta formación se la reconoce tanto en la denominada Cuchilla de Las Águilas como en el área de Sierra La Juanita (Figura 4.5), yace sobre una brecha silícea y está conformada por 3 facies bien representadas que, en conjunto registran espesores que oscilan entre los 25 a 30 metros.

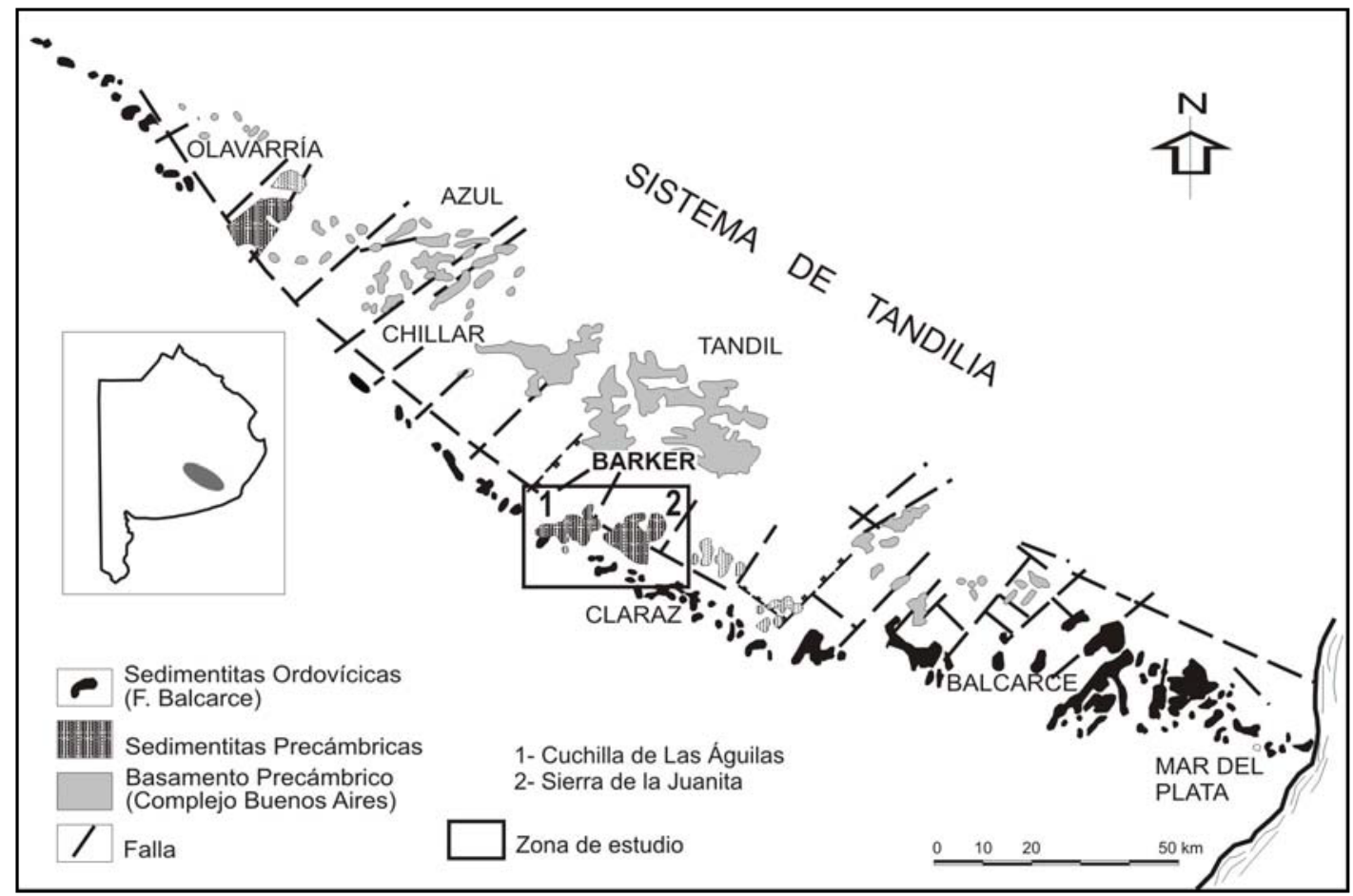

Figura 4.5. Mapa de ubicación de los sectores de estudio (modificado de Iñiguez et al., 1989). 
El primer banco de pelitas ferruginosas masivas de 6-8 metros de espesor, presenta altos contenidos de óxidos e hidróxidos de hierro, llegando en sectores a contener concentraciones de hasta $70 \%$ de $\mathrm{Fe}_{2} \mathrm{O}_{3}$ y un promedio de $30-40 \%$. A este banco de arcillas masivas le sigue un segundo nivel arcilloso de estructura laminar con intercalaciones ferríferas, cuyo conjunto presenta un espesor del orden de los 3 metros. Sobre este segundo banco se registra una sucesión de pelitas heterolíticas de colores blanquecinos, grises, amarillentos y en parte violáceos, de varios metros de espesor (Figura 4.6). De acuerdo a Nigro et al. (2013) se determinaron espesores máximos de 15 metros y mínimos de 6 metros para estos tres niveles en distintas canteras del área. Los óxidos de hierro se presentan en forma compacta, con colores rojos en general y en parte violáceo-morados.
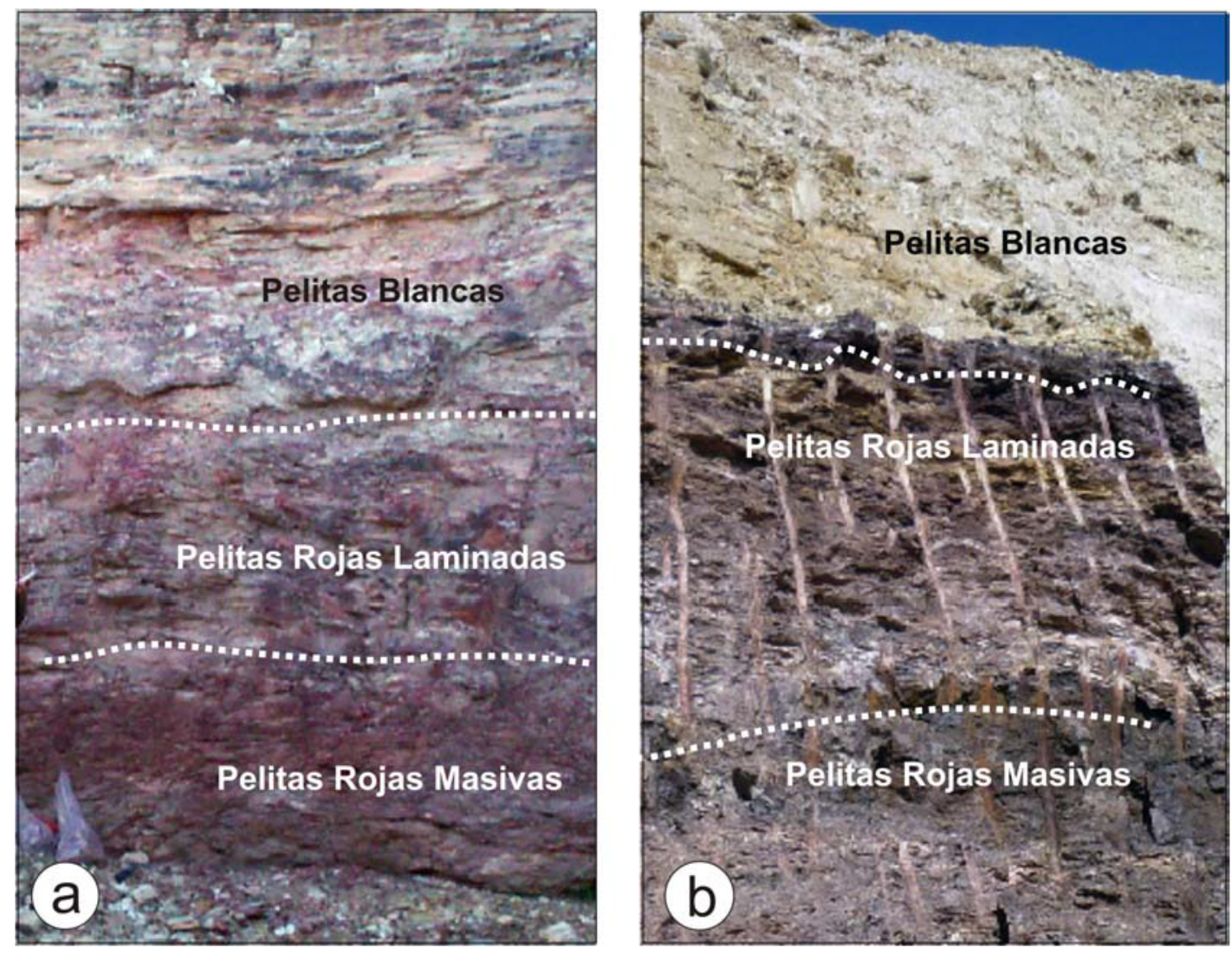

Figura 4.6. Niveles pelíticos reconocidos en: a) Cuchilla de Las Águilas, cantera El Fortín y b) Sierra de La Juanita, cantera Martín Fierro (modificado de Nigro et al., 2013).

Las pelitas ferruginosas masivas están formadas por hematita y goethita, con presencia de caolinita, illita, esmectitas y pirofilita. Los niveles de pelitas ferruginosas laminadas presentan caolinita, pirofilita, illita, esmectitas y hematita en cantidades similares, con menores proporciones de cuarzo. Por último los niveles de pelitas claras están conformados por illita, pirofilita, esmectitas, cuarzo y caolinita. Es de destacar que se determinó una alta correlación para las muestras analizadas, a partir de los contenidos en elementos mayoritarios, minoritarios y trazas; así como una 
composición mineralógica semejante en la Sierra de La Juanita y Cuchilla de Las Águilas. Esta correlación entre ambas sierras, separadas unos $10 \mathrm{~km}$, le otorga al sector una importante potencialidad como una fuente futura de Fe (Nigro et al., 2013).

El mineral ferruginoso, presente en las arcillas, tiende a incrementar su dureza y a disminuir su plasticidad a medida que aumenta su contenido en hierro. Los valores de plasticidad de Atterberg oscilan entre 12 y 14 y su peso específico es en torno de los 2,48 g por centímetros cúbicos (Domínguez y Schalamuk, 1999). Este mineral, de amplias reservas, se comercializa para abastecer a la industria cementera, para la elaboración de clinker y también se destina a la industria cerámica. Se estima que su producción en los últimos años es del orden de las 300.000 toneladas.

Si bien existen numerosos depósitos arcillosos, se seleccionaron los que por su coloración, parecen registrar los mayores contenidos en hierro y se encuentran ubicados próximos a localidades y accesos a rutas. Se reconocieron varias acumulaciones arcillosas y se muestrearon para realizar los ensayos de tratamiento en el laboratorio. En la Tabla 4.1 se presentan las coordenadas y la denominación de las muestras extraídas, en tanto que en las Fotos 4.2 a 4.6 se muestran vistas y detalles de las áreas muestreadas.

Tabla 4.1. Posición geográfica de las áreas y denominación de las muestras estudiadas.

\begin{tabular}{c|cc|c}
\hline Area & \multicolumn{2}{|c|}{ Coordenadas } & Muestra \\
\hline & 5551739 & 5837986 & 8 AFO \\
Zona 1 & 5551748 & 5838026 & 9 AFO \\
& 5551718 & 5838026 & 10 AFO \\
& 5551759 & 5838046 & 11 AFO \\
\hline Zona 2 & 5551008 & 5835127 & 12 AFO \\
\hline Zona 3 & 5549505 & 5834253 & 1AFO a 7AFO \\
\hline
\end{tabular}

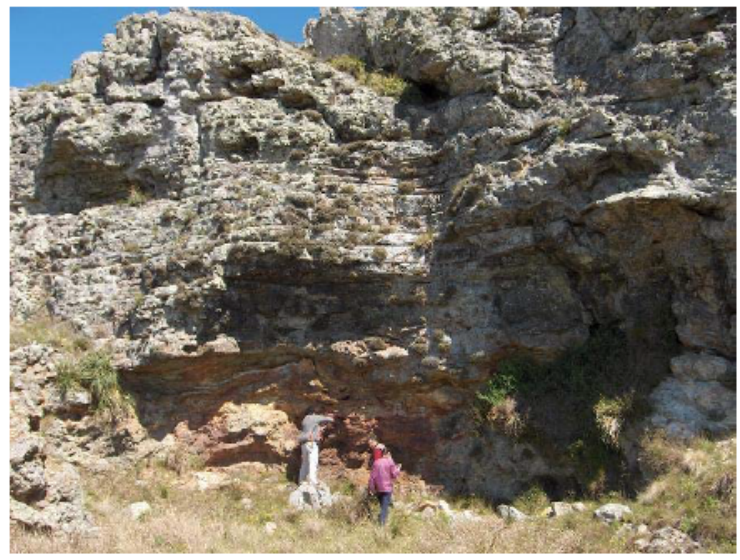

Foto 4.2. Vista general de la Zona 1.

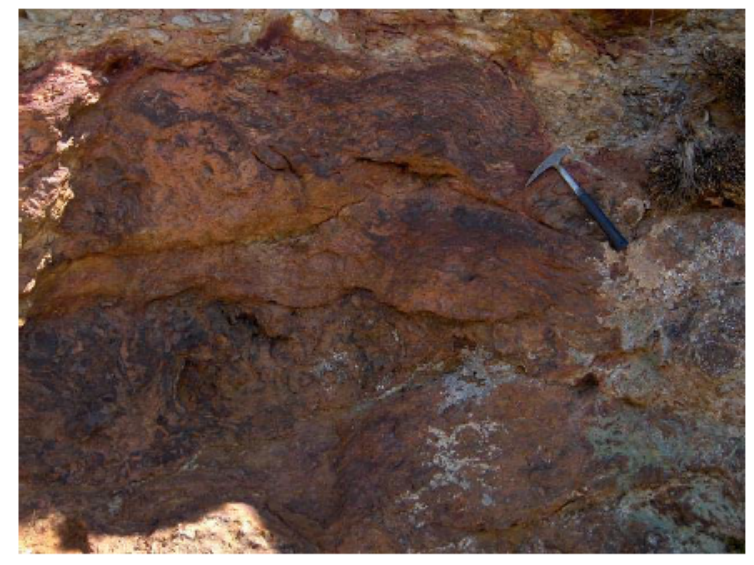

Foto 4.3. Detalle de banco de arcilla. 


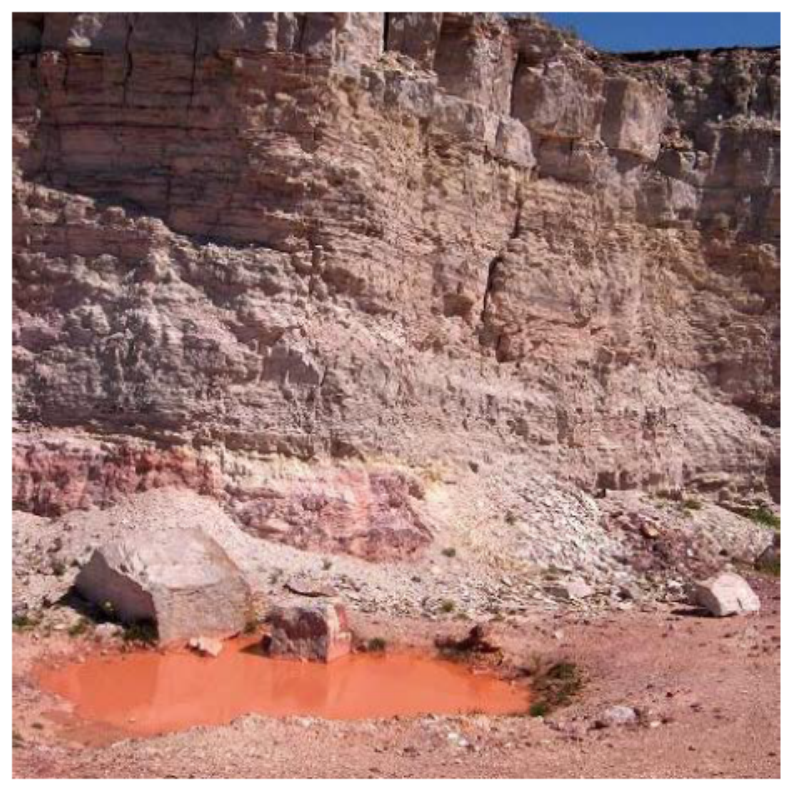

Foto 4.4. Vista panorámica del frente de Zona 2.

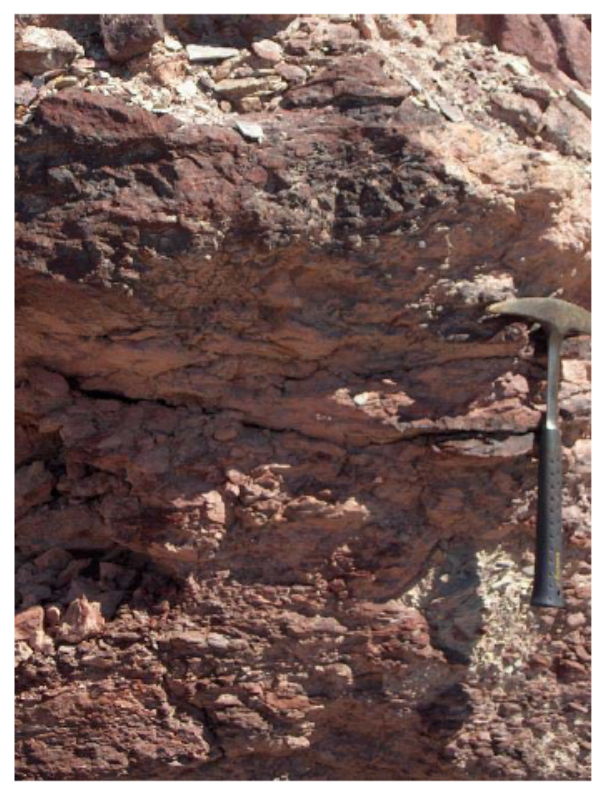

Foto 4.5. Detalle de la muestra tomada.

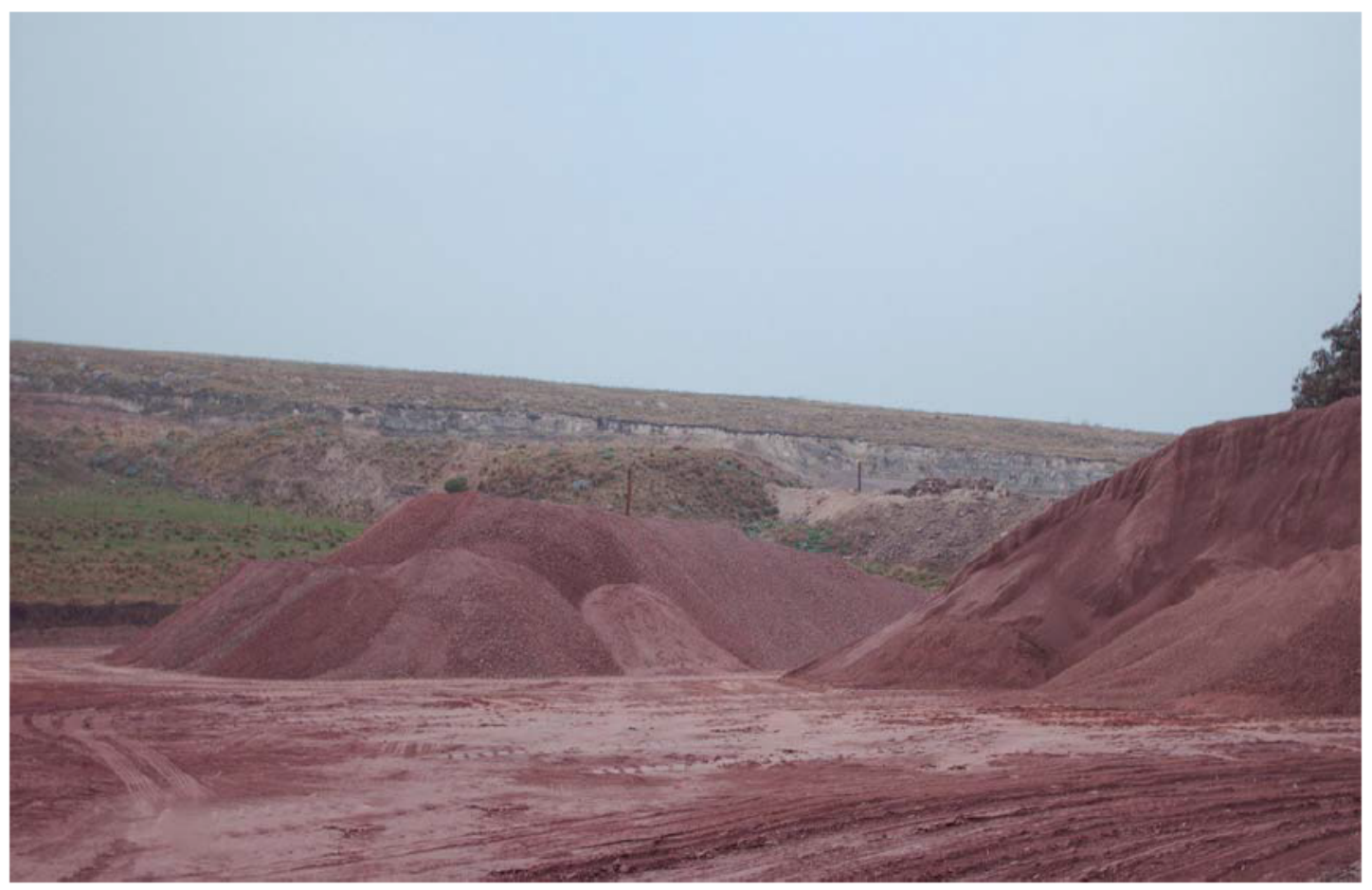

Foto 4.6. Vista general de acopios de arcilla ferruginosa en Zona 3.

\subsubsection{Yacimientos Oolíticos de Hierro. Provincias de Salta y Jujuy}

Las provincias de Jujuy y Salta (Figura 4.7) contienen los mayores recursos del país en mineral de hierro, sus depósitos se localizan en la cuenca sedimentaria de las Sierras Subandinas. Se trata de horizontes hematíticos que forman parte de la secuencia silúrica de la región. Estos horizontes se emplazan en las sierras de Zapla, Puesto Viejo y Cerro Labrado (departamento Capital) y Santa Bárbara (departamento homónimo), en la provincia de Jujuy y en las sierras de Unchimé (departamento Güemes), en la provincia de Salta. Las concentraciones de hierro se conocen como de 
tipo Clinton (USA) o también como yacimiento de Hierro Oolítico (Schalamuk et al., 1989). El origen de estas acumulaciones ferríferas se atribuyen a la sedimentación marina en una cuenca nerítica (aguas someras), donde se depositó originalmente chamosita que luego por un proceso diagenético se hematizó con pérdida de algunos de sus elementos y separación de sílice coloidal, a través de un proceso oxidante (Angelelli, 1984).

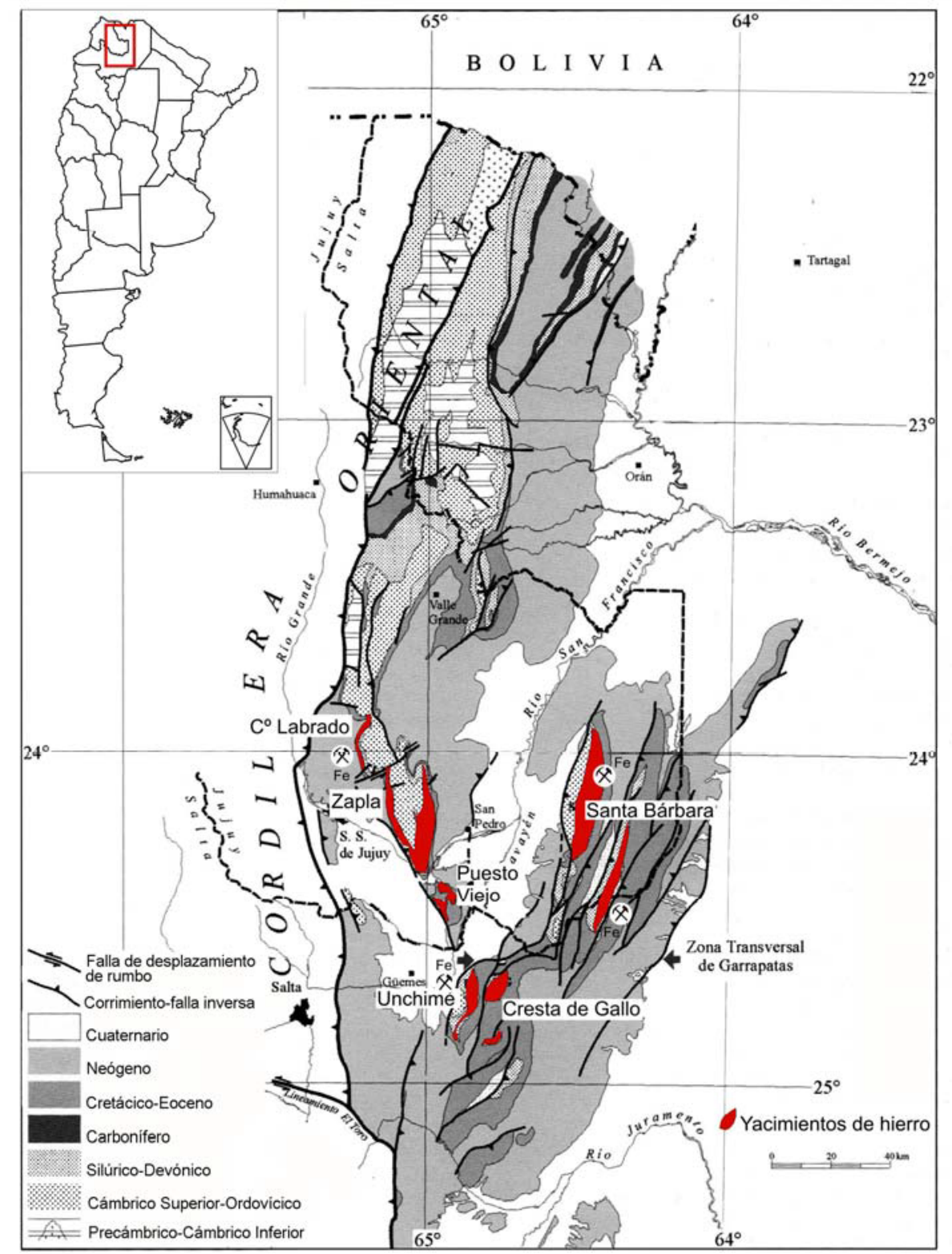

Figura 4.7. Mapa geológico regional de la cuenca ferrífera de Salta y Jujuy.

Del conjunto de yacimientos es Zapla, descubierto en 1939 y más tarde Puesto Viejo, el primero que registró producción a partir de 1945, fecha en que se instaló en la ciudad de Palpalá el Alto Horno (paralizado en los años noventa). Tanto Zapla como Puesto Viejo fueron los proveedores de mineral que alimentaron el complejo minero 
Siderúrgico Altos Hornos Zapla, de la Ex Dirección General de Fabricaciones Militares. Más tarde (1957) se suma Unchimé que abastece parcialmente al complejo siderúrgico y provee de mineral de hierro a la fábrica de cemento Portland de Güemes (Salta). Recientemente la empresa Loma Negra realizó trabajos de exploración de detalle de un sector del yacimiento de Unchimé (mediante sondeos) a los efectos de programar su explotación para abastecer de mineral de hierro a la fábrica de cemento Portland instalada en la provincia de Catamarca (Schalamuk et al., 2011).

El material ensayado en el presente trabajo proviene de muestras representativas de los horizontes ferríferos de Unchimé. Dicho depósito se encuentra en la Provincia de Salta, a unos $70 \mathrm{~km}$ al este de la capital provincial, en el departamento de Güemes. Las muestras fueron identificadas con la siguiente denominación: MU2, MU4, MU5 y MU7.

En el área en consideración se presentan dos mantos u horizontes de mineral de hierro, denominados Horizonte I (Fotos 4.7 y 4.8 ) y Horizonte II (Foto 4.9). El espesor de estos mantos oscila frecuentemente entre 1 a 4 metros y su distancia en sentido vertical varía entre 90 y 160 metros. Los estudios de exploración realizados (Angelelli, 1984) permitieron reconocer a los horizontes ferríferos en una longitud de $33 \mathrm{~km}$, donde se llevaron a cabo 329 calicatas de reconocimiento y se tomaron 636 muestras comunes.

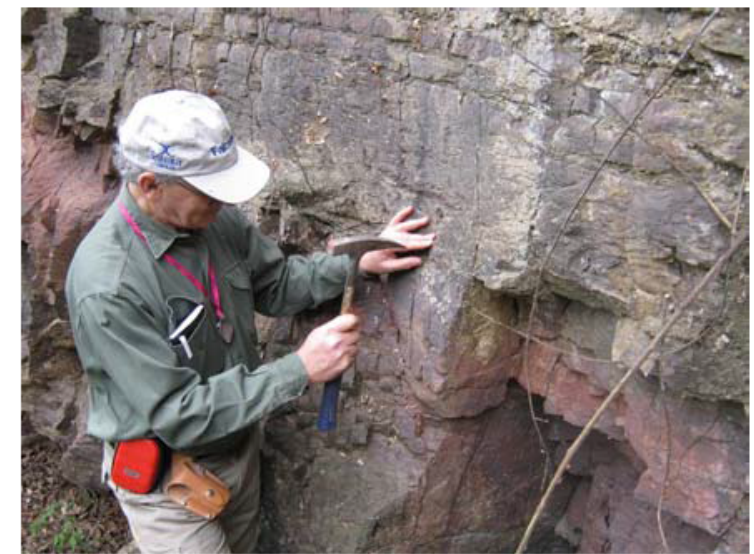

Foto 4.7. Horizonte I (Unchimé, Salta).

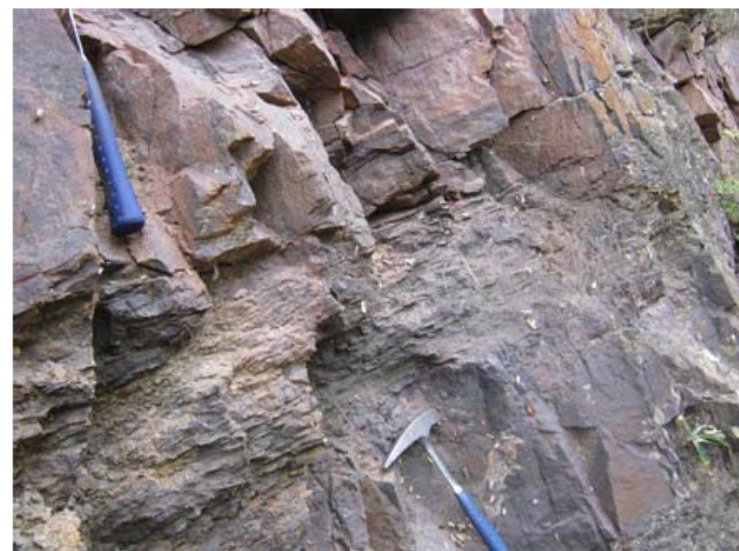

Foto 4.8. Detalle del mineral de hierro del Horizonte I.

El mineral en lo concerniente a su estructura se presenta en general de aspecto homogéneo, en ciertos bancos se asemeja a una arenisca de grano fino y acusa una coloración rojo oscuro hasta rojo pardusco. Es compacto y suele presentar textura oolítica y estructura entrecruzada. Su composición mineralógica consiste en: hematita, mineral preponderante, cuarzo, en granos finos y en astillas y también en rodados, sílice hidratada, producto de la alteración a partir de chamosita que a menudo 
acompaña a la hematita en hojuelas muy pequeñas, siderita, apatita, moscovita y pirita, esta última en muy pequeña proporción. Existen sectores con abundante chamosita y otros muy ricos en hematita. En general los contenidos en hierro oscilan entre $34 \%$ y $65 \%$ de $\mathrm{Fe}_{2} \mathrm{O}_{3}$.

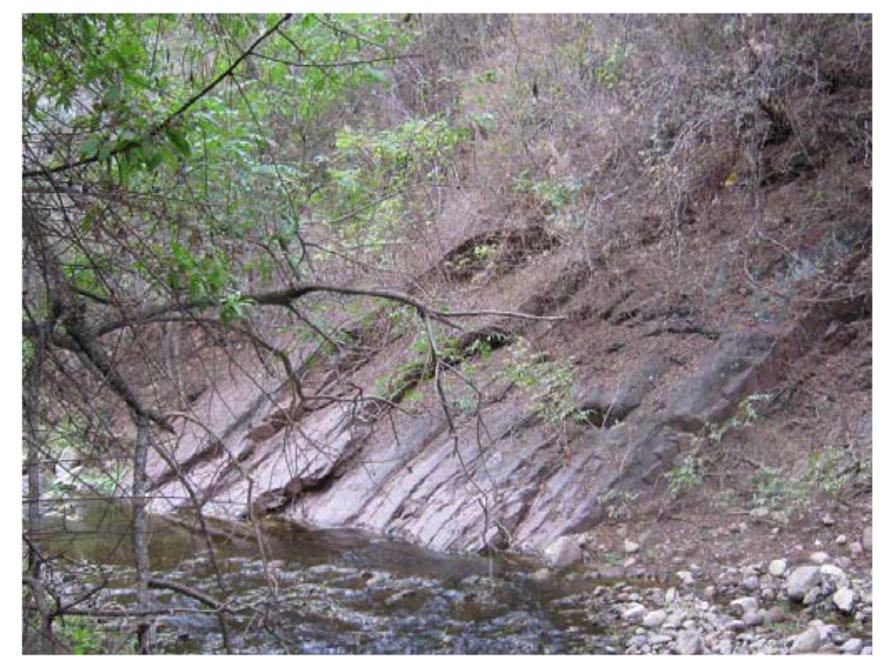

Foto 4.9. Vista del Horizonte II (Unchimé, Salta).

\subsubsection{Especies minerales con bajo contenido de hierro}

Finalmente, se analizó la posibilidad de aprovechamiento de especies minerales procedentes de yacimientos argentinos con bajos contenidos de hierro (inferior al $5 \%$ como $\mathrm{Fe}_{2} \mathrm{O}_{3}$ ) que permitieran, mediante una modificación química adecuada, la obtención de geomateriales activados aptos en el proceso de adsorción de As. El tratamiento químico de las especies se realizó mediante el empleo de soluciones de sales de $\mathrm{Fe}(\mathrm{III})$, a partir de un proceso hidrolítico y ligero ajuste de $\mathrm{pH}$, promoviendo la formación y agregación de "clusters" de Fe dando lugar a la presencia en superficie de especies de hierro amorfas. La activación química se explicará en detalle en el Capítulo 7.

Se seleccionaron aluminosilicatos laminares de tipo estructural 1:1 y 2:1, aluminosilicatos tridimensionales de origen vulcanoclástico (toba zeolitizada rica en clinoptilolita) y diatomitas.

\section{_ Caolín de Mina Pana, distrito Mamil Choique, Pcia. de Río Negro \\ El mineral ensayado, denominado $\mathrm{K}$, proviene de un yacimiento localizado en las proximidades de la localidad de Mamil Choique, provincia de Río Negro (Figura 4.4). En ese distrito minero se explotan depósitos arcillosos cuyo material se comercializa como caolín para uso cerámico. Sin embargo un reciente estudio mineralógico (Cravero et al., 2009) determina que el principal mineral que integra estos depósitos corresponde a halloysita, que se encuentra acompañada por caolinita y cantidades}


menores de esmectita y cristobalita. Este mineral es el único reportado como halloyista en Argentina y es muy poco frecuente en el mundo. El origen de estos yacimientos se atribuye a procesos de alteración hidrotermal o por acción de meteorización sobre rocas alcalinas. En el caso de los depósitos rionegrinos se sostiene que las condiciones paleoclimáticas favorecieron la formación de halloysita a partir de rocas volcánicas ignimbriticas, de composición riolítica del Eoceno (Figura 4.8).

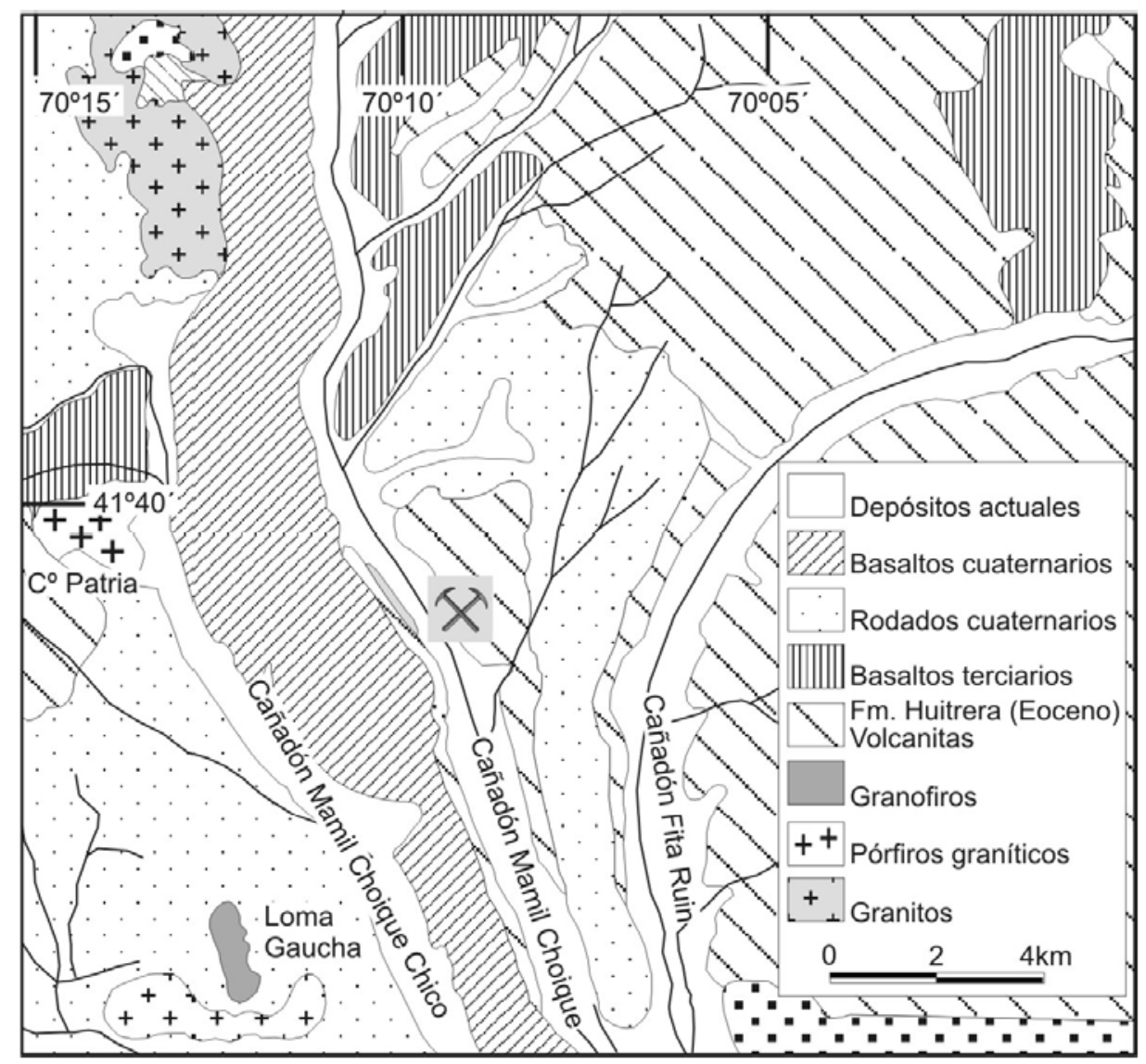

Figura 4.8. Geología del área caolinítica de Mamil Choique (simplificado de Cravero et al., 2009).

La halloysita $\left(\mathrm{Al}_{2} \mathrm{Si}_{2} \mathrm{O}_{5}(\mathrm{HO})_{4}\right)$ es un mineral que presenta una estructura y composición semejante a la caolinita, dikita y nacrita. En este mineral las laminas están separadas por una capa de moléculas de agua, de modo tal que la halloysita registra una distancia basal de $10 \AA$, la cual cuando se deshidrata se reduce en forma irreversible a $7 \AA$. Las partículas de halloysita pueden registrar formas muy variadas, sin embargo son más frecuentes las cilíndricas o en tubos alongados.

El mineral seleccionado se lo emplea en la industria cerámica y también, dada su blancura, como aislante térmico en plantaciones de manzanos, utilizándolo como polvo que se esparce sobre las plantas y frutos para protegerlas de las altas temperaturas durante los meses de verano, permitiendo obtener mayores rendimientos. 


\section{_ Pirofilita de Arroyo Auquén, provincia de Neuquén}

El material pirofilítico utilizado en el presente trabajo, denominado Py, proviene del yacimiento que se encuentra ubicado sobre la vertiente oriental de la Cordillera del Viento, a unos $7 \mathrm{~km}$ al norte de la localidad de Vavarcó, en el departamento Minas, Provincia del Neuquén (Figura 4.4).

En el área del depósito (Danieli et al., 2002) afloran vulcanitas del Grupo Choiyoi (Pérmico inferior-Triásico inferior), integradas por mantos de ignimbritas, brechas y tobas andesíticas. El conjunto esta intruido por un stock granodioritico, denominado Granodiorita Vavarcó, asignado al Cretácico superior. En discordancia erosiva se registran afloramientos asilados de coladas de basalto moderno (Neógeno) (Figura 4.9).

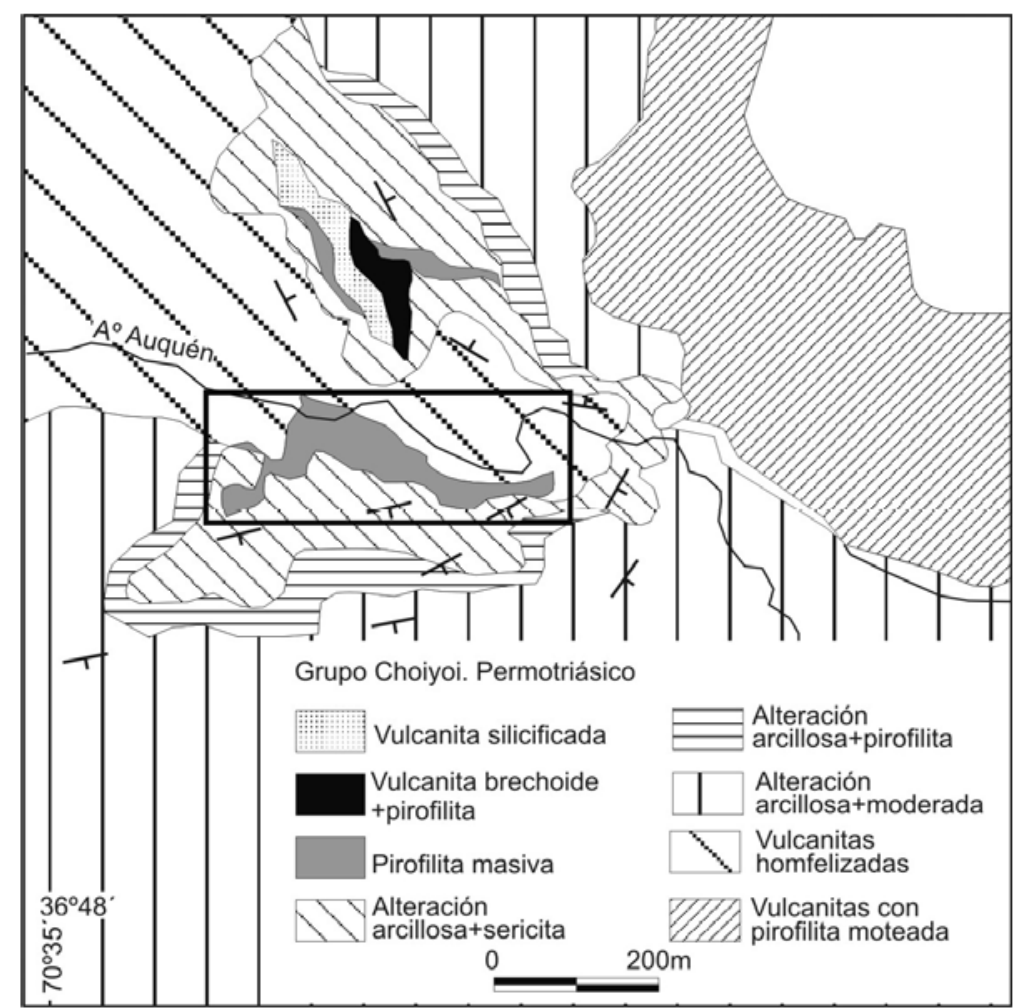

Figura 4.9. Yacimiento de pirofilita de Arroyo Auquén, Neuquén (simplificado de Danieli et al., 2002).

Los bancos o niveles mineralizados con pirofilita registran, en conjunto, una potencia de hasta 70 metros y unos 400 metros de longitud. El estudio realizado por Danieli et al. (2002) demuestra la existencia de diferentes niveles de pirofilita distinguiendo diferentes sectores 0 zonas mineralizadas; a) de pirofilita \pm clorita/esmectita; b) de illita \pm pirofilita; c) de pirofilita \pm Illita; d) pirofilita \pm caolinita y e) zona de pirofilita predominante. A los fines del presente estudio se seleccionaron muestras de la zona consignada como de pirofilita predominante. 


\section{_ Illita del depósito Los Cardales, provincia de Buenos Aires}

El material illítico modificado en la presente tesis, denominado I, proviene del depósito Los Cardales que se encuentra en las Sierras Septentrionales de la PBA (Figura 4.4). La muestra empleada formó parte de las muestras estudiadas en el trabajo de tesis doctoral de la Dra. Katthy López Escobar dirigida por el Dr. R. Etcheverry (INREMI) y la Dra. I.L. Botto (CEQUINOR) (López Escobar, 2006).

El perfil pelítico en Los Cardales de piso a techo alcanza aproximadamente 1314 metros de espesor, está integrado fundamentalmente por illita-cuarzo, acompañados de caolinita y goethita. En la Foto 4.10 se observa el material utilizado de color verde amarillento claro, masivo y untuoso al tacto.

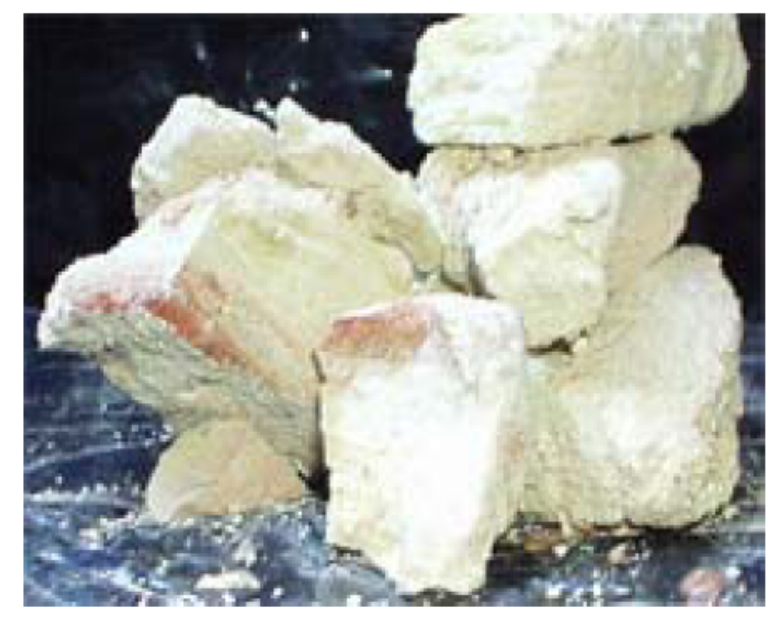

Foto 4.10. Detalle de la muestra illítica.

\section{_ Zeolita de Cantera EI Toba, Paganzo, Provincia de La Rioja}

El material tobáceo ensayado, denominado $Z$, proviene de un ambiente sedimentario procedente de la Cantera El Toba, situada a $7 \mathrm{~km}$ al este de la localidad de Paganzo, provincia de La Rioja (Figura 4.4). La muestra fue seleccionada previamente en el marco del PICT 14-12174/02 (Agosto, 2012).

La secuencia clástica del área se encuentra dominada por limonitas arcillosas algo calcáreas, de colores pardos y castaños grisáceos claros en bancos tabulares dispuestos en una estructura homoclinal con un rumbo general NNO-SSE e inclinaciones entre 60 y $70^{\circ}$ al este. Intercalados en la sucesión sedimentaria se observan niveles piroclásticos constituidos por tobas de caída finas a chonitas, algo retrabajadas, de colores blanquecinos y espesores oscilantes entre unos pocos centímetros y máximos de 1 metro que son los portadores del material zeolítico estudiado. Los estudios petrográficos realizados indican que los niveles piroclásticos están constituidos generalmente por un $80 \%$ de vidrio, de coloración castaña a 
incolora y un $20 \%$ de fragmentos cristalinos (feldespatos, cuarzo y biotita) que permiten clasificar a las rocas como tobas vitrocristalinas (Agosto et al., 2005).

\section{_ Bentonita Lago Pellegrini, Provincia de Río Negro}

La muestra de bentonita empleada en este trabajo, denominada $B$, fue proporcionada por la empresa MINARMCO S.A. que se dedica a la extracción, procesamiento y comercialización de bentonitas sódicas naturales de origen nacional. La empresa cuenta con 20 yacimientos de bentonita en el área del Lago Pellegrini, Provincia de Río Negro, de Edad Cretácica y origen marino, y otros yacimientos en la zona de Bardas Negras, Provincia de Neuquén, que nacen en el Mioceno Superior en el fondo de lagos intermontanos. La muestra seleccionada proviene de los yacimientos de la provincia de Río Negro (Figura 4.4).

La bentonita MINARMCO es un aluminosilicatos hidratado de sodio, magnesio y calcio en el que predomina el catión sodio, motivo por el cual se la identifica como una bentonita sódica. Estas características le confieren propiedades coloidales especiales, una estructura molecular que le permite absorber grandes cantidades de agua intermicelar aumentado enormemente su volumen y además, una elevada capacidad de intercambio iónico.

\section{_ Diatomitas del Depósito de Catua, Cerro Blanco, Provincias de Jujuy y Salta}

La diatomita constituye una roca industrial de especial interés debido a sus características físicas y químicas que la convierten en un material adecuado para una gran variedad de aplicaciones. Actualmente, el término diatomita se utiliza para rocas sedimentarias silíceas de interés económico, compuestas por la acumulación de restos fósiles de diatomeas. Dicho de otra manera son acumulaciones de frústulas de diatomeas depositadas en medio indistinto de agua dulce o salada.

Las diatomeas son algas unicelulares (Clase Bacillariophycae), cuyas paredes celulares están silicificadas, formando una frústula que comprende dos valvas. Desde un punto de vista morfológico, las diatomeas presentan formas circulares o elípticas. Su clasificación se basa en estos aspectos morfológicos, a partir de los cuales se han establecido más de 300 géneros y unas 16.000 especies diferentes.

La roca se presenta como un material más o menos suelto, liviano, poroso y, a veces, estratificado en capas de variado espesor. En su estado de mayor pureza contienen más de $80 \%$ de sílice, menos de $10 \%$ de materia orgánica y menos de $10 \%$ de sales, material arcilloso, cenizas, $\mathrm{CaCO}_{3}$, óxidos de $\mathrm{Fe}$, entre otras impurezas.

Las muestras de material diatomitico ensayadas en esta Tesis, provienen del yacimiento que se localiza en La Puna Salteña-Jujeña, a unos $6 \mathrm{~km}$ al noroeste de la 
localidad de Catua, en el límite entre las provincias de Salta y Jujuy (Figura 4.4). La zona se caracteriza por un relieve de suaves ondulaciones y el depósito se emplaza a medio faldeo de una extensa lomada, la que se encuentra cubierta por una capa de sedimentos sueltos (Cuaternario aluvial-salino y Cuaternario de pie de monte). Se registran tobas e ignimbritas (blancas amarillentas y verdes grisáceos). Aparentemente se trata de un relleno de cuenca por material limoso, arcilloso y cenizas volcánicas, que contienen niveles diatomíticos y en el conjunto un banco mas definido con diatomita de coloración gris-blanquecino (Schalamuk et al., 2004).

El depósito está conformado por dos bancos de diatomitas, bien definidos, con intercalaciones de arcillas bentonititas, de coloración gris-blanquecina. Los bancos son discontinuos y pueden extenderse varios centenares de metros, el espesor medido en los laboreos, mediante perfiles, es del orden de 1 a menos de 2 m (Fotos 4.11 y 4.12 ).

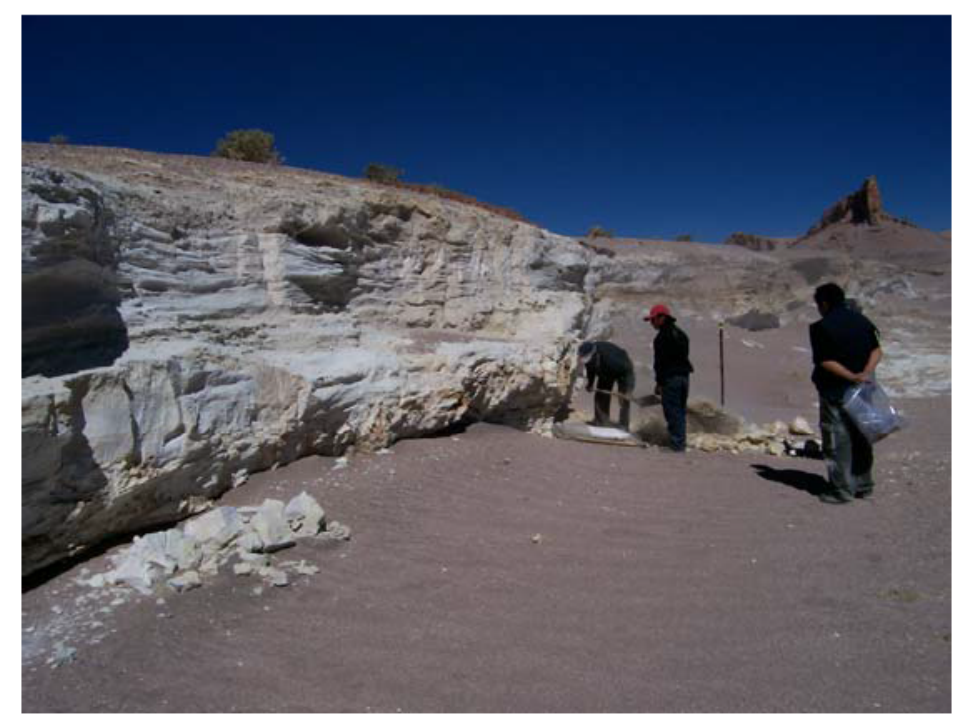

Foto 4.11. Vista panorámica de los bancos de diatomitas.

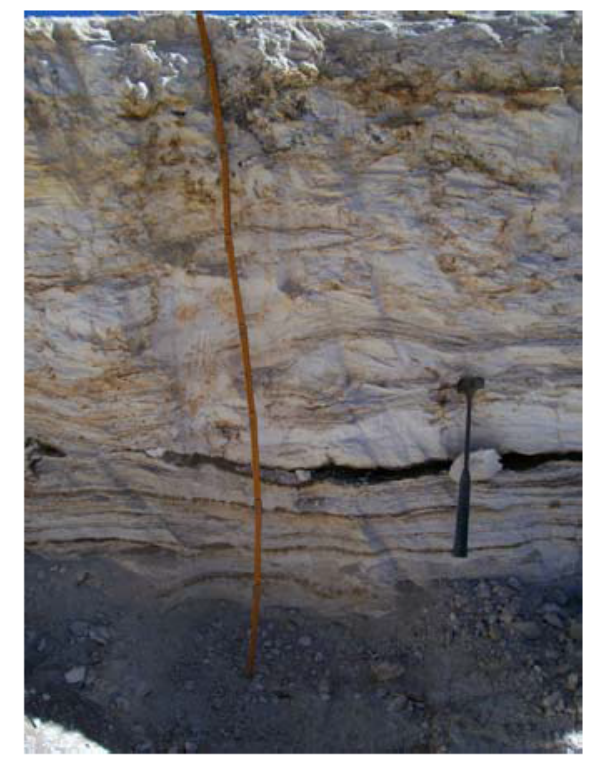

Foto 4.12. Detalle de la muestra extraída. 


\section{CAPITULO 5}

\section{Parte experimental}

En este capítulo se describen detalladamente los aspectos metodológicos llevados a cabo en la investigación. Primeramente se hace referencia a las técnicas fisicoquímicas de análisis empleadas en la caracterización de los materiales seleccionados en el capítulo anterior. En segundo lugar se presenta el procedimiento seguido en el laboratorio para la preparación de las muestras de agua utilizadas en los ensayos de adsorción, así como las técnicas empleadas para evaluar la calidad fisicoquímica de las mismas. En tercer lugar se detallan los métodos empleados en la determinación de As en muestras líquidas y, finalmente se presenta el procedimiento seguido en la determinación de otros parámetros que fueron analizados para evaluar la calidad del agua después del tratamiento de adsorción.

Cabe aclarar, que la metodología seguida en los ensayos de adsorción para evaluar el potencial adsorbente de los geomateriales será descripta en el Capítulo 6. Asimismo, el procedimiento realizado para la activación de las muestras pobres en hierro se detalla en el Capítulo 7.

\subsection{Técnicas fisicoquímicas de análisis}

Los materiales seleccionados para ser aplicados como adsorbentes del As requieren de una caracterización fisicoquímica adecuada para asegurar su efectividad en el proceso de adsorción. Estos materiales deberán reunir características que los distingan de las alternativas convencionales de tratamiento en lo que se refiere a: bajo costo, facilidad operativa, estabilidad química y térmica, debiendo resultar también eco-compatibles.

En este punto, se describen las diferentes técnicas de análisis fisicoquímicas dirigidas a la caracterización de las muestras seleccionadas en la etapa anterior. Tanto las especies minerales originales y las modificadas así como los productos de las fases del tratamiento (residuos sólidos agotados) se analizarán mediante las mismas técnicas aquí descriptas.

El análisis químico en cualquiera de sus formas (desde la convencional, hasta las espectroscópicas, como AA, ICP) permite determinar los elementos mayoritarios y particularmente los elementos traza (ICP-MS). En especial la presencia de fases de hierro amorfas puede ser evaluada mediante técnicas de tratamiento en solución (ácidos carboxílicos) que permiten su cuantificación. 
La caracterización estructural se basa en el empleo de la difracción por rayos $\mathrm{X}$ que permite identificar mineralógicamente a los geomateriales y determinar el grado de cristalinidad.

Los estudios texturales (SEM, EDS) así como los de superficie (BET) definen la calidad del mineral como adsorbente. En particular las comparaciones entre análisis de superficie y de "bulk" facilitan la comprensión del proceso geoquímico de depositación de fases de hierro por alteración mineral o por efecto de su síntesis.

Otras técnicas tales como la espectroscopia vibracional (FTIR y Raman), ayudan en el análisis de aspectos moleculares asociados a las especies presentes, que contribuyen al reconocimiento de las distintas formas de presentación del hierro, impurezas, orden cristalino en aluminosilicatos, etc.

El estudio del comportamiento térmico también aporta información acerca de la estabilidad estructural, cambios de fase, reacciones en estado sólido, deshidroxilación, etc. En particular la técnica TPR es de importancia para diferenciar las formas de hierro.

A continuación se describe brevemente cada una de las técnicas fisicoquímicas empleadas en la caracterización de los sólidos de este trabajo de Tesis.

\subsubsection{Análisis químico por ICP-AES e ICP-MS}

La técnica ICP-AES (Inductively Coupled Plasma-Atomic Emission Spectroscopy) es una de las técnicas cuantitativas disponibles en espectroscopia atómica analítica. Actualmente es utilizada para la determinación de elementos mayoritarios y traza en muestras naturales inorgánicas.

El plasma consiste en un gas altamente ionizado eléctricamente neutro, formado por iones, electrones y átomos. La energía que genera un plasma de análisis químico se deriva de un campo eléctrico o magnético, generado por inducción de energía perteneciente a ondas de radio (Skoog et al., 2001). Los plasmas se caracterizan por sus altas temperaturas de análisis (entre 600 y $8000 \mathrm{~K}$ ), así como por presentar densidades iónicas y electrónicas elevadas (Manning and Grow, 1997). La mayoría de los plasmas analíticos operan con $\operatorname{Ar}$ o He puro, lo que hace que no se genere combustión.

La técnica ICP ofrece varias ventajas comparada con los métodos de llama y electrotérmicos, entre ellas, la determinación simultánea de varios elementos y su susceptibilidad baja con respecto a interferencias químicas. Otra ventaja destacable es su bajo límite de detección, por lo que es especialmente adecuada para la 
determinación de concentraciones pequeñas (traza). Asimismo, es apropiada para determinar elementos difíciles de atomizar como los elementos de las tierras raras (REE), los alcalinotérreos, B, Si, U y Ta. Estos elementos, caracterizados por una alta afinidad respecto a oxígeno, introducidos en una llama de absorción atómica tienden a formar radicales de óxido o de hidróxido, que no se disocian.

El análisis químico de las muestras estudiadas se llevó a cabo mediante la técnica de ICP-AES para elementos mayoritarios y de ICP-MS para elementos traza, fue realizado en el laboratorio Als Chemex, Canadá (www.alsglobal.com). La rutina empleada en estos laboratorios para determinar los principales componentes en una matriz geológica se conoce como análisis de roca total, los elementos principales y secundarios se informan como óxidos. La técnica tiene la expectativa que la suma de los principales óxidos sea cercana a $100 \%$. También se determina la pérdida por ignición a $1000{ }^{\circ} \mathrm{C}$. En el presente trabajo se han recalculado los valores aportados por el laboratorio de manera que la suma sea $100 \%$. Antes de la determinación por ICPAES se realiza una fusión de la muestra empleando metaborato de litio.

En relación a la determinación de elementos traza y tierras raras, previo a la determinación por ICP-MS se realiza la fusión de la muestra empleando borato de litio. Los resultados se expresan en ppm.

En las Tablas 5.1 y 5.2 se indican los elementos y rangos determinados en cada técnica.

Tabla 5.1. Elementos mayoritarios determinados por ICP-AES (análisis de roca total).

\begin{tabular}{lll|lll}
\hline \multicolumn{5}{c}{ Elementos y rangos $(\%)$} \\
\hline $\mathrm{Si}$ & $\mathrm{SiO}_{2}$ & $(0,01-100)$ & $\mathrm{Cr}$ & $\mathrm{Cr}_{2} \mathrm{O}_{3}$ & $(0,01-100)$ \\
$\mathrm{Al}$ & $\mathrm{Al}_{2} \mathrm{O}_{3}$ & $(0,01-100)$ & $\mathrm{Ti}$ & $\mathrm{TiO}_{2}$ & $(0,01-100)$ \\
$\mathrm{Fe}$ & $\mathrm{Fe}_{2} \mathrm{O}_{3}$ & $(0,01-100)$ & $\mathrm{Mn}$ & $\mathrm{MnO}$ & $(0,01-100)$ \\
$\mathrm{Ca}$ & $\mathrm{CaO}$ & $(0,01-100)$ & $\mathrm{P}$ & $\mathrm{P}_{2} \mathrm{O}_{5}$ & $(0,01-100)$ \\
$\mathrm{Mg}$ & $\mathrm{MgO}$ & $(0,01-100)$ & $\mathrm{Sr}$ & $\mathrm{SrO}$ & $(0,01-100)$ \\
$\mathrm{Na}$ & $\mathrm{Na}_{2} \mathrm{O}$ & $(0,01-100)$ & $\mathrm{Ba}$ & $\mathrm{BaO}$ & $(0,01-100)$ \\
$\mathrm{K}$ & $\mathrm{K}_{2} \mathrm{O}$ & $(0,01-100)$ & $\mathrm{Pé}$ érdida por ignición (LOI) & $(0,01-100)$ \\
\hline
\end{tabular}

Tabla 5.2. Elementos traza y tierras raras determinados por ICP-MS.

\begin{tabular}{lr|lr|lr|lr}
\hline \multicolumn{7}{c}{ Elementos y rangos $(\mathrm{ppm})$} \\
\hline $\mathrm{Ag}$ & $(1-1000)$ & $\mathrm{Ga}$ & $(0,1-1000)$ & $\mathrm{Pb}$ & $(5-10000)$ & $\mathrm{Tm}$ & $(0,01-1000)$ \\
$\mathrm{Ba}$ & $(0,5-10000)$ & $\mathrm{Gd}$ & $(0,05-1000)$ & $\mathrm{Pr}$ & $(0,03-1000)$ & $\mathrm{U}$ & $(0,5-1000)$ \\
$\mathrm{Ce}$ & $(0,5-10000)$ & $\mathrm{Hf}$ & $(0,2-10000)$ & $\mathrm{Rb}$ & $(0,2-10000)$ & $\mathrm{V}$ & $(5-10000)$ \\
$\mathrm{Co}$ & $(0,5-10000)$ & $\mathrm{Ho}$ & $(0,1-1000)$ & $\mathrm{Sm}$ & $(0,03-1000)$ & $\mathrm{W}$ & $(1-10000)$ \\
$\mathrm{Cr}$ & $(10-10000)$ & $\mathrm{La}$ & $(0,5-10000)$ & $\mathrm{Sn}$ & $(1-10000)$ & $\mathrm{Y}$ & $(0,5-10000)$ \\
$\mathrm{Cs}$ & $(0,01-10000)$ & $\mathrm{Lu}$ & $(0,1-1000)$ & $\mathrm{Sr}$ & $(0,1-10000)$ & $\mathrm{Yb}$ & $(0,03-1000)$ \\
$\mathrm{Cu}$ & $(5-10000)$ & $\mathrm{Mo}$ & $(0,2-10000)$ & $\mathrm{Ta}$ & $(0,1-10000)$ & $\mathrm{Zn}$ & $(0,5-10000)$ \\
$\mathrm{Dv}$ & $(0,05-1000)$ & $\mathrm{Nb}$ & $(0,1-10000)$ & $\mathrm{Tb}$ & $(0,01-1000)$ & $\mathrm{Zr}$ & $(0,5-10000)$ \\
$\mathrm{Er}$ & $(0,03-1000)$ & $\mathrm{Nd}$ & $(0,1-10000)$ & $\mathrm{Th}$ & $(0,05-1000)$ & & \\
\hline
\end{tabular}


En el mismo laboratorio, también se realizó la determinación de As en las muestras sólidas, mediante la técnica ICP-MS previa digestión con agua regia (3:1 de $\mathrm{HCl}: \mathrm{HNO}_{3}$ ) recomendada para la cuantificación de elementos volátiles como el As. El rango de medida de la técnica es de 0,1-250 ppm.

\subsubsection{Difracción por rayos $X$}

La técnica de difracción por rayos $X(D R X)$ resulta la base de la caracterización mineralógica de muestras mono y policristalinas. Proporciona información sobre el ordenamiento atómico de un material y resulta el método más adecuado y práctico para determinar los componentes cristalinos de una muestra mineral (Cullity, 1967; Skoog et al., 2001).

La cristalografía de rayos $X$ consiste en hacer incidir un haz de rayos $X$ a través de un cristal de la sustancia sujeta a estudio. El haz se escinde en varias direcciones debido a la simetría de la agrupación de átomos y, por difracción, da lugar a un patrón de intensidades que puede interpretarse según la ubicación de los átomos en el cristal, aplicando la ley de Bragg:

\section{$n \lambda=2 d \operatorname{sen} \theta$}

Donde, $\lambda$ es la longitud de onda de la radiación $\mathrm{X}$ incidente, $\boldsymbol{\theta}$ es el ángulo de incidencia y también el de difracción de la radiación, $\boldsymbol{d}$ es la separación entre planos del sólido cristalino y $\boldsymbol{n}$ se denomina orden de la difracción. El valor de $n$ tiene en cuenta que dado un máximo para el cual el desfasaje corresponda a $\lambda$, para sucesivos ángulos de incidencia mayores, los máximos corresponderán a diferencias de fase entre rayos mayores, es decir, $2 \lambda, 3 \lambda$, $4 \lambda$, etc.

La difracción de rayos $X$ ocurre sólo cuando la longitud de onda es del mismo orden que los centros de dispersión. Así, para estas ondas electromagnéticas se necesitan rejillas de dispersión del orden de A. Sólo en la naturaleza y, en particular, en las separaciones interatómicas se encuentran estas distancias.

Dada la base fundamentalmente estructural de la clasificación de los minerales de arcilla, la técnica DRX es una herramienta elemental para la tipificación. El estudio cualitativo mediante DRX se basa en el uso de patrones (PC-PDF), así como en la aplicación de tratamientos fisicoquímicos especiales (principalmente térmicos y de saturación con sustancias orgánicas) que posibilitan la modificación de las distancias interplanares $d$ de las reflexiones basales según la estructura cristalina del mineral de arcilla. Es de destacar que estos tratamientos permiten modificar el apilamiento sin alterar la estructura de la disposición laminar (Eslinger and Pevear, 1988). 
En términos generales, se toma en consideración la característica de la reflexión basal, que se encuentra próxima a los $7 \AA$ en minerales 1:1 (caolinita), del orden de los $10 \AA$ para minerales $2: 1$ no-expandibles (pirofilita, illita), próxima a los $14 \AA$ en especies usualmente expandibles (esmectita y vermiculita) (Brown and Brindley, 1980). La Tabla 5.3 resume algunos aspectos de la identificación preliminar de los minerales de arcilla estudiados en el presente trabajo, los que se encuentran relacionados con el espaciado $\mathrm{d}(001)$.

Tabla 5.3. Valores del espaciado (d) en $\AA$ correspondientes a la reflexión basal (001), para identificación diagnóstica de minerales de arcilla, según tratamientos realizados.

\begin{tabular}{c|c|c|c|c|c}
\hline Minerales & $\begin{array}{c}\text { Roca total } \\
\text { (orientación } \\
\text { aleatoria) }\end{array}$ & $\begin{array}{c}\text { Tratamiento } \\
\text { de secado al } \\
\text { aire } \\
\text { (orientada) }\end{array}$ & $\begin{array}{c}\text { Tratamiento } \\
\text { con } \\
\text { etilenglycol }\end{array}$ & $\begin{array}{c}\text { Tratamiento } \\
\text { térmico } \\
\left(550^{\circ} \mathrm{C}\right) \\
\text { (calcinada) }\end{array}$ & $\begin{array}{c}\text { Rango } \\
\text { temperaturas de } \\
\text { amorfización } \\
\text { (desaparición de } \\
\text { la reflexión) }\end{array}$ \\
\hline $1: 1$ & $7,15-7,20$ & 7 & 7 & - & $500-550^{\circ} \mathrm{C}$ \\
\hline $\begin{array}{c}2: 1 \\
\text { no expandibles }\end{array}$ & $10-10,50$ & 10 & 10 & 10 & $800-1000^{\circ} \mathrm{C}$ \\
\hline $\begin{array}{c}2: 1 \\
\text { expandibles }\end{array}$ & Variable & 12 & $12-17$ & 10 & $700-1000^{\circ} \mathrm{C}$ \\
\hline
\end{tabular}

\section{Equipo y Metodología}

Los diagramas de difracción de Rayos $X$ fueron registrados en un difractómetro Phillips Pw 3710 digitalizado (FCNyM, UNLP); usando radiación Cu Ka ( $\lambda=1,54056 \AA$ ) y filtro de $\mathrm{Ni}$. Se determinaron los espectros bajo las siguientes condiciones operativas: voltaje $40 \mathrm{kV}$; corriente $20 \mathrm{~mA}$; velocidad del goniómetro $2 \theta \mathrm{min}^{-1} ; 2000 \mathrm{c} / \mathrm{s}$.

Eventualmente, se realizaron algunas medidas adicionales en un difractómetro Philips PW1710 (LANADI-FCE, UNLP).

Se determinaron los diagramas de polvos (roca total y fracción arcilla) de las muestras seleccionadas. A tal fin, muestras representativas de los afloramientos fueron molidas en mortero de ágata y secadas en estufa a $60^{\circ} \mathrm{C}$. Posteriormente se molieron aproximadamente $50 \mathrm{mg}$ de muestra en un mortero de ágata hasta reducir el tamaño de partícula ( $(4 \mu \mathrm{m})$, colocando el polvo en porta muestras con una orientación aleatoria (roca total).

La preparación de la fracción arcilla (diámetro esférico equivalente $<4 \mu \mathrm{m}$ ), se basó en la ley de Stokes, que describe la caída de una partícula esférica, por acción de la gravedad en un fluido viscoso mediante la expresión:

$$
V=\frac{2 q a^{2}\left(d_{1}-d_{2}\right)}{9 \eta}
$$


Donde, $\boldsymbol{V}$ es la velocidad de caída en $\mathrm{cm} \mathrm{seg}^{-1}$, a es el radio de la esfera en $\mathrm{cm}, \boldsymbol{d}_{\mathbf{1}} \mathrm{y} \boldsymbol{d}_{\mathbf{2}}$ son las densidades de la esfera y del medio respectivamente (en $\mathrm{g} \mathrm{cm}^{-3}$ ) y $\eta$ el coeficiente de viscosidad expresado en dinas seg $\mathrm{cm}^{-2}$.

La Tabla 5.4 muestra las opciones aplicadas para la selección del mineral de tamaño arcilla en función del tiempo y la profundidad del recipiente (a partir de la superficie de la suspensión del material en agua destilada) en condiciones de depositación a gravedad normal y temperatura ambiente.

Tabla 5.4. Tiempo de sedimentación de partículas según tamaño aplicando la ley de Stokes (T ambiente). Valores para una suspensión en agua destilada.

\begin{tabular}{c|c|c|c}
\hline \multicolumn{2}{c|}{ Tamaño de partícula expresado en: } & Vel. de caída & Tiempo/Profundidad \\
\hline$(\mu \mathrm{m})$ & $(\mathrm{cm})$ & $\left(\mathrm{cm} \mathrm{seg}^{-1}\right)$ & $\left(\mathrm{min} \mathrm{cm}^{-1}\right)$ \\
\hline 10 & 0,010 & 0,0080 & $10 / 5$ \\
5 & 0,005 & 0,0020 & $40 / 5$ \\
2 & 0,002 & 0,0003 & $40 / 1$ \\
\hline
\end{tabular}

Las partículas separadas de la suspensión se distribuyeron sobre un porta muestras, en forma de una fina lámina, la que luego fue secada a temperatura ambiente.

El tratamiento posterior con etilenglicol resulta útil para diagnosticar la presencia de minerales de arcilla 2:1 y estratificados. Este solvente es de baja volatilidad y miscible con agua de modo que las muestras hidratadas no se ven afectadas por el tratamiento. La solvatación consiste en exponer la muestra a los vapores del agente orgánico durante 8 horas. Para esto se utilizan entre 100 y $200 \mathrm{ml}$ de etilenglicol en un desecador donde se introduce la muestra con la superficie hacia arriba para entrar en contacto con el agente orgánico en fase vapor. Después de la solvatación la muestra se analiza inmediatamente.

La tipificación de las muestras se basa en la identificación del mineral de arcilla mayoritario, según las reflexiones más intensas y el empleo de patrones, teniendo en cuenta la presencia de otras especies arcillosas acompañantes (a partir de las reflexiones de media intensidad). Las líneas de difracción de intensidad baja corresponden a los minerales no arcillosos, denominados accesorios. Los diagramas de DRX fueron analizados sobre la base de los siguientes patrones: pirofilita (PDF 461308), illita (PDF 26-0911), caolinita (89-6538) y para las especies no arcillosas: cuarzo (PDF 89-8941), hematita (PDF 88-2359) y goethita (PDF 29-0713).

\subsubsection{Microscopía electrónica (SEM-EDS)}

Las características de la forma, disposición y composición de las muestras, son analizadas a partir de las fotomicrografías obtenidas por la técnica de Microscopía 
Electrónica de Barrido (SEM) con la adición de un analizador que permite un análisis químico semicuantitativo de superficie (EDS).

En el microscopio de barrido de electrones, un haz de electrones de elevada energía barre la muestra produciendo diversas señales: electrones retrodispersados, secundarios y Auger, fotones de fluorescencia y fotones de diferente energía. Para el estudio de la morfología de una muestra y la producción de su micrografía correspondiente se utilizan los electrones secundarios (Skoog et al., 2001).

Los microscopios electrónicos permiten alcanzar una capacidad de aumento muy superior a los microscopios convencionales debido a que la longitud de onda de los electrones es mucho menor que la de los fotones.

En el microscopio electrónico de barrido la muestra es recubierta con una capa de metal delgado y es barrida con electrones enviados desde un cañón. Un detector mide la cantidad de electrones enviados siendo capaz de mostrar figuras en tres dimensiones, proyectadas en una pantalla de PC. Su resolución está entre 3 y $20 \mathrm{~nm}$, dependiendo del microscopio. La luz se sustituye por un haz de electrones, las lentes por electroimanes y las muestras se hacen conductoras metalizando su superficie.

Esta técnica nos suministra información sobre tamaño de partícula o cristales, morfología de los mismos, modificaciones superficiales, resultando de gran interés para estudiar y caracterizar superficies de sólidos.

Los estudios de microanálisis con sonda de electrones (EDS), permiten determinar la composición elemental (análisis semicuantitativo). Consiste en analizar los rayos $\mathrm{X}$ generados por una muestra que ha sido bombardeada con un haz de electrones. Los valores de longitud de onda e intensidad de las líneas del espectro característico emitido, permiten realizar análisis químico en áreas muy pequeñas. El análisis cualitativo consiste en la identificación de los elementos presentes a partir de su correspondiente longitud de onda, mientras que en el análisis semicuantitativo las intensidades son comparadas, en general, con las muestras patrones de composición conocida. Las intensidades medidas deben ser corregidas por efecto del instrumento utilizado, como así también por el fondo, cuya fuente principal es el espectro continuo de rayos $X$.

\section{Equipo y Metodología}

El equipo utilizado fue un microscopio electrónico de barrido Phillips modelo SEM 505 (CINDECA, FCE UNLP, CONICET-La Plata). El microscopio tiene adicionado un sistema de microanálisis de rayos $X$, dispersivo en energía EDS (EDAX 9100), que procesa los espectros realizando un análisis semicuantitativo de la 
superficie observada en el microscopio. Los resultados del análisis químico son expresados como \% de óxidos. Los datos obtenidos fueron los promedios estadísticos de entre 3 y 10 determinaciones.

Para la realización de mapeos de elementos, el programa de digitalización ADDAll, tiene un adquisidor de imágenes que permite observar la distribución de un elemento 0 varios, obteniéndose una imagen de puntos proporcional a la concentración del elemento de interés. Las imágenes son digitalizadas por un software (Soft Imaging Sistem ADDA II).

Adicionalmente, se realizaron algunas determinaciones en un microscopio electrónico de barrido marca FEI Quanta 200. El microanálisis se realizó con un detector EDAX Apollo 40 (Laboratorio LIMF, FI, UNLP).

\subsubsection{Parámetros texturales y medidas de superficie mediante BET}

El área superficial de un material es una propiedad de importancia fundamental para el control de la velocidad de interacción química entre sólidos y gases o líquidos. La técnica de fisisorción de gases es la más empleada en la determinación de áreas superficiales y distribución de tamaños de sólidos micro y meso porosos.

Al ponerse en contacto un gas inerte con la superficie de un sólido desgasificado, se produce un equilibrio entre las moléculas adsorbidas y las moléculas en fase gaseosa, que depende de la presión del gas y de la temperatura. La relación entre las moléculas adsorbidas y la presión a temperatura constante se puede representar en una isoterma de adsorción. El método clásico de medición de área superficial, método BET (Brunauer, Emmett and Teller, 1938), implica la determinación de la cantidad de nitrógeno gaseoso, requerido para formar una capa con un espesor mono molecular sobre la superficie de una muestra a una temperatura criogénica.

Clásicamente, las mediciones necesarias son llevadas a cabo utilizando una muestra evacuada encerrada en una cámara y enfriada en un baño de $\mathrm{N}_{2}$ líquido al cual se admite la entrada de cantidades conocidas de $\mathrm{N}_{2}$ gaseoso. La medición de la presión de gas y de los cambios de presión permiten determinar el punto en el cual se forma la monocapa. Las isotermas se expresan como volúmenes de gas adsorbido, en condiciones normales de presión y temperatura (CNPT), por gramo de adsorbente, en función de la presión de equilibrio. Las isotermas constan de un proceso de adsorción y un proceso de desorción. Cuando el camino de desorción no coincide con el de adsorción se produce histéresis. Estas isotermas, informan directamente el volumen adsorbido a una determinada presión y también permiten calcular el área superficial del sólido, el tamaño de poro y su distribución. 
El área superficial se obtiene mediante la ecuación:

$$
S A=\frac{N C_{A} q}{m \text { V }}
$$

Donde, $\boldsymbol{S A}$ es el área superficial en $\mathrm{m}^{2} \mathrm{~g}^{-1}, \boldsymbol{N}$ es el número de Avogadro, $\boldsymbol{C}_{\boldsymbol{A}}$ es la densidad molar del adsorbato, $\boldsymbol{q}$ es el área del sólido que cubre la molécula adsorbida, $\boldsymbol{m}$ es la masa del sólido y $\mathbf{V m}$ es el volumen de gas por gramo de adsorbente requerido para formar una monocapa en CNTP expresado en $\mathrm{cm}^{3} \mathrm{~g}^{-1}$.

Usando como adsorbato al $\mathrm{N}_{2}$, la ecuación para obtener el área superficial se reduce a:

$$
\mathrm{SA}\left(\mathrm{m}^{2} \mathrm{~g}^{-1}\right)=4,35 \mathrm{Vm}
$$

Donde 4,35 es una constante que involucra el área cubierta por una molécula de $\mathrm{N}_{2}$.

Pese a que el modelo de BET ha sufrido varias críticas debido a que las superficies reales de los sólidos no siguen todas las aproximaciones del modelo (Anderson and Dawson, 1976), es el método más ampliamente usado para determinar área superficial de sólidos.

\section{Equipo y Metodología}

Para el análisis superficial se empleó un equipo del tipo sortómetro marca Micromeritics modelo ASAP 2020 (CINDECA, FCE-UNLP, CONICET-La Plata). Las muestras fueron desgasificadas durante 10 horas a una presión menor de $10 \mu \mathrm{m}$ de $\mathrm{Hg}$, a una temperatura de $100^{\circ} \mathrm{C}$. El área superficial específica, fue determinada por el método BET a partir de la isoterma de adsorción de $\mathrm{N}_{2}$ a $77 \mathrm{~K}$ en el rango de presiones $\left(p / p_{0}\right)$ 0,01-0,3.

Una propiedad importante a analizar en los materiales es su distribución de tamaño de poros, la cual brinda información sobre la abundancia de poros de un dado tamaño que existe en el material. La distribución de tamaño de poros de las muestras en estudio fue obtenida utilizando la teoría de la densidad funcional (DFT, "Density Functional Theory"). La distribución de tamaño de poros se obtuvo de la misma isoterma, en el rango de presiones de $\left(\mathrm{p} / \mathrm{p}_{0}\right)$ 0,01-0,99.

La IUPAC ha sugerido la siguiente clasificación de los poros de acuerdo a su tamaño:

- microporo: inferiores a $20 \AA$

- mesoporo: de 20 a $500 \AA$

- macroporo: mayores de $500 \AA$ 
Si bien la mayoría de los materiales poseen las tres clases de poros, es común referirse a materiales micro, meso o macroporosos. Con esta nomenclatura se da cuenta de que la porosidad de dicho material esta principalmente concentrada en una determinada zona del rango de poros.

\subsubsection{Espectroscopía de Infrarrojo}

La espectroscopía de Infrarrojo (FTIR) es una técnica de análisis rápida, económica y efectiva que contribuye al conocimiento de la estructura de los minerales de arcilla y de las especies asociadas. En tal sentido, en las últimas décadas las investigaciones en argilominerales han sido fuertemente influenciadas por el desarrollo de esta y otras técnicas espectroscópicas, proporcionando información detallada a nivel molecular (Wilson, 1994).

Para los silicatos la identificación se basa en la presencia de modos de estiramiento Si-O simétrico y antisimétrico $\left(v_{1}\right.$ y $\left.v_{3}\right)$ y modos de deformación angular OSi-O simétrica y antisimétrica respectivamente $\left(v_{2}\right.$ y $\left.v_{4}\right)$ (Nakamoto, 1986). Sin embargo, si la simetría tetraédrica $\left(T_{d}\right)$ de esa unidad estructural es preservada, solamente dos de esos cuatro modos $\left(v_{3}\right.$ y $\left.v_{4}\right)$ son activos en infrarrojo.

El concepto de tetraedro aislado, de simetría $T_{d}$, es una abstracción que está lejos de ser real en un sólido cristalino. En principio y aún en aquellas estructuras donde la misma permanezca relativamente aislada de las restantes que conforman la red cristalina, es imposible descartar la perturbación causada por efecto de los cationes que, en dicha red, son responsables de la cohesión entre aniones $\mathrm{SiO}_{4}$.

Por otra parte, la fuerza del enlace Si-O se ve fuertemente afectada por efectos de polimerización (formación de cadenas, anillos, capas, o estructuras tridimensionales) donde la unidad estructural se encuentra compartida en mayor o menor grado, según la complejidad estructural de la cristaloquímica de los silicatos. En estos casos, los cationes se encuentran unidos débilmente a las estructuras condensadas de unidades tetraédricas de fuerte carácter covalente y por consiguiente las zonas de vibración Si-O características no se afectan mayormente. No obstante lo acotado del rango de vibración, el efecto de la polimerización se traduce en el desdoblamiento de las bandas IR, observándose como componentes del modo vibracional característico. Los modos inactivos en IR (simetría $T_{d}$ ) pueden también activarse por efectos de deformación del poliedro (disminución de la simetría del sitio). Como consecuencia del conjunto de efectos, la frecuencia de las vibraciones puede sufrir ligeros corrimientos (refuerzo y/o debilitamiento del enlace por distorsión de la geometría tetraédrica). 
Cabe recordar que, genéricamente, la fuerza de un enlace es proporcional a $\mathrm{z} / \mathrm{hr}$, donde $z$ es la carga formal del átomo central, $n$ el número de coordinación y $r$ la distancia entre el átomo central y el átomo ligado. De esta manera, la fuerza del enlace para los siguientes poliedros $\mathrm{SiO}_{4}, \mathrm{AlO}_{4}, \mathrm{AlO}_{6}, \mathrm{MgO}_{6}$ y $\mathrm{NaO}_{8}$ (los más comúnmente hallados en los minerales de silicio) se encuentran en relación de $12 ; 9 ; 5 ; 3 ; 1$ respectivamente (Farmer, 1974), encontrándose en regiones características del espectro IR que facilitan su interpretación.

\section{Equipo y Metodología}

Los espectros fueron registrados en un espectrofotómetro de infrarrojo (FTIR) modelo Brucker Equinox 55 por transformadas de Fourier, registrando la región comprendida entre 4000 y $400 \mathrm{~cm}^{-1}$ con una resolución de $4 \mathrm{~cm}^{-1}$. El equipo se encuentra conectado a una computadora para almacenamiento y procesamiento de datos. Pequeñas cantidades de mineral (inferior a $2 \mathrm{mg}$ ) fueron dispersadas en $\mathrm{KBr}$ utilizando el método de pastillado de forma de obtener una lámina translúcida. E tamaño de partícula fue llevado a $\sim 4 \mathrm{~m}$ en mortero de ágata, equivalente al diámetro esferoidal ideal para ser examinado por esta técnica (Wilson, 1994).

\subsubsection{Espectroscopía Raman}

Los espectros Raman se obtienen al irradiar una muestra con una potente fuente láser de radiación monocromática en la región del infrarrojo medio. El fenómeno está relacionado con el mismo tipo de cambios vibracionales cuantizados que se producen en la absorción infrarroja. Así ambos espectros resultan muchas veces complementarios.

La espectroscopía micro Raman es una técnica útil para definir la mineralogía de materiales compuestos, poco cristalinos, constituyéndose en un censor puntual que permite identificar las especies presentes, aisladas o embebidas en la matriz. Se considera una herramienta poderosa en la identificación de minerales porque las posiciones de las bandas son únicas a pesar de que los minerales naturales pobremente cristalinos puedan presentar ensanchamientos de bandas o pequeñas diferencias en las intensidades relativas (Das and Hendry, 2011).

La espectroscopía Raman es utilizada para identificar una amplia variedad de minerales y en algunos casos, también puede proporcionar información química y estructural. Parte de esta información puede obtenerse utilizando técnicas como DRX, IR o FTIR, sin embargo, la espectroscopía Raman presenta algunas ventajas adicionales. En relación con DRX, ambas técnicas son rápidas y se llevan a cabo con una mínima preparación de la muestra. Una ventaja adicional de la espectroscopía 
Raman sobre DRX es que se puede identificar elementos de interés adsorbidos sobre las fases de óxidos de hierro, tales como ferrihidrita o hematita (Das and Hendry, 2011).

Los espectros Raman, a diferencia de los FTIR, presentan señales más estrechas permitiendo distinguir, con más éxito, a los minerales en una mezcla. Finalmente, es de destacar que los espectros Raman son fáciles de identificar porque el agua y la mayoría de los gases dan señales muy débiles, por lo tanto las probabilidades de interferencias espectral son bajas (Das and Hendry, 2011).

En relación con los óxidos de hierro, Das and Hendry (2011), emplearon la espectroscopía Raman para la identificación rápida de una amplia variedad de minerales, caracterizando fases minerales naturales y sintéticas conteniendo hierro, tales como óxidos (hematita, magnetita), hidróxidos (ferrihidrita, goethita, lepidocrocita), carbonatos (siderita), sulfatos (Na-jarosita) y arseniatos férricos (escorodita). Asimismo, evaluaron muestras de ferrihidrita con distintas cantidades de arseniato adsorbidas, identificando claramente en el análisis Raman las diferencias entre los espectros producidos por ferrihidrita pura y muestras con arseniato adsorbido. Es de destacar que estas diferencias fueron indistinguibles por DRX.

En el presente trabajo de Tesis, la espectroscopía Raman se realizó sobre los minerales originales, los minerales activados con fases amorfas de hierro y los minerales agotados luego del proceso de adsorción del As. En la Tabla 5.5 se muestran los valores bibliográficos de las principales bandas de los espectros Raman para algunos minerales de Fe.

En relación a los minerales de arcilla, en aluminosilicatos naturales la unidad estructural es el anión complejo $\mathrm{Si}_{2} \mathrm{O}_{5}{ }^{2-}$ que presenta estiramientos simétricos $\mathrm{Si}-\mathrm{O}-\mathrm{Si}$ y las correspondientes deformaciones angulares, que se encuentran en las regiones entre 700 y $450 \mathrm{~cm}^{-1}$ y por debajo de $400 \mathrm{~cm}^{-1}$, respectivamente, siendo las primeras las de mayor intensidad. La Tabla 5.6 muestra las señales características de algunas especies laminares. Asimismo, la Figura 5.1, muestra espectros típicos de especies laminares di y tri octaédricas (Wang et al., 2002).

\section{Equipo y Metodología}

Los espectros de microscopía Raman fueron realizados en un equipo Renishaw que opera con láseres de 488 y $785 \mathrm{~nm}$, magnificación entre 5-20 x, 10 scanner y 20 segundos (Dipartimento de Chimica, Universitá de Roma La Sapienza, Italia). El ajuste de las posiciones de las bandas se realizó a partir de los datos de literatura de las sustancias puras mediante un programa de cálculo Jandel, AISN. 
Tabla 5.5. Principales líneas Raman $\left(\mathrm{en}^{-1}\right.$ ) para minerales de hierro (modificado de Das and Hendry, 2011).

\begin{tabular}{|c|c|c|c|c|c|}
\hline Mineral & Hematita & Magnetita & Ferrihidrita & Goethita & Escorodita \\
\hline $\begin{array}{c}\text { Thibeau et } \\
\text { al. } \\
(1978) \\
\end{array}$ & $\begin{array}{c}227,245,293, \\
298,414,501,612\end{array}$ & 616,663 & 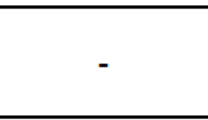 & $\begin{array}{c}298,397,414, \\
474,550\end{array}$ & 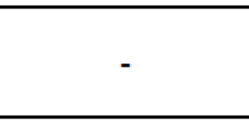 \\
\hline $\begin{array}{c}\text { de Faria et } \\
\text { al. } \\
(1997) \\
\end{array}$ & $\begin{array}{c}225,247,293, \\
299,412 \\
498,613 \\
\end{array}$ & $300,532,661$ & - & $\begin{array}{c}243,299 \\
385,479 \\
550,685\end{array}$ & - \\
\hline $\begin{array}{c}\text { Oh et al. } \\
(1998)\end{array}$ & $\begin{array}{l}226,245,292, \\
411,497,612 \\
\end{array}$ & 532,667 & - & $\begin{array}{c}205,247,300, \\
386,418,481,549\end{array}$ & - \\
\hline $\begin{array}{l}\text { Legodi and } \\
\text { de Wall } \\
(2007) \\
\end{array}$ & $\begin{array}{l}223,245 \\
291,407, \\
495,608 \\
\end{array}$ & $307,532,667$ & 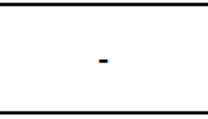 & $\begin{array}{l}225,297, \\
393,482, \\
565,676 \\
\end{array}$ & - \\
\hline $\begin{array}{l}\text { Hanesch } \\
(2009)\end{array}$ & $\begin{array}{c}225,245,290 \\
412 \\
\end{array}$ & $310,540,670$ & $370,510,710$ & $\begin{array}{l}244,299,385, \\
480,548,681 \\
\end{array}$ & - \\
\hline $\begin{array}{l}\text { Filippi et al. } \\
\text { (2009) }\end{array}$ & - & - & - & - & $\begin{array}{c}135,180,251, \\
293,335,383 \\
422,450,799,893 \\
\end{array}$ \\
\hline $\begin{array}{c}\text { Das and } \\
\text { Hendry } \\
(2011)\end{array}$ & $\begin{array}{l}222,230,290, \\
408,490,607\end{array}$ & $295,521,662$ & $\begin{array}{c}361,508 \\
707 \\
1045 \\
\end{array}$ & $\begin{array}{c}162,243,297, \\
384,477,545,655\end{array}$ & $\begin{array}{c}128,176,254, \\
287,333,376, \\
416,444,796,886\end{array}$ \\
\hline
\end{tabular}

Tabla 5.6. Principales líneas Raman para algunas especies laminares (modificado de Sidorov, 2007).

\begin{tabular}{ccc}
\hline Mineral & Señal Raman $\left(\mathrm{cm}^{-1}\right)$ & Referencia \\
\hline Caolinita & $636,340,205$ & Frost (1995) \\
Talco & $679,366,197$ & Blaha and Rosasco (1978) \\
Muscovita & $705,360,198$ & Loh (1973) \\
\hline
\end{tabular}
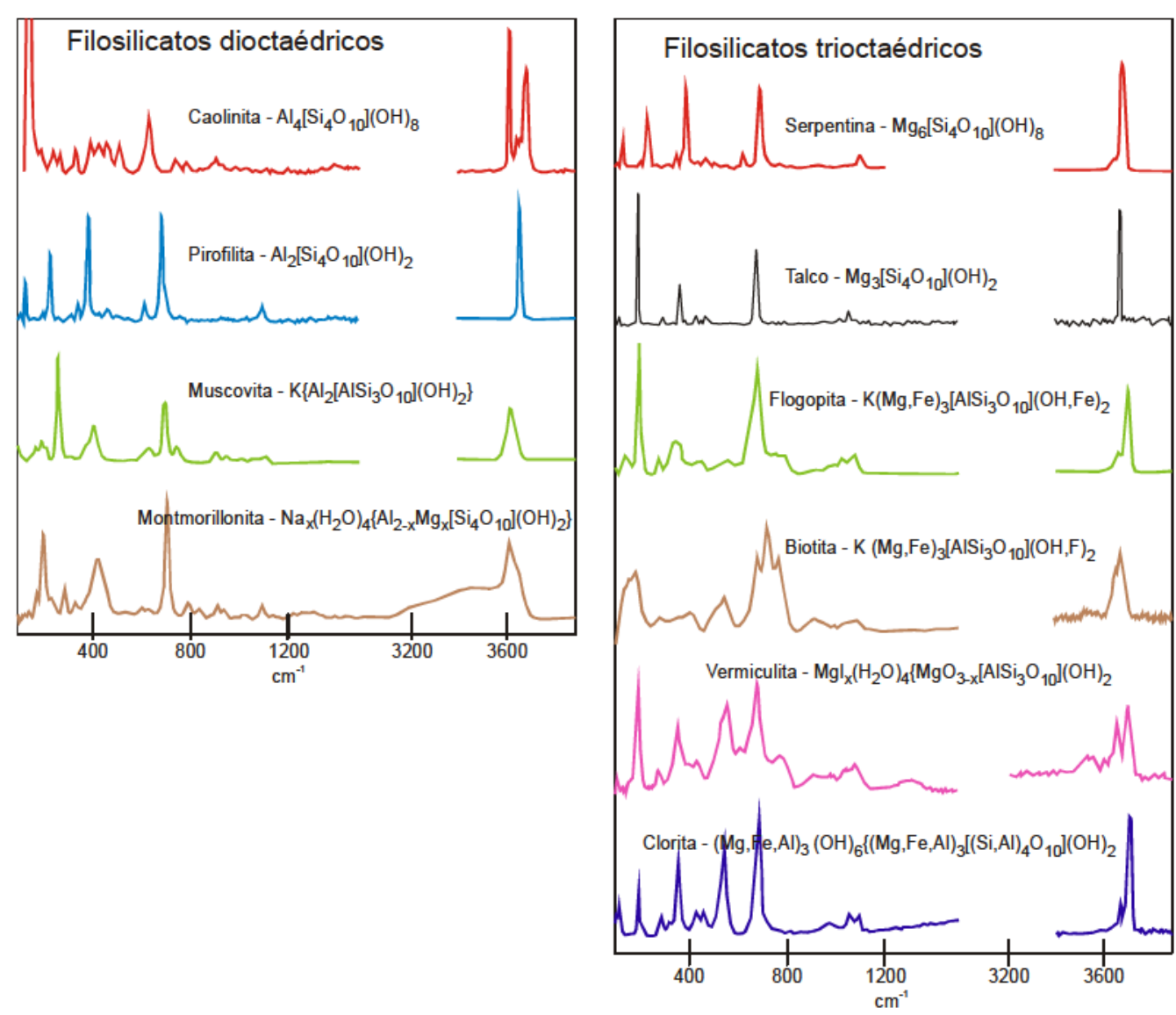

Figura 5.1. Espectros Raman típicos de filosilicatos di y trioctaédricos (Wang et al., 2002). 


\subsubsection{Análisis térmicos}

Los métodos de análisis térmicos se basan en la medida de la relación entre la temperatura y alguna propiedad de un sistema, como la masa o el calor de reacción. Se utilizó el análisis termogravimétrico (TGA) y la reducción a temperatura programada (TPR). Asimismo, se realizaron estudios térmicos complementarios en mufla con control de temperatura.

\subsubsection{Análisis termogravimétrico (TGA)}

En el análisis termogravimétrico se registra de forma continua, en atmósfera controlada, la masa de una muestra a medida que aumenta su temperatura en forma lineal desde temperatura ambiente hasta temperaturas del orden de $1000{ }^{\circ} \mathrm{C}$. La gráfica de la masa en función de la temperatura se denomina termograma y proporciona información cualitativa y cuantitativa de las muestras. También se puede representar la derivada de la masa en función de la temperatura (o tiempo, dependiendo si la experiencia es estática o dinámica), generándose un termograma diferencial.

El análisis se realiza en una termobalanza, dispositivo que consta de una balanza analítica ubicada dentro de un horno que puede ser calentado según un programa de temperatura controlado. A la muestra se le puede hacer llegar flujos de distintos gases controlando de esta manera el ambiente gaseoso. En dicho ambiente la muestra puede ganar o perder peso. Los casos más usuales de pérdida de peso en función de la temperatura en distintas atmósferas donde se controla la composición y la presión son:

- Evaporación, sublimación, descomposición.

- Cambios químicos con o sin pérdida estequiométrica de uno o más de los elementos constituyentes.

- Corrosión con formación de compuestos volátiles.

Los casos más comunes donde la muestra gana peso son la oxidación y la adsorción de distintas especies en la superficie del material. Para este tipo de técnica no solamente es importante la temperatura sino también la atmósfera en la cual está inmersa la muestra.

\section{Equipo y Metodología}

Los diagramas de termogravimetría fueron realizados con una termobalanza Shimadzu TGA-50 (CINDECA, FCE, UNLP). 


\subsubsection{Reducción a temperatura programada (TPR)}

Entre las técnicas de análisis aplicadas al estudio de especies metálicas en distinto estado de oxidación en una matriz oxídica, la reducción a temperatura programada es un método termoanalítico simple desarrollado y aplicado para la caracterización de materiales catalíticos (Jones and McNicol, 1986). El mismo permite analizar la reducibilidad de las especies presentes en un sólido oxídico mediante la acción de un gas reductor $\left(\mathrm{H}_{2}\right.$ diluido en $\left.\mathrm{N}_{2}\right)$ y el efecto de un aumento simultáneo de la temperatura del sistema. Este procedimiento, sencillo y rápido, se ha aplicado en los últimos años en la caracterización mineralógica de especies conteniendo elementos como Fe, Mn y W, entre otros (Botto et al., 2000), brindando información en lo que respecta a la estabilidad cristalina, tipo y fuerza del enlace químico, sitios cristalográficos, grado de interacción estructural, estado de oxidación del elemento reducible, etc.

En forma muy básica el proceso de reducción puede interpretarse mediante la reacción entre un óxido metálico con $\mathrm{H}_{2}$ para dar $\mathrm{M}^{\circ}$ (o un óxido inferior) y agua según la reacción:

$$
\mathrm{MO}_{(\mathrm{s})}+\mathrm{H}_{2(\mathrm{~g})} \rightarrow \mathrm{M}_{(\mathrm{s})}+\mathrm{H}_{2} \mathrm{O}_{(\mathrm{g})}
$$

En general la temperatura de reducción de los metales de transición se encuentra relacionada con los valores de los potenciales estándar de reducción, observándose que los metales más oxidantes se reducen a menor temperatura que aquellos de características más reductoras. En el caso de elementos con diferentes estados de oxidación, el potencial de reducción correspondiente a la transición del estado más elevado a uno intermedio es más favorable que el pasaje del estado intermedio al menor (o aún al estado metal), lo que se traduce en una temperatura de reducción menor en el primer caso. Por otra parte, las características del enlace químico (longitud, fuerza, carácter covalente) y de la simetría de los sitios en el óxido sólido se manifiestan también por una variación de la temperatura dentro del rango típico para cada especie, de modo que a mayor fuerza del enlace, más inaccesible el sitio metálico en la red, menor será la posibilidad de interacción del gas reductor y mayor la temperatura de reducción.

La diferencia de composición de la mezcla gaseosa a la entrada y a la salida del reactor (previamente secada en el último caso) se analiza continuamente con un detector de conductividad térmica. Los datos se registran como consumo de $\mathrm{H}_{2}$ vs temperatura en ${ }^{\circ} \mathrm{C}$. 
Los resultados que interesan se obtienen del análisis del consumo de gas necesario para reducir la/s especie/s catiónica/s y se visualiza en el perfil de reducción mediante señales individuales para cada proceso de reducción. La posición de las señales (en ${ }^{\circ} \mathrm{C}$ ) están determinadas por la naturaleza química del elemento (Eh) así como del entorno en la red, jugando un rol determinante la coordinación, la simetría del sitio, la fuerza y longitud del enlace químico en el sólido e incluso la magnitud de la interacción superficial cuando la especie se encuentra adsorbida. Asimismo, el área del pico permite cuantificar la concentración del elemento reducible, ya sea mediante el uso de patrones o en forma comparativa (relacionada con el número de electrones puestos en juego, las moléculas de agua formadas o la cantidad de hidrógeno consumido).

En este trabajo de tesis se analiza la potencialidad de la técnica de TPR dirigida al estudio de fases de hierro formando parte de los minerales de arcilla como elemento estructural o como fase segregada tanto en forma de sólidos cristalinos como amorfos.

\section{Equipo y Metodología}

Para la realización de medidas experimentales mediante la técnica de TPR se hizo uso de un equipo Thermo Scientific TPDRO 1100 utilizando un detector de $\mathrm{H}_{2}$ TCD. Se utilizó una mezcla de gas reductor de alta pureza en una relación $5 \% \mathrm{H}_{2}$ y $95 \% \mathrm{~N}_{2}$ con una velocidad del flujo gaseoso de $10 \mathrm{~cm}^{3} \mathrm{STP}_{\mathrm{T}} \mathrm{min}^{-1}$. La temperatura se incrementa a razón de $10{ }^{\circ} \mathrm{C} \min ^{-1}$ y el rango de temperatura analizado es el comprendido entre temperatura ambiente y $900{ }^{\circ} \mathrm{C}$. La reducción del hierro fue evaluada a partir del consumo de $\mathrm{H}_{2}$ y reportada como electrones intercambiados por átomo de hierro.

Adicionalmente, y con fines comparativos, se procedió a realizar un tratamiento de oxidación del material producto del TPR. El experimento TPO fue realizado utilizando una mezcla oxidante $5 \% \mathrm{O}_{2} / \mathrm{He}$ con una velocidad de flujo de $10 \mathrm{~cm}^{3}$ sTP $\min ^{-1}$, desde temperatura ambiente hasta $800^{\circ} \mathrm{C}$, con una rampa de calentamiento de $20{ }^{\circ} \mathrm{C} \mathrm{min}^{-1}$.

\subsubsection{Análisis granulométrico}

Para la realización del estudio granulométrico el material fue previamente secado en estufa a $60^{\circ} \mathrm{C}$ y luego fue separado en distintas fracciones empleando tamices de diferente apertura (Tabla 5.7). El tamizado se efectuó con la ayuda de un agitador mecánico Zony test. Este ensayo permitió determinar la distribución de tamaño de partículas de las muestras y determinar el porcentaje de retención según la malla, con respecto al total de muestra. 
Tabla 5.7. Tamices empleados para determinar la distribución de tamaño de partícula.

\begin{tabular}{c|c|c}
\hline $\begin{array}{c}\mathrm{N}^{\circ} \text { MALLA } \\
\text { ASTM }\end{array}$ & $\begin{array}{c}\text { APERTURA NOMINAL } \\
(\mathrm{mm})\end{array}$ & $\begin{array}{c}\text { LIMITE DE TAMAÑO } \\
(\mathrm{mm})\end{array}$ \\
\hline 6 & 3,360 & $>3,360$ \\
12 & 1,680 & $3,360-1,680$ \\
16 & 1,190 & $1,680-1,190$ \\
30 & 0,590 & $1,190-0,590$ \\
140 & 0,105 & $0,590-0,105$ \\
270 & 0,053 & $0,105-0,053$ \\
400 & 0,037 & $0,053-0,037$ \\
fondo & $<0,037)$ & $<0,037$ \\
\hline
\end{tabular}

\subsection{Muestras de aguas empleadas en los ensayos de adsorción}

Se utilizaron diferentes muestras de agua para la realización de los ensayos de adsorción:

- Soluciones de arsénico preparadas con agua destilada a la que se le adicionó una sal de $\mathrm{As}(\mathrm{V})$ para obtener distintas concentraciones del elemento. Estas soluciones fueron empleadas en los ensayos preliminares de adsorción.

- Soluciones de arsénico preparadas con agua de red de la ciudad de La Plata a la que se le adicionó una sal de $\mathrm{As}(\mathrm{V})$ para obtener concentraciones variables del elemento. Se empleó agua de red debido a que para lograr la coagulación del adsorbente se necesita una suficiente cantidad de electrolitos en el agua. Estas soluciones fueron empleadas en los ensayos de adsorción que involucraron una etapa posterior de coagulación/sedimentación.

En ambos casos, las soluciones con las distintas concentraciones de $\mathrm{As}(\mathrm{V})$, fueron preparadas a partir del agregado del volumen necesario de una solución patrón de $\mathrm{Na}_{2} \mathrm{HAsO}_{4} .7 \mathrm{H}_{2} \mathrm{O}$ de $1 \mathrm{~g}$ de As $\mathrm{L}^{-1}$. Esta solución patrón fue obtenida pesando $4,24 \mathrm{~g}$ de sal (p.a. Mallinckrodt, pureza 98\%, PMR: 312) y llevando a un volumen final de 1 litro con $\mathrm{H}_{2} \mathrm{O}$ destilada.

- Agua natural de origen subterráneo extraída mediante el empleo de una bomba desde una profundidad de alrededor de 60 metros (procedente del Paraje La Viruta, Punta Indio, provincia de Buenos Aires). Los contenidos de As presentan variaciones estacionales entre 170 y $220 \mu \mathrm{g} \mathrm{L}^{-1}$. Fue empleada con fines comparativos para evaluar el efecto de una matriz acuosa real en el proceso de adsorción. Estas muestras fueron tomadas en frascos estériles y refrigeradas hasta su utilización.

Se realizaron análisis de rutina para determinar la composición fisicoquímica del agua de red de la ciudad de La Plata y el agua subterránea de Punta Indio siguiendo técnicas analíticas estandarizadas. Los parámetros medidos según la metodología 
empleada en el laboratorio INDUSER se muestran en la Tabla 5.8. En el Anexo 1 se incluye los valores permitidos en el Capítulo XII del CAA para los principales parámetros fisicoquímicos e inorgánicos del agua potable (CAA, 2012).

Tabla 5.8. Parámetros fisicoquímicos determinados en las aguas naturales siguiendo la metodología descripta en Standar Methods (APHA, 2005).

\begin{tabular}{|c|c|c|c|}
\hline Parámetro & Unidad & $\begin{array}{c}\text { Límite de } \\
\text { cuantificación }\end{array}$ & Método SM \\
\hline $\mathrm{pH}$ & U de pH & 0,1 & $4500 \mathrm{H}-\mathrm{B}$ \\
\hline Conductividad & $\mu \mathrm{mhos} \mathrm{cm}^{-1}$ & 1 & $2510-B$ \\
\hline Turbiedad & NTU & 1 & $2130-B$ \\
\hline Color & Esc.Pt-Co & 3 & $2120-B$ \\
\hline Olor & - & - & 2150 - B - Organoléptico \\
\hline Aspecto & - & - & 2110 \\
\hline Dureza & $\mathrm{mg} \mathrm{CaCO}_{3} \mathrm{~L}^{-1}$ & 1 & $2340 \mathrm{~B}$ \\
\hline Alcalinidad Total & $\mathrm{mg} \mathrm{CaCO} \mathrm{L}^{-1}$ & 1 & $2320 \mathrm{~B}$ \\
\hline Calcio & $\mathrm{mg} \mathrm{L}^{-1}$ & 1 & $3500 \mathrm{Ca}-\mathrm{D}$ \\
\hline Magnesio & $\mathrm{mg} \mathrm{L}^{-1}$ & 1 & $3500 \mathrm{Mg}-\mathrm{E}$ \\
\hline Sodio & $\mathrm{mg} \mathrm{L}^{-1}$ & 1 & $3500 \mathrm{Na} D$ \\
\hline Potasio & $\mathrm{mg} \mathrm{L}^{-1}$ & 1 & 3500 K D \\
\hline Carbonatos & $\mathrm{mg} \mathrm{L}^{-1}$ & 1 & $2310 \mathrm{~B}$ \\
\hline Bicarbonatos & $\mathrm{mg} \mathrm{L}^{-1}$ & 1 & $2310 \mathrm{~B}$ \\
\hline Cloruros & $\mathrm{mg} \mathrm{L}^{-1}$ & 1 & $4110-B$ \\
\hline Sulfatos & $\mathrm{mg} \mathrm{L}^{-1}$ & 1 & $4110-B$ \\
\hline Nitratos & $\mathrm{mg} \mathrm{L}^{-1}$ & 0,5 & $4110-B$ \\
\hline Nitritos & $\mathrm{mg} \mathrm{L}^{-1}$ & 0,005 & 4500- NO2- -B \\
\hline Fluoruros & $\mathrm{mg} \mathrm{L}^{-1}$ & 0,03 & $4110-B$ \\
\hline Arsénico & $\mathrm{mg} \mathrm{L}^{-1}$ & 0,01 & EPA $7060 \mathrm{~A}$ \\
\hline Amonio & $\mathrm{mg} \mathrm{L}^{-1}$ & 0,1 & $4500 \mathrm{NH} 3 \mathrm{~B} / \mathrm{F}$ \\
\hline
\end{tabular}

\subsection{Ensayos de determinación de As en muestras líquidas}

Existen diferentes metodologías para la detección de arsénico en agua, entre ellas se pueden mencionar: métodos espectrofotométricos UV-Vis, absorción atómicageneración de hidruros (AAS-HG), absorción atómica con horno de grafito (AAS-GF), espectroscopia de emisión-plasma inductivo de argón, espectrometría de masa con plasma inductivamente acoplado, entre otras. Cada una de estas técnicas presenta ventajas y desventajas en precisión, costos y sensibilidad en la medición. Debido a la reglamentación vigente sobre los niveles permitidos de As en agua, las metodologías analíticas empleadas para cuantificar el elemento deben permitir determinar con precisión concentraciones bajas de As en agua $\left(<10 \mu \mathrm{g} \mathrm{l}^{-1}\right)(\mathrm{EPA}, 1999)$.

AAS-GF y AAS-HG son los métodos más frecuentemente empleados para determinar As. Ambas técnicas ofrecen ventajas importantes como, límites de detección muy bajos y especificidad analítica mediante la medición de la absorbancia a una longitud de onda específica. Sin embargo, AAS-GF es el método de elección para la medición de As en agua, debido a que un mayor porcentaje de átomos del 
analito se vaporizan dentro del tubo de grafito, obteniendo una mayor sensibilidad analítica y límites de detección más bajos (EPA, 1999). Asimismo, las muestras que presenten una turbidez menor a 1 NTU pueden analizarse directamente sin una digestión previa, lo que disminuye el tiempo de la determinación.

En relación al tratamiento de las muestras de agua para la determinación de As, Silva y Ciminelli (2009), recomiendan que las muestras sean filtradas y conservadas con un reactivo adecuado. La filtración de la muestra elimina la mayor parte del material coloidal disuelto. La acidificación evita la coprecipitación o adsorción del As en hidróxidos de hierro y manganeso.

En el presente trabajo se emplearon frascos de cierre hermético para la recolección de las muestras. Para la descontaminación los frascos y tapas fueron llenados con $\mathrm{HNO}_{3} 10 \% \mathrm{v} / \mathrm{v}$ y dejados en inmersión durante 24 hs. Luego se vaciaron y enjuagaron 5 veces con $\mathrm{H}_{2} \mathrm{O}$ destilada (Silva y Ciminelli, 2009).

Es de señalar que en aguas es posible distinguir dos fracciones de As: el As en fase acuosa (disuelto) y el As ligado a material particulado o coloidal (suspendido). La separación entre dichas fracciones puede hacerse a través de filtros de membrana (policarbonato o ésteres de celulosa). Lo que queda retenido corresponde a los sólidos en suspensión, mientras que lo que pasa por el filtro corresponde al As disuelto. Este procedimiento debe realizarse antes del agregado de cualquier preservante químico (Silva y Ciminelli, 2009). En el presente trabajo de tesis se emplearon filtros de membrana de 0,45 $\mu \mathrm{m}$ (Micron Separation Inc.) para la determinación del As disuelto. Cabe mencionar, que con fines comparativos, en algunas determinaciones no se realizó esta filtración obteniendo el dato de As disuelto + As suspendido. Para realizar dichas determinaciones fue necesario realizar una digestión previa de la muestra siguiendo la metodología propuesta por la EPA en el método 3020A (EPA, 1992).

La preservación de las muestras se realizó ajustando el $\mathrm{pH}$ a valores menores a 2 con $\mathrm{HNO}_{3} 0,15 \% \mathrm{v} / \mathrm{v}$ y conservando las muestras en la heladera para evitar cambios de volumen por evaporación. En estas condiciones las muestras pueden permanecer estables por hasta 6 meses. Es de destacar que en todos los casos el análisis fue realizado dentro de la semana de su recolección.

A continuación se describen los métodos empleados en el presente trabajo de tesis para la determinación de As.

\subsubsection{Método colorimétrico del dietilditiocarbamato de plata (SDDC)}

La espectroscopía UV-Vis utiliza la radiación del espectro electromagnético ( $\lambda$ entre 100 y $800 \mathrm{~nm}$ ), su efecto sobre la materia es producir transiciones electrónicas 
entre los orbitales atómicos y/o moleculares de la sustancia. En los espectros UV-Vis, se observa una señal debida a cada transición electrónica desde un estado fundamental a un estado excitado. Los átomos dan líneas agudas, mientras que las moléculas poliatómicas dan señales en forma de bandas debido a que la absorción de luz involucra también energía suficiente para causar cambios en energía vibracional y rotacional. Para una sustancia determinada, la longitud de onda a la cual se produce el máximo de absorbancia en el espectro se conoce como $\lambda$ máx. (Castro de Esparza et al., 2009).

La señal espectral permite determinar la concentración de una sustancia empleando la ley de Lambert-Beer, que establece que la absorbancia de una solución es directamente proporcional a la concentración del analito en esa solución. La espectrometría UV-Vis se emplea en la determinación cuantitativa de la concentración en solución de especies químicas como iones metálicos de transición y compuestos orgánicos muy conjugados. Muchas de las determinaciones incluyen un paso de reacción entre la especie y un compuesto que origine un derivado coloreado o absorbente en el UV-Vis (Castro de Esparza et al., 2009).

Los métodos colorimétricos empleados para la cuantificación de As se basan en el método de Gutzeit (Gutzeit, 1891). El método consiste en la reducción del As presente en la muestra a gas arsina $\left(\mathrm{H}_{3} \mathrm{As}\right)$ en un generador Gutzeit, empleando zinc en medio ácido. La arsina liberada reacciona con una solución clorofórmica o piridínica de dietilditiocarbamato de plata (AgDDTC) generando un complejo soluble de color rojo que absorbe a $520 \mathrm{~nm}$. Es necesario un pretratamiento de la muestra con yoduro de potasio y cloruro de estaño(II) para reducir el $\mathrm{As}(\mathrm{V})$ a $\mathrm{As}(\mathrm{III})$. La arsina generada se hace pasar por una lana de vidrio impregnada con acetato de plomo para retener el sulfuro de hidrogeno interferente antes de ser absorbida en la solución de AgDDTC.

Este método es aplicable a la determinación de arsénico en muestras de agua potable, superficial, subterránea y residual. Se puede determinar el arsénico en un rango de 5 a $200 \mu \mathrm{g} \mathrm{L}^{-1} \mathrm{y}$, por dilución, mayores concentraciones. La técnica permite límites de detección en el rango de $\mu \mathrm{g} \mathrm{L}^{-1}$ con una instrumentación relativamente sencilla. El límite de detección se calcula de acuerdo al procedimiento establecido por cada laboratorio (Castro de Esparza et al., 2009).

Las determinaciones fueron realizadas con un espectrofotómetro marca METROLAB UV-Vis modelo M-1700 en el laboratorio INDUSER, siguiendo la metodología establecida en el Standar Methods SM 3500AsB (APHA, 2005). 


\subsubsection{Medidas por Absorción atómica-generación de hidruros (AAS-HG)}

La espectroscopía de absorción atómica se fundamenta en la absorción de radiación de una longitud de onda determinada. Esta radiación es absorbida selectivamente por átomos que tengan niveles energéticos cuya diferencia en energía corresponda en valor a la energía de los fotones incidentes. La luz incidente es emitida por una lámpara de cátodo hueco o de descarga sin electrodo y es absorbida por la solución que contiene el analito a cuantificar. La luz que se absorbe sigue la ley de Lambert-Beer, que relaciona la cantidad de fotones absorbidos con la concentración de la especie absorbente.

La técnica AAS-HG permite cuantificar en el orden de ppb $\left(\mu \mathrm{g} \mathrm{L}^{-1}\right)$ elementos como As, Se, Hg, Sn, Sb, Ge, Bi y Te, que tienen la propiedad de formar hidruros. Este método es aplicable a la determinación de arsénico en muestras de agua potable, superficial, subterránea y residual. Es una metodología sencilla que requiere instrumentación relativamente económica, con excelente poder de detección para As total e inorgánico. El límite de detección de este método es $0,10 \mu \mathrm{g} \mathrm{As} \mathrm{L}^{-1}$, permitiendo determinar el elemento en un rango de 0,10 hasta $10,00 \mu \mathrm{g} \mathrm{As} \mathrm{L}^{-1}$, y por dilución a concentraciones mayores (Armienta et al., 2009).

Específicamente, el método para la determinación de As consta de tres etapas: la generación y volatilización del hidruro $\left(\mathrm{AsH}_{3}\right)$, la transferencia del mismo y su posterior atomización en el espectrómetro de absorción atómica. La generación de hidruro se logra tratando el arsénico trivalente de la muestra con una solución de un agente reductor en medio ácido diluido (zinc o borohidruro de sodio en ácido clorhídrico). Generalmente, el reductor empleado es el borohidruro de sodio $\left(\mathrm{NaBH}_{4}\right)$ con $\mathrm{HCl}$ (Armienta et al., 2009).

Este hidruro es transportado por un gas portador como nitrógeno hacia una celda de cuarzo donde es atomizado. La celda de cuarzo, es calentada por una llama de aire-acetileno a una temperatura optimizada $\left(900^{\circ} \mathrm{C}\right)$ para producir la atomización del analito según la ecuación:

$$
2 \mathrm{AsH}_{3} \rightarrow 2 \mathrm{As}^{0}+3 \mathrm{H}_{2}
$$

Al pasar la luz emitida por la lámpara $(\lambda 193,7 \mathrm{~nm})$ a través del conjunto de átomos, la absorción crece a medida que éstos se producen, llega a un máximo y cae al consumirse el elemento y agotarse los átomos de la celda de absorción. Se puede registrar el máximo de absorción, que corresponde a la altura de pico o el área bajo la curva, para relacionarlas con la concentración del analito (Armienta et al., 2009). 
Previamente a la generación de hidruro, la muestra debe ser sometida a un proceso de digestión para destruir los compuestos orgánicos del As y oxidarlo a $\mathrm{As}(\mathrm{V})$. El $\mathrm{As}(\mathrm{V})$ presente en el mineralizado es luego reducido a $\mathrm{As}(\mathrm{III})$ por reacción con yoduro de potasio o cloruro de estaño, el que posteriormente es convertido a arsina (Armienta et al., 2009).

Las determinaciones por este método se realizaron en el laboratorio INDUSER. El procedimiento seguido por dicho laboratorio se basa en la metodología establecida en el método EPA SW 846 M 7061A de la EPA (EPA, 1992). En las determinaciones se empleó un Espectrofotómetro de Absorción Atómica marca Perkin Elmer, modelo AAnalyst 100 .

Las muestras fueron preservadas como se comentó previamente hasta su determinación que en ningún momento superó el máximo permitido de 6 meses.

\subsubsection{Medidas por Absorción atómica con horno de grafito (AAS-GF)}

La Absorción atómica con horno de grafito (AAS-GF) se basa en la absorción de luz por parte de un elemento en estado atómico. La longitud de onda a la cual la luz es absorbida es específica de cada elemento (para As $\lambda=193,7 \mathrm{~nm}$ ), siendo la cantidad de radiación absorbida proporcional a la cantidad de átomos del elemento presentes. Involucra fundamentalmente 2 procesos: la atomización de la muestra y la absorción de radiación proveniente de una fuente por los átomos libres. El tratamiento de la muestra hasta la atomización comprende las siguientes etapas (Mañay et al., 2009):

1. Secado: la muestra inyectada $(2-20 \mu \mathrm{L})$ en el horno de grafito es sometida a una temperatura algo inferior al punto de ebullición del solvente $\left(80-180{ }^{\circ} \mathrm{C}\right)$, logrando la evaporación del solvente y los componentes volátiles de la matriz.

2. Calcinación o incineración: en esta etapa, la temperatura es elevada para eliminar la materia orgánica $\left(350-1300^{\circ} \mathrm{C}\right)$.

3. Atomización: en esta etapa, el horno es calentado rápidamente, de manera de pasar al analito al estado atómico $\left(1800-2800{ }^{\circ} \mathrm{C}\right)$. Este proceso lleva a la creación de átomos libres en el camino óptico. Se mide la absorbancia durante este paso.

La AAS-GF es un método simple, rápido y aplicable a un gran número de metales en muestras ambientales. Este método es aplicable a la determinación de As en todo tipo de muestras de aguas superficiales, subterráneas y potables. El límite de detección es 1,0 $\mu \mathrm{g}$ As $\mathrm{L}^{-1}$ y el límite de cuantificación es $5,0 \mu \mathrm{g} A s \mathrm{~L}^{-1}$. Mediante este método se puede determinar el arsénico en un rango de $5-40 \mu \mathrm{g} \mathrm{As} \mathrm{L}^{-1}$ y por dilución concentraciones mayores (Mañay et al., 2009). 
Las determinaciones por este método se realizaron en el laboratorio INDUSER. El procedimiento seguido por dicho laboratorio se basa en la metodología propuesta en el método 7010 de la EPA (EPA, 2007). Se empleó un espectrofotómetro de absorción atómica marca Perkin Elmer modelo ANALYST 200 acoplado a horno de grafito marca Perkin Elmer modelo HGA-900 con tecnología STPF (Stabilized Temperature Platform Furnace) y automuestreador Perkin Elmer AS 800.

El análisis es de elementos disueltos no requiere digestión si la muestra se ha filtrado y acidificado (Mañay et al., 2009). Sin embargo, en el laboratorio INDUSER realizan la digestión para facilitar la mineralización y eliminar posibles interferencias, optimizando la medición posterior del analito. La digestión de la muestra se realiza siguiendo el protocolo descripto por el método EPA 3020A (EPA, 1992).

Las muestras fueron preservadas como se comentó previamente hasta su determinación.

\subsubsection{Método colorimétrico semicuantitativo con tiras de ensayo}

Algunos laboratorios como Merck, Hach Tech y Wagtech, han diseñado pruebas portátiles para obtener resultados en campo sin la necesidad de transportar las muestras hasta laboratorios especializados. De esta forma, se reduce el costo y el tiempo en los resultados, aspectos a tener en cuenta en países de bajos recursos.

La mayoría de estos kits se basan en el método Gutzeit, cuyos fundamentos ya fueron explicados en el punto 5.3.1. Sintéticamente, la arsina generada reacciona con algún agente químico contenido en una tira reactiva formando complejos coloreados sobre la tira. El color de la mancha es proporcional a la concentración de As, la cual se compara con manchas estándar (Arora et al., 2009).

El kit de Merck empleado en los ensayos fue el Test de Arsénico 1.17927.0001Merckoquant. La técnica tiene su base en la formación de halogenuros mixtos coloreados de arsénico y mercurio sobre la tira analítica del kit. Cuando el Zn en polvo, un ácido sólido y un agente oxidante (para eliminar las interferencias de los iones sulfuro) se añaden a los compuestos de $A s(I I I)$ y $A s(V)$, se libera arsina. El hidruro volátil, reacciona con el bromuro de mercurio(II) contenido en la zona de reacción de la tira analítica para formar halogenuros mixtos de As y Hg de color amarillo-marrón. La concentración de As se determina semicuantitativamente por comparación visual de la zona de reacción de la tira de prueba con los campos de una escala colorimétrica provista por el kit.

En la Foto 5.1 puede verse el contenido del kit que a continuación se enumera: _ 1 frasco de reactivo As-1 (agente oxidante $\mathrm{KMnO}_{4}$ ), en cuentagotas. 
_ 1 frasco de reactivo As-2 (ácido malónico), sólido.

_ 1 frasco de reactivo As-3 (Zn), en polvo.

_ 1 cuchara dosificadora roja para el reactivo As-2.

_ 1 cuchara dosificadora verde para el reactivo As-3.

_ 2 frascos de reacción de $60 \mathrm{ml}$ cada uno.

_ tiras para 100 determinaciones.

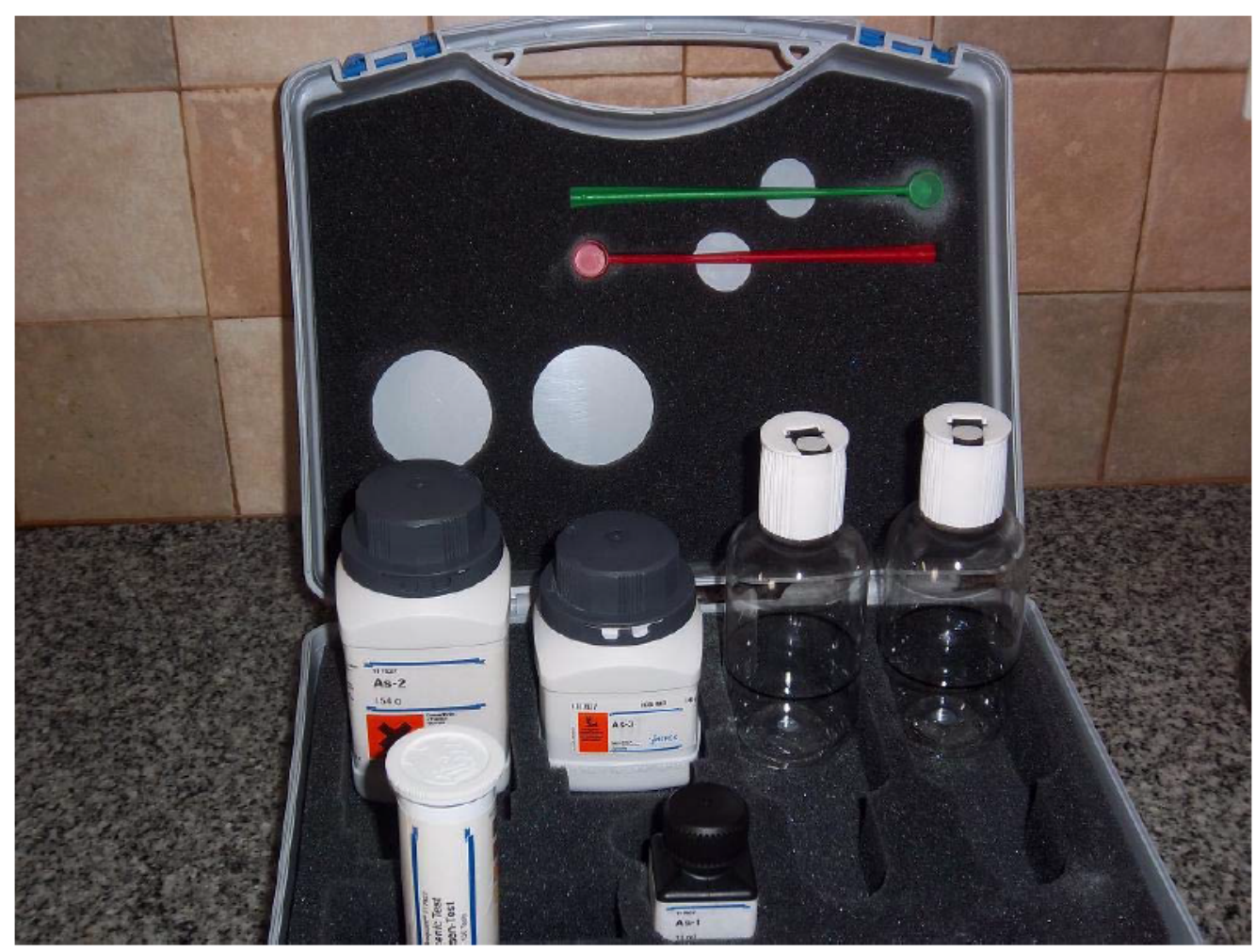

Foto 5.1. Kit de Arsénico 1.17927.0001-Merckoquant empleado en las determinaciones.

El procedimiento general, que puede verse en la Figura 5.2, consiste en colocar el volumen de agua indicado en los frascos de reacción $(60 \mathrm{ml})$, luego se agregan dos gotas de reactivo As-1 y se agita ligeramente, se agrega una medida de reactivo As-2 y se agita hasta la completa disolución, por último se agrega una medida de reactivo As-3 y se cierra inmediatamente el frasco de reacción. Se coloca en la ranura de la tapa la tira reactiva y se homogeniza lentamente. Se deja en reposo 20 minutos, agitando ligeramente dos o tres veces en forma circular. Se retira la tira, se sumerge brevemente en agua destilada, se sacude para eliminar el exceso de líquido y por último se compara el color de la tira con la escala provista en el kit. Las tiras se colorearán según la concentración de As en la solución problema. La graduación de la escala colorimétrica, que puede visualizarse en la Figura 5.3, es la siguiente: 0,005$0,01-0,025-0,05-0,1-0,25-0,5 \mathrm{mg}_{\text {As total }} \mathrm{L}^{-1}$. 
Se realizó el control del procedimiento, tal como indican las instrucciones del test, empleando una solución patrón de arsénico (solución patrón CertiPUR $1000 \mathrm{mg}$ $\mathrm{L}^{-1}$ de As art. 119773).

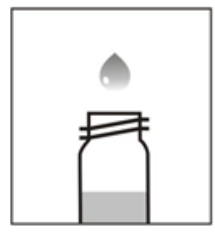

$60 \mathrm{ml}$
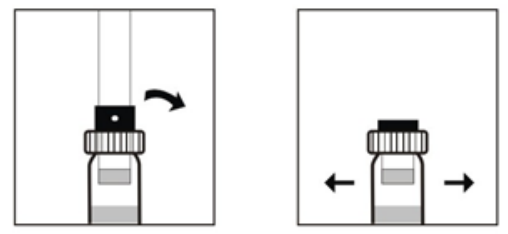

$20 \mathrm{~min}$

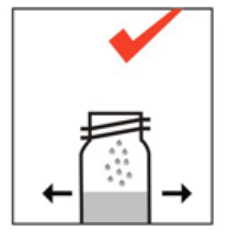

$1 \times$ As-2

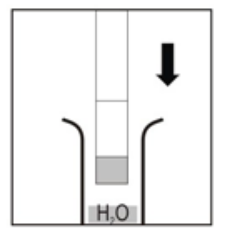

$<1 \mathrm{~s}$

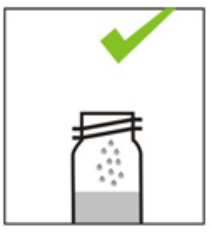

$1 \times$ As-3
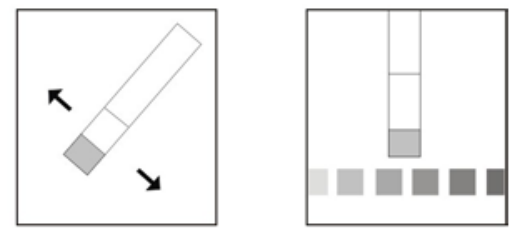

Figura 5.2. Esquema del procedimiento general para la determinación de As con el Test 1.17927.0001-Merckoquant.

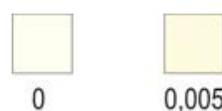

0,005
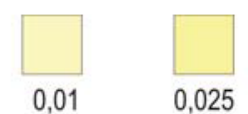

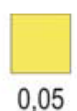

0,05

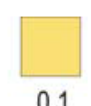

0,1
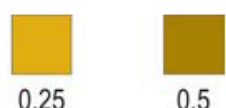

$\mathrm{mg} \mathrm{L}^{-1} \mathrm{As}^{3+/ 5+}$

Figura 5.3. Graduación de la escala colorimétrica del Test 1.17927.0001-Merckoquant.

El test determina arsénico trivalente y pentavalente. Puede emplearse para aguas potables y minerales, agua de pozo, aguas subterráneas y superficiales.

Este test fue utilizado para determinar el agotamiento de los adsorbentes (Capítulos 6-8), el que fue establecido a partir del ciclo en el que la concentración de As en la solución supera el valor de $10 \mu \mathrm{g} \mathrm{L}^{-1}$. El empleo del kit en estas determinaciones economizó las medidas permitiendo la evaluación rápida de los resultados.

\subsection{Otras determinaciones en muestras líquidas}

Adicionalmente a la determinación de As, en algunos ensayos de adsorción de los Capítulos 6 a 9, se determinaron los siguientes parámetros para evaluar la calidad del agua después del tratamiento:

pH: se utilizó un equipo Denver Instrument Ultrabasic Benchtop. Para su calibración se emplearon soluciones patrones de $\mathrm{pH} 4,7$ y 10 .

Turbidez: se determinó mediante el empleo de un turbidímetro Hanna HI 93703, que mide turbidez por el método nefelométrico. Las medidas se expresan en Unidades 
Nefelométricas de Turbidez (NTU). La calibración del equipo se realizó con patrones de turbidez conocida ( 0,10 y 500 NTU). Para la realización de la medida se carga el volumen indicado en la celda, se tapa y se mide inmediatamente para evitar la decantación de la muestra.

Conductividad: se utilizó un equipo LIDA DDS-12DW. La calibración se realizó utilizando como patrón una solución de $\mathrm{KCl} 0,1 \mathrm{~N}$.

Aluminio: se realizó mediante el protocolo SM-3500-Al B que consiste en la determinación espectrofotométrica $(\lambda 535 \mathrm{~nm}$ ) del complejo rojo-rosado que forma la eriocromocianina $\mathrm{R}$ con $\mathrm{Al}(\mathrm{III})$ (APHA, 2005). Las curvas de calibración se prepararon con las distintas matrices acuosas descriptas previamente (agua destilada, agua de red y agua subterránea).

Cloruros: se realizó mediante el método titulométrico SM-4500-Cl-B (APHA, 2005). El cloruro se determina por titulación con $\mathrm{AgNO}_{3}$ nitrato de plata estándar, usando $\mathrm{K}_{2} \mathrm{CrO}_{4}$ como indicador del punto final.

Fe(III) total: se realizó mediante la determinación espectrofotométrica $(\lambda 540 \mathrm{~nm})$ del compuesto coloreado formado entre el Fe(III) y el KSCN.

\subsection{Ensayos de laboratorio de modificación química de arcillas}

Siguiendo las estrategias planteadas en los objetivos de trabajo se consideró en particular la posibilidad de modificación química de los geomateriales, a fin de mejorar las características de adsorción. Se postuló la realización de tratamientos simples, mediante el empleo de soluciones de sales de Fe(III) que, por hidrólisis, conduzcan a la depositación de oxi/hidróxidos activos. Para la caracterización de los productos activados se utilizaron algunas de las técnicas fisicoquímicas antes mencionadas en el punto 5.1 .

La activación química fue realizada mediante la técnica descripta por Schwertmann and Cornell (2000) para la obtención de ferrihidrita. Para ello se utilizó solución de una sal de $\mathrm{Fe}(\mathrm{III})$ y $\mathrm{KOH} 1 \mathrm{M}$ (relación $\mathrm{Fe}^{+3} / \mathrm{OH}^{-}=1 / 3$ ), ajustando el $\mathrm{pH}$ a 7 . Siguiendo la misma técnica se sintetizó ferrihidrita que fue empleada como referencia.

En los Capítulos 7 y 8 se discutirá en detalle la metodología seguida en la activación de las muestras, así como la caracterización de las muestras y su empleo en el proceso de adsorción de As. 


\section{CAPÍTULO 6}

\section{Arcillas ferruginosas de la PBA como adsorbentes del As}

Considerando las características físicas y químicas de los minerales de arcilla (tamaño de partícula, propiedades estructurales, composición química, propiedades de superficie, abundancia, bajo costo, disponibilidad, etc.) se evaluó la posibilidad de uso de aluminosilicatos laminares ricos en hierro, como materias primas adsorbentes. En tal sentido, se procedió a la caracterización fisicoquímica de las arcillas ferruginosas procedentes de los depósitos de la PBA mencionadas en el Capítulo 4, sobre las cuales se llevaron a cabo una serie de ensayos tentativos de empleo en el proceso de remoción de As en aguas.

En el presente capítulo, en primer término se discuten los resultados de la caracterización fisicoquímica de las muestras de arcillas ferruginosas, particularmente los datos mineralógicos y químicos, permitiendo la selección de algunos minerales de arcilla, que, en una etapa posterior, se evaluarán en el laboratorio para su potencial empleo como adsorbentes del arsénico. Por otra parte, los resultados permitirán analizar las principales variables que afectan el proceso de adsorción, los que serán tenidos en cuenta para el escalado a nivel de planta piloto.

\subsection{Caracterización fisicoquímica}

Como se comentó en los capítulos precedentes, un mineral apropiado para la remoción del arsénico por adsorción es aquel que tiene afinidad química por el arsénico o por sus formas presentes en el agua y propicia interacciones con los mismos. Los arseniatos, principal especie de arsénico presente en las aguas contaminadas de los acuíferos de nuestro país, se adsorben sobre óxidos e hidróxidos de algunos metales. Particularmente, con los oxi/hidróxidos de hierro, las reacciones superficiales involucradas son altamente específicas.

Para cumplir con los objetivos fijados, es necesario primeramente caracterizar la muestra natural rica en hierro, evaluando fundamentalmente:

a) Las propiedades estructurales y de superficie.

b) La composición química (en particular el contenido de hierro).

En este punto se muestran los resultados obtenidos para las muestras procedentes de las Sierras Septentrionales de la PBA haciendo uso de las distintas técnicas de análisis fisicoquímicas que fueron descriptas en detalle en el Capítulo 5. Las muestras para su análisis fueron identificadas con un número y la abreviatura AFO correspondiente 
a Arcilla Ferruginosa Original (que no ha sido sometida a ningún tratamiento químico y que no ha sido empleada para el tratamiento de remoción del contaminante).

\subsubsection{Caracterización mediante análisis químico (ICP AES-MS), por DRX y SEM- EDS}

El análisis químico de los materiales originales mediante la técnica de ICP para elementos mayoritarios se efectuó según la rutina descripta en el Capítulo 5 para la totalidad de las muestras descritas en el ítem 4.4.1, mientras que el análisis de elementos traza se realizó para algunas de esas muestras que fueron seleccionadas por los resultados del análisis químico de elementos mayoritarios teniendo en cuenta su potencialidad en el proceso de adsorción de As.

En la Tabla 6.1 se muestran los resultados del análisis de elementos mayoritarios expresados como óxidos, mientras que en la Tabla 6.2 se indican los valores obtenidos para el elemento As empleando ICP-MS.

De los resultados surge que existen materiales muy ricos en hierro (del orden del $70 \%$ como $\mathrm{Fe}_{2} \mathrm{O}_{3}$ ) mientras que los procedentes de otras áreas tienen un valor promedio entre 40 y $50 \%$. Estos datos se encuentran en concordancia con los reportados por Nigro et al. (2013) para materiales procedentes de la misma zona.

En referencia a los datos de As, se observa una relación directa entre el contenido de hierro y de arsénico, en las muestras procedentes de la Zona 3. Sin embargo, en las muestras de la Zona 2 con un contenido de hierro considerablemente mayor, la relación Fe/As difiere de las anteriores, como puede observarse en la Figura 6.1. Las diferencias deberían atribuirse a un origen distinto en la formación de las fases de hierro.

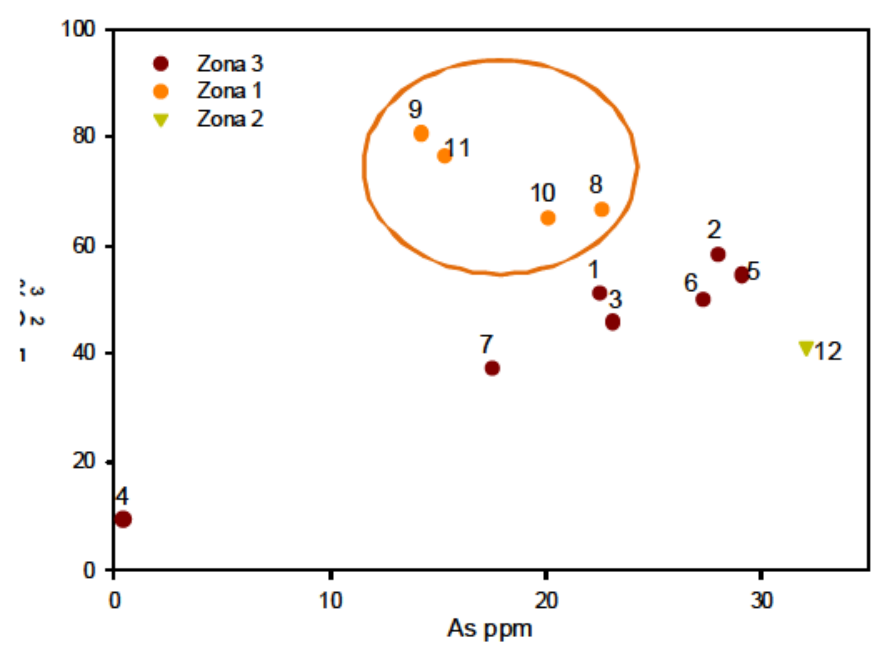

Figura 6.1. Relación entre el contenido de As y de $\mathrm{Fe}_{2} \mathrm{O}_{3} \%$ para las muestras AFO. 


\begin{tabular}{|c|c|}
\hline 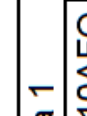 & 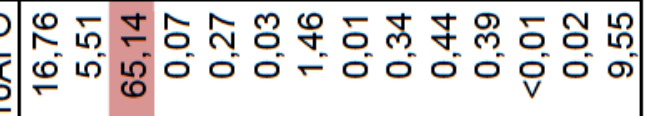 \\
\hline & $\hat{\tau}$ \\
\hline & 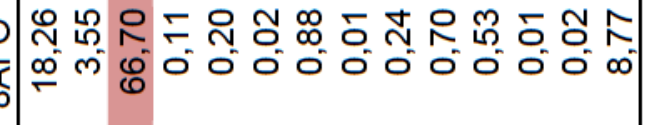 \\
\hline & 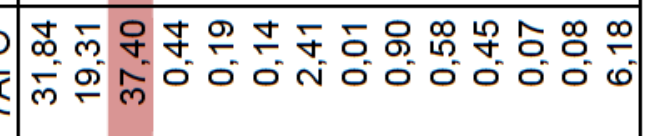 \\
\hline & $\hat{\vdots}$ \\
\hline & $\mid$ \\
\hline & 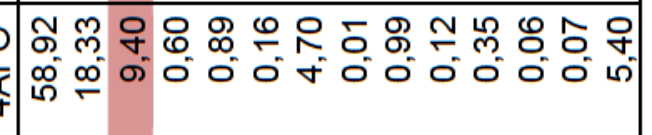 \\
\hline & 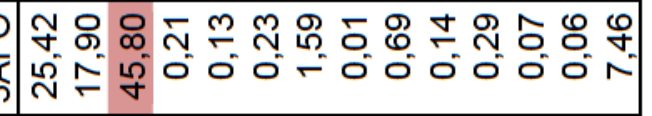 \\
\hline & 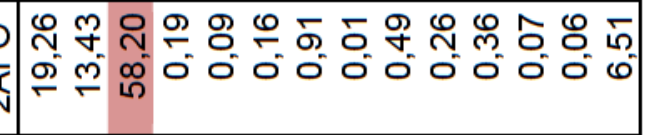 \\
\hline & 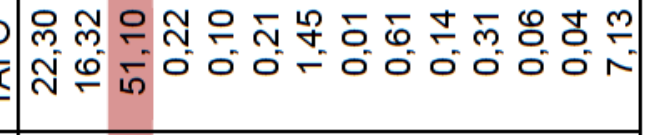 \\
\hline : & $\begin{array}{l}0 \\
0 \\
0\end{array}$ \\
\hline
\end{tabular}

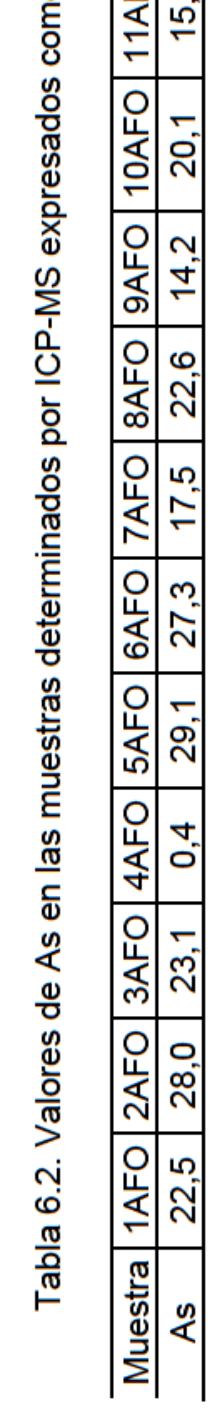


En la Tabla 6.3 se muestran los resultados obtenidos empleando la rutina ICPMS por la cual se determinaron 38 elementos traza, expresados en ppm. Se han resaltado los elementos de las tierras raras (REE) y el $Y$. Los contenidos totales de REE + Y para las arcillas de la Zona 3 (entre 661,92 y 1.004,5) y de la Zona $2(810,69)$ son comparables con los datos reportados por Nigro et al. (2013). Para las muestras de la Zona 1 los valores son considerablemente inferiores (entre 71,82 y 157,16) seguramente asociados a diferentes procesos de fragmentación de la fuente.

Tabla 6.3. Análisis químico de elementos traza por ICP-MS expresados como ppm.

\begin{tabular}{|c|c|c|c|c|c|c|c|c|c|c|}
\hline Muestra & $1 \mathrm{AFO}$ & 2AFO & $3 \mathrm{AFO}$ & $5 \mathrm{AFO}$ & $6 \mathrm{AFO}$ & $8 \mathrm{AFO}$ & 9AFO & $10 \mathrm{AFO}$ & $11 \mathrm{AFO}$ & $12 \mathrm{AFO}$ \\
\hline $\mathrm{Ag}$ & $<1$ & $<1$ & $<1$ & $<1$ & $<1$ & $<1$ & $<1$ & $<1$ & $<1$ & $<1$ \\
\hline $\mathrm{Ba}$ & 730 & 558 & 791 & 825 & 789 & 152 & 61,6 & 171 & 378 & 1005 \\
\hline $\mathrm{Ce}$ & 439 & 715 & 497 & 547 & 490 & 42,6 & 23,1 & 47,9 & 21,6 & 364 \\
\hline Co & 7,1 & 14,5 & 6,7 & 9,8 & 8,1 & 51,9 & 49,6 & 35,3 & 65,6 & 34,9 \\
\hline $\mathrm{Cr}$ & 20 & 10 & 20 & 10 & 10 & 10 & $<10$ & 10 & $<10$ & 50 \\
\hline Cs & 1,12 & 0,69 & 1,28 & 1,26 & 1,39 & 0,90 & 0,40 & 1,21 & 0,53 & 1,97 \\
\hline $\mathrm{Cu}$ & 30 & 46 & 44 & 41 & 41 & 45 & 27 & 51 & 47 & 53 \\
\hline Dy & 5,02 & 6,01 & 5,53 & 6,35 & 5,75 & 3,46 & 2,05 & 5,12 & 2,49 & 12,55 \\
\hline $\mathrm{Er}$ & 3,17 & 3,14 & 3,19 & 3,38 & 3,10 & 1,93 & 1,04 & 3,08 & 1,35 & 6,89 \\
\hline Eu & 1,86 & 2,24 & 2,13 & 2,16 & 1,83 & 1,15 & 0,76 & 1,46 & 0,71 & 4,29 \\
\hline Ga & 12,2 & 11,4 & 12,4 & 14,0 & 12,6 & 4,8 & 1,8 & 6,6 & 2,2 & 27,6 \\
\hline Gd & 10,35 & 11,00 & 11,40 & 10,55 & 9,44 & 4,33 & 2,69 & 5,49 & 2,75 & 19,90 \\
\hline $\mathrm{Hf}$ & 5,7 & 4,4 & 6,1 & 7,1 & 6,7 & 1,8 & 0,3 & 2,6 & 1,0 & 8,0 \\
\hline Ho & 1,02 & 1,10 & 1,08 & 1,16 & 1,03 & 0,65 & 0,37 & 1,02 & 0,48 & 2,34 \\
\hline La & 86,4 & 118,0 & 91,3 & 106,5 & 94,1 & 19,6 & 10,0 & 23,1 & 10,6 & 140,0 \\
\hline Lu & 0,44 & 0,43 & 0,46 & 0,52 & 0,48 & 0,25 & 0,11 & 0,41 & 0,17 & 0,90 \\
\hline Mo & 6 & 6 & 6 & 6 & 6 & 2 & $<2$ & 2 & $<2$ & 4 \\
\hline $\mathrm{Nb}$ & 7,1 & 5,5 & 7,0 & 7,6 & 6,9 & 5,9 & 0,3 & 8,1 & 2,1 & 19,0 \\
\hline $\mathrm{Nd}$ & 60,1 & 80,4 & 64,9 & 71,2 & 63,7 & 22,4 & 13,0 & 25,5 & 11,6 & 133,5 \\
\hline $\mathrm{Ni}$ & $<5$ & $<5$ & $<5$ & $<5$ & $<5$ & 9 & 7 & 7 & 6 & 53 \\
\hline $\mathrm{Pb}$ & 29 & 31 & 32 & 31 & 30 & 32 & 28 & 76 & 120 & 30 \\
\hline $\mathrm{Pr}$ & 18,40 & 24,50 & 19,60 & 22,30 & 19,80 & 5,49 & 3,05 & 6,08 & 2,83 & 35,30 \\
\hline $\mathrm{Rb}$ & 47,7 & 30,2 & 48,6 & 57,3 & 56,4 & 27,1 & 0,7 & 0,8 & 14,1 & 90,2 \\
\hline $\mathrm{Sm}$ & 10,10 & 13,50 & 11,00 & 11,95 & 10,85 & 4,73 & 2,83 & 5,68 & 2,55 & 22,60 \\
\hline Sn & 1 & 1 & 1 & 1 & 1 & $<1$ & $<1$ & 1 & $<1$ & 4 \\
\hline $\mathrm{Sr}$ & 518 & 586 & 568 & 610 & 526 & 38,8 & 20,3 & 30,2 & 26,5 & 878 \\
\hline $\mathrm{Ta}$ & 0,5 & 0,4 & 0,4 & 0,5 & 0,4 & 0,3 & $<0,1$ & 0,4 & 0,1 & 1,4 \\
\hline $\mathrm{Tb}$ & 1,10 & 1,29 & 1,19 & 1,31 & 1,15 & 0,64 & 0,38 & 0,86 & 0,43 & 2,60 \\
\hline Th & 10,65 & 9,01 & 10,95 & 13,50 & 12,50 & 2,96 & 1,65 & 3,97 & 1,81 & 17,50 \\
\hline $\mathrm{TI}$ & $<0,5$ & $<0,5$ & $<0,5$ & $<0,5$ & $<0,5$ & $<0,5$ & $<0,5$ & $<0,5$ & $<0,5$ & $<0,5$ \\
\hline $\mathrm{Tm}$ & 0 , & 44 & 0,30 & 0,50 & 0,47 & 0,26 & 0,13 & 0,44 & 0,19 & 0,92 \\
\hline U & 3,29 & 3,76 & 3,29 & 4,66 & 4,41 & 2,48 & 0,80 & 2,46 & 3,07 & 4,62 \\
\hline V & 124 & 97 & 110 & 166 & 165 & 87 & 9 & 127 & 23 & 116 \\
\hline W & 5 & 3 & 5 & 11 & 10 & 3 & 1 & 3 & 2 & 4 \\
\hline$Y$ & 1,7 & & 2,8 & 25,9 & 24,6 & 17,5 & 11,5 & 28,1 & 13,1 & 58,6 \\
\hline $\mathrm{Yb}$ & 2,99 & 2,85 & 3,25 & 3,23 & 3,07 & 1,83 & 0,81 & 2,92 & 1,19 & 6,30 \\
\hline $\mathrm{Zn}$ & 39 & 58 & 37 & 55 & 80 & 100 & 94 & 129 & 378 & 63 \\
\hline $\mathrm{Zr}$ & 218 & 161 & 216 & 256 & 239 & 69 & 11 & 99 & 38 & 266 \\
\hline
\end{tabular}


En lo que respecta al uso de los elementos traza como indicadores de procesos geoquímicos, es útil agruparlos según sus propiedades periódicas, particularmente radio y carga que definen el potencial iónico. Asimismo, otros aspectos a considerar están relacionados al comportamiento redox y ácido base (fundamentalmente ácidos y bases de Pearson) que definen la estabilidad mineral.

Algunos de los grupos de elementos traza que tienen importancia geoquímica son:

a) elementos del bloque fo lantánidos (Z 57 al 71).

b) elementos del bloque d del grupo del Pt metales nobles ( $Z 44$ a 46 y 76 a 79 ).

c) elementos de la primera serie de transición ( $Z 21$ al 30, incluye a los mayoritarios Fe y $\mathrm{Mn})$.

d) elementos pesados de los grupos I y II (Rb, Cs, Sr y Ba) así como el Pb por su similitud química.

e) elementos 40 y 41 así como 72 y 73 ( $\mathrm{Zr}-\mathrm{Hf}$ y Nb-Ta) por su similitud química.

f) el elemento de número atómico $39(\mathrm{Y})$ por su similitud con los lantánidos.

g) elementos actínidos Th y U.

h) el elemento $P$.

En sistemas magmáticos la propiedad más utilizada para realizar la clasificación de elementos en compatibles e incompatibles es el carácter polarizante definido por la relación carga/radio. En tal sentido, los cationes más polarizantes o de mayor potencial iónico se denominan HFS (high field strength). Difieren de los menos polarizantes o LFS (low field strength), también conocidos como litófilos o "large ion lithophile elements" (LILE). Se deduce entonces que los de mayor potencial iónico (con gran capacidad para deformar la nube electrónica de los aniones, particularmente el ion óxido) tienden a segregar de la masa fundida en forma de óxidos binarios, de tipo covalente de red. Presentan un considerable carácter ácido (según la teoría de Lux Flood) así como gran resistencia física y química. Dichos elementos (entre los que pueden mencionarse los lantánidos, Sc, Y, Th, U, Zr, Hf, Ti, Nb y Ta), tienden a comportarse como compatibles entre sí. Los elementos cuyo comportamiento es opuesto (alcalinos como Cs, Rb y eventualmente el $\mathrm{K}$ según la especie mineral, alcalino-térreos como el $\mathrm{Ba}$ y $\mathrm{Sr}$, el $\mathrm{Eu}(\mathrm{II})$ y el $\mathrm{Pb}$ ) actúan como litósferos formando parte de la masa fundida.

En general puede establecerse que los elementos del grupo LFS ( $\mathrm{Cs}, \mathrm{Sr}, \mathrm{K}, \mathrm{Rb}$, Ba) son móviles en tanto que los HFS son inmóviles. En adición, los metales de transición $\mathrm{Mn}, \mathrm{Zn}$ y $\mathrm{Cu}$ (como iones divalentes) tienden a ser móviles en tanto que el 
$\mathrm{Co}, \mathrm{Ni}, \mathrm{V}$ y $\mathrm{Cr}$ (en estados de oxidación preferentemente >2) tienden a ser inmóviles. La movilidad de los elementos lantánidos (en su estado de oxidación tres) depende de muchos factores entre los que pueden mencionarse el tipo de sólido (amorfo/cristalino) y las características del fluido mineralizante (rico en halogenuros, carbonatos, etc.) entre otros. La Figura 6.2 muestra la secuencia de elementos trazas que usualmente presentan cierta compatibilidad (Jochum et al., 1990).

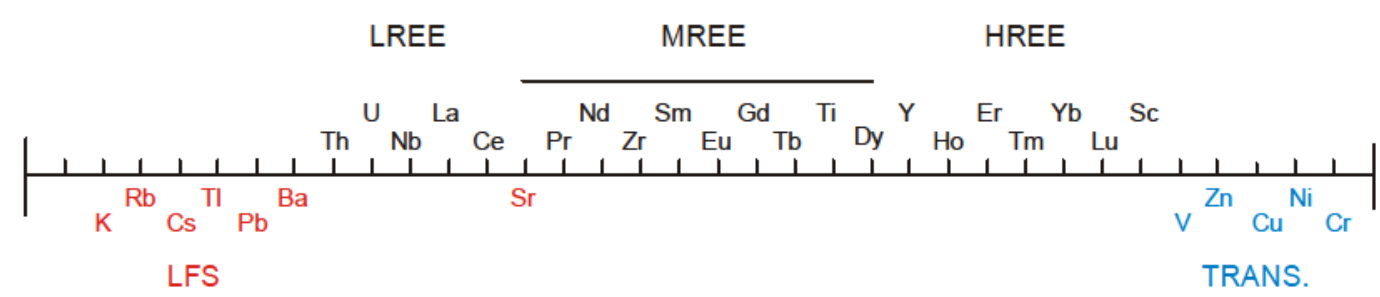

Figura 6.2. Elementos que se concentran en la corteza. HFS (parte superior: LREE, MREE, HREE): elementos inmóviles, LFS: elementos móviles y TRANS: elementos de la primera serie de transición.

Los elementos lantánidos se dividen en livianos (LREE light rare earth elements), pesados (HREE high rare earth elemtens) e intermedios (MREE middle rare earth elements, como el $\mathrm{Sm}$ y $\mathrm{Ho}$ ). Los elementos de importancia geoquímica con estado de oxidación diferente de tres (típico de la serie) son el Ce(IV) y el Eu(II). En general todos ellos (incluyendo al $\mathrm{Y}$ por su semejanza química) son relativamente inmóviles durante el metamorfismo de bajo grado, la meteorización y la alteración hidrotermal.

El tratamiento de los elementos traza permite estimar el tipo de fuente de las sedimentitas. En tal sentido, los diagramas "spider" o de multielementos posibilitan inferir una relación de componentes. El tratamiento de los resultados obtenidos de los análisis químicos se realizó con el software Petrograph normalizando a la composición meteorítica condrito.

La Figura 6.3.a corresponde a los diagramas spider para los elementos lantánidos de todas las muestras estudiadas, observándose un comportamiento diferente para los materiales procedentes de los distintos depósitos. Por tal razón las Figuras $6.3 \mathrm{~b}$, c y d muestran, en forma separada, el comportamiento para cada una de las zonas estudiadas. En todos los casos se observa una disminución de los lantánidos pesados respecto a los livianos. La Figura 6.3.b corresponde al material de la Zona 3 en el que se observa claramente un enriquecimiento en los HREE, con una anomalía positiva para el Ce y una anomalía negativa para el Eu. Ambas anomalías pueden ser atribuidas a la posibilidad de existencia de otros estados de oxidación estables: $\mathrm{Ce}(\mathrm{IV})$ y $\mathrm{Eu}(\mathrm{II})$ y la posibilidad de estabilización de los mismos de acuerdo a los procesos de meteorización que han tenido lugar. 

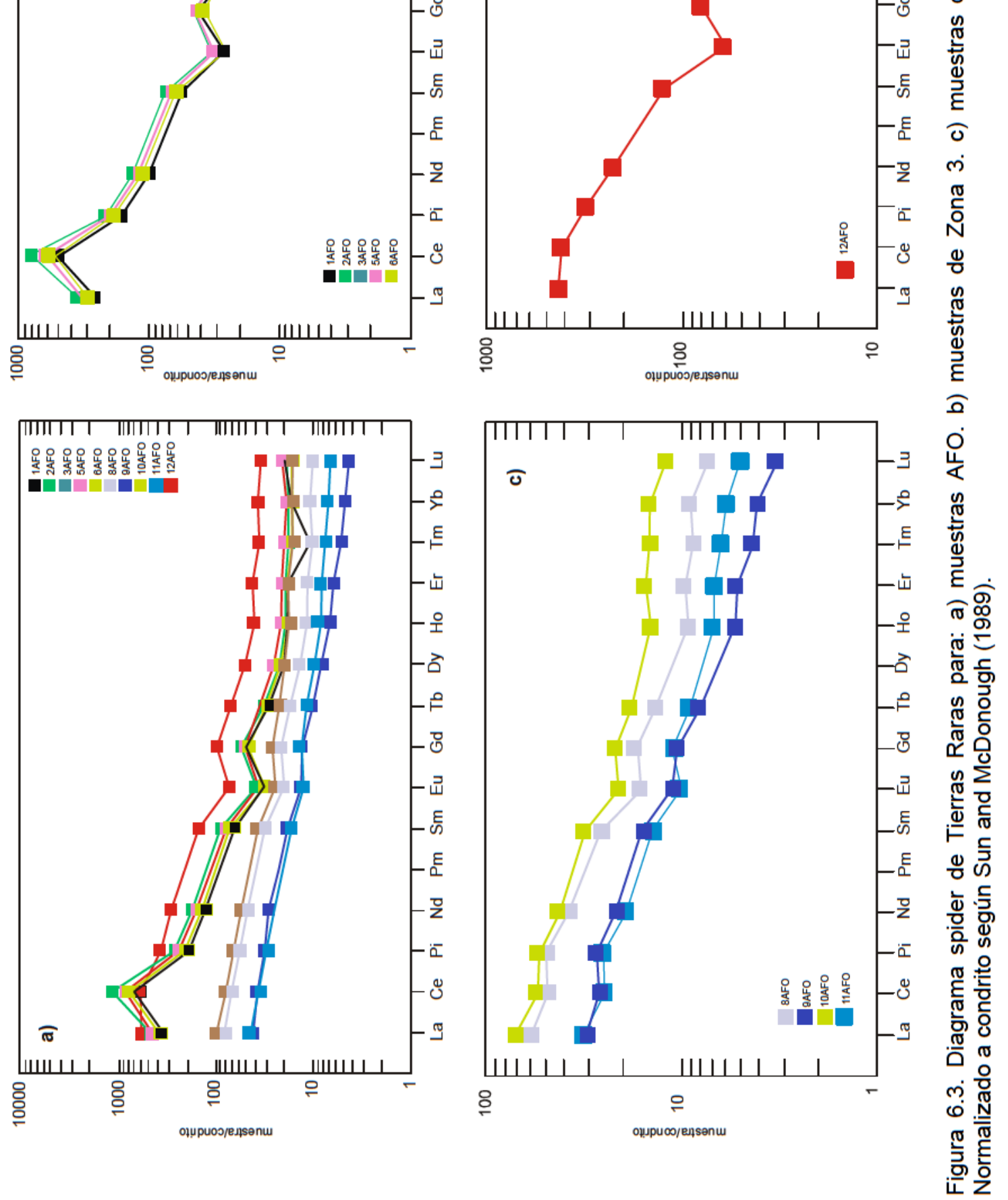
Tripathi and Rajamani (2007) han explicado la anomalía positiva del Ce a partir de su retención como $\mathrm{Ce}^{+4}$, coprecipitando como $\mathrm{CeO}_{2}$ con los oxi/hidroxidos de $\mathrm{Fe}$ producidos por meteorización. Este comportamiento ha sido reportado en otros depósitos de la región de las Sierras Septentrionales (Fernández et al., 2010).

Por otra parte, la disminución del Eu puede ser atribuida a su incorporación en la cristalización de fases accesorias como los feldespatos (sustituyendo al Ca y/o Sr). Un comportamiento semejante para el Eu se observa en el material 12AFO (Figura 6.3.d), el que presenta una mineralogía similar (ver más adelante). En lo que respecta al material de Zona 1 (Figura 6.3.c) no se observan las anomalías anteriores, mostrando un comportamiento típico de fraccionamiento de REE. Estos resultados indican una génesis diferente en las materiales de los distintos sectores muestreados.

La tipificación o identificación estructural de las muestras se llevó a cabo mediante la técnica de difracción por RX. Las muestras analizadas corresponden a roca total (polvo sin orientar) y fracción arcilla (orientada y calcinada en algunos casos), como se explicó en detalle en el Capítulo 5. Los diagramas de RX obtenidos fueron analizados utilizando los siguientes patrones: illita PDF 26-0911, caolinita PDF 89-6538, pirofilita PDF 46-1308, hematita PDF 88-2359, cuarzo PDF 89-8941 y goethita PDF 29-0713.

Los diagramas de las Figuras 6.4 a 6.10 corresponden a las muestras seleccionadas en la Zona 3 con contenidos de hierro variables, como se observa en la Tabla 6.1. El contenido podría, en principio, asociarse a la presencia del hierro en su máximo estado de oxidación en base a la coloración observada.

En la Figura 6.4 correspondiente al difractograma de la muestra $4 \mathrm{AFO}$, con menor contenido en $\mathrm{Fe}_{2} \mathrm{O}_{3}$, se observa la presencia de las especies arcillosas illita ( $d=$ $10,02-5,00-4,48-3,75-3,35-2,57 \AA)$ y caolinita $(7,19-3,58 \AA)$. Las reflexiones en 3,35 y $4,27 \AA$ se deben a la presencia de cuarzo. Las líneas de pequeña intensidad en 2,71 y $2,52 \AA$ corresponden a hematita. Los difractogramas de la fracción arcilla, confirman la presencia de illita y caolinita como especies arcillosas predominantes, además de revelar la presencia de pirofilita $(9,25-4,61-3,07 \AA)$. Por último, el difractograma de la fracción arcilla calcinada confirma la presencia de caolinita.

En la Figura 6.5 se muestra el diagrama de difracción por $\mathrm{RX}$ de la muestra 7AFO, indicando la presencia de pirofilita $(9,19-4,62-3,07 \AA)$, caolinita $(7,19-3,59 \AA)$ e illita $(10,02-5,07-3,69-3,35-2,56 \AA)$, mientras que las reflexiones en 2,71 y $2,52 \AA$ indican la presencia de hematita. Los diagramas de la fase arcilla confirman la presencia de caolinita (reflexiones 7,24-3,59 $\AA$ presentes en el diagrama orientado y 
ausentes en el calcinado), pirofilita $(9,23-4,60-3,07 \AA)$ e illita $(10,07-5,00-3,35-2,57 \AA)$. Las reflexiones en 4,27 y $3,35 \AA$ indican la presencia de cuarzo. La señal en $15,18 \AA$ en la fracción arcilla orientada sugiere la presencia de una arcilla expandible.

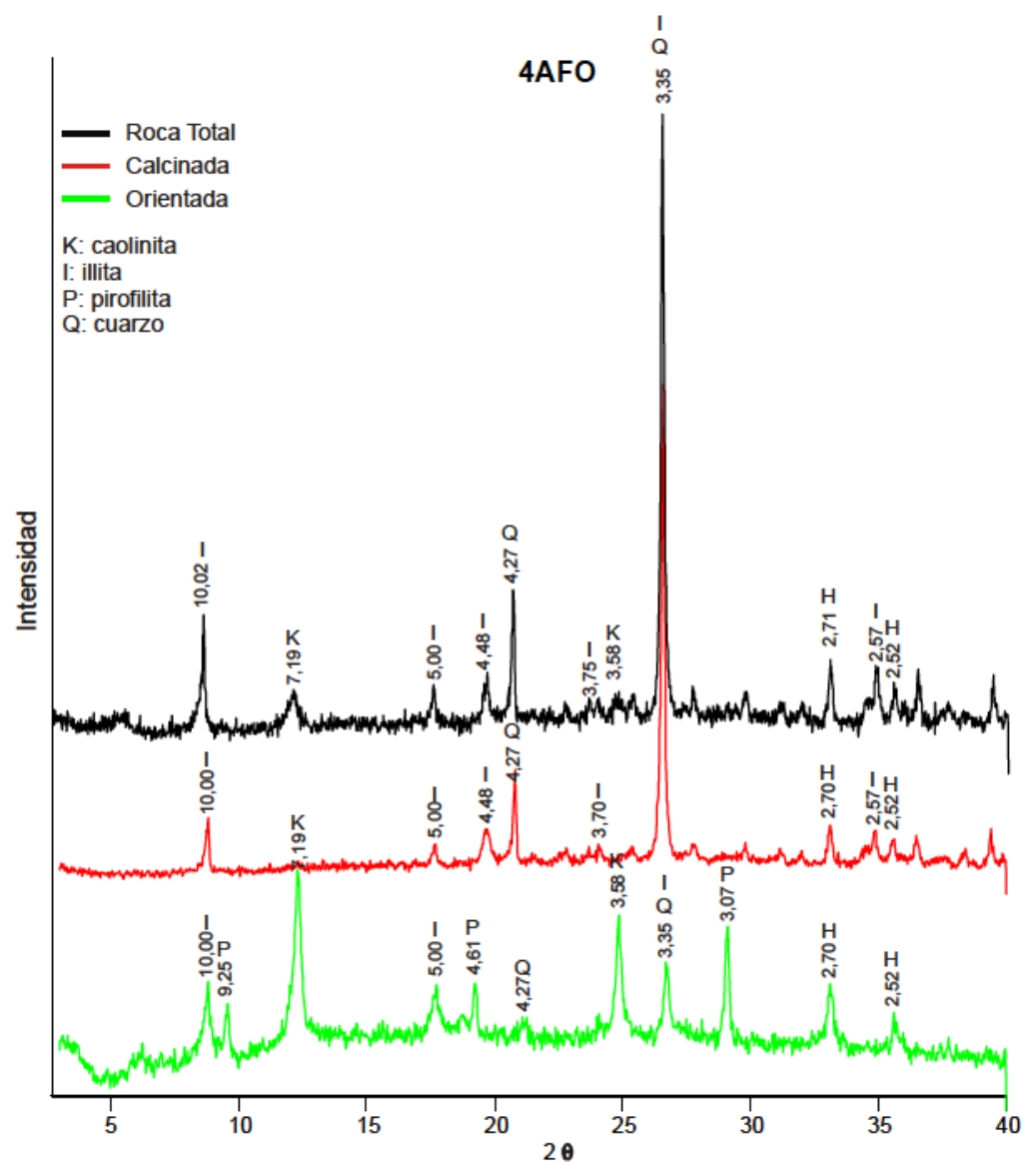

Figura 6.4. Diagrama DRX de la muestra 4AFO.

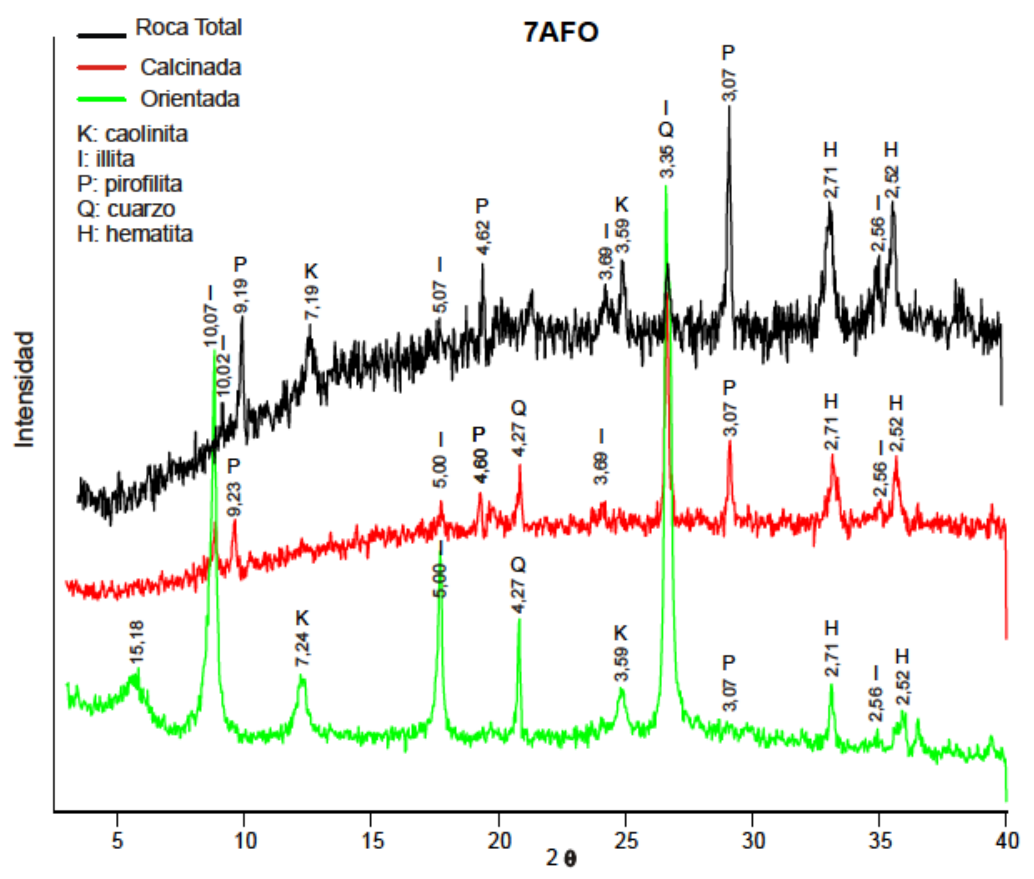

Figura 6.5. Diagrama DRX de la muestra 7AFO. 
En las Figuras 6.6 a 6.9 se muestran los difractogramas de las muestras $1 \mathrm{AFO}$, $3 \mathrm{AFO}, 5 \mathrm{AFO}$ y $6 \mathrm{AFO}$ respectivamente, presentando todos el mismo patrón. En el difractograma de roca total se observa la presencia de las especies arcillosas pirofilita

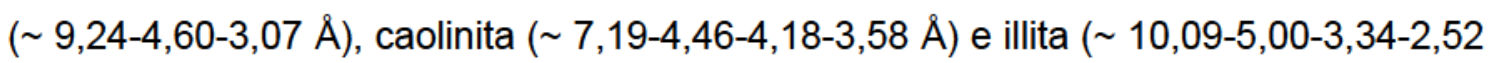
$\AA)$. La intensa reflexión en 2,70 se asigna a la presencia de hematita ( 2,70-2,52-3,68 $\AA$ ). En los difractogramas de la fracción arcilla orientada, se observan las reflexiones de filosilicatos tipo 2:1 y 1:1 (illita, pirofilita y caolinita). Los diagramas presentan también las reflexiones correspondientes a la fase hematita $\alpha \mathrm{Fe}_{2} \mathrm{O}_{3}$.

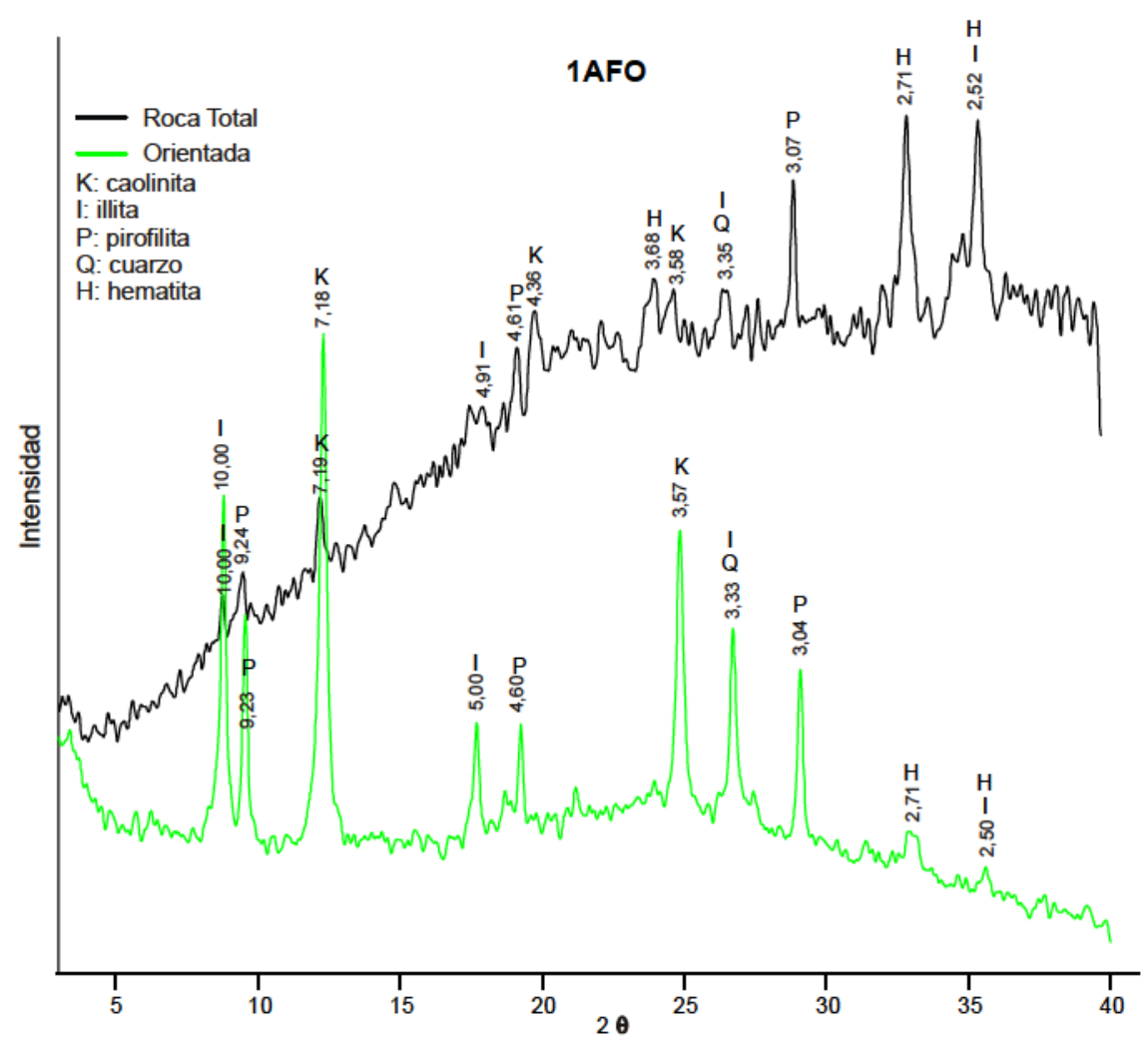

Figura 6.6. Diagrama DRX de la muestra $1 \mathrm{AFO}$.

Es interesante el comportamiento de la arcilla 2AFO mostrado en la Figura 6.10. La muestra como roca total presenta las reflexiones típicas de los filosilicatos pirofilita, illita y caolinita. Asimismo se observan las intensas reflexiones de la hematita. Por otra parte se asigna la reflexión en $4,19 \AA$ a la especie goethita. Resulta importante recalcar que el diagrama de la fracción arcilla revela la presencia de los filosilicatos mencionados y además la de las fases de hierro oxidicas goethita y hematita, las que se presentan como agudas e intensas señales. Este comportamiento puede atribuirse a la presencia de microcristales de ambas fases, que por su tamaño no han podido separarse de las partículas de la fracción arcilla. El diagrama de DRX de la muestra calcinada indica la presencia de filosilicatos $2: 1$ y hematita como fases mayoritarias, sin apreciarse la señal de la goethita que, debido al tratamiento térmico ha 
transformado en hematita. A dicha temperatura también la caolinita se ha transformado a metacaolín (amorfo a los rayos $\mathrm{X}$ ).

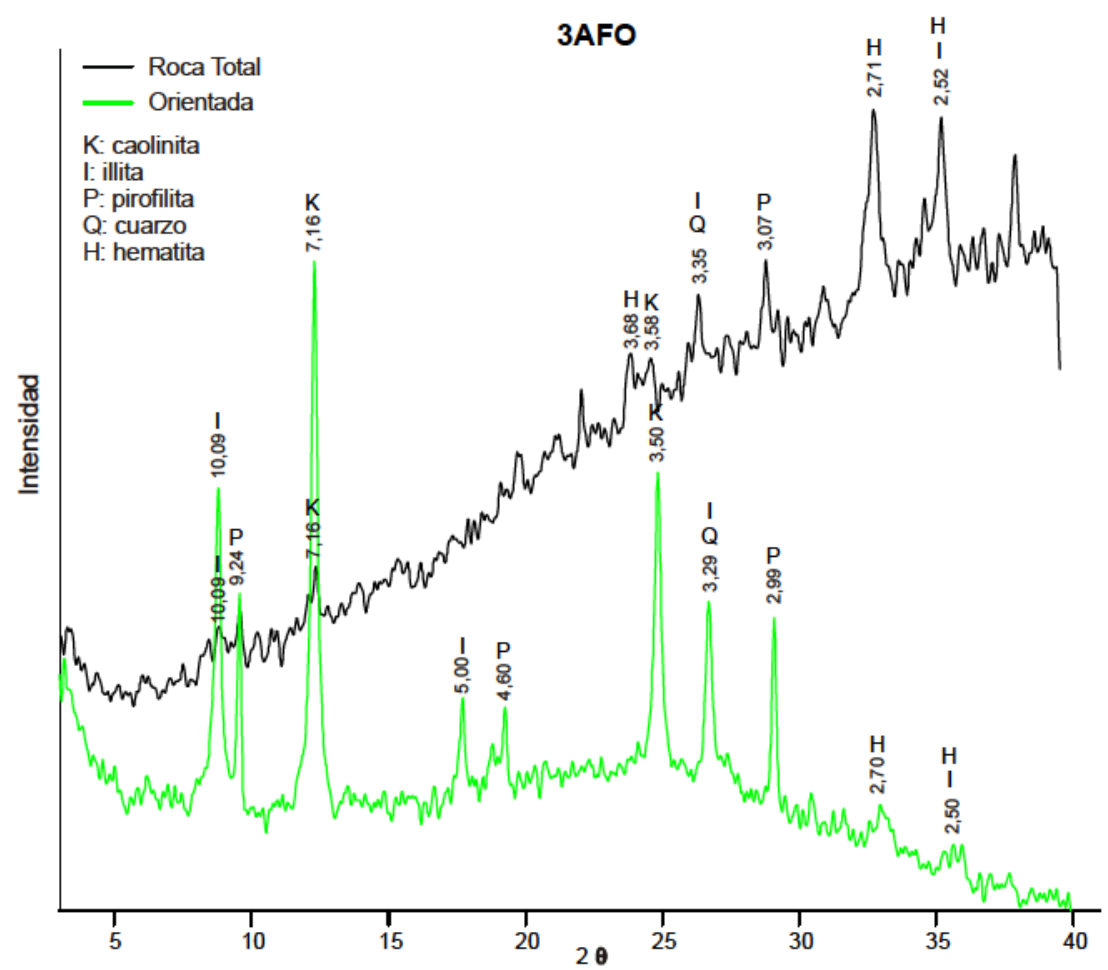

Figura 6.7. Diagrama DRX de la muestra 3AFO.

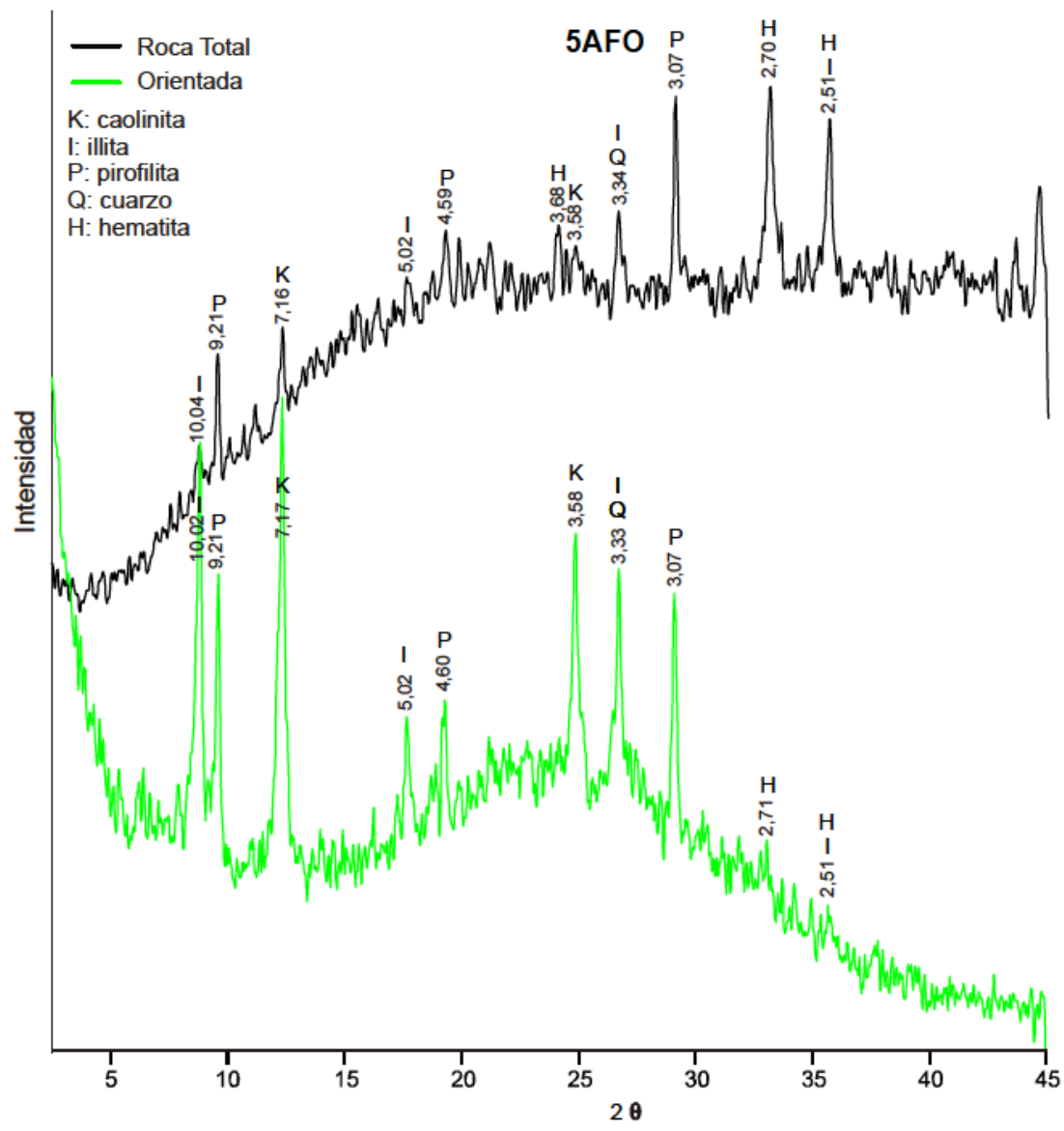

Figura 6.8. Diagrama DRX de la muestra 5AFO. 


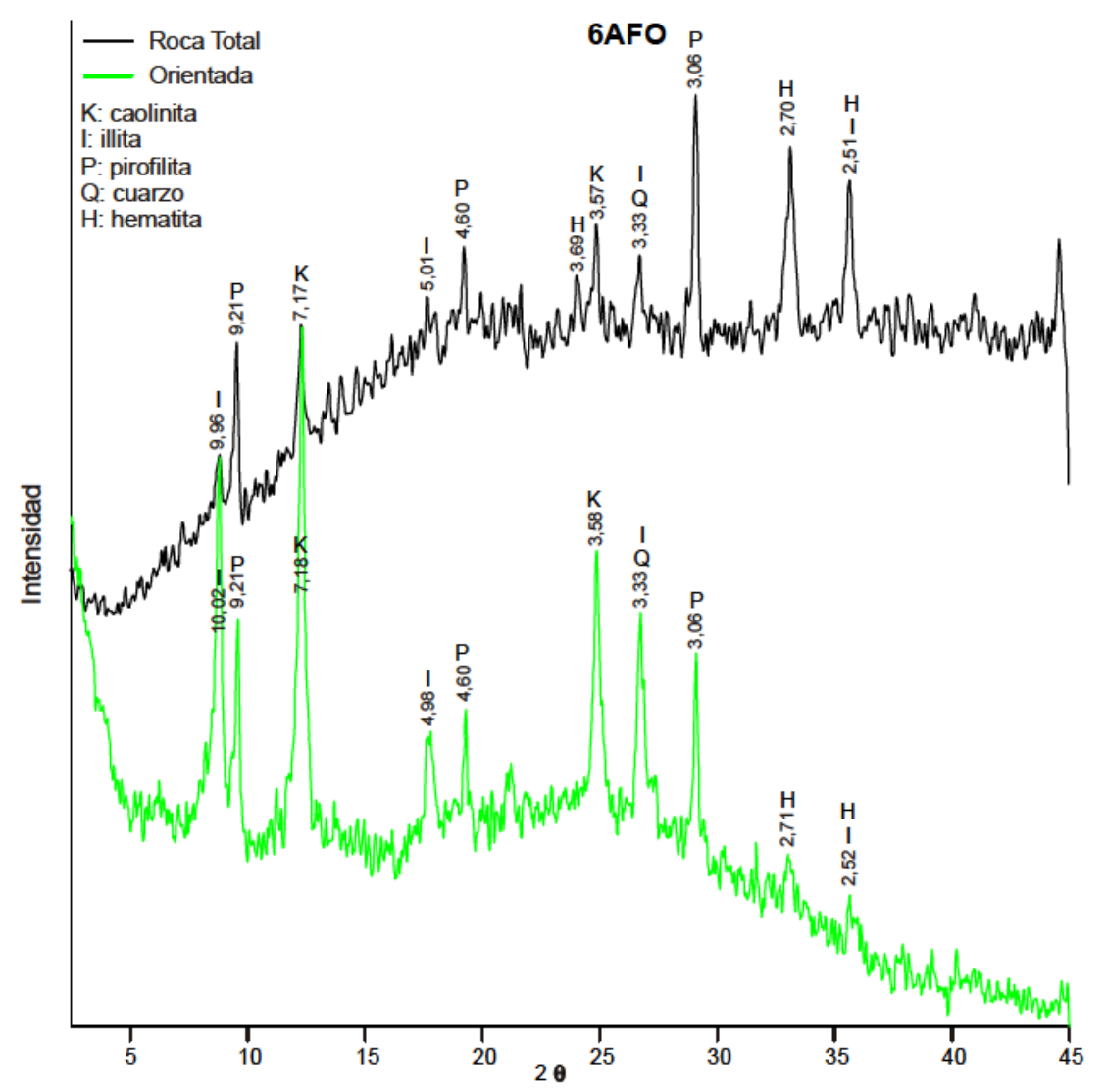

Figura 6.9. Diagrama DRX de la muestra 6AFO.

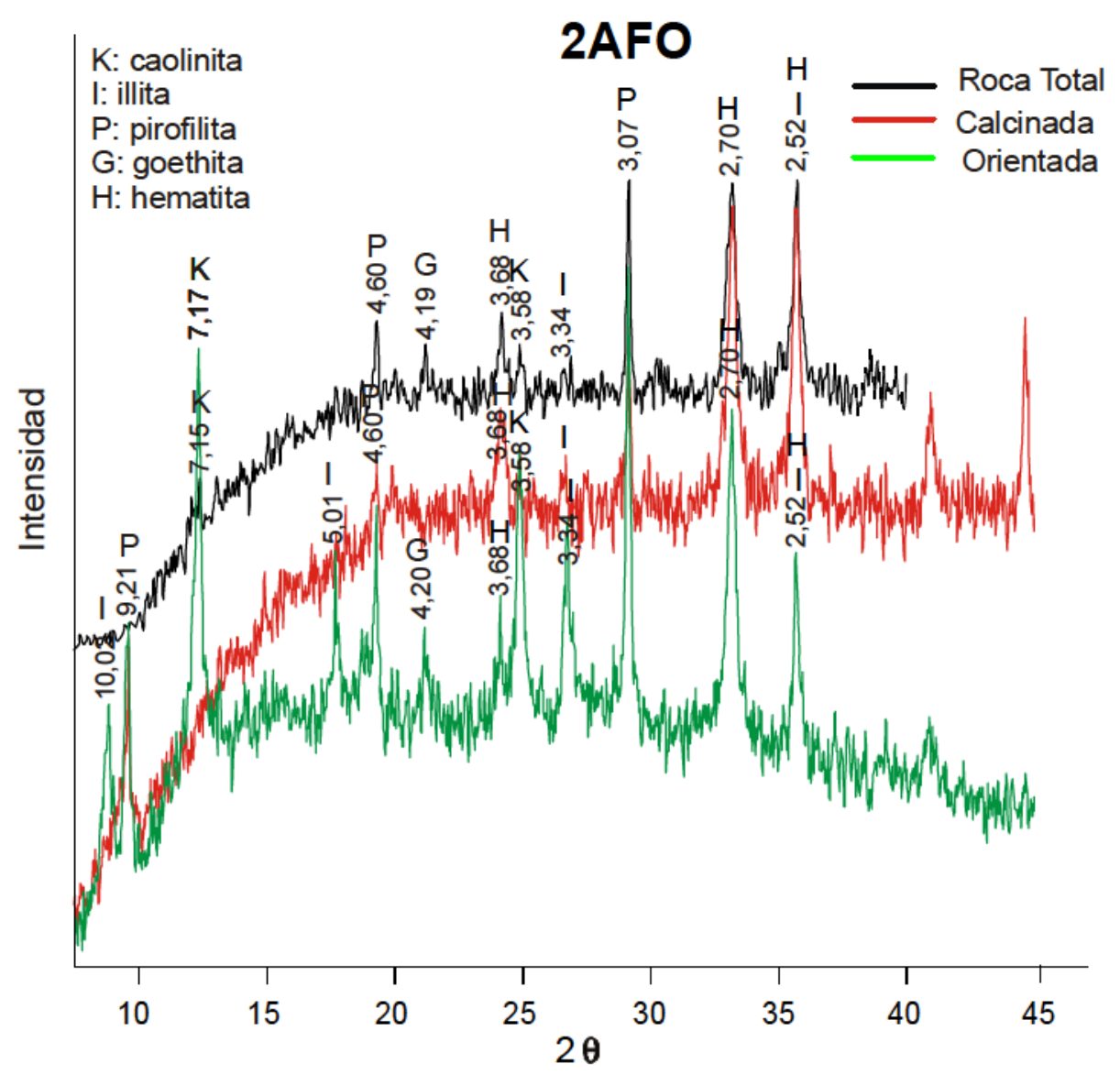

Figura 6.10. Diagrama DRX de la muestra 2AFO. 
En las Figuras 6.11 a 6.14 se muestran los difractogramas de las muestras obtenidas en la Zona 1 (8AFO a 11AFO). Todos los diagramas presentan un comportamiento similar, destacándose la presencia de goethita y hematita, resultando de muy baja intensidad las señales de los filosilicatos, particularmente en la última en la que el cuarzo parece ser la especie silícea que predomina, con la ausencia de líneas de especies laminares. Por otra parte, la fracción arcilla también revela la presencia de los óxidos de hierro en diferente proporción, aspectos que pueden relacionarse con la cristalinidad y tamaño de partícula de las especies. Por último cabe mencionar que todas las muestras presentan un elevado fondo, relacionado con el contenido de hierro y la posible presencia de una fracción de baja cristalinidad, sugiriendo que la transformación desde las fases amorfas o hidratadas (FeOOH) a la fase estable hematita no ha concluido. Es de destacar que estas muestras no guardan la relación esperada con el As, tal como se observó en la Figura 6.1.

Finalmente, en la Figura 6.15 se muestra el difractograma correspondiente a la muestra $12 \mathrm{AFO}$ de la Zona 2, la que presenta un comportamiento similar al observado en las muestras $1,3,5$ y 6 AFO.

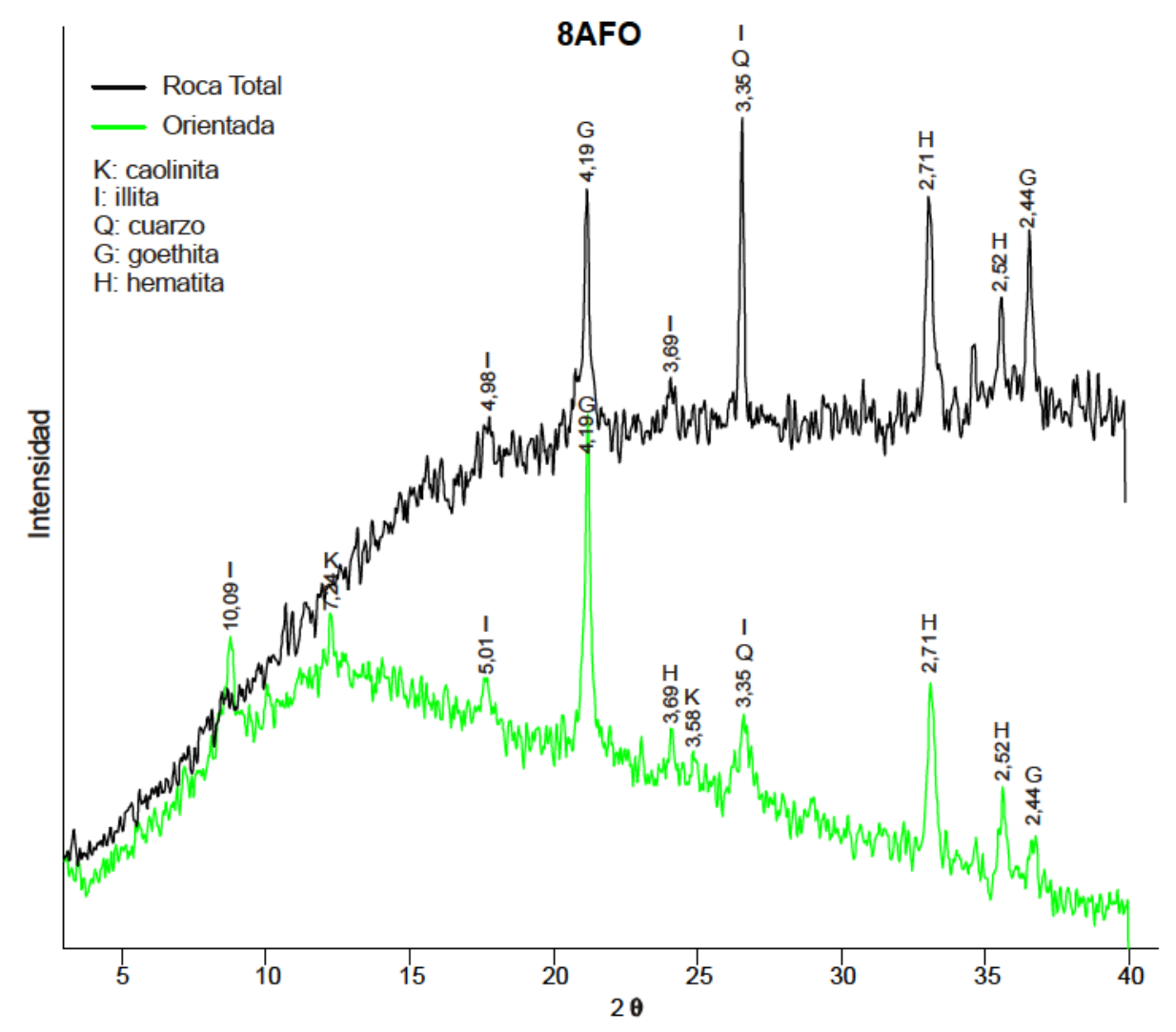

Figura 6.11. Diagrama DRX de la muestra 8AFO. 


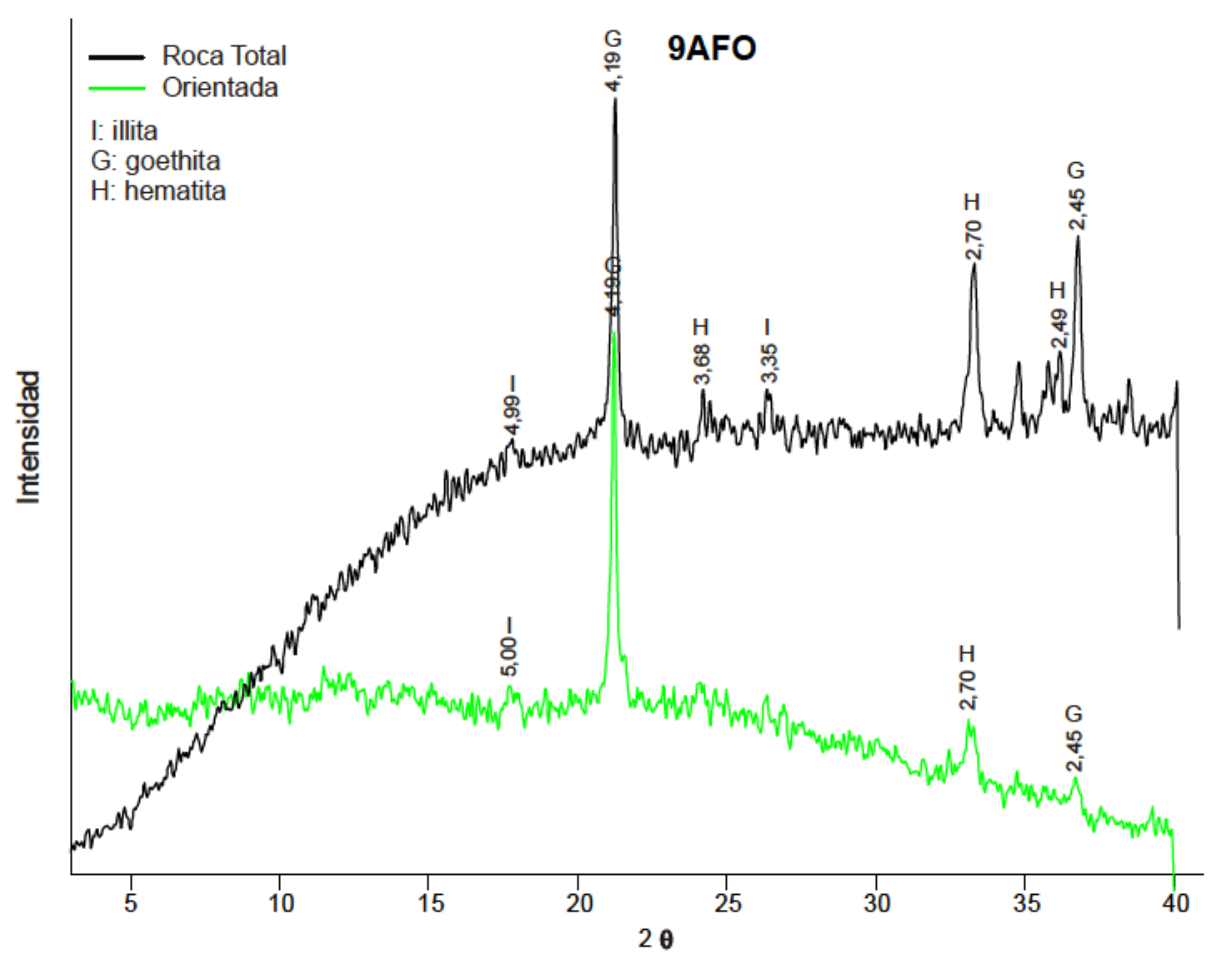

Figura 6.12. Diagrama DRX de la muestra 9AFO.

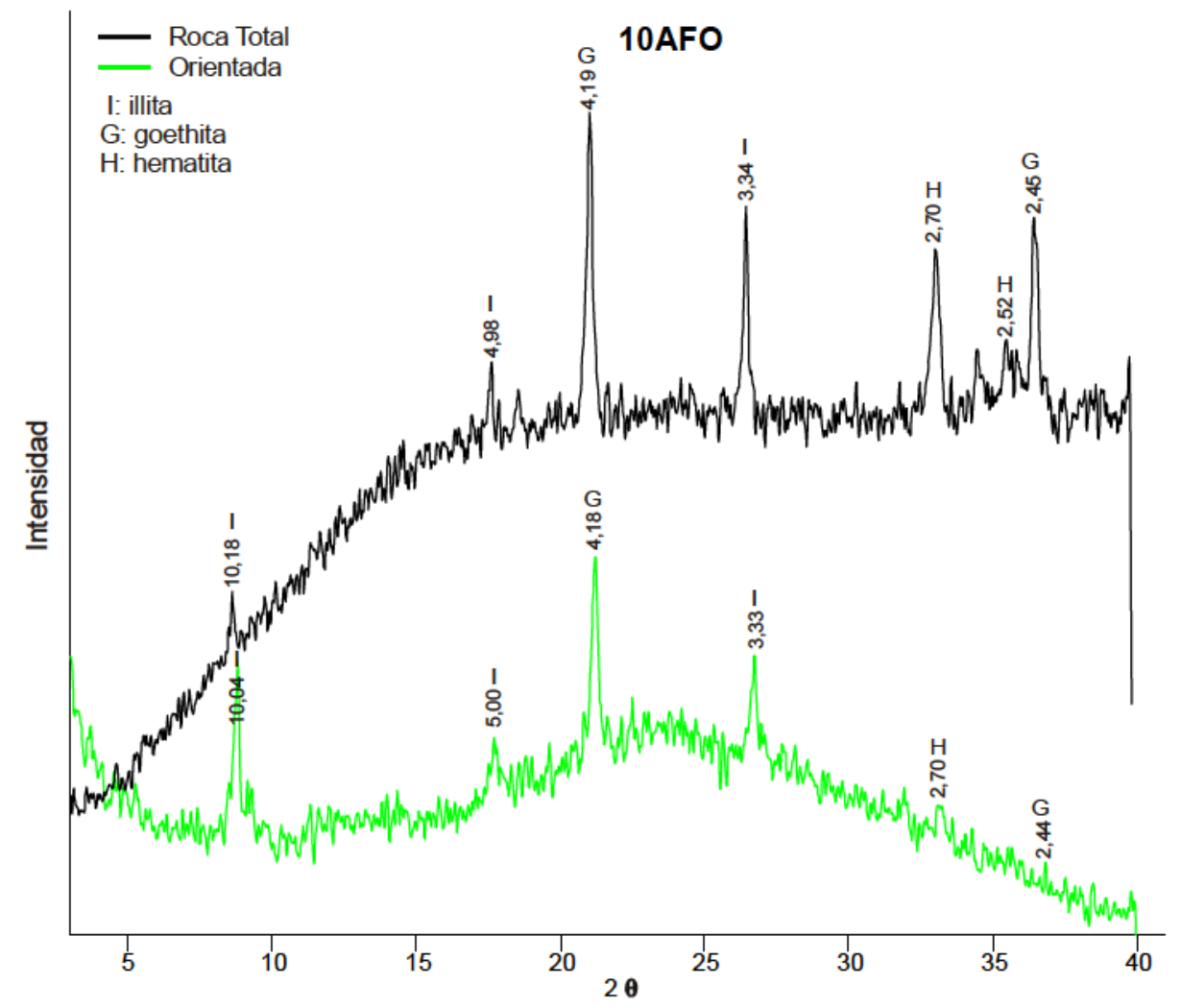

Figura 6.13. Diagrama DRX de la muestra 10AFO. 


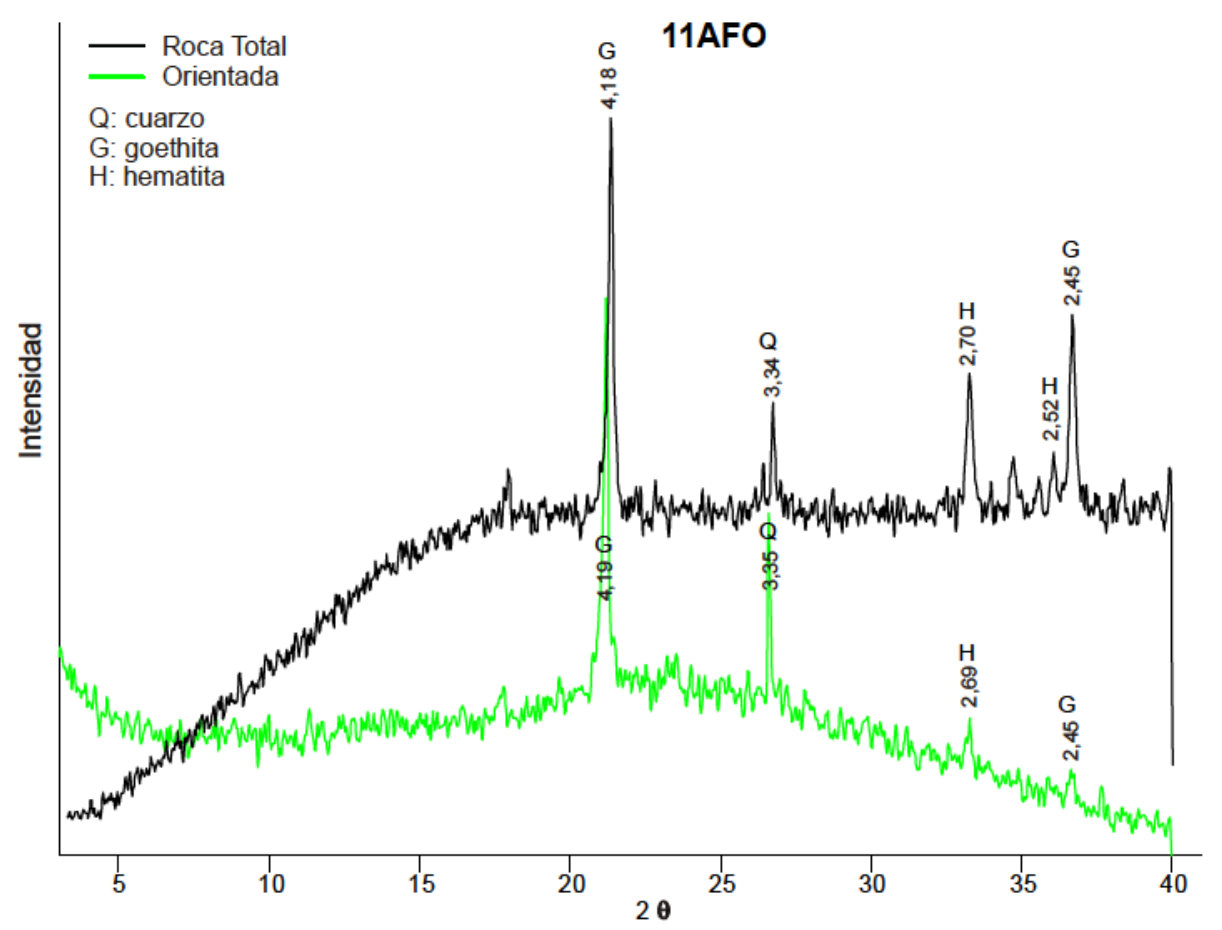

Figura 6.14. Diagrama DRX de la muestra 11AFO.

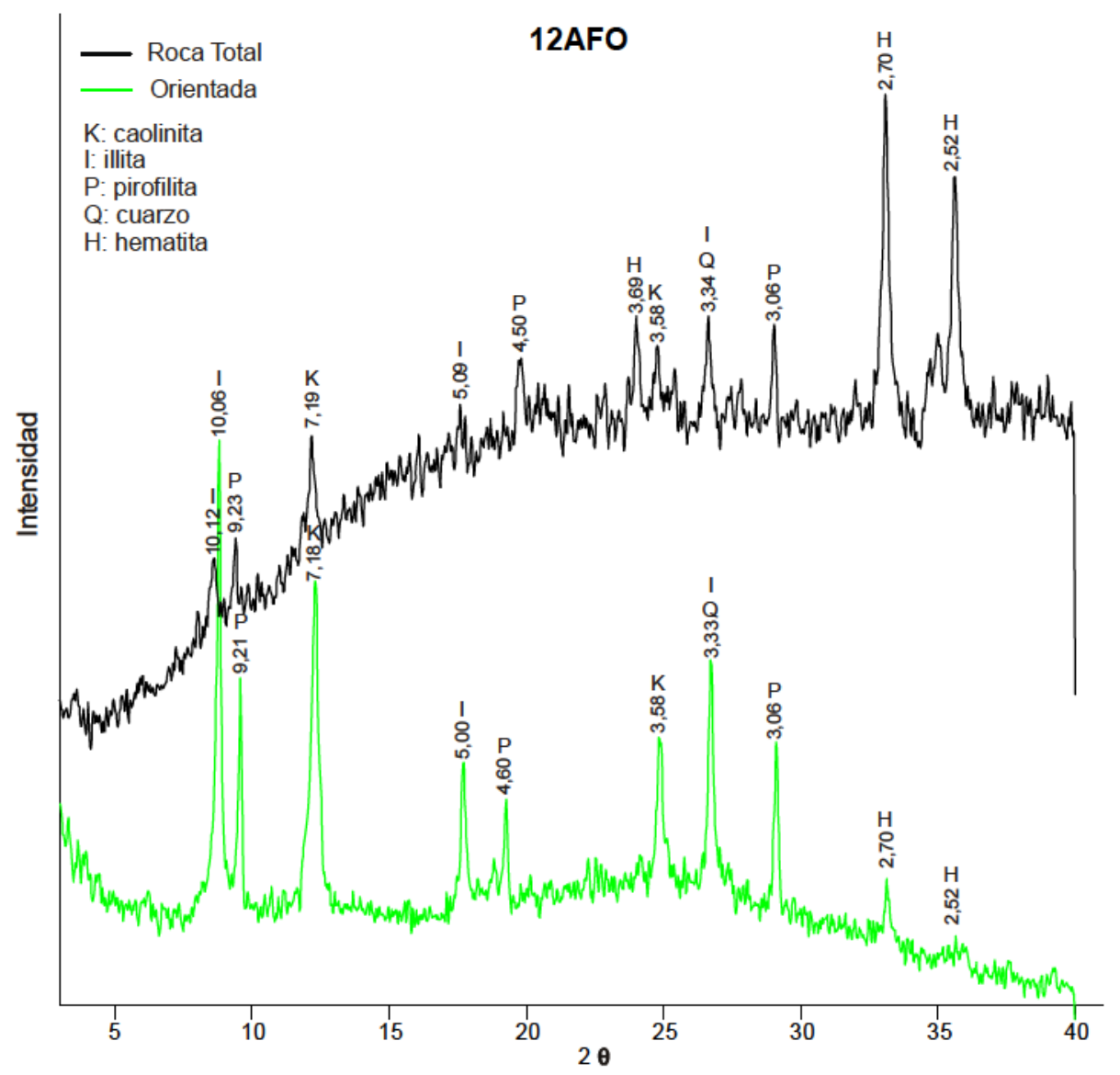

Figura 6.15. Diagrama DRX de la muestra 12AFO.

Para el estudio del material por microscopía electrónica se seleccionaron algunas muestras, procedentes de la Zona 3 y Zona 1. Las Figuras 6.16 a y b 
corresponden al material arcilloso 2AFO, indicando la morfología de la especie laminar (a) y la presencia de pequeñas esférulas (b), eventualmente asociadas al hierro.
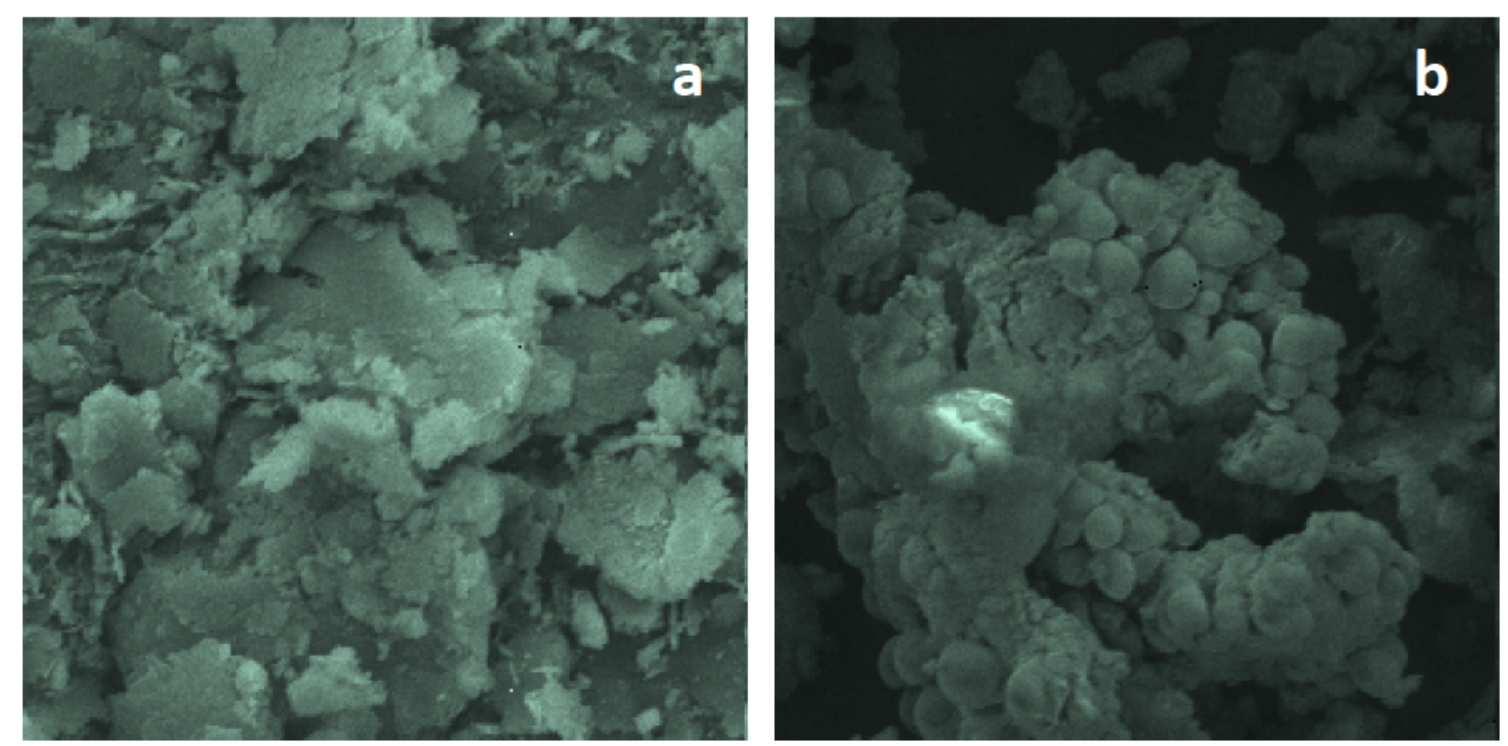

Figura 6.16. Micrografías de la muestra 2AFO. a) Fracción arcilla $\times 1000(63,75 \mu \mathrm{m})$. b) Detalle de las esférulas $x 1000(63,75 \mu \mathrm{m})$.

Este mismo comportamiento se observa en otras muestras con contenidos en hierro del mismo orden, indicando en las micrografías de la Figura 6.17 a y b el comportamiento observado para la muestra 6AFO.
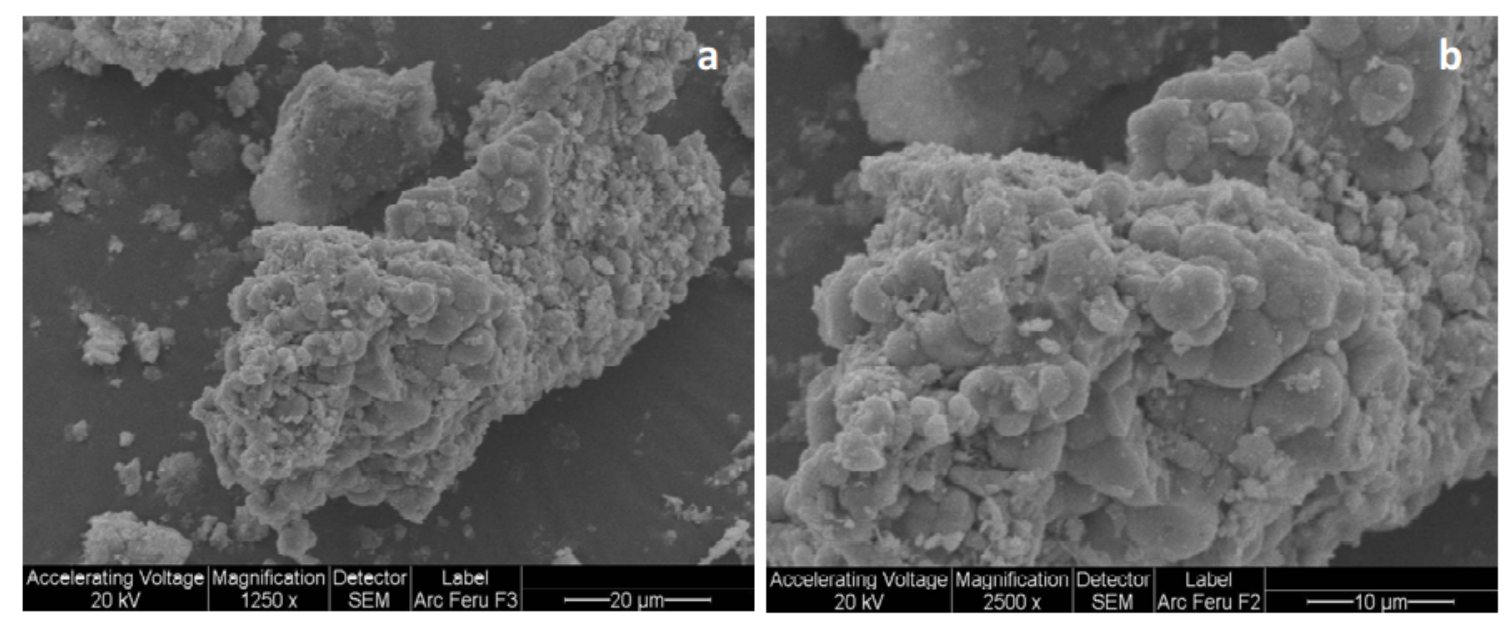

Figura 6.17. Detalle de las esférulas encontradas en la muestra 6AFO a distinta magnificación.

La Figura 6.18 corresponde al espectro EDS del material de la Figura 6.17.b, equivalente a un contenido en $\mathrm{Fe}_{2} \mathrm{O}_{3}$ del $78 \%$. La comparación con el dato químico másico $(50 \%)$ indica que la fase de hierro tapiza en forma relativamente uniforme la superficie de las partículas arcillosas. 


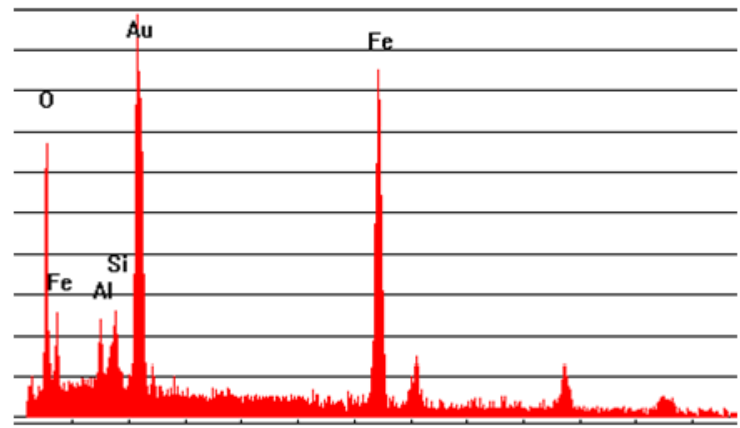

1.002 .003 .004 .005 .006 .007 .008 .009 .0010 .0611 .0012 .00

Figura 6.18. Espectro EDS correspondiente a la micrografía 6.15 b.

La Figura 6.19 corresponde a un detalle de la textura correspondiente a la consolidación de las especies de arcilla en la muestra 5AFO.

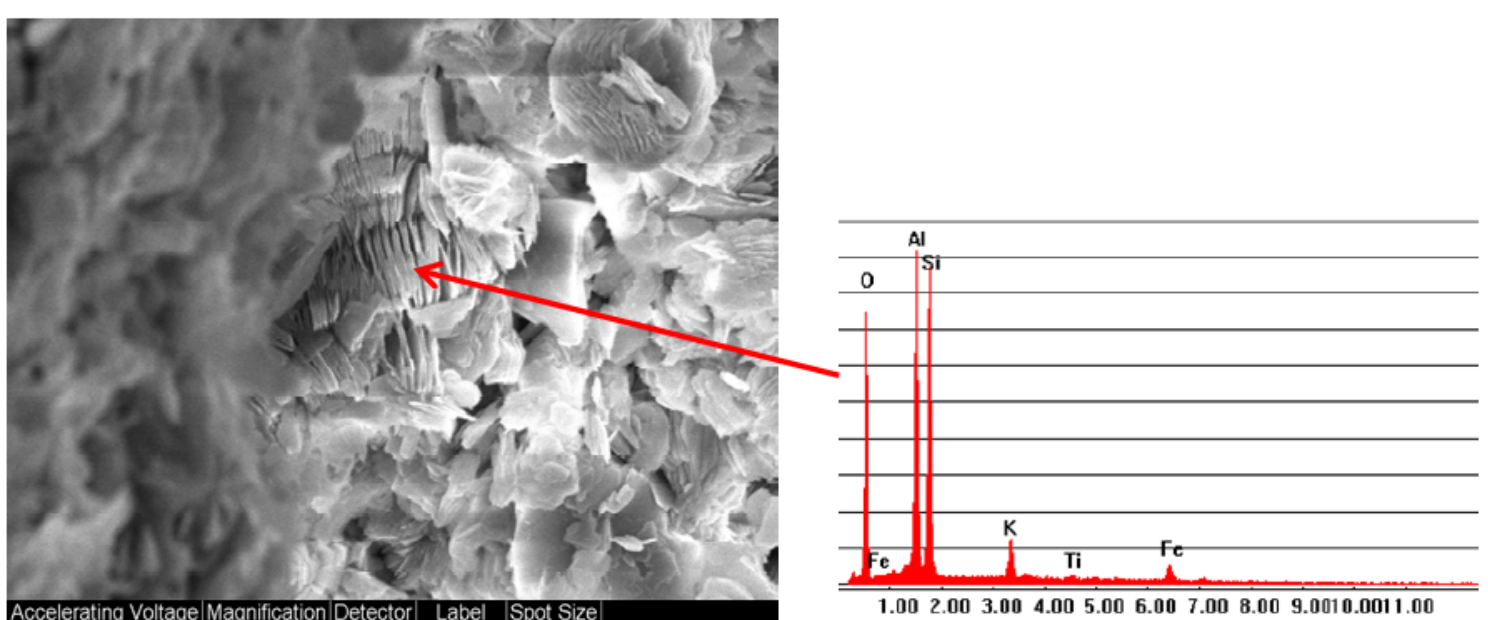

Figura 6.19. Detalle de textura de material rico en arcilla (muestra 5AFO).

Asimismo se han detectado cristales bien desarrollados asociados a la presencia de hematita, como se evidencia en la Figura 6.20.
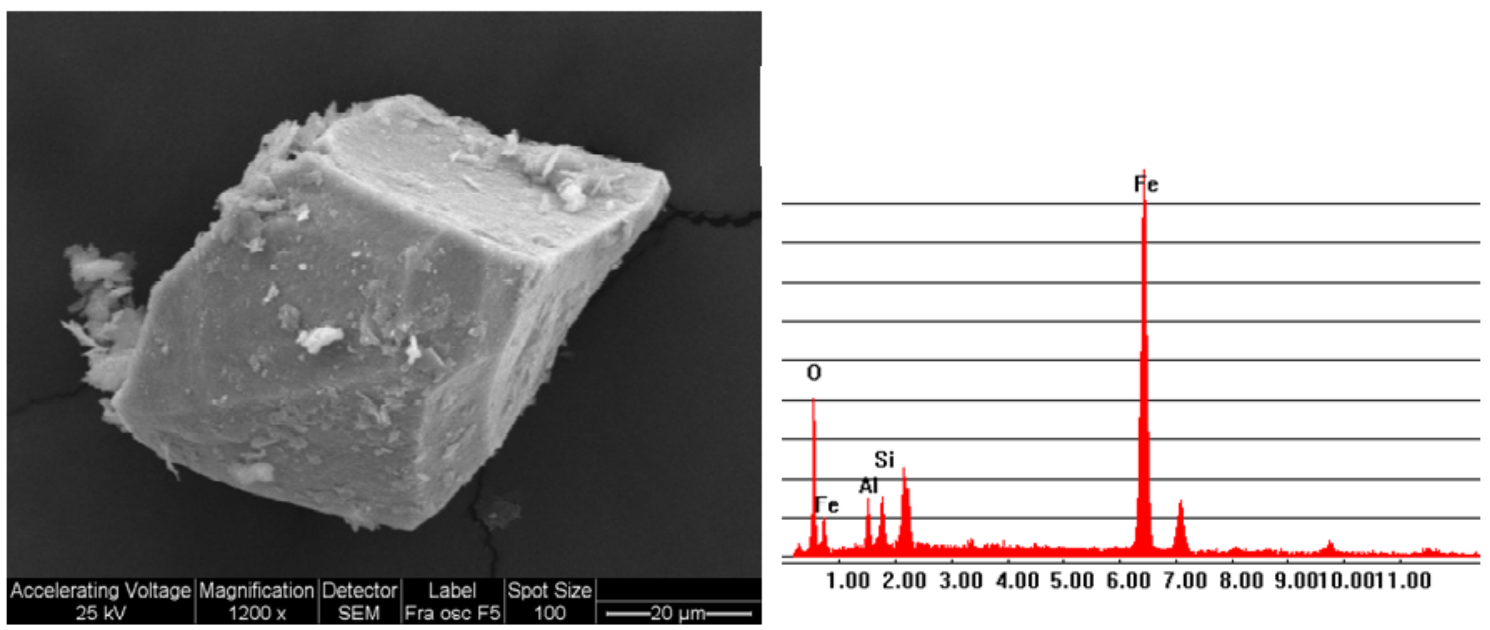

Figura 6.20. Fase cristalina incluida en la matriz de material 5AFO. 
Las Figuras 6.21 b, c, d y e muestran el mapeo de $\mathrm{Si}, \mathrm{Al}$, Fe y O correspondiente a la micrografía de la Figura 6.21.a del material 5AFO. Se observa una clara vinculación entre los elementos $\mathrm{Si}$ y $\mathrm{Al}$, en tanto que la presencia de hierro es más uniforme con una mayor dispersión sobre la superficie de la partícula.
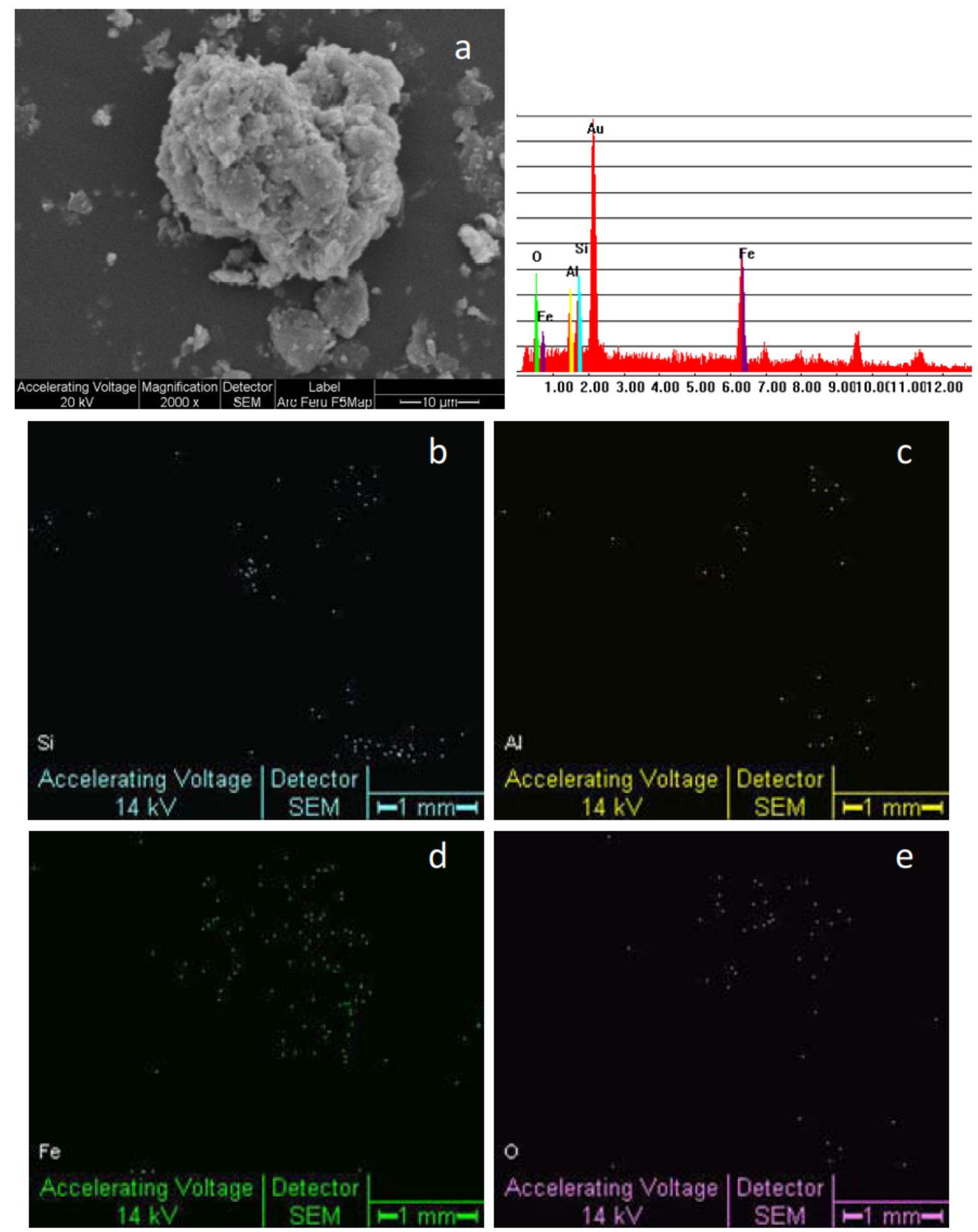

Figura 6.21. a) Micrografía y espectro SEM del material 5AFO. b) Mapeo para el elemento Si. c) Mapeo para el elemento Al. d) Mapeo para el elemento Fe. e) Mapeo para el elemento $\mathrm{O}$. 
En las figuras que se muestran a continuación (Figura 6.22 a y b) correspondientes a las muestras 4AFO y 7 AFO (de menor contenido en hierro) puede observarse más claramente la estructura laminar, sin la alteración del depósito de fases de hierro.
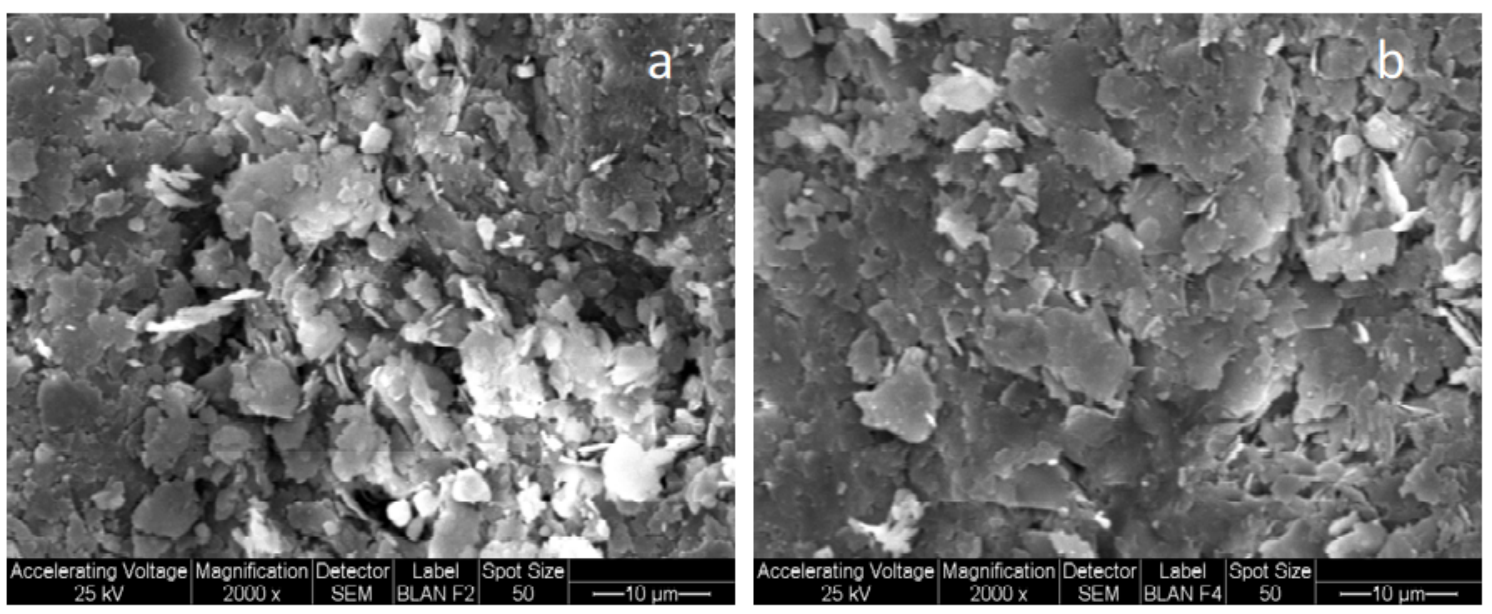

Figura 6.22. Micrografías correspondientes a las muestras 4AFO (a) y 7AFO (b).

En relación al material procedente de la Zona 1 la micrografía de la Figura 6.23 corresponde a la muestra 8AFO, en tanto que el análisis EDS incluido en la misma figura, pone en evidencia el elevado contenido de hierro superficial que, modifica la textura típica de los materiales laminares. El incremento en superficie del contenido de hierro (mostrado en la Tabla 6.4) respecto al análisis másico no afecta marcadamente la relación $\mathrm{SiO}_{2} / \mathrm{Al}_{2} \mathrm{O}_{3}$ que se mantiene en el orden de 2. Resulta evidente que el material arcilloso forma conglomerados cementados por la presencia de fases de hierro.
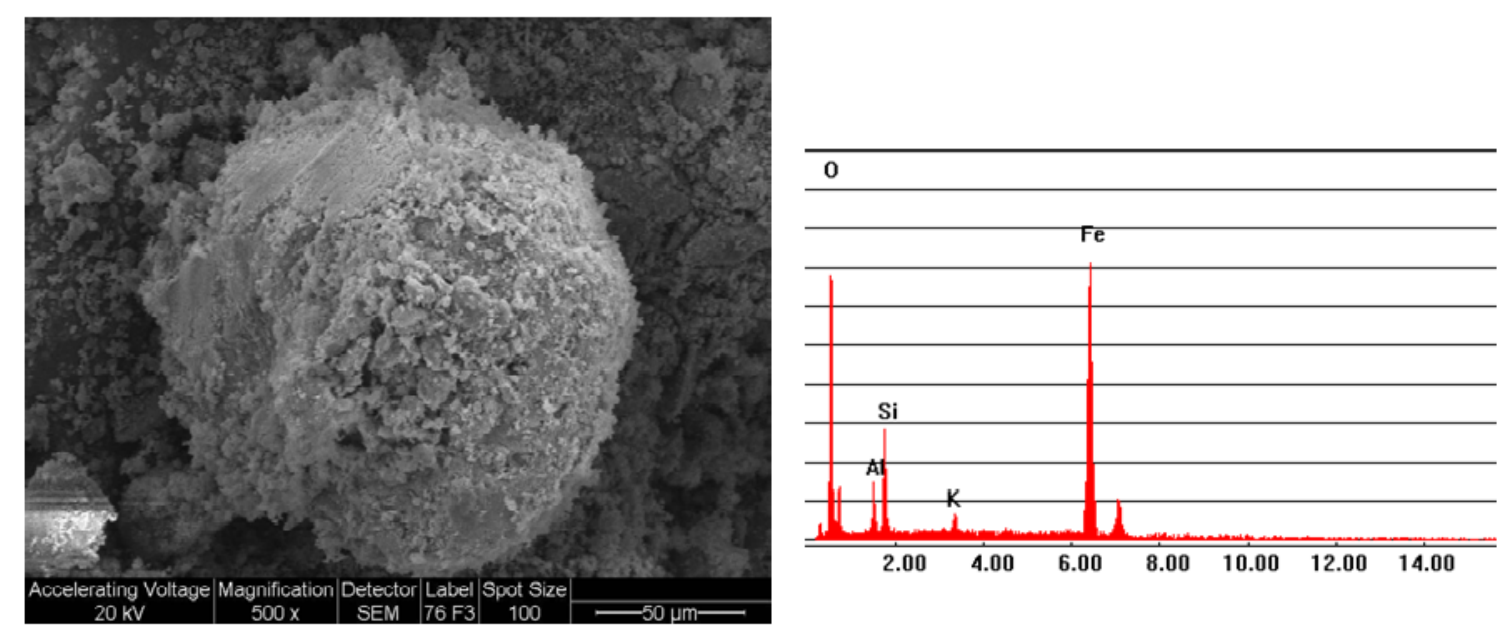

Figura 6.23. Micrografía SEM y análisis EDS del material 8AFO. 
Tabla 6.4. Análisis químico superficial por EDS correspondiente a las micrografías de las muestras procedentes de Zona 1.

\begin{tabular}{c|r|r|r|r}
\hline$\%$ Oxido & \multicolumn{1}{|c|}{8 AFO } & \multicolumn{1}{c|}{ 9AFO } & \multicolumn{1}{|c|}{$10 \mathrm{AFO}$} & $11 \mathrm{AFO}$ \\
\hline $\mathrm{Al}_{2} \mathrm{O}_{3}$ & 8,00 & 4,96 & 11,16 & 5,48 \\
$\mathrm{SiO}_{2}$ & 15,63 & 9,70 & 16,39 & 9,72 \\
$\mathrm{~K}_{2} \mathrm{O}$ & 1,63 & 0,48 & 1,63 & 1,01 \\
$\mathrm{Fe}_{2} \mathrm{O}_{3}$ & 74,74 & 84,86 & 70,82 & 83,79 \\
\hline
\end{tabular}

La Figura 6.24 corresponde a la muestra denominada 9AFO incluyendo el espectro EDS. Los valores de hierro promedio son de $84,86 \%$ (Tabla 6.4). Es evidente que las partículas arcillosas se encuentran totalmente cubiertas por la/s fase/s de hierro, mostrando una pequeña diferencia entre los contenidos másicos y de superficie. La distribución resulta homogénea y un detalle a mayor magnificación se observa en la Figura 6.25. Resulta clara la presencia de un material poroso rico en hierro que, de acuerdo a los datos químicos puede asociarse a la totalidad de los conglomerados en los que las fases de hierro juegan un rol aglutinante.
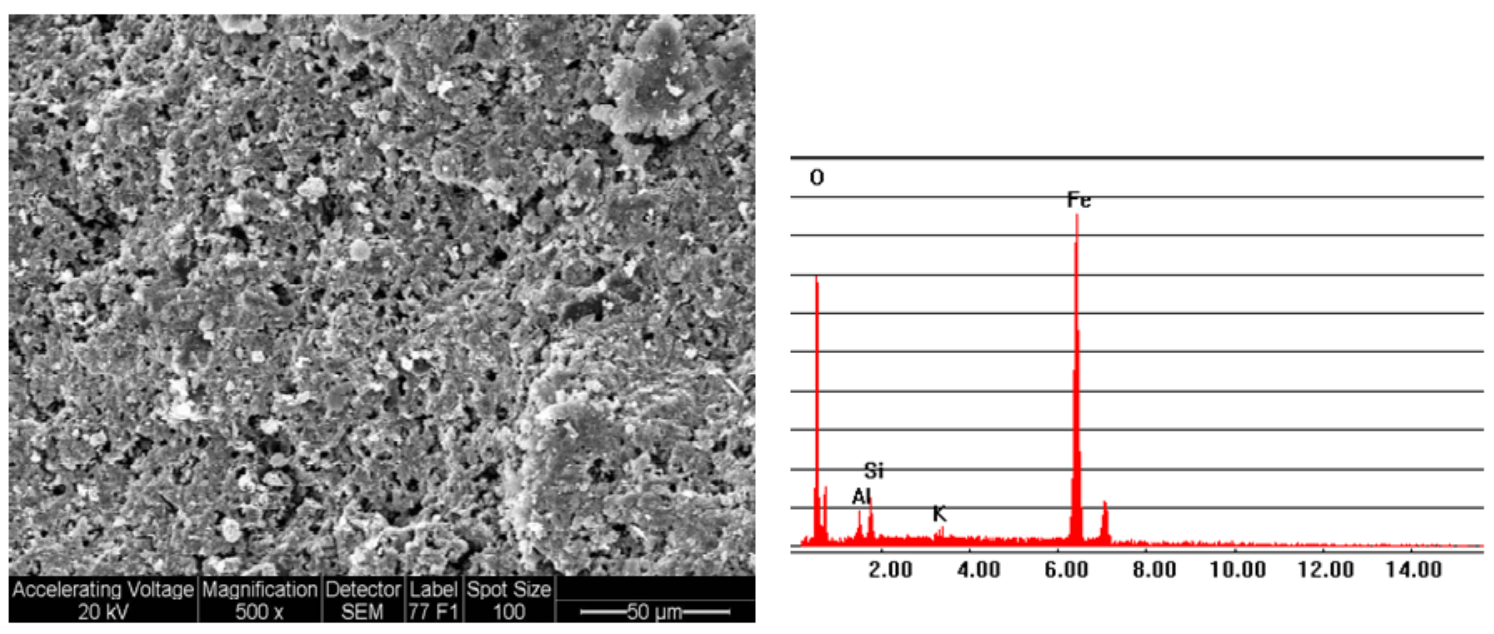

Figura 6.24. Micrografía SEM y análisis EDS del material 9AFO.

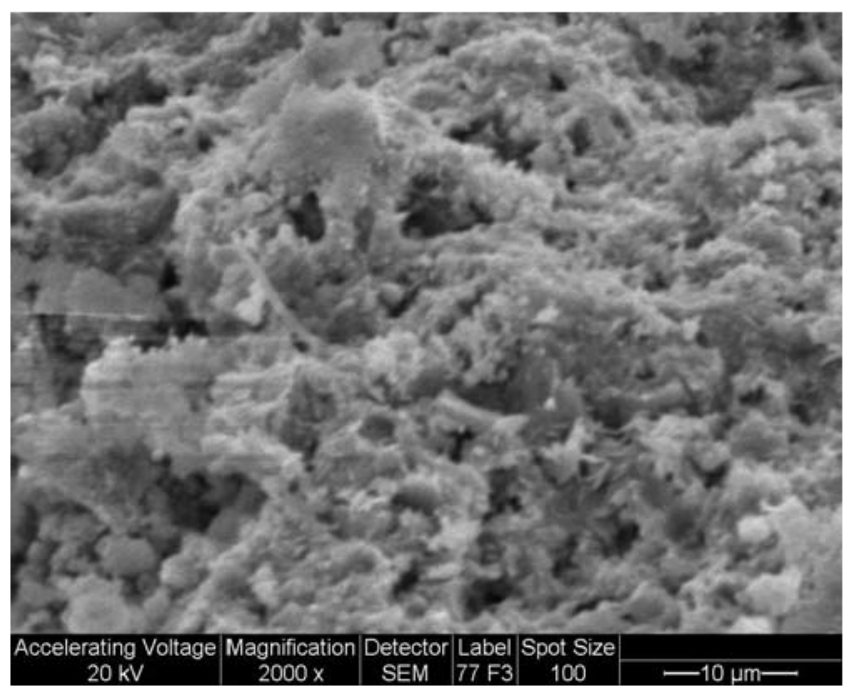

Figura 6.25. Detalle de la muestra 9AFO. 
La Figura 6.26 correspondiente a la muestra 10AFO presenta un comportamiento similar a la $8 \mathrm{AFO}$, con valores de hierro del orden del $70 \%$ como se indica en la Tabla 6.4. Sin embargo, se observa una menor tendencia a la formación de conglomerados.

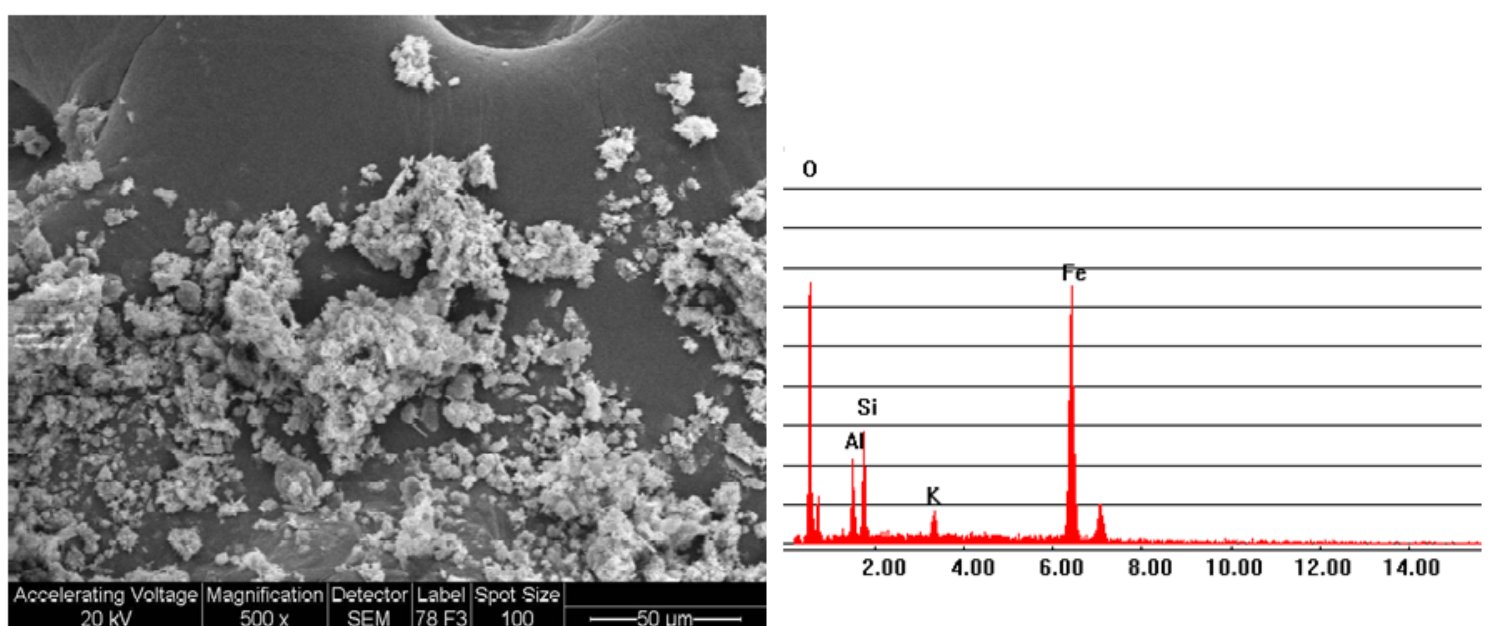

Figura 6.26. Micrografía SEM y análisis EDS del material 10AFO.

Finalmente, la Figura 6.27 muestra una micrografía del material $11 \mathrm{AFO}$ con un valor másico de hierro del $76,30 \%$. Resulta el material con una mayor diferencia entre los contenidos de hierro superficiales (83,79\% Tabla 6.4) y másicos. Este dato podría correlacionarse con la presencia de un material rico en cuarzo, con escasa proporción de mineral de arcilla, por lo que la morfología difiere de los casos anteriores debido a la segregación de las especies de hierro, no afines a la depositación superficial, como ocurre en las partículas laminares. El hierro no alcanza a consolidar el material particulado, como en el caso de la muestra 9AFO. El análisis EDS corresponde a la partícula de mayor tamaño, la que puede asociarse a la presencia de mineral de arcilla.

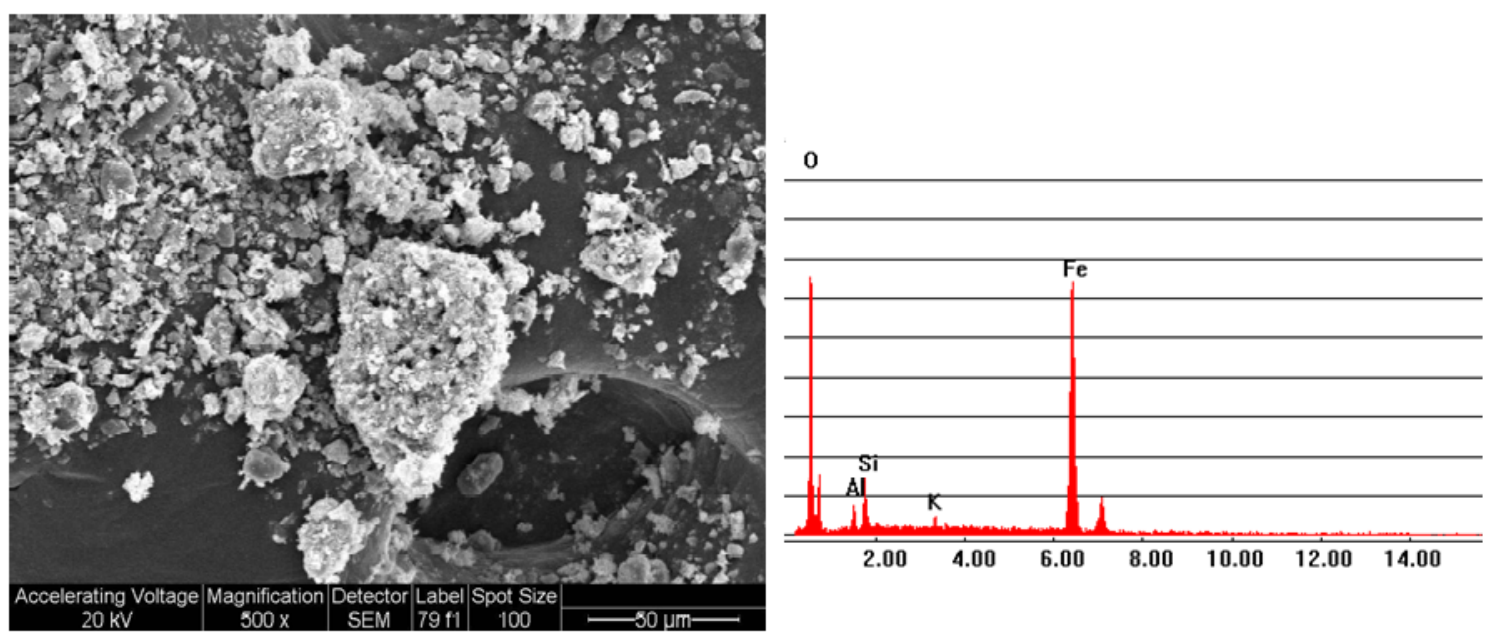

Figura 6.27. Micrografía SEM y análisis EDS del material 11AFO. 
Por último cabe mencionar que el material procedente de la Zona 2 presenta un comportamiento similar al observado en las muestras de la Zona 3, con contenidos EDS en óxido férrico que oscilan entre 45 y $50 \%$ y una morfología caracterizada por la presencia de conglomerados.

Conclusiones parciales: En el presente ítem se ha procedido a la caracterización de una serie de muestras de arcillas ferruginosas procedentes de diferentes canteras de la PBA. El análisis mineralógico, químico y por microscopía electrónica, contribuyó a la selección de un material de estudio para su aplicación en el desarrollo de un adsorbente para la remoción de As. En base a la presencia de aluminosilicatos como fase soporte de las especies de hierro activas en el proceso mencionado, se descartó el material procedente de la Zona 1, aun considerando su contenido en hierro. Por otra parte, teniendo en cuenta otros aspectos como los relacionados con la accesibilidad y potencialidad del depósito, se ha optado por profundizar el estudio del material procedente de la Zona 3, particularmente aquel cuyo contenido en óxido férrico sea del orden del $50 \%$.

\subsubsection{Aplicación de otras técnicas de caracterización fisicoquímica}

La Tabla 6.5 presenta los resultados de las determinaciones de la superficie específica $B E T$ ( $S_{B E T}$ ) y del tamaño promedio de poro (DPP) para las muestras seleccionadas en el ítem anterior. Las muestras presentan una $\mathrm{S}_{\mathrm{BET}}$ comprendida entre 10,91 y $12,40 \mathrm{~m}^{2} \mathrm{~g}^{-1}$. Es destacable que los poros promedio se encuentran localizados en el rango de los mesoporos según lo establecido por la IUPAC (20-500 A).

Tabla 6.5. Propiedades de superficie para las muestras seleccionadas: superficie específica BET expresada en $\mathrm{m}^{2} \mathrm{~g}^{-1} \mathrm{y}$ tamaño de poro promedio (DPP) expresado en $\AA$.

\begin{tabular}{c|r|r}
\hline Muestra & \multicolumn{1}{|c|}{$\mathrm{S}_{\mathrm{BET}}$} & \multicolumn{1}{c}{$\mathrm{DPP}$} \\
\hline 1AFO & 11,31 & 97,46 \\
2AFO & 10,91 & 92,72 \\
3AFO & 11,25 & 95,24 \\
5AFO & 12,40 & 89,47 \\
6AFO & 12,10 & 93,51 \\
\hline
\end{tabular}

La distribución de tamaño de poros fue calculada utilizando la teoría de la densidad funcional (DFT). Las cinco muestras seleccionadas presentaron un comportamiento similar, destacándose el alto contenido de poros en el rango de los mesoporos. En la Figura 6.28 se muestra, a modo de ejemplo, la distribución de tamaño de poro para las muestras denominadas 2AFO y $6 \mathrm{AFO}$. 

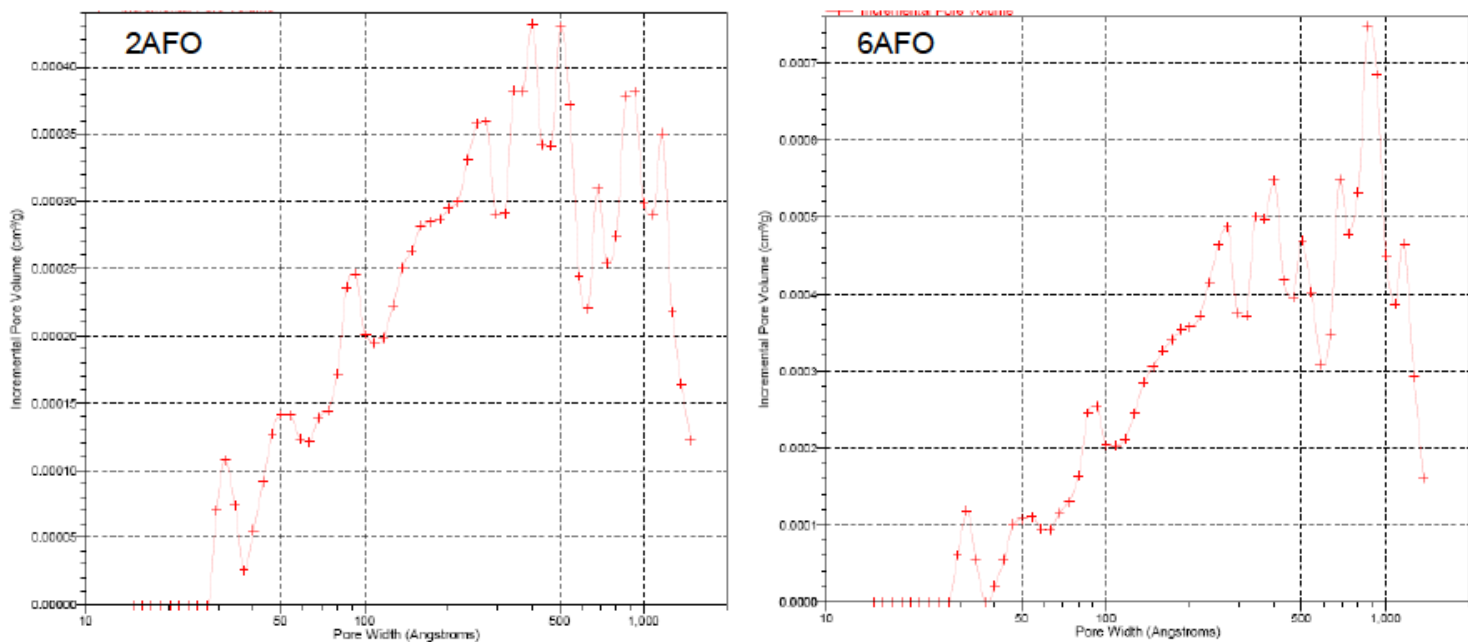

Figura 6.28. Distribución de tamaño de poros (DFT) para 2AFO y 6 AFO.

La técnica de espectroscopia FTIR brinda información respecto a la estructura molecular de las unidades $\mathrm{TO}_{4}$ en la estructura laminar que prevalece en la mezcla de mineral de arcilla. Todos los materiales estudiados presentaron un comportamiento similar.

Las Figuras 6.29 y 6.30 muestran los espectros FTIR entre 1200 y $400 \mathrm{~cm}^{-1}$ de la muestra denominada $2 \mathrm{AFO}$ original y tratada térmicamente a $600{ }^{\circ} \mathrm{C}$, respectivamente. Se observa una variación de la forma de las bandas en la zona de $1000 \mathrm{~cm}^{-1}$ (región de los estiramientos antisimétricos T-O de los grupos $\mathrm{TO}_{4}, \mathrm{~T}=\mathrm{Si}, \mathrm{Al}$ ), con un ligero corrimiento de las mismas hacia mayores frecuencias. Básicamente el desplazamiento puede atribuirse a la ruptura de los enlaces por puente de hidrógeno con un refuerzo del enlace T-O. Asimismo, la transformación caolinita $\rightarrow$ metacaolinita, con un efecto de amorfización del material, afecta la posición de la banda por lo que la misma resulta la envolvente de una serie de procesos superpuestos de los filosilicatos presentes (Farmer, 1974; Djomgoue and Njopwouo, 2013; Chukanov, 2014).

Resulta también interesante la modificación en la forma y posición de las bandas en la zona media y baja del espectro por efecto de la temperatura, con la desaparición de bandas débiles entre 600 y $900 \mathrm{~cm}^{-1}$ y el ensanchamiento de la banda centrada en $541 \mathrm{~cm}^{-1}$, definiendo más claramente las señales correspondientes al $\alpha \mathrm{Fe}_{2} \mathrm{O}_{3}\left(612 \mathrm{~cm}^{-}\right.$ 1 inflexión, $560 \mathrm{~cm}^{-1}$ fuerte, $470 \mathrm{~cm}^{-1}$ medio, Farmer, 1974). Estas bandas se encuentran superpuestas con las deformaciones angulares de los grupos $\mathrm{TO}_{4}$ corridas ligeramente hacia mayores frecuencias por el efecto térmico. Este efecto puede corroborar la presencia de goethita en la muestra original (señales en 796, 564, 468 y $432 \mathrm{~cm}^{-1}$ respectivamente, Chukanov, 2014), observada anteriormente por DRX. 


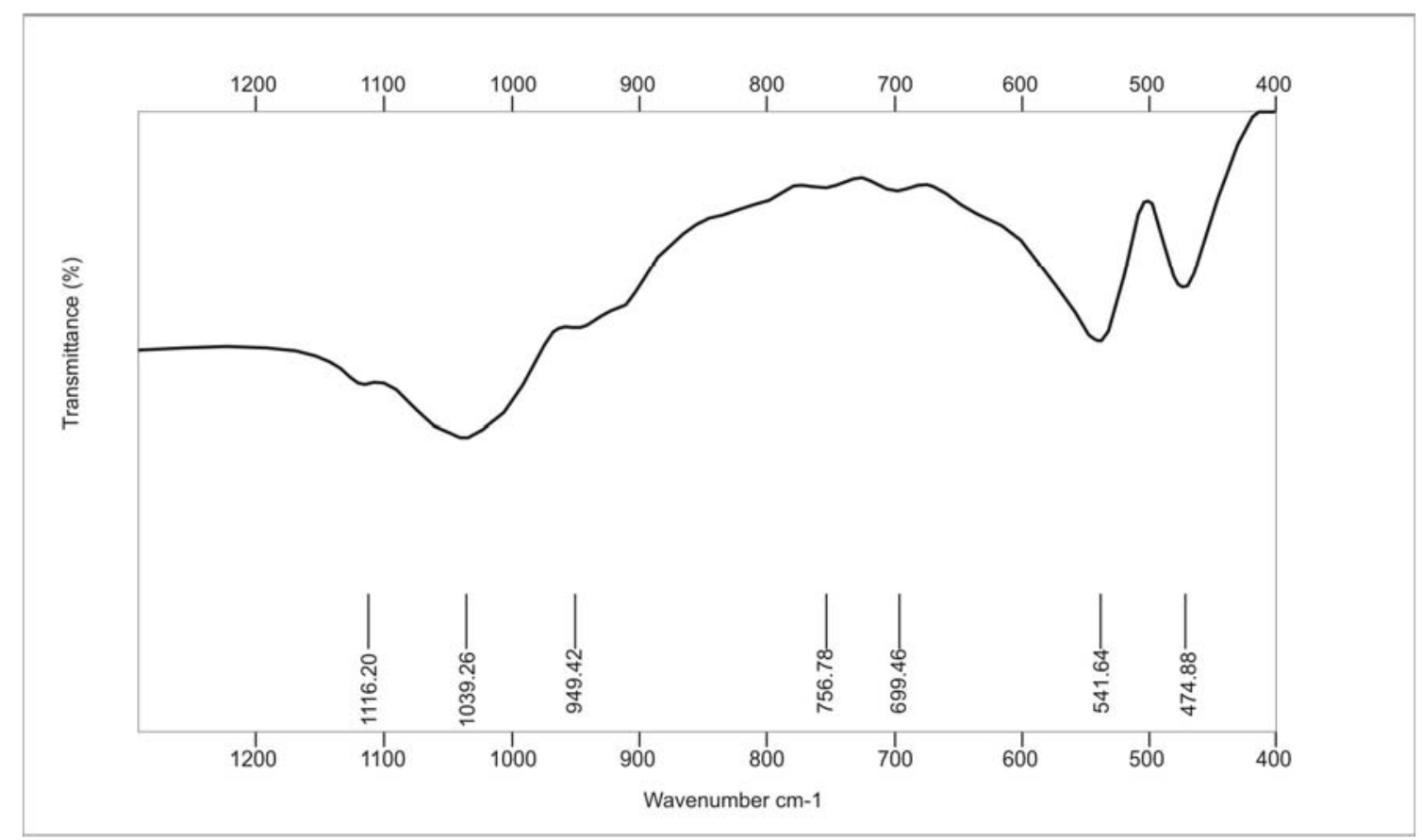

Figura 6.29. Espectro FTIR de la muestra 2AFO sin tratamiento térmico.

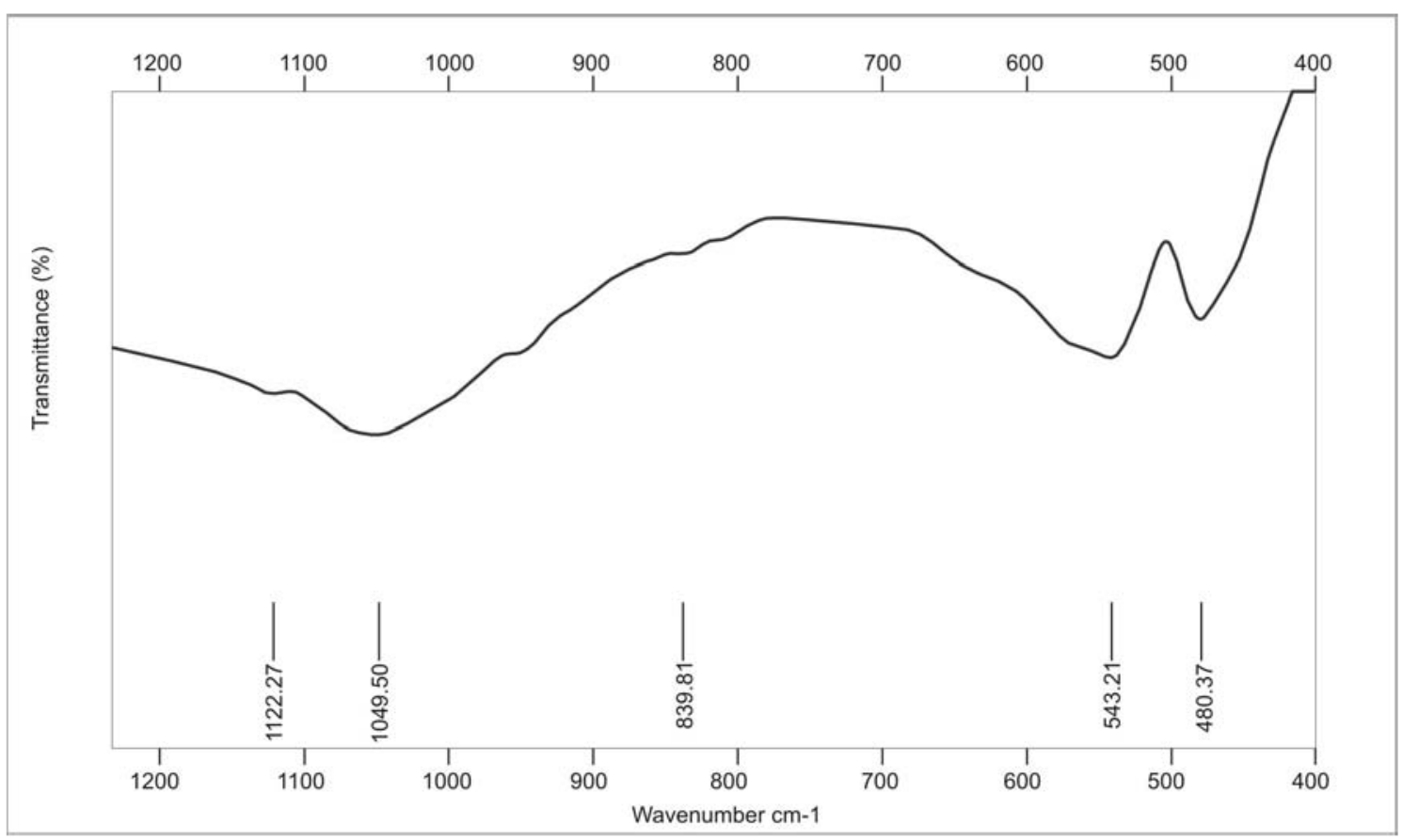

Figura 6.30. Espectro FTIR de la muestra 2AFO tratada térmicamente.

Por otra parte, el espectro Raman del material 5AFO de la Figura 6.31 revela la presencia de las fases arcillosas y férricas, teniendo en cuenta los patrones de referencia indicados en el Capítulo 5.

Las bandas localizadas en $225, \sim 300, \sim 412,500$ y $611 \mathrm{~cm}^{-1}$ coinciden con las reportadas para la hematita natural (Hanesch, 2009; Das and Hendry, 2011), si bien en este caso se debe contemplar el aporte de los silicatos particularmente en la zona 400$600 \mathrm{~cm}^{-1}$. La espectroscopia vibracional complementa la información obtenida por 
otras técnicas a partir de las cuales es posible determinar más concretamente la composición de la mezcla de mineral de arcilla. Como en el caso de la espectroscopia FTIR, los resultados de las restantes muestras revelan similitud en el comportamiento.

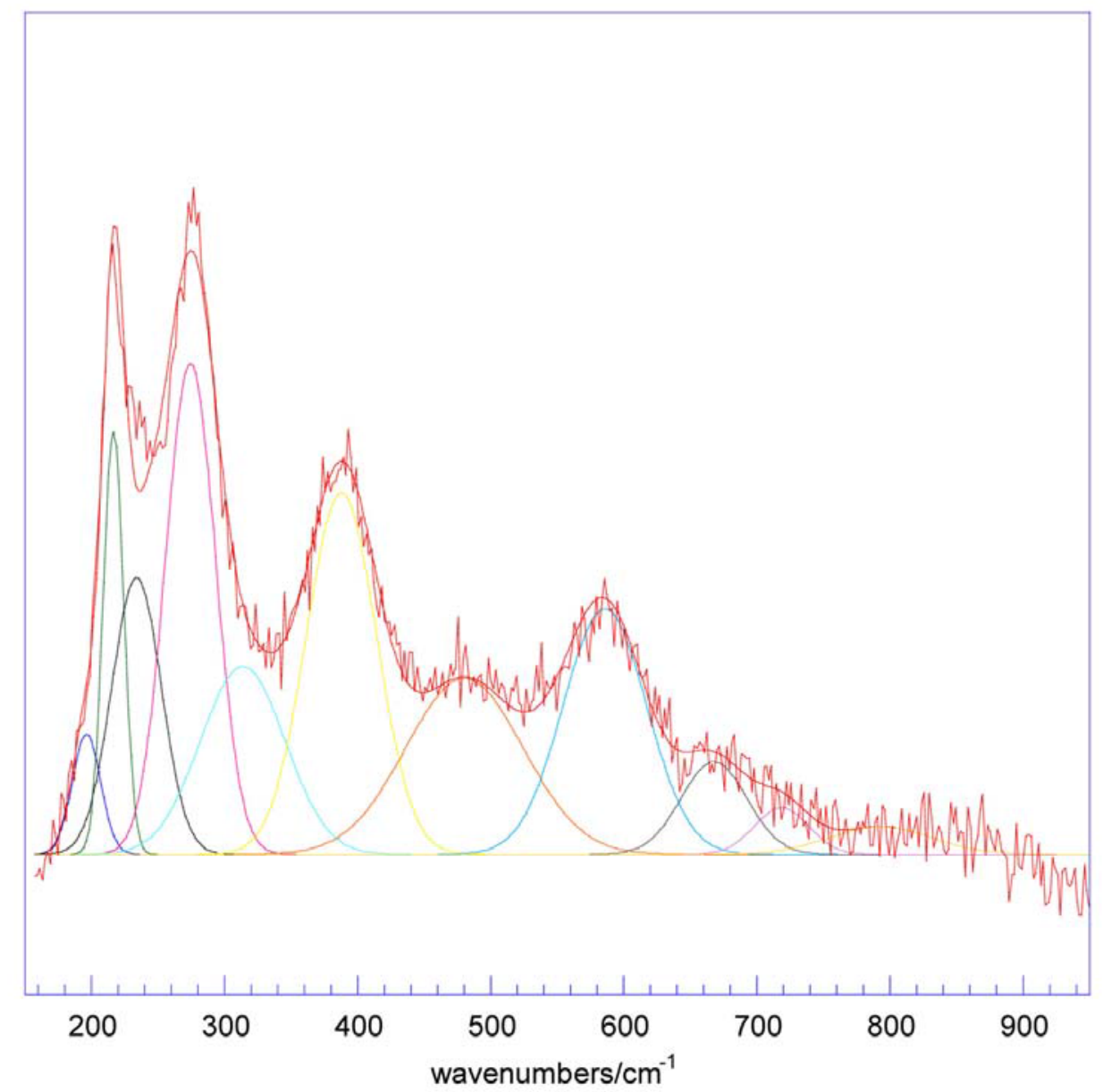

Figura 6.31. Espectro Raman para la muestra 5AFO.

Se realizaron estudios térmicos en ambiente oxidante e inerte en una termobalanza Shimadzu TGA-50 como se indicó en el Capítulo 5, realizando experiencias adicionales en mufla con control de temperatura. Dado que el comportamiento de las muestras resulta similar en base a una composición mineralógica compuesta por la presencia de pirofilita, caolinita, illita y eventualmente goethita, a modo de ejemplo se muestra en la Figura 6.32 el diagrama TG-DTG del material $6 \mathrm{AFO}$, que previamente fue secado en estufa a $60^{\circ} \mathrm{C}$. Se observan sucesivas pérdidas de peso, atribuidas a la eliminación de agua de cristalización de las fases de hierro y de las arcillas $\left(2,44 \%\right.$ hasta $\left.287^{\circ} \mathrm{C}\right)$ y de deshidroxilación (arcillas y oxi/hidróxidos, $3,45 \%, 500-600{ }^{\circ} \mathrm{C}$ ), con una pérdida de peso total de $6,10 \%$ a $900{ }^{\circ} \mathrm{C}$. Este resultado resulta concordante con el observado en la Tabla 6.1 (LOI=5,76). 


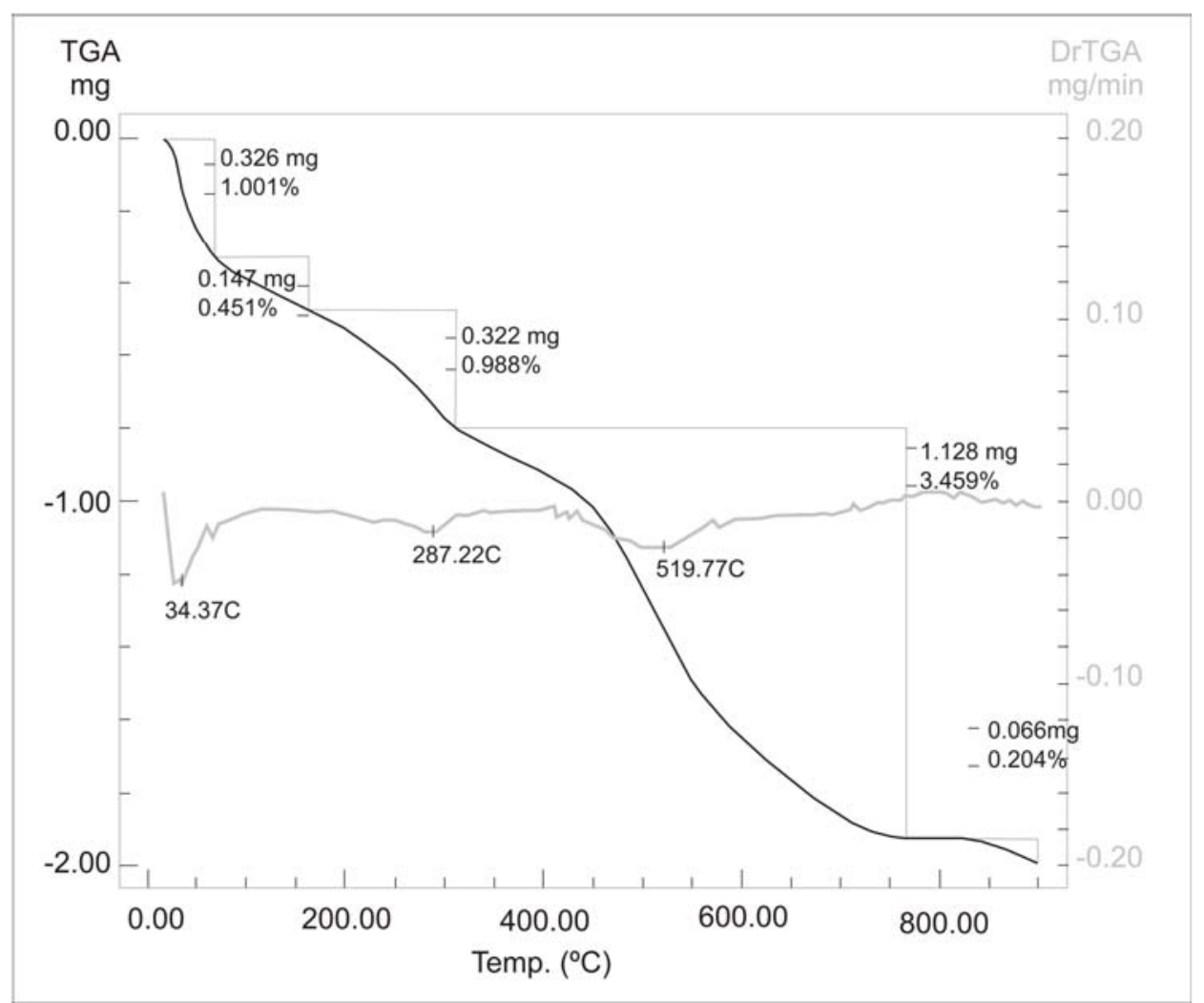

Figura 6.32. Diagrama TG-DTG de la muestra 6AFO.

La técnica de TPR resulta interesante para analizar la reducibilidad del hierro, elemento de transición que forma parte de la mezcla arcillosa como fase mayoritaria. En minerales de arcilla el hierro puede presentarse como $\mathrm{Fe}(\mathrm{III}) \circ \mathrm{Fe}(\mathrm{II})$, dependiendo de la especie estructural. El Fe(II) se puede observar sustituyendo al $\mathrm{Mg}$ (II) y $\mathrm{Mn}$ (II) en coordinación octaédrica, en tanto el $\mathrm{Fe}(\mathrm{III})$ es hallado en especies laminares dioctaédricas así como en la hematita y otras especies oxídicas relacionadas. En este sentido cabe recalcar que el hierro estructural en los aluminosilicatos puede ser observado por TPR sólo con posterioridad al colapso de la red.

El Fe(II) en aluminosilicatos es fácilmente lixiviado, conduciendo en la naturaleza a fases que conducen a hematita por procesos de oxidación e hidrólisis. Estas últimas especies presentan un diferente comportamiento a la reducción (mayor exposición del hierro a la especie reductora) (Jones and McNicol, 1986).

La hematita, especie termodinámicamente muy estable, es la fase más abundante en la naturaleza, mostrando un diagrama TPR típico de reducción en etapas. La primera etapa ocurre en la zona de $500-550{ }^{\circ} \mathrm{C}$ siendo asociada a la formación de $\mathrm{Fe}_{3} \mathrm{O}_{4}$, de acuerdo a la siguiente ecuación:

$$
3 \mathrm{Fe}_{2} \mathrm{O}_{3}+\mathrm{H}_{2} \rightarrow 2 \mathrm{Fe}_{3} \mathrm{O}_{4}+\mathrm{H}_{2} \mathrm{O}
$$


A mayor temperatura $\left(\sim 700^{\circ} \mathrm{C}\right)$, la magnetita se reduce a hierro metálico, a través de la formación de $\mathrm{FeO}$, para dar:

$$
2 \mathrm{Fe}_{3} \mathrm{O}_{4}+8 \mathrm{H}_{2} \rightarrow 6 \mathrm{Fe}+8 \mathrm{H}_{2} \mathrm{O}
$$

El consumo de $\mathrm{H}_{2}$ (o la producción de agua) puede ser establecido en cada etapa por el área integrada de las señales de TPR. El valor teórico, dado por los electrones involucrados en el proceso de reducción es igual a 3 en tanto que la relación de intensidades entre ambas señales es igual o próxima a 8 , de acuerdo a las ecuaciones precedentes. Las señales de TPR para la hematita, usada como referencia, se encuentran localizadas en 536 y $660^{\circ} \mathrm{C}$.

La Figura 6.33 muestra el diagrama de TPR del material identificado como 6AFO caracterizado por la presencia de hematita y de los aluminosilicatos pirofilita, caolinita e illita. En base al contenido de hierro original (50\% como $\mathrm{Fe}_{2} \mathrm{O}_{3}$, equivalente a 6,25 mmol $\mathrm{Fe} \mathrm{g}^{-1}$ ) y al consumo de $\mathrm{H}_{2}$ (8,95 mmoles por $\mathrm{g}$ de material) es posible determinar que el número de electrones puestos en juego en el proceso conduce al valor de 2,86, levemente inferior a 3 , indicando que hasta la máxima temperatura alcanzada la reducción no se ha completado. Este efecto puede ser atribuido a dos factores: a) una disminución de los sitios activos por depósito de hierro metal, que impide el acceso del gas reductor y b) la presencia de hierro estructural, que se evidenciaría a una temperatura superior a la máxima alcanzada, por colapso de la red. Por consiguiente, la relación de áreas observada $(7,2)$ no alcanza el valor de 8.

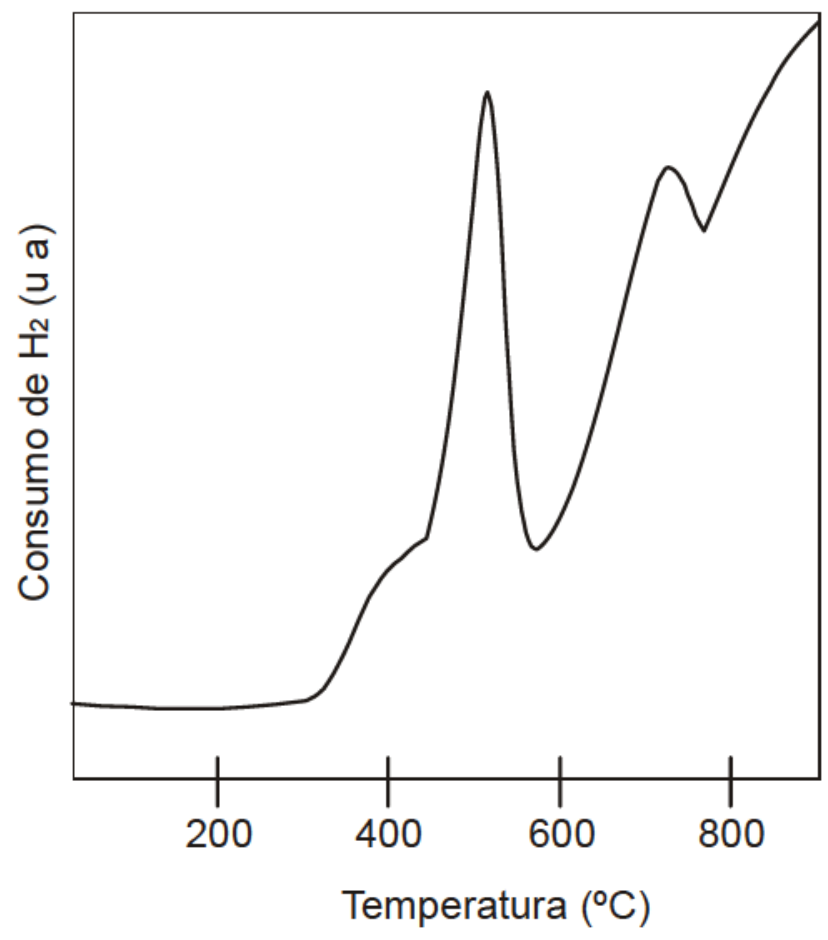

Figura 6.33. Diagrama de TPR del material 6AFO. 
Por otra parte, el comienzo de la reducción ocurre a una temperatura cercana a los $300{ }^{\circ} \mathrm{C}$ (con un hombro a $400{ }^{\circ} \mathrm{C}$ en la primera señal de TPR), sugiriendo la presencia de una fracción del elemento de transición en estado de elevada reducibilidad (fase amorfa o de muy baja cristalinidad). Mientras que el máximo de la primera señal se observa a una temperatura ligeramente menor que la correspondiente a la hematita pura, la segunda señal ocurre a una temperatura de 725 ${ }^{\circ} \mathrm{C}$, superior a la registrada para la sustancia pura, diferencias asociadas a la reducción del hierro en la mezcla arcillosa.

\subsection{Ensayos de adsorción a nivel laboratorio}

Para la realización de los ensayos de adsorción, las muestras seleccionadas en el ítem 6.1, fueron sometidas a un proceso de trituración, obteniéndose una distribución de tamaño de partícula típica como el observado en la Figura 6.34. Con posterioridad y a los efectos de mejorar las posibilidades de adsorción se efectuó una molienda en molino de martillo (PlaPiMu), obteniendo la distribución de tamaño que se observa en la Figura 6.35.

En función de los resultados de las figuras anteriores se clasificó el material como procedente de molienda gruesa (tamaño de partícula mayormente comprendido entre 0,59 y $3,36 \mathrm{~mm}$ ) y de molienda fina (tamaño de partícula mayormente comprendido entre $0,105-1,19 \mathrm{~mm}$, con un aporte de las partículas de tamaño inferior a $0,037 \mathrm{~mm}$ obtenidas por desagregación de la arcilla).

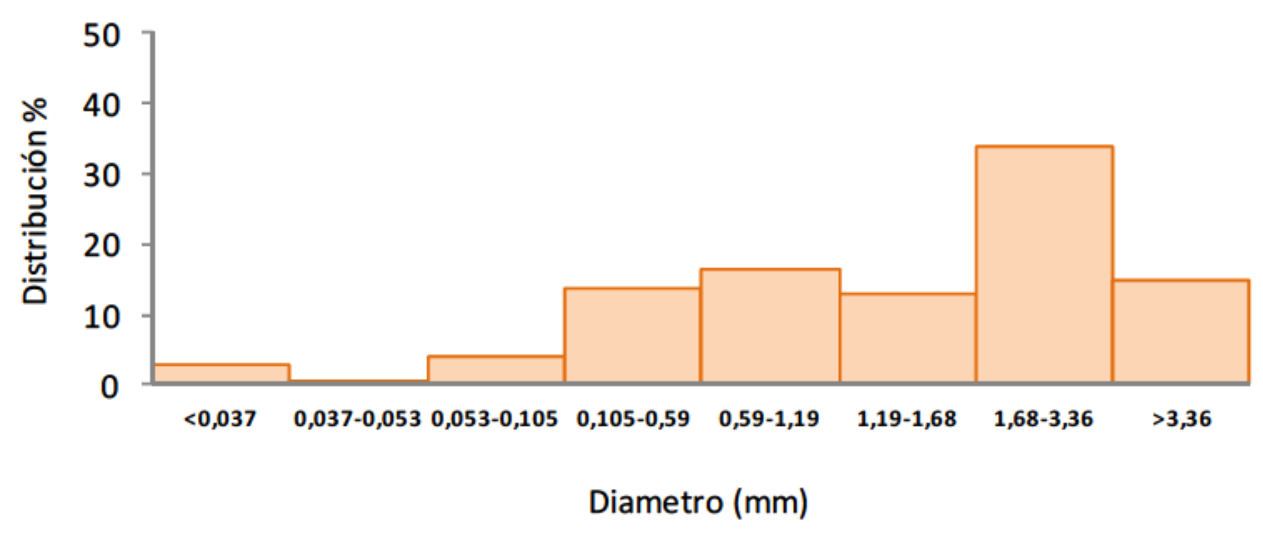

Figura 6.34. Distribución de tamaño de partícula del mineral sometido a trituración (molienda gruesa). 


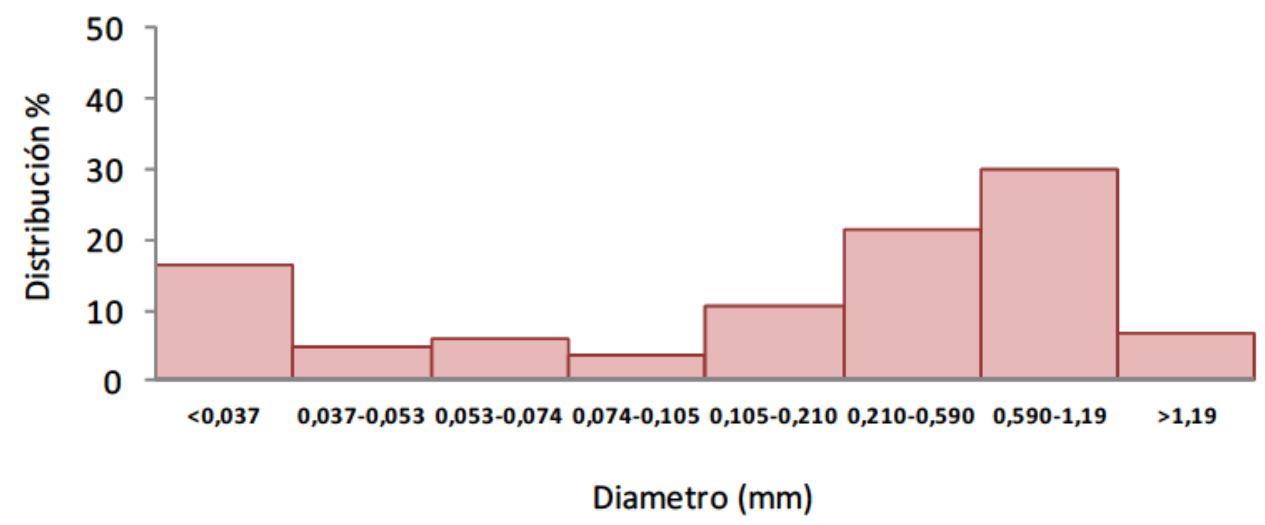

Figura 6.35. Distribución de tamaño de partícula del mineral molido en molino de martillo (molienda fina).

\subsubsection{Pruebas preliminares}

Estas pruebas se llevaron a cabo con la muestra identificada como 2AFO, molienda gruesa. Los ensayos consistieron en el contacto del material con el agua conteniendo el contaminante en un recipiente de vidrio sin tapa. De esta manera, se facilitó el contacto con el oxígeno ambiental y con la luz solar, ambos factores contribuyen a la oxidación de las formas de As(III) que eventualmente pudieran estar presentes, conduciendo al oxoanión de $\mathrm{As}(\mathrm{V})$, más fácil de interaccionar con el adsorbente.

La separación del agua tratada de la arcilla se realizó por simple decantación y posterior filtración (filtro de $0,45 \mu \mathrm{m}$ ), determinando el $\mathrm{pH}$ y el contenido de As del agua remanente.

El As en el agua original y posterior al tratamiento se determinó por el método colorimétrico del dietilditiocarbamato de plata (SDDC), siguiendo el procedimiento indicado en el Capítulo 5. Con los datos obtenidos se calculó el porcentaje de retención del material $(\% \operatorname{Re})$ empleando la expresión:

$$
\% \operatorname{Re}=\frac{\left(C_{0}-C_{f}\right) \times 100}{C_{0}}
$$

Donde $C_{o}$ corresponde al As original en el agua y $C_{f}$ al As en el agua luego del tratamiento.

Inicialmente, se trabajó tentativamente con $10 \mathrm{~g}$ de arcilla y $200 \mathrm{ml}$ de agua conteniendo $200 \mu \mathrm{g} \mathrm{L}^{-1}$ de As, realizando diferentes experiencias en función de dos variables (tiempo de contacto total y tiempo de agitación). 
Ensayo A: 24 hs de contacto con agitación inicial (5 min).

Ensayo B: 48 hs de contacto con 2 etapas de agitación ( $5 \mathrm{~min} \mathrm{c} / \mathrm{u}$ ): inicial y a las 24 hs. Ensayo C: 72 hs de contacto con 3 etapas de agitación ( 5 min c/u): inicial, a las 24 y a las $48 \mathrm{hs}$.

Ensayo D: 24 hs de contacto. Agitación constante empleando un agitador magnético.

Ensayo $\mathrm{E}: 48$ hs de contacto. Agitación constante empleando un agitador magnético.

Ensayo F: 72 hs de contacto. Agitación constante empleando un agitador magnético.

En todos los casos el agua utilizada en los ensayos procede de la localidad de Punta Indio, reportando un contenido de arsénico de $200 \mu \mathrm{g} \mathrm{L}^{-1}$ y un $\mathrm{pH}$ de 8,20.

\section{Resultados y conclusiones de las pruebas preliminares}

Los resultados obtenidos de los ensayos indicados en el punto anterior, se observan en la Tabla 6.6. Cabe aclarar que, los valores de $\mathrm{pH}$ y de concentración de As corresponden a los determinados en el agua remanente luego del tratamiento, para cada ensayo en particular.

Tabla 6.6. Resultados de los ensayos preliminares de laboratorio.

\begin{tabular}{c|c|c|c}
\hline Ensayo & $\mathrm{pH}$ & $\mathrm{As} \mu \mathrm{g} \mathrm{L}^{-1}$ & $\% \mathrm{Re}$ \\
\hline A & 8,35 & 120 & 40 \\
B & 8,33 & 100 & 50 \\
C & 8,26 & 60 & 70 \\
D & 8,29 & $<20^{*}$ & $>90$ \\
E & 8,27 & $<20^{\star}$ & $>90$ \\
F & 8,37 & $<20^{\star}$ & $>90$ \\
\hline
\end{tabular}

*límite de detección del método analítico

En los primeros 3 ensayos se observa que al aumentar el tiempo de contacto aumenta la cantidad de As retenida. La agitación durante periodos de $5 \mathrm{~min}$, facilita la separación de las fases al cabo del tiempo total de contacto. En los ensayos D-F, con agitación constante, se observa que si bien se logra un mayor porcentaje de retención de arsénico, se dificulta la decantación del sólido, imposibilitando la filtración, razón por la que se debió recurrir a una centrifugación previa para facilitar la etapa de filtración.

Es de destacar que en todos los ensayos no se registraron cambios significativos en el valor del $\mathrm{pH}$ luego del tratamiento con el adsorbente.

A grandes rasgos puede decirse que es factible la adsorción del As contenido en aguas de origen natural a partir del empleo de material arcilloso conteniendo hierro.

\subsubsection{Optimización de condiciones de tratamiento}

\subsubsection{Experimentos realizados}


En función de los resultados obtenidos en el ítem precedente, resulta evidente que es necesario contemplar el ajuste de algunas variables de tratamiento a fin de optimizar el proceso para lograr una mayor eficiencia. Para la realización de éstos ensayos se han analizado algunas variables generales que pueden afectar el proceso de adsorción.

En una primera etapa se analizaron dos aspectos que permiten asegurar el estado de oxidación del As y la granulometría más apropiada para los restantes ensayos. Estos se realizaron en condiciones similares a las utilizadas en los ensayos preliminares.

Ensayo 1) Estado de oxidación de la especie de As: Para la realización de este ensayo se utilizó el agua subterránea empleada en los ensayos preliminares. La finalidad de este ensayo está dirigida a conocer si es requerido el empleo de un oxidante ante la eventual presencia de As(III), sabiendo que el estado de oxidación $\mathrm{V}$ presenta mayor facilidad de adsorción. Si bien se ha reportado que los acuíferos presentan características oxidantes, se realiza un ensayo haciendo uso de un agente oxidante como el peróxido de hidrógeno para analizar comparativamente el comportamiento respecto al ensayo A de las pruebas preliminares. Se empleó un exceso de oxidante $\left(2 \mathrm{ml} \mathrm{H}_{2} \mathrm{O}_{2} 10 \mathrm{~V}\right)$, sobre la suposición de que la única especie presente fuese As (III) $\left(\mathrm{Eh} \mathrm{H}_{2} \mathrm{O}_{2} / \mathrm{H}_{2} \mathrm{O}=1,776 \mathrm{v}\right.$ y $\left.\mathrm{AsO}_{4}{ }^{-3} / \mathrm{AsO}_{3}{ }^{-3}=0,580 \mathrm{v}\right)$.

Las condiciones experimentales fueron: agua natural con un contenido de As de 200 $\mu \mathrm{g} \mathrm{L}^{-1}, 24$ hs de contacto y una etapa inicial de agitación de $5 \mathrm{~min}$. El contenido de As original y posterior al tratamiento se determinó por el método SDDC.

Ensayo 2) Granulometría del adsorbente: Este ensayo permite la comparación con las condiciones de la prueba preliminar A (molienda gruesa) empleando material 2AFO sometido a molienda fina.

Fijada la granulometría más apropiada (molienda fina), los restantes ensayos se realizaron utilizando un equipo Jar test marca VELP Scientifica modelo JLT6. EI mismo consiste en un sistema que permite la agitación simultánea y a la misma velocidad de 6 paletas agitadoras a través de un sistema de poleas acopladas. Está constituido principalmente por un motor de $1 / 2 \mathrm{HP}$ (intensidad máxima $1 \mathrm{~A}$ ) y el rango de velocidad es de $0-250 \mathrm{rpm}$. Tanto el eje como las paletas agitadoras de $7,5 \mathrm{~cm}$ de ancho y 2,5 $\mathrm{cm}$ de altura son de acero inoxidable. El equipo, ilustrado en la Figura 6.36, está provisto de iluminación artificial producida por un tubo fluorescente ubicado por detrás de las jarras/reactores, que permite visualizar mejor el proceso de clarificación permitiendo distinguir los perfiles de descenso. Como jarras/reactores se utilizaron 6 
vasos de precipitado de vidrio de $1000 \mathrm{ml}$ de capacidad que permiten utilizar volúmenes de hasta $750 \mathrm{ml}$ dejando libre un volumen suficiente como para evitar rebalses debidos al vórtice formado durante la agitación. Los ensayos fueron realizados a temperatura ambiente.

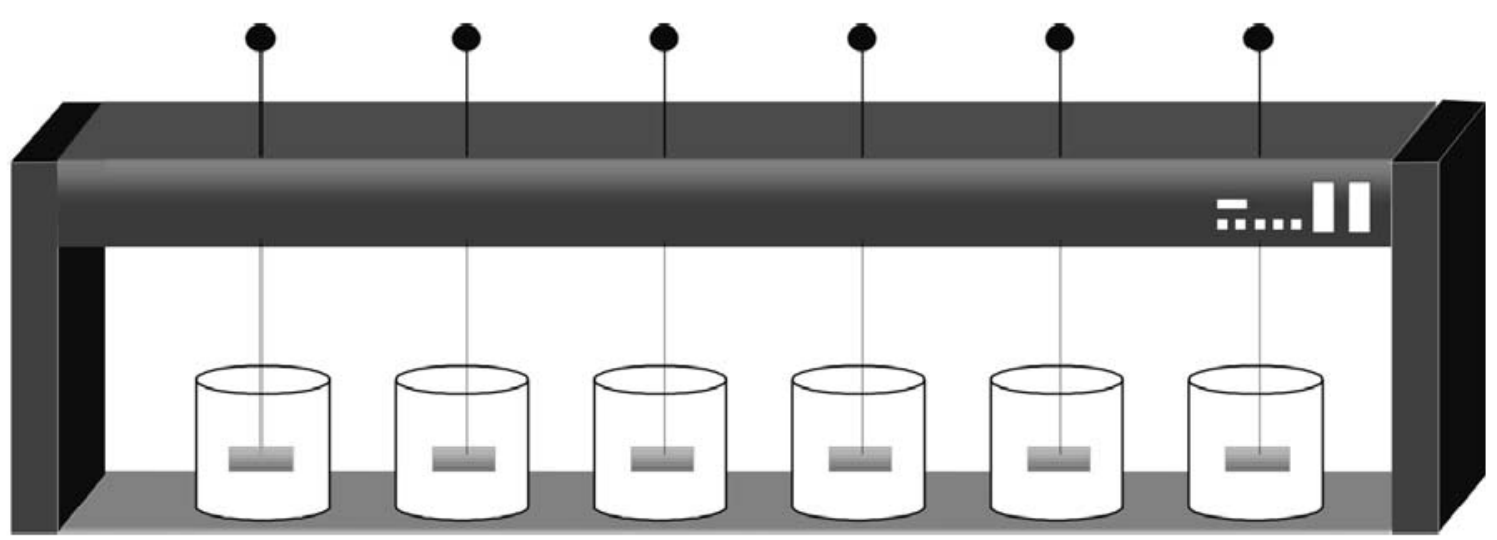

Figura 6.36. Esquema del equipo Jar test y las seis jarras/reactores.

La toma de muestra se realizó con una jeringa de $60 \mathrm{ml}$ adosada a una manguera de $1 / 8$ de pulgada de diámetro y de $5 \mathrm{~cm}$ de longitud ambas de material plástico transparente (Figura 6.37). Las pequeñas dimensiones de la manguera permiten que esta ingrese al líquido sin generar perturbaciones significativas, manteniendo el perfil de descenso lo más estanco posible para no generar turbulencia durante la coagulación/floculación.

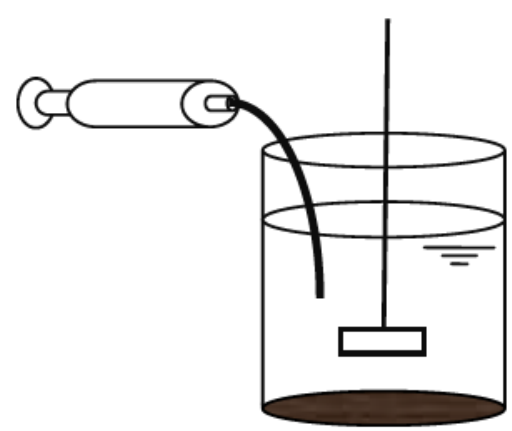

Figura 6.37. Esquematización de la toma de muestra.

Los ensayos que se describen a continuación estuvieron orientados a evaluar las siguientes variables, manteniendo fijas las restantes.

Ensayo 3) Relación sólido/líquido: Con el objetivo de evaluar la cantidad óptima de arcilla para lograr la remoción del arsénico, se pusieron en contacto distintas cantidades de arcilla 2AFO (molienda fina, que fuera seleccionada en el ensayo 2) con la misma cantidad de agua. Se pesaron $15,30,45,60,75,150$ y $225 \mathrm{~g}$ de adsorbente los que se trataron con $600 \mathrm{ml}$ de solución preparada en el laboratorio conteniendo $200 \mu \mathrm{g} \mathrm{L}^{-1}$ de As. El tiempo de contacto se fijó en 30 minutos y la agitación en 200 
rpm. Esta etapa fue seguida por 24 hs de decantación, según los resultados preliminares. Las muestras fueron filtradas y se determinó el As por el método AAS-GF (EPA 3020/7010) en el que el límite de detección $<10 \mu \mathrm{g} \mathrm{L}^{-1}$.

Ensayo 4) Tiempo de contacto: Se realizaron experiencias con el adsorbente 2AFO, una solución de partida de $370 \mu \mathrm{g} \mathrm{L}^{-1}$ de As y la relación sólido/líquido 1/10, seleccionada de acuerdo a los resultados del inciso anterior. Los tiempos ensayados fueron $30,60,150,360$ y 480 minutos, trabajando, en todos los casos con agitación de $200 \mathrm{rpm}$. El tratamiento de agitación, detenido a los tiempos indicados, conduce a suspensiones en las que resulta imposible la determinación química de As. Eso hizo necesario proceder a una etapa de centrifugación para facilitar la separación, la que se completó con una filtración (filtro $0,45 \mu \mathrm{m}$ ). Estas dos últimas operaciones permiten la determinación de As por AAS-GF (EPA 3020/7010) en dos condiciones de tratamiento diferentes: posterior a la centrifugación y luego de la filtración.

Análisis de turbidez: Las soluciones resultantes de los diferentes tiempos de contacto procedentes de la separación sólido-líquido por centrifugación y filtración conducen a soluciones de diferente turbidez (determinada mediante el turbidímetro indicado en el Capítulo 5). A fin de obtener valores de turbidez de acuerdo a los indicados en la normativa vigente $(<3 \mathrm{NTU})$, se procedió a incluir el empleo de un coagulante, que será mencionado a continuación como una de las variables que contribuyen a la optimización del proceso.

Ensayo 5) Uso de coagulante: Es bien conocido el efecto del agregado de un coagulante en aquellas soluciones en las que se supone la existencia de un sistema coloidal (por ejemplo presencia de material arcilloso). A tal fin y para evitar la centrifugación se procedió al agregado de un exceso de $\mathrm{Al}_{2}\left(\mathrm{SO}_{4}\right)_{3}$ coagulante ampliamente usado en las plantas potabilizadoras. Se empleó una solución $2 \mathrm{~N}$ (equivalente a $45 \mathrm{mg}_{\mathrm{Al}} \mathrm{L}^{-1}$ ), empleando una relación de $2,5 \mathrm{ml}$ de solución de coagulante por litro de agua a tratar. Para evaluar su eficiencia, se repitió el ensayo del punto 4 , en todos los tiempos de contacto indicados, agregando el coagulante 5 min antes de finalizada la agitación. La turbidez se determinó luego de 3 y 24 hs de decantación. El contenido de As se determinó a las 24 hs sin filtrar.

Ensayo 6) Efecto del pH: Se realizaron ensayos para evaluar el efecto del pH de la solución inicial en el rango de $\mathrm{pH}$ comprendido entre 4 y 9 . Los ensayos se realizaron con el adsorbente 2AFO, relación sólido/líquido 1/10, concentración inicial de As de $1000 \mu \mathrm{g} \mathrm{L}^{-1}, 60$ minutos de agitación a $200 \mathrm{rpm}$ y posterior decantación durante 24 hs, sin agregado de coagulante. El pH de la solución fue variado por agregado gota a gota 
de solución $0,1 \mathrm{M}$ de $\mathrm{NaOH}$ ó solución $0,1 \mathrm{M}$ de $\mathrm{HCl}$, según corresponda. Empleando el pHchímetro indicado en el Capítulo 5 se determinaron los siguientes valores de $\mathrm{pH}$ de las soluciones preparadas: 3,97-5,03-5,99-6,92-7,94-8,98. Transcurrido el tiempo indicado se determinó el pH y el As en la solución remanente posterior a la filtración.

\subsubsection{Resultados y conclusiones del ajuste}

En relación a los ensayos realizados para ajustar las diferentes variables que operan en el sistema de remoción de arsénico mediante el empleo de arcilla ferruginosa, a continuación se discuten los resultados obtenidos.

\section{- Ensayo 1: Empleo de agua oxigenada como oxidante}

La retención de As por parte del adsorbente mediante el empleo de agua oxigenada como agente oxidante fue de $41 \%$, valor prácticamente similar al obtenido sin agregado de oxidante en las mismas condiciones (40\%, Tabla 6.6). Estos resultados indican que el porcentaje de adsorción del As no se ve afectado por el agregado de peróxido de hidrógeno, poniendo en evidencia la preponderancia de la especie más oxidada en el agua empleada.

\section{- Ensayo 2: Efecto de la granulometría}

El ensayo realizado empleando el material 2AFO molienda fina, conduce a un valor de As de $65 \mu \mathrm{g} \mathrm{L}^{-1}$. La comparación con el ensayo preliminar A (Tabla 6.6), realizados ambos en similares condiciones, indica que obviamente el proceso se ve favorecido a partir del empleo de material de menor granulometría.

En base a los resultados de estos dos ensayos, se ha seleccionado el material de molienda fina para la realización de todas las pruebas y el empleo de soluciones preparadas en el laboratorio a partir de sales de $A s(V)$.

\section{- Ensayo 3: Efecto de la cantidad de adsorbente}

En el gráfico de la Figura 6.38 se presentan los resultados de los ensayos realizados con distinta masa del adsorbente $2 \mathrm{AFO}$, representando el $\%$ de remoción de $\mathrm{As}(\% \mathrm{Re})$ vs dosis de adsorbente en $\mathrm{g} \mathrm{L}^{-1}$.

De los resultados obtenidos, surge que la dosis óptima de adsorbente se encuentra comprendida entre 100 y $125 \mathrm{~g}$ de mineral por litro de agua a tratar. Estos valores se corresponden con una relación sólido/líquido que oscila entre 1/10 a 1/8, conduciendo a valores de As muy próximos o dentro de los sugeridos por la OMS y la legislación nacional $\left(10 \mu \mathrm{g} \mathrm{L}^{-1}\right)$. A los fines de optimización de variables, se ha seleccionado la relación 1/10 (dosis de adsorbente $100 \mathrm{~g} \mathrm{~L}^{-1}$ ), en función del ajuste de las restantes variables. 


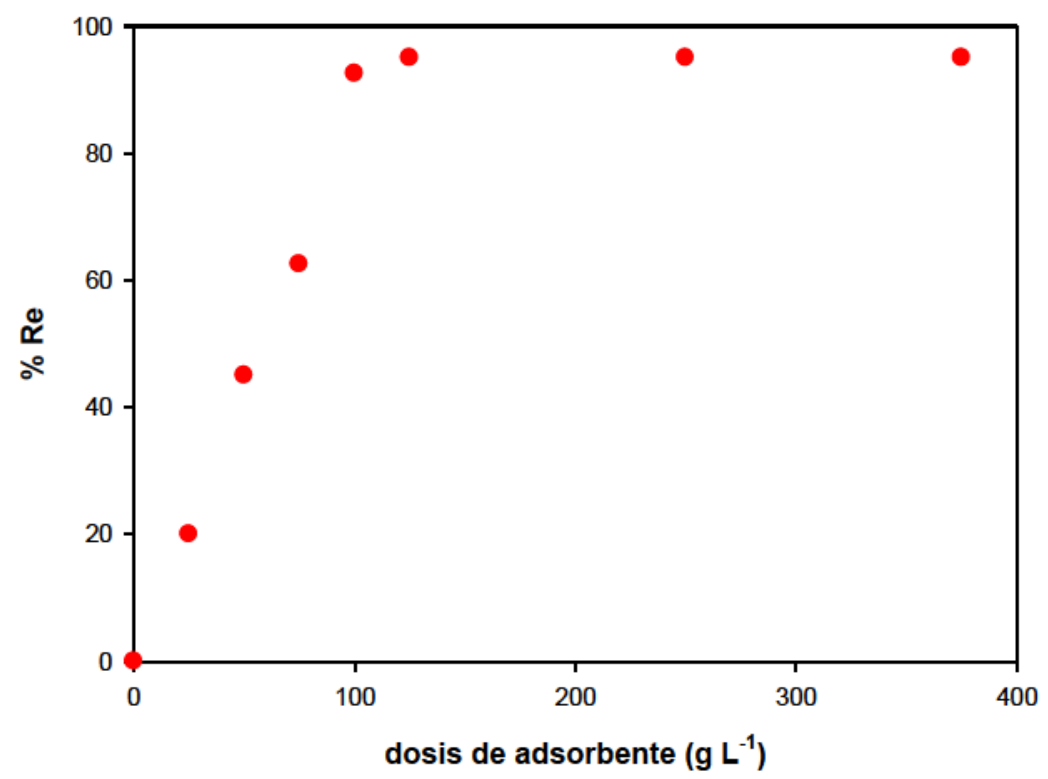

Figura 6.38. Relación entre el As removido (expresado como \% Re) y la masa de adsorbente empleada (expresada como dosis de adsorbente en $\mathrm{g} \mathrm{L}^{-1}$ ). Condiciones experimentales: As inicial $200 \mu \mathrm{g} \mathrm{L}{ }^{-1}$, tiempo: 1 hs a $200 \mathrm{rpm}+24$ hs de decantación.

\section{- Ensayos 4 y 5: Tiempo de contacto y efecto del agregado de un coagulante}

En la Tabla 6.7 se muestran los resultados obtenidos en los ensayos de adsorción empleando el material 2AFO, considerando como variable el tiempo de agitación. Es evidente que la agitación seguida de la centrifugación resulta insuficiente para la remoción total del contaminante como puede observarse en la Figura 6.39. Si bien el contenido de As disminuye al aumentar el tiempo de contacto con agitación, la remoción del contaminante solo alcanza un valor ligeramente superior al $35 \%$ al cabo de $480 \mathrm{~min}$. Esto es atribuido a la presencia de flóculos de adsorbente portadores de As que continúan en suspensión favorecida por efectos de desagregación del material arcilloso. Las partículas tamaño arcilla no han podido ser aún decantados por centrifugación, efecto que se evidencia por lo valores altos de turbidez. El posterior proceso de filtración contribuye a la separación de dichos flóculos, efecto que se manifiesta por la disminución de la turbidez y consecuentemente del contenido de As.

Debido a que la filtración de un sistema coloidal es un proceso lento y difícil de realizar a gran escala, se debe recurrir a una estrategia adicional que permita eliminar el proceso de filtración. De lo expuesto surge la necesidad de emplear un coagulante (Ensayo 5). A tal fin se hizo uso de un exceso de sulfato de aluminio, indicando los resultados obtenidos en las últimas columnas de la Tabla 6.7. En estas condiciones se evidencia una remoción superior al $97 \%$ luego de una hora de tratamiento. Estos resultados permiten concluir la necesidad de uso de un coagulante, estableciendo un 
tiempo óptimo de agitación de 60 minutos, lográndose la máxima coagulaciónsedimentación al cabo de 24 hs.

Tabla 6.7. Datos químicos de As $\left(\mu \mathrm{g} \mathrm{L}^{-1}\right)$ y turbidez (NTU) vs tiempos de tratamiento en distintas condiciones.

\begin{tabular}{|c|c|c|c|c|c|c|c|}
\hline \multirow{3}{*}{$\begin{array}{l}\text { Tiempo de } \\
\text { tratamiento } \\
\text { (min) }\end{array}$} & \multicolumn{7}{|c|}{ CONDICIÓN } \\
\hline & \multicolumn{2}{|c|}{ CENTRIFUGACIÓN } & \multicolumn{2}{|c|}{ FILTRACIÓN } & \multicolumn{3}{|c|}{ COAGULACIÓN } \\
\hline & As & NTU & As & NTU & As & $\begin{array}{l}\text { NTU } \\
3 \text { hs }\end{array}$ & $\begin{array}{l}\text { NTU } \\
24 \text { hs }\end{array}$ \\
\hline 30 & 300 & 187 & 70 & 0,30 & 40 & 7,75 & 0,65 \\
\hline 60 & 310 & 183 & 10 & 0,27 & $<10$ & 9,96 & 0,82 \\
\hline 150 & 280 & 209 & $<10$ & 0,12 & $<10$ & 8,60 & 0,88 \\
\hline 360 & 250 & 211 & $<10$ & 0,20 & $<10$ & 9,70 & 0,56 \\
\hline 480 & 240 & 215 & $<10$ & 0,14 & $<10$ & 10,12 & 0,71 \\
\hline
\end{tabular}

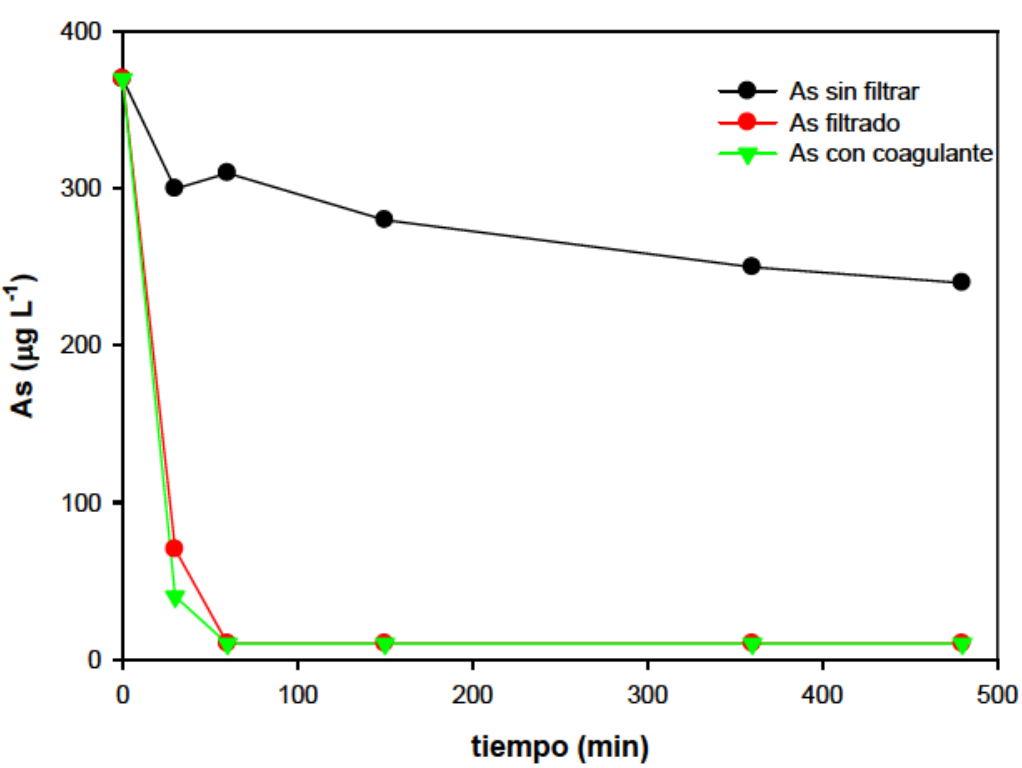

Figura 6.39. Ensayos de adsorción de $A s(V)$ expresados como $\mu \mathrm{L}^{-1}$ de As en función del tiempo de tratamiento en distintas condiciones. Condiciones experimentales: As inicial $370 \mu \mathrm{g} \mathrm{L}^{-1}$, relación sólido/líquido: 1/10.

\section{- Ensayo 6: efecto del pH}

El efecto del pH fue evaluado a través de la realización de ensayos de adsorción fijando las variables optimizadas en los puntos anteriores y variando el pH entre 4 y 9. En la Tabla 6.8 se muestran los resultados de la optimización del pH.

Tabla 6.8. Resultados de la optimización del pH.

\begin{tabular}{c|c|c|c}
\hline $\mathrm{pH}_{\text {inicial }}$ & $\mathrm{As}\left(\mu \mathrm{g} \mathrm{L}^{-1}\right)$ & $\mathrm{Re} \%$ & $\mathrm{pH}_{\text {final }}$ \\
\hline 3,97 & $<10$ & $>99$ & 7,17 \\
5,03 & $<10$ & $>99$ & 6,83 \\
5,99 & $<10$ & $>99$ & 7,49 \\
6,92 & $<10$ & $>99$ & 7,76 \\
7,94 & 10 & 99 & 7,82 \\
8,98 & 12 & 98,8 & 7,96 \\
\hline
\end{tabular}


Se logran porcentajes de retención del orden del $99 \%$, indicando que la adsorción no se ve afectada en el rango mencionado. Es de destacar, que independientemente del $\mathrm{pH}$ inicial, los valores finales de $\mathrm{pH}$ tienden a la neutralidad $(6,83-7,96)$ en coincidencia con datos reportados en la literatura empleando adsorbentes naturales como hematita (Guo et al., 2007; Maji et al., 2008).

\section{Evaluación global de las variables mencionadas precedentemente}

Del análisis global de los datos obtenidos en esta etapa de laboratorio, es posible señalar las condiciones que favorecen una adsorción óptima:

a) Molienda del adsorbente, en base a los resultados obtenidos trabajando con el material denominado molienda fina.

b) Relación sólido/líquido 1/10 (dosis de adsorbente: $100 \mathrm{~g}$ por L de agua a tratar).

c) Tiempo de agitación 60 minutos a $200 \mathrm{rpm}$.

d) Empleo de un coagulante que permite alcanzar la turbidez adecuada transcurridas 24 hs.

e) No se han observado variaciones apreciables en la remoción de As en el rango de $\mathrm{pH}$ estudiado.

\subsubsection{Isoterma de adsorción}

La sorción es uno de los procesos más importantes en el área de la hidrogeoquímica regulando el transporte de contaminantes químicos en acuíferos y suelos. En general pueden distinguirse tres grandes grupos de procesos de adsorción entre un soluto y un adsorbente: a) adsorción de tipo electrostático, b) adsorción de van der Waals y c) adsorción de naturaleza química. El primer caso está prácticamente referido al intercambio iónico en el que la carga del ión es el factor determinante. A igualdad de cargas es el tamaño como ión hidratado el que determina el orden de preferencia para la adsorción. Al respecto, en general todos los minerales tienen cierta capacidad de sustitución y en particular las arcillas presentan esa propiedad más acentuadamente. Como se comentó en capítulos anteriores, a pH normales las arcillas se encuentran cargadas negativamente. Las cargas negativas libres en superficie pueden ser compensadas por cationes, con una fuerza de enlace que depende de su potencial iónico (involucrando carga, tamaño efectivo e hidratación). En realidad el radio hidratado del catión determina la fuerza de la adsorción siendo más retenido el que presenta menor radio hidratado (recordando que la hidratación es directamente proporcional a la carga del ión e inversamente proporcional al radio iónico). Por otra parte, los iones divalentes son adsorbidos con mayor fuerza que los monovalentes, selectividad que es favorecida por la dilución, proceso que afecta el mecanismo de la 
adsorción. En lo que respecta a las arcillas, algunos cationes sufren un proceso de fijación irreversible debido al tamaño de las especies por ejemplo $\mathrm{K}(\mathrm{I})$ y amonio no hidratados, mencionando que también ocurre con el $\mathrm{Li}(\mathrm{l})$ por su pequeño tamaño y elevada hidratación y el $\mathrm{Mg}$ (II) con quien el anterior guarda una similitud diagonal. En la naturaleza el proceso de intercambio catiónico involucra principalmente a las especies $\mathrm{Ca}(\mathrm{II}), \mathrm{Mg}(\mathrm{II}), \mathrm{Na}(\mathrm{I})$ y $\mathrm{K}(\mathrm{I})$ siendo $\mathrm{Ca}(\mathrm{II})-\mathrm{Na}(\mathrm{I})$ los reemplazos más comunes por su similitud en cuanto al potencial iónico.

La adsorción mediante fuerzas de van der Waals o adsorción física está referida al proceso que ocurre en la interfase, sin que se establezca un lugar fijo de la superficie. Contrariamente, la adsorción química o quimisorción ocurre en sitios preferenciales o activos para el proceso en los que entre adsorbente y adsorbato se establece un fuerte vínculo (tipo enlace químico).

En general, la fuerza de la unión con que los iones son retenidos en la superficie (en el caso de quimisorción implicando enlaces de tipo covalente y en el caso de la adsorción física uniones de van der Waals, dipolo-dipolo o puentes de hidrógeno) depende de ciertos factores entre los que pueden mencionarse:

a) La temperatura.

b) Carga y tamaño del ión. El radio hidratado o la polarización del ión determinan la fuerza de la adsorción siendo los iones hidratados más pequeños los más fuertemente retenidos.

c) Concentración relativa de los iones.

d) Efecto dilución.

Las isotermas de adsorción se utilizan para describir cómo interactúan los solutos con el adsorbente y corresponden a la relación entre la masa de soluto adsorbida por unidad de adsorbente (qe) y la concentración del soluto en la solución en el equilibrio (Ce) a temperatura constante (Bradl, 2004). Existen diferentes modelos matemáticos para describir las isotermas que se obtienen experimentalmente, contemplando una serie de consideraciones en cada caso. Los modelos de Langmuir y de Freundlich, son los más frecuentemente usados para la interpretación de la remoción de contaminantes en fase acuosa.

La mayoría de los procesos de adsorción de los oxoaniones de As se describen mediante las isotermas de Langmuir, condicionadas por ciertos factores como:

a) temperatura constante

b) adsorción localizada 
c) superficie homogénea y en forma de monocapa, asumiendo que cada sitio de adsorción da lugar a la adhesión de solo una especie

d) energía de adsorción similar para todos los sitios activos

e) ausencia de interacciones entre las especies adsorbidas

La ecuación matemática del modelo se expresa de la siguiente manera:

$$
q_{e}=\frac{a_{m} b C_{e}}{1+b C_{e}}
$$

Donde $\boldsymbol{b}$ está relacionada con la energía de adsorción $\left(\mathrm{L} \mathrm{mg}{ }^{-1}\right)$ y $\boldsymbol{q}_{m}$ es la cantidad de adsorbato requerida para formar una monocapa sobre una unidad de masa $\left(\mathrm{mg} \mathrm{g}^{-1}\right)$, también denominada capacidad máxima de adsorción. Los valores $q_{m}$ y $b$ se pueden determinar reordenando la ecuación de forma lineal de acuerdo a la ecuación 6.3.

$$
\frac{c_{e}}{q_{e}}=\frac{1}{b q_{m}}+\frac{c_{e}}{q_{m}}
$$

Para encontrar $q_{m}$ se grafica $C_{e} / q_{e}$ vs $C_{e} y$ se obtiene del valor de la pendiente de la línea. El valor de $b$ se calcula con el dato de $q_{m} y$ el valor de la ordenada al origen de la línea.

La isoterma de Langmuir se puede expresar en términos de un parámetro adimensional $\boldsymbol{R}_{L}$ que expresa la favorabilidad de la adsorción, de tal manera que si el valor de $R_{L}$ se encuentra entre 0 y 1 indica que la adsorción es favorable (Bhattacharya et al. 2008, Maji et al., 2008).

$$
R_{L}=1 /\left(1+b C_{0}\right)
$$

Donde $\boldsymbol{b}$ es la constante de Langmuir y $\boldsymbol{C}_{\mathrm{o}}$ es la concentración inicial de adsorbato en $\mathrm{mg} \mathrm{L}^{-1}$.

Por otra parte, los cambios de energía libre de Gibbs estándar $\left(\Delta G^{0}\right)$ para el proceso de adsorción pueden ser calculados mediante la ecuación 6.5 , donde $\boldsymbol{b}$ es la constante de la isoterma de Langmuir, $\boldsymbol{R}$ la constante universal de los gases $(8,3145 \mathrm{~J}$ $\mathrm{mol}^{-1} \mathrm{~K}^{-1}$ ) y $T$ es la temperatura absoluta (Maji et al., 2008; Amiri et al., 2011).

$$
\ln (1 / b)=\frac{\Delta G^{0}}{R T}
$$

\section{Ensayos de laboratorio}

La caracterización del proceso de adsorción se evaluó a partir de isotermas sólido-líquido en "batch", permitiendo ampliar el conocimiento del efecto de la concentración de arsénico en el agua a tratar. 
La isoterma de adsorción se realizó empleando la arcilla denominada 6AFO (molienda fina) como adsorbente. Se usaron concentraciones iniciales de $\mathrm{As}(\mathrm{V})$ desde $1,06 \mathrm{mg} \mathrm{L}^{-1}$ hasta $25,8 \mathrm{mg} \mathrm{L}^{-1}$. Las experiencias se realizaron utilizando las condiciones experimentales optimizadas en los incisos anteriores: relación sólido/líquido $1 / 10$ (30 g de arcilla en $300 \mathrm{ml}$ de solución), tiempo de contacto $60 \mathrm{~min}$ a $200 \mathrm{rpm}, \mathrm{pH} 7,45$, sin agregado de coagulante para evaluar sólo el efecto del adsorbente. Las pruebas se realizaron simultáneamente en el equipo Jar test a temperatura ambiente $\left(25 \pm 2{ }^{\circ} \mathrm{C}\right)$. Los ensayos se realizaron por duplicado y el valor reportado es el promedio de ambas determinaciones.

Las soluciones se prepararon como se indicó en el Capítulo 5 empleando agua de red (cuyo análisis se indica en la segunda columna de la Tabla 6.9). Es de destacar que se emplean concentraciones de arsénico lo suficientemente altas como para lograr la saturación del adsorbente, asegurando de esta forma, que la concentración remanente del analito sea mayor al límite de detección del método empleado para su determinación.

Tabla 6.9. Calidad de las aguas empleadas en los ensayos (según protocolo indicado en el Capítulo 5)

\begin{tabular}{l|c|c}
\hline \multicolumn{1}{c|}{ Parámetro } & Agua de red sin modificar & Agua subterránea natural \\
\hline $\mathrm{pH}$ & 7,45 & 8,3 \\
Conductividad $\left(\mu \mathrm{S} \mathrm{cm}^{-1}\right)$ & 637 & 790 \\
Turbiedad $(\mathrm{NTU})$ & $<1$ & 1,4 \\
Color & $<3$ & $<3$ \\
Olor & Inodoro & Inodoro \\
Aspecto & Límpido & Límpido \\
Dureza $\left(\mathrm{mg} \mathrm{de} \mathrm{CaCO}_{3} \mathrm{~L}^{-1}\right)$ & 162 & 57 \\
Alcalinidad $\left(\mathrm{mg} \mathrm{de} \mathrm{CaCO}_{3} \mathrm{~L}^{-1}\right)$ & 99 & 421 \\
Calcio $\left(\mathrm{mg} \mathrm{L}^{-1}\right)$ & 35 & 13 \\
Magnesio $\left(\mathrm{mg} \mathrm{L}^{-1}\right)$ & 18 & 6 \\
Sodio $\left(\mathrm{mg} \mathrm{L}^{-1}\right)$ & 145 & 181 \\
Potasio $\left(\mathrm{mg} \mathrm{L}^{-1}\right)$ & 8 & 10 \\
Carbonatos $\left(\mathrm{mg} \mathrm{L}^{-1}\right)$ & No contiene & 26 \\
Bicarbonatos $\left(\mathrm{m} \mathrm{L} \mathrm{L}^{-1}\right)$ & 121 & 456 \\
Cloruros $\left(\mathrm{mg} \mathrm{L}^{-1}\right)$ & 150 & 33,4 \\
Sulfatos $\left(\mathrm{mg} \mathrm{L}^{-1}\right)$ & 80 & 11 \\
Nitratos $\left(\mathrm{mg} \mathrm{L}^{-1}\right)$ & 7,8 & 13,4 \\
Nitritos $\left(\mathrm{mg} \mathrm{L}^{-1}\right)$ & $<0,005$ & $<0,005$ \\
Fluoruros $\left(\mathrm{mg} \mathrm{L}^{-1}\right)$ & 0,18 & 1,36 \\
Arsénico $\left(\mathrm{mg} \mathrm{L}^{-1}\right)$ & $<0,01$ & 0,18 \\
Amonio $\left(\mathrm{mg} \mathrm{L}^{-1}\right)$ & 0,1 & $<0,1$ \\
\hline
\end{tabular}

Luego del periodo de agitación se procedió a la centrifugación, filtración (filtro de $0,45 \mu \mathrm{m})$ y determinación de arsénico utilizando el método EPA 3020/7010. Finalmente, los datos experimentales fueron ajustados por medio del modelo de Langmuir y se calcularon las constantes. 
La Tabla 6.10 resume los resultados obtenidos, mientras que en la Figura 6.40 se muestra la isoterma de adsorción obtenida para la remoción de $\mathrm{As}(\mathrm{V})$.

Tabla 6.10. Resultados de los ensayos de adsorción.

\begin{tabular}{|c|c|c|c|c|}
\hline $\begin{array}{c}\mathrm{C}_{\mathrm{o}} \\
\left(\mathrm{mg} \mathrm{As} \mathrm{L}^{-1}\right)\end{array}$ & $\begin{array}{c}\mathrm{C}_{\mathrm{e}} \\
\left(\mathrm{mg} \mathrm{As} \mathrm{L}^{-1}\right)\end{array}$ & $\begin{array}{c}\mathrm{q}_{\mathrm{e}} \\
\left(\mathrm{mg} \mathrm{As} \mathrm{g}_{\mathrm{ad}}{ }^{-1}\right)\end{array}$ & $\begin{array}{c}\mathrm{q}_{\mathrm{e}} \\
\left(\mu \mathrm{g} \mathrm{As} \mathrm{g}_{\mathrm{ad}}^{-1}\right)\end{array}$ & $\begin{array}{c}\mathrm{C}_{\mathrm{e}} / \mathrm{q}_{\mathrm{e}} \\
\left(\mathrm{g}_{\mathrm{ad}} \mathrm{L}^{-1}\right)\end{array}$ \\
\hline 1,06 & 0,010 & 0,0105 & 10,5 & 0,9523 \\
\hline 2,17 & 0,010 & 0,0216 & 21,6 & 0,4629 \\
\hline 5,40 & 0,052 & 0,0535 & 53,5 & 0,9719 \\
\hline 10,5 & 0,113 & 0,1039 & 103,9 & 1,0876 \\
\hline 15,3 & 0,351 & 0,1495 & 149,5 & 2,3478 \\
\hline 20,9 & 0,860 & 0,2004 & 200,4 & 4,2914 \\
\hline 24,6 & 1,370 & 0,2323 & 232,3 & 5,8975 \\
\hline 25,8 & 1,790 & 0,2401 & 240,1 & 7,4552 \\
\hline
\end{tabular}

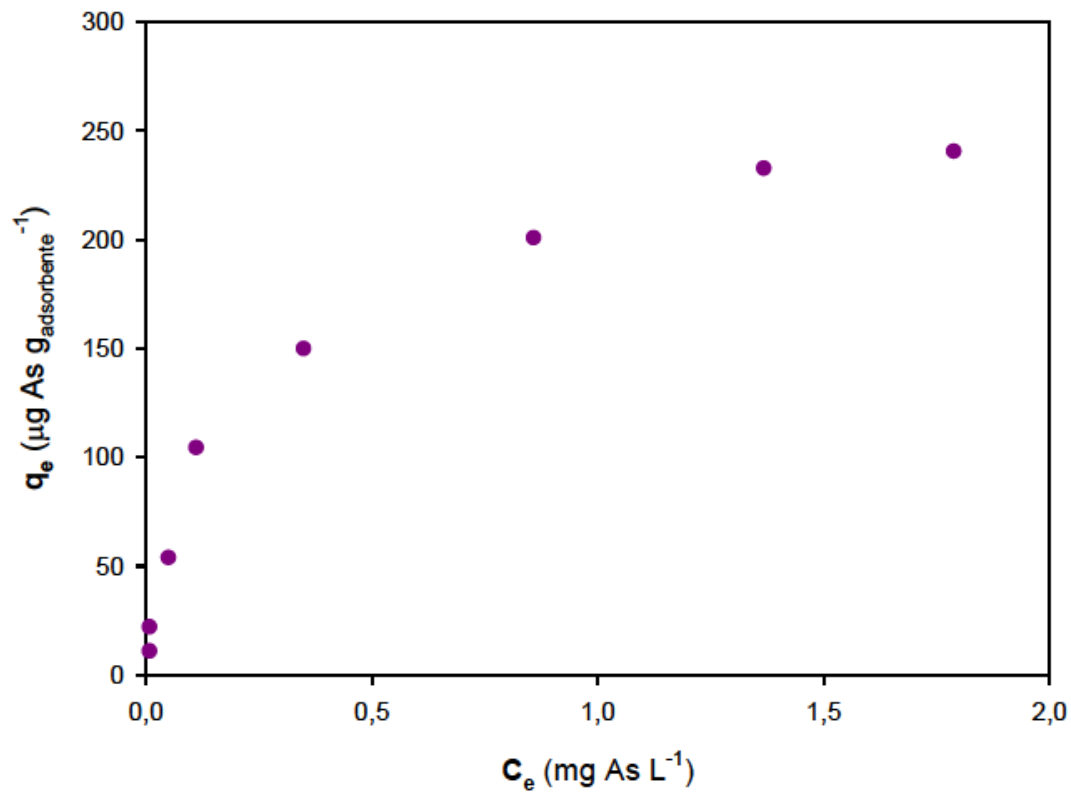

Figura 6.40. Isoterma de adsorción para la remoción de $\mathrm{As}(\mathrm{V})$ empleando arcilla ferruginosa $6 \mathrm{AFO}$ como adsorbente. Condiciones experimentales: relación sólido/líquido $1 / 10$, tiempo de contacto $60 \mathrm{~min}$ a $200 \mathrm{rpm}, \mathrm{pH} \mathrm{7,45.}$

En la Figura 6.41 se presenta la linealización de la isoterma de Langmuir, en la que se obtiene un coeficiente de correlación de 0,9939 , lo que significa un buen ajuste lineal a este modelo. El valor de $\mathrm{q}_{\mathrm{m}}$ calculado es de 263,6 $\mu \mathrm{g}$ de $\mathrm{As}(\mathrm{V})$ adsorbidos por gramo de arcilla y el valor de la constante b es de 4,905 $\mathrm{L} \mathrm{mg}^{-1}$. Para el intervalo de concentraciones considerado se encontró un valor de $R_{L}$ comprendido entre 0 y 1 indicando que la adsorción de $\mathrm{As}(\mathrm{V})$ sobre arcilla ferruginosa es favorable. Por otra parte, el valor calculado de $\Delta \mathrm{G}^{0}$ es de $-3,94 \mathrm{KJ} \mathrm{mol}^{-1}$ indicando el carácter espontáneo del proceso de adsorción.

Los resultados obtenidos son comparables con datos reportados en la literatura en los que la adsorción de As(V) cumple con el modelo de Langmuir. En tal sentido se puede destacar el empleo de carbón activado y clinoptilolita (Payne and Abdel-Fattah, 
2005), "red mud" (Altundogan et al., 2000), arena recubierta con óxido férrico (Thirunavukkarasu et al., 2003), hidróxido de hierro amorfo (Harper and Kingham, 1992), óxido férrico hidratado (Wilkie and Hering, 1996), dióxido de titanio (Bang et al., 2005), siderita y hematita naturales (Guo et al., 2007), óxidos de hierro y aluminio comerciales (Jeong et al., 2007), laterita (Maji et al., 2008), hematita y goethita (Mamindy-Pajany et al., 2011). En todos estos casos se ha sugerido que la adsorción se produce en forma de una monocapa sobre sitios activos de naturaleza homogénea con valores de energías de adsorción similares (Guo et al., 2007, Amiri et al., 2011).

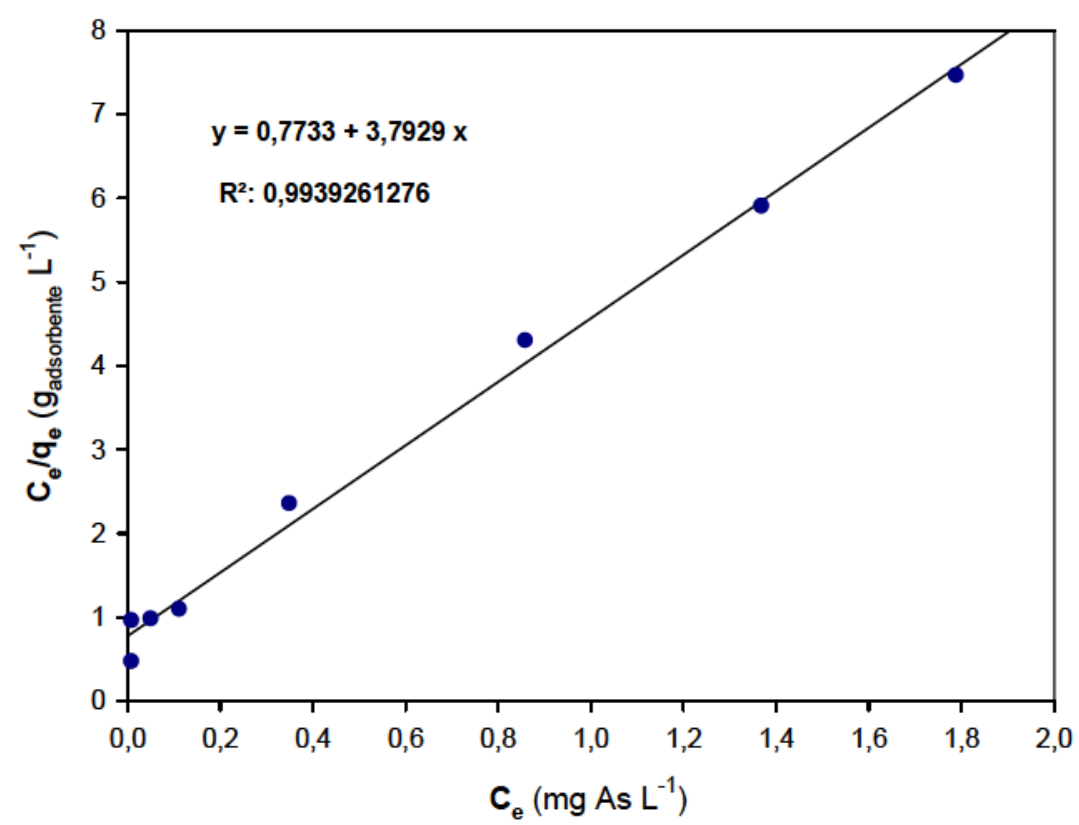

Figura 6.41. Linealización de la isoterma de adsorción según el modelo de Langmuir.

\subsubsection{Estudio de la etapa de coagulación}

En los puntos anteriores, se observó la necesidad de complementar el proceso de adsorción con el de coagulación-floculación a fin de eliminar la turbidez y coloración que puedan afectar la efectividad de la remoción de arsénico.

Los procesos de coagulación y floculación representan conjuntamente una etapa en la cual las partículas se aglutinan en pequeñas masas llamadas flóculos tal que su peso específico supere al del agua y precipiten. Los fundamentos de ambos procesos se describirán en detalle en el Capítulo 9, sin embargo en esta instancia cabe mencionar que:

a) La coagulación es el proceso de desestabilización de las partículas suspendidas de modo tal que se reduzcan las fuerzas de separación entre ellas mediante el agregado de un producto químico y ocurre en fracciones de segundo. 
b) La floculación se relaciona con los fenómenos de transporte que ocurren en el seno del líquido para que las partículas hagan contacto. Esto implica la formación de puentes químicos entre partículas de modo que se forme un floculo suficientemente grande y pesado como para sedimentar.

Los productos más empleados como coagulantes son las sales de cationes con alto potencial iónico como el $\mathrm{Al}(\mathrm{III})$ y el $\mathrm{Fe}(\mathrm{III})$, especies que por hidrólisis generan productos catiónicos que son fuertemente adsorbidos sobre las partículas negativas de las arcillas y producen una desestabilización efectiva conduciendo a la especie coloidal:

$$
\mathrm{M}\left(\mathrm{H}_{2} \mathrm{O}\right)_{6}{ }^{+3} \rightarrow \mathrm{M}\left(\mathrm{H}_{2} \mathrm{O}\right)_{5}(\mathrm{OH})^{+2} \rightarrow \mathrm{M}\left(\mathrm{H}_{2} \mathrm{O}\right)_{4}(\mathrm{OH})_{2}{ }^{+1} \rightarrow \mathrm{M}(\mathrm{OH})_{3}
$$

Donde $\mathrm{M}$ representa a los cationes $\mathrm{Al}(\mathrm{III})$ y $\mathrm{Fe}(\mathrm{III})$.

En este trabajo de tesis se comenzó estudiando a las sales de aluminio como coagulantes, y en ese aspecto se realizaron las experiencias preliminares mediante el uso de sulfato de aluminio. Considerando que otras sales de aluminio como el policloruro de aluminio (PAC) se han mostrado efectivas en los tratamientos de purificación de aguas, se realizaron experiencias comparativas para optimizar el uso de coagulante en el proceso general de remoción de As.

Las características de los coagulantes empleados son:

Coagulante 1: se preparó a partir de $\mathrm{Al}_{2}\left(\mathrm{SO}_{4}\right)_{3} \cdot 18 \mathrm{H}_{2} \mathrm{O}$, sólido cristalino (Riedel de Haën) de modo de obtener una solución de $10 \mathrm{~g} \mathrm{~L}^{-1}$. La concentración final de $\mathrm{Al}(\mathrm{III})$ en la solución determinada por el método SM-3500-Al B equivale a $856,6 \mathrm{mg}_{\mathrm{Al}(\mathrm{III})} \mathrm{L}^{-1}(\mathrm{pH}$ 4,4).

Coagulante 2: se preparó a partir de una solución al 50\% de PAC (Parafarm, pH 3,5), de modo de obtener una solución 1/10. La concentración final de Al determinada por el método SM-3500-Al B equivale a $288,9 \mathrm{mg} \mathrm{AI}(\mathrm{III}) \mathrm{L}^{-1}(\mathrm{pH} 4,5)$.

Para evaluar la dosis óptima de cada coagulante, se realizaron ensayos empleando la arcilla denominada 6 AFO molienda fina. Las condiciones usadas son las indicadas en los estudios anteriores, específicamente una relación sólido/líquido $1 / 10$ y una agitación a 200 rpm durante 60 min.

Las experiencias se realizaron en el equipo Jar test que se ha descripto previamente. En base al tipo de experiencia a realizar, se utilizó la capacidad máxima de las jarras $(750 \mathrm{ml})$ y una masa de arcilla de $75 \mathrm{~g}$ a fin de mantener la relación sólido/líquido establecida de 1/10. La modificación realizada respecto a las experiencias sin uso de coagulante es la incorporación de este último a los 50 min de agitación, a fin de dar lugar a que en los últimos 10 minutos (para completar los 60), la 
mezcla resulte perfectamente homogénea. Se utilizaron dosis de coagulante 1 de 2,5; $5 ; 7,5$ y $10 \mathrm{ml}$, mientras que el coagulante 2 fue empleado en dosis de 0,$33 ; 0,5 ; 1$ y 2 $\mathrm{ml}$.

A partir de los 60 minutos de tratamiento, los sistemas fueron monitoreados en función del tiempo, analizando la turbidez (en unidades NTU), situación que permitió la realización de los perfiles de turbidez. Transcurridas las 24 hs, en la solución remanente se efectuó la medida de arsénico, turbidez y $\mathrm{pH}$. Cabe destacar, que la determinación de As se realizó sobre la muestra sin filtrar de manera tal de determinar el As disuelto y el suspendido. Las medidas se realizaron por el método EPA 3020/7010 que fuera comentado en el Capítulo 5.

El agua utilizada, cuyo análisis fisicoquímico se indica en la segunda columna de la Tabla 6.9, procede de la red de la ciudad de La Plata. Dicha agua fue modificada químicamente de manera de obtener una solución de $300 \mu \mathrm{g} \mathrm{L}^{-1}$ de As.

Es interesante destacar que se utiliza agua natural para realizar las soluciones de trabajo, debido a que las experiencias preliminares realizadas con agua destilada incorporaban un problema adicional a las pruebas de remoción de As, asociado a la marcada dificultad y lentitud en la decantación, aún con el agregado de coagulante, indicando que la presencia de otras especies iónicas juega un rol importante en el proceso (especialmente la alcalinidad del agua).

En la Tabla 6.11 se comparan los resultados obtenidos con ambos coagulantes. Resulta evidente que el coagulante 2 resulta más efectivo, tanto en lo referido a la turbidez (valor recomendado por la legislación $<3$ NTU) como al contenido de arsénico del agua tratada. En la tabla se han resaltado las condiciones óptimas en el caso de uso del sulfato de aluminio o de PAC para su empleo en la etapa de coagulación. En base a estos resultados se ha procedido a la selección de policloruro de aluminio para su empleo en los procesos de coagulación-sedimentación.

Tabla 6.11. Ensayos de coagulación con los coagulantes estudiados. Valores de As, pH y turbidez medidos a $24 \mathrm{hs}$.

\begin{tabular}{c|cccccc}
\hline Coagulante & $\begin{array}{c}\text { Volumen } \\
(\mathrm{ml})\end{array}$ & $\begin{array}{c}\mathrm{Al} \\
\left(\mathrm{mg} \mathrm{L}^{-1}\right)\end{array}$ & $\begin{array}{c}\text { Turbidez } \\
(\mathrm{NTU})\end{array}$ & $\mathrm{pH}$ & $\begin{array}{c}\text { As } \\
\left(\mu \mathrm{g} \mathrm{L}^{-1}\right)\end{array}$ & $\begin{array}{c}\text { Remoción } \\
\%\end{array}$ \\
\hline \multirow{4}{*}{1} & 2,5 & 2,855 & 19,23 & 7,42 & 46 & 84,7 \\
& 5,0 & 5,711 & 5,45 & 7,37 & 17 & 94,3 \\
& $\mathbf{7 , 5}$ & $\mathbf{8 , 5 6 6}$ & $\mathbf{3 , 0 0}$ & $\mathbf{7 , 1 9}$ & $\mathbf{1 0}$ & $\mathbf{9 6 , 7}$ \\
& 10,0 & 11,421 & 2,97 & 6,85 & $<10$ & $>96,7$ \\
\hline \multirow{3}{*}{2} & 0,33 & 0,127 & 3,56 & 7,43 & 13 & 95,7 \\
& $\mathbf{0 , 5 0}$ & $\mathbf{0 , 1 9 3}$ & $\mathbf{2 , 1 3}$ & $\mathbf{7 , 4 1}$ & $\mathbf{1 0}$ & $\mathbf{9 6 , 7}$ \\
& 1,00 & 0,385 & 1,87 & 7,40 & 10 & 96,7 \\
& 2,00 & 0,770 & 1,42 & 7,34 & $<10$ & $>96,7$ \\
\hline
\end{tabular}


La Figura 6.42 muestra el perfil de turbidez para el coagulante 1 para las diferentes concentraciones empleadas. Las pequeñas variaciones observadas en los primeros momentos del proceso podrían estar asociadas a un problema cinético de formación de flóculos. La Figura 6.43 indicando los perfiles de turbidez para el coagulante 2 muestra un comportamiento más definido, revelando una cinética más rápida de formación de flóculos.

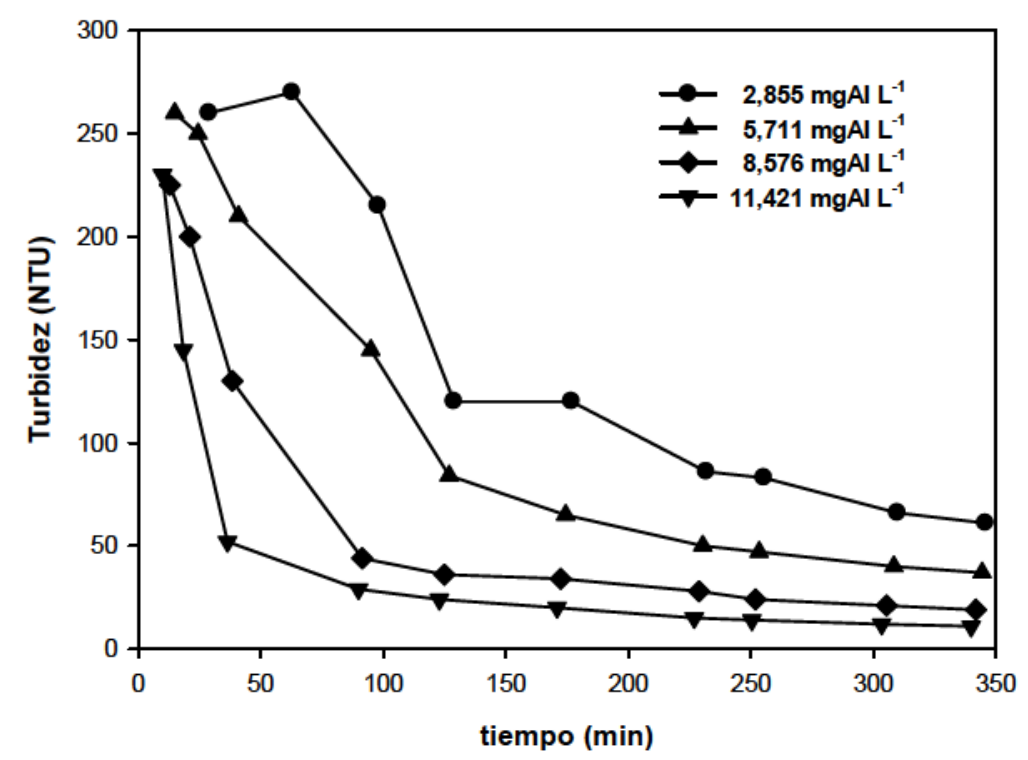

Figura 6.42. Perfiles de turbidez empleando sulfato de aluminio como coagulante.

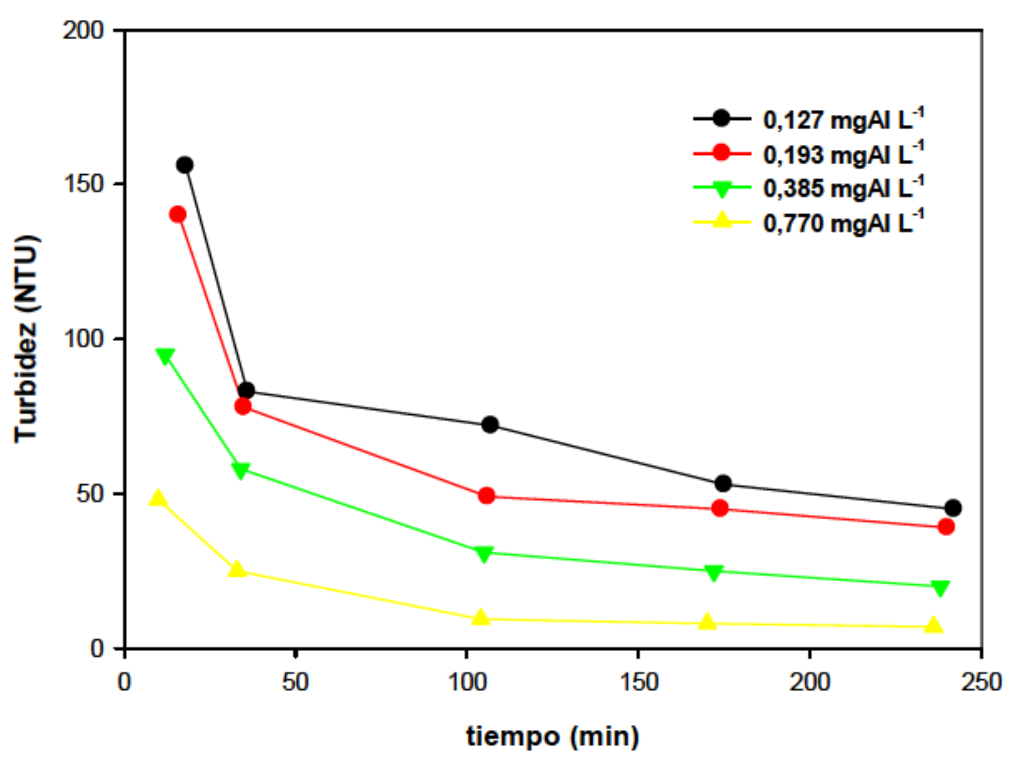

Figura 6.43. Perfiles de turbidez empleando policloruro de aluminio como coagulante.

Resulta interesante hacer referencia a la realización de un ensayo de control para evaluar la sedimentación de la arcilla sin el agregado de coagulante (perfil de turbidez). A tal fin se dejó decantar la arcilla bajo el efecto de la gravedad, empleando 
los dos tipos de agua indicados en la Tabla 6.9. Se hizo uso de un procedimiento similar al empleado en ensayos previos (relación sólido/líquido 1/10, tiempo de agitación a $200 \mathrm{rpm} 60 \mathrm{~min}$ ). Los valores de turbidez fueron determinados a partir de los 10 min de interrumpida la agitación.

La Figura 6.44 revela que en ambos casos es necesario un tiempo superior a las 70 horas para lograr valores de turbidez inferiores a las 3 NTU. Es importante resaltar el efecto sinérgico de la mezcla arcilla-coagulante para la reducción del contenido de As, evitando la presencia del mismo en los flóculos en suspensión, resultado que permite prescindir de una etapa de filtración.

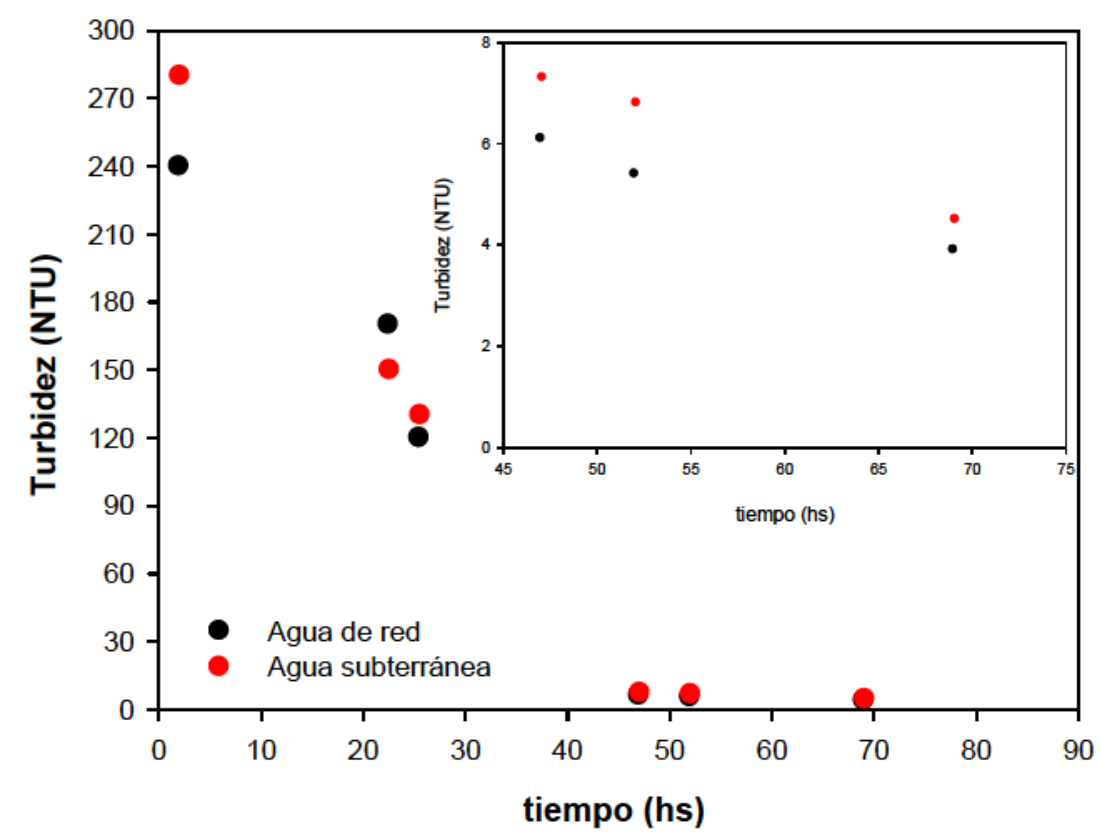

Figura 6.44. Turbidez vs tiempo con arcilla sola sin agregado de coagulante.

Entre las variables que pueden afectar el proceso de coagulación se ha analizado el efecto del $\mathrm{pH}$, la forma de agregado del coagulante y las características de la matriz acuosa.

_ Efecto del pH: Se realizaron ensayos de coagulación modificando el $\mathrm{pH}$ de la solución acuosa empleada $(\mathrm{pH} 7,45)$, mediante el agregado de $\mathrm{HCl} \circ \mathrm{NaOH}$ hasta obtener valores de 6,62 y 8,36 en base a la recomendación del CAA $(6,5-8,5)$. Con la dosis óptima de coagulante $\left(0,193 \mathrm{mg}_{\mathrm{Al}} \mathrm{L}^{-1}\right)$, determinada previamente, se obtienen los datos de la Tabla 6.12 revelando que la turbidez y concentración de As finales no se ven afectados por el $\mathrm{pH}$ inicial. Sin embargo se observa claramente que el $\mathrm{pH}$ final tiende a valores próximos a 7 , independientemente del valor inicial. Estos resultados indican que no es necesario regular el pH antes ni después del tratamiento. La Figura 
6.45 muestra que la turbidez tiende asintóticamente al valor de 3 NTU, el que se logra a las 24 hs.

Tabla 6.12. Efecto del pH inicial en la coagulación. Determinación de turbidez, pH y As al cabo de 24 hs.

\begin{tabular}{cccc}
\hline $\mathrm{pH}_{\text {inicial }}$ & $\begin{array}{c}\text { Turbidez } \\
(\mathrm{NTU})\end{array}$ & $\mathrm{pH}_{\text {final }}$ & $\begin{array}{c}\mathrm{As} \\
\left(\mu \mathrm{g} \mathrm{L}^{-1}\right)\end{array}$ \\
\hline 6,62 & 2,84 & 7,38 & $<10$ \\
8,36 & 2,56 & 7,89 & $<10$ \\
\hline
\end{tabular}

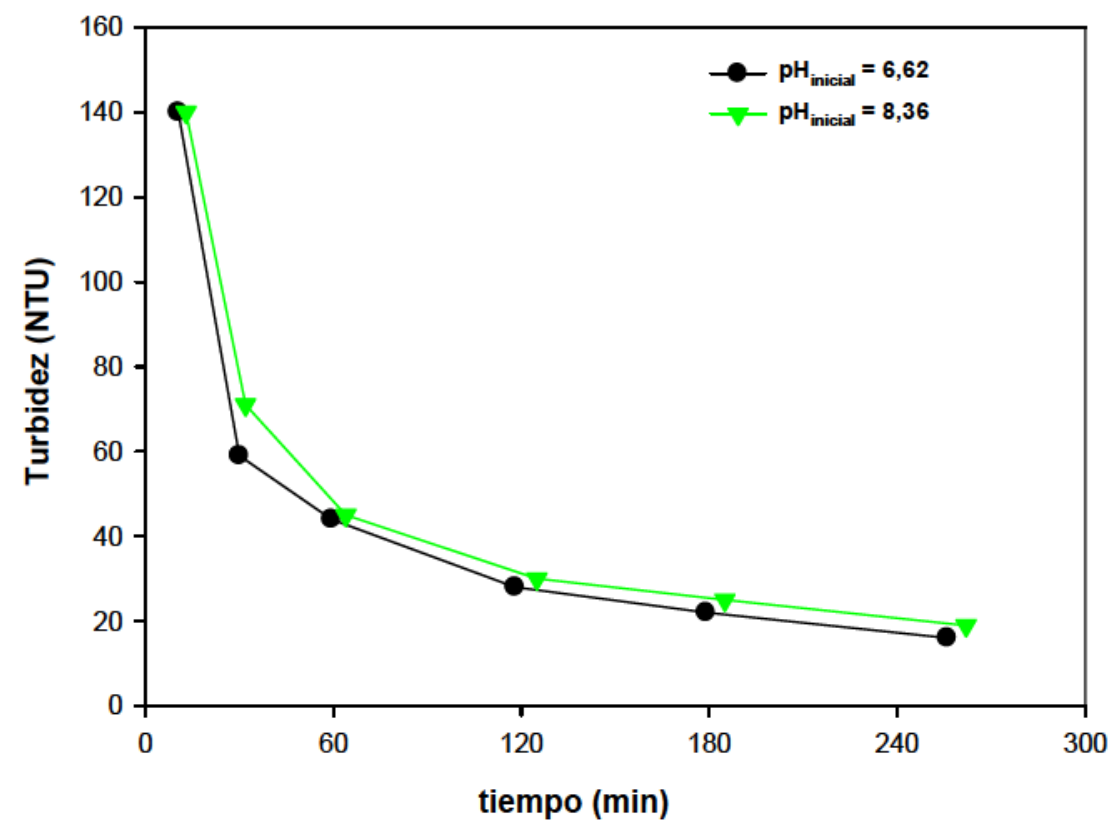

Figura 6.45. Perfil de turbidez de los sistemas analizados variando el pH inicial.

_ Condiciones de mezcla: Este ensayo fue realizado empleando PAC, coagulante que resultó más efectivo. Se realizaron experiencias utilizando dos condiciones de mezcla:

a) Mezcla Rápida (MR): se efectuó en una sola etapa, a $200 \mathrm{rpm}$ durante los últimos 10 minutos del proceso.

b) Mezcla diferencial $(M D)$ : consta de dos etapas, una primera de agitación rápida a 200 rpm durante 2 min seguida de una etapa de agitación lenta de 8 minutos a 50 rpm. Esta diferenciación se realizó con el objeto de facilitar, en un principio, una dispersión rápida del coagulante en el seno de la mezcla para luego permitir la nucleación y el crecimiento de los flóculos durante la etapa lenta.

En las Figuras 6.46 y 6.47 se observan los perfiles de turbidez obtenidos en las dos condiciones de mezcla ensayadas. Las gráficas muestran los beneficios del proceso de MD, dado que comparativamente a igual concentración de coagulante la cinética es más rápida, alcanzando niveles de turbidez inferiores a 10 NTU al cabo de 50 min luego de interrumpida la agitación. 


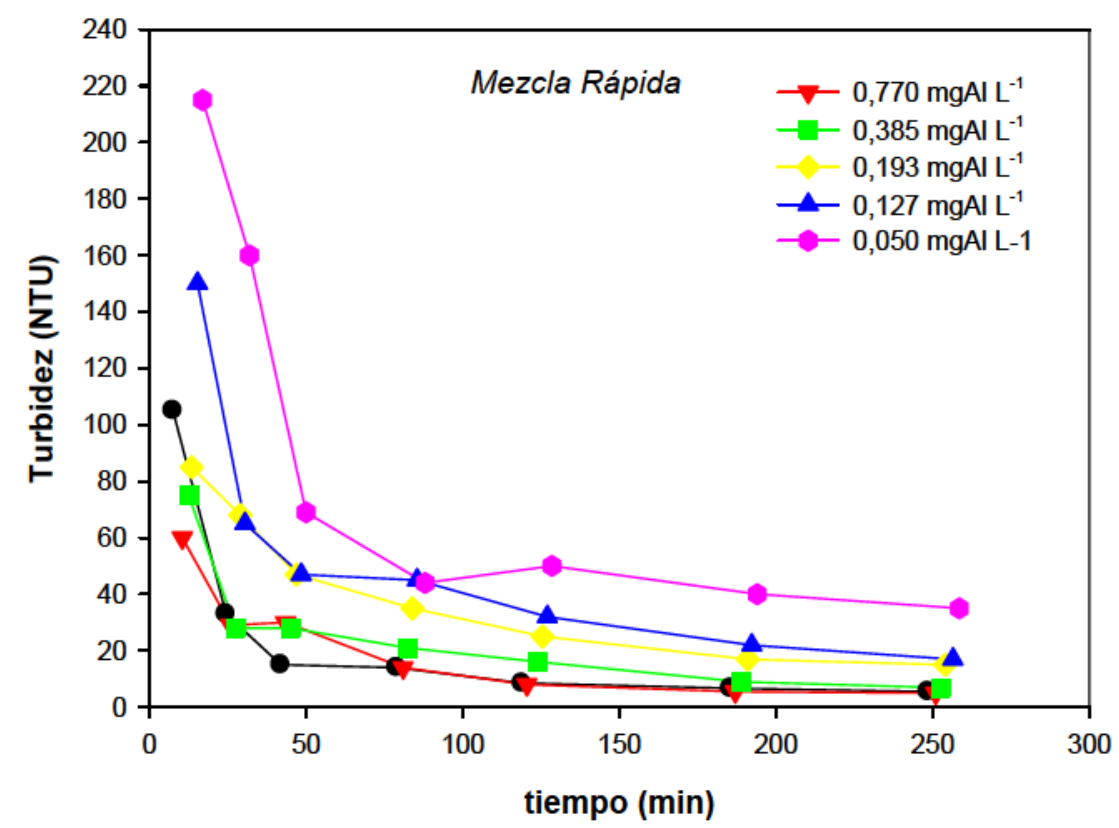

Figura 6.46. Perfiles de turbidez empleando mezcla rápida.

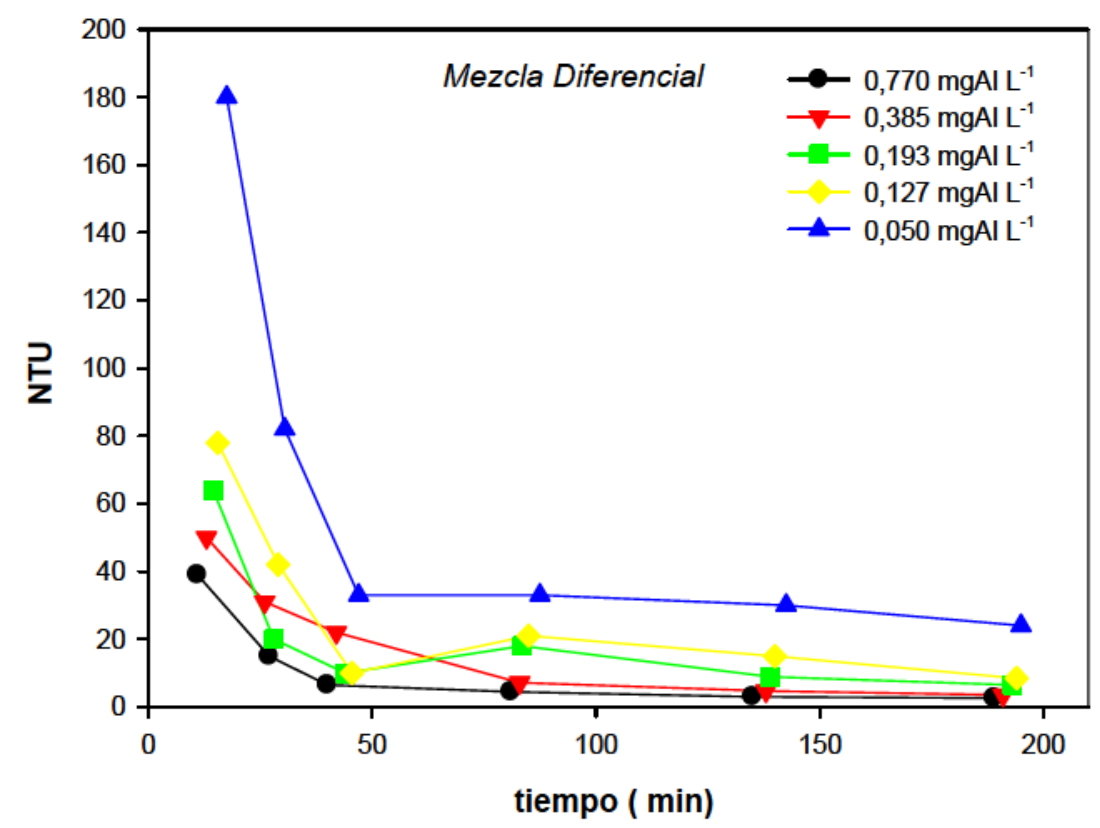

Figura 6.47. Perfiles de turbidez empleando mezcla diferencial.

En la Tabla 6.13 se resumen los resultados de la turbidez obtenidos a 24 hs para las 5 dosis de coagulantes ensayadas en las dos condiciones de agitación. Es posible observar que la MD permite una disminución en la cantidad de coagulante agregada. Sin embargo, a fin de asegurar la obtención de valores de turbidez adecuados, se ha decidido emplear la dosis de $0,193 \mathrm{mg}_{\mathrm{Al}} \mathrm{L}^{-1}$ para realizar todos los ensayos que se realizarán a posteriori en este trabajo de tesis. 
Tabla 6.13. Resultados de turbidez medida a 24 hs en las dos condiciones de agitación.

\begin{tabular}{l|cc}
\hline Agitación & mg Al L $^{-1}$ & $\begin{array}{c}\text { Turbidez } \\
\text { (NTU) }\end{array}$ \\
\hline & 0,050 & 5,63 \\
Mezcla Rápida & 0,127 & 3,56 \\
& $\mathbf{0 , 1 9 3}$ & $\mathbf{2 , 7 2}$ \\
& 0,385 & 1,88 \\
& 0,770 & 1,45 \\
\hline & 0,050 & 3,92 \\
Mezcla & $\mathbf{0 , 1 2 7}$ & $\mathbf{2 , 5 7}$ \\
Diferencial & 0,193 & 1,71 \\
& 0,385 & 1,05 \\
& 0,770 & 1,54 \\
\hline
\end{tabular}

_ Efecto de la matriz acuosa. En este ítem se procura comparar los resultados obtenidos con el agua de red modificada con arsénico (análisis químico indicado en la Tabla 6.9), con un agua de origen subterráneo conteniendo arsénico. Esta última procede de la Localidad de La Viruta, Partido de Punta Indio PBA y su análisis fisicoquímico se indica en la columna 3 de la Tabla 6.9.

Para la realización de los ensayos se seleccionó como coagulante PAC, el que se presentó más eficiente. Las experiencias se realizaron en el equipo Jar test utilizando seis concentraciones de coagulante (desde 0,050 hasta $1,156 \mathrm{mg}_{\mathrm{Al}} \mathrm{L}^{-1}$ ). La relación sólido líquido fue $1 / 10$, empleando un tiempo de contacto de 60 minutos con agitación diferencial (MD), realizando a las 24 hs la determinación de los parámetros más relevantes que hacen a la efectividad del procedimiento propuesto $(\mathrm{pH}$, conductividad, turbidez, concentración de arsénico, de aluminio, de hierro y de cloruros).

En los gráficos de la Figura 6.48 se muestra la evolución de los parámetros citados según el agua empleada y las dosis de coagulante utilizadas en cada caso. A modo de referencia, se incluyen los valores iniciales del parámetro correspondiente para cada agua así como el valor máximo permitido por la legislación vigente (CAA, 2007).

La Figura 6.48.a muestra que la variación del pH con el agregado de coagulante es muy pequeña, observándose una ligera disminución del $\mathrm{pH}$ a las mayores concentraciones de PAC. La conductividad (Figura 6.48.b) se ve levemente afectada por el agregado de PAC, pero se encuentra muy por debajo del valor correspondiente a un agua potable $\left(<2500 \mu \mathrm{S} \mathrm{cm}^{-1}\right)$. Por otra parte, se observa que la turbidez disminuye marcadamente. Los datos de las Figuras 6.48 c y d revelan la relación que guardan los parámetros allí indicados, debido a que el contaminante queda retenido en las partículas de arcilla en suspensión. En lo que respecta a la concentración de $\mathrm{Al}(\mathrm{III})$, el valor encontrado es muy similar en ambos tipos de agua, no obstante el agregado 
de diferentes concentraciones de coagulante (Figura 6.48.f). Asimismo, la concentración del cloruro permanece por debajo del valor estipulado (Figura 6.48.e). Es de destacar que las diferencias observadas en el gráfico son atribuidas al contenido inicial en cada matriz acuosa.
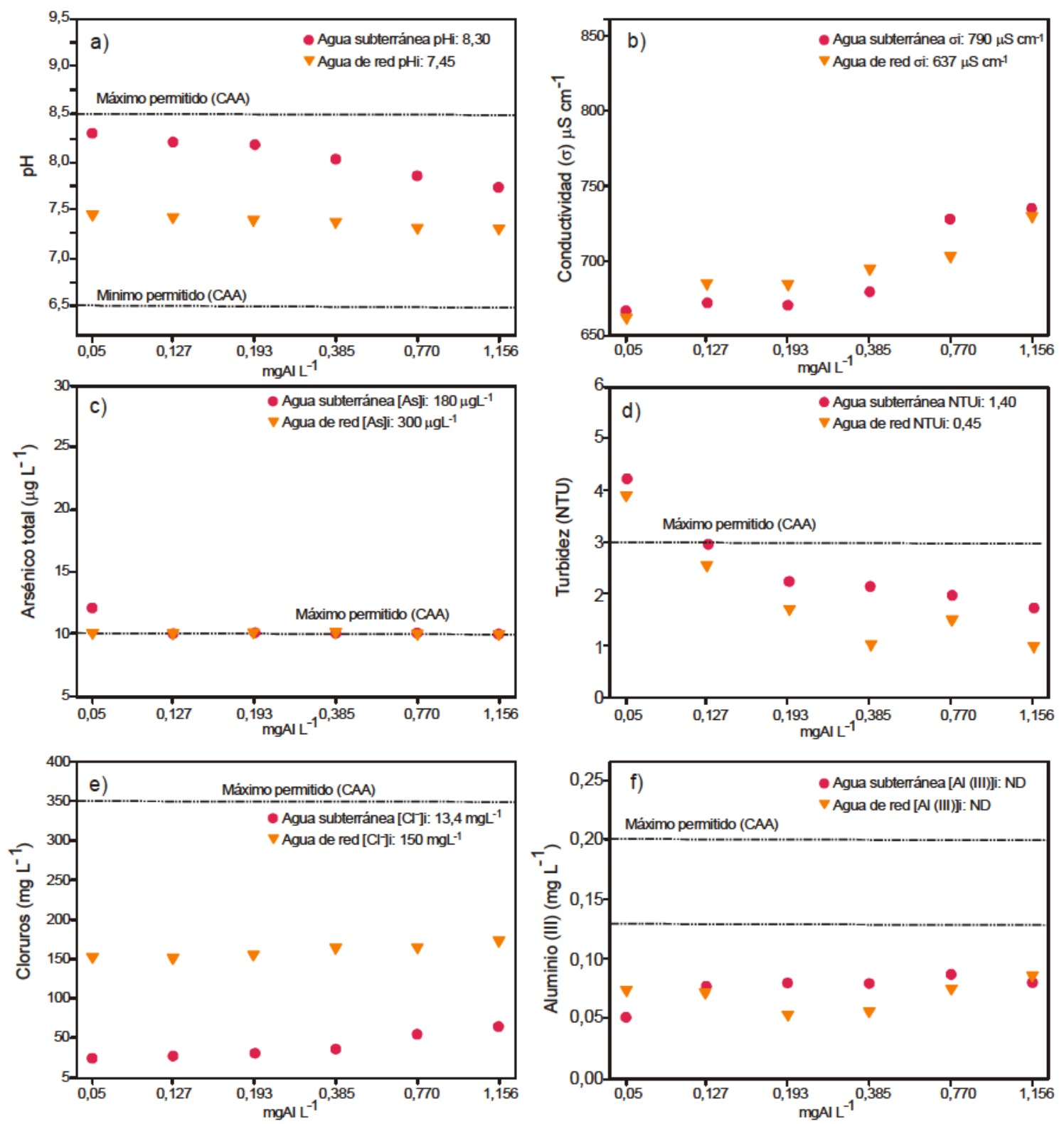

Figura 6.48. Principales parámetros determinados en las aguas luego del tratamiento con distintas dosis de PAC. a) pH vs dosis de PAC. b) conductividad vs dosis de PAC. c) As vs dosis de PAC. d) turbidez vs dosis de PAC. e) Cloruros vs dosis de PAC. f) Al vs dosis de PAC.

En lo que respecta a la variación de los valores de hierro por agregado de diferentes concentraciones de coagulante, en todos los casos la concentración de $\mathrm{Fe}$ (III) es inferior al límite de detección $\left(<0,03 \mathrm{mg} \mathrm{L}^{-1}\right)$ por lo que se deduce que el hierro presente en el material adsorbente no se solubiliza. 
Por último es posible destacar que no se observan diferencias apreciables el comportamiento de ambas matrices acuosas.

Conclusiones parciales: Se puede concluir que es necesario el uso de un coagulante para obtener valores de turbidez dentro de lo permitido por el CAA. El coagulante a base de Al que mostró mejor eficiencia en el proceso fue el policloruro de aluminio y la dosis óptima recomendada es de $0,5 \mathrm{ml}$ de coagulante en $750 \mathrm{ml}$ de agua por jarra/reactor, que equivale a $0,193 \mathrm{mg}$ Al por litro de agua a tratar.

\subsubsection{Efectividad del adsorbente}

El objetivo de este ítem es determinar el agotamiento del adsorbente, con los parámetros previamente optimizados, que permiten esquematizar el proceso global "batch" como se indica en la Figura 6.49. A tal fin se utilizó el material 5AFO y distintas concentraciones iniciales de As.

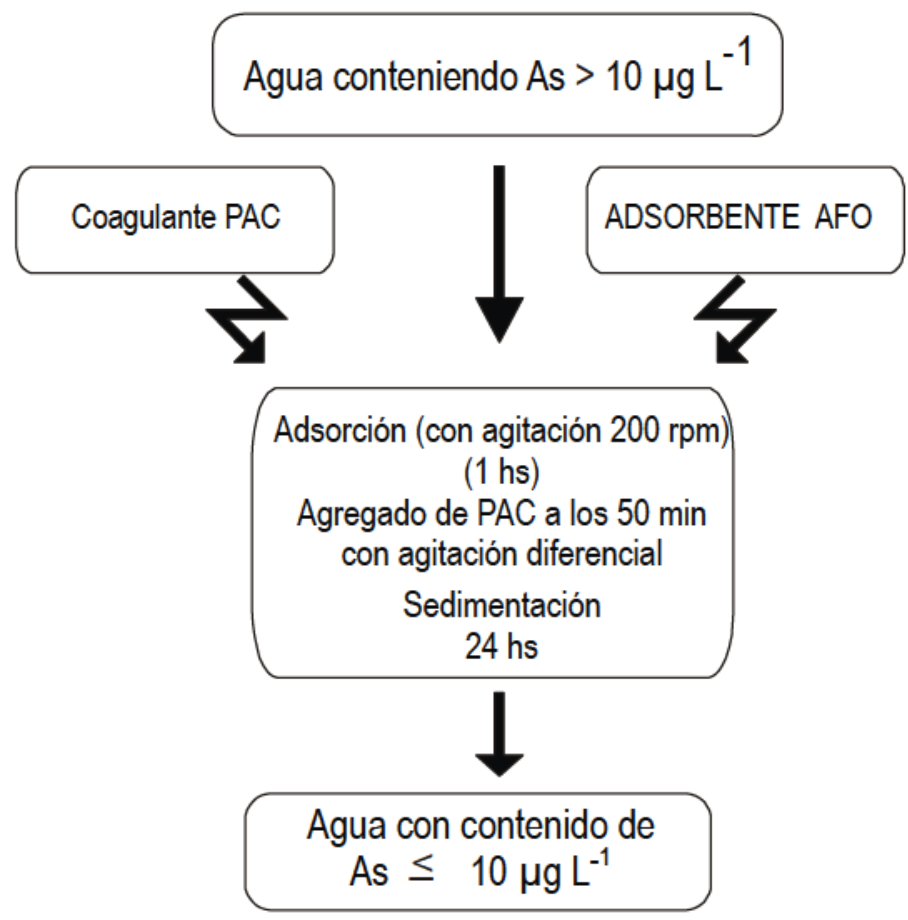

Figura 6.49. Esquema del ciclo de tratamiento a nivel laboratorio.

Los ensayos de adsorción se realizaron en el equipo Jar test utilizando 6 concentraciones distintas de As en simultáneo $\left(200,400,600,800,1000\right.$ y $2000 \mu \mathrm{g} \mathrm{L}^{-}$ $\left.{ }^{1}\right)$. Las soluciones fueron preparadas con agua de red la cual fue modificada químicamente con $\mathrm{As}(\mathrm{V})$, como fue comentado en el Capítulo 5. Se empleó una relación sólido/líquido de $75 \mathrm{~g}$ en $750 \mathrm{ml}$.

El monitoreo de cada reactor se realizó tomando muestras transcurridas las 24 hs de sedimentación. Se determinaron turbidez y contenido de As. Para este último se 
hizo uso del kit de As Merck cuyas características fueron dadas en el Capítulo 5. Periódicamente se corroboraron las mediciones del kit realizando medidas de As por el método EPA 3020/7010.

Los ciclos de tratamiento se repitieron hasta el agotamiento del adsorbente, que fue establecido a partir del ciclo en el que la concentración de As en la solución luego del tratamiento supera el valor de $10 \mu \mathrm{g} \mathrm{L}^{-1}$.

\section{Resultados}

En la Tabla 6.14 y en la Figura 6.50 se muestran los resultados globales obtenidos. El número de ciclos posibles sin cambiar el adsorbente indica la efectividad del mismo. La cantidad de arsénico total adsorbido se expresa en $\mu \mathrm{g}$ de arsénico/gramo de arcilla considerando para el cálculo los ciclos efectivos. En el Anexo 2 se incluyen los resultados de cada ciclo y los cálculos realizados.

Tabla 6.14. Efectividad de adsorbente medida como número de ciclos y cantidad de As retenida.

\begin{tabular}{c|c|c}
\hline $\begin{array}{c}\text { As inicial } \\
\left(\mu \mathrm{L} \mathrm{L}^{-1}\right)\end{array}$ & $\mathrm{N}^{0}$ Ciclos & $\mu \mathrm{g} \mathrm{As} \mathrm{retenidos} / \mathrm{g}_{\text {adsorbente }}$ \\
\hline 200 & 336 & 651,20 \\
400 & 148 & 581,25 \\
600 & 87 & 514,75 \\
800 & 58 & 460,05 \\
1000 & 45 & 447,45 \\
2000 & 20 & 398,00 \\
\hline
\end{tabular}

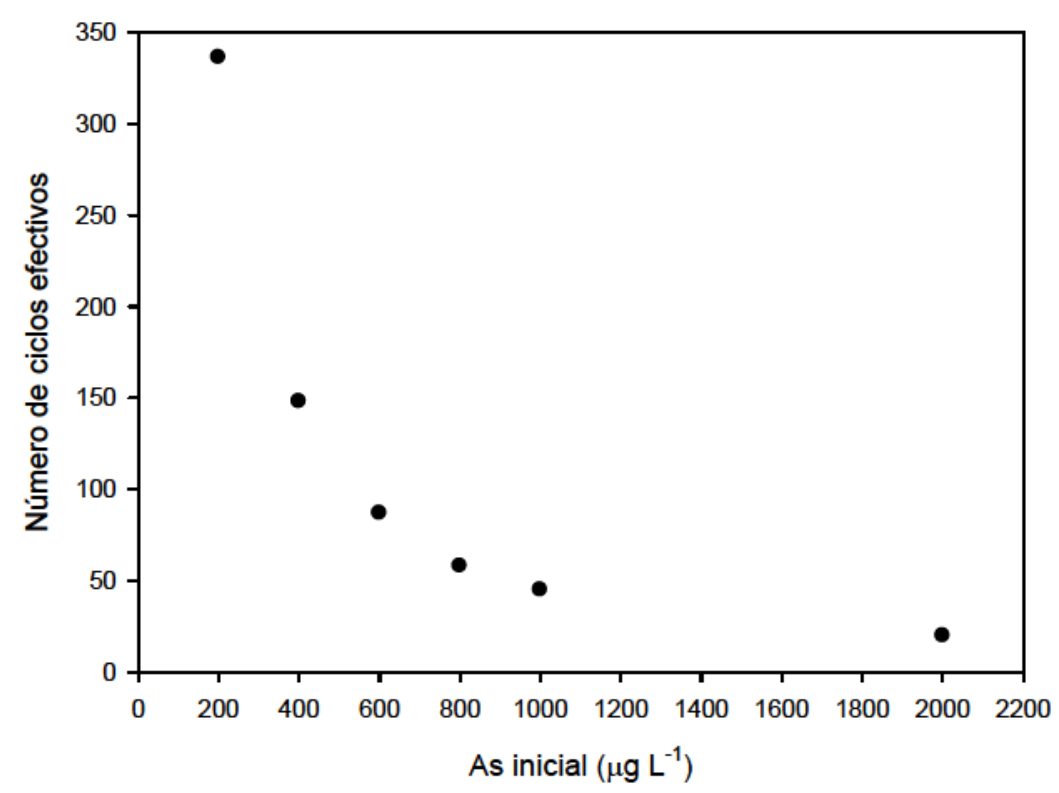

Figura 6.50. Cantidad de ciclos efectivos vs concentración de As en la solución inicial.

Se observa que la retención de As experimental en las condiciones indicadas resulta superior a la calculada a partir de la isoterma de adsorción. Esta diferencia 
puede ser atribuida a un mayor tiempo de contacto, así como al agregado de coagulante, factores que contribuyen a la efectividad del proceso.

Del gráfico también se observa que la cantidad de As en la solución inicial afecta la eficacia de la adsorción, siendo proporcionalmente más efectiva en soluciones diluidas. Este efecto se atribuye a la concentración del contaminante en las proximidades del adsorbente, provocando una contracción de la capa difusa que disminuye la posibilidad de arribo a los sitios de adsorción. Al respecto, el potencial eléctrico decae más rápidamente a medida que la distancia a la superficie crece.

Los resultados obtenidos resultan de interés para el desarrollo del proceso a escala piloto.

\subsubsection{Estudio complementario mediante espectroscopia Raman "microprobe" para visualizar la presencia del contaminante en la arcilla ferruginosa}

Como se comentó en el Capítulo 5, la espectroscopia Raman resulta una herramienta de suma utilidad en la identificación de fases minerales aun en sistemas complejos (Das and Hendry, 2011) y/o en los casos en los que la concentración de la especie a determinar es muy baja o se encuentra dispersa en superficie de manera no homogénea. De esta forma es posible determinar la presencia de silicatos accesorios (cuarzo, feldespatos, etc.) así como otras especies primarias y secundarias como óxidos binarios y oxoaniones de distinta geometría molecular como carbonatos, boratos, fosfatos, sulfatos, arseniatos, etc. En particular la técnica de Raman "microprobe" permite registrar puntualmente el espectro de micropartículas posibilitando el estudio de la interacción superficial de especies adsorbidas en base a los corrimientos y desdoblamientos observados a raíz de la disminución de simetría. Asimismo, esta técnica ha resultado interesante para la detección de As en aguas (hasta $1 \mu \mathrm{g} \mathrm{L}^{-1}$ ) como ha sido reportado por Mulvihill et al. (2008).

Es de señalar que en el sistema saturado la baja relación As/mineral y la complejidad estructural del sólido adsorbente, dificulta la identificación de las especies de As adsorbidas mediante el empleo de técnicas convencionales como DRX o FTIR. En este último caso debido a la superposición de las bandas de estiramiento antisimétrico de los oxoaniones tetraédricos $\mathrm{TO}_{4}$ y $\mathrm{AsO}_{4}$.

Para evaluar la presencia de la especie contaminante en la arcilla ferruginosa luego del tratamiento de adsorción, se realizaron medidas micro-Raman empleando la muestra de material 5AFO con posterioridad a la adsorción del arseniato (material agotado luego de 148 ciclos de tratamiento empleando una concentración inicial de As de $400 \mu \mathrm{g} \mathrm{L}^{-1}$ ). Los espectros fueron contrastados con los de la muestra de arcilla sin 
contacto con aguas contaminadas. Es de destacar que la proporción de As/arcilla en el material agotado es extremadamente baja: $581,25 \mu \mathrm{g}$ de As por $\mathrm{g}$ de mineral según cálculos experimentales de tratamiento (Tabla 6.14) coincidentes con el valor de $0,06 \%$ en As obtenido por ICP-AES. Es de hacer notar que la técnica ICP-MS empleada para la determinación de As como elemento traza en muestras sólidas no pudo utilizarse dado que el contenido del elemento superaba el límite de detección por dicho método (250 ppm).

En relación a las vibraciones del ión $\mathrm{AsO}_{4}{ }^{-3}$ de simetría $\mathrm{Td}$, el ión libre se caracteriza por una muy intensa línea Raman en $837 \mathrm{~cm}^{-1}$ (estiramiento simétrico $\square_{1}$ ) y una intensa banda FTIR en $878 \mathrm{~cm}^{-1}$ (estiramiento antisimétrico As-O) que se superpone con las bandas de la especie $\mathrm{SiO}_{4}$ (aproximadamente $1000 \mathrm{~cm}^{-1}$ ). La vibración $\square_{1}$ de las especies silícicas condensadas se encuentra corrida a menores frecuencias. Cabe recordar que los espectros Raman de distintos minerales arcillosos y oxídicos de hierro, presentan líneas características por debajo de $700 \mathrm{~cm}^{-1}$.

En la Figura 6.51 se muestra el espectro Raman de la muestra sin tratamiento. Como se comentara previamente en el ítem 6.1.2, el hierro se asocia fundamentalmente a la presencia de hematita $\left(225,294,400,600\right.$ y $\left.700 \mathrm{~cm}^{-1}\right)$, observándose también la presencia de filosilicatos dioctaédricos (Hanesch, 2009; Das and Hendry, 2011).

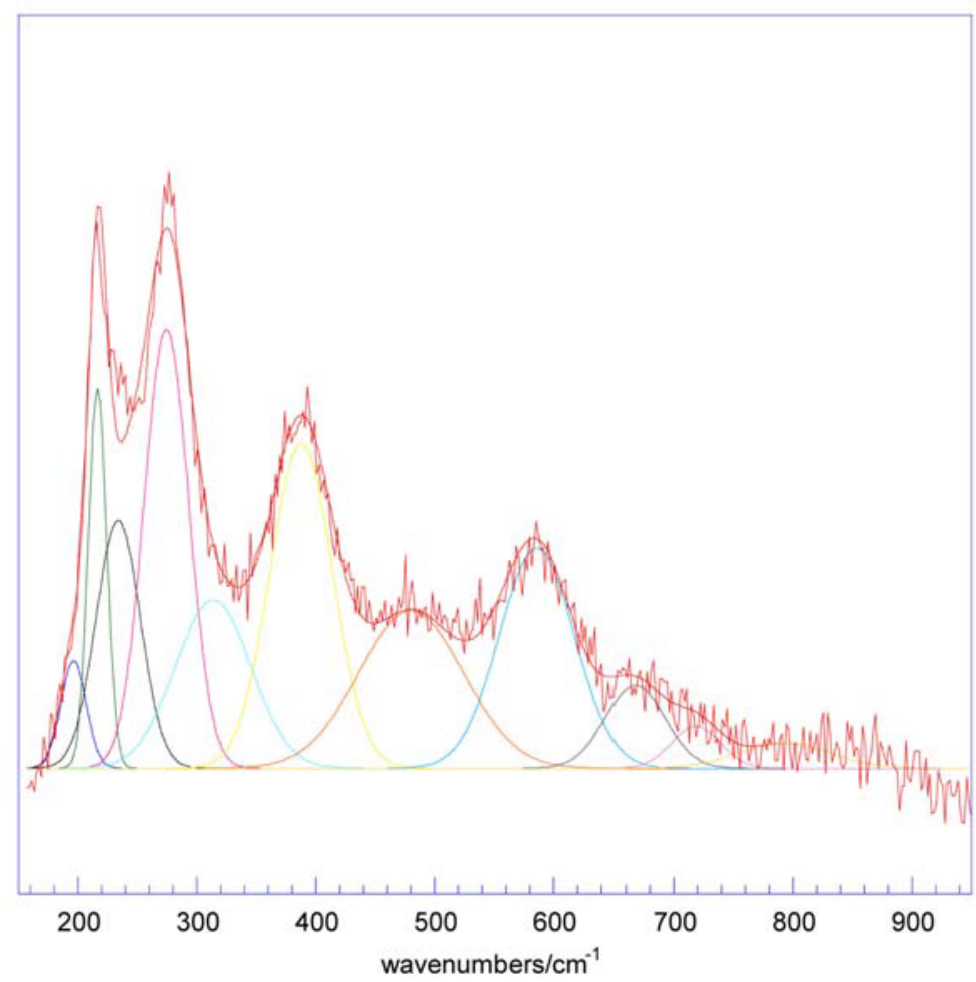

Figura 6.51. Espectro micro-Raman de la muestra 5AFO sin contacto con agua conteniendo As. 
En la Figura 6.52 se muestran los espectros de la arcilla ferruginosa agotada sometida a un ligero tratamiento térmico $\left(130^{\circ} \mathrm{C}\right)$ para favorecer la interacción arseniato-Fe. Se observa un incremento paulatino de la resolución de las líneas Raman correspondientes al óxido férrico así como una incipiente señal en la zona típica del arseniato.

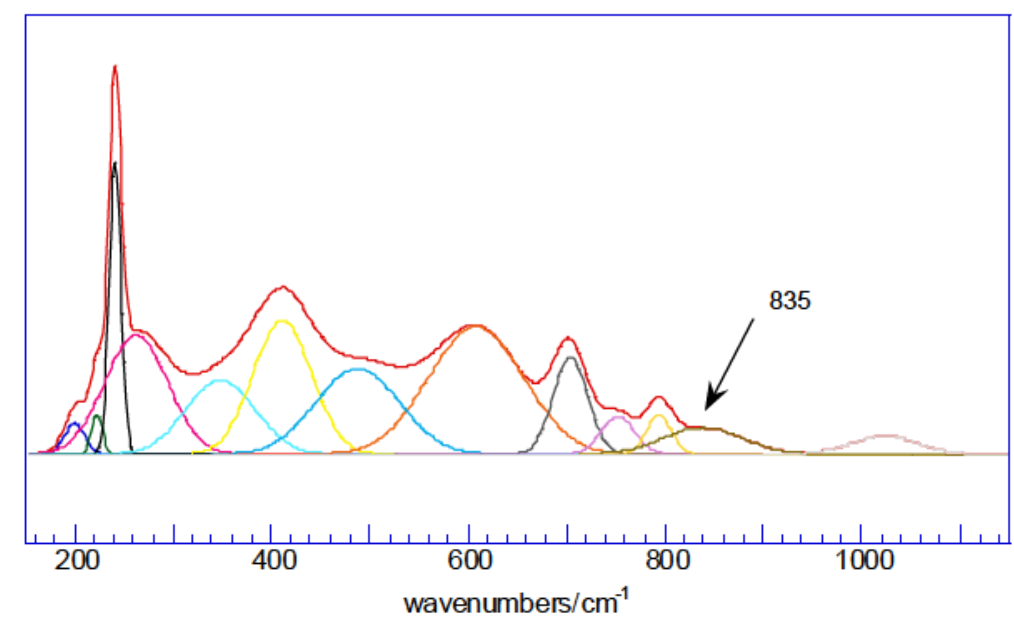

Figura 6.52. Espectro micro-Raman de la muestra $5 \mathrm{AFO}$ agotada (148 ciclos de tratamiento con agua conteniendo una concentración inicial de As de $400 \mu \mathrm{g} \mathrm{L}^{-1}$ ).

En la Figura 6.53 se muestra un detalle de la zona entre $500-900 \mathrm{~cm}^{-1}$, que permite visualizar más claramente las señales en la zona de $800 \mathrm{~cm}^{-1}$ que sugieren la presencia de tetraedros $\mathrm{AsO}_{4}$ distorsionados. La banda a menor frecuencia se atribuye al estiramiento simétrico de la especie tetraédrica $\left(\mathrm{AsO}_{4}\right)^{3-}$, mientras que la banda a $\sim 830 \mathrm{~cm}^{-1}$ se puede atribuir al estiramiento simétrico As-O de las especies superficiales $\mathrm{HAsO}_{4}{ }^{2-} \mathrm{y} \mathrm{H}_{2} \mathrm{AsO}_{4}{ }^{1-}$ (Myneni et al., 1998).

Estos datos sugieren que la interacción entre las fases oxídicas de hierro con el arsénico ocurre a través de la formación de complejos de esfera interna mono y/o bidentados en concordancia con datos reportados en la literatura que fueran citados en el ítem 4.3 del Capítulo 4.

La espectroscopía Raman "microprobe" ha permitido revelar la presencia de la especie arseniato interaccionada en la muestra arcillosa agotada luego de ser empleada en el proceso de adsorción, preferentemente en sitios ricos en hierro. 


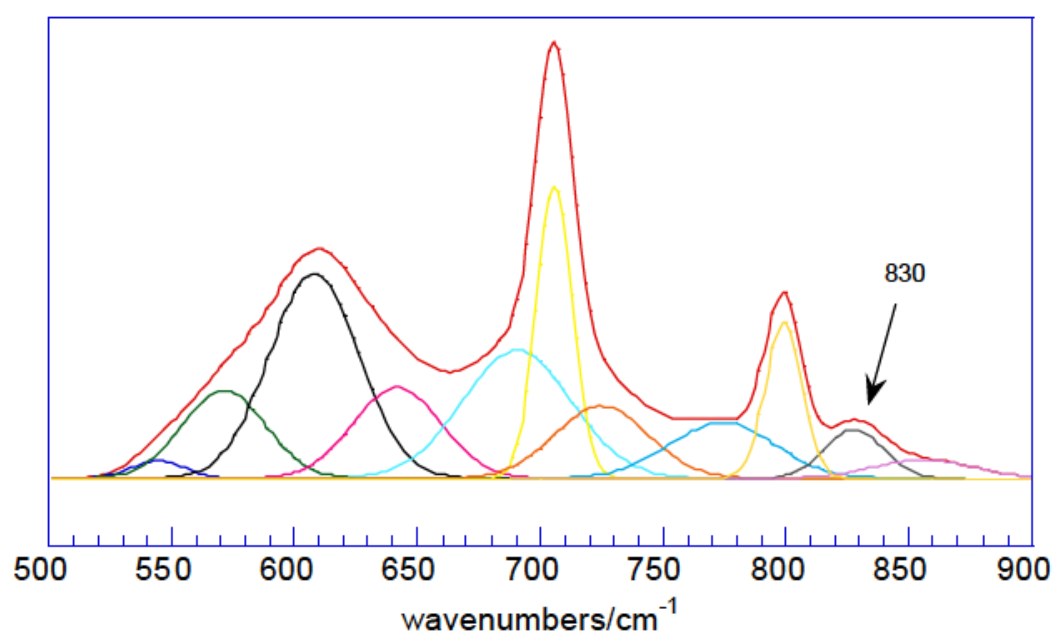

Figura 6.53. Detalle de la zona del espectro comprendida entre 500 y $900 \mathrm{~cm}^{-1}$.

\subsection{Escalado a nivel planta piloto}

En una primera etapa, se realizaron ensayos a escala banco en base a las condiciones optimizadas a nivel laboratorio que se muestran en el esquema operativo de la Figura 6.49. A tal fin se utilizó un reactor cilíndrico de lecho fijo de 5 litros de capacidad, dotado de un dispositivo de agitación vertical, trabajando con $400 \mathrm{~g}$ de adsorbente y $4 \mathrm{~L}$ de agua preparada en el laboratorio con agua de red conteniendo $1000 \mu \mathrm{g} \mathrm{L}^{-1}$ de As. El arsénico original y posterior al tratamiento se determinó con el Kit Merck.

Como se observa en la Tabla 6.15 , al cabo de 5 ciclos de tratamiento, la concentración de As disminuye al valor requerido por la normativa vigente, sin embargo la turbidez resulta ligeramente superior a 3 NTU, sin que ese pequeño exceso afecte el valor del contenido de arsénico. Este comportamiento indica la necesidad de ajustar las condiciones de tratamiento o modificar el esquema operativo.

Tabla 6.15. Resultados de turbidez para los primeros 5 ciclos de tratamiento a escala banco.

\begin{tabular}{c|c|c}
\hline Ciclo de tratamiento & Turbidez (NTU) & As \\
\hline 1 & 4,34 & 10 \\
2 & 3,79 & $<10$ \\
3 & 4,23 & 10 \\
4 & 3,98 & $<10$ \\
5 & 4,21 & 10 \\
\hline
\end{tabular}

De esta forma, a fin de evita el agregado de una mayor cantidad de coagulante o incrementar el tiempo de permanencia en el reactor, se incluyó una segunda etapa, en la cual el líquido sobrenadante fue transferido a un segundo recipiente para que se complete la sedimentación (denominado reactor de sedimentación). En este segundo 
reactor se dejó en reposo el líquido durante 24 hs adicionales. La eficiencia del tratamiento fue evaluada, determinando en cada ciclo de tratamiento efectivo la turbidez en ambos reactores y la concentración de As.

En la Figura 6.54 se muestran los valores de turbidez en el reactor con agitación (reactor 1) y en el de sedimentación (reactor 2), obtenidos en los 41 ciclos de tratamiento que resultó efectivo el adsorbente. El agregado del segundo reactor representa una alternativa interesante para llegar a los valores de turbidez adecuados.
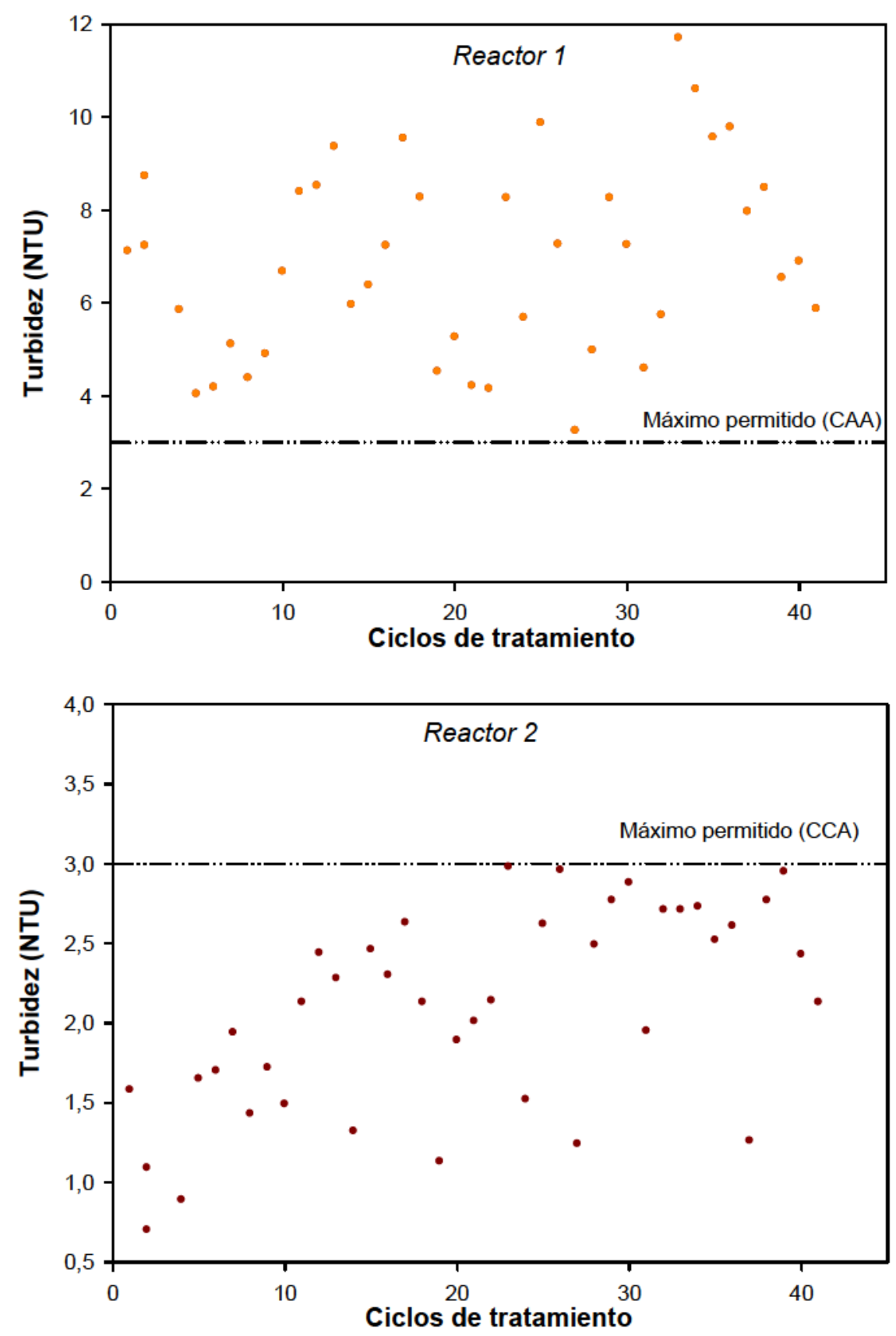

Figura 6.54. Turbidez medida en los reactores 1 y 2 para los ciclos de tratamiento efectivos. 
La Figura 6.55 representa la nueva secuencia de etapas que conducen a un agua con valores finales de As $\leq 10 \mu \mathrm{g} \mathrm{L}^{-1}$ y de turbidez $\leq 3 \mathrm{NTU}$.

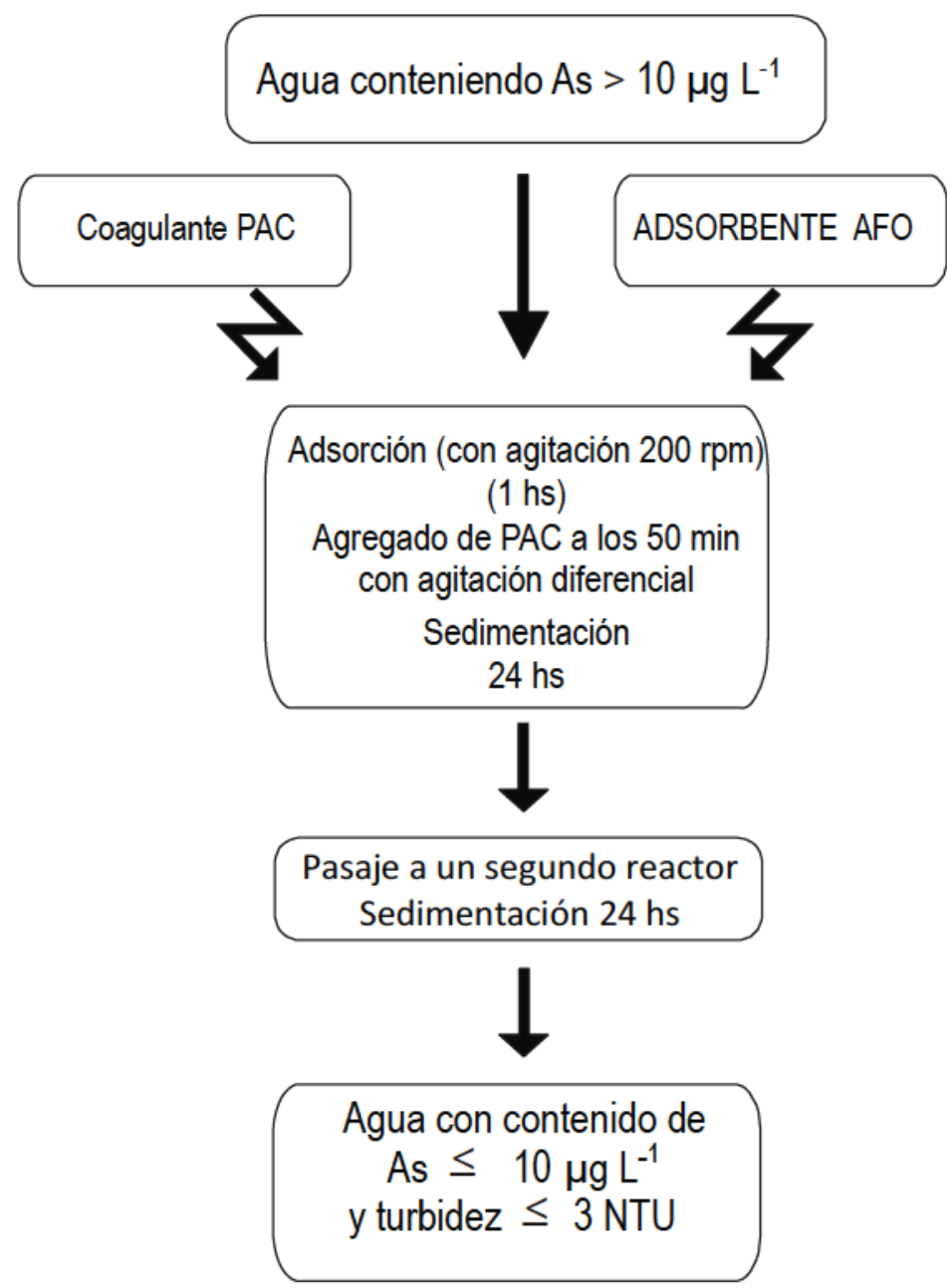

Figura 6.55. Esquema del ciclo de tratamiento a nivel banco.

El escalado a nivel planta piloto se llevo a cabo en el centro PlaPiMu-CICPBA, dirigido por el Prof. Dr. H. Thomas, donde, con la participación de un equipo técnico, se logró el tratamiento de un volumen mayor de agua, sobre la base del esquema mostrado en la Figura 6.55 .

El equipo, esquematizado en la Figura 6.56, consta de tres tanques de $2500 \mathrm{~L}$ de capacidad, indicando a continuación la función de cada uno de ellos. En el tanque número 1 , se produce el proceso de contacto adsorbente-agua. Para evitar efectos de vórtice, se emplea una proporción de $200 \mathrm{~kg}$ de adsorbente y $2000 \mathrm{~L}$ de agua. Tanto el mineral como el agua a tratar son incorporados por la parte superior del tanque. En el caso de proceder al tratamiento de un agua natural, el proceso incluye el agregado de hipoclorito de sodio comercial ( 2 gotas por litro de agua a tratar) para asegurar el mantenimiento de la calidad microbiológica del agua y la presencia del arsénico en su mayor estado de oxidación. 


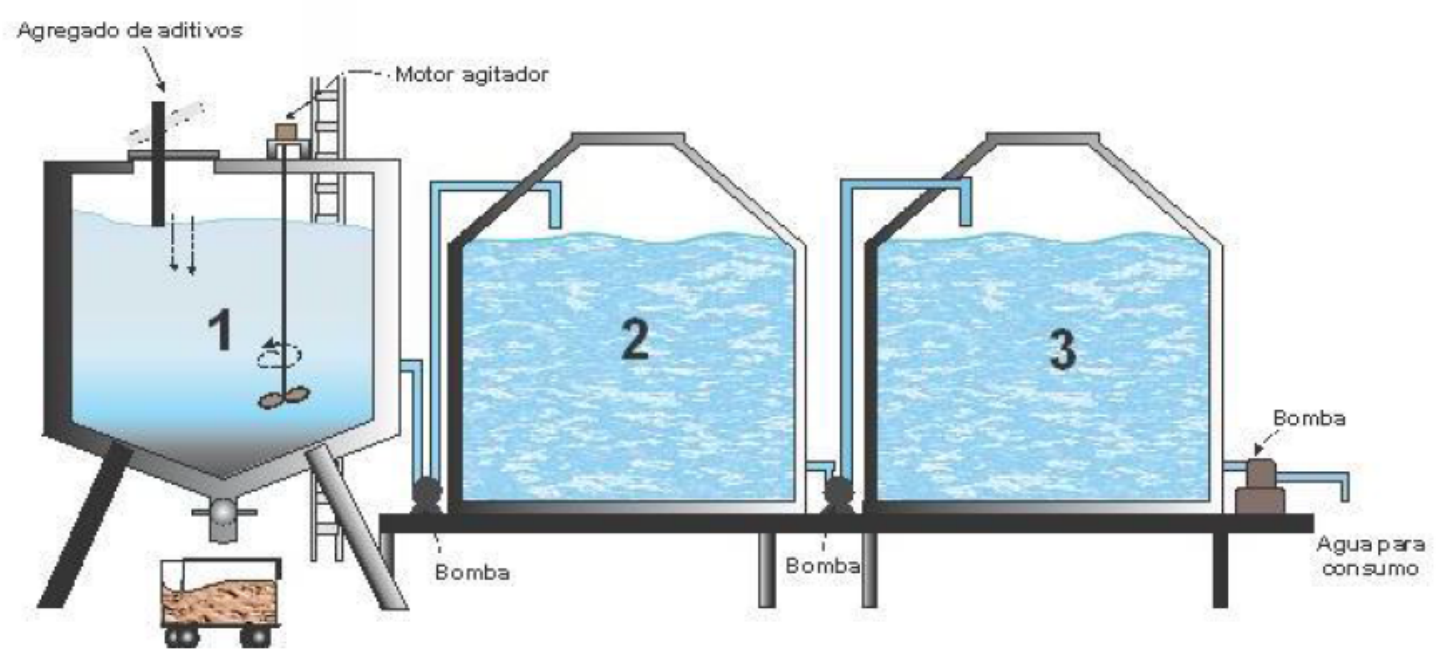

Figura 6.56. Esquema del equipo de tratamiento para la reducción de As.

Debido a la necesidad de movilizar una masa considerable de lodo, se emplea un sistema de agitación que consta de un motor eléctrico trifásico de 1HP, una barra de 2,2 $\mathrm{m}$ de longitud y 2 paletas de $0,40 \mathrm{~m}$ de longitud cada una, en acero inoxidable. El sistema cuenta, además, con un programa de arranque a baja velocidad que facilita la movilidad inicial del lodo y luego va aumentando conforme a una rampa preestablecida hasta llegar a la velocidad final de $700 \mathrm{rpm}$.

El rol del tanque 2 está dirigido a completar la sedimentación, depositándose en el fondo del mismo una pequeña cantidad de sólido, inferior al $0,1 \%$ de la masa de sólido incorporada al tanque 1.

El tanque final número 3 tiene por simple objeto el almacenamiento del agua en condiciones aptas para su consumo.

Una vez trasvasada el agua al tanque 2, se vuelve a repetir el ciclo de tratamiento en el tanque 1, tantas veces hasta que la concentración de As medida supere el valor establecido, momento en el cual es requerido el cambio de adsorbente.

El lodo agotado se retira por la parte inferior cónica del tanque 1 (Figura 6.56).

Los pasos seguidos para el logro de una estrategia de tratamiento que permite la remoción del arsénico en aguas, en base al empleo de arcillas ferruginosas de la PBA con un contenido en óxido férrico del orden de 40-60\%, constituye una contribución interesante y sencilla para la remediación de la problemática en zonas rurales carentes de aguas de red. El tratamiento conduce a valores de As adecuados para su consumo, evitando serios riesgos para la salud de la población. El diseño del equipo, de tipo discontinuo, resulta de simple construcción y facilidad operativa, y su eficiencia depende particularmente de las características fisicoquímicas de las aguas naturales. 
La primera planta de tratamiento fue instalada en el año 2009 en la Escuela $\mathrm{N}^{0} 1$ del Paraje La Viruta, Partido de Punta Indio (PBA), asegurando la provisión de agua en el establecimiento educativo y en las poblaciones aledañas (Fotos 6.1 y 6.2).

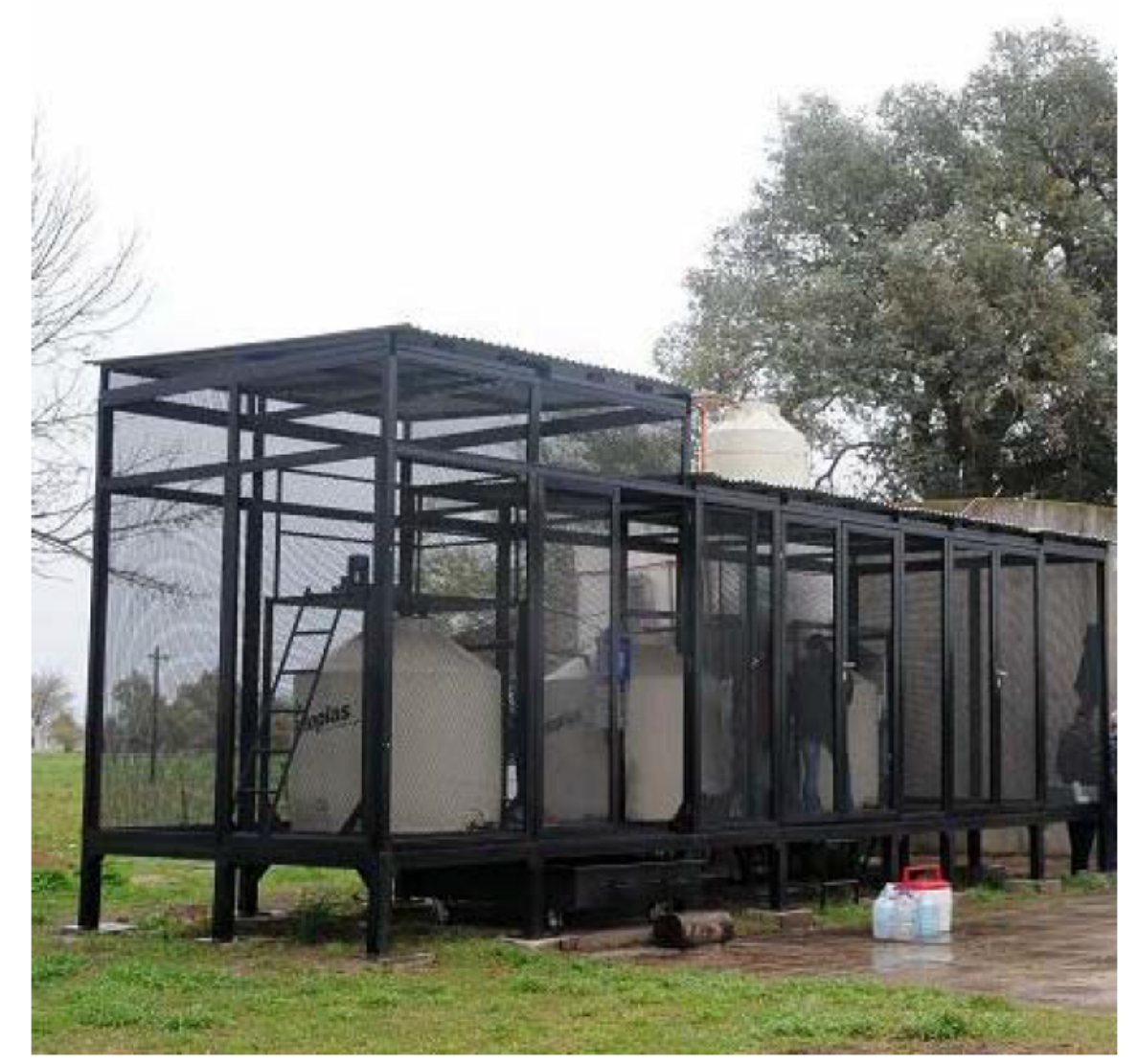

Foto 6.1. Planta de tratamiento instalada en la Escuela $N^{0} 1$ del Paraje La Viruta, Punta Indio.

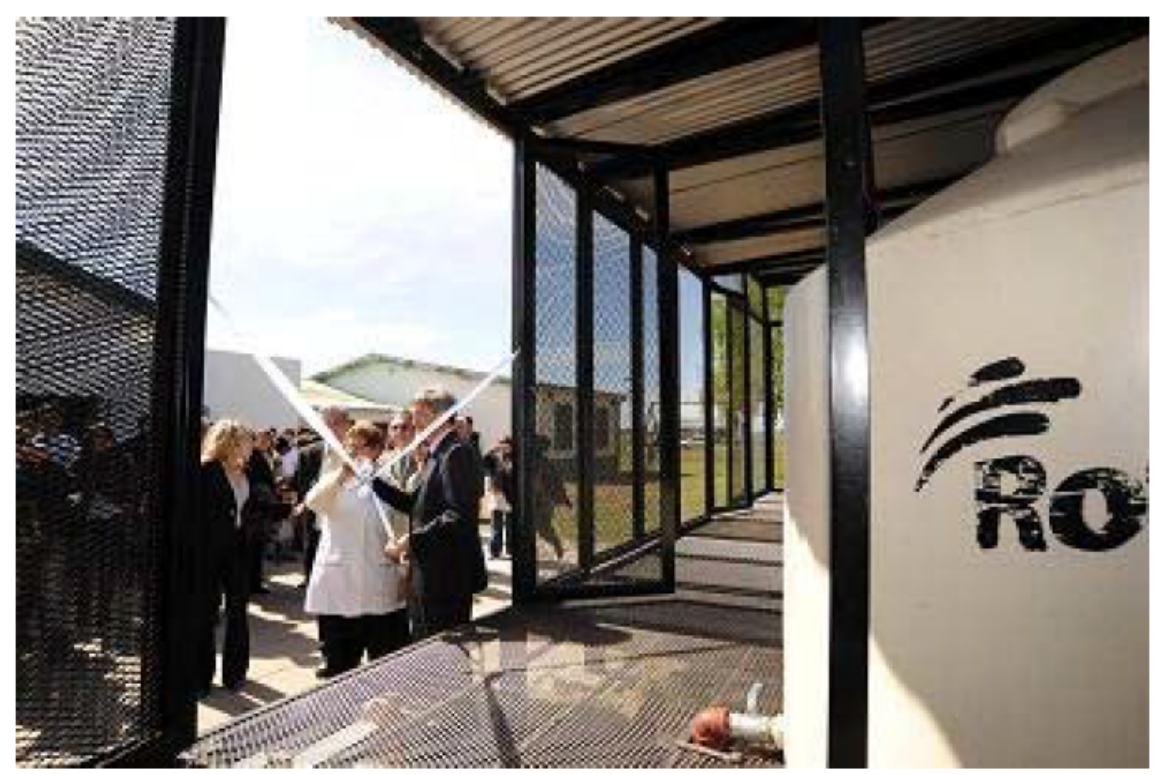

Foto 6.2. Inauguración de la planta de tratamiento ( 25 de Septiembre de 2009). 


\section{CAPÍTULO 7}

\section{Potencialidad de otros geomateriales naturales y químicamente modificados en el proceso de adsorción de arsénico}

En este capítulo se presentan los resultados de los ensayos de adsorción realizados empleando como adsorbentes otros minerales provenientes de depósitos nacionales.

En una primera instancia se analizó la posibilidad de aprovechamiento de especies minerales con bajos contenidos de hierro (inferior al $5 \%$ como $\mathrm{Fe}_{2} \mathrm{O}_{3}$ ) que permitieran, mediante una modificación química adecuada, la obtención de geomateriales activados aptos en el proceso de adsorción de As. Este punto incluye el tratamiento químico de las especies mediante el empleo de soluciones de sales de $\mathrm{Fe}(\mathrm{III})$, la caracterización de las muestras originales y activadas y su posterior utilización en el tratamiento de remoción de As, comparándolas con los datos obtenidos para las arcillas ferruginosas.

Finalmente, se analizó el empleo de otros minerales ricos en hierro procedentes del yacimiento Unchimé. Las muestras fueron caracterizadas fisicoquímicamente y empleadas en el tratamiento de remoción de As. Los datos de estos ensayos fueron comparados con los obtenidos para las arcillas ferruginosas de la PBA.

7.1. Potencialidad en el proceso de adsorción de As de geomateriales químicamente modificados

\subsubsection{Algunos aspectos relacionados a la adsorción de As con minerales activados}

Algunos aluminosilicatos como arcillas y zeolitas se encuentran ampliamente dispersos en la naturaleza y representan fuentes de muy bajo costo. Los minerales de arcilla se encuentran en muchos casos asociados a especies oxídicas de hierro, producto de procesos de lixiviación de otros minerales que han conducido a la depositación de dichas fases. Es así que en muchos casos, como en el de las arcillas AFO analizadas en el capítulo anterior, la presencia de este material ferruginoso sustenta la posibilidad de su aplicación en el proceso de remoción de arseniatos.

Por otra parte, los minerales de arcilla con bajo contenido de hierro no presentan propiedades adsorbentes selectivas para los contaminantes aniónicos debido a su bajo punto de carga cero (Capítulos 3 y 4). Sin embargo, estos materiales son susceptibles de ser modificados químicamente para transformarlos en aptos para el proceso de adsorción de As. En consecuencia, se han reportado estudios tendientes al desarrollo de nuevos materiales con recubrimiento de hierro debido a la fuerte afinidad 
del Fe(III) hacia las especies inorgánicas de arsénico (Amiri et al., 2011). Entre ellos, arena, alúmina, zeolita, "red mud", metacaolinita, arcillas (Joshi and Chaudhuri, 1996; Thirunavukkarasu et al., 2003; Doušová et al., 2006; Chen et al., 2007; Zhang et al., 2008; Doušová et al., 2009; Jeon et al., 2009; Amiri et al., 2011). Haque et al. (2008) han reportado que el tratamiento con sales de hierro crea sitios de adsorción favorables para el arsénico a través de diversos mecanismos de adsorción tales como la formación de complejos de superficie mono y bidentados.

A escala de laboratorio la precipitación "in situ" de los oxi/hidróxidos de Fe es lograda empleando sales de hierro(III) y ajustando el $\mathrm{pH}$ mediante un hidróxido alcalino para lograr la precipitación del oxi/hidróxido (Giles et al., 2011). La hidrólisis rápida de soluciones de $\mathrm{Fe}(\mathrm{III})$ conduce a la precipitación inicial de ferrihidrita (Schwertmann and Cornell, 2000). La ferrihidrita juega un papel importante como adsorbente activo en ambientes naturales, debido a su área superficial muy alta (Davis et al., 1993; Schwertmann and Cornell, 2000). En condiciones acuosas las partículas coloidales de la ferrihidrita pueden formar grandes flóculos o agregados de partículas (Davis et al., 1993). De esta forma, la capacidad de adsorción de la ferrihidrita es extremadamente alta, lo que puede explicarse mediante la visualización de una estructura abierta, altamente hidratada, permeable a los iones hidratados (Pierce and Moore, 1982). Los iones son libres para difundir en toda la estructura no quedando solo restringidos a los sitios de la superficie externa como ocurre en un sólido de mayor cristalinidad.

\subsubsection{Activación de las muestras}

En el esquema de la Figura 7.1 se muestran los pasos seguidos para la preparación de las muestras activadas, su posterior caracterización y empleo en el proceso de remoción de As bajo las mismas condiciones experimentales que fueran optimizadas en el Capítulo 6 para las arcillas ferruginosas.

Se activaron las especies minerales descriptas en el ítem 4.4.3, las que para su análisis fueron identificadas con la siguiente nomenclatura: I, K, Py, B, Z, D y $D_{2}$. Todas las muestras fueron molidas en molino de martillo para obtener la distribución granulométrica denominada molienda fina, que fuera empleada para la arcilla ferruginosa (Capítulo 6).

La precipitación "in situ" de ferrihidrita sobre los minerales se realizó siguiendo la técnica de Schwertmann and Cornell (2000) para la obtención de ferrihidrita, utilizando solución de $\mathrm{Fe}\left(\mathrm{NO}_{3}\right)_{3} .9 \mathrm{H}_{2} \mathrm{O}$ en medio de $\mathrm{KOH} 1 \mathrm{M}$ (relación $\mathrm{Fe}^{+3} / \mathrm{OH}^{-}=1 / 3$ ), ajustando el $\mathrm{pH}$ a 7 . En estas condiciones de hidrólisis rápida a $\mathrm{pH}$ neutro y a temperatura 
ambiente se obtiene ferrihidrita "2-line". Sin embargo, la existencia de una continua transición entre ferrihidrita "2-line" y "6-line" indica la cercana relación entre ambas formas y justifica la denominación simplemente de "ferrihidrita" (Schwertmann and Cornell, 2000).

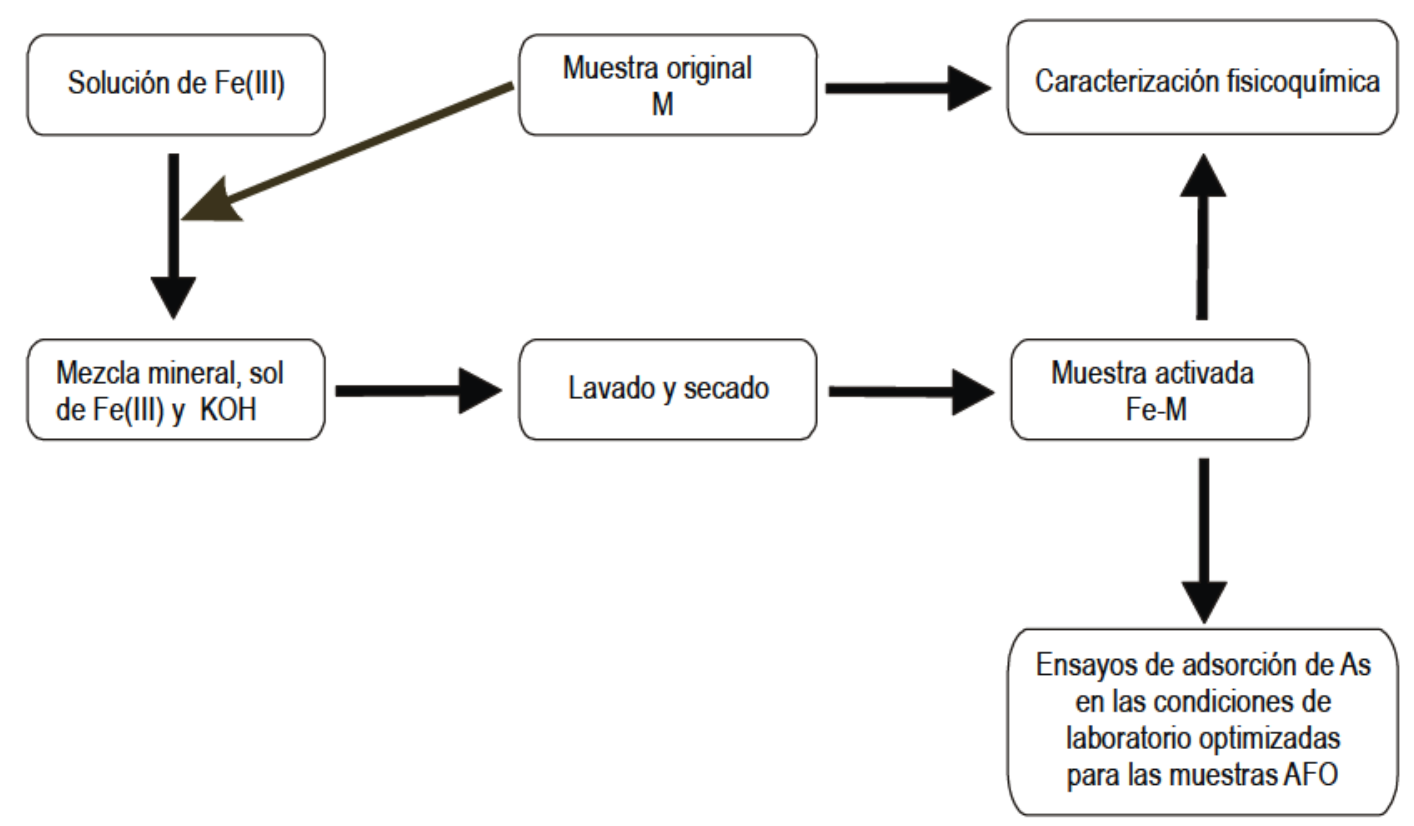

Figura 7.1. Esquema de preparación y uso de las muestras activadas.

Se activaron $100 \mathrm{~g}$ de cada mineral trabajando en vasos de precipitado de 1000 ml. Se agregaron $250 \mathrm{ml}$ de $\mathrm{H}_{2} \mathrm{O}$ destilada y $20 \mathrm{~g}$ de $\mathrm{Fe}\left(\mathrm{NO}_{3}\right)_{3} \cdot 9 \mathrm{H}_{2} \mathrm{O}$ (Merck). En todos los casos se determinó el $\mathrm{pH}$ luego de la disolución de la sal $\left(\mathrm{pH}_{1}\right)$. Con agitación magnética se agregaron $155 \mathrm{ml}$ de $\mathrm{KOH} 1 \mathrm{M}$ y se volvió a determinar el $\mathrm{pH}\left(\mathrm{pH}_{2}\right)$. Posteriormente se llevó a neutralidad mediante el agregado de $\mathrm{KOH} 1 \mathrm{M}$ en constante agitación. Las muestras modificadas, fueron centrifugadas (10 min a $2000 \mathrm{rpm}$ ), lavadas hasta la eliminación total de nitratos y secadas en estufa a $60^{\circ} \mathrm{C}$.

Los valores de $\mathrm{pH}$ de cada etapa determinados con tiras (Merck) así como los volúmenes agregados de base para llegar a neutralidad y la cantidad de lavados realizados se indican en la Tabla 7.1.

Las muestras activadas químicamente fueron identificadas con el agregado del símbolo Fe al inicio de la nomenclatura de la muestra original.

Con fines comparativos se sintetizó ferrihidrita utilizando el procedimiento indicado previamente, disolviendo $20 \mathrm{~g}$ de sal férrica en $250 \mathrm{ml} \mathrm{de} \mathrm{H}_{2} \mathrm{O}$ destilada. Con agitación magnética se agregaron $155 \mathrm{ml}$ de $\mathrm{KOH} 1 \mathrm{M}$ y finalmente se llevó a pH neutro por el agregado gota a gota de solución de $\mathrm{KOH} 1 \mathrm{M}$. La separación se realizó por centrifugación (10 min a $2000 \mathrm{rpm}$ ). El sólido se lavó con $\mathrm{H}_{2} \mathrm{O}$ destilada hasta 
reacción de identificación de nitratos negativa (se realizaron 3 lavados). Finalmente, el sólido se secó a T ambiente.

Tabla 7.1. Datos de $\mathrm{pH}$, volumen de $\mathrm{KOH}$ y lavados realizados en la activación de los geomateriales.

\begin{tabular}{c|c|c|c|c}
\hline Muestra & $\mathrm{pH}_{1}$ & $\mathrm{pH}_{2}$ & $\begin{array}{c}\mathrm{V}_{\mathrm{KOH}} \text { agregado } \\
(\mathrm{ml})\end{array}$ & $\begin{array}{c}\text { Cantidad de } \\
\text { lavados }\end{array}$ \\
\hline $\mathrm{I}$ & 2 & 5 & 74 & 3 \\
$\mathrm{Z}$ & 2 & $5-6$ & 75 & 4 \\
$\mathrm{D}_{1}$ & 2 & 5 & 40 & 4 \\
$\mathrm{D}_{2}$ & 3 & $8-9$ & $*$ & 4 \\
$\mathrm{~K}$ & $1-2$ & $2-3$ & 53 & 5 \\
$\mathrm{Py}$ & 2 & 3 & 54 & 5 \\
$\mathrm{~B}$ & 2 & $2-3$ & 69 & 4 \\
\hline
\end{tabular}

* Para la muestra $\mathrm{D}_{2}$ luego del agregado de la cantidad calculada de $\mathrm{KOH}$ el $\mathrm{pH}$ obtenido superó la neutralidad. En este caso el pH se llevó a 7 mediante el agregado de $\mathrm{HNO}_{3} 10 \%$, siendo necesario el agregado de $5 \mathrm{ml}$.

Para la identificación cualitativa de los nitratos en el agua de lavado, se empleó la reacción con sulfato ferroso, en la cual se produce la oxidación del catión $\mathrm{Fe}^{+2}$ y la reducción del nitrato a monóxido de nitrógeno. La reacción se llevó a cabo en un tubo de ensayo donde se agregaron $2 \mathrm{ml}$ del agua de lavado y $4 \mathrm{ml}$ de solución saturada de $\mathrm{FeSO}_{4}$ preparada en el momento. Luego, se agregaron lentamente por las paredes del tubo $1 \mathrm{ml}$ de $\mathrm{H}_{2} \mathrm{SO}_{4}$ (c). La formación de un anillo pardo o negro en la interface de las dos soluciones indica la presencia de nitratos en la solución.

\subsubsection{Caracterización de las muestras originales y activadas químicamente}

En la caracterización de las muestras originales y activadas se emplearon las siguientes técnicas: análisis químico de elementos mayoritarios (ICP-AES), DRX, SEM-EDS y superficie específica BET. Se realizaron estudios complementarios por espectroscopia Raman.

En la Tabla 7.2 se muestran los resultados obtenidos en la determinación de los elementos mayoritarios expresados como óxidos. Como resultado de la activación en todos los casos se observa un incremento en el contenido de hierro (expresado como $\mathrm{Fe}_{2} \mathrm{O}_{3} \%$ ), ligeramente inferior a $5 \%$ (entre 3,31 y 4,11 ). Los valores de la relación $\mathrm{SiO}_{2} / \mathrm{Al}_{2} \mathrm{O}_{3}$ para las muestras originales y modificadas, presentan una coincidencia aceptable como puede apreciarse en la última fila de la Tabla 7.2. Las ligeras diferencias observadas en los restantes elementos, particularmente en las especies laminares 2:1, pueden asociarse al tratamiento alcalino, observando que la pérdida de silicio es más efectiva en las estructuras con mayor número de capas tetraédricas.

Los valores de As de las muestras originales (obtenido por la técnica ICP-MS) se presentan en la Tabla 7.3, observándose que los mismos en los productos laminares guardan una relación directa con el contenido de hierro. 
Las Fotos 7.1 a y b muestran comparativamente las muestras originales y modificadas. Puede apreciarse el cambio en la coloración de las muestras originales como consecuencia de la activación química con las sales de hierro.
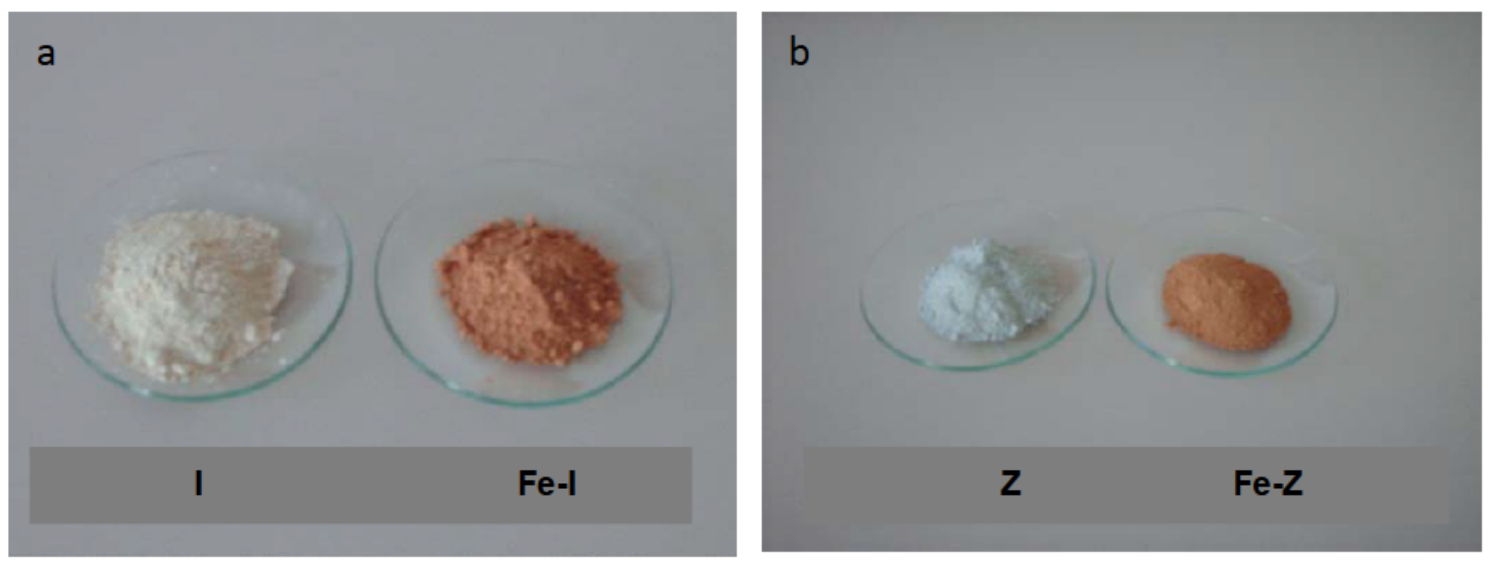

Foto 7.1. Modificación de color producto de la activación química a) muestra I, b) muestra Z.

En la Figura 7.2 se observa el diagrama de difracción de la ferrihidrita sintetizada como control, secada a temperatura ambiente (a) y en estufa a $150{ }^{\circ} \mathrm{C}$ durante $2 \mathrm{hs}$ (b).
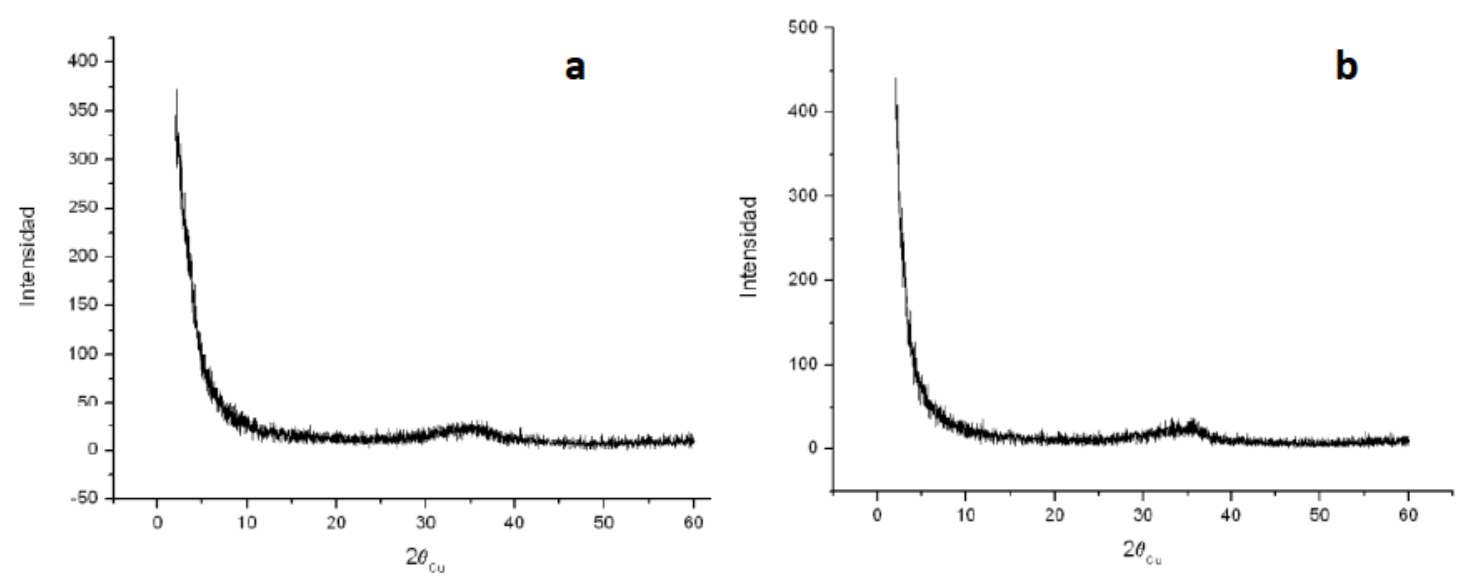

Figura 7.2. Diagrama DRX de la ferrihidrita a) secada a temperatura ambiente y b) secada en estufa a $150^{\circ} \mathrm{C} 2 \mathrm{hs}$ (difractómetro Philips PW1710, LANADI-FCE, UNLP).

Los difractogramas obtenidos son típicos de materiales de muy baja cristalinidad, observándose una banda ancha aproximadamente a $35^{\circ}$ de $2 \theta$. Estos datos están en coincidencia con los reportados por Schwertmann and Cornell (2000) y Das and Hendry (2011) quienes caracterizan a la ferrihidrita por 2 picos anchos aproximadamente en $34^{\circ}$ y $61^{\circ}$ de $2 \theta$. Es de destacar que no se observa que la cristalinidad se vea favorecida por un tratamiento térmico suave, motivo por el cual se puede emplear temperatura para disminuir el tiempo de secado de las muestras sin aumentar la cristalinidad. 
En las Figuras 7. 3 a 9 se observan comparativamente los diagramas de DRX de las muestras originales y activadas. Es de destacar que los difractogramas de las muestras luego de la activación, no han revelado cambios estructurales significativos en comparación con los de las especies minerales originales, no revelando líneas de difracción correspondientes a la ferrihidrita u otras formas cristalinas de óxidos de Fe. Esto sugeriría que la fase de hierro producto de la modificación química es de tipo amorfo. Este comportamiento, reportado por Celis et al. (1998) para las especies caolinita y montmorillonita asociadas a ferrihidrita, puede deberse al agregado de una baja concentración de Fe, como así también a la inhibición del crecimiento cristalino de la ferrihidrita causada por los minerales de arcilla.

Los diagramas de DRX de la muestras denominadas I y Fe-I (Figura 7.3), indican la presencia de la especie illita (PDF 26-0911), con cuarzo como accesorio (PDF 872096).

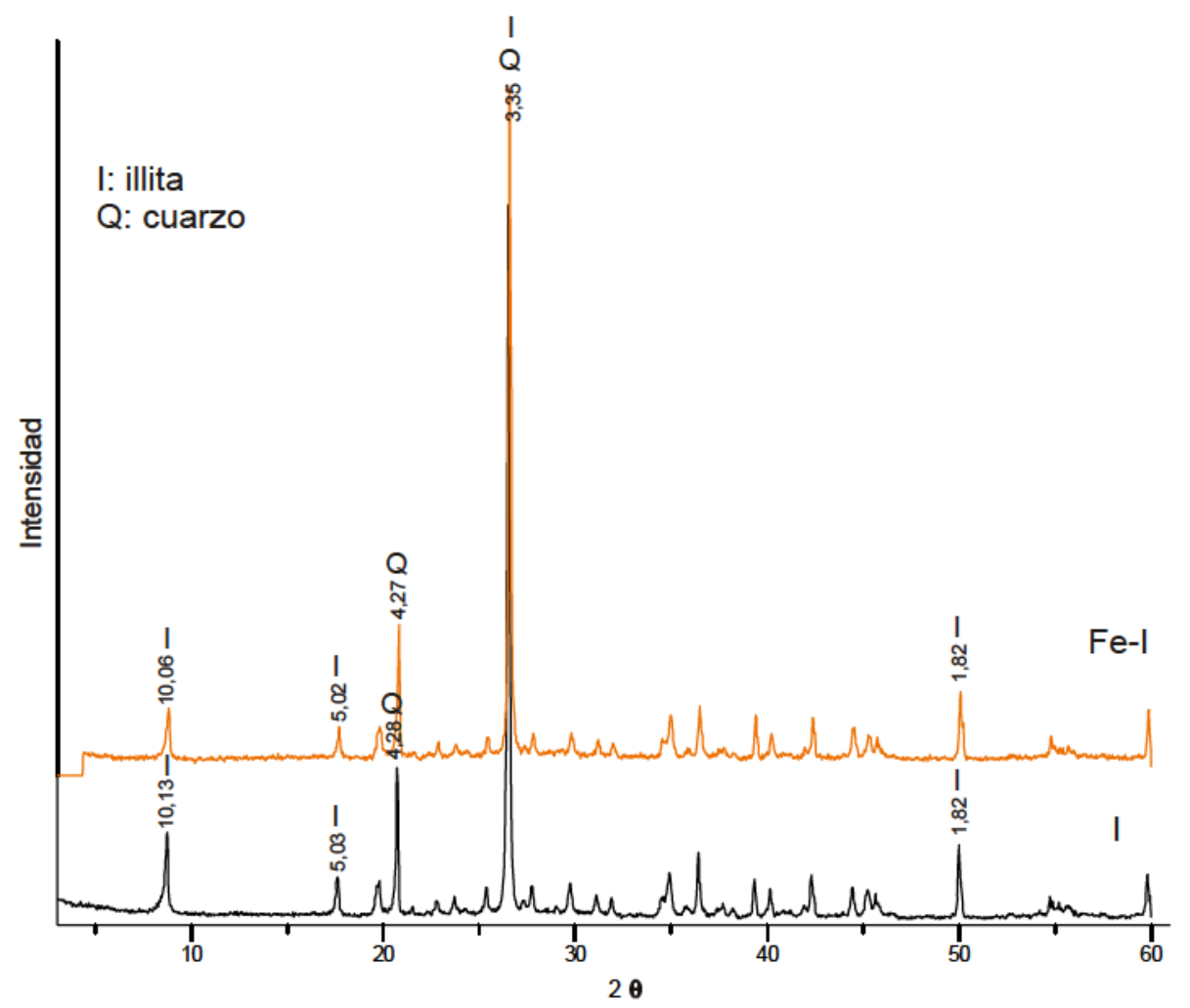

Figura 7.3. Diagramas de difracción de rayos $x$ comparativos de I y Fe-l.

Los diagramas de Py y Fe-Py mostrados en la Figura 7.4 corresponden a la fase predominante pirofilita (PDF 46-1308), observándose líneas de illita y cuarzo en menor proporción. 


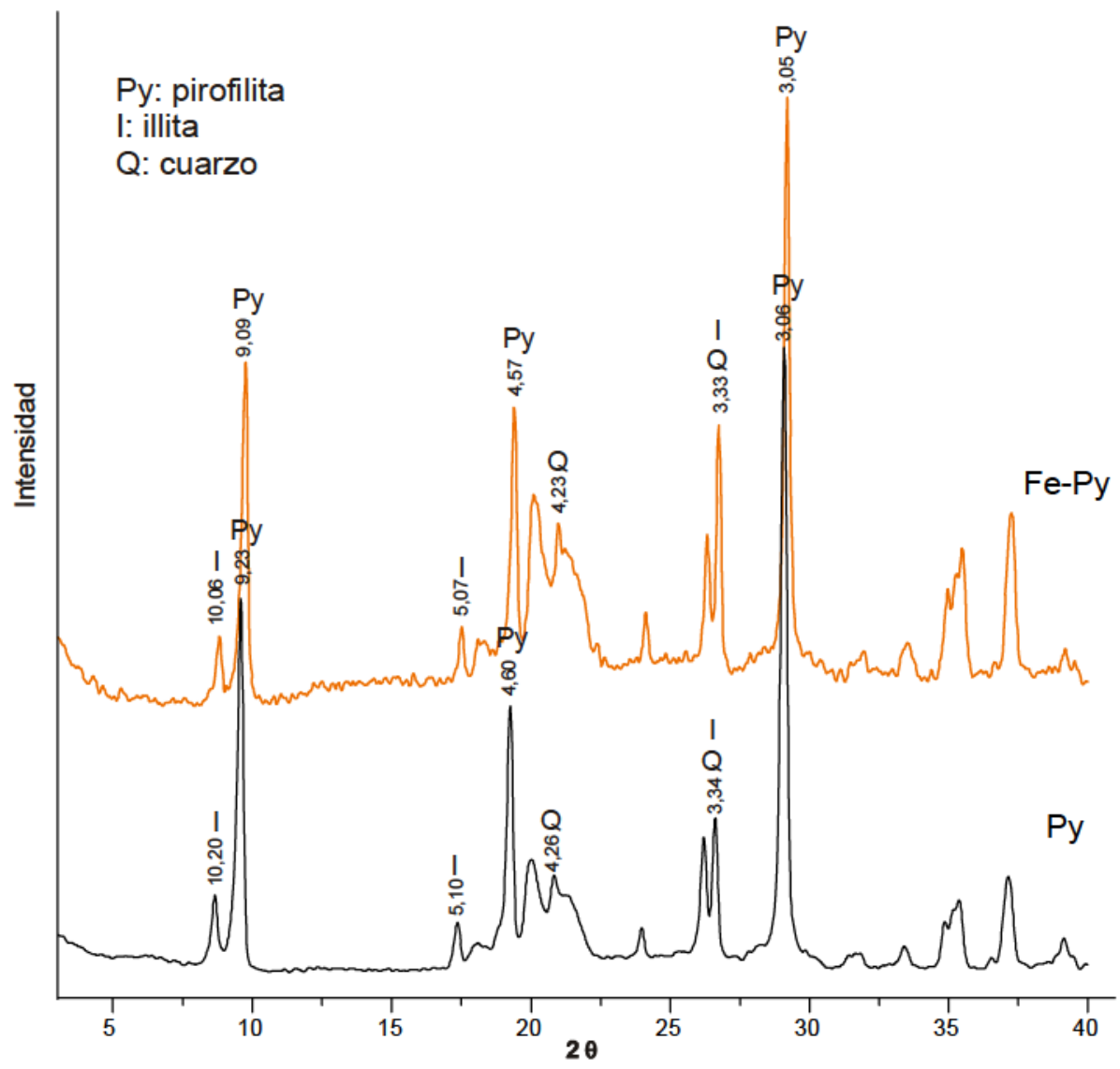

Figura 7.4. Diagramas de difracción de rayos $x$ comparativos de Py y Fe-Py.

Los diagramas DRX de $\mathrm{K}$ y Fe-K sugieren la presencia de especies de arcilla 1:1. Los diagramas de la Figura 7.5 se identifican con los observados en el sistema caolinita/halloysita- $7 \AA$, con un desdoblamiento en la zona entre $20-25^{\circ}$ de $2 \theta$ resultando imposible discernir respecto a la proporción de ambas especies (Bobos et al., 2001). Al respecto, es interesante destacar que la distinción entre halloysita y caolinita en los yacimientos de caolín, suele ser difícil debido a la similitud estructural entre ambas especies, especialmente cuando la halloysita aparece en la forma $7 \AA$. De acuerdo con el estado de hidratación, la halloysita puede presentarse principalmente en dos grupos diferentes: la forma hidratada (10 $\AA)$ con fórmula mínima $\mathrm{Al}_{2} \mathrm{Si}_{2} \mathrm{O}_{5}(\mathrm{OH})_{4} \cdot 2 \mathrm{H}_{2} \mathrm{O}$ y la forma deshidratada (7 $\AA$ ) con fórmula mínima $\mathrm{Al}_{2} \mathrm{Si}_{2} \mathrm{O}_{5}(\mathrm{OH})_{4}$. La halloysita- $10 \AA$ se encuentra generalmente en regiones húmedas, mientras que en las zonas con clima seco, rara vez se ha reportado la forma hidratada. La halloysita$10 \AA$ pierde fácilmente su capa intermedia de agua de modo que es probable que se convierta en su forma de $7 \AA$. Puesto que este proceso es irreversible, a menudo es difícil diferenciar halloysita de caolinita por DRX en muestras en las que la halloysita se encuentre en gran parte deshidratada (Bordeepong et al., 2011). En los diagramas se observa también cuarzo como especie asociada. 


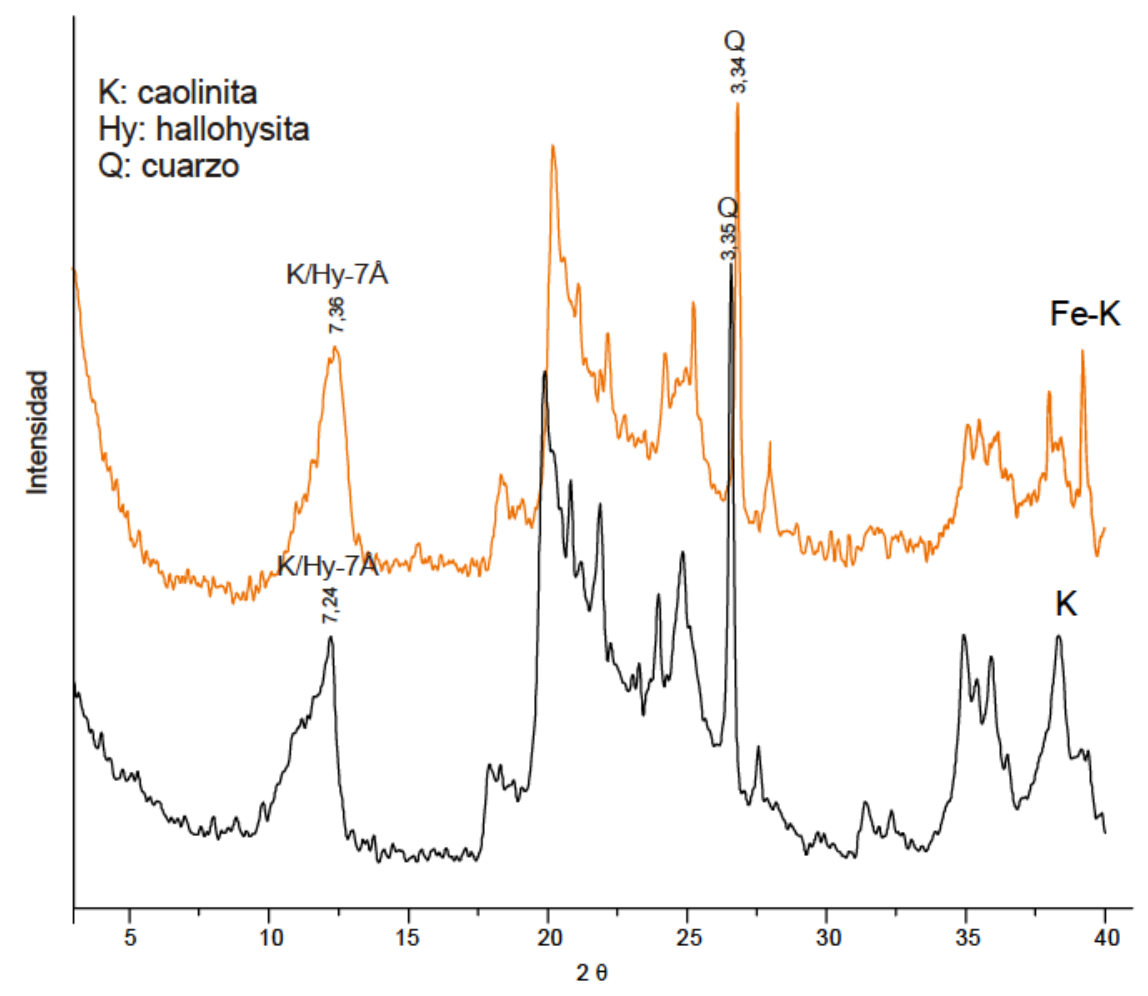

Figura 7.5. Diagramas de difracción de rayos $\mathrm{x}$ comparativos de $\mathrm{K}$ y Fe-K.

La Figura 7.6 incluye los diagramas de los materiales identificados como Z y Fe$Z$, indicando la presencia de la zeolita clinoptilolita (PDF 89-7539) y de cuarzo como mineral accesorio.

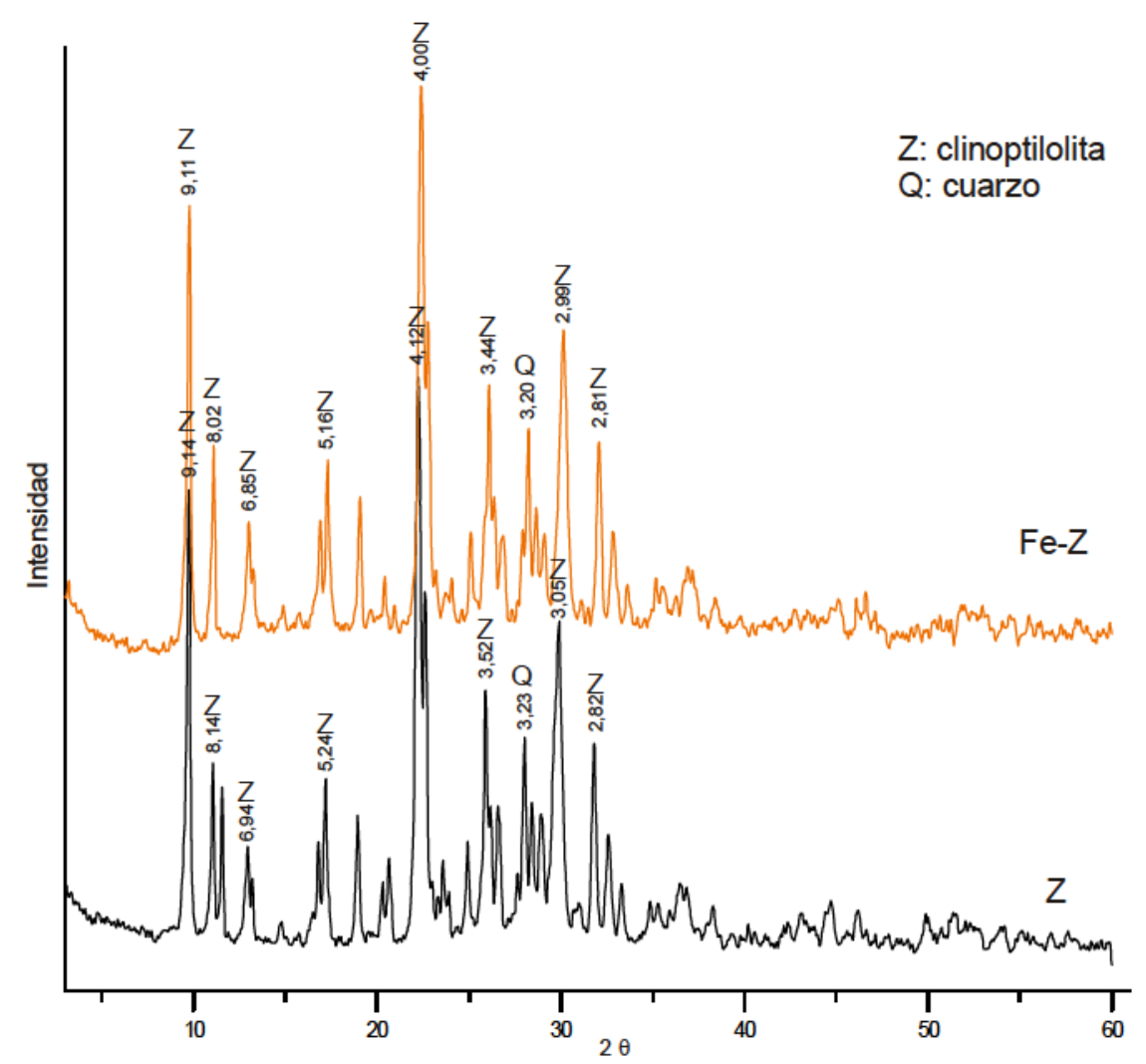

Figura 7.6. Diagramas de difracción de rayos $x$ comparativos de $Z$ y Fe-Z. 
La Figura 7.7 correspondiente a las especies B y B-Fe, se identifica con la montmorillonita (PDF 13-0135), con una muy pequeña proporción de cuarzo. Se observa un ligero corrimiento de la señal del plano basal a valores de $2 \theta$ mayores y una disminución de la intensidad del mismo por efecto del agregado de hierro, como fuera reportado por Celis et al. (1998).

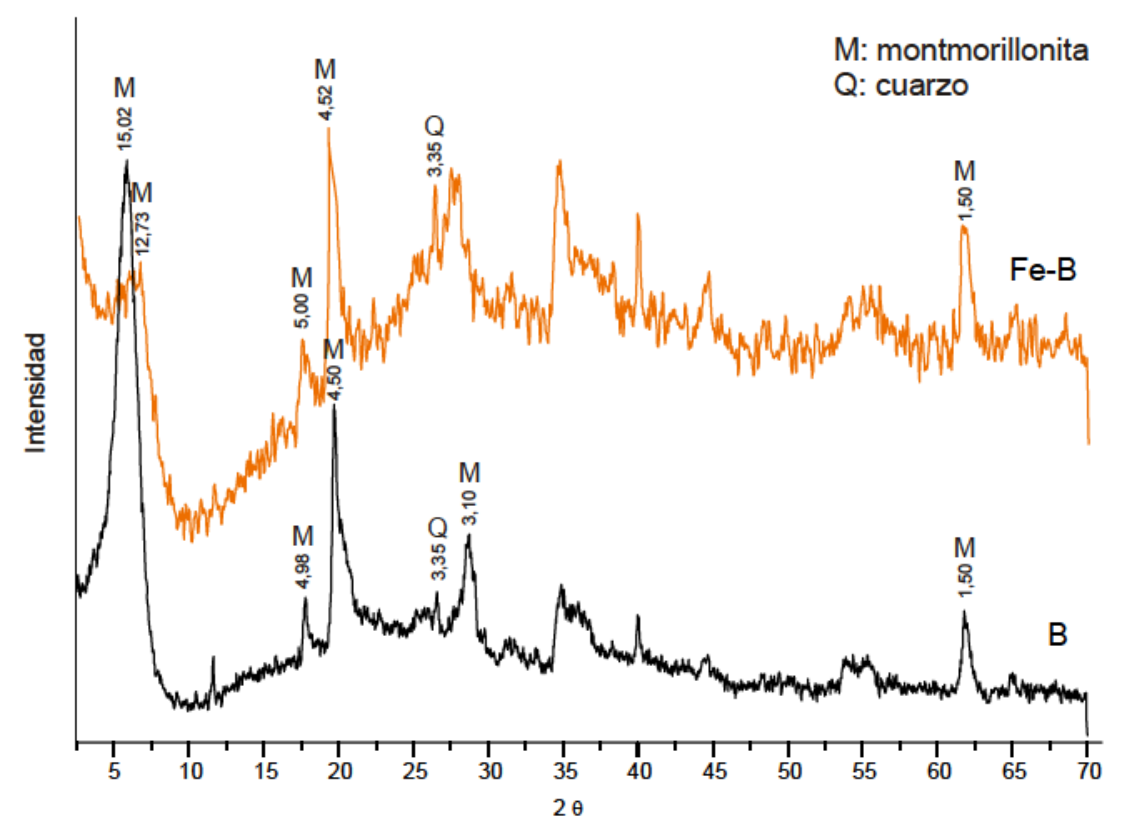

Figura 7.7. Diagramas de difracción de rayos $x$ comparativos de B y Fe-B.

Por último los diagramas de DRX de las Figuras 7.8 y 7.9 corresponden a las diatomitas $D_{1}$ y $D_{2}$ originales y modificadas.

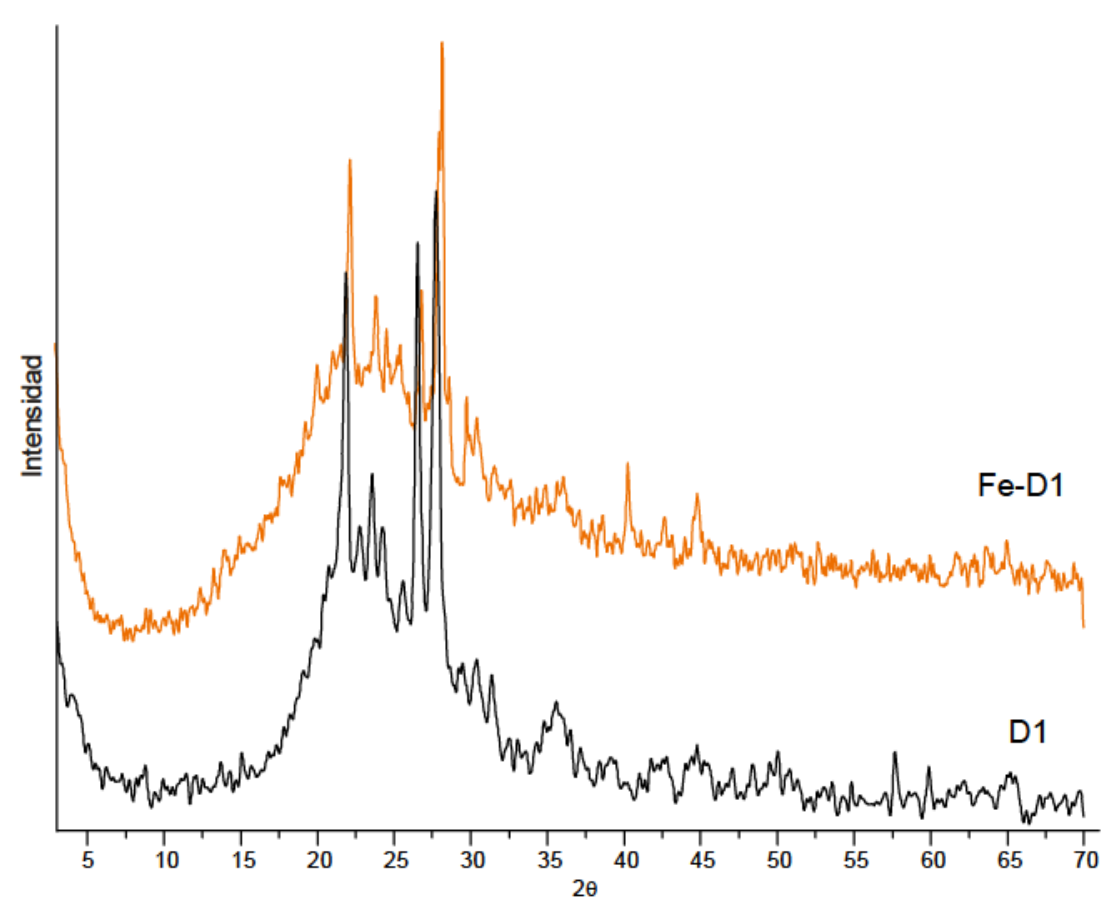

Figura 7.8. Diagramas de difracción de rayos $x$ comparativos de $D_{1}$ y Fe- $D_{1}$. 
Ambas muestras de diatomitas, basadas en una composición de sílice biogénica, revelan una mineralogía constituida por formas cristalinas del carbonato de calcio (PDF 05-0586) y $\mathrm{SiO}_{2}$ (cuarzo PDF 87-2096 y cristobalita PDF 39-1425), sugiriendo también, la presencia de minerales de arcilla. Se destaca en ambas una señal ancha entre $20-30^{\circ}$ de $2 \theta$ característica del ópalo $\left(\mathrm{SiO}_{2} \cdot \mathrm{nH}_{2} \mathrm{O}\right)$, que se encuentra superpuesta con líneas de las especies de mayor cristalinidad (Naranjo-Merchán et al., 2007).

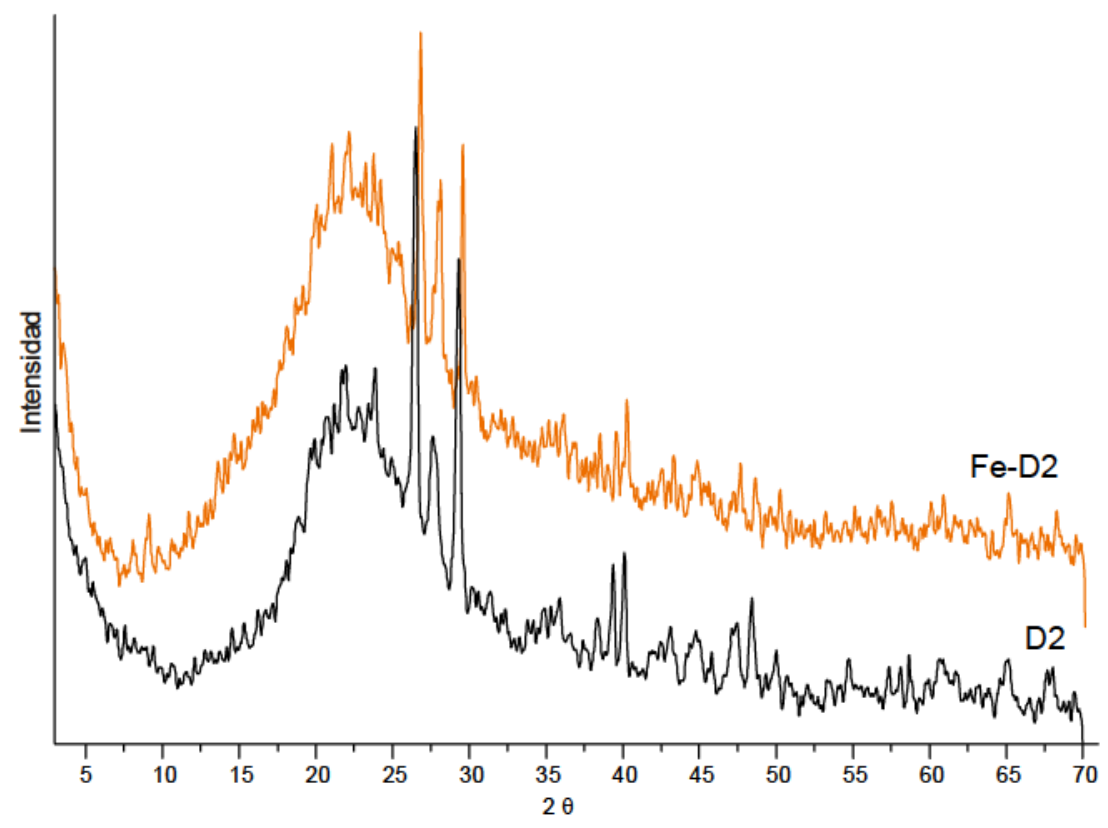

Figura 7.9. Diagramas de difracción de rayos $x$ comparativos de $D_{2}$ y Fe- $D_{2}$.

En la Figura 7.10 se muestra una micrografía SEM de la ferrihidrita y su correspondiente análisis EDS. Como ha sido reportado por Schwertmann and Cornell (2000) la ferrihidrita secada al aire tiende a formar agregados de las nanopartículas, muy difíciles de dispersar por métodos físicos.
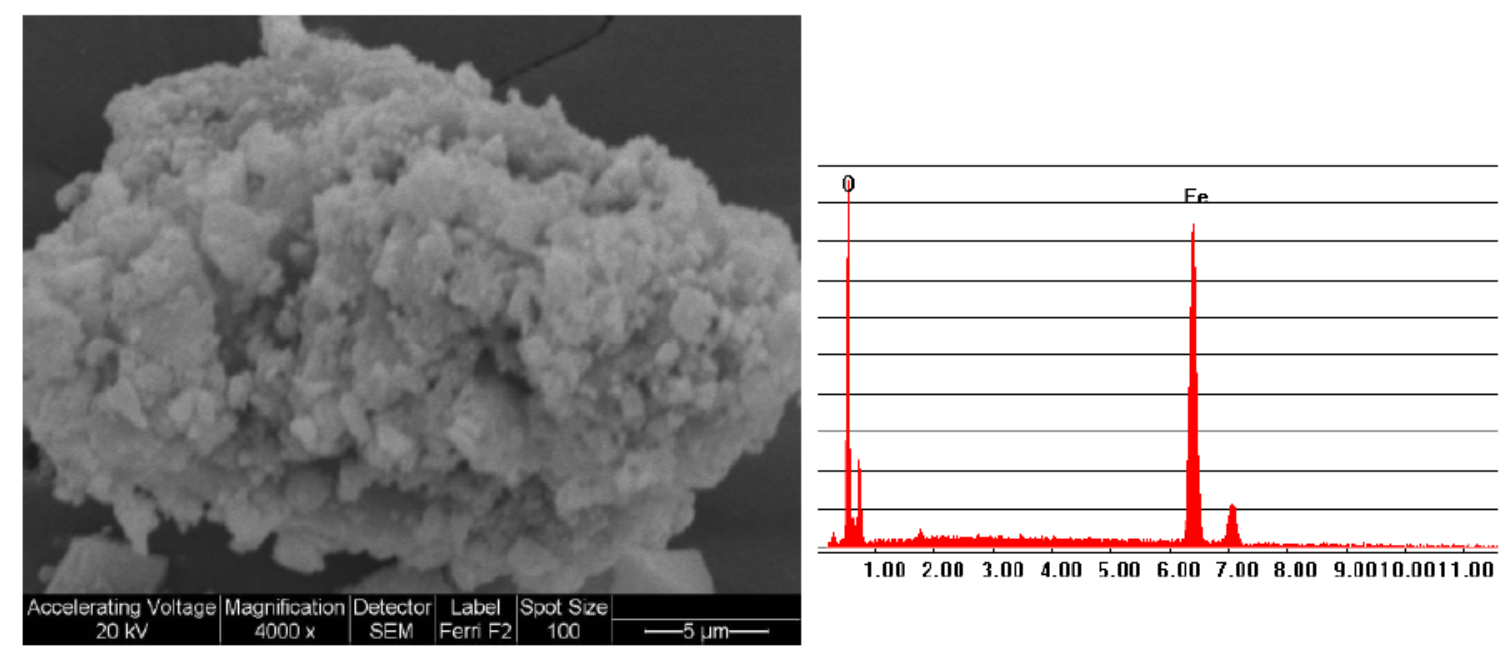

Figura 7.10. Agregado de partículas de ferrihidrita y su correspondiente análisis EDS. 
En la Tabla 7.4 se muestran los valores del análisis químico de superficie para las muestras de los aluminosilicatos originales y modificados químicamente. Se observa que en todos los casos se produce un aumento superficial de Fe.

Tabla 7.4. Análisis químico superficial por EDS para los aluminosilicatos originales y activados.

\begin{tabular}{c|c|c|c|c|c|c|c|c|c|c}
\hline Oxido & $\mathrm{I}$ & $\mathrm{Fe}-\mathrm{I}$ & $\mathrm{Z}$ & $\mathrm{Fe}-\mathrm{Z}$ & $\mathrm{K}$ & $\mathrm{Fe}-\mathrm{K}$ & $\mathrm{Py}$ & $\mathrm{Fe}-\mathrm{Py}$ & $\mathrm{B}$ & $\mathrm{Fe}-\mathrm{B}$ \\
\hline $\mathrm{SiO}_{2}$ & 65,70 & 65,36 & 71,86 & 66,35 & 55,69 & 50,85 & 68,91 & 64,23 & 64,73 & 60,91 \\
$\mathrm{Al}_{2} \mathrm{O}_{3}$ & 23,26 & 20,60 & 14,29 & 12,96 & 42,65 & 38,05 & 31,09 & 28,60 & 24,43 & 22,17 \\
$\mathrm{Fe}_{2} \mathrm{O}_{3}$ & 1,89 & 7,04 & 0,18 & 10,70 & 0,24 & 8,32 & - & 7,17 & 4,43 & 9,92 \\
$\mathrm{CaO}$ & - & - & 3,93 & 1,88 & 0,14 & - & - & - & - & - \\
$\mathrm{MgO}$ & - & - & 1,27 & 1,03 & 0,44 & 0,65 & - & - & 3,14 & 3,06 \\
$\mathrm{Na}_{2} \mathrm{O}$ & - & - & 7,22 & 5,61 & 0,46 & 0,30 & - & - & 3,27 & 3,94 \\
$\mathrm{~K}_{2} \mathrm{O}$ & 6,85 & 5,86 & 1,25 & 1,47 & - & 0,68 & - & - & - & - \\
$\mathrm{TiO}_{2}$ & 2,30 & 1,14 & - & - & 0,38 & 1,15 & - & - & - & - \\
\hline
\end{tabular}

En las Figura 7.11 y 7.12 se muestra a modo de ejemplo, el comportamiento de algunas muestras originales y activadas.
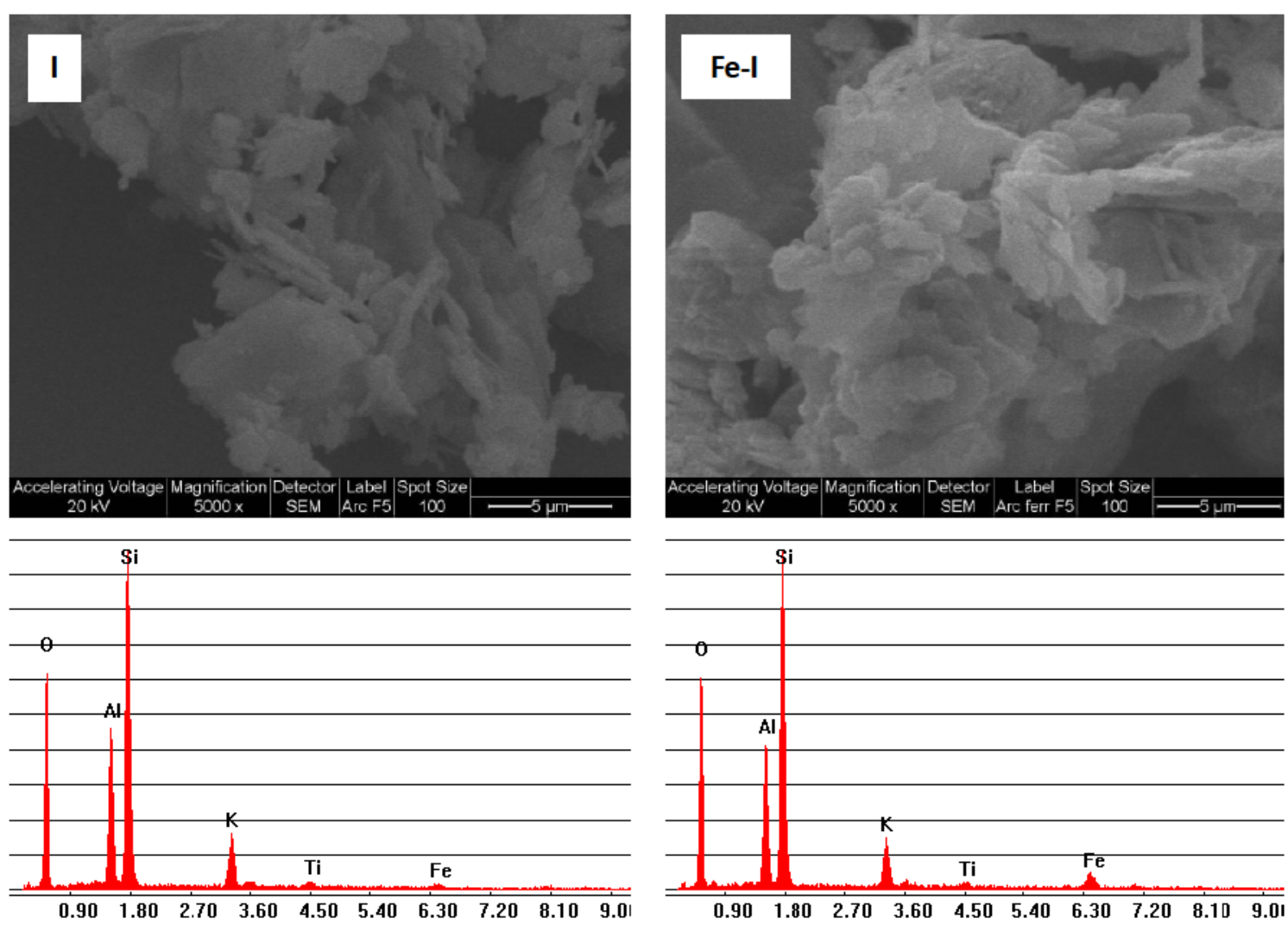

Figura 7.11. Micrografías SEM y espectros EDS para las muestras I y Fe-I.

Las Figuras 7.13 y 7.14 corresponden a muestras de las diatomitas, $D_{1}$ y $D_{2}$, originales y modificadas con hierro. Se observa la morfología típica de las frústulas, revelando en el análisis químico un contenido variable de carbono y calcio. En efecto, en la Figura 7.14, la micrografía de $D_{2}$ presenta un agregado cristalino que, por su composición EDS sugiere la presencia de fases de carbonatos de alcalino-térreos. 

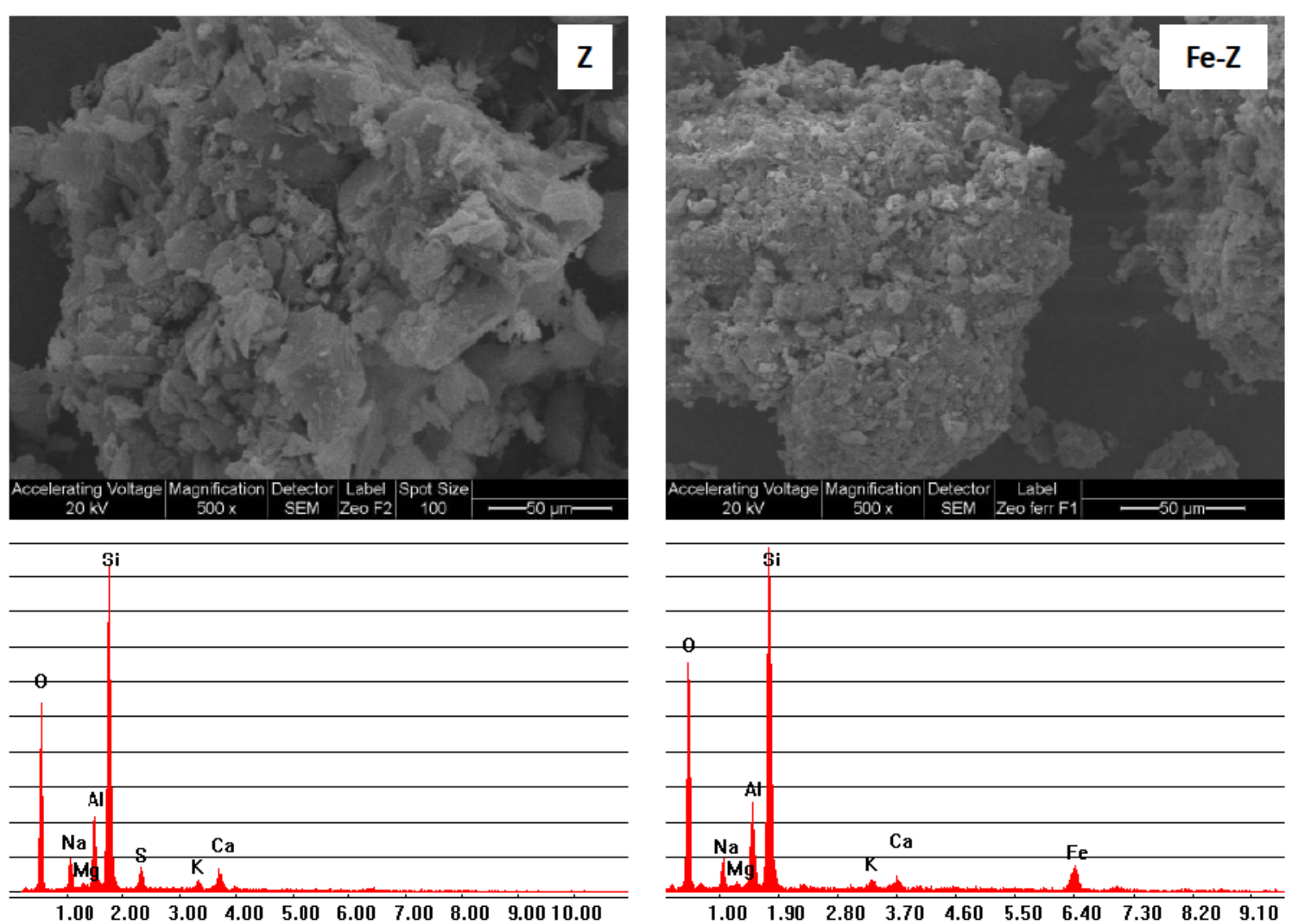

Figura 7.12. Micrografías SEM y espectros EDS para las muestras $Z$ y Fe-Z.
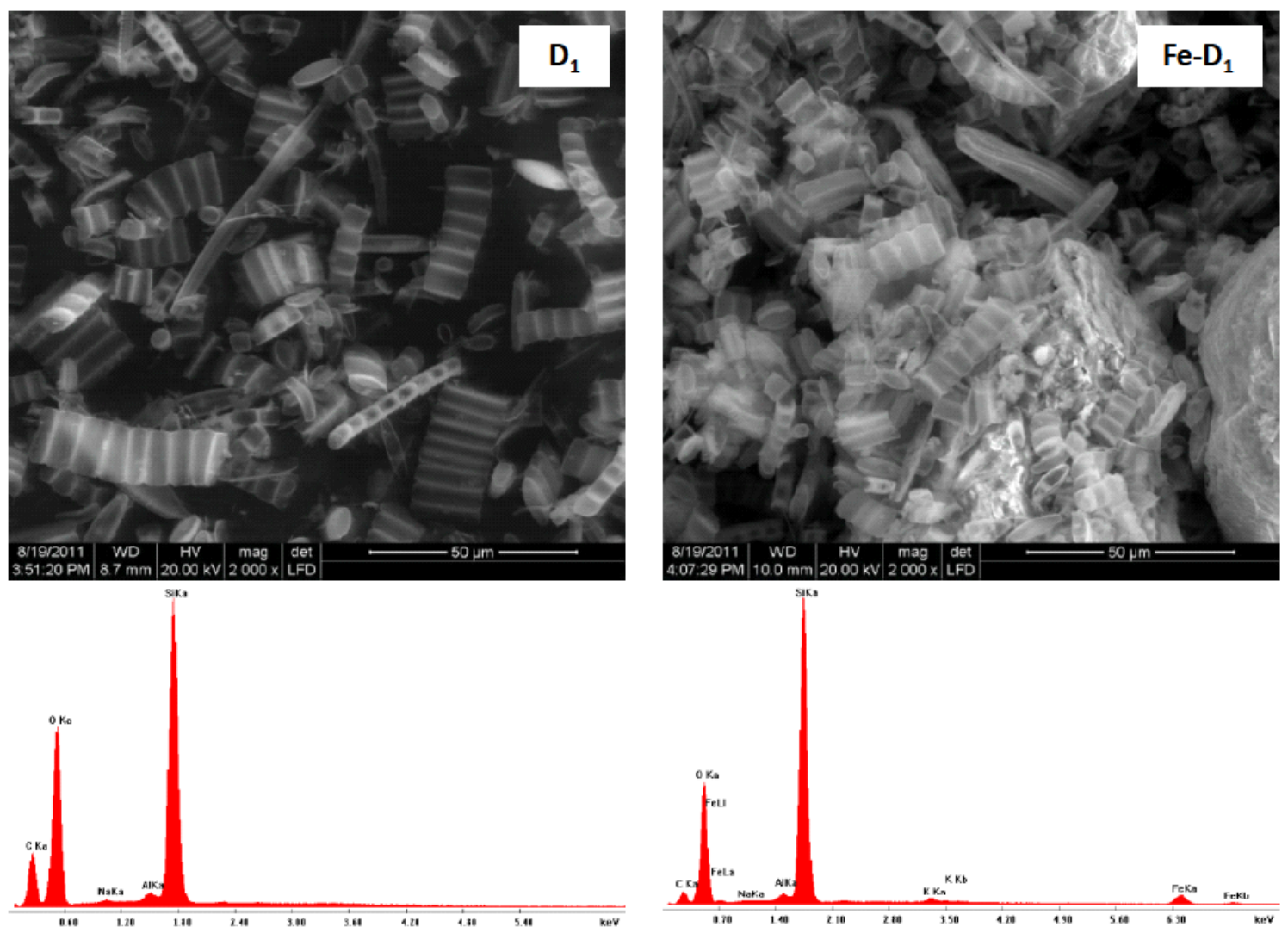

Figura 7.13. Micrografías SEM y espectros EDS para las muestras $D_{1}$ y Fe- $D_{1}$. 

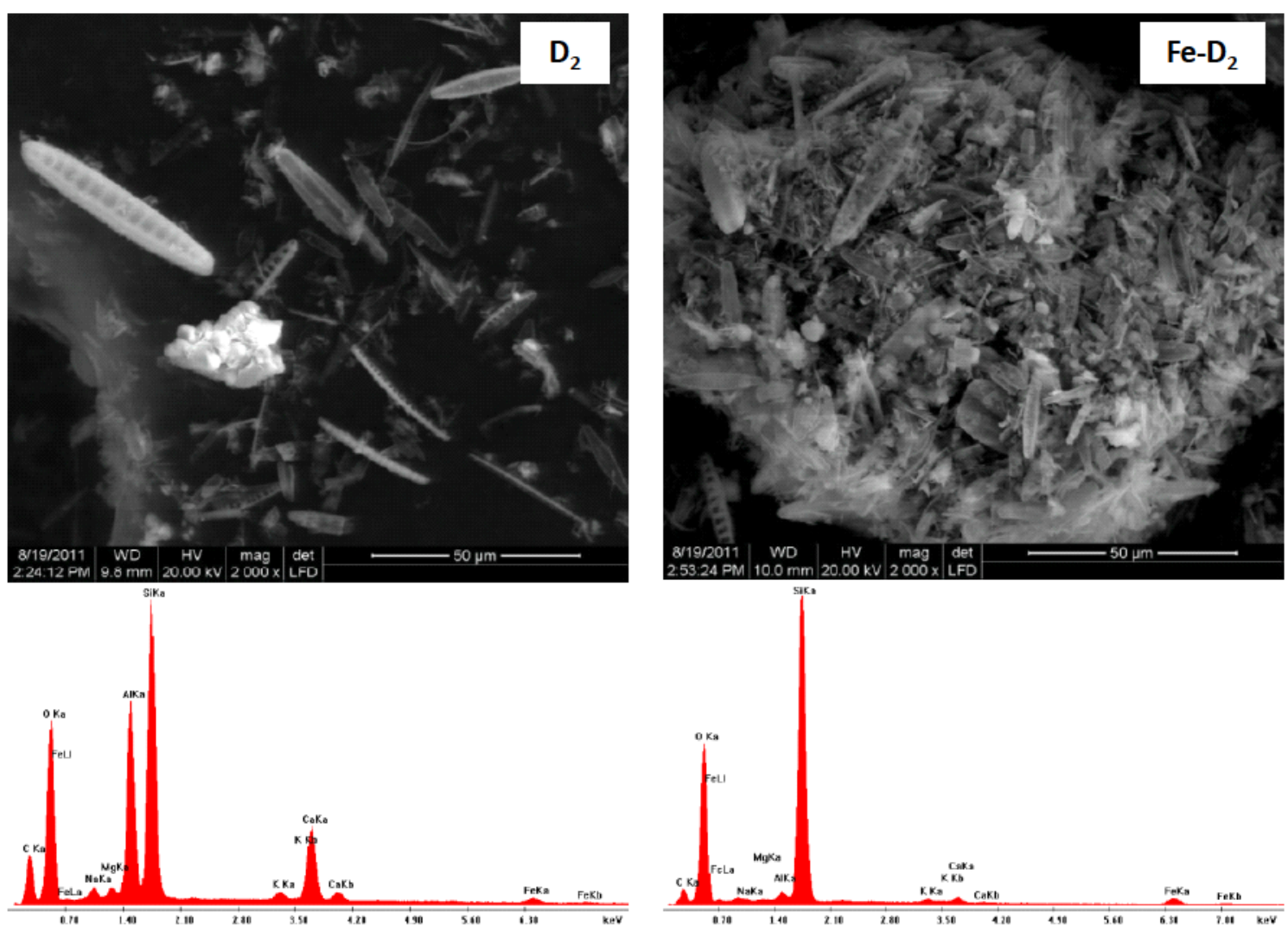

Figura 7.14. Micrografías SEM y espectros EDS para las muestras $D_{2}$ y Fe- $D_{2}$.

En los casos analizados, las diferencias morfológicas y texturales se atribuyen al depósito superficial de fases de hierro, hecho constatado claramente por los datos químicos de EDS, si bien también el incremento en hierro, en menor proporción, ha sido revelado por análisis químico másico.

En la Tabla 7.5 se observan los resultados de las determinaciones de la superficie específica BET $\left(\mathrm{S}_{\mathrm{BET}}\right)$ y del tamaño promedio de poro (DPP) determinados para las muestras originales y activadas.

Tabla 7.5. Resultados de Superficie específica BET expresada en $\mathrm{m}^{2} \mathrm{~g}^{-1}$ y de tamaño de poro promedio (DPP) expresado en $\AA$.

\begin{tabular}{c|r|r|c|r|r}
\hline \multicolumn{3}{c|}{ Muestras originales } & \multicolumn{3}{c}{ Muestras activadas } \\
\hline Muestra & \multicolumn{1}{|c|}{ S $_{\text {BET }}$} & \multicolumn{1}{c|}{ DPP } & Muestra & \multicolumn{1}{c}{ S $_{\text {BET }}$} & \multicolumn{1}{c}{ DPP } \\
\hline I & 4,97 & 134,27 & Fe-I & 27,27 & 49,83 \\
K & 9,09 & 137,65 & Fe-K & 71,60 & 111,84 \\
Py & 7,68 & 162,65 & Fe-Py & 30,06 & 62,94 \\
B & 50,92 & 74,45 & Fe-B & 84,11 & 48,80 \\
Z & 9,48 & 135,76 & Fe-Z & 35,92 & 65,78 \\
$\mathrm{D}_{1}$ & 10,91 & 116,50 & Fe-D & 30,67 & 78,63 \\
$D_{2}$ & 16,66 & 96,44 & Fe- $D_{2}$ & 43,95 & 64,94 \\
\hline
\end{tabular}

Los valores para la ferrihidrita pura, sintetizada como referencia, revelan una superficie específica de $322,44 \mathrm{~m}^{2} \mathrm{~g}^{-1}$ y un DPP de $28,46 \AA$, en coincidencia con los valores reportados en literatura (Schwwertmann and Cornell, 2000). Cabe destacar 
que estos valores fueron obtenidos tratando la muestra de ferrihidrita a $150{ }^{\circ} \mathrm{C}$. Se comprobó mediante difracción de rayos $X$ (Figura 7.2) que el calentamiento de la muestra no influyó en la cristalinidad de la misma no observándose la presencia de fases cristalinas.

Los resultados de las muestras originales, se encuentran en concordancia con los bibliográficos reportados para aluminosilicatos naturales, observando un mayor valor para la arcilla expandible (B). Es evidente en todas las muestras modificadas, el incremento de la superficie específica como consecuencia de la activación química, asociado al recubrimiento con las fases de Fe(III).

Sin embargo, el comportamiento de la superficie no es similar para todas las muestras activadas, observando que para la arcilla expandible, la modificación

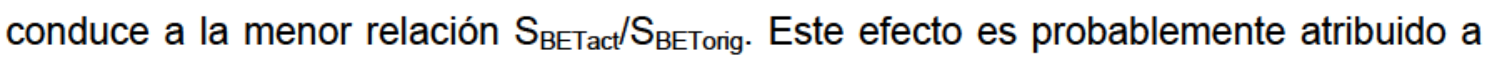
las características de estructura de la especie y a la posibilidad de intercalación laminar de "clusters" de hierro. Valverde et al. (2005) observaron en la preparación de PILCs conteniendo hierro, la formación de óxidos de hierro que bloquean los poros formados en el proceso de pilareado. Por otra parte, Celis et al. (1998) reportaron que los aspectos antes mencionados conducen a la pérdida de la señal característica del plano basal y una disminución de la cristalinidad de la arcilla, como se viera en la Figura 7.7, en la que se muestran comparativamente los diagramas de difracción de $B$ y Fe-B.

En relación a los valores del tamaño promedio de poro para las muestras originales y activadas, puede observarse que los poros promedio se encuentran localizados en el rango de los mesoporos según lo establecido por la IUPAC (20-500 $\AA$ ). Es evidente que el incremento de la superficie específica como consecuencia de la modificación química, se acompaña de una disminución del diámetro medio de poro. Las partículas de la ferrihidrita se depositan sobre los meso y macro poros de las muestras originales disminuyendo su diámetro y aumentando la superficie específica.

Las curvas de la Figura 7.15 representan: a) la derivada del volumen de poro versus el ancho de poro ( $\mathrm{dV} / \mathrm{dw} \mathrm{cm}^{3} / \mathrm{g} \AA$ vs ancho de poro) y b) la distribución de tamaño de poro calculada mediante el método DFT para la ferrihidrita. Se observa que la ferrihidrita, que presenta el menor valor de DPP (aun dentro del rango de los mesoporos), se caracteriza por una distribución de tamaño menor de poros, presentando ausencia de macroporos y el predominio de mesoporos con escasos microporos. 

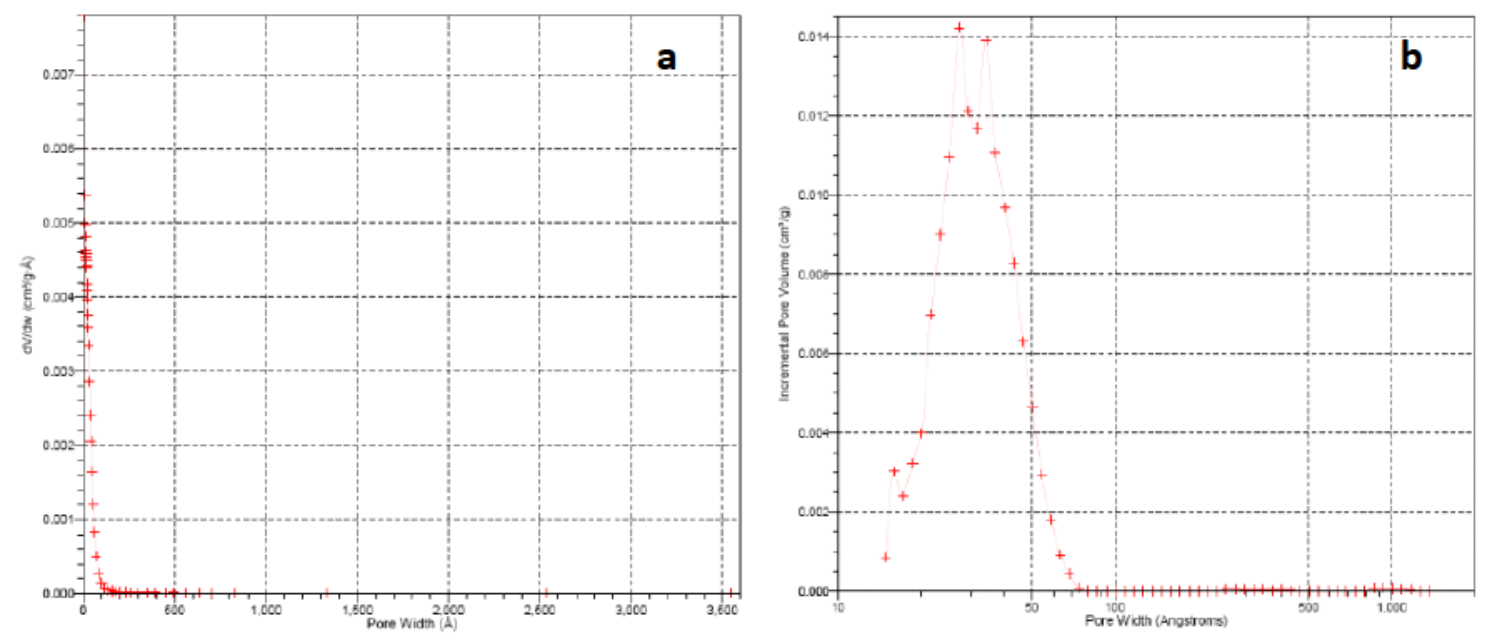

Figura 7.15. a) Derivada del volumen de poro versus el ancho de poro y b) distribución de tamaño de poro calculada por el método DFT para la ferrihidrita.

En general, en las muestras activadas el agregado de ferrihidrita contribuye a la reducción del tamaño de los poros, favoreciendo el incremento de la $\mathrm{S}_{\mathrm{BET}}$. Por consiguiente, las muestra originales se caracterizan por una distribución de poros de mayor tamaño, en tanto que las muestras activadas presentan una situación intermedia entre la muestra original y la ferrihidrita con una marcada reducción del tamaño de los poros.

Las Figuras 7.16 a 7.18, correspondientes a Py, Z y B (originales y activadas) ejemplifican el comportamiento mencionado.
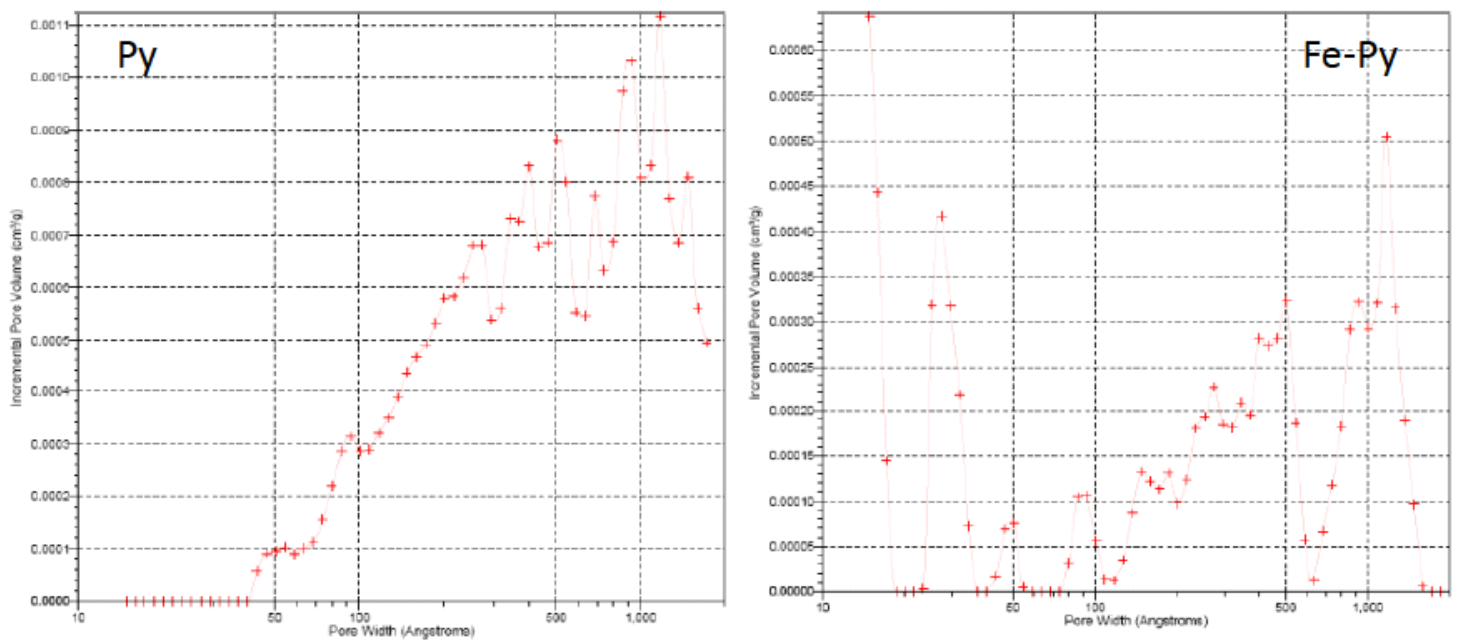

Figura 7.16. Comparación de la distribución de tamaño de poro para Py y Fe-Py. 

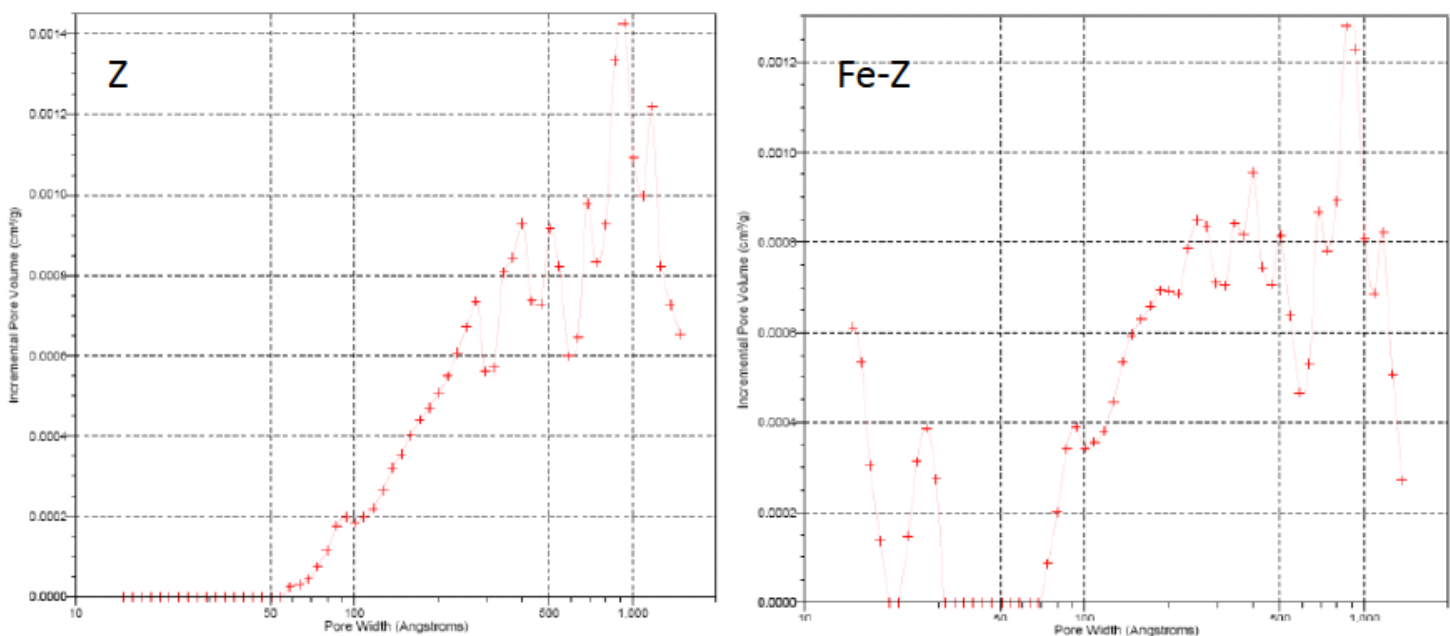

Figura 7.17. Comparación de la distribución de tamaño de poro para Z y Fe-Z.
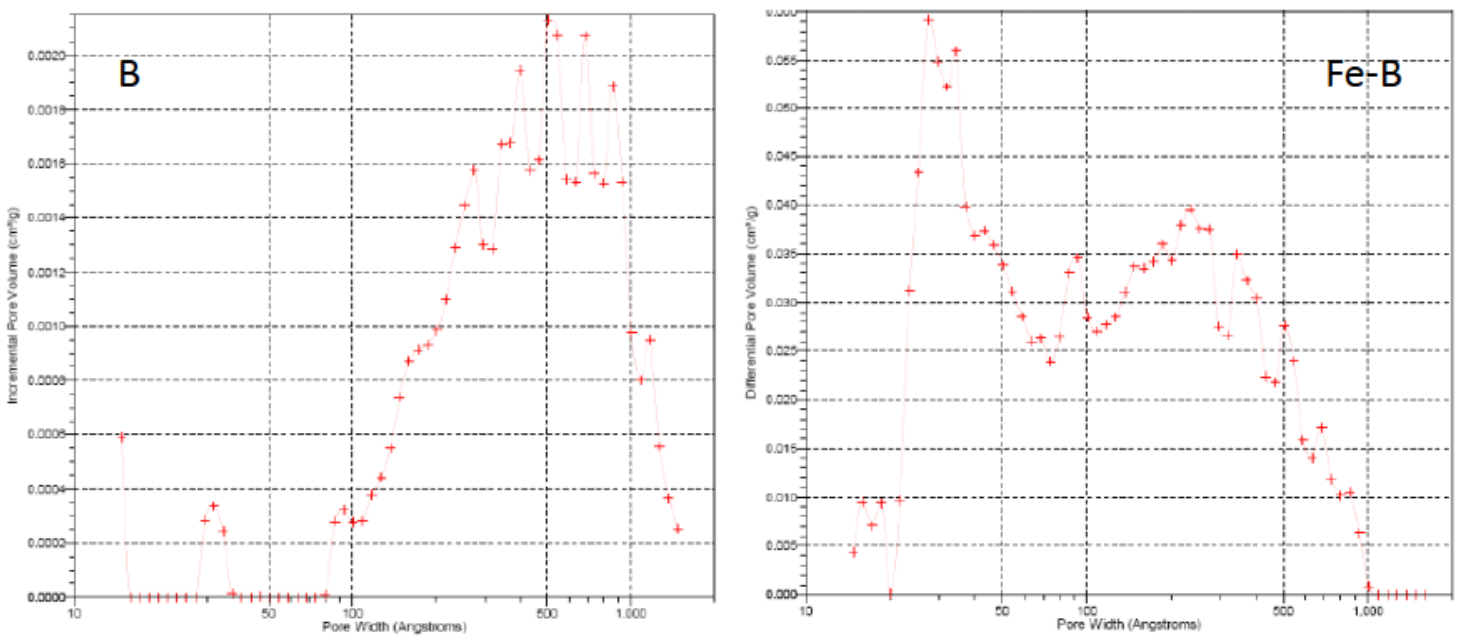

Figura 7.18. Comparación de la distribución de tamaño de poro para B y Fe-B.

\subsubsection{Evaluación de la remoción de As a nivel laboratorio}

Finalmente, las muestras activadas se emplearon en el proceso de remoción de arsénico. En una primera etapa se realizaron pruebas preliminares tendientes a evaluar la factibilidad del uso de las muestras naturales y activadas. Posteriormente, se determinó el agotamiento de los adsorbentes que resultaron efectivos, empleando los parámetros previamente optimizados en el Capítulo 6 para las arcillas ferruginosas, siguiendo el esquema mostrado en la Figura 6.49.

Para estos ensayos se usaron muestras de agua preparadas en el laboratorio con agua de red la cual fue modificada químicamente con $\mathrm{As}(\mathrm{V})$.

\section{Ensayos preliminares de factibilidad}

Para estos ensayos se seleccionaron las muestras originales I, K, Py y Z y sus correspondientes muestras activadas. Los experimentos en "batch" se llevaron a cabo en el equipo Jar test usando $50 \mathrm{~g}$ de adsorbente y $500 \mathrm{ml}$ de agua conteniendo $200 \mathrm{\mu g}$ $\mathrm{L}^{-1}$ de As. La suspensión se agitó durante $60 \mathrm{~min}$ a $200 \mathrm{rpm}$. En esta etapa, los 
experimentos se llevaron a cabo sin la adición de coagulante para observar el comportamiento de los minerales originales. La separación se realizó por simple decantación y el As original y posterior al tratamiento se determinó por el método EPA 3020/7010, previa filtración empleando filtro de nylon de 0,45 $\mu \mathrm{m}$.

Los resultados de los tratamientos de adsorción preliminares que se muestran en la Tabla 7.6 indican que las muestras sin activar no resultan efectivas en el proceso de remoción de As. Considerando que el agua original en todos los casos contenía 200 $\mu \mathrm{g} \mathrm{L}^{-1}$, en la segunda columna se observan valores de As en el agua tratada ligeramente superiores indicando que dichas muestras lixivian el As originalmente presente en los minerales. Este comportamiento no se observa en las arcillas ferruginosas de la PBA, poniendo en evidencia el rol fundamental de las especies de Fe en la adsorción del arsénico.

Tabla 7.6. Resultados de los tratamientos preliminares de adsorción de As(V).

\begin{tabular}{c|c|c|c}
\hline \multicolumn{2}{c|}{ Muestran originales } & \multicolumn{2}{c}{ Muestras activadas } \\
\hline Identificación & As $\left(\mu \mathrm{g} \mathrm{L}^{-1}\right)$ & Identificación & As $\left(\mu \mathrm{g} \mathrm{L}^{-1}\right)$ \\
\hline I & 230 & Fe-I & $<10$ \\
Z & 340 & Fe-Z & $<10$ \\
K & 210 & Fe-K & $<10$ \\
Py & 215 & Fe-Py & $<10$ \\
\hline
\end{tabular}

Resulta interesante destacar que el efecto del tratamiento con sales de hierro(III), genera muestras activadas que en igualdad de condiciones conducen a una muy eficiente disminución del contenido original de As del agua, alcanzando los valores sugeridos por la OMS y la legislación argentina actual.

De los resultados preliminares, puede concluirse que empleando los materiales activados se logra una retención del contaminante superior al $95 \%$, resultando una metodología altamente auspiciosa, por su facilidad de implementación y bajo costo.

\section{Efectividad de los minerales activados}

Las muestras activadas fueron probadas con el fin de determinar la saturación de los adsorbentes. A tal efecto se utilizó una solución de $1000 \mu \mathrm{g} \mathrm{L}^{-1}$ de arsénico. Los ensayos se realizaron en simultáneo en el equipo Jar test utilizando como referencia las condiciones experimentales determinadas como óptimas en el Capítulo 6 para la arcilla ferruginosa. Se empleó una relación sólido/líquido de $75 \mathrm{~g}$ en $750 \mathrm{ml}$. El sólido suspendido se decantó con la ayuda de la dosis óptima de PAC $(0,193 \mathrm{mg}$ de Al por litro de agua). La eficacia del material se estableció a través del número de ciclos útiles de tratamiento consecutivos. El adsorbente se considera saturado cuando la concentración de arsénico en la solución excede el límite permitido de $10 \mu \mathrm{g} \mathrm{L}^{-1}$. 
Como control, en el primer ciclo se trabajó con la muestra original con y sin PAC y con la muestra activada con y sin PAC, determinando durante las primeras 4 hs el perfil de turbidez en cada condición.

El monitoreo de cada jarra se realizó tomando muestras transcurridas las 24 hs de sedimentación, determinando turbidez y concentración de As. Para este último se hizo uso del kit de As Merck, corroborando periódicamente las mediciones por el método EPA 3020/7010.

En la Tabla 7.7 se observan los valores determinados a 24 hs en los distintos ciclos realizados para las muestras I y Fe-I. En relación a los valores de As, la muestra sin activar con o sin coagulante, no logra un contenido adecuado de As en el primer ciclo de tratamiento. Sin embargo, la muestra activada con y sin PAC, al cabo del primer ciclo obtuvieron valores de As $<5 \mu \mathrm{g} \mathrm{L}^{-1}$. La muestra Fe-I logra disminuir el As por debajo de los límites permitidos durante 6 ciclos, no ajustándose en todos los casos los valores de turbidez. En tanto, la misma muestra activada con el agregado de coagulante, es eficiente durante 20 ciclos. Se observa el efecto sinérgico coagulanteactivación aumentando la efectividad del tratamiento de remoción del contaminante.

Tabla 7.7. Resultados de NTU y As $\left(\mu \mathrm{g} \mathrm{L}^{-1}\right)$ durante los distintos ciclos de tratamiento realizados con las muestras I y Fe-I con y sin coagulante.

\begin{tabular}{|c|c|c|c|c|c|c|c|c|}
\cline { 2 - 9 } \multicolumn{1}{c|}{} & \multicolumn{1}{|c|}{} & \multicolumn{2}{c|}{ I + PAC } & \multicolumn{2}{c|}{ Fe-I } & \multicolumn{2}{c|}{ Fe-I + PAC } \\
\hline Ciclo & NTU & As & NTU & As & NTU & As & NTU & As \\
\hline 1 & 7,98 & $>500$ & 0,28 & $250-500$ & 4,75 & $<5$ & 1,83 & $<5$ \\
\hline 2 & - & - & - & - & 3,83 & 5 & 2,24 & 5 \\
\hline 3 & - & - & - & - & 3,75 & 5 & 2,09 & 5 \\
\hline 4 & - & - & - & - & 3,92 & 5 & 2,96 & 5 \\
\hline 5 & - & - & - & - & 3,19 & 5 & 2,04 & 5 \\
\hline 6 & - & - & - & - & 2,52 & 5 & 1,86 & 5 \\
\hline 7 & - & - & - & - & 2,56 & 25 & 2,29 & 10 \\
\hline 8 & - & - & - & - & - & - & 1,63 & 10 \\
\hline 9 & - & - & - & - & - & - & 1,84 & 10 \\
\hline 10 & - & - & - & - & - & - & 0,96 & 10 \\
\hline 11 & - & - & - & - & - & - & 1,67 & 10 \\
\hline 12 & - & - & - & - & - & - & 1,52 & 10 \\
\hline 13 & - & - & - & - & - & - & 0,65 & 10 \\
\hline 14 & - & - & - & - & - & - & 2,03 & 10 \\
\hline 15 & - & - & - & - & - & - & 2,55 & 10 \\
\hline 16 & - & - & - & - & - & - & 4,54 & 10 \\
\hline 17 & - & - & - & - & - & - & 1,55 & 10 \\
\hline 18 & - & - & - & - & - & - & 1,21 & 10 \\
\hline 19 & - & - & - & - & - & - & 1,48 & 10 \\
\hline 20 & - & - & - & - & - & - & 1,42 & 10 \\
\hline 21 & - & - & - & - & - & - & 1,43 & 25 \\
\hline
\end{tabular}

Por otra parte, la Figura 7.19 muestra el perfil de turbidez para las distintas condiciones ensayadas. Se observa una disminución progresiva de la turbidez, que se efectiviza más claramente con el agregado de coagulante. 


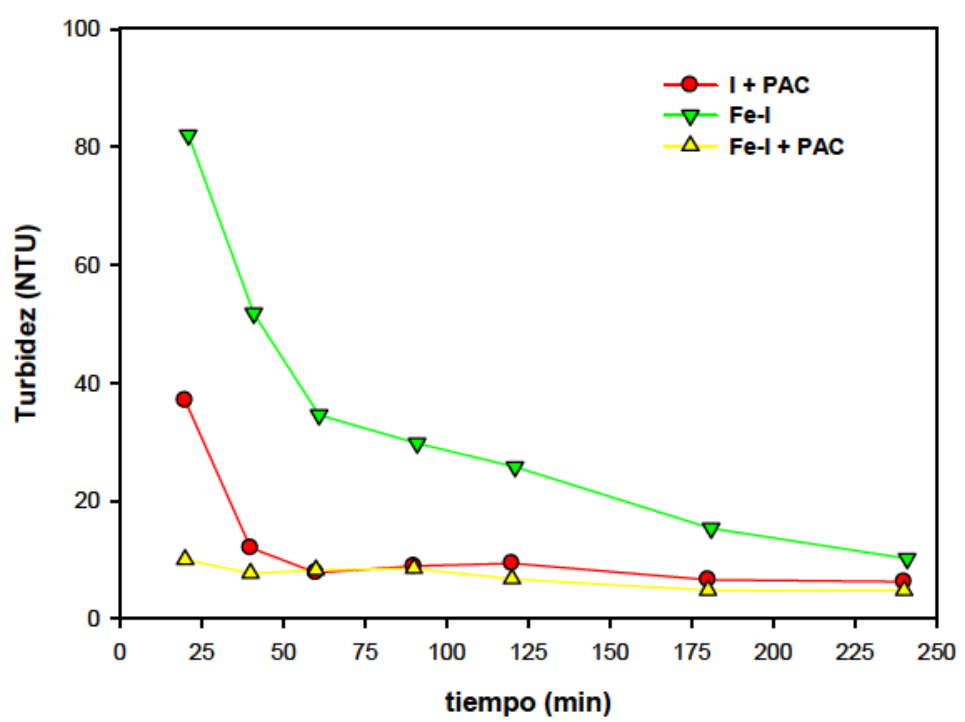

Figura 7.19. Perfil de turbidez determinado durante el primer ciclo para las muestras I y Fe-I.

En las Tablas $7.8,7.9$ y 7.10 se observan los valores determinados a 24 hs en los distintos ciclos realizados para las muestras originales $\mathrm{K}$, Py y $\mathrm{Z}$ y sus correspondientes muestras activadas (Fe-K, Fe-Py y Fe-Z). En las Figuras 7.20 a 7.22 se observan los perfiles de turbidez para las distintas condiciones ensayadas en todos los casos mencionados. Se aprecia un comportamiento similar al observado para las muestras I y Fe-I anteriormente comentado. La muestra Fe-K aun presentando una turbidez > 3 NTU logra disminuir el As por debajo de los límites permitidos durante 10 ciclos, mientras que la muestra activada con coagulante, es eficiente durante 12 ciclos con valores adecuados de turbidez. En el caso de las muestras preparadas en base al empleo de pirofilita, la Fe-Py y la Fe-Py + PAC resultan activas durante 7 y 27 ciclos respectivamente. Finalmente, la muestra $\mathrm{Fe}-\mathrm{Z}$ es activa por 3 ciclos mientras que la Fe-Z + PAC logra ser efectiva por 17 ciclos.

Tabla 7.8. Resultados de NTU y As $\left(\mu \mathrm{g} \mathrm{L}^{-1}\right)$ durante los distintos ciclos de tratamiento realizados con las muestras $\mathrm{K}$ y Fe-K con y sin coagulante.

\begin{tabular}{|c|c|c|c|c|c|c|c|c|}
\cline { 2 - 9 } \multicolumn{1}{c|}{} & \multicolumn{2}{c|}{ K } & \multicolumn{2}{c|}{ K + PAC } & \multicolumn{2}{c|}{ Fe-K } & \multicolumn{2}{c|}{ Fe-K + PAC } \\
\hline Ciclo & NTU & As & NTU & As & NTU & As & NTU & As \\
\hline 1 & 16,91 & $>500$ & 2,81 & $250-500$ & 13,30 & $<5$ & 2,10 & $<5$ \\
\hline 2 & - & - & - & - & 19,10 & 10 & 2,36 & 5 \\
\hline 3 & - & - & - & - & 13,00 & 10 & 0,71 & 5 \\
\hline 4 & - & - & - & - & 12,68 & 10 & 0,87 & 5 \\
\hline 5 & - & - & - & - & 9,03 & 10 & 1,14 & 5 \\
\hline 6 & - & - & - & - & 8,22 & 10 & 0,56 & 5 \\
\hline 7 & - & - & - & - & 9,49 & 10 & 0,79 & 5 \\
\hline 8 & - & - & - & - & 4,96 & 10 & 0,65 & 10 \\
\hline 9 & - & - & - & - & 5,47 & 10 & 0,43 & 10 \\
\hline 10 & - & - & - & - & 7,24 & 10 & 0,76 & 10 \\
\hline 11 & - & - & - & - & 10,10 & 25 & 0,58 & 10 \\
\hline 12 & - & - & - & - & - & - & 0,88 & 10 \\
\hline 13 & - & - & - & - & - & - & 0,67 & 25 \\
\hline
\end{tabular}




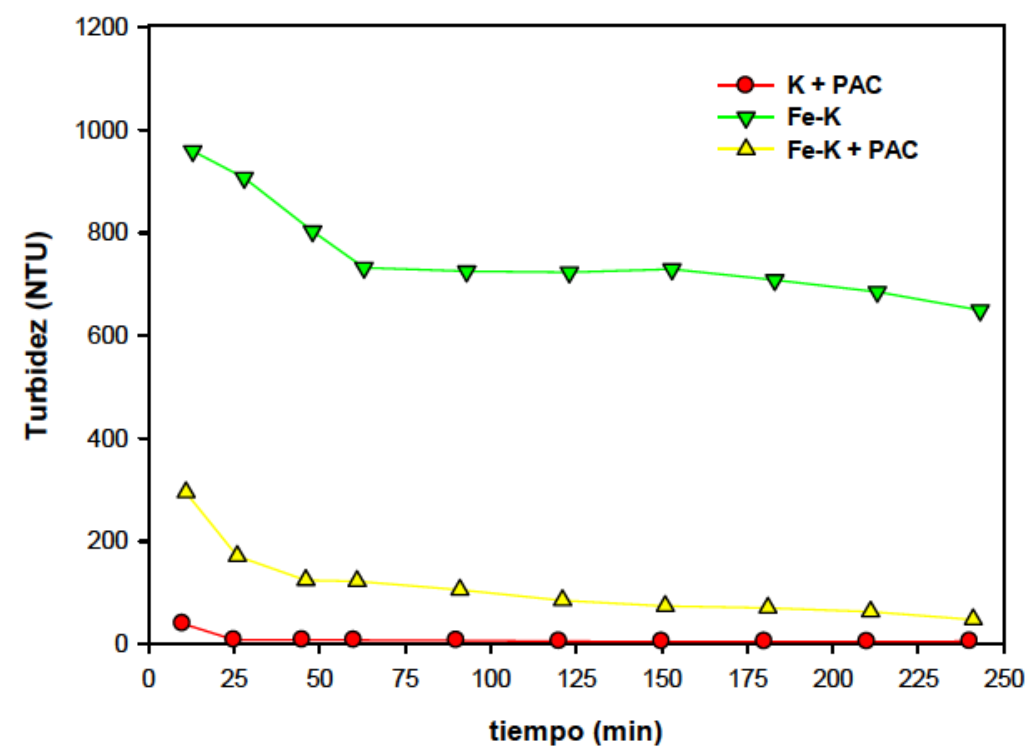

Figura 7.20. Perfil de turbidez determinado durante el primer ciclo para las muestras $\mathrm{K}$ y Fe-K.

Tabla 7.9. Resultados de NTU y As $\left(\mu \mathrm{g} \mathrm{L}^{-1}\right)$ durante los distintos ciclos de tratamiento realizados con las muestras Py y Fe-Py con y sin coagulante.

\begin{tabular}{|c|c|c|c|c|c|c|c|c|}
\cline { 2 - 9 } \multicolumn{1}{c|}{} & \multicolumn{2}{c|}{ Py } & \multicolumn{2}{c|}{ Py + PAC } & \multicolumn{2}{c|}{ Fe-Py } & \multicolumn{2}{c|}{ Fe-Py + PAC } \\
\hline Ciclo & NTU & As & NTU & As & NTU & As & NTU & As \\
\hline 1 & 116 & $>500$ & 2,35 & $250-500$ & 0,50 & $<5$ & 0,04 & $<5$ \\
\hline 2 & - & - & - & - & 1,15 & 5 & 0,82 & 5 \\
\hline 3 & - & - & - & - & 3,26 & 5 & 0,75 & 5 \\
\hline 4 & - & - & - & - & 2,86 & 5 & 0,54 & 5 \\
\hline 5 & - & - & - & - & 1,87 & 10 & 1,16 & 5 \\
\hline 6 & - & - & - & - & 2,38 & 10 & 1,09 & 5 \\
\hline 7 & - & - & - & - & 1,74 & 10 & 0,73 & 5 \\
\hline 8 & - & - & - & - & 2,89 & 25 & 1,79 & 5 \\
\hline 9 & - & - & - & - & - & - & 2,14 & 5 \\
\hline 10 & - & - & - & - & - & - & 1,76 & 10 \\
\hline 11 & - & - & - & - & - & - & 1,65 & 10 \\
\hline 12 & - & - & - & - & - & - & 2,45 & 10 \\
\hline 13 & - & - & - & - & - & - & 1,66 & 10 \\
\hline 14 & - & - & - & - & - & - & 1,87 & 5 \\
\hline 15 & - & - & - & - & - & - & 1,58 & 5 \\
\hline 16 & - & - & - & - & - & - & 2,82 & 5 \\
\hline 17 & - & - & - & - & - & - & 2,57 & 5 \\
\hline 18 & - & - & - & - & - & - & 2,84 & 10 \\
\hline 19 & - & - & - & - & - & - & 2,10 & 10 \\
\hline 20 & - & - & - & - & - & - & 2,95 & 10 \\
\hline 21 & - & - & - & - & - & - & 2,04 & 10 \\
\hline 22 & - & - & - & - & - & - & 2,57 & 10 \\
\hline 23 & - & - & - & - & - & - & 3,03 & 10 \\
\hline 24 & - & - & - & - & - & - & 2,21 & 10 \\
\hline 25 & - & - & - & - & - & - & 1,58 & 10 \\
\hline 26 & - & - & - & - & - & - & 1,42 & 10 \\
\hline 27 & - & - & - & - & - & - & 2,51 & 10 \\
\hline 28 & - & - & - & - & - & - & 1,49 & 25 \\
\hline
\end{tabular}




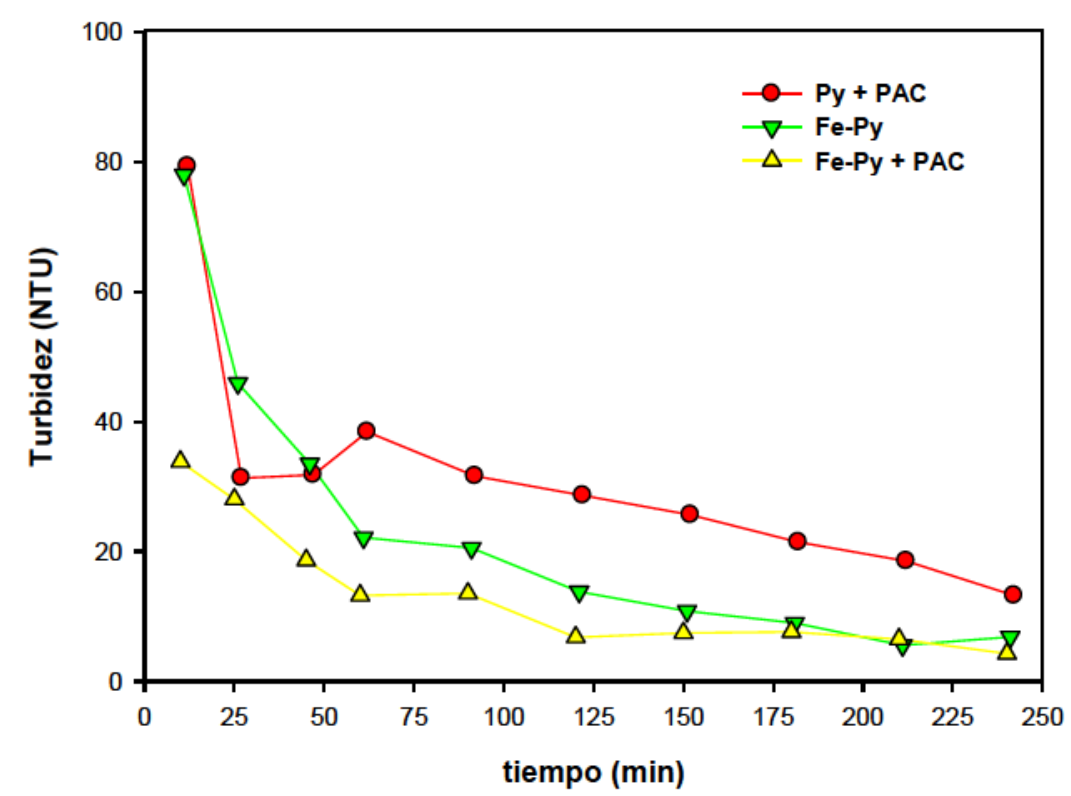

Figura 7.21. Perfil de turbidez determinado durante el primer ciclo para las muestras Py y FePy.

Tabla 7.10. Resultados de NTU y As $\left(\mu \mathrm{g} \mathrm{L}^{-1}\right)$ durante los distintos ciclos de tratamiento realizados con las muestras $Z$ y Fe-Z con y sin coagulante.

\begin{tabular}{|c|c|c|c|c|c|c|c|c|}
\cline { 2 - 9 } \multicolumn{1}{c|}{} & \multicolumn{2}{c|}{$Z$} & \multicolumn{2}{c|}{ Z + PAC } & \multicolumn{2}{c|}{ Fe-Z } & \multicolumn{2}{c|}{ Fe-Z + PAC } \\
\hline Ciclo & NTU & As & NTU & As & NTU & As & NTU & As \\
\hline 1 & 7,34 & $>500$ & 1,70 & $>500$ & 0,37 & $<5$ & 2,37 & 5 \\
\hline 2 & - & - & - & - & 2,39 & $5-10$ & 0,44 & 10 \\
\hline 3 & - & - & - & - & 7,17 & 10 & 2,29 & 10 \\
\hline 4 & - & - & - & - & 12,68 & 25 & 1,03 & 10 \\
\hline 5 & - & - & - & - & - & - & 1,67 & 10 \\
\hline 6 & - & - & - & - & - & - & 1,52 & 10 \\
\hline 7 & - & - & - & - & - & - & 1,56 & 10 \\
\hline 8 & - & - & - & - & - & - & 1,51 & 10 \\
\hline 9 & - & - & - & - & - & - & 0,88 & 10 \\
\hline 10 & - & - & - & - & - & - & 0,52 & 10 \\
\hline 11 & - & - & - & - & - & - & 3,02 & 10 \\
\hline 12 & - & - & - & - & - & - & 2,87 & 10 \\
\hline 13 & - & - & - & - & - & - & 1,84 & 10 \\
\hline 14 & - & - & - & - & - & - & 1,68 & 10 \\
\hline 15 & - & - & - & - & - & - & 0,99 & 10 \\
\hline 16 & - & - & - & - & - & - & 2,07 & 10 \\
\hline 17 & - & - & - & - & - & - & 1,53 & 10 \\
\hline 18 & - & - & - & - & - & - & 1,46 & 25 \\
\hline
\end{tabular}




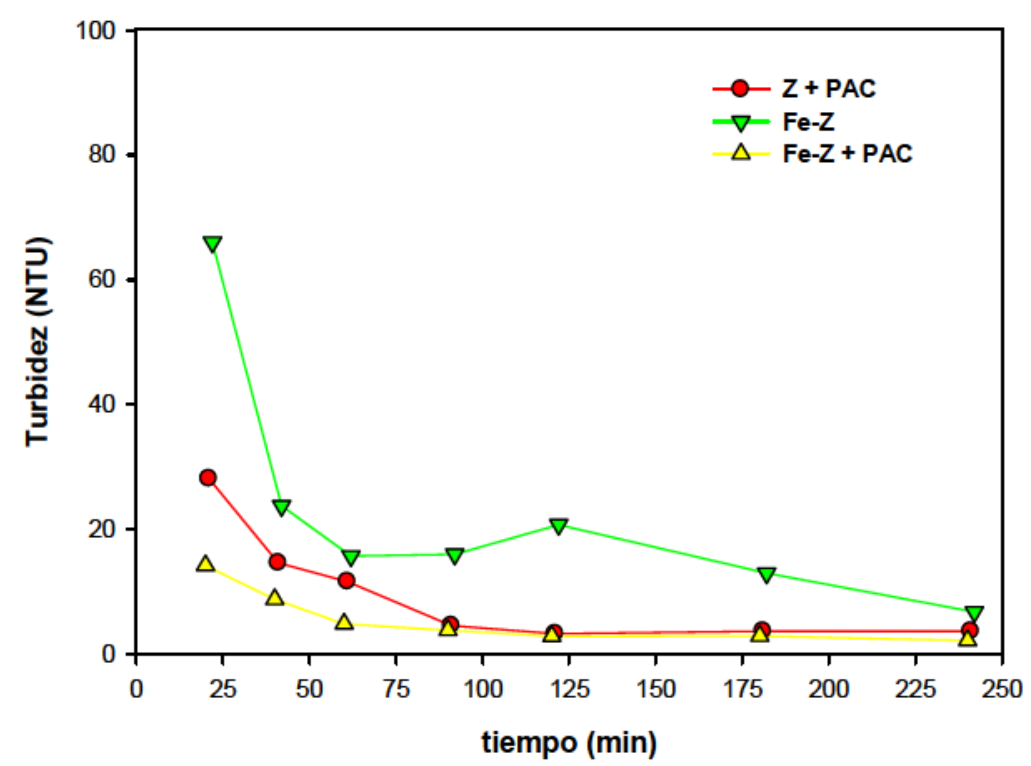

Figura 7.22. Perfil de turbidez determinado durante el primer ciclo para las muestras $Z$ y Fe-Z.

Para el caso de la bentonita (B), las muestras sin el empleo de coagulante fueron imposibles de procesar, por la dificultad presentada en el proceso de decantación, teniendo en cuenta las características estructurales de este tipo de arcillas (hinchamiento). Por este motivo solo se tiene el resultado de las muestras con el agregado de coagulante. La muestra de B + PAC, presentó un valor de As superior al límite de detección del kit $\left(500 \mu \mathrm{g} \mathrm{L}^{-1}\right)$. En el caso de la Fe-B + PAC, el perfil de turbidez no pudo obtenerse por presentar valores superiores a 1000 NTU en el periodo empleado para la determinación del mismo (hasta 4 hs después de terminada la agitación). Es de destacar que transcurridas las 24 hs la turbidez continúa elevada (89120 NTU) razón por la cual la muestra debió ser centrifugada y filtrada para poder determinar el valor de As. En estas nuevas condiciones de trabajo se alcanzan valores de As del orden de $10 \mu \mathrm{g} \mathrm{L}^{-1}$. Debido a la complejidad del proceso de sedimentación, se descartó el uso de este material para su empleo en el proceso diseñado. Esto significa que, para el uso de este aluminosilicato, deberían seleccionarse nuevas condiciones de trabajo que conduzcan a resultados aceptables.

Finalmente, en las Tablas 7.11 y 7.12 , se muestran los valores de As y turbidez determinados a 24 hs en los distintos ciclos realizados con las diatomitas, $D_{1}$ y $D_{2}$, originales y activadas. En ambos casos, las muestras sin activar con o sin coagulante, no logran valores de As aceptables en el primer ciclo de tratamiento. El As disminuye a los valores recomendados cuando los ensayos se realizaron con las muestras activadas. Si bien, para las dos diatomitas activadas se logra un mayor número de ciclos con el agregado de PAC, la muestra $F e-D_{1}$ es más efectiva que la $F e-D_{2}$. En 
efecto, la muestra $\mathrm{Fe}-\mathrm{D}_{1}$ reduce el As durante 7 ciclos, mientras que la $\mathrm{Fe}-\mathrm{D}_{2}$ solo logra ser eficiente 2 ciclos de tratamiento. Con el agregado de PAC estos ciclos aumentan a 17 para $F e-D_{1}+$ PAC y a 5 para $F e-D_{2}+$ PAC.

En las Figuras 7.23 y 7.24 se muestran los perfiles de turbidez para las distintas condiciones ensayadas para las muestras de diatomitas. Se observa un comportamiento similar al registrado para los aluminosilicatos mencionados precedentemente (excepto la bentonita).

Tabla 7.11. Resultados de NTU y As $\left(\mu \mathrm{g} \mathrm{L}^{-1}\right)$ durante los distintos ciclos de tratamiento realizados con las muestras $D_{1}$ y $F e-D_{1}$ con y sin coagulante.

\begin{tabular}{|c|c|c|c|c|c|c|c|c|}
\cline { 2 - 9 } \multicolumn{1}{c|}{} & \multicolumn{2}{c|}{$\mathrm{D}_{1}$} & \multicolumn{2}{c|}{$\mathrm{D}_{1}+\mathrm{PAC}$} & \multicolumn{2}{c|}{$\mathrm{Fe}_{1} \mathrm{D}_{1}$} & \multicolumn{2}{c|}{ Fe- ${ }_{1}+\mathrm{PAC}$} \\
\hline Ciclo & NTU & As & NTU & As & NTU & As & NTU & As \\
\hline 1 & 544 & $>500$ & 1,29 & $250-500$ & 1,58 & $<5$ & 0,41 & $<5$ \\
\hline 2 & - & - & - & - & 3,71 & 5 & 0,46 & 5 \\
\hline 3 & - & - & - & - & 1,72 & 5 & 0,79 & 5 \\
\hline 4 & - & - & - & - & 3,85 & 5 & 0,66 & 5 \\
\hline 5 & - & - & - & - & 1,57 & 5 & 0,72 & 5 \\
\hline 6 & - & - & - & - & 1,64 & 10 & 0,77 & 5 \\
\hline 7 & - & - & - & - & 1,87 & 10 & 0,66 & 5 \\
\hline 8 & - & - & - & - & 3,84 & 25 & 0,92 & 5 \\
\hline 9 & - & - & - & - & - & - & 1,01 & 10 \\
\hline 10 & - & - & - & - & - & - & 1,09 & 10 \\
\hline 11 & - & - & - & - & - & - & 1,01 & 10 \\
\hline 12 & - & - & - & - & - & - & 1,01 & 10 \\
\hline 13 & - & - & - & - & - & - & 1,17 & 10 \\
\hline 14 & - & - & - & - & - & - & 1,01 & 10 \\
\hline 15 & - & - & - & - & - & - & 1,23 & 10 \\
\hline 16 & - & - & - & - & - & - & 0,84 & 10 \\
\hline 17 & - & - & - & - & - & - & 1,17 & 10 \\
\hline 18 & - & - & - & - & - & - & 1,12 & 25 \\
\hline
\end{tabular}

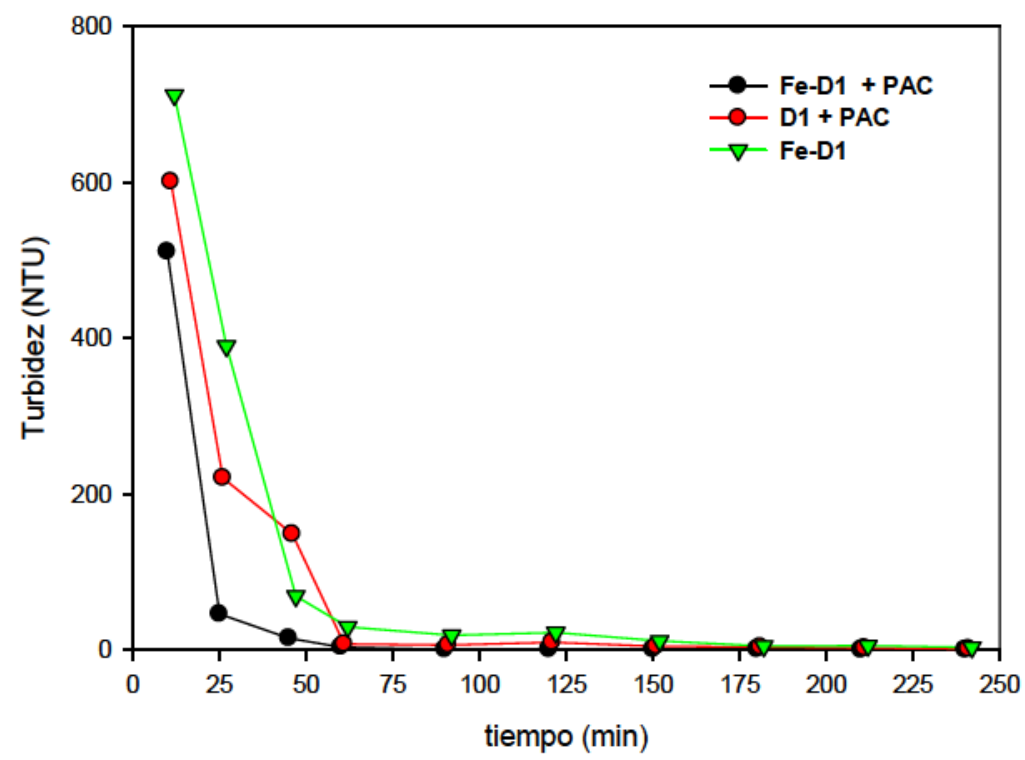

Figura 7.23. Perfil de turbidez determinado durante el primer ciclo para $D_{1}$ y Fe- $D_{1}$. 
Tabla 7.12. Resultados de NTU y As $\left(\mu \mathrm{g} \mathrm{L}^{-1}\right.$ ) durante los distintos ciclos de tratamiento realizados con las muestras $D_{2}$ y Fe- $D_{2}$ con y sin coagulante.

\begin{tabular}{|c|c|c|c|c|c|c|c|c|}
\cline { 2 - 9 } \multicolumn{1}{c|}{} & \multicolumn{2}{c|}{$\mathrm{D}_{2}$} & \multicolumn{2}{c|}{$\mathrm{D}_{2}+$ PAC } & \multicolumn{2}{c|}{$\mathrm{Fe}_{2} \mathrm{D}_{2}$} & \multicolumn{2}{c|}{$\mathrm{Fe}-\mathrm{D}_{2}+\mathrm{PAC}$} \\
\hline Ciclo & NTU & As & NTU & As & NTU & As & NTU & As \\
\hline 1 & 9,99 & $>500$ & 0,57 & $250-500$ & 2,10 & $<5$ & 1,17 & $<5$ \\
\hline 2 & - & - & - & - & 11,40 & 10 & 2,29 & 5 \\
\hline 3 & - & - & - & - & 20,20 & 25 & 1,06 & 10 \\
\hline 4 & - & - & - & - & - & - & 0,98 & 10 \\
\hline 5 & - & - & - & - & - & - & 1,16 & 10 \\
\hline 6 & - & - & - & - & - & - & 0,91 & 25 \\
\hline
\end{tabular}

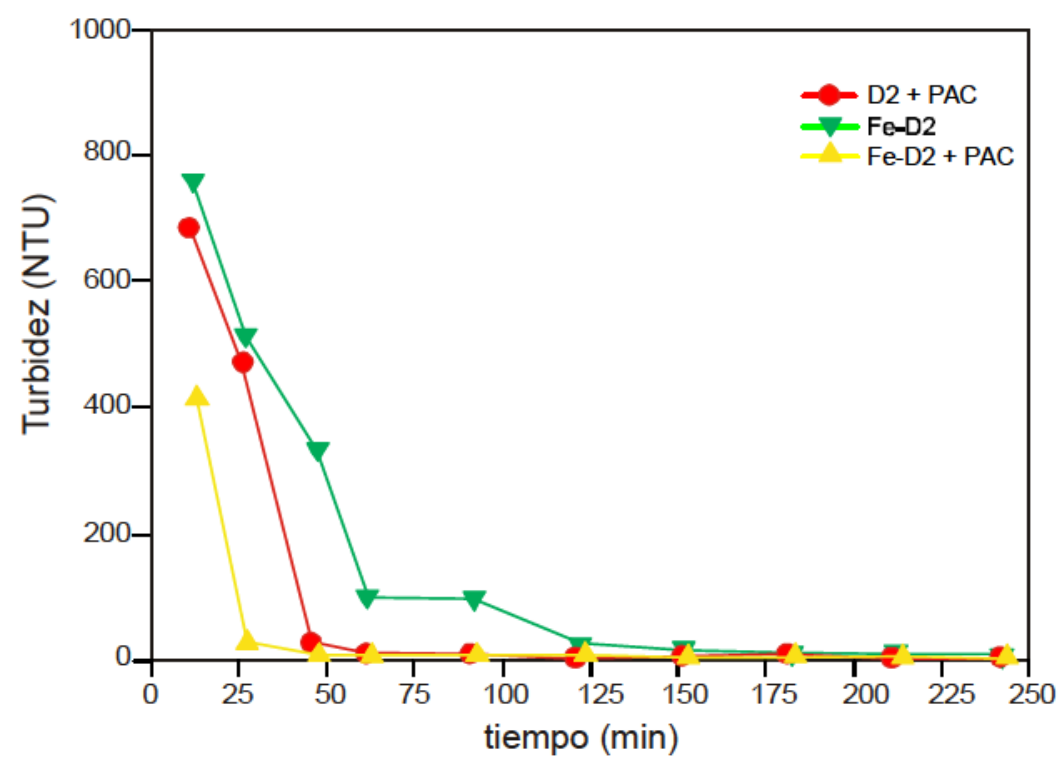

Figura 7.24. Perfil de turbidez determinado durante el primer ciclo para $D_{2}$ y Fe- $D_{2}$.

En la Tabla 7.13 y en la Figura 7.25 se resumen los resultados obtenidos en la efectividad de la remoción de As mediante el empleo de los minerales activados. A modo comparativo se han incluido los valores obtenidos en el Capítulo 6 para las arcillas AFO.

La activación de los minerales pobres en hierro por medio de la depositación de especies como ferrihidrita, conduce a geomateriales efectivos en la estrategia de eliminación de As que fuera optimizada para las arcillas ferruginosas. La asociación fase amorfa de hierro-mineral, incrementa notablemente la potencialidad del sistema para la eliminación de As en aguas. Pequeños incrementos en el contenido de hierro son suficientes para aumentar el rendimiento operacional del adsorbente a partir de un incremento en la superficie específica con una disminución en el tamaño de poros, asociados a la presencia de una fase estructuralmente desordenada precursora de la hematita.

Sin embargo, se observan diferencias entre las distintas muestras activadas, que pueden ser atribuidas a las características estructurales y de composición. La depositación de un contenido similar de fase de hierro(III) es comparativamente más 
eficaz en las arcillas 2:1 (I y Py) que en la caolinita (1:1). Para los tipos estructurales tridimensionales (Z) y/o amorfos (D) la efectividad se puede relacionar a la distribución del hierro. En la especie zeolita es posible sugerir la presencia de procesos de adsorción + intercambio catiónico (CIC) que implican la incorporación de la especie activa en canales y sitios interiores que resultan inaccesibles para la adsorción. En el caso de las diatomitas, la efectividad puede asociarse a efectos de alteración, que se visualizan a través de la presencia de iones alcalinos, generando un comportamiento similar al observado en los minerales de arcilla. Asimismo, la presencia de carbonato de calcio se hace más evidente en la mezcla mineral para la muestra denominada $D_{2}$, para la cual se observa una menor efectividad.

Tabla 7.13. Efectividad de los minerales activados en la remoción de As.

\begin{tabular}{c|c|c}
\hline Muestra & $\mathrm{N}^{0}$ Ciclos & $\mu \mathrm{g}$ As retenidos $/$ gadsorbente \\
\hline AFO & 45 & 447,45 \\
Fe-I & 20 & 208,05 \\
Fe-K & 12 & 128,90 \\
Fe-Py & 27 & 277,70 \\
Fe-Z & 17 & 178,10 \\
Fe-D & 5 & 59,35 \\
Fe-D & 17 & 178,45 \\
\hline
\end{tabular}

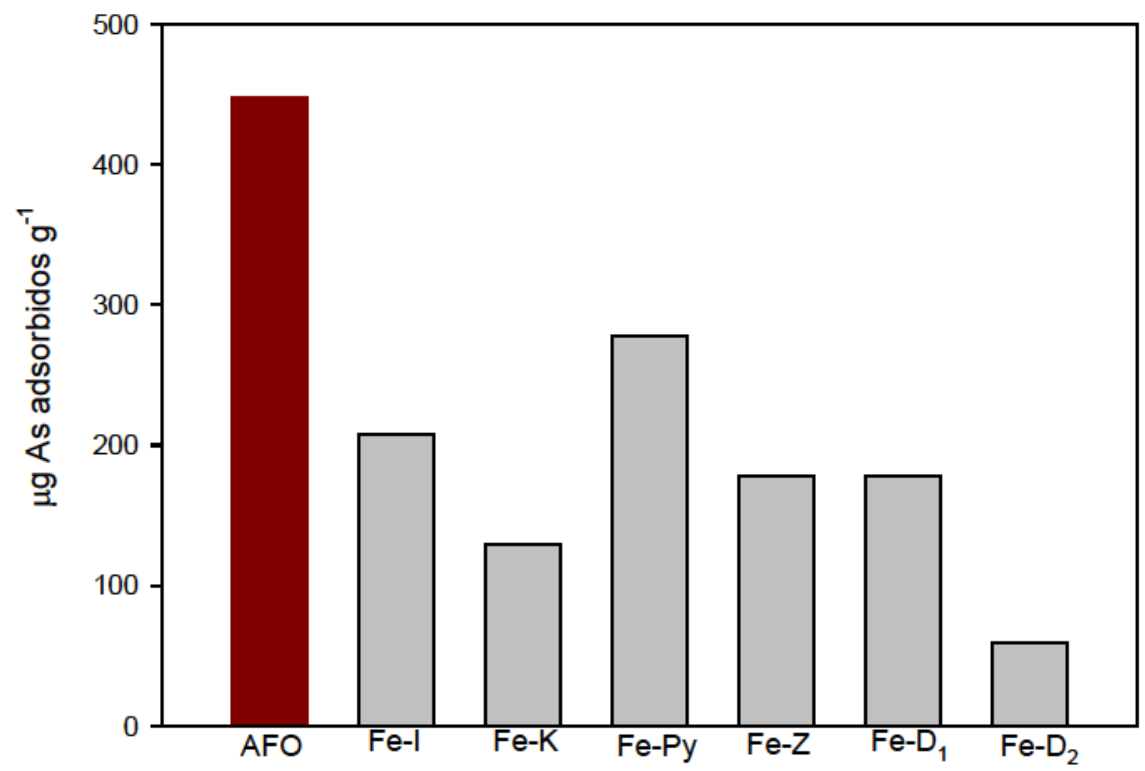

Figura 7.25. Efectividad en la remoción de As de las muestras activadas en comparación con las arcillas AFO.

Los resultados corroboran la importancia del rol de las especies de hierro(III) en la adsorción del contaminante y ponen de manifiesto las diferentes posibilidades que ofrecen los aluminosilicatos estudiados, ya sea aquellos cuyo contenido original en hierro resulte adecuado para el tratamiento, como los posibles de ser modificados por un simple tratamiento químico. 


\subsubsection{Estudio complementario para visualizar la presencia del contaminante en el adsorbente}

La evidencia directa del $\mathrm{As}(\mathrm{V})$ adsorbido sobre las fases activadas pudo observarse por la técnica de espectroscopia micro-Raman. La Figura 7.26 muestra comparativamente el espectro Raman de la Fe-Py antes y con posterioridad a la adsorción del contaminante (material agotado luego de 27 ciclos de tratamiento).

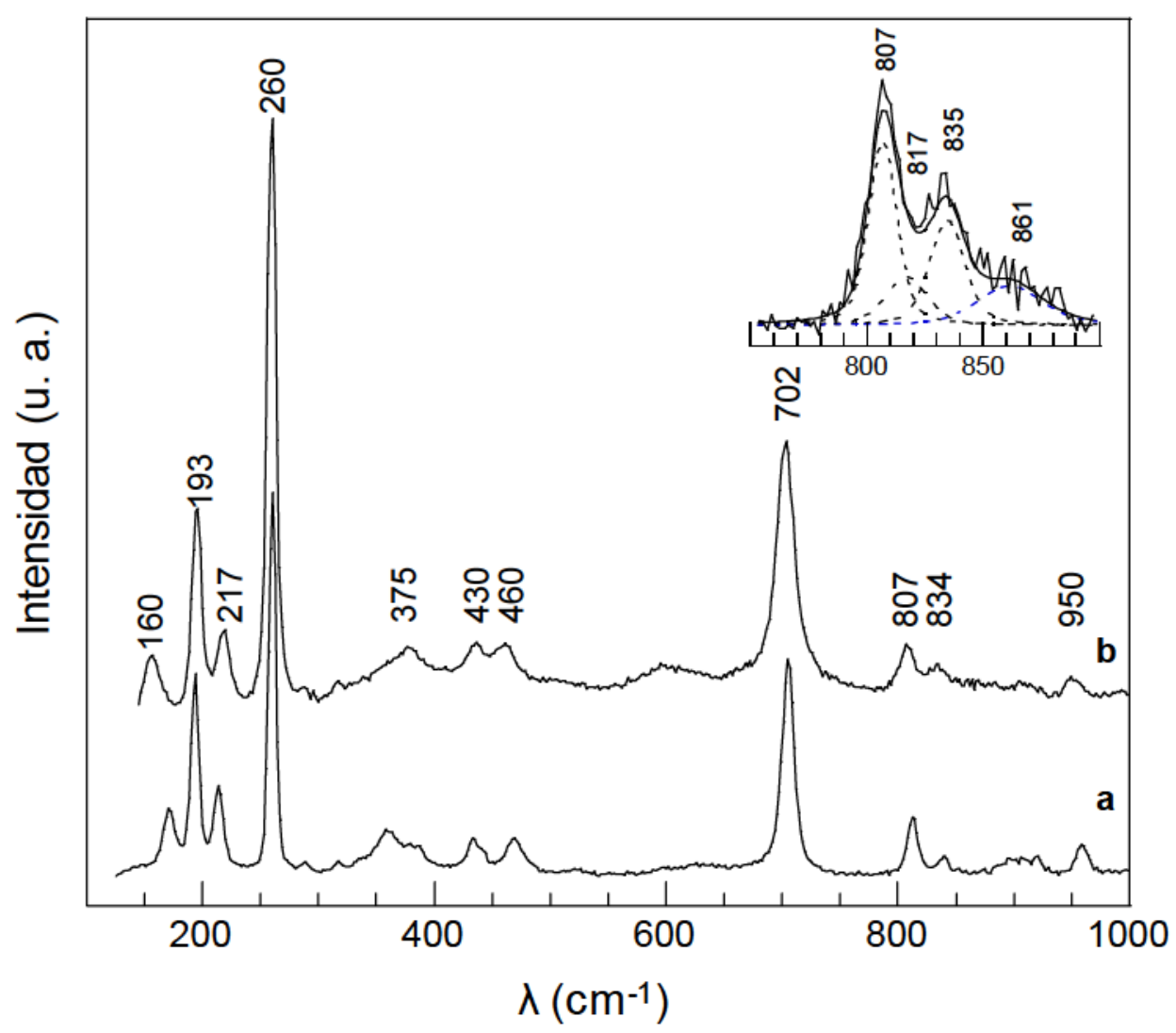

Figura 7.26. Espectro micro-Raman, a) muestra Fe-Py y b) muestra Fe-Py agotada.

La curva a de la Figura 7.26 se corresponde con el espectro típico de la pirofilita (RRUFF-database), presentando las principales líneas Raman en 194, 260, 702, 810 y $957 \mathrm{~cm}^{-1}$. Las bandas en la región $800-1100 \mathrm{~cm}^{-1}$ son atribuidas a los estiramientos de los enlaces $\mathrm{Si}-\mathrm{O}$ del tetraedro $\mathrm{SiO}_{4}$, mientras que la intensa señal alrededor de 700 $\mathrm{cm}^{-1}$ corresponde al modo vibracional Si-O-Si producto de la condensación de los tetraedros típico por espectroscopia Raman. Las vibraciones correspondientes a las deformaciones angulares $\mathrm{Al}^{3+}-\mathrm{Fe}^{3+}-\mathrm{OH}$ y $\mathrm{Fe}^{3+}-\mathrm{Fe}^{3+}-\mathrm{OH}$ de las especies de carga +3 en

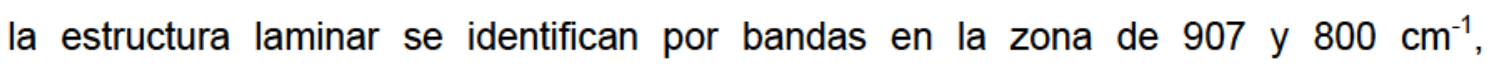
respectivamente (Lantenois et al., 2007). La región por debajo de $600 \mathrm{~cm}^{-1}$ es compleja de asignar debido a que en la misma aparecen los modos correspondientes a vibraciones de la estructura covalente y las de los cationes de especies segregadas, en sitios octaédricos (señales típicas de los óxidos de Fe(III) cristalinos y amorfos). La 
fuerte señal en $260 \mathrm{~cm}^{-1}$ es común en los filosilicatos di octaédricos (Wang et al., 2002).

En relación a los óxidos de hierro, la Figura 7.27 muestra las señales de las fases goethita, magnetita y hematita, presentadas como referencia. Es de destacar que la ferrihidrita presenta líneas Raman anchas y centradas en 370-380 y 508-510 $\mathrm{cm}^{-1}$, mientras que una intensa línea se observa en la región $707-710 \mathrm{~cm}^{-1}$ (Müller et al., 2010). De este modo, la zona baja del espectro presenta un intenso solapamiento que puede dificultar la asignación.

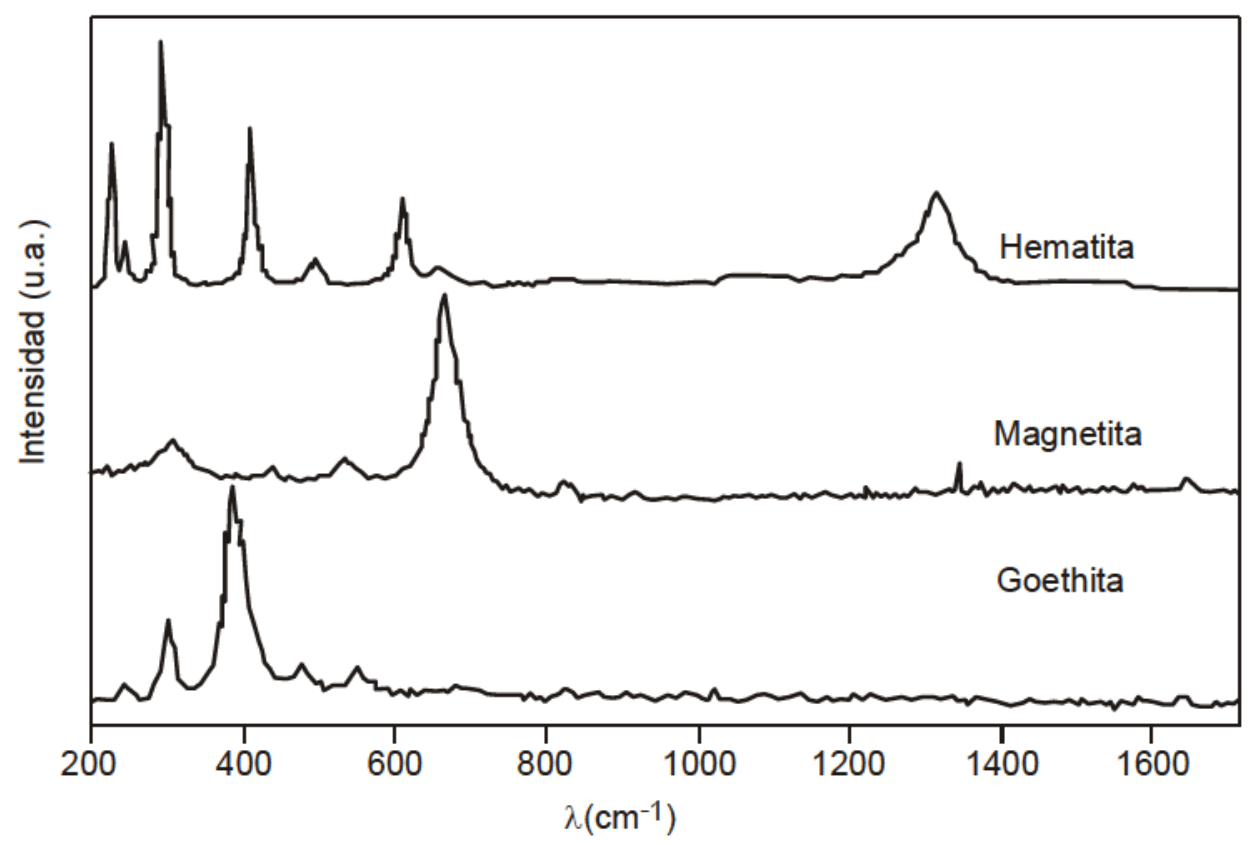

Figura 7.27. Señales Raman típicas de los principales óxidos de hierro.

Es importante señalar, que la identificación de la presencia de hierro mediante espectroscopía Raman resulta compleja dado que la especie ferrihidrita es una fase inestable, precursora de la fase final hematita y se altera por efecto de la potencia del laser, de modo que solo puede verse en forma clara trabajando a una potencia de laser muy baja. En las condiciones utilizadas en este trabajo si se emplea un láser de baja potencia se dificulta la observación de las otras señales de la fase silícica.

La Figura 7.28 muestra, a modo de ejemplo, la transformación que ocurre por efecto de la potencia del láser sobre la fase goethita, que permite visualizar la transformación a hematita. Estos datos justifican la dificultad en definir los efectos de la transformación operada en la muestra estudiada. 


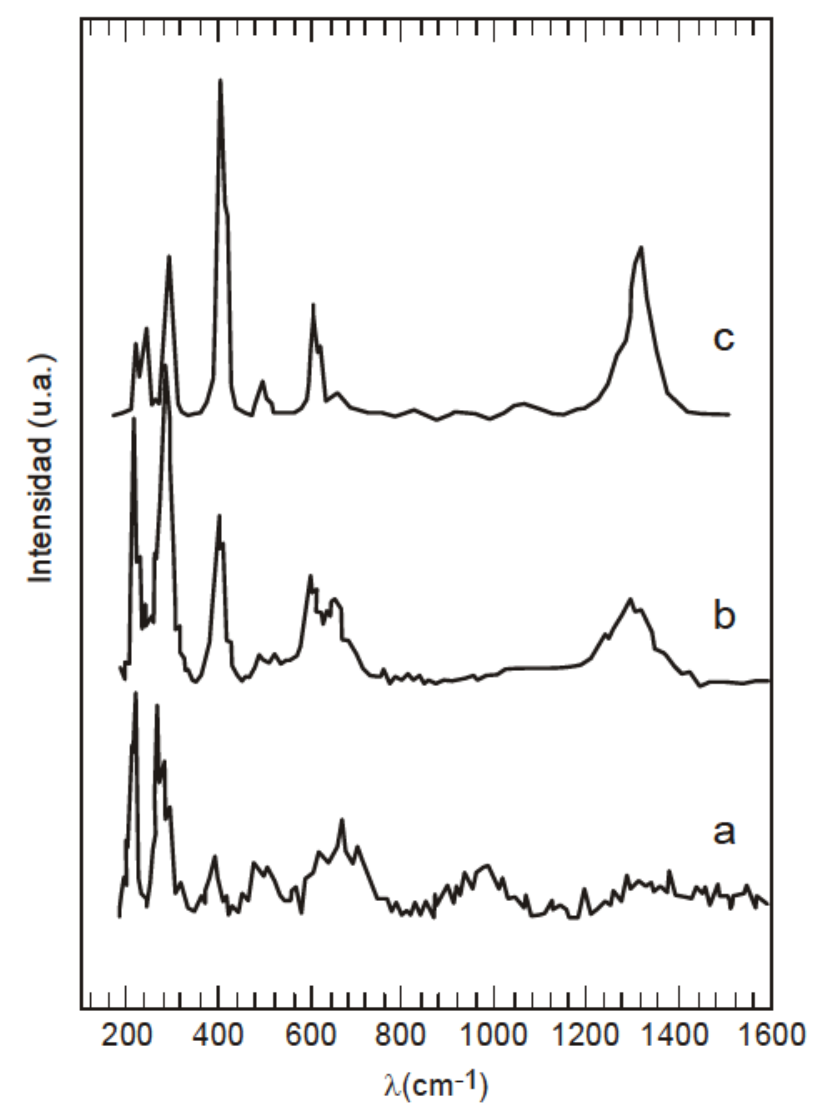

Figura 7.28. Transformación de goethita por efecto de la potencia del laser: a) $18 \mathrm{mv}$, b) $24 \mathrm{mv}$, c) $60 \mathrm{mv}$.

En el espectro Raman de la curva b de la Figura 7.26, correspondiente a la fase Fe-Py conteniendo el As adsorbido durante los ciclos efectivos de tratamiento, se observa un comportamiento similar al espectro de la muestra Fe-Py sin agotar, a excepción de la zona entre $750-900 \mathrm{~cm}^{-1}$, cuyo detalle se indica en la parte superior derecha de la figura. En este caso, la banda ubicada en $807 \mathrm{~cm}^{-1}$ típica de la Fe-Py, sufre una modificación en su forma, evidenciándose la presencia de nuevas componentes localizadas en $817 \mathrm{~cm}^{-1}$ y $861 \mathrm{~cm}^{-1}$, así como un incremento en la intensidad de la banda y un corrimiento de la envolvente que puede centrarse en 835 $\mathrm{cm}^{-1}$.

Las diferencias observadas pueden ser atribuidas a la presencia de arseniato(V). La banda a menor frecuencia se atribuye al estiramiento simétrico de la especie tetraédrica $\left(\mathrm{AsO}_{4}\right)^{3-}$, mientras que las bandas a 835 y $861 \mathrm{~cm}^{-1}$ se pueden atribuir a los estiramientos simétricos As-O de las especies superficiales $\mathrm{HAsO}_{4}{ }^{2-}$ y $\mathrm{H}_{2} \mathrm{AsO}_{4}{ }^{1-}$ (Myneni et al., 1998). Estos datos sugieren que la interacción entre los oxi/hidróxidos de hierro con el arsénico ocurre a través de la formación de complejos de esfera interna mono y/o bidentados en concordancia con datos reportados en la literatura (citados en el ítem 4.3 del Capítulo 4). 
7.2. Potencialidad de las muestras del yacimiento Unchimé en el proceso de adsorción de As

En este ítem se caracterizan muestras ricas en hierro procedentes del depósito Unchimé (Salta), para posteriormente ser empleadas en el tratamiento de remoción de As, cuyos parámetros fueran optimizados para las arcillas AFO en el Capítulo 6.

En la Figura 7.29 se muestran los pasos seguidos en este ítem para evaluar la potencialidad de las muestras de este yacimiento.

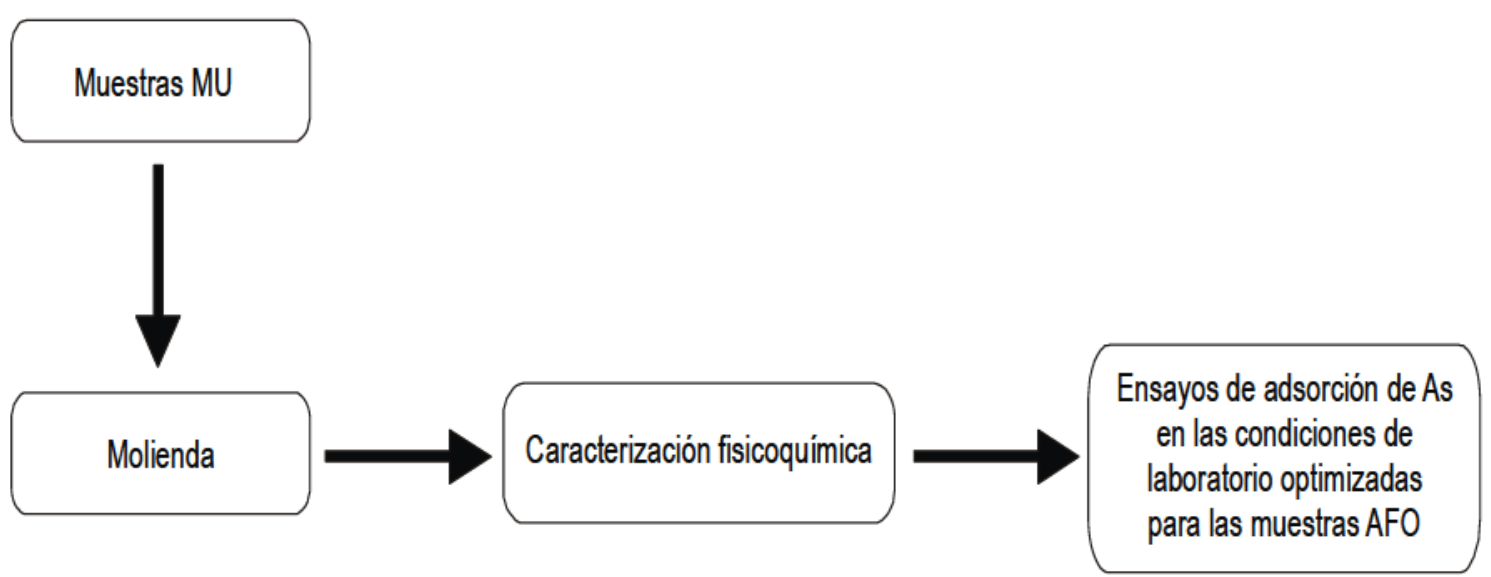

Figura 7.29. Esquema de los pasos seguidos con las muestras de Unchimé.

\subsubsection{Caracterización fisicoquímica de las muestras}

Las muestras seleccionadas fueron denominadas con las siglas MU2, MU4, MU5 y MU7. Las mismas fueron molidas igual que las muestras AFO en un molino de martillo obteniendo la distribución de tamaño de partícula denominada molienda fina.

Las muestras fueron caracterizadas mediante difracción de rayos $X$ (roca total y fracción arcilla orientada, calcinada y glicolada), análisis químico de elementos mayoritarios por ICP-AES (expresado en óxidos \%), determinación de As por ICP-MS (expresado en ppm) y medidas de superficie específica BET.

En la Tabla 7.14 se muestran los resultados del análisis químico para elementos mayoritarios expresados en \% de óxidos para las cuatro muestras seleccionadas. En la última columna de la misma tabla se incluye el valor de As en ppm.

Al igual que en las arcillas ferruginosas de la Zona 3 de las Sierras Septentrionales de la provincia de Buenos Aires, se observa una correlación entre el contenido de hierro (expresado como $\mathrm{Fe}_{2} \mathrm{O}_{3} \%$ ) y el de As que se muestra en la Figura 7.30. 
Tabla 7.14. Análisis químico de elementos mayoritarios por ICP-AES (expresado en óxidos \%) y de As por ICP-MS (expresado en ppm).

\begin{tabular}{l|c|r|r|r|r}
\hline \multicolumn{2}{c|}{ Muestra } & \multicolumn{1}{c|}{ MU2 } & \multicolumn{1}{c|}{ MU4 } & \multicolumn{1}{c}{ MU5 } & \multicolumn{1}{c}{ MU7 } \\
\hline $\mathrm{SiO}_{2}$ & $(\%)$ & 21,0 & 46,9 & 33,5 & 40,2 \\
$\mathrm{Al}_{2} \mathrm{O}_{3}$ & $(\%)$ & 4,97 & 9,93 & 7,87 & 8,62 \\
$\mathrm{Fe}_{2} \mathrm{O}_{3}$ & $(\%)$ & 65,13 & 34,66 & 50,81 & 42,11 \\
$\mathrm{CaO}$ & $(\%)$ & 3,28 & 0,68 & 1,19 & 1,09 \\
$\mathrm{MgO}$ & $(\%)$ & 0,54 & 1,05 & 0,77 & 0,92 \\
$\mathrm{Na}_{2} \mathrm{O}$ & $(\%)$ & 0,08 & 0,08 & 0,07 & 0,06 \\
$\mathrm{~K}_{2} \mathrm{O}$ & $(\%)$ & 0,03 & 0,76 & 0,37 & 0,60 \\
$\mathrm{Cr}_{2} \mathrm{O}_{3}$ & $(\%)$ & $<0,01$ & $<0,01$ & $<0,01$ & 0,01 \\
$\mathrm{TiO}_{2}$ & $(\%)$ & 0,29 & 0,64 & 0,56 & 0,50 \\
$\mathrm{MnO}$ & $(\%)$ & 0,01 & 0,14 & 0,02 & 0,17 \\
$\mathrm{P}_{2} \mathrm{O}_{5}$ & $(\%)$ & 2,33 & 0,36 & 0,69 & 0,69 \\
$\mathrm{SrO}_{\mathrm{BaO}}$ & $(\%)$ & 0,01 & 0,02 & 0,02 & 0,01 \\
$\mathrm{LOI}$ & $(\%)$ & 0,08 & 0,13 & 0,04 & 0,05 \\
$\mathrm{As}$ & $(\mathrm{ppm})$ & 2,24 & 4,88 & 4,08 & 4,97 \\
$\mathrm{M}$ & 112,5 & 23,1 & 49,2 & 29,9 \\
\hline
\end{tabular}

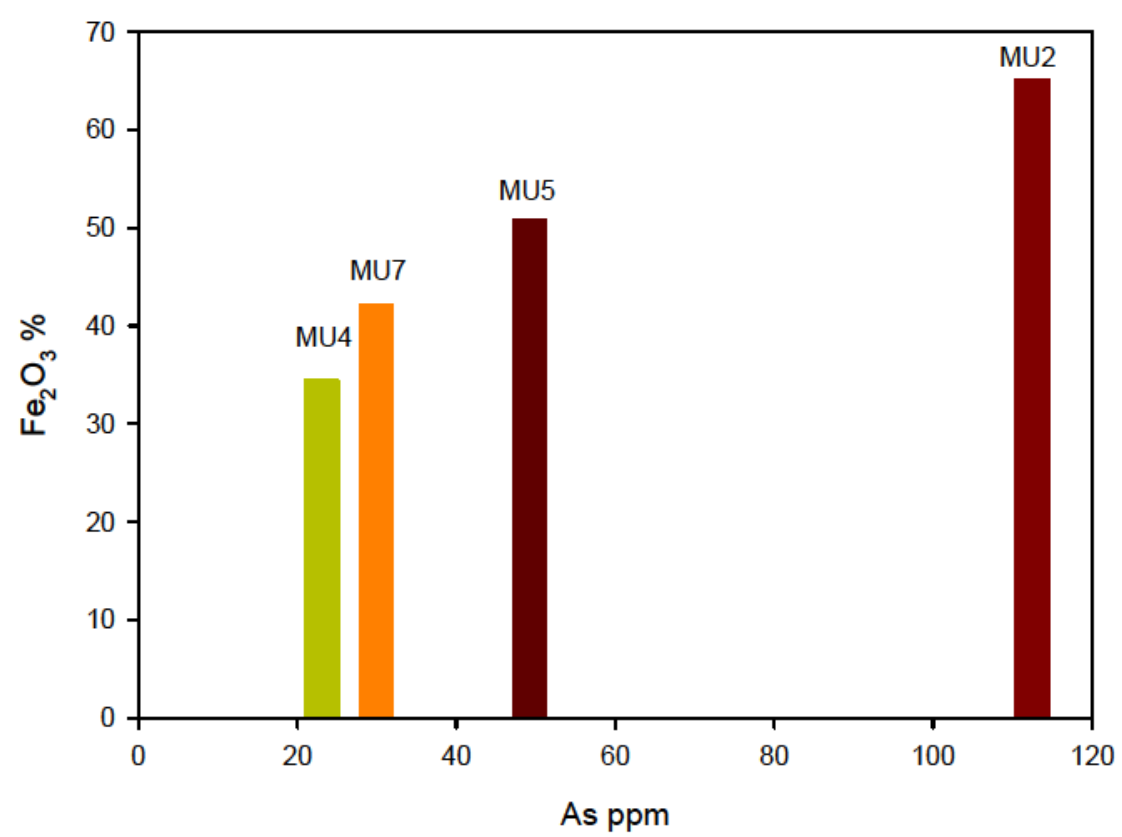

Figura 7.30. Relación entre el contenido de $\mathrm{As}$ y de $\mathrm{Fe}_{2} \mathrm{O}_{3} \%$ para las muestras del yacimiento Unchimé.

En la Figura 7.31 se muestran los diagramas de difracción de rayos $X$ de roca total para las 4 muestras estudiadas. En estos diagramas todas las muestras presentan la fase mineral hematita (PDF 88-2359), acompañado de cuarzo como especie accesoria. Asimismo, se observan débiles reflexiones de especies arcillosas. Estas últimas se evidencian con mayor resolución en los difractogramas de la fracción arcilla (líneas basales en la zona de $7 \AA$ para la caolinita y de $10 \AA$ para la illita), que se muestran en las Figuras 7.32 a 7.35. 


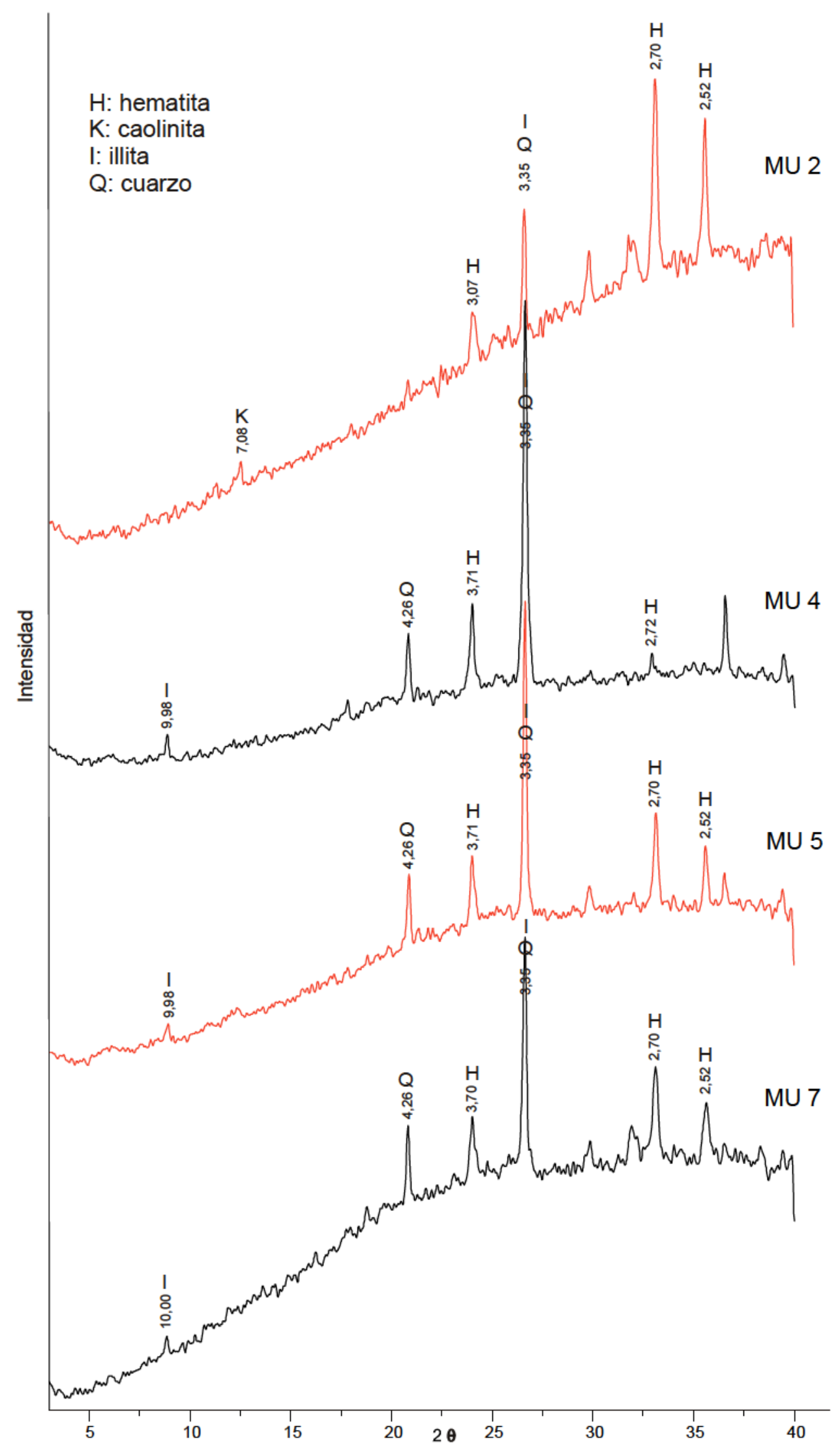

Figura 7.31. Diagramas DRX roca total de las cuatro muestras seleccionadas del yacimiento Unchimé. 


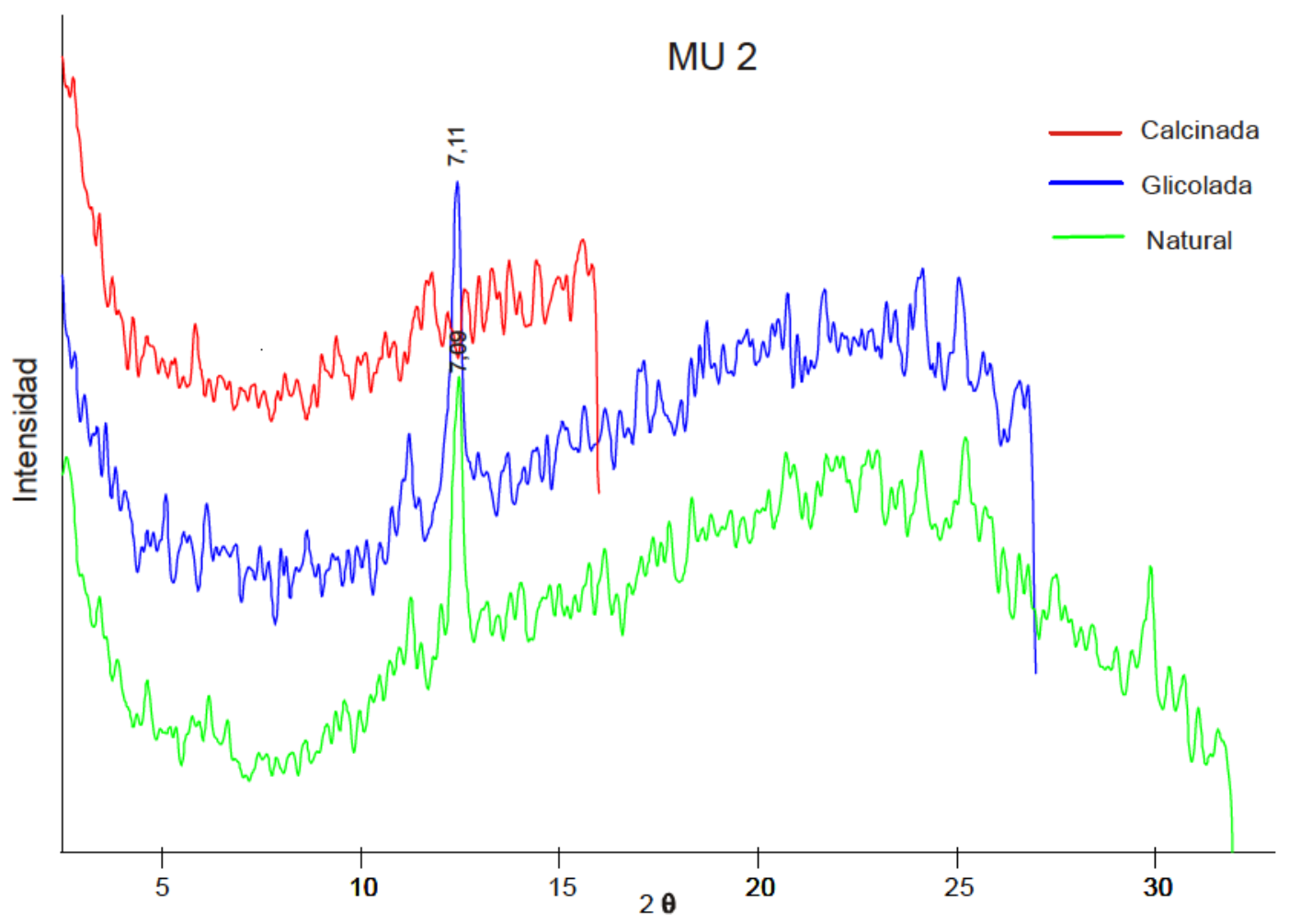

Figura 7.32. Difractogramas DRX de la fracción arcilla para la muestra MU2.

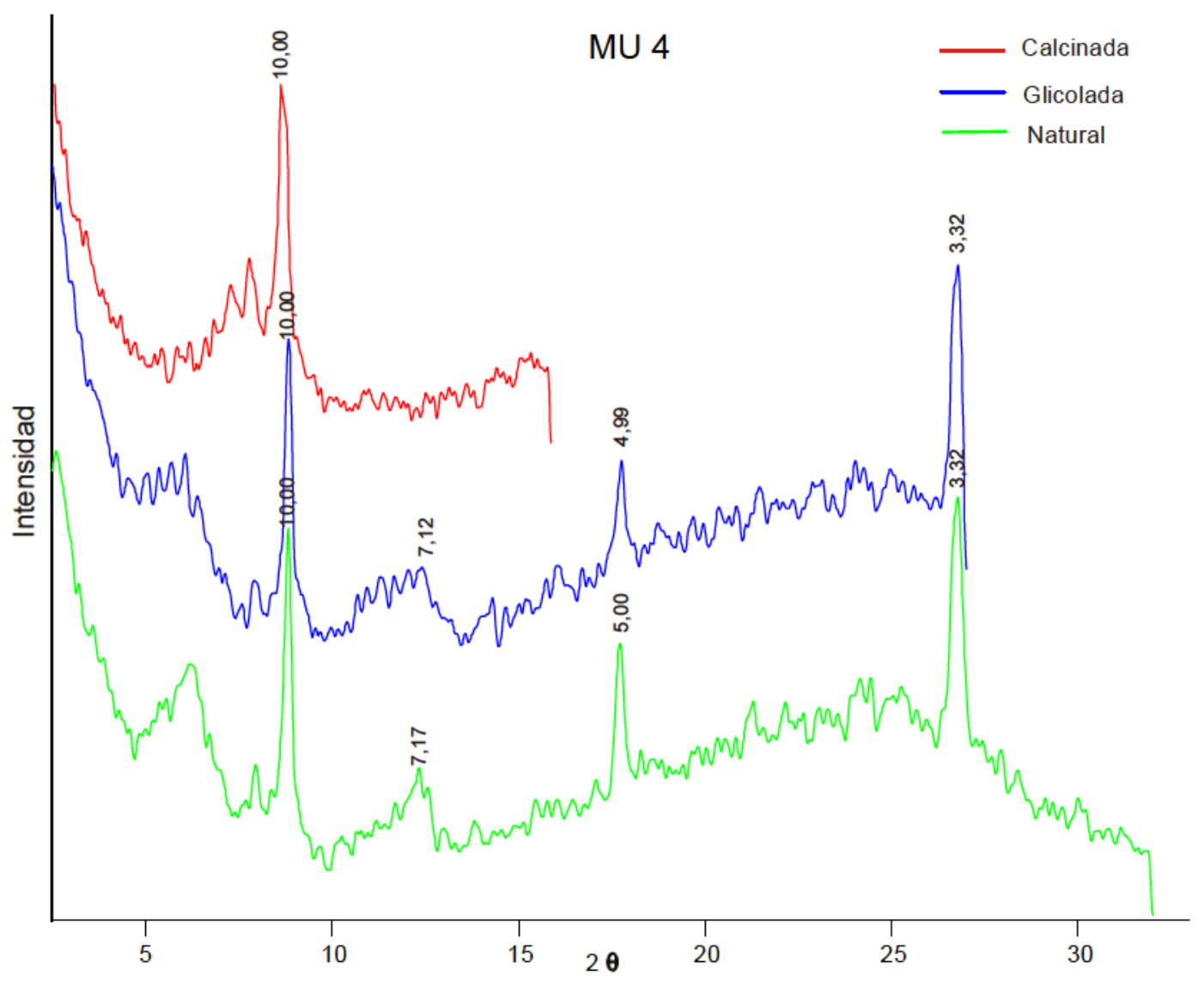

Figura 7.33. Difractogramas DRX de la fracción arcilla para la muestra MU4. 


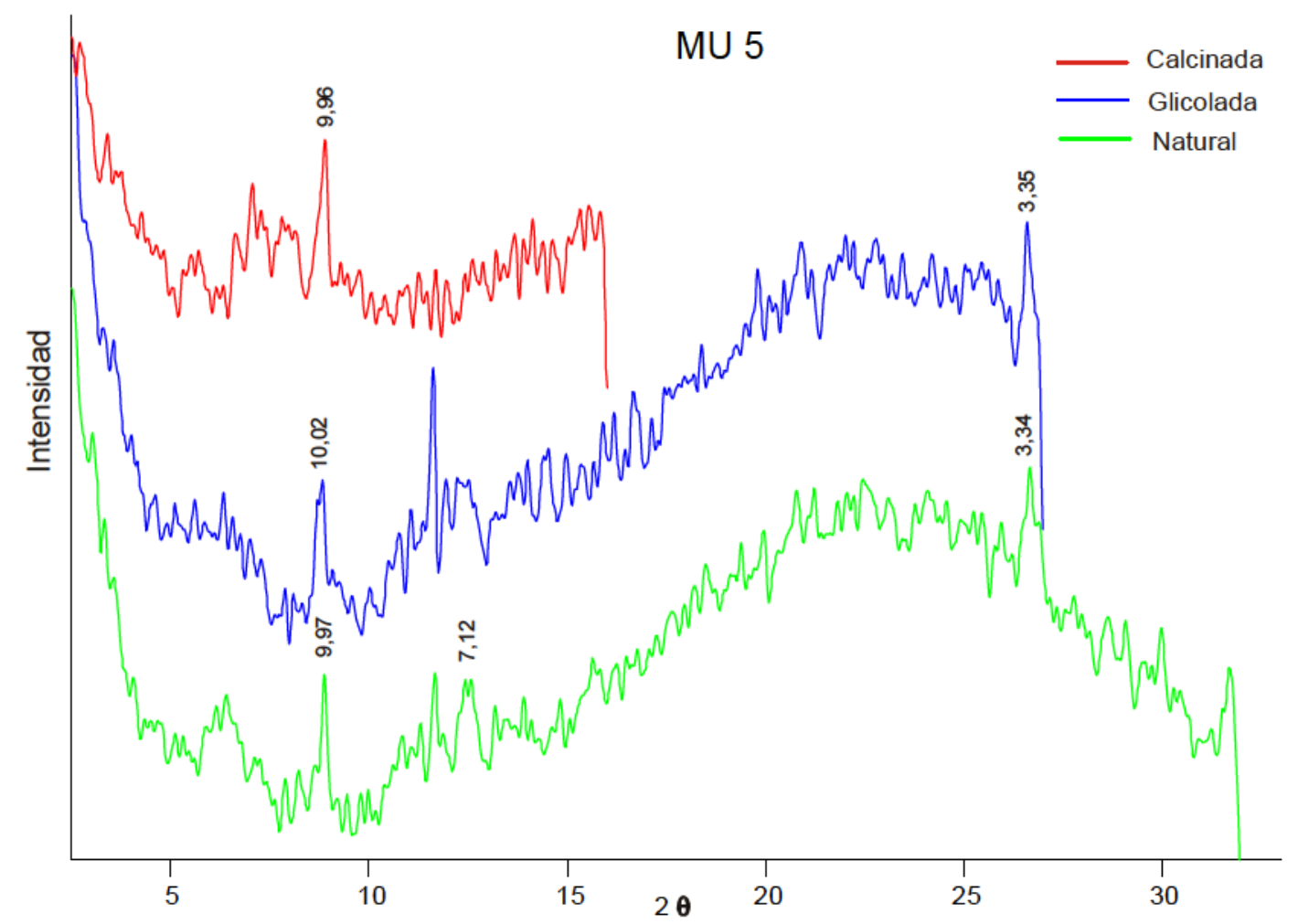

Figura 7.34. Difractogramas DRX de la fracción arcilla para la muestra MU5.

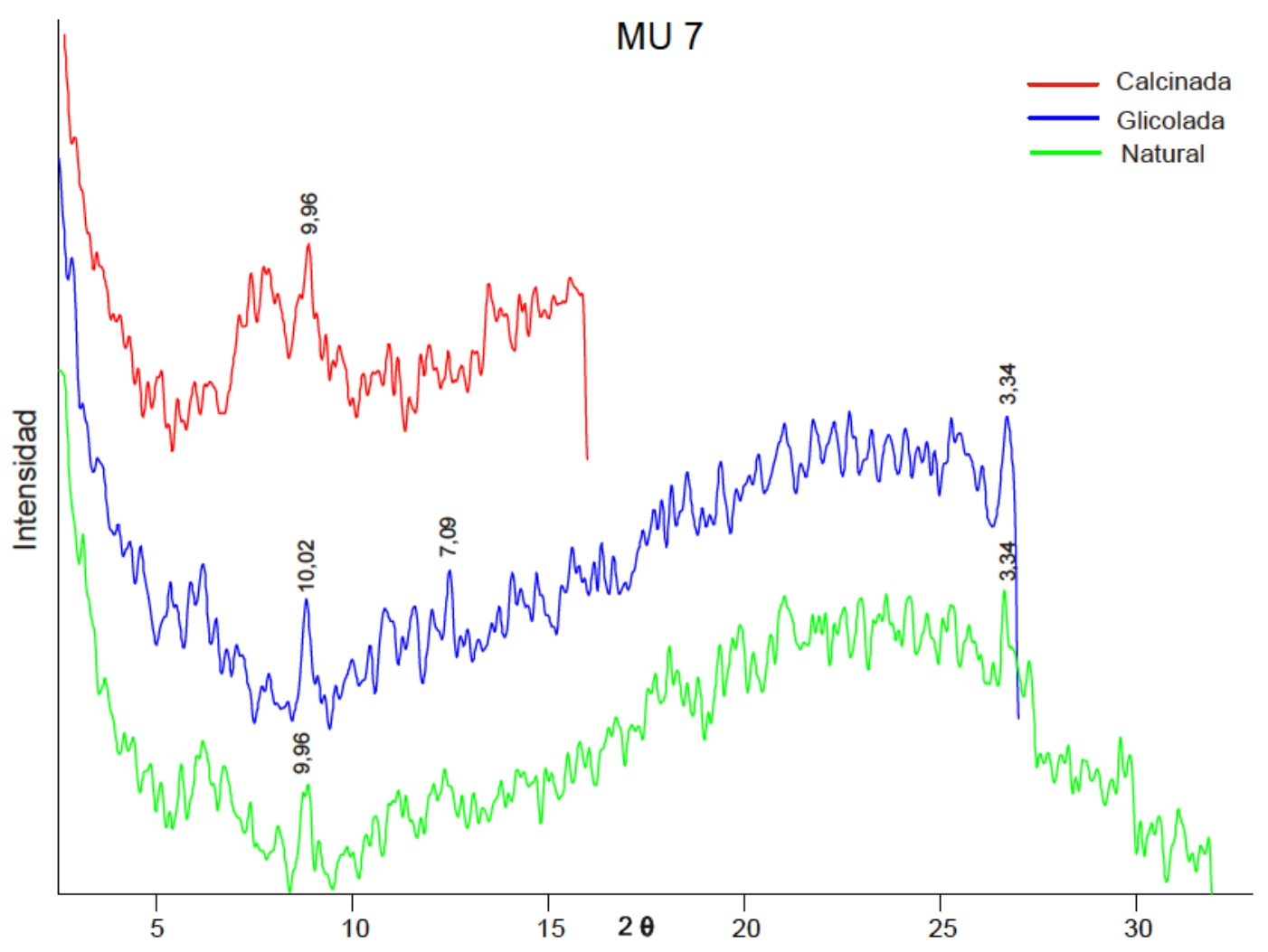

Figura 7.35. Difractogramas DRX de la fracción arcilla para la muestra MU7.

En la Tabla 7.15, se muestran los resultados de la superficie BET y del tamaño promedio de poros. Los valores de la superficie específica son comparables con los de 
las arcillas ferruginosas de la PBA. Asimismo, el tamaño de poros promedio se encuentra comprendido en la zona de los mesoporos. La distribución de tamaño de poros calculada mediante la teoría DFT se muestra en la Figura 7.36. Se destaca, al igual que en las arcillas $\mathrm{AFO}$, un alto contenido de poros en el rango de los mesoporos.

Tabla 7.15. Resultados de Superficie específica BET expresada en $\mathrm{m}^{2} \mathrm{~g}^{-1}$ y de tamaño de poro promedio (DPP) expresado en $\AA$.

\begin{tabular}{c|r|r}
\hline Muestra & \multicolumn{1}{|c|}{ S $_{\text {BET }}$} & \multicolumn{1}{c}{ DPP } \\
\hline MU2 & 8,34 & 81,18 \\
MU4 & 20,61 & 43,39 \\
MU5 & 17,25 & 55,30 \\
MU7 & 19,19 & 45,15 \\
\hline
\end{tabular}
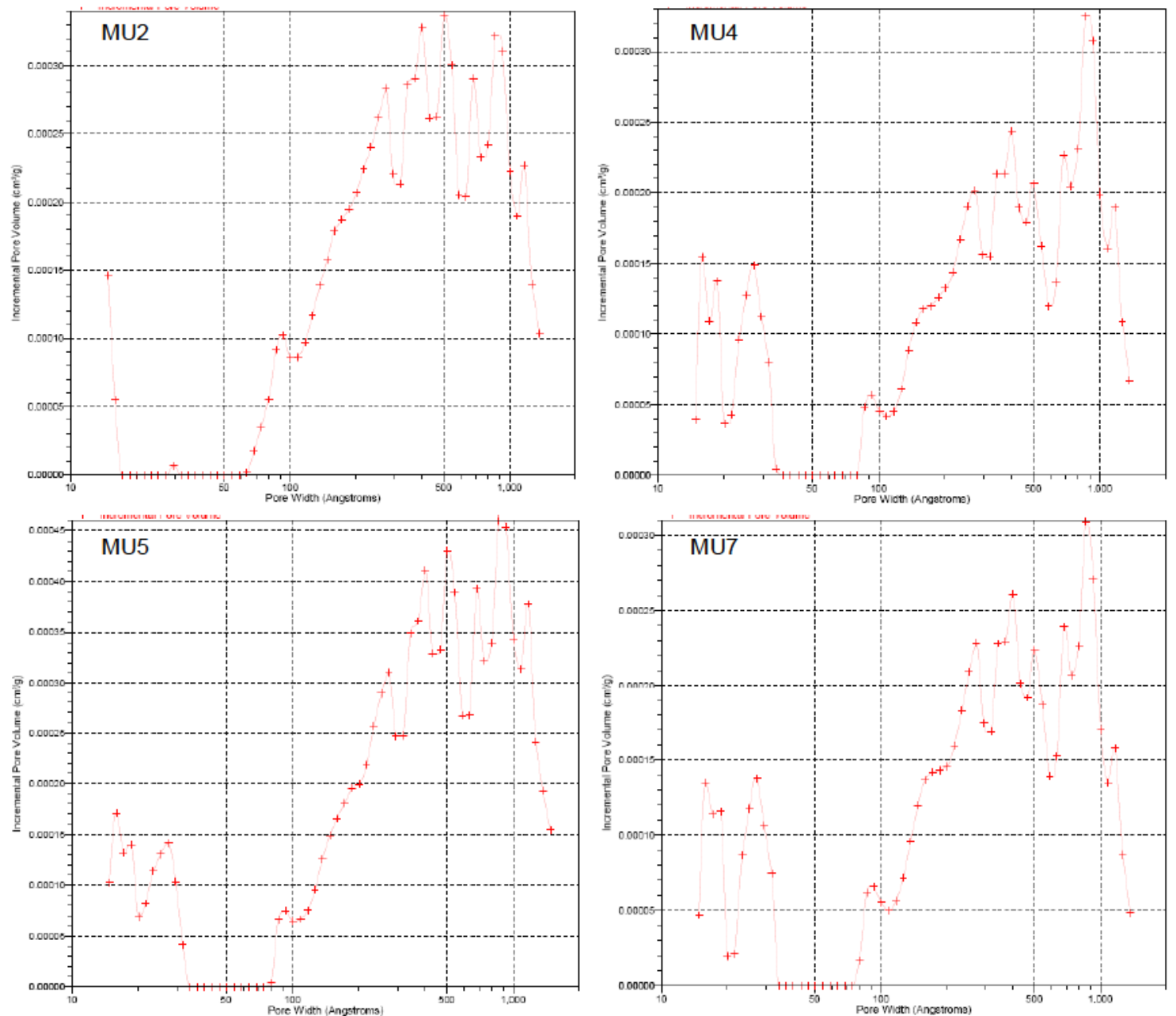

Figura 7.36. Distribución de tamaño de poros (DFT) para las muestras de Unchimé.

\subsubsection{Evaluación de la remoción de As a nivel laboratorio}

Las muestras caracterizadas se emplearon en el proceso de remoción de arsénico, determinando el agotamiento de los adsorbentes. Se emplearon los parámetros previamente optimizados en el Capítulo 6 para las arcillas ferruginosas siguiendo el esquema mostrado en la Figura 6.49. 
Para estos ensayos se usaron muestras de agua preparadas en el laboratorio con agua de red la cual fue modificada químicamente con $\mathrm{As}(\mathrm{V})$ para obtener soluciones conteniendo $1000 \mu \mathrm{g} \mathrm{L}^{-1}$ de arsénico. Los ensayos se realizaron en simultáneo en el equipo Jar test empleando $75 \mathrm{~g}$ de material en $750 \mathrm{ml}$, decantando el sólido suspendido con la ayuda de la dosis óptima de $\operatorname{PAC}(0,193 \mathrm{mg}$ de $\mathrm{Al}$ por litro de agua). La eficacia del material se estableció a través del número de ciclos útiles de tratamiento consecutivos, considerando agotado el adsorbente cuando la concentración de arsénico en la solución excede el límite permitido de $10 \mu \mathrm{g} \mathrm{L}^{-1}$.

El monitoreo de cada jarra se realizó tomando muestras transcurridas las 24 hs de sedimentación. Se determinaron turbidez y contenido de As. Para este último se hizo uso del kit de As Merck. Periódicamente se corroboraron las mediciones del kit realizando medidas de As por el método EPA 3020/7010. En el primer ciclo de tratamiento se realizó un control de cada muestra sin el agregado de coagulante para evaluar la necesidad de utilización del mismo, analizando, en cada caso el perfil de turbidez midiendo el valor de NTU durante las primeras 4 hs.

En los gráficos de la Figura 7.37 se observan los perfiles de turbidez obtenidos para las 4 muestras durante las primeras horas del primer ciclo de tratamiento.
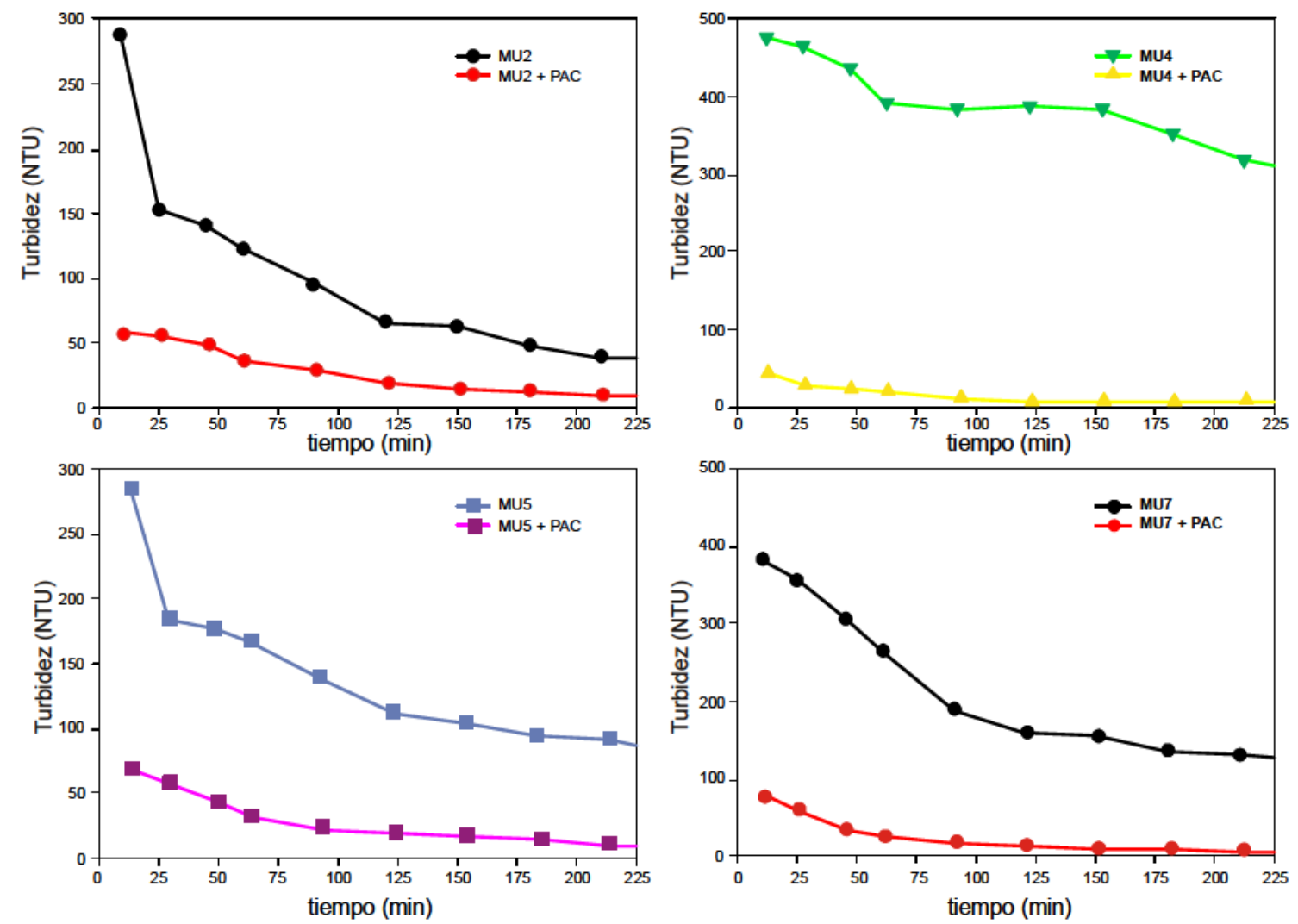

Figura 7.37. Perfiles de turbidez para las muestras MU con y sin el agregado de PAC. 
En todos los casos la turbidez inicial con el agregado de coagulante es mucho menor que sin el agregado del mismo. El agregado de coagulante mejora la sedimentación del material motivo por el cual su utilización es necesaria para obtener valores aceptables de turbidez.

En la Tabla 7.16 se muestran los resultados de As y turbidez a las 24 hs para el primer ciclo de tratamiento, para las 4 muestras con y sin el agregado de coagulante. Se observa que las muestras que no fueron tratadas con el PAC no logran alcanzar la turbidez requerida por el CAA. Asimismo, probablemente como consecuencia del material en suspensión, el As no es disminuido hasta los valores recomendados, a excepción de la muestra MU5 que presenta un valor de As de $10 \mu \mathrm{g} \mathrm{L}^{-1}$. Sin embargo, es de destacar que en todos los casos los contenidos de As disminuyeron, logrando una remoción mayor al $90 \%$.

Tabla 7.16. Resultados de As y turbidez del primer ciclo de tratamiento empleando como adsorbente las muestras del yacimiento Unchimé ( 24 hs de sedimentaión).

\begin{tabular}{c|c|c|c}
\hline Muestra & As $\left(\mu \mathrm{g} \mathrm{L}^{-1}\right)$ & NTU & $\%$ Remoción As \\
\hline MU2 & $25-50$ & 5,50 & $97,5-95$ \\
MU2 + PAC & $<5$ & 1,75 & $>99,5$ \\
MU4 & $10-25$ & 46,7 & $99-97,5$ \\
MU4 + PAC & $<5$ & 1,18 & $>99,5$ \\
MU5 & 10 & 12,3 & 99 \\
MU5 + PAC & $<5$ & 2,58 & $>99,5$ \\
MU7 & 100 & 15,2 & 90 \\
MU7 + PAC & $<5$ & 1,24 & $>99,5$ \\
\hline \multicolumn{4}{|r}{}
\end{tabular}

Las muestras sin coagulante que no lograron la turbidez requerida fueron evaluadas a mayor tiempo (48 hs), los resultados de turbidez y As se muestran en la Tabla 7.17. Si bien se observa una disminución de la turbidez, no siempre se acompaña con una disminución adecuada en el contenido de arsénico. Se obtienen valores aceptables de turbidez y de As solo para la muestra MU2. Los resultados demuestran que el agregado de coagulante es indispensable para la calidad final del agua.

Tabla 7.17. Valores de As y turbidez del primer ciclo de tratamiento empleando como adsorbente las muestras del yacimiento Unchimé a mayor tiempo de sedimentación ( $48 \mathrm{hs}$ ).

\begin{tabular}{c|c|r}
\hline Muestra & As $\left(\mu \mathrm{g} \mathrm{L}^{-1}\right)$ & NTU \\
\hline MU2 & 5 & 1,95 \\
MU4 & 25 & 13,00 \\
MU7 & $25-50$ & 3,26 \\
\hline
\end{tabular}

Finalmente, en la Tabla 7.18, se muestran los resultados globales obtenidos de los ciclos de tratamiento consecutivos realizados con el objeto de evaluar la efectividad de los adsorbentes. Los ensayos fueron realizados con las 4 muestras con el 
agregado de PAC. Cabe destacar que un ensayo paralelo realizado con la muestra MU5 sin PAC, que presentó un contenido de As adecuado en el primer ciclo, no fue exitoso, agotándose al cabo del segundo ciclo y presentando una turbidez mayor a 3 NTU. Se observa que al aumentar el contenido de hierro (expresado como $\mathrm{Fe}_{2} \mathrm{O}_{3}$ ), aumentan la cantidad de ciclos efectivos de tratamiento (Figura 7.38).

Tabla 7.18. Resultados de la efectividad de las muestras del yacimiento Unchimé.

\begin{tabular}{c|c|c|c}
\hline Muestra & $\mathrm{N}^{0}$ Ciclos & $\mathrm{Fe}_{2} \mathrm{O}_{3} \%$ & $\mu \mathrm{g}$ As retenidos $/ \mathrm{g}_{\text {adsorbente }}$ \\
\hline MU2 + PAC & 42 & 65,1 & 416,60 \\
MU5 + PAC & 36 & 50,8 & 356,95 \\
MU7 + PAC & 28 & 42,1 & 277,65 \\
MU4 + PAC & 22 & 34,4 & 218,30 \\
\hline
\end{tabular}

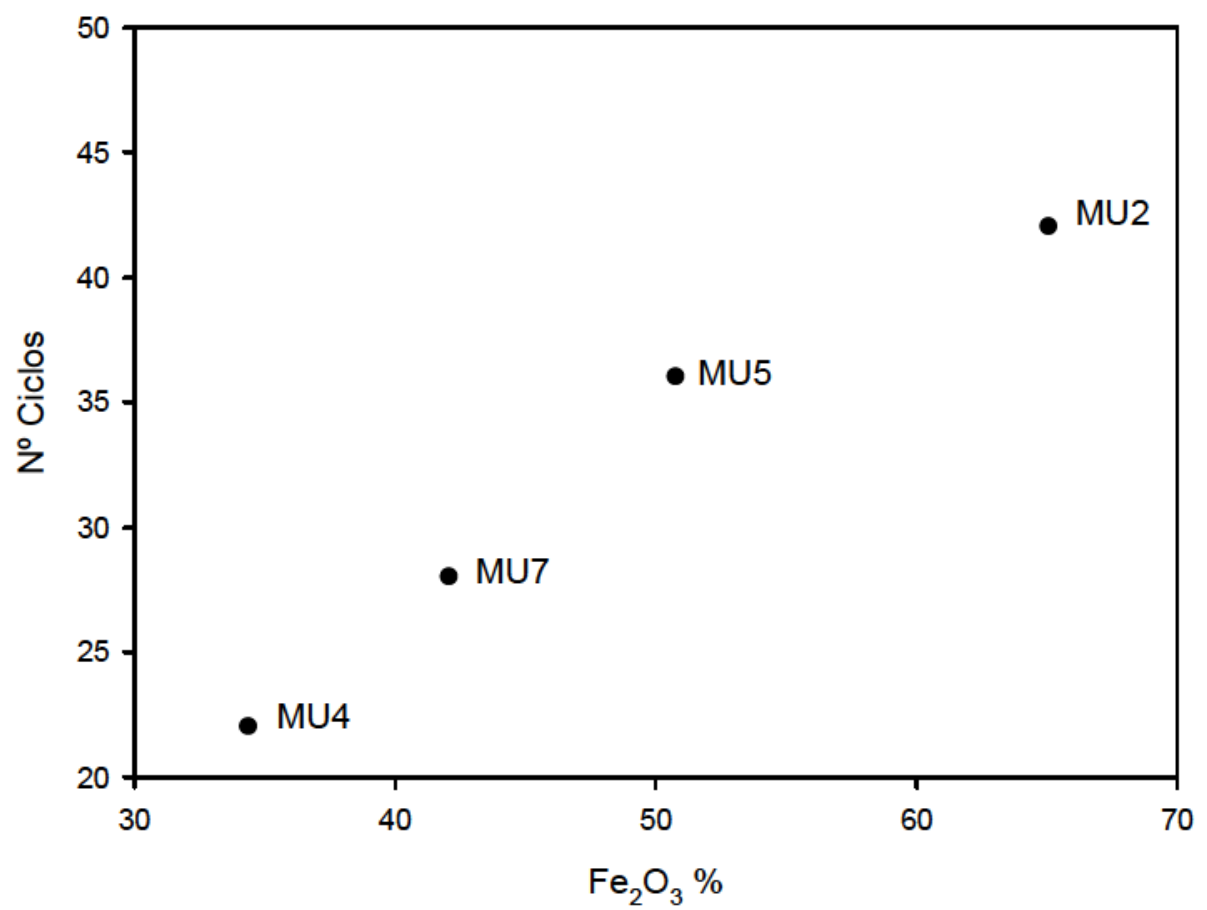

Figura 7.38. Relación entre la cantidad de ciclos efectivos y el contenido de hierro.

En relación a los datos indicados en la Tabla 7.18, cabe destacar que, en la muestra MU2 se presentaron dificultades para disminuir la turbidez a los valores recomendados por el CAA a partir del ciclo 19, si bien el contenido de As se mantiene por debajo de $10 \mu \mathrm{g} \mathrm{L}^{-1}$ hasta el ciclo 42.

De los ensayos realizados surge claramente que la efectividad en la remoción de As se encuentra relacionada directamente con el contenido en hierro. En la Figura 7.39 se observa comparativamente los $\mu \mathrm{g}$ de As retenidos por $\mathrm{g}$ de mineral para las muestras del yacimiento de Unchimé, incluyendo el dato de la AFO (PBA) con fines comparativos. 
Es de señalar, que los resultados obtenidos corresponden a los realizados en condiciones similares, siguiendo el esquema de la Figura 6.49 (24 hs de sedimentación). Un ajuste de las variables operativas para la muestra MU2 (mayor contenido de hierro) podría conducir a un aumento del número de ciclos teniendo en cuenta las características estructurales y composicionales del material adsorbente.

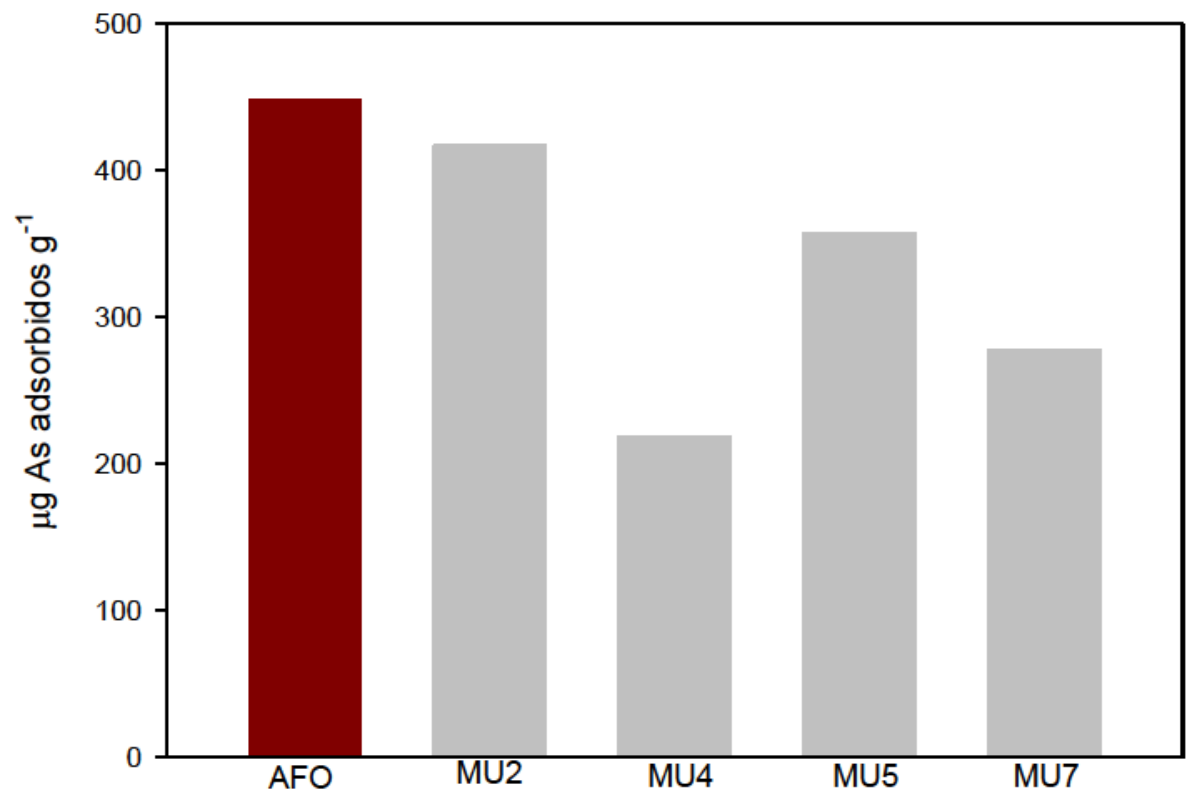

Figura 7.39. As retenidos por las muestras del yacimiento de Unchimé en comparación con las arcillas AFO.

Al respecto se analizaron aspectos tendientes a lograr una turbidez adecuada. En una primera etapa se duplicó la cantidad de coagulante, no observando una mejora en la calidad del agua. En segundo término y usando la cantidad original de coagulante, se duplicó el tiempo de sedimentación, logrando en este caso valores de turbidez acordes a los requeridos. De este modo para el ciclo 43 donde se determinó un valor de turbidez de 25,3 NTU y entre $10-25 \mu_{\text {g L}}^{-1}$ para 24 hs de sedimentación, al elevar el tiempo a $48 \mathrm{hs}$, se obtienen valores de $3,08 \mathrm{NTU}$ y $<10 \mu \mathrm{g} \mathrm{L}^{-1}$ de As. Las diferencias observadas en el comportamiento de la muestra MU2 respecto a las restantes se podría atribuir al valor excesivo de la relación hierro/arcilla, sugiriendo una deficiente interacción entre ambas especies y la imposibilidad de sedimentación de la especie de hierro en suspensión mediante el agregado de sal de aluminio. 


\section{CAPÍTULO 8}

\section{Activación de las arcillas ferruginosas}

En base a los resultados obtenidos en el capítulo anterior, pareció interesante evaluar el efecto de la modificación química de la arcilla ferruginosa con sales de hierro, a fin de considerar la posibilidad de activación de dichas arcillas para mejorar el proceso de remoción de As.

El trabajo a nivel laboratorio, se dividió en tres etapas. En la primera se realizó la activación de la arcilla ferruginosa empleando una sal de hierro(III) en medio básico. En la segunda etapa, las muestras activadas fueron caracterizadas empleando distintas técnicas de análisis fisicoquímicas. Finalmente, se evaluó el uso de las arcillas activadas en la remoción de As y se comparó su efectividad con la arcilla sin activar.

En la Figura 8.1 se muestra el esquema de los pasos seguidos en este capítulo.

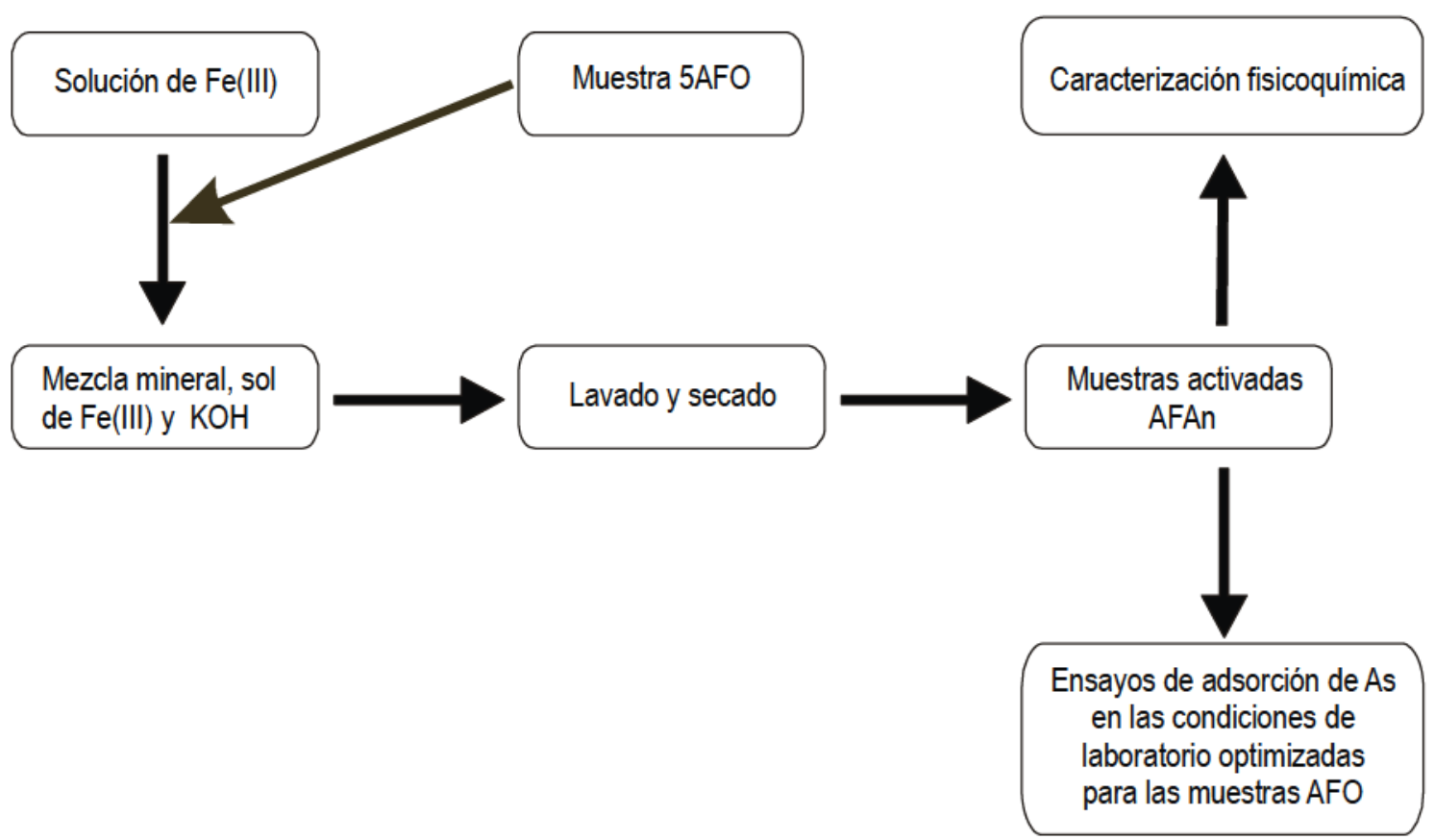

Figura 8.1. Esquema de los pasos seguidos para evaluar la efectividad de las muestras de arcilla ferruginosa activadas.

\subsection{Activación de la muestra de arcilla ferruginosa}

Para la realización de estos ensayos se seleccionó la arcilla ferruginosa 5AFO, que fuera empleada en las pruebas de evaluación de la efectividad del adsorbente en el Capítulo 6. La activación de las muestras se realizó según la técnica descripta en el Capítulo 7 para la activación de las muestras pobres en hierro, empleando una relación $\mathrm{Fe}^{+3} / \mathrm{OH}^{-}=1 / 3$. Manteniendo esta relación constante, se prepararon cinco 
muestras de arcilla activada mediante el agregado de cantidades variables de hierro a partir de $\mathrm{FeCl}_{3} .6 \mathrm{H} 2 \mathrm{O}$ (Biopack, pureza $99,6 \%$ ) y $\mathrm{KOH} 1 \mathrm{M}$. En la Tabla 8.1 se indican las cantidades empleadas en la preparación de cada muestra activada.

Tabla 8.1. Cantidades de arcilla, sal de hierro(III), agua y solución de $\mathrm{KOH} 1 \mathrm{M}$ agregados en la preparación de cinco muestras activadas (AFAn).

\begin{tabular}{c|c|c|c|c|c|c|c|c}
\hline Muestra & $\begin{array}{c}5 \mathrm{AFO} \\
(\mathrm{g})\end{array}$ & $\begin{array}{c}\mathrm{H}_{2} \mathrm{O} \\
(\mathrm{ml})\end{array}$ & $\begin{array}{c}\text { Sal pura } \\
(\mathrm{g})\end{array}$ & $\mathrm{Mol} \mathrm{Fe}^{+3}$ & $\begin{array}{c}\mathrm{V}_{1} \mathrm{KOH}_{(\mathrm{ml})} \\
\left(\mathrm{Mol} \mathrm{OH}^{-}\right.\end{array}$ & $\mathrm{Fe}^{+3} / \mathrm{OH}^{-}$ & $\begin{array}{c}\mathrm{V}_{2} \mathrm{KOH}^{*} \\
(\mathrm{ml})\end{array}$ \\
\hline AFA1 & 200 & 500 & 13,00 & 0,0480 & 160,0 & 0,1600 & 0,33 & 50 \\
AFA2 & 200 & 500 & 20,00 & 0,0740 & 246,5 & 0,2465 & 0,33 & 65 \\
AFA3 & 200 & 500 & 26,78 & 0,0990 & 330,0 & 0,3300 & 0,33 & 85 \\
AFA4 & 200 & 500 & 34,00 & 0,1260 & 419,5 & 0,4195 & 0,33 & 105 \\
AFA5 & 200 & 500 & 41,00 & 0,1516 & 505,0 & 0,5050 & 0,33 & 130 \\
\hline
\end{tabular}

$* \mathrm{~V}_{2}$ de $\mathrm{KOH}$ : volumen agregado para llevar a neutralidad.

Para cada condición se activaron $200 \mathrm{~g}$ de $5 \mathrm{AFO}$, trabajando en vasos de precipitados de $1000 \mathrm{ml}$. Se agregó $500 \mathrm{ml}$ de $\mathrm{H}_{2} \mathrm{O}$ destilada y la cantidad de sal indicada en la Tabla 8.1. Con agitación magnética se agregó el volumen de $\mathrm{KOH} 1 \mathrm{M}$ indicado en la sexta columna de la misma tabla $\left(\mathrm{V}_{1}\right)$ y posteriormente se llevó a neutralidad mediante el agregado de $\mathrm{KOH} 1 \mathrm{M}$ en constante agitación. La cantidad de base agregada para llegar a la neutralidad, en cada caso se muestra en la última columna de la Tabla $8.1\left(\mathrm{~V}_{2}\right)$.

Las muestras modificadas, fueron lavadas hasta la eliminación total de cloruros y secadas en estufa a $60^{\circ} \mathrm{C}$. La reacción empleada en la identificación de cloruros es la precipitación de $\mathrm{AgCl}$ por agregado de $\mathrm{AgNO}_{3}$ al agua de lavado.

Los materiales activados se denominaron con la sigla AFAn, $\mathrm{n}$ igual a número de muestras $(n=1-5)$.

\subsection{Caracterización de las muestras activadas}

Las muestras fueron caracterizadas mediante análisis químico másico por ICPAES, DRX, SEM-EDS y superficie específica BET. Para el análisis DRX se empleó el difractómetro Philips PW1710, mientras que las determinaciones SEM-EDS fueron realizadas en un microscopio electrónico de barrido marca FEl Quanta 200. El microanálisis se realizó con un detector EDAX Apollo 40.

La Tabla 8.2 muestra los resultados del análisis químico por ICP de elementos mayoritarios de las 5 muestras activadas. En la segunda columna de la tabla se agregaron los datos de la arcilla ferruginosa sin activar con fines comparativos. Se aprecia el incremento en los valores de hierro, expresado como $\% \mathrm{Fe}_{2} \mathrm{O}_{3}$, de acuerdo a la cantidad empleada en la preparación. Los valores de hierro incorporados (expresados como $\mathrm{Fe}_{2} \mathrm{O}_{3}$ ) oscilan entre 1,90 y 5,28\%. Por otra parte la muestra AFA3 
equivalente a las condiciones empleadas para activar las muestras pobres en hierro presenta un incremento del $3,60 \%$, en coincidencia con los valores observados en la activación de dichas muestras.

Tabla 8.2. Análisis químico de elementos mayoritarios por ICP-AES (expresado en \% óxidos) para la muestra original (5AFO) y las 5 muestras activadas (AFAn).

\begin{tabular}{l|r|r|r|r|r|r}
\hline \multicolumn{1}{c|}{$\%$} & \multicolumn{1}{c|}{$5 \mathrm{AFO}$} & \multicolumn{1}{c|}{$\mathrm{AFA}_{1}$} & $\mathrm{AFA}_{2}$ & $\mathrm{AFA}_{3}$ & $\mathrm{AFA}_{4}$ & $\mathrm{AFA}_{5}$ \\
\hline $\mathrm{SiO}_{2}$ & 21,10 & 19,42 & 18,79 & 17,95 & 17,67 & 17,38 \\
$\mathrm{Al}_{2} \mathrm{O}_{3}$ & 15,66 & 15,01 & 14,48 & 14,48 & 13,90 & 13,43 \\
$\mathrm{Fe}_{2} \mathrm{O}_{3}$ & 54,50 & 56,40 & 57,38 & 58,10 & 58,96 & 59,78 \\
$\mathrm{CaO}$ & 0,22 & 0,20 & 0,20 & 0,19 & 0,20 & 0,18 \\
$\mathrm{MgO}$ & 0,12 & 0,11 & 0,10 & 0,10 & 0,10 & 0,09 \\
$\mathrm{Na}_{2} \mathrm{O}$ & 0,23 & 0,18 & 0,19 & 0,19 & 0,19 & 0,19 \\
$\mathrm{~K}_{2} \mathrm{O}$ & 1,40 & 1,47 & 1,53 & 1,62 & 1,68 & 1,66 \\
$\mathrm{Cr}_{2} \mathrm{O}_{3}$ & 0,01 & 0,01 & 0,01 & 0,01 & 0,01 & 0,01 \\
$\mathrm{Ti}_{2}$ & 0,61 & 0,61 & 0,59 & 0,59 & 0,57 & 0,57 \\
$\mathrm{MnO}$ & 0,13 & 0,13 & 0,14 & 0,13 & 0,13 & 0,13 \\
$\mathrm{P}_{2} \mathrm{O}_{5}$ & 0,29 & 0,38 & 0,28 & 0,30 & 0,23 & 0,25 \\
$\mathrm{SrO}$ & 0,06 & 0,05 & 0,06 & 0,06 & 0,06 & 0,06 \\
$\mathrm{BaO}$ & 0,07 & 0,08 & 0,08 & 0,08 & 0,08 & 0,08 \\
$\mathrm{LOI}$ & 5,60 & 5,95 & 6,17 & 6,20 & 6,22 & 6,19 \\
\hline
\end{tabular}

En las Figura 8.2 se observan, comparativamente, los diagramas de rayos $x$ de la muestra sin activar y tres de las muestras activadas.
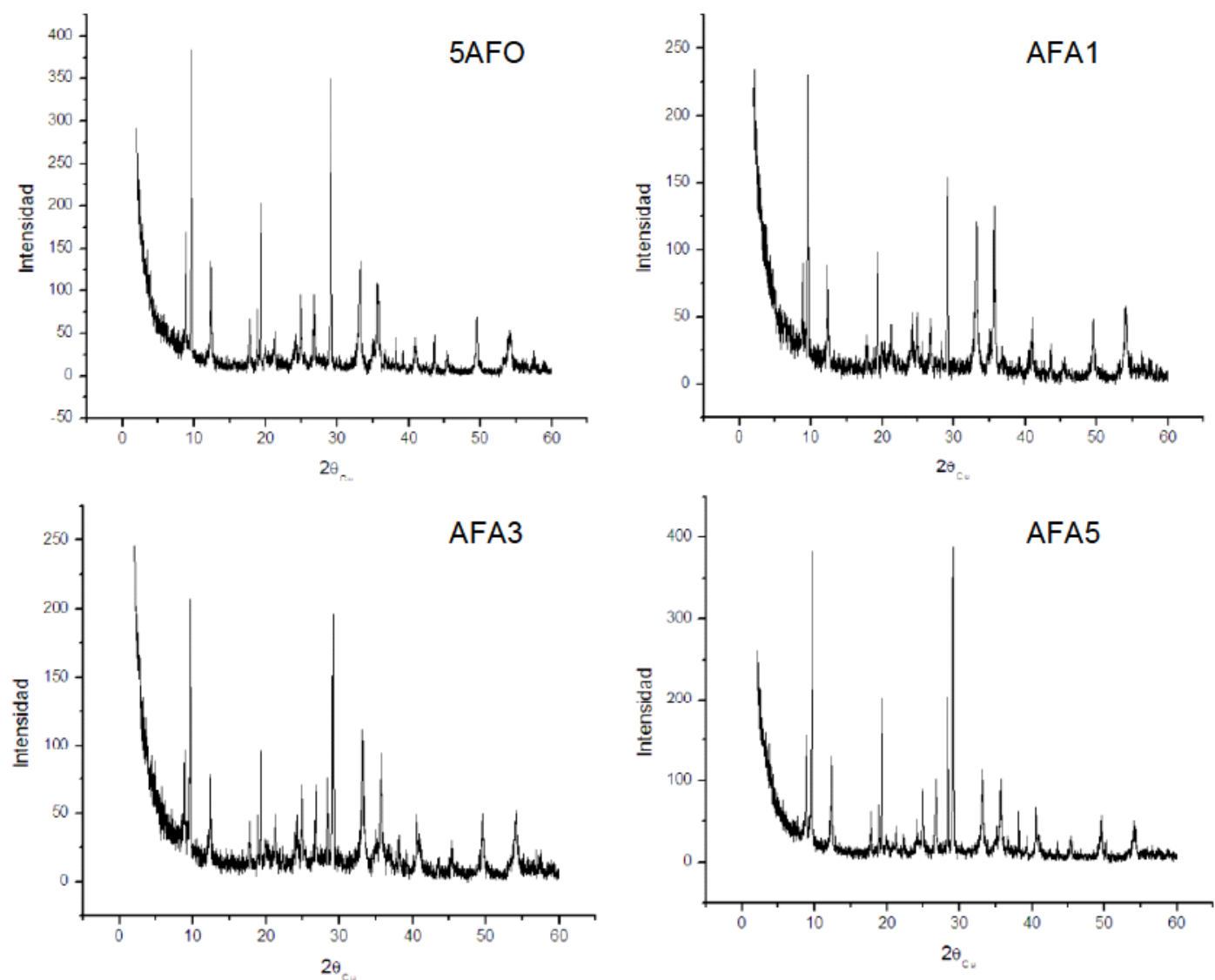

Figura 8.2. Diagramas DRX de la muestra original y tres de las muestras activadas. 
El mineral de arcilla 5AFO, que fuera caracterizado mineralógicamente en el Capítulo 6, se encuentra constituido por una mezcla de illita (PDF 26-0911), pirofilita (PDF 46-1308), caolinita (89-6538) y cuarzo (PDF 89-8941), con un contenido de hierro visualizado a través de líneas de difracción de la hematita (PDF 88-2359). Los difractogramas de las muestras activadas no presentan variaciones ni en la intensidad ni en la posición de las líneas respecto a la muestra original, comportamiento similar al observado en la activación detallada en el Capítulo 7 para las muestras pobres en Fe.

Los resultados EDS de las Figuras 8.3 y 8.4 , correspondientes a las muestras $5 A F O$ y AFA5 respectivamente, revelan el incremento de hierro superficial producto de la modificación química.

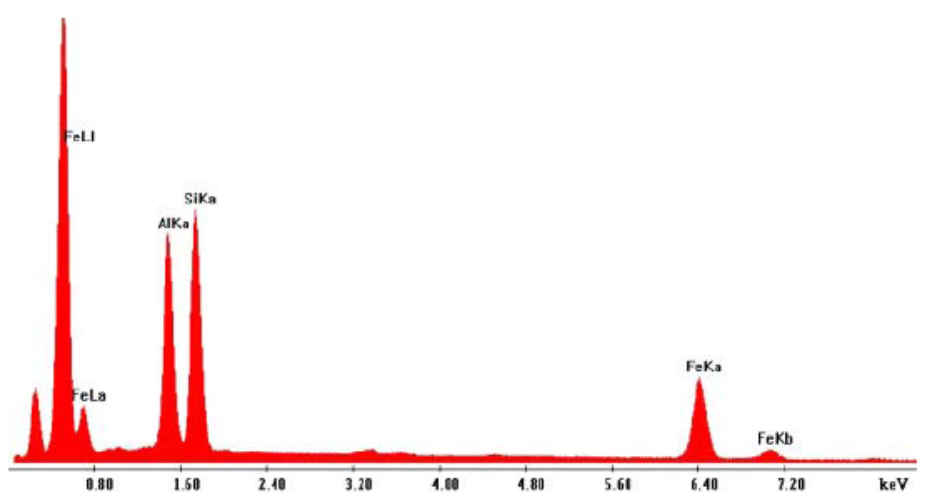

Figura 8.3. Diagrama EDS de la muestra 5AFO.

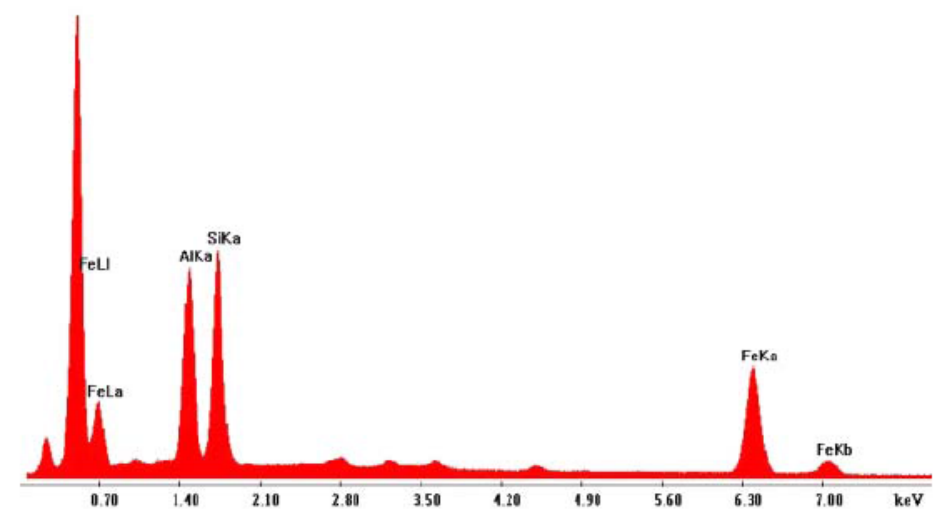

Figura 8.4. Diagrama EDS de la muestra activada denominada AFA5.

Es de destacar que la cuantificación de estos resultados, revelan para la muestra $5 \mathrm{AFO}$ un contenido en óxido férrico de $71,8 \%$, muy superior respecto al valor másico por ICP. Este comportamiento significa que ya la muestra original cuenta con un 
depósito natural de fase de hierro sobre el material arcilloso. Por otra parte el contenido de hierro superficial de las muestras activadas AFA3 y AFA5 alcanzan valores de $80 \%$ y $85,1 \%$ respectivamente, revelando fehacientemente que el mineral de arcilla se encuentra prácticamente cubierto por la fase de hierro.

La Tabla 8.3 presenta los datos de las principales propiedades texturales de los materiales activados: superficie específica $\left(\mathrm{S}_{\mathrm{BET}}\right)$ y tamaño promedio de poro (DPP). En la tabla se incluyen los valores de la muestra 5AFO comparativamente. Cabe recordar, que los valores para la ferrihidrita pura, sintetizada como referencia, revelaron una superficie específica de $322,44 \mathrm{~m}^{2} \mathrm{~g}^{-1} \mathrm{y}$ un DPP de $28,46 \AA$. Es evidente el incremento progresivo de la superficie específica con el agregado de ferrihidrita en las muestras activadas. Es también destacable que los poros promedio se encuentran localizados en el rango de los mesoporos, si bien el tamaño disminuye por el agregado de la fase de hierro. El comportamiento observado como resultado de la modificación química, es comparable al presentado por las muestras activadas del Capítulo 7. En general, el agregado de ferrihidrita contribuye a la reducción del diámetro medio de poro, favoreciendo el incremento de la $\mathrm{S}_{\mathrm{BET}}$.

Tabla 8.3. Principales propiedades texturales de las muestras activadas.

\begin{tabular}{c|c|c}
\hline Muestra & $\begin{array}{c}\mathrm{S}_{\mathrm{BET}} \\
\left(\mathrm{m}^{2} \mathrm{~g}^{-1}\right)\end{array}$ & $\begin{array}{c}\text { DPP } \\
(\AA)\end{array}$ \\
\hline 5AFO & 12,40 & 89,47 \\
AFA1 & 14,07 & 79,16 \\
AFA2 & 22,61 & 63,07 \\
AFA3 & 19,04 & 62,46 \\
AFA4 & 20,90 & 62,89 \\
AFA5 & 24,52 & 54,91 \\
\hline
\end{tabular}

Las curvas de la Figura 8.5 muestran comparativamente, la distribución de tamaño de poros (DFT) correspondientes a las muestras ferrihidrita, 5AFO y tres de las muestras activadas (AFA1, AFA3 y AFA5). La ferrihidrita presenta una distribución de tamaño de poros de menor tamaño, con ausencia de macroporos y el predominio de mesoporos con escasos microporos. La muestra 5AFO se caracteriza por una distribución de poros de mayor tamaño, destacándose el alto contenido de poros en el rango de los mesoporos. Las muestras activadas presentan una situación intermedia entre la muestra original y la ferrihidrita, el agregado de la fase de hierro contribuye a una marcada reducción del tamaño de los poros. En las curvas correspondientes a las muestras AFA1, AFA3 y AFA5, se observa progresivamente una disminución de los poros de mayor tamaño y un aumento en la zona de los mesoporos. 

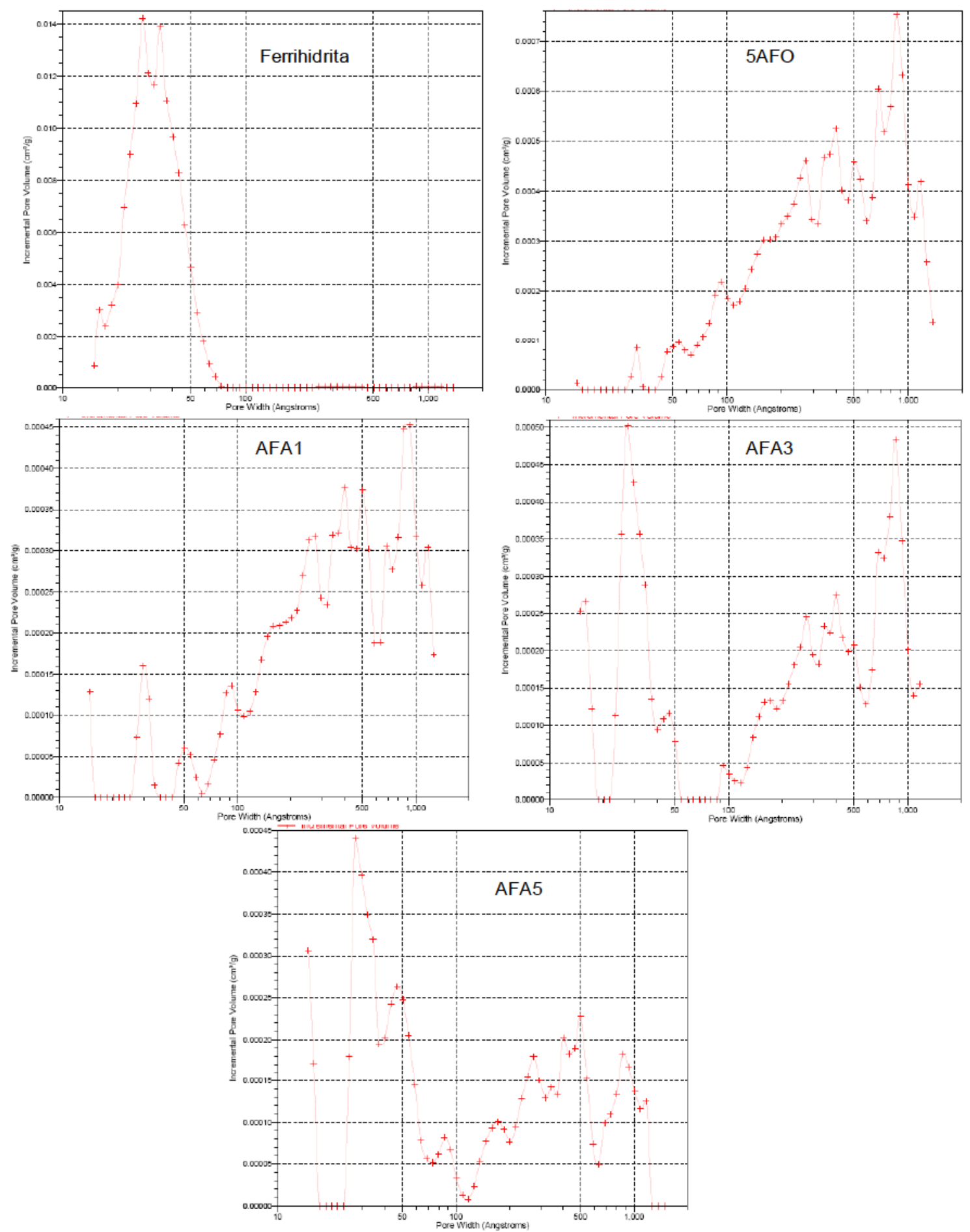

Figura 8.5. Distribución de tamaño de poro (DFT) para la muestra original, la ferrihidrita y tres de las muestras activadas.

\subsection{Evaluación de la remoción de As a nivel laboratorio}

Para evaluar la eficiencia de las cinco muestras activadas en el proceso de remoción de arsénico, se determinó el agotamiento de los geominerales, empleando los parámetros previamente optimizados en el Capítulo 6 para las arcillas ferruginosas, siguiendo el esquema mostrado en la Figura 6.49. 
Para estos ensayos se usaron muestras de agua preparadas en el laboratorio con agua de red la cual fue modificada químicamente con $\mathrm{As}(\mathrm{V})$ para obtener una solución de $1000 \mu \mathrm{g} \mathrm{L}^{-1}$ del elemento. Los ensayos se realizaron en simultáneo en el equipo Jar test utilizando una relación sólido/líquido de $75 \mathrm{~g}$ en $750 \mathrm{ml}$. El sólido suspendido se decantó con la ayuda de la dosis óptima de PAC $(0,193 \mathrm{mg}$ de $\mathrm{Al}$ por litro de agua). La eficacia del material se estableció a través del número de ciclos útiles de tratamiento consecutivos. El adsorbente se considera saturado cuando la concentración de arsénico en la solución excede el límite permitido de $10 \mu \mathrm{g} \mathrm{L}^{-1}$.

El monitoreo de cada jarra se realizó tomando muestras transcurridas las 24 hs de sedimentación, determinando turbidez y concentración de As, empleando el kit de As Merck y corroborando periódicamente las mediciones por el método EPA $3020 / 7010$.

En la Tabla 8.4 y en la Figura 8.6 se presentan los resultados globales de las determinaciones realizadas luego de los ciclos efectivos de tratamiento de remoción de As. Sin embargo, como se comentará más adelante, estos resultados no resultan del todo comparables con los obtenidos con las arcillas ferruginosas porque se presentaron dificultades para seguir los pasos indicados en el esquema de tratamiento optimizado para las arcillas AFO.

Tabla 8.4. Resultados de la efectividad de las muestras de arcilla activada en la remoción de As. Se incluyen los valores de la muestra sin activar (5AFO).

\begin{tabular}{l|c|c}
\hline \multicolumn{1}{c|}{ Muestra } & $\mathrm{N}^{0}$ Ciclos & $\mu \mathrm{g}$ As retenidos $/ \mathrm{g}_{\text {adsorbente }}$ \\
\hline 5AFO & 45 & 447,45 \\
AFA1 & 52 & 516,85 \\
AFA2 & 58 & 576,50 \\
AFA3 & 65 & 646,05 \\
AFA4 & 68 & 676,25 \\
AFA5 & 70 & 696,10 \\
\hline
\end{tabular}

La muestra 5AFO mostró una reducción de la turbidez y de la concentración de As a los valores permitidos durante el número de ciclos efectivos totales indicados en la tabla, mientras que, para las muestras activadas se observó que si bien la concentración de As se reduce, la turbidez adecuada no se logra efectivamente desde los primeros ciclos. Los valores finales indicados en la tabla solo se obtienen mediante un proceso adicional de filtración que permite clarificar la solución sobrenadante.

Es evidente que existe una diferente interacción entre la fase nanoscopica formada in situ y la superficie del material a activar. En el caso de los aluminosilicatos laminares pobres en hierro la carga superficial favorece la interacción con la fase coloidal de hierro en tanto que en la arcilla ferruginosa la presencia de una elevada 
proporción de fase cristalina de hierro recubriendo las partículas produce un efecto inverso.

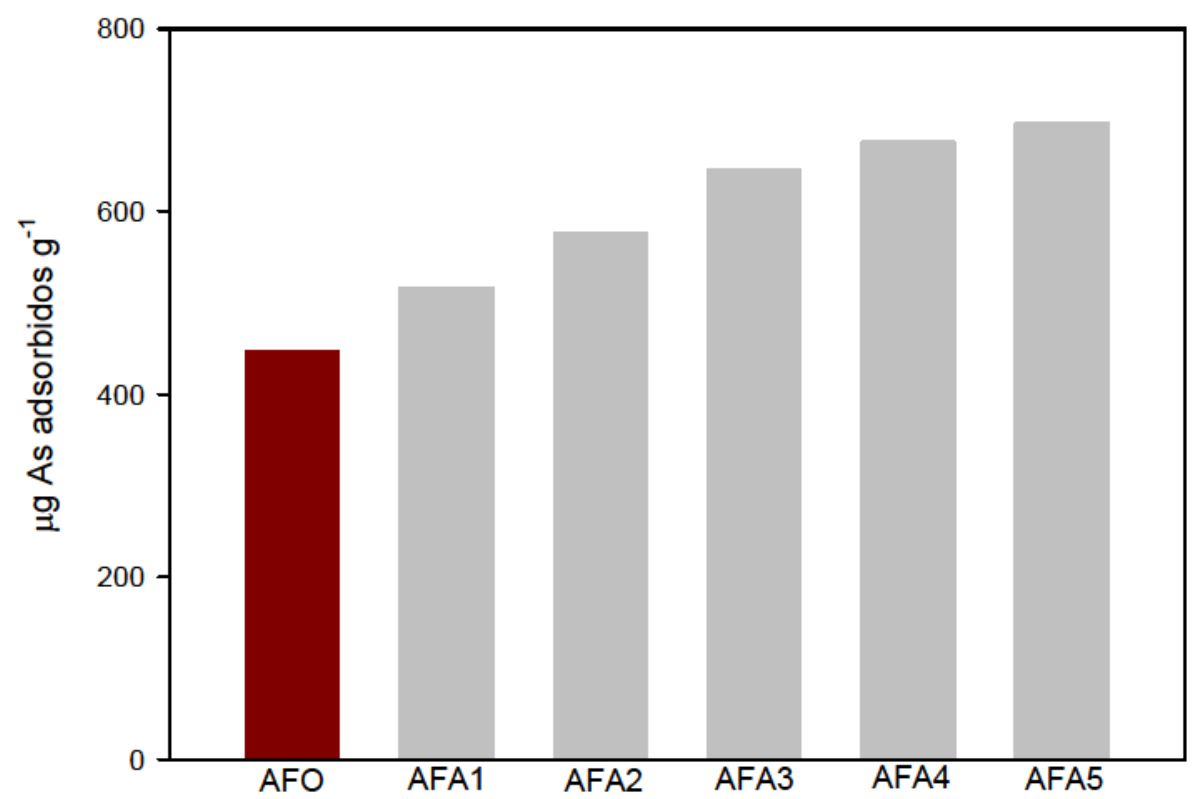

Figura 8.6. Efectividad en la remoción de As de las muestras activadas en comparación con la arcilla $5 \mathrm{AFO}$.

Cabe señalar que si bien se incrementa la vida útil del adsorbente por efectos de la activación, el aumento en la cantidad del hierro empleado en las últimas dos muestras no parece mejorar significativamente los resultados de la muestra anterior.

Por otro lado estos resultados fueron obtenidos a partir de un tratamiento adicional de filtración. Es evidente que para evitar la filtración deberían analizarse distintas estrategias para mejorar la coagulación, que podrían tener en cuenta un aumento del tiempo de sedimentación, el agregado de mayor cantidad de coagulante, un cambio de coagulante o una modificación del medio.

La asociación ferrihidrita-arcilla ferruginosa aun con bajos agregados de fase amorfa de hierro, incrementa la potencialidad del método de eliminación de arsénico sobre la base de las propiedades estructurales de la asociación. Si bien la variación en la superficie BET es poco significativa, la activación produce una reducción importante en el tamaño de poros. En base a las características cristalográficas de la fase de hierro soportada sobre la arcilla presentando un ensamble atómico de poliedros $\mathrm{FeO}_{6}$ altamente desordenado constituye la base de la reactividad del sistema. De esta forma, se generan nuevos sitios de actividad preferencial para la coordinación de las especies $\mathrm{AsO}_{4}$. 


\section{CAPÍTULO 9}

\section{Preparación de coagulantes a partir de especies minerales}

En los capítulos anteriores se ha visto que en la tecnología propuesta, existe una correlación entre el contenido de As en el agua luego del tratamiento y los valores de turbidez. Para obtener valores adecuados de ambos parámetros sin la necesidad de recurrir a un proceso posterior de filtración se ha propuesto el uso de un coagulante. En base a estos resultados, pareció interesante analizar la posibilidad de obtención de coagulantes a partir materias primas de bajo costo, accesibles y que estructuralmente permitan la extracción de Al y/o Fe.

A tal efecto, en este capítulo, se evalúa la preparación de sales de $\mathrm{Al}(\mathrm{III})$ a partir de caolinita y la obtención de sales de $\mathrm{Fe}$ (III) a partir de arcillas ferruginosas de la PBA. Los coagulantes obtenidos fueron utilizados en el tratamiento de remoción de As a fin de evaluar su potencialidad para ser utilizados en el procedimiento. Finalmente, el residuo sólido de la extracción de caolinita fue activado con sales de $\mathrm{Fe}$ (III) y evaluado en el tratamiento de eliminación de As optimizado para las arcillas ferruginosas.

\subsection{Algunas consideraciones sobre el empleo de coagulantes}

La clarificación del agua tiene por objeto retirar los sólidos suspendidos, sólidos finamente divididos y materiales coloidales, convirtiéndolos en partículas más grandes que se pueden remover con mayor facilidad (Cogollo Flores, 2011).

Desde el punto de vista físico los sólidos totales se pueden dividir en: sólidos en suspensión; sólidos disueltos y coloides. Estos últimos, tienen un tamaño intermedio entre las partículas en solución verdaderas y las partículas en suspensión. Los sólidos en suspensión pueden tener un tamaño y densidad tal que puedan ser eliminados del agua por simple sedimentación, pero algunas partículas, como las coloidales, son de un tamaño tan pequeño y tienen una carga eléctrica superficial que las hace repelerse continuamente, impidiendo su aglomeración y la formación de una partícula más pesada que pueda sedimentar. Entre los coloides más importantes en el tratamiento de aguas se encuentran las arcillas y algunos óxidos metálicos.

Los coloides generalmente son estables en solución al predominar los factores estabilizantes sobre los desestabilizantes, se entiende por estabilidad la propiedad inherente de las partículas coloidales a permanecer dispersadas durante mucho tiempo, mientras que por inestabilidad se expresa la tendencia de dichas partículas a flocularse siempre que entren en contacto entre sí. Los factores estabilizantes son aquellas fuerzas que provocan repulsión entre las partículas como son las fuerzas electrostáticas y la propia hidratación. Los factores desestabilizantes son por el 
contrario las fuerzas de atracción que dan lugar a la unión, entre estas figuran el movimiento Browniano, las fuerzas de Van der Waals y también en menor grado la fuerza de gravedad. La coagulación es por tanto el proceso de desestabilización de las partículas coloidales con el objeto de anular o disminuir las fuerzas de repulsión.

Si las fuerzas eléctricas de repulsión entre las partículas se reducen lo suficiente como para permitir que estas establezcan contactos entre sí (favorecidas por el movimiento browniano), las fuerzas de London - Van der Waals permitirán que las partículas se adhieran unas a otras, formándose una aglomeración progresiva de estas (floculación).

Como se comentó en el Capítulo 4, el origen de las cargas en las arcillas se debe a: 1) en la cara basal a las sustituciones isomórficas en las láminas tetraédricas y octaédricas, que dejan un exceso de carga negativa permanente, independiente de la composición iónica del medio y 2) en la cara lateral donde las cargas se generan por los enlaces de los bordes rotos, producto de los sitios $\mathrm{Al}-\mathrm{OH}$ y $\mathrm{Si}-\mathrm{OH}$ en contacto con el medio. Esta carga puede ser positiva o negativa dependiendo del pH del medio.

Por lo expuesto, en una partícula de mineral de arcilla en contacto con agua se desarrolla una carga eléctrica superficial neta. Esta carga puede ser positiva o negativa dependiendo del $\mathrm{pH}$ del medio que afecta la carga de la cara lateral. $\mathrm{A} \mathrm{pH}$ ácido cuando las cargas de la cara basal y lateral tienen signos opuestos es posible la formación de agregados. Cuando las cargas positivas igualan a las negativas no hay repulsión entre las partículas y permiten que coagulen. A pH básicos ambas caras tienen carga negativa y las repulsiones son dominantes.

La carga superficial de las partículas de arcilla, es compensada por una distribución equivalente de carga opuesta en la región de interfaz (sólido-liquido). Estos iones se denominan contraiones de la capa de Stern que forman una capa compacta sobre la superficie del mineral. Entre esta capa y el seno del líquido se forma una capa difusa de contraiones que tienen la libertad de moverse y es la que se llama capa difusa. Los iones de la capa de Stern y los de la capa difusa en conjunto forman la denominada doble capa eléctrica. En la Figura 9.1 se ha representado la doble capa suponiendo que el mineral de arcilla está cargado negativamente.

Como consecuencia de un exceso de contraiones en la superficie de la partícula, se genera una diferencia de potencial electrostático, siendo máximo en la superficie de la partícula y disminuyendo a medida que aumenta la distancia a la misma. El potencial zeta $(Z)$ corresponde al potencial en el cual la capa de Stern y la capa difusa 
se unen, es decir es el potencial entre la capa de Stern y la capa difusa. Representa una medida de la diferencia de potencial entre el seno de la solución y la partícula.

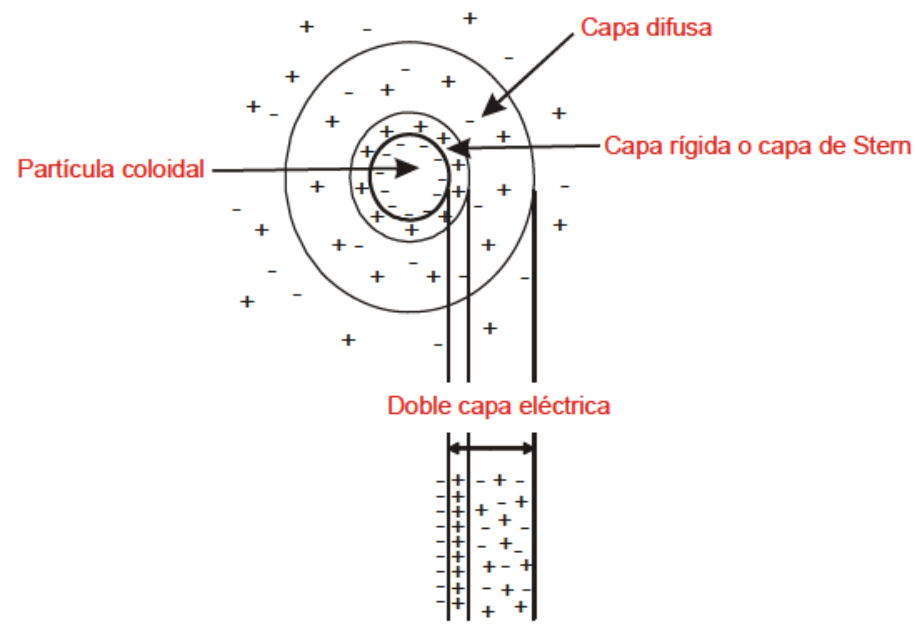

Figura 9.1. Esquema de la doble capa eléctrica alrededor de una partícula coloidal.

Cuando se acercan dos partículas coloidales se produce una interacción entre sus capas difusas, dando lugar a una fuerza repulsiva que impide la unión de ambas partículas. Entre estas capas difusas, también se generan fuerzas de interacción atractivas responsables de la agregación. La suma de ambas fuerzas determina la estabilidad de los coloides. Para fuerzas iónicas bajas suele predominar la repulsión.

Esta repulsión neta constituye una energía de activación que debe superarse haciéndola más pequeña o incluso nula para que dominen las fuerzas de atracción. El potencial $Z$ es una medida de esta fuerza de repulsión. A medida que disminuye el potencial $Z$ las partículas pueden aproximarse aumentando la posibilidad de interacción. Los coagulantes proporcionan cargas de signo contrario para eliminar ese potencial, al aumentar la concentración de contraiones en la capa difusa. Ello genera una disminución del volumen de dicha capa haciendo desaparecer la barrera potencial, priorizando las fuerzas atractivas.

La clarificación incluye los subprocesos de coagulación, floculación y sedimentación (Cogollo Flores, 2011). Como se hizo referencia precedentemente, la coagulación es el proceso de desestabilización de las partículas suspendidas de modo tal que se reduzcan las fuerzas de separación entre ellas mediante el agregado de un producto químico. Requiere de una agitación vigorosa y comienza en el mismo instante en que se agrega el coagulante durando solo fracciones de segundo. Desde el punto de vista electrostático, el propósito de la coagulación es reducir el potencial Z por adición de iones específicos que inducen la desestabilización de las partículas por neutralización de las cargas de los coloides produciendo la aglomeración (Ghafari et al., 2008). 
La floculación es el proceso mediante el cual se juntan las partículas desestabilizadas o coaguladas para formar un aglomerado más grande llamado flóculo y se debe a un mecanismo de formación de puentes químicos o enlaces físicos. Operativamente, la floculación se consigue recurriendo a una mezcla moderada y prolongada que transforma las partículas coaguladas de tamaño submicroscópico en otras suspendidas, discretas y visibles (Cogollo Flores, 2011).

Finalmente, la sedimentación es la remoción de partículas más pesadas que el agua por acción de la fuerza de la gravedad. Mediante este proceso se eliminan materiales en suspensión empleando un tiempo de retención adecuado.

Los coagulantes más comunes que se usan en el tratamiento de aguas son compuestos inorgánicos de aluminio o hierro como el sulfato de aluminio, sulfato ferroso, sulfato férrico y cloruro férrico. Los cationes trivalentes de aluminio o hierro neutralizan las cargas eléctricas negativas que suelen rodear a las partículas coloidales dispersas en el agua. Cada coagulante tiene un rango específico de $\mathrm{pH}$ donde presenta la mínima solubilidad y ocurre la máxima precipitación dependiendo, también, de las características químicas del agua cruda.

En los últimos años se ha desarrollado una nueva generación de coagulantes inorgánicos prepolimerizados tales como PAC's (policloruro de aluminio), los cuales se comportan diferentes a los coagulantes convencionales en el proceso de clarificación debido a sus características de especiación química (Ye et al., 2007). Los PAC's son capaces de producir con mayor rapidez y perfección flóculos con mayor velocidad de sedimentación y poder clarificante, logrando remociones más altas de turbiedad respecto a otras sales de aluminio. Los flóculos de PAC's forman pequeñas esferas y/o estructuras tipo cadena con tamaño menor a $25 \mathrm{~mm}$ (Van Bonschoten and Edzwald, 1990). Los PAC's son producidos adicionando una base al cloruro de aluminio hasta lograr la fórmula empírica $\mathrm{Al}(\mathrm{OH})_{n} \mathrm{Cl}_{3 n}$, donde $\mathrm{n}$ toma valores que van de 1 a 2,5. El pH óptimo de funcionamiento se encuentra entre 5 y 9.

En relación a los coagulantes conteniendo $\mathrm{Al}(\mathrm{III})$, el $\mathrm{Al}$ en solución acuosa se encuentra coordinado con seis moléculas de agua en su esfera primaria de hidratación de geometría octaédrica. Debido a que estas moléculas están polarizadas pueden perder un protón dependiendo del pH de la solución. Esto indica que las moléculas de $\mathrm{H}_{2} \mathrm{O}$ de la esfera de coordinación son progresivamente reemplazadas por iones oxidrilos a medida que el $\mathrm{pH}$ de la solución se incrementa, según la siguiente secuencia:

$$
\mathrm{Al}\left(\mathrm{H}_{2} \mathrm{O}\right)_{6}{ }^{3+} \rightarrow \mathrm{Al}\left(\mathrm{H}_{2} \mathrm{O}\right)_{5}(\mathrm{OH})^{2+} \rightarrow \mathrm{Al}\left(\mathrm{H}_{2} \mathrm{O}\right)_{4}(\mathrm{OH})_{2}{ }^{+} \rightarrow \mathrm{Al}\left(\mathrm{H}_{2} \mathrm{O}\right)_{3}(\mathrm{OH})_{3} \rightarrow \mathrm{Al}\left(\mathrm{H}_{2} \mathrm{O}\right)_{2}(\mathrm{OH})_{4}^{-}
$$


Además pueden formarse dímeros, trímeros, especies polinucleares, así como precipitados, pudiendo encontrarse las siguientes especies (Stol et al., 1976; Letterman and Asolekar, 1990):

Monómeros: $\mathrm{Al}\left(\mathrm{H}_{2} \mathrm{O}_{4+}{ }_{4+}{ }^{3+}, \mathrm{Al}\left(\mathrm{H}_{2} \mathrm{O}_{5+} \mathrm{OH}^{2+}, \mathrm{Al}\left(\mathrm{H}_{2} \mathrm{O}\right)_{4+}(\mathrm{OH})_{2}{ }^{+}, \mathrm{Al}\left(\mathrm{H}_{2} \mathrm{O}\right)_{3}(\mathrm{OH})_{3}\right.\right.$ y $\mathrm{Al}\left(\mathrm{H}_{2} \mathrm{O}\right)_{2}(\mathrm{OH})_{4}$ Polímeros: $\mathrm{Al}_{2}(\mathrm{OH})_{2}, \mathrm{Al}_{3}(\mathrm{OH})_{4}, \mathrm{Al}_{13} \mathrm{O}_{4}(\mathrm{OH})_{24}$ (conocido como $\mathrm{Al}_{13}$ ) Precipitado: $\mathrm{Al}(\mathrm{OH})_{3(\mathrm{~s})}$

La química de los iones férricos no se ha desarrollado en la misma extensión que la del Al. Se postula la presencia de algunos coloides en equilibrio con monómeros $\left(\mathrm{Fe}^{3+}, \mathrm{Fe}(\mathrm{OH})^{2+}, \mathrm{Fe}(\mathrm{OH})_{2}^{+}, \mathrm{Fe}(\mathrm{OH})_{4}\right)^{-}$. En ciertas condiciones se pueden generar polímeros de pequeño tamaño del tipo $\mathrm{Fe}_{2}(\mathrm{OH})_{2}{ }^{4+}, \mathrm{Fe}_{3}(\mathrm{OH})_{4}{ }^{5+} \mathrm{y}^{\mathrm{Fe}} \mathrm{e}_{4} \mathrm{O}(\mathrm{OH})_{4}{ }^{6+}$. En un margen de $\mathrm{pH}$ entre 4,5 y 8 la especie predominante es $\mathrm{Fe}(\mathrm{OH})_{2}{ }_{2}^{+}$, mientras que $\mathrm{el} \mathrm{Fe}^{3+}$ es siempre un componente minoritario en presencia de $\mathrm{Fe}(\mathrm{OH})_{3}$ (s) (Torra et al., 1998).

Según Stumm and O'Melia (1968) las especies de aluminio (o hierro) pueden desestabilizar coloides y partículas de dos maneras:

- Las especies catiónicas se adsorben en las partículas cargadas negativamente, neutralizando su carga y permitiendo su agregación. También pueden adsorberse en la superficie de las partículas, formando puentes de unión entre ellas.

- Precipitación de $\mathrm{Al}(\mathrm{OH})_{3(\mathrm{~s})}\left(\mathrm{Fe}(\mathrm{OH})_{3(\mathrm{~s})}\right)$ quedando la materia coloidal atrapada en el precipitado de hidróxido (eliminación por barrido).

La dosis de coagulante es un parámetro crítico dado que si éste se adiciona por debajo de la cantidad requerida, no se neutralizan totalmente las cargas de las partículas, la formación de microflóculos es escasa y la turbiedad del agua tratada es elevada. Por otro lado, si se adiciona en exceso, se produce la inversión de las cargas de las partículas y la sucesiva formación de gran cantidad de microflóculos con tamaños muy pequeños y velocidades de sedimentación muy bajas y la turbidez del agua tratada es, igualmente, elevada (Cogollo Flores, 2011).

Para el diseño de un proceso de coagulación-floculación es necesario llevar a cabo la prueba de jarras, comúnmente denominada ensayo "jar-test", con la finalidad de determinar el tipo de coagulante óptimo, la dosis óptima de coagulante, el pH óptimo para el tratamiento, el tiempo de retención y la velocidad de agitación óptima que aseguren una buena mezcla en el proceso de coagulación y un buen contacto entre las partículas en el proceso de floculación. Es necesario resaltar que los 
resultados de las pruebas de jarras, sólo son aplicables para el rango de turbiedad del agua cruda objeto de estudio y con características fisicoquímicas similares.

\subsection{Obtención de coagulantes de $\mathrm{Al}(\mathrm{III})$ a partir de caolinita}

En este ítem se estudia la factibilidad de preparación de sulfato de aluminio a partir de mineral de arcilla, considerando el proceso de lixiviación del metal Al, directamente como sulfato, a partir de arcilla calcinada mediante el empleo de ácido sulfúrico. La ventaja del método consiste en separar por filtración o decantación el aluminio solubilizado de un residuo rico en sílice.

Los aspectos químicos que se han contemplado en la etapa de laboratorio, fueron: el pretratamiento de la arcilla, la lixiviación del Al a partir de la arcilla calcinada mediante el empleo de $\mathrm{H}_{2} \mathrm{SO}_{4}$ y la separación de la solución de sulfato de aluminio del sólido remanente.

La etapa de pretratamiento de la arcilla resulta determinante para el proceso, debido a que la extracción del Al se encuentra asociada al colapso de la red del aluminosilicato por efecto térmico, situación que resulta variable para los distintos tipos de arcillas (Foo et al., 2011; Belver et al., 2004). En tal caso, se ha observado que las arcillas mayoritariamente caoliníticas requieren de un tratamiento térmico más suave para el colapso estructural respecto al observado en las arcillas prevalentemente illíticas. Se ha observado que la transformación caolinita $\rightarrow$ metacaolinita ocurre a una temperatura del orden de $550{ }^{\circ} \mathrm{C}$, proceso que se visualiza mediante una intensa señal endotérmica. El proceso se encuentra asociado a una importante pérdida de peso ( 12-18\%) y corresponde a la eliminación de las moléculas de agua y grupos oxidrilos que se liberan durante la reacción de destrucción de la estructura original, que deja una estructura base de aluminosilicato, de composición " $\mathrm{Al}_{2} \mathrm{O}_{3} \cdot 2 \mathrm{SiO}_{2}$ ", altamente desordenada y amorfa a los $\mathrm{RX}$ y que por consiguiente resulta atacable fácilmente por tratamiento químico de ácidos y/o álcalis (Belver et al., 2004).

\subsubsection{Preparación del coagulante}

Para la preparación del coagulante se utilizó la muestra de caolinita denominada $\mathrm{K}$ en el Capítulo 4 y que fuera caracterizada en el Capítulo 7. La muestra fue calcinada en mufla a $550^{\circ} \mathrm{C}$ durante 2 hs. Esta muestra fue denominada MK.

Posteriormente, se pesaron $150 \mathrm{~g}$ de MK y se mezclaron con $720 \mathrm{ml}$ de solución 1:1 de $\mathrm{H}_{2} \mathrm{SO}_{4}$ durante 1 hora a $80{ }^{\circ} \mathrm{C}$ con agitación manual. Se dejó decantar durante 72 horas. Se separó este líquido y al sólido se le realizaron 2 extracciones sucesivas empleando en cada una $500 \mathrm{ml}$ de solución 1:1 de $\mathrm{H}_{2} \mathrm{SO}_{4}$, con agitación manual durante 1 hora a $80{ }^{\circ} \mathrm{C}$. Se dejó decantar durante 72 horas. En todos los casos, la 
solución fue separada del sólido por decantación. Al final de las 3 extracciones, el volumen total de líquido obtenido fue de $1652,5 \mathrm{ml}$. La solución resultante fue denominada líquido de extracción de aluminio (LEA).

La muestra de arcilla remanente fue lavada con $\mathrm{H}_{2} \mathrm{O}$ destilada hasta la eliminación de sulfatos. La reacción empleada en la identificación de sulfatos es la precipitación de $\mathrm{BaSO}_{4}$ por agregado de $\mathrm{BaCl}_{2}$ al agua de lavado. El sólido lavado fue secado en estufa a $60^{\circ} \mathrm{C}$ y se denominó MKE (metacaolinita extraída). Este sólido fue guardado para ser activado con sales de $\mathrm{Fe}(\mathrm{III})$ tal como se comentará en el ítem 9.4 del presente capítulo.

El esquema de la Figura 9.2 muestra los pasos seguidos en la preparación del coagulante a base de $\mathrm{Al}(\mathrm{III})$.

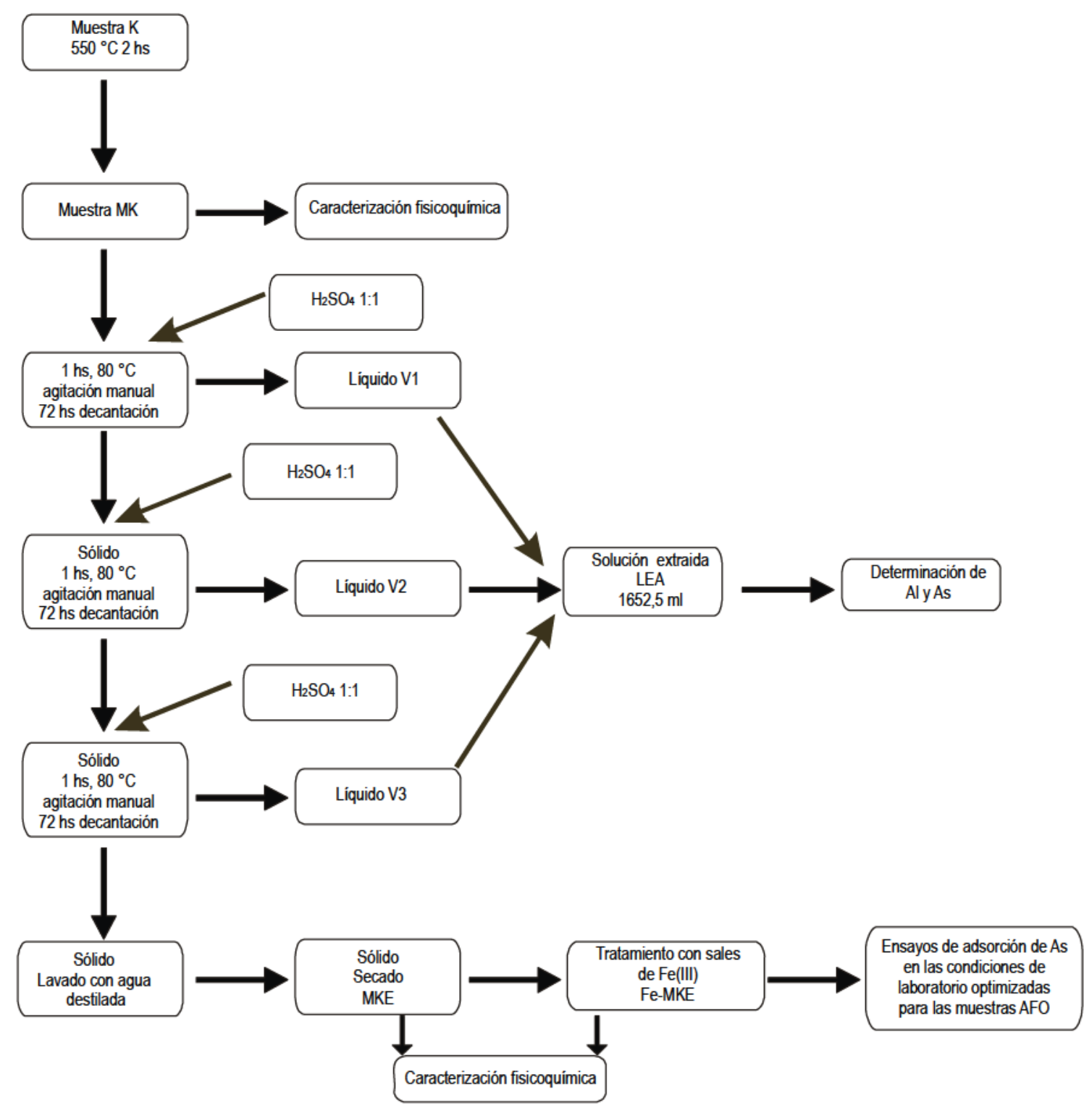

Figura 9.2. Pasos seguidos en la obtención del coagulante a base de $\mathrm{Al}(\mathrm{III})$. 


\subsubsection{Determinaciones y resultados}

Las muestras sólidas MK y MKE, fueron caracterizadas mediante DRX, FTIR, SEM-EDS y estudios de superficie BET. En tanto que, en la muestra líquida se determinó Al por el método EPA SW 846 M 3010A-M7020 EAA y As por la técnica EPA SW 846 M 7061A (EPA, 2007).

Las Figuras 9.3 y 9.4 muestran los diagramas de DRX de las muestras MK y MKE, respectivamente. Se observa una marcada disminución de la señal típica del plano basal (001) de la K, en la MK, demostrando la efectividad de la calcinación y una banda ancha entre 15 y $30^{\circ}$ en la MKE indicando la presencia de sílice amorfa. En ambos diagramas se observan las líneas del cuarzo originalmente presente en el mineral, que no es eliminado durante el tratamiento ácido.

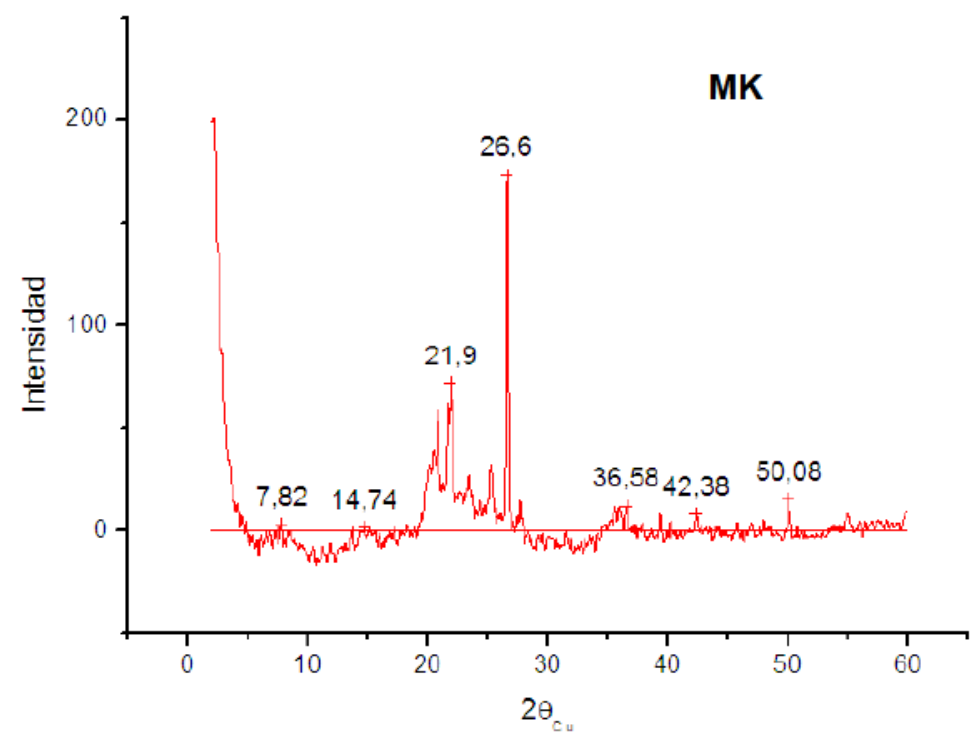

Figura 9.3. Diagrama DRX de la muestra de metacaolinita.

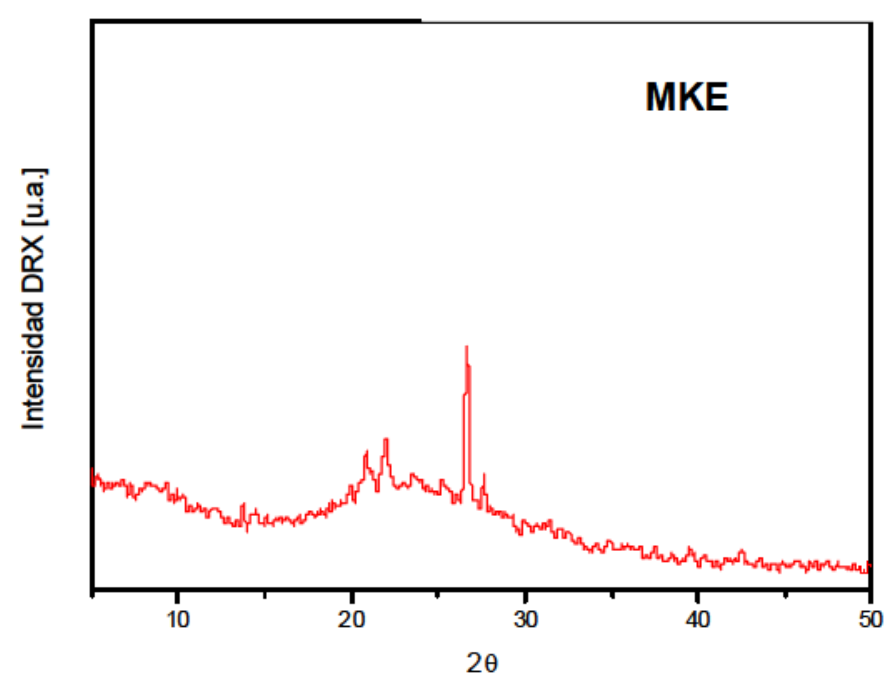

Figura 9.4. Diagrama DRX de la muestra de metacaolinita extraída con $\mathrm{H}_{2} \mathrm{SO}_{4}$. 
En la Figura 9.5 se muestra a distinta magnificación dos micrografías obtenidas para la muestra extraída. Se observa la formación de partículas amorfas a partir de las láminas de la metacaolinita producto del tratamiento ácido.
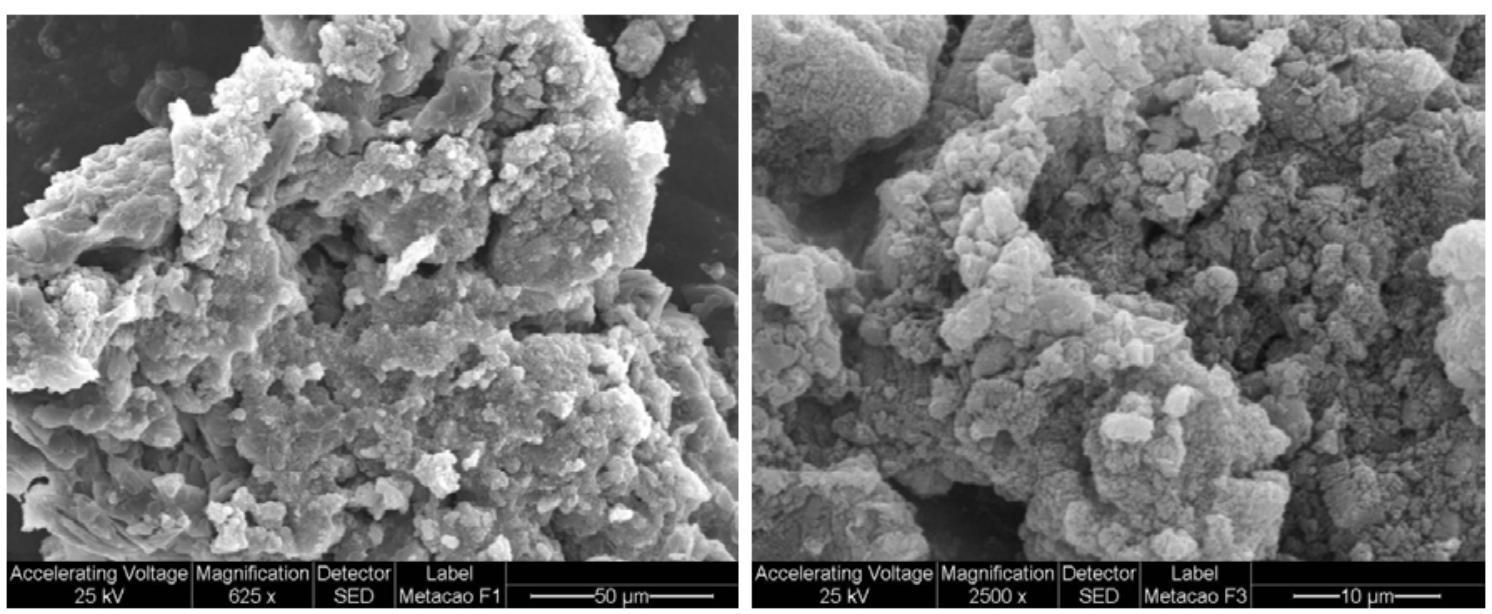

Figura 9.5. SEM de MKE a distinta magnificación.

La Figura 9.6 muestra comparativamente los espectros EDS de la metacaolinita antes y después del tratamiento ácido, demostrando la disminución en el contenido de Al. Estos resultados demuestran, al igual que el análisis químico ICP (Tabla 9.1), que el tratamiento ácido produce la disolución de los cationes $\mathrm{Al}^{3+}$ de la capa octaédrica de la caolinita, lo cual conlleva un aumento en el contenido en $\mathrm{SiO}_{2}$.

MK

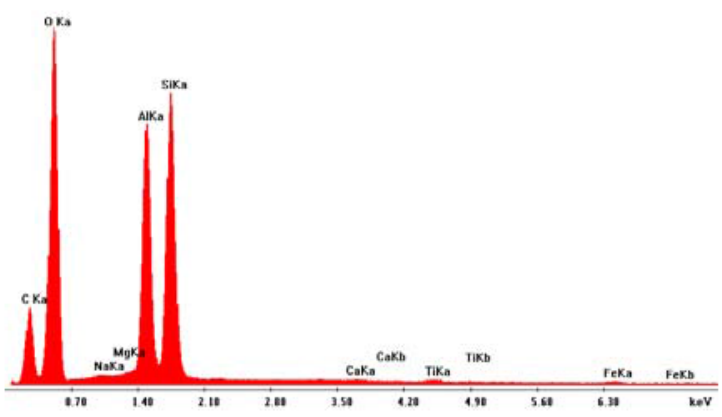

MKE

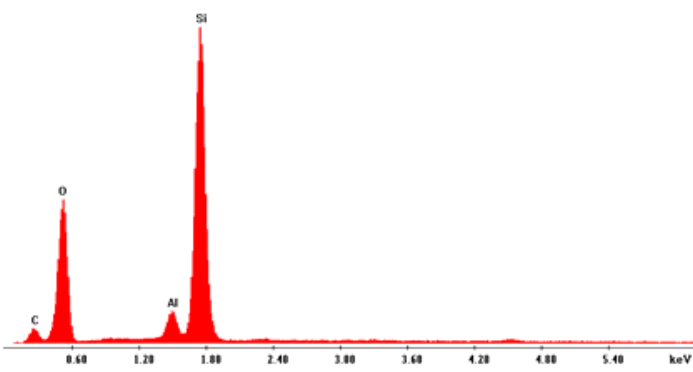

Figura 9.6. EDS comparativo entre MK y MKE.

En las Figuras 9.7 y 9.8 se muestran los espectros de infrarrojo de las muestras MK y MKE, respectivamente. En el espectro FTIR del metacaolinita se observa un ensanchamiento en la zona de $1000 \mathrm{~cm}^{-1}$, producto de la amorfización del material. Asimismo, se observa que la estrecha banda, típica de la caolinita (centrada en 1100 $\mathrm{cm}^{-1}$ ), persiste en el espectro del material térmicamente tratado, revelando la presencia de una pequeña fracción del geomaterial sin transformar. 
Tabla 9.1. Análisis químico de elementos mayoritarios por ICP-AES (expresado en \% óxidos).

\begin{tabular}{l|r|r}
\hline \multicolumn{1}{c|}{$\%$} & \multicolumn{1}{c|}{ MKE } & \multicolumn{1}{c}{$\mathrm{K}$} \\
\hline $\mathrm{SiO}_{2}$ & 75,42 & 51,92 \\
$\mathrm{Al}_{2} \mathrm{O}_{3}$ & 10,25 & 32,32 \\
$\mathrm{Fe}_{2} \mathrm{O}_{3}$ & 0,73 & 1,05 \\
$\mathrm{CaO}$ & 0,11 & 0,45 \\
$\mathrm{MgO}$ & 0,13 & 0,23 \\
$\mathrm{Na}_{2} \mathrm{O}$ & 0,13 & 0,30 \\
$\mathrm{~K}_{2} \mathrm{O}$ & 0,15 & 0,20 \\
$\mathrm{Cr}_{2} \mathrm{O}_{3}$ & 0,01 & 0,01 \\
$\mathrm{TiO}_{2}$ & 1,69 & 1,16 \\
$\mathrm{MnO}$ & 0,01 & 0,01 \\
$\mathrm{P}_{2} \mathrm{O}_{5}$ & 0,01 & 0,05 \\
$\mathrm{SrO}_{\mathrm{BaO}}$ & 0,01 & 0,01 \\
$\mathrm{BaI}$ & 0,03 & 0,02 \\
$\mathrm{SiO}$ & 11,32 & 12,27 \\
\hline
\end{tabular}

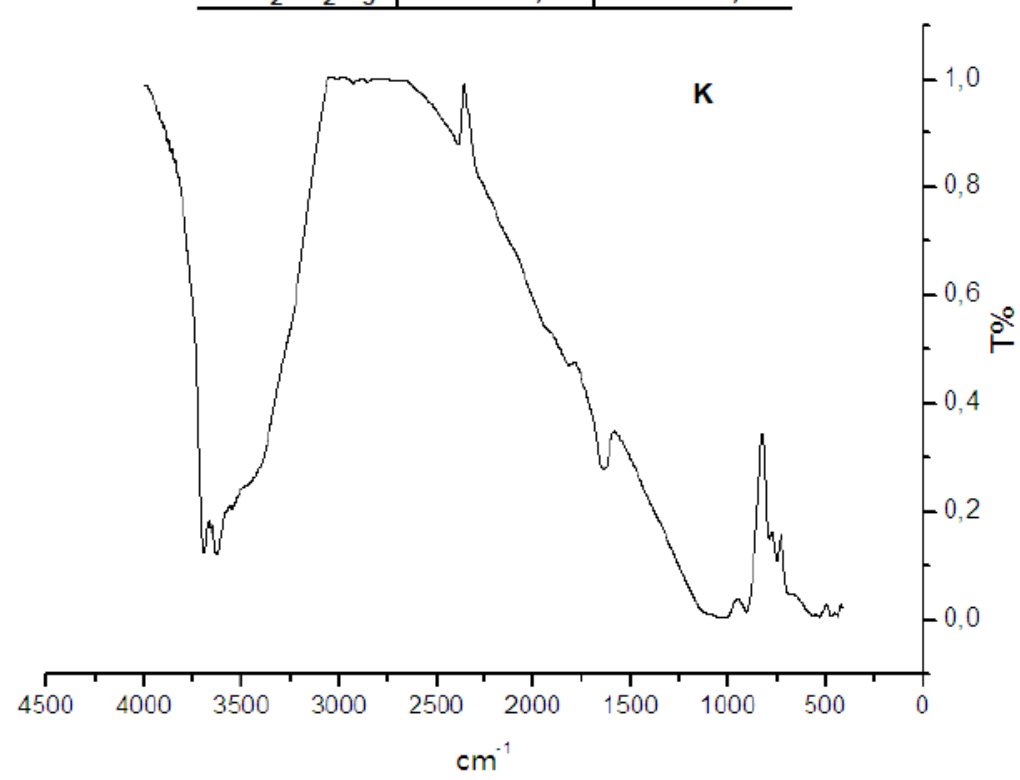

Figura 9.7. Espectro de infrarrojo de la caolinita.

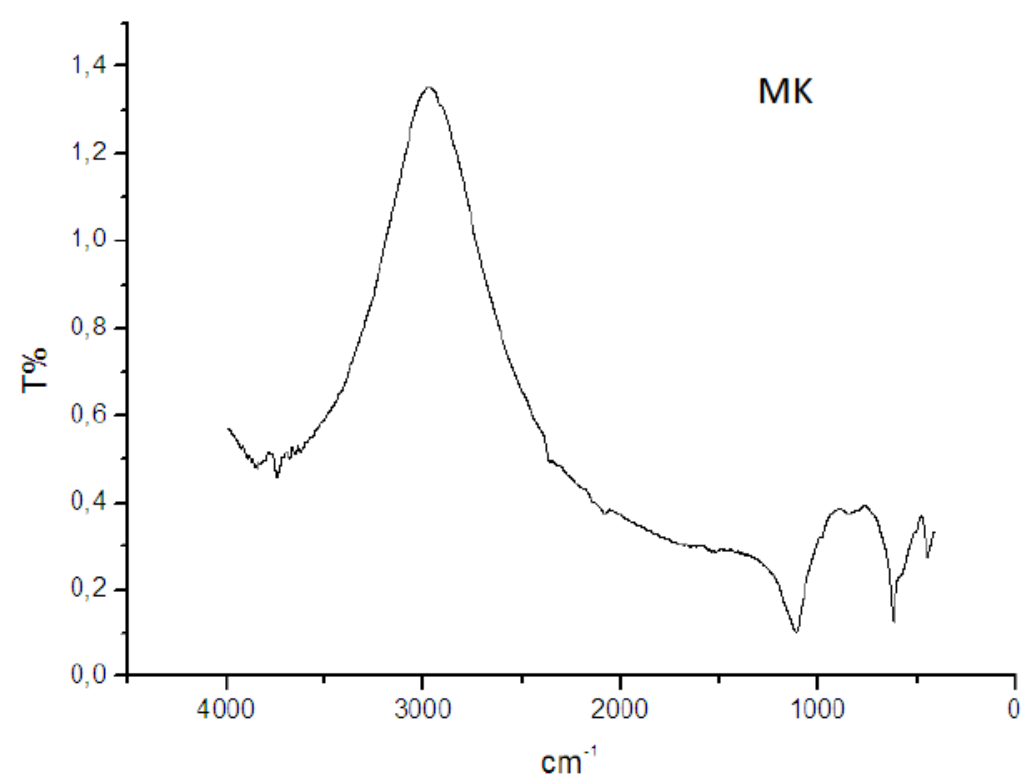

Figura 9.8.Espectro de infrarrojo de la metacaolinita. 
En relación a las propiedades texturales de los sólidos, la superficie BET obtenida para la muestra $\mathrm{K}$ fue de $9,09 \mathrm{~m}^{2} \mathrm{~g}^{-1}$, mientras que dicho valor para la muestra MK fue inferior $\left(6,50 \mathrm{~m}^{2} \mathrm{~g}^{-1}\right)$. Esto es debido a la distorsión sufrida durante la calcinación que puede producir la sinterización de las partículas (Belverde et al., 2004). En relación a la muestra extraída, MKE, el valor de superficie específica fue de $160,9 \mathrm{~m}^{2} \mathrm{~g}^{-1}$, demostrando que el tratamiento ácido conduce a un aumento considerable de la $\mathrm{S}_{\mathrm{BET}}$, que se acompaña de una disminución en el tamaño promedio

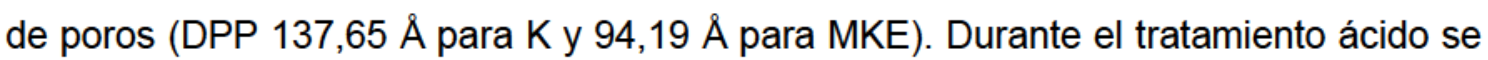
produce la desmineralización de la metacaolinita junto a la formación de sílice porosa.

Las concentraciones de Al y As en el líquido de extracción del tratamiento ácido, fueron 8823,16 y $0,036 \mathrm{mg} \mathrm{L}^{-1}$, respectivamente. Teniendo en cuenta los contenidos iniciales de $\mathrm{Al}$ y $\mathrm{As}$ en el material extraído $(25,66 \mathrm{~g}$ de $\mathrm{Al}$ y $0,27 \mathrm{mg}$ de As) y el volumen de líquido LEA, los porcentajes de Al y de As extraídos son del $56,82 \%$ y $22,03 \%$, respectivamente.

En relación al empleo de esta solución en el procedimiento de remoción de As, en base a los resultados obtenidos en el Capítulo 6, empleando sulfato de aluminio como coagulante, se requiere una dosis óptima de $\mathrm{Al}$ equivalente a $8,566 \mathrm{mg} \mathrm{L}^{-1}$. Utilizando el líquido LEA corresponde al agregado de 0,97 $\mathrm{ml}$ del líquido de extracción por litro de agua a tratar. Esta cantidad de coagulante contendría una cantidad de As insignificante (del orden de $0,03 \mu \mathrm{g}$ ) que no aumentaría el contenido inicial del agua a tratar.

El ensayo realizado en similares condiciones a las realizadas mediante el empleo de sulfato de aluminio (Capitulo 6) para evaluar la efectividad del coagulante LEA, indica que $1 \mathrm{ml}$ del mismo es suficiente para obtener un valor de turbidez de 1,25 NTU y un valor de As $<10 \mu \mathrm{g} \mathrm{L}^{-1}$. Este resultado indica que este coagulante es apto en el proceso de remoción de As.

\subsection{Obtención de coagulantes de $\mathrm{Fe}$ (III) a partir de arcilla ferruginosa}

La intención es extraer como cloruro férrico parte del Fe que posee la arcilla ferruginosa. A tal fin, se realizaron extracciones de la arcilla ferruginosa denominada $1 \mathrm{AFO}$ con $\mathrm{HCl}$ empleando diferentes condiciones de tratamiento. Asimismo, fue evaluada la extracción conjunta del As originalmente presente en la arcilla.

\subsubsection{Preparación del coagulante}

Con el fin de solubilizar la mayor cantidad de hierro(III) se probaron distintas condiciones de extracción evaluando las siguientes variables: 
a) Concentración de $\mathrm{HCl}$ : los ensayos de extracción se realizaron a temperatura ambiente, empleando concentraciones de $\mathrm{HCl}$ comprendidas entre 0,1 y $7 \mathrm{M}$. La relación arcilla 1AFO/solución $\mathrm{HCl}$ empleada fue de 1/10 (30 g de 1AFO y $300 \mathrm{ml}$ de solución). El tiempo total de contacto fue de 2 hs, con una agitación inicial de $1 \mathrm{~h}$ a 350 rpm en agitador magnético. La separación de la solución se realizó por centrifugación (15 min a $2000 \mathrm{rpm})$.

b) Tiempo de contacto: los ensayos se realizaron a temperatura ambiente, empleando $\mathrm{HCl} 4 \mathrm{M}$ y una relación sólido/ácido de $1 / 10$ (30 g de $1 \mathrm{AFO}$ y $300 \mathrm{ml}$ de ácido). Se realizaron tres ensayos con los siguientes tiempos:

- $t_{1}$ : tiempo total $24 \mathrm{hs}, 1 \mathrm{~h}$ a $350 \mathrm{rpm}$ en agitador magnético +23 hs sin agitación.

- $\mathrm{t}_{2}$ : tiempo total $48 \mathrm{hs}, 1 \mathrm{~h}$ a $350 \mathrm{rpm}$ en agitador magnético +47 hs sin agitación.

- $\mathrm{t}_{3}$ : tiempo total $72 \mathrm{hs}, 1 \mathrm{~h}$ a $350 \mathrm{rpm}$ en agitador magnético +71 hs sin agitación.

c) Relación sólido/líquido: se trabajó a temperatura ambiente, empleando una concentración de $\mathrm{HCl} 4 \mathrm{M}$ y un tiempo de contacto total de 72 hs (1h a $350 \mathrm{rpm}$ en agitador magnético +71 horas sin agitación). Las relaciones arcilla/ácido empleadas fueron:

- $m_{1}: 1 \mathrm{~g}$ de arcilla y $300 \mathrm{ml}$ de solución. Relación 1/300.

- $\mathrm{m}_{2}: 2,5 \mathrm{~g}$ de arcilla y $300 \mathrm{ml}$ de solución. Relación 1/120.

- $\mathrm{m}_{3}: 5 \mathrm{~g}$ de arcilla y $300 \mathrm{ml}$ de solución. Relación 1/60.

- $m_{4}: 10 \mathrm{~g}$ de arcilla y $300 \mathrm{ml}$ de solución. Relación 1/30.

- m5: $20 \mathrm{~g}$ de arcilla y 300ml de solución. Relación 1/15.

d) Temperatura: se empleó $\mathrm{HCl}$ 4M, una relación arcilla/ácido: 1/300 (1 g de 1AFO y $300 \mathrm{ml}$ de ácido) y un tiempo de contacto total de $72 \mathrm{hs}$ (1h a $350 \mathrm{rpm}$ en agitador magnético +71 horas sin agitación). Se realizaron 3 ensayos con las siguientes temperaturas:

- $\mathrm{T}_{1}$ : temperatura ambiente $25^{\circ} \mathrm{C}$.

$-\mathrm{T}_{2}: 60^{\circ} \mathrm{C}$.

$-\mathrm{T}_{3}: 80^{\circ} \mathrm{C}$.

En todos los ensayos la separación de la solución se realizó por decantación y posterior filtrado. En las muestras líquidas, producto de cada tratamiento de extracción, se determinó Fe y As, empleando las técnicas EPA SW 846 M 3010AM7380 EAA y EPA SW 846 M 7061A, respectivamente (EPA, 2007). 


\subsubsection{Resultados obtenidos en la preparación del coagulante}

Para la evaluación de la eficiencia en el proceso de extracción de Fe y As, cabe recordar, los valores originales de ambos elementos en la arcilla 1AFO: 51,10\% $\mathrm{Fe}_{2} \mathrm{O}_{3}$ $(35,77 \% \mathrm{Fe})$ y $22,5 \mathrm{ppm}$ de As.

En la Tabla 9.2 se muestran los resultados de la cantidad extraida de Fe y de As (en $\mathrm{mg} \mathrm{L}^{-1}$ ) variando la concentración de ácido. Claramente se observa el brusco incremento en la extracción de $\mathrm{Fe}$ al aumentar la concentración de $\mathrm{HCl}$. Asimismo, es posible apreciar un paralelismo con el comportamiento del As, indicando que en el sistema mineral las fases de Fe han actuado naturalmente reteniendo al contaminante.

Tabla 9.2. Extracción de Fe y As empleando distintas concentraciones de $\mathrm{HCl}$.

\begin{tabular}{c|r|r|r|r}
\hline $\mathrm{HCl}$ & \multicolumn{2}{|c|}{$\mathrm{Fe}$} & \multicolumn{2}{|c}{ As } \\
\hline $\mathrm{M}$ & $\mathrm{mg} \mathrm{L}^{-1}$ & \% extracción & \multicolumn{1}{c}{$\mathrm{mg} \mathrm{L}^{-1}$} & \multicolumn{1}{c}{ \% extracción } \\
\hline 0,12 & 7,1 & 0,02 & $<0,02$ & 0,88 \\
1,2 & 28,2 & 0,09 & 0,06 & 2,67 \\
2,4 & 48,2 & 0,13 & 0,12 & 5,33 \\
3,5 & 57,4 & 0,16 & 0,14 & 6,22 \\
4,7 & 82,6 & 0,23 & 0,24 & 10,67 \\
5,9 & 176,0 & 0,49 & 0,34 & 15,11 \\
7,0 & 689,0 & 1,92 & 0,50 & 22,22 \\
\hline
\end{tabular}

Asimismo, en la Tabla 9.2 se muestran los porcentajes de extracción de cada elemento logrados a cada concentración de $\mathrm{HCl}$, evidenciando, en ambos casos, que no solo no se ha logrado la extracción total de ambas especies, sino que el porcentaje de extracción es muy bajo siendo muy notorio en el caso del $\mathrm{Fe}(<2 \%)$. En la Figura 9.9 se evidencia el porcentaje de extracción de Fe y As para cada concentración de ácido utilizada, donde puede verse que en todas las concentraciones empleadas el porcentaje de As extraído es mayor que el de Fe.

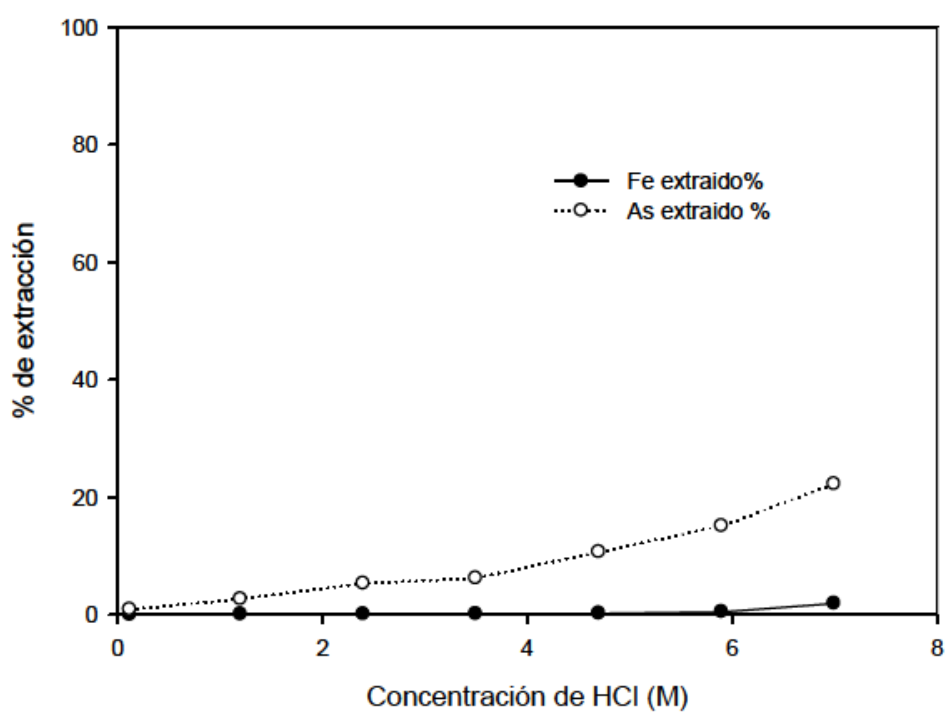

Figura 9.9. Porcentajes de extracción de Fe y As empleando distintas concentraciones de $\mathrm{HCl}$. 
De los resultados obtenidos, surge que para alcanzar mayores extracciones de hierro en la solución deberían emplearse concentraciones muy altas de $\mathrm{HCl} \circ$ modificar otras variables operacionales. A los fines prácticos, en el presente trabajo se ha fijado la concentración de ácido en $4 \mathrm{M}$ y se seguirán optimizando otras variables.

En la Tabla 9.3 se muestra la cantidad de Fe y de As extraídos variando el tiempo de contacto, mientras que en la Figura 9.10 se representa el \% de extracción de cada elemento a cada tiempo ensayado. Si bien, entre las 48 y 72 hs de contacto no se observan diferencias significativas en la extracción, es de destacar que un mayor tiempo favorece la decantación del sólido remanente facilitando la separación de las fases. Se observa el mismo comportamiento que en los ensayos anteriores, evidenciando una mayor extracción de As.

Tabla 9.3. Extracción de $\mathrm{Fe}$ y As con $\mathrm{HCl} 4 \mathrm{M}$ empleando distintos tiempos de extracción.

\begin{tabular}{c|r|r|r|r}
\hline tiempo & \multicolumn{2}{|c|}{$\mathrm{Fe}$} & \multicolumn{2}{c}{ As } \\
\hline $\mathrm{hs}$ & \multicolumn{1}{|c|}{$\mathrm{mg} \mathrm{L}^{-1}$} & $\%$ extracción & $\mathrm{mg} \mathrm{L}^{-1}$ & $\%$ extracción \\
\hline 24 & 51,875 & 0,14 & 0,046 & 2,04 \\
48 & 158,625 & 0,44 & 0,072 & 3,20 \\
72 & 155,125 & 0,43 & 0,068 & 3,02 \\
\hline
\end{tabular}

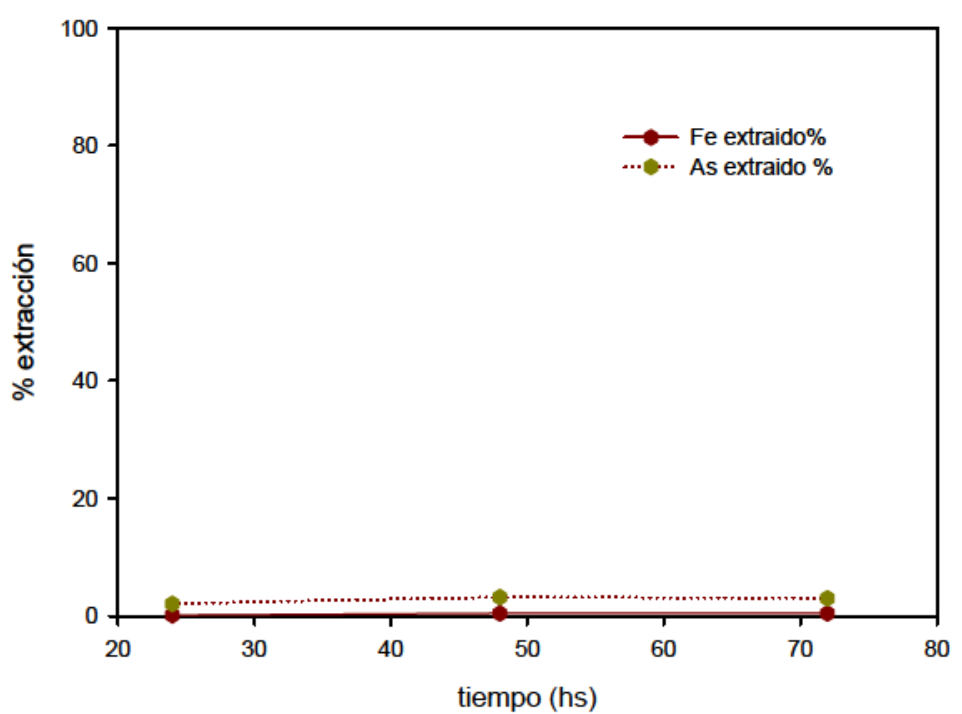

Figura 9.10. Porcentajes de extracción de $\mathrm{Fe}$ y $\mathrm{As}$ con $\mathrm{HCl} 4 \mathrm{M}$ empleando distintos tiempos de extracción.

En la Tabla 9.4 y en la Figura 9.11 se muestra la cantidad de Fe y As extraídos y el porcentaje de extracción variando la relación sólido/líquido.

Finalmente, en la Tabla 9.5 se muestra la cantidad extraída de cada elemento y el porcentaje de extracción variando la temperatura. Cabe aclarar que para el cálculo del \% de extracción se ha tenido en cuenta el efecto de la evaporación. El volumen luego del calentamiento a $60^{\circ} \mathrm{C}$ fue de $276 \mathrm{ml}$ y a $80^{\circ} \mathrm{C}$ fue de $250 \mathrm{ml}$. 
Tabla 9.4. Extracción de $\mathrm{Fe}$ y As con $\mathrm{HCl} 4 \mathrm{M}$ y 72 hs de contacto empleando distintas relaciones arcilla/ácido.

\begin{tabular}{c|r|r|r|r}
\hline Relación & \multicolumn{2}{|c|}{$\mathrm{Fe}$} & \multicolumn{2}{|c}{ As } \\
\cline { 2 - 5 } 1AFO/acido & \multicolumn{1}{|c|}{$\mathrm{mg} \mathrm{L}^{-1}$} & $\%$ extracción & $\mathrm{mg} \mathrm{L}^{-1}$ & $\%$ extracción \\
\hline $1 / 300$ & 56,875 & 4,77 & 0,033 & 44,00 \\
$1 / 120$ & 122,250 & 4,10 & 0,041 & 21,87 \\
$1 / 60$ & 73,875 & 1,24 & 0,061 & 16,27 \\
$1 / 30$ & 155,125 & 1,30 & 0,068 & 9,07 \\
$1 / 15$ & 183,875 & 0,77 & 0,041 & 2,73 \\
\hline
\end{tabular}

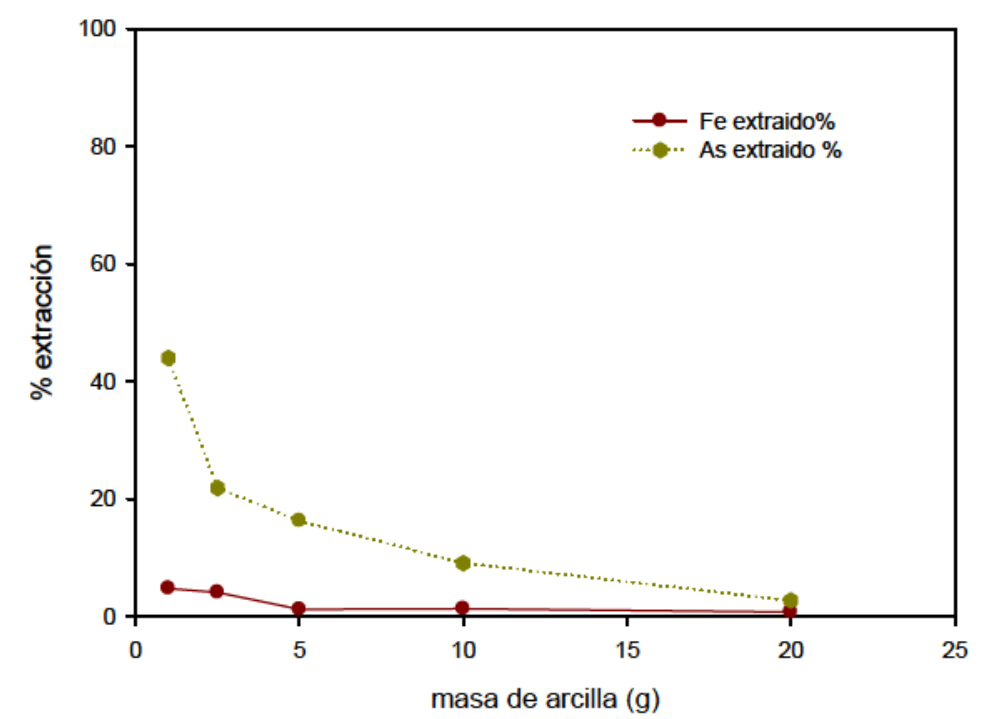

Figura 9.11. Porcentajes de extracción de $\mathrm{Fe}$ y As empleando distintas relaciones sólido/líquido.

Tabla 9.5. Extracción de Fe y As con $\mathrm{HCl} 4 \mathrm{M}, 72$ hs de contacto y relación arcilla/ácido 1/300 empleando distintas temperaturas.

\begin{tabular}{c|r|r|r|r}
\hline $\mathrm{T}$ & \multicolumn{2}{|c|}{$\mathrm{Fe}$} & \multicolumn{2}{c}{ As } \\
\hline${ }^{\circ} \mathrm{C}$ & \multicolumn{1}{|c|}{$\mathrm{mg} \mathrm{L}^{-1}$} & $\%$ extracción & $\mathrm{mg} \mathrm{L}^{-1}$ & $\%$ extracción \\
\hline 25 & 56,875 & 4,77 & 0,033 & 44,00 \\
60 & 82,625 & 6,37 & 0,020 & 24,53 \\
80 & 1235,250 & 86,33 & 0,051 & 56,67 \\
\hline
\end{tabular}

De los resultados obtenidos surge claramente que la temperatura es el factor determinante para mejorar la etapa extractiva.

\subsubsection{Ensayos de coagulación/sedimentación}

Para evaluar el efecto del coagulante a base de $\mathrm{Fe}(\mathrm{III})$ en el proceso de remoción de As detallado en el Capítulo 6, en una primera instancia se analizó el empleo de una solución comercial de $\mathrm{FeCl}_{3}$ a fin de obtener la concentración de coagulante óptima a usar en el procedimiento.

En tal sentido, se utilizó como coagulante una solución al $10 \%$ preparada a partir de $\mathrm{FeCl}_{3} \cdot 6 \mathrm{H}_{2} \mathrm{O}$ comercial (Biopack, pureza 99,6\%). A partir de esta solución se preparó una solución al $1 \%$ que fue la usada para los ensayos de coagulación. El contenido de Fe de esta solución es de 207,02 $\mathrm{mg} \mathrm{Fe}^{+3}$. 
Para que los ensayos sean comparables con los obtenidos en el Capítulo 6, se trabajó en el equipo Jar test siguiendo las variables operacionales que fueron empleadas para determinar la dosis óptima de los coagulantes ensayados en dicho capítulo: $75 \mathrm{~g}$ de arcilla $6 \mathrm{AFO}, 750 \mathrm{ml}$ de $\mathrm{H}_{2} \mathrm{O}$ de red a la cual se le agregó As para obtener una concentración de $300 \mu \mathrm{g} \mathrm{L}^{-1}, 1$ hs con agitación a $250 \mathrm{rpm}$ y 24 hs de sedimentación.

Se realizó un primer ensayo empleando las dosis de coagulante indicadas en la Tabla 9.6.

Tabla 9.6. Dosis de coagulante $\mathrm{FeCl}_{3}$ empleadas en el primer ensayo.

\begin{tabular}{c|c|c}
\hline Jarra & Volumen coagulante $(\mathrm{ml})$ & $\mathrm{mgFe}^{+3} \mathrm{~L}^{-1}$ \\
\hline 1 & 1,0 & 2,76 \\
2 & 1,2 & 3,31 \\
3 & 1,9 & 5,24 \\
4 & 3,8 & 10,49 \\
5 & 5,6 & 15,45 \\
6 & 7,5 & 20,71 \\
\hline
\end{tabular}

En base a los resultados del primer ensayo fue necesario realizar un segundo ensayo empleando dosis de coagulante mayores. Las dosis empleadas se muestran en la Tabla 9.7.

Tabla 9.7. Dosis de coagulante $\mathrm{FeCl}_{3}$ empleadas en el segundo ensayo.

\begin{tabular}{c|c|c}
\hline Jarra & Volumen coagulante $(\mathrm{ml})$ & $\mathrm{mgFe}^{+3} \mathrm{~L}^{-1}$ \\
\hline 1 & 10,0 & 27,60 \\
2 & 12,5 & 34,51 \\
3 & 15,0 & 41,40 \\
4 & 20,0 & 55,20 \\
\hline
\end{tabular}

En cada jarra se realizó el perfil de turbidez y a las 24 hs se determinó As empleando el kit Merck y la turbidez.

En la Tabla 9.8 se muestran los resultados de turbidez y As obtenidos a las 24 hs para las dosis de coagulante del primer ensayo, en tanto que en la Figura 9.12 se representa el perfil de turbidez en cada condición. Se observa que no se logran resultados de turbidez aceptables (por debajo de 3 NTU) en los tiempos en los cuales se han venido realizando los ensayos. Estos valores recién se obtienen a las 72 hs (valor incluido en la última columna de la tabla). Los valores de turbidez de las primeras 24 hs se correlacionan (en las dosis mas bajas) con el contenido de As del agua tratada.

En la Tabla 9.9 y en la Figura 9.13 , se muestran los resultados de la turbidez para el segundo ensayo, donde puede apreciarse que al aumentar la cantidad de 
coagulante se logran valores de turbidez aceptables para el proceso, comparables a los obtenidos en el Capítulo 6 empleando otros coagulantes.

Tabla 9.8. Resultados de turbidez y As en el primer ensayo.

\begin{tabular}{c|r|r|r}
\hline Jarra & As $\left(\mu \mathrm{g} \mathrm{L}^{-1}\right)$ & NTU 24 hs & NTU 72 hs \\
\hline 1 & $25-10$ & 11,90 & 0,81 \\
2 & $25-10$ & 12,70 & 0,38 \\
3 & $25-10$ & 11,90 & 1,11 \\
4 & $<5$ & 11,30 & 0,49 \\
5 & $<5$ & 7,40 & 0,25 \\
6 & $<5$ & 5,39 & 0,71 \\
\hline
\end{tabular}

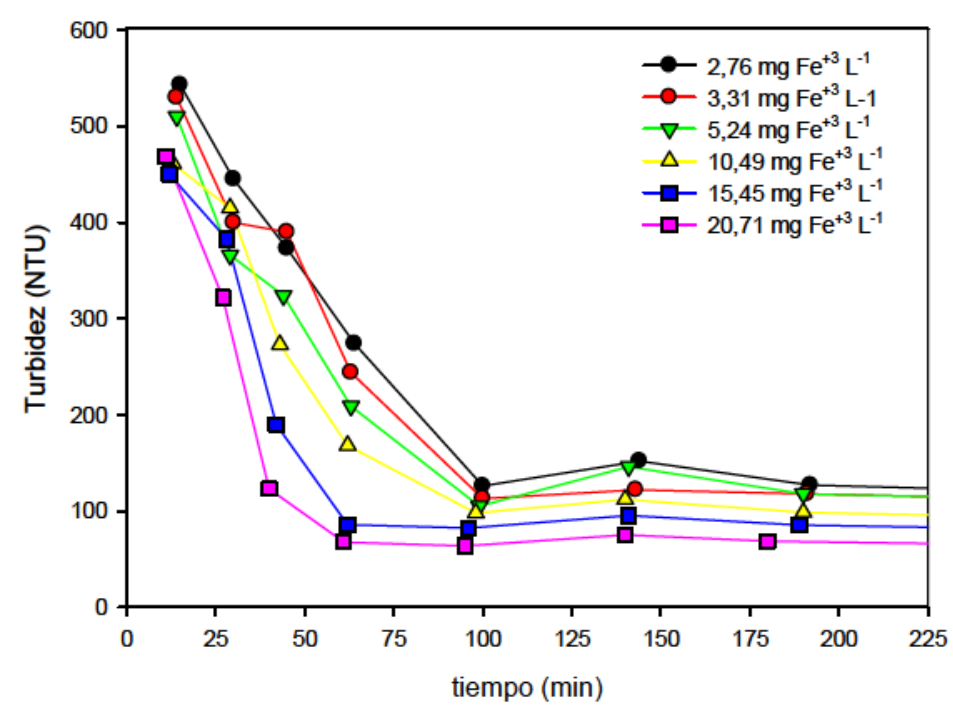

Figura 9.12. Perfil de turbidez empleando las dosis de Fe indicadas para el primer ensayo.

Tabla 9.9. Resultados de turbidez y As en el segundo ensayo.

\begin{tabular}{c|c|c}
\hline Jarra & As $\left(\mu \mathrm{g} \mathrm{L}^{-1}\right)$ & NTU \\
\hline 1 & $<5$ & 2,98 \\
2 & $<5$ & 2,72 \\
3 & $<5$ & 2,18 \\
4 & $<5$ & 1,27 \\
\hline
\end{tabular}

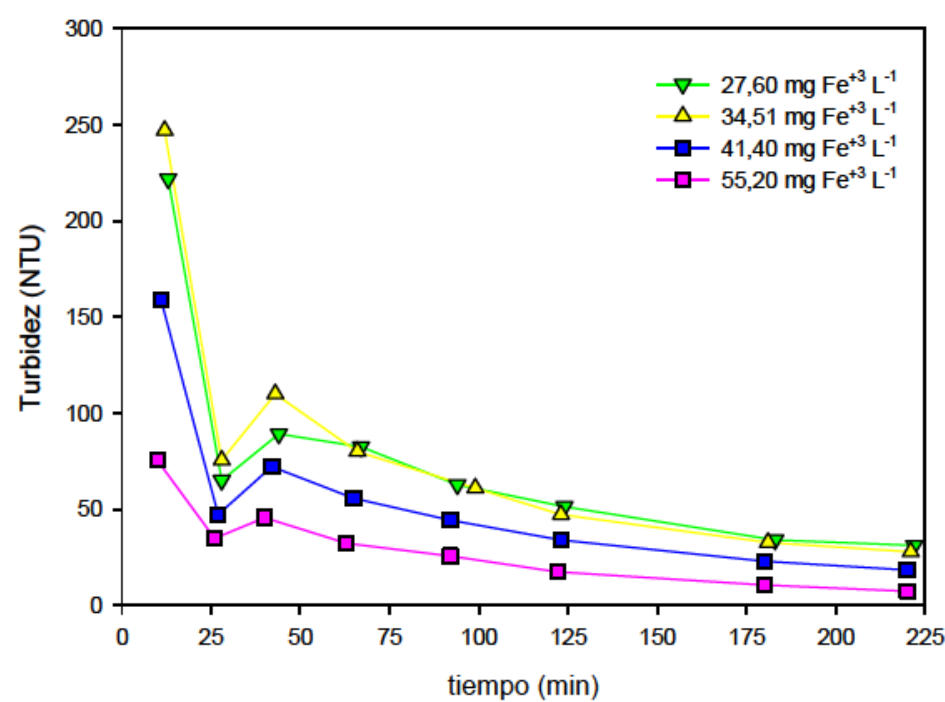

Figura 9.13. Perfil de turbidez empleando las dosis de Fe indicadas para el segundo ensayo. 
En función de los valores obtenidos, la concentración óptima de coagulante sería la correspondiente a la jarra 1 del segundo ensayo (10 $\mathrm{ml}$ de coagulante al $1 \%$ ). Empleando esta dosis óptima se repitió el ensayo utilizando el coagulante obtenido luego de la extracción a $80^{\circ} \mathrm{C}$.

Según los datos obtenidos empleando la solución comercial se requieren 20,7 mg Fe en los $750 \mathrm{ml}\left(27,60 \mathrm{mg} \mathrm{Fe} \mathrm{L}^{-1}\right)$. Empleando la solución extraída a los $80^{\circ} \mathrm{C}$ con una concentración de hierro de $1235,25 \mathrm{mg} \mathrm{L}^{-1}$ se deberían agregar a la jarra de reacción un volumen de solución de 16,75 ml. Empleando esta concentración se obtuvieron valores de As < 5 y turbidez 1,36 NTU.

\subsection{Activación del residuo del tratamiento extractivo de la metacaolinita con sales de $\mathrm{Fe}$ (III)}

Con el fin de aprovechar el sólido producido en la extracción de la metacaolinita con $\mathrm{H}_{2} \mathrm{SO}_{4}$, se procedió a la activación del mismo empleando una sal de hierro(III). La muestra activada, denominada Fe-MKE, fue caracterizada y empleada en el proceso de remoción de As, siguiendo los parámetros optimizados para las arcillas AFO.

\subsubsection{Activación del sólido}

El procedimiento empleado en la activación fue el indicado en el Capítulo 7 para la modificación química de las muestras minerales pobres en hierro. Para comparar en igualdad de condiciones de tratamiento, se empleó la misma relación geomaterial/sal férrica/agua/KOH. El detalle de la preparación de la muestra activada se describe a continuación:

Se activaron $50 \mathrm{~g}$ de mineral, a los que se le agregaron $125 \mathrm{ml}$ de $\mathrm{H}_{2} \mathrm{O}$ destilada y $10 \mathrm{~g}$ de $\mathrm{Fe}\left(\mathrm{NO}_{3}\right)_{3} \cdot 9 \mathrm{H}_{2} \mathrm{O}$. Con agitación magnética se agregaron $77,5 \mathrm{ml}$ de $\mathrm{KOH} 1 \mathrm{M}$ y se llevó a neutralidad mediante el agregado de $\mathrm{KOH} 1 \mathrm{M}$ en constante agitación (43 $\mathrm{ml}$ ). La muestra modificada (Fe-MKE) fue centrifugada (10 min a $2000 \mathrm{rpm}$ ), lavada hasta la eliminación total de nitratos (4 lavados) y secadas en estufa a $60^{\circ} \mathrm{C}$.

\subsubsection{Caracterización de la muestra activada}

La muestra activada fue caracterizada mediante determinación de elementos mayoritarios por ICP-AES, SEM-EDS y análisis de superficie BET.

En la Tabla 9.10 se muestran los resultados del análisis químico de la muestra Fe-MKE. A modo de comparación se incluyen los valores para la arcilla $\mathrm{K}$ y la arcilla $\mathrm{K}$ activada (Fe-K). Como consecuencia de la activación química, la muestra Fe-MKE presenta un aumento en el contenido de hierro (expresado como $\mathrm{Fe}_{2} \mathrm{O}_{3} \%$ ) de 2,63\% respecto a la caolinita $(\mathrm{K})$. Este valor es inferior al observado para la caolinita activada 
directamente $(\mathrm{Fe}-\mathrm{K})$ presentando un valor de $4,11 \%$. Los resultados obtenidos pueden atribuirse a la diferente interacción de las especies de hierro con la superficie de la partícula, demostrando que el material extraído, aun con una elevada superficie específica, presenta una mayor relación Si/Al, siendo el Si un elemento con mayor potencial iónico, razón por la cual muestra una menor afinidad por las fases de hierro que la especie cristalina laminar con un mayor número de sitios activos Al.

Tabla 9.10. Análisis químico de elementos mayoritarios por ICP-AES (expresado en \% óxidos) para la muestra activada. Análisis químicos de $\mathrm{K}$ y Fe-K incluidos como referencia.

\begin{tabular}{l|r|r|r}
\hline \multicolumn{1}{c|}{$\%$} & \multicolumn{1}{c|}{ Fe-MKE } & \multicolumn{1}{c|}{$\mathrm{K}$} & \multicolumn{1}{c}{$\mathrm{Fe}-\mathrm{K}$} \\
\hline $\mathrm{SiO}_{2}$ & 72,47 & 51,92 & 49,57 \\
$\mathrm{Al}_{2} \mathrm{O}_{3}$ & 9,27 & 32,32 & 30,85 \\
$\mathrm{Fe}_{2} \mathrm{O}_{3}$ & 3,68 & 1,05 & 5,16 \\
$\mathrm{CaO}$ & 0,11 & 0,45 & 0,19 \\
$\mathrm{MgO}$ & 0,13 & 0,23 & 0,17 \\
$\mathrm{Na}_{2} \mathrm{O}$ & 0,13 & 0,30 & 0,23 \\
$\mathrm{~K}_{2} \mathrm{O}$ & 0,70 & 0,20 & 0,63 \\
$\mathrm{Cr}_{2} \mathrm{O}_{3}$ & 0,01 & 0,01 & 0,01 \\
$\mathrm{TiO}_{2}$ & 1,69 & 1,16 & 1,11 \\
$\mathrm{MnO}$ & 0,01 & 0,01 & 0,01 \\
$\mathrm{P}_{2} \mathrm{O}_{5}$ & 0,01 & 0,05 & 0,07 \\
$\mathrm{SrO}$ & 0,01 & 0,01 & 0,01 \\
$\mathrm{BaO}$ & 0,03 & 0,02 & 0,01 \\
$\mathrm{LOI}$ & 11,77 & 12,27 & 11,98 \\
$\mathrm{SiO}$ & & 1,61 & 1,61 \\
\hline
\end{tabular}

Las Figuras 9.14 y 9.15 muestran los espectros EDS del material MKE y FeMKE, observando el incremento superficial de la especie de hierro. Por otra parte, la Figura 9.16 presenta comparativamente la morfología de ambas muestras.

MKE

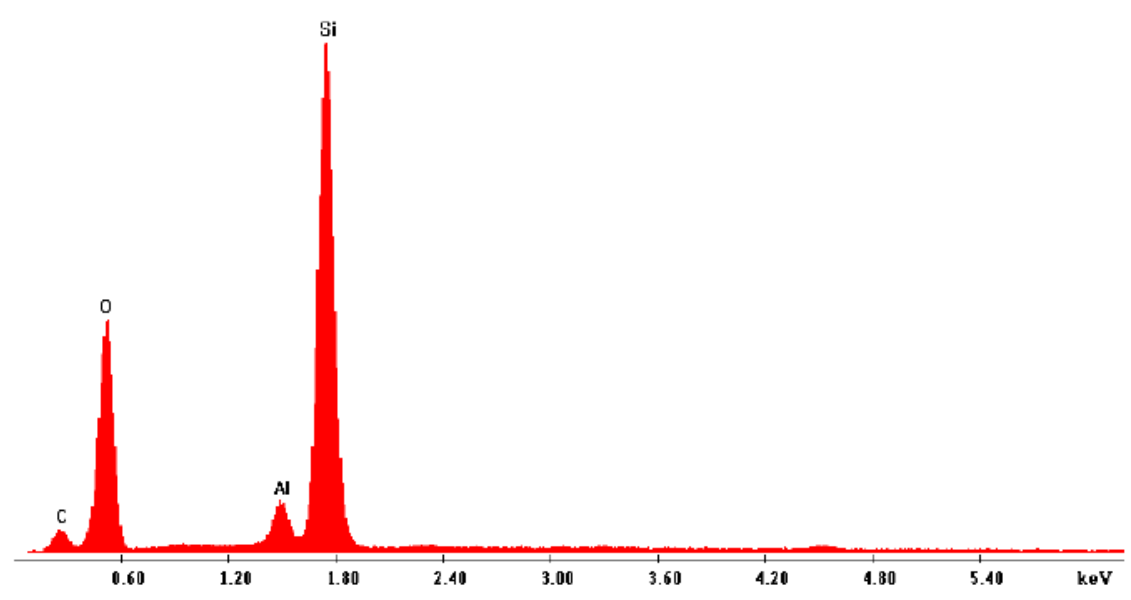

Figura 9.14. Espectro EDS de la muestra de metacaolinita extraída con $\mathrm{H}_{2} \mathrm{SO}_{4}$. 


\section{Fe-MKE}

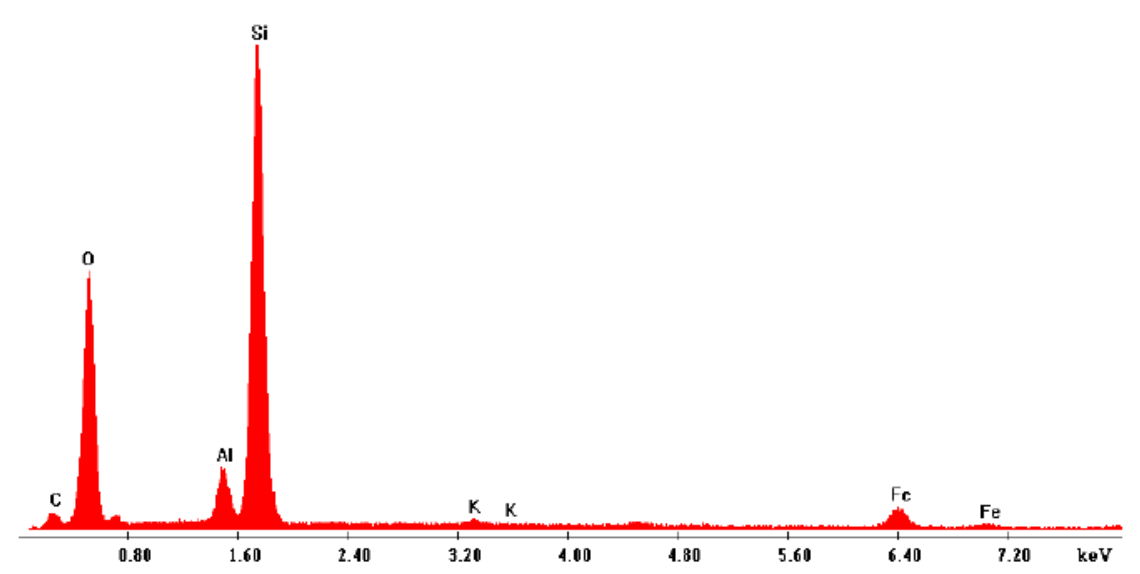

Figura 9.15. Espectro EDS de la muestra de metacaolinita extraída con $\mathrm{H}_{2} \mathrm{SO}_{4}$ activada con $\mathrm{Fe}$.
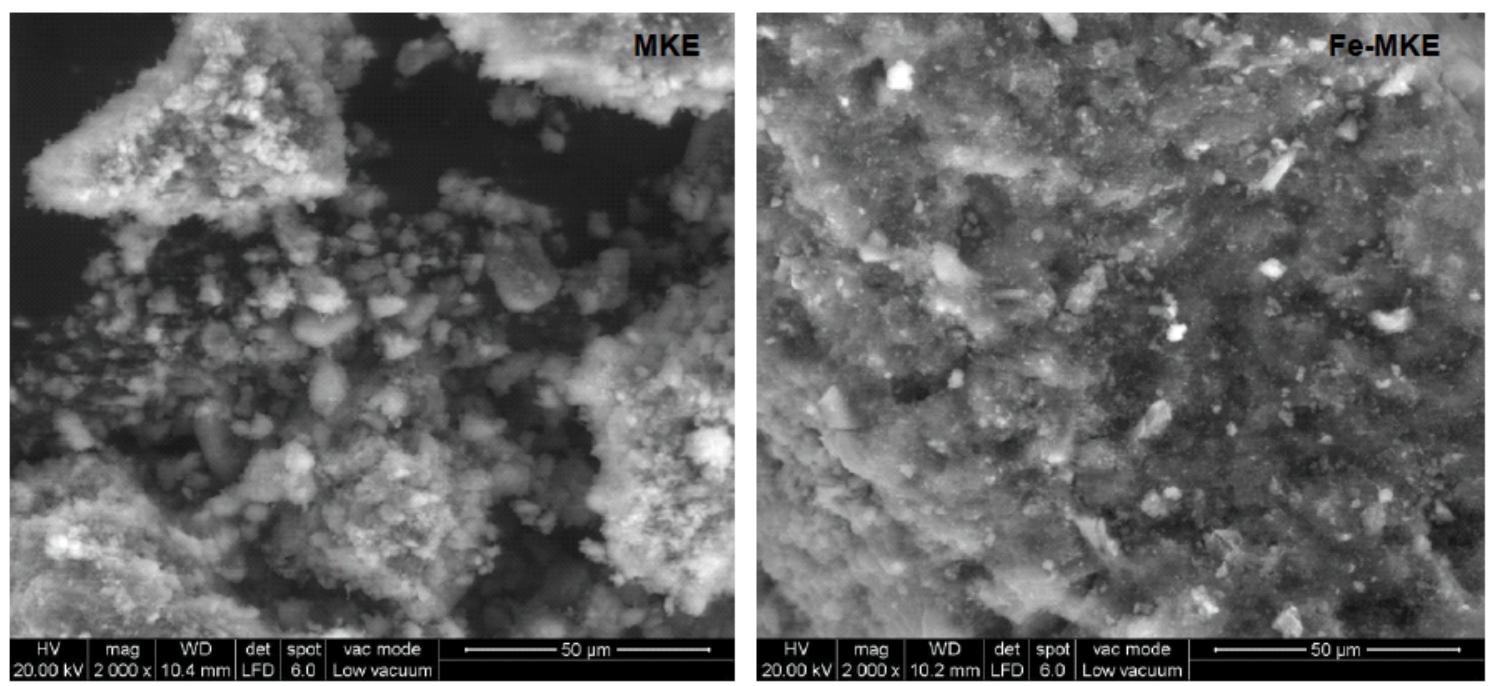

Figura 9.16. Micrografías SEM para las muestras MKE y Fe-MKE.

Los resultados de la superficie específica BET, del tamaño promedio de poro (DPP) y volumen total de poros (Vp) se presentan en la Tabla 9.11, donde se incluyen los valores para la caolinita y la caolinita activada a modo de comparación. Es de destacar el aumento en la superficie BET producido, en primer lugar, por el tratamiento con ácido $y$, en segundo lugar, por la activación con Fe. Los resultados para las muestras MKE y Fe-MKE son superiores a los logrados por la simple activación de la caolinita, aspecto relacionado con el desorden estructural generado por la transformación térmica y el posterior tratamiento ácido. 
En la Figura 9.17 se muestra comparativamente el aumento en el volumen total de poros, preferentemente en la zona de los mesoporos, de acuerdo a los datos observados en la Tabla 9.11.

Tabla 9.11. Propiedades superficiales. $\mathrm{S}_{\mathrm{BET}}\left(\mathrm{m}^{2} \mathrm{~g}^{-1}\right)$, DPP $(\AA)$ y Vp $\left(\mathrm{cm}^{3} \mathrm{~g}^{-1}\right)$.

\begin{tabular}{c|r|r|r}
\hline Muestra & \multicolumn{1}{|c|}{$\mathrm{S}_{\mathrm{BET}}$} & \multicolumn{1}{c|}{ DPP } & \multicolumn{1}{c}{ Vp } \\
\hline $\mathrm{K}$ & 9,09 & 137,65 & 0,028 \\
MKE & 160,90 & 94,19 & 0,276 \\
Fe-MKE & 437,67 & 88,39 & 0,649 \\
Fe-K & 71,60 & 111,84 & 0,136 \\
\hline
\end{tabular}
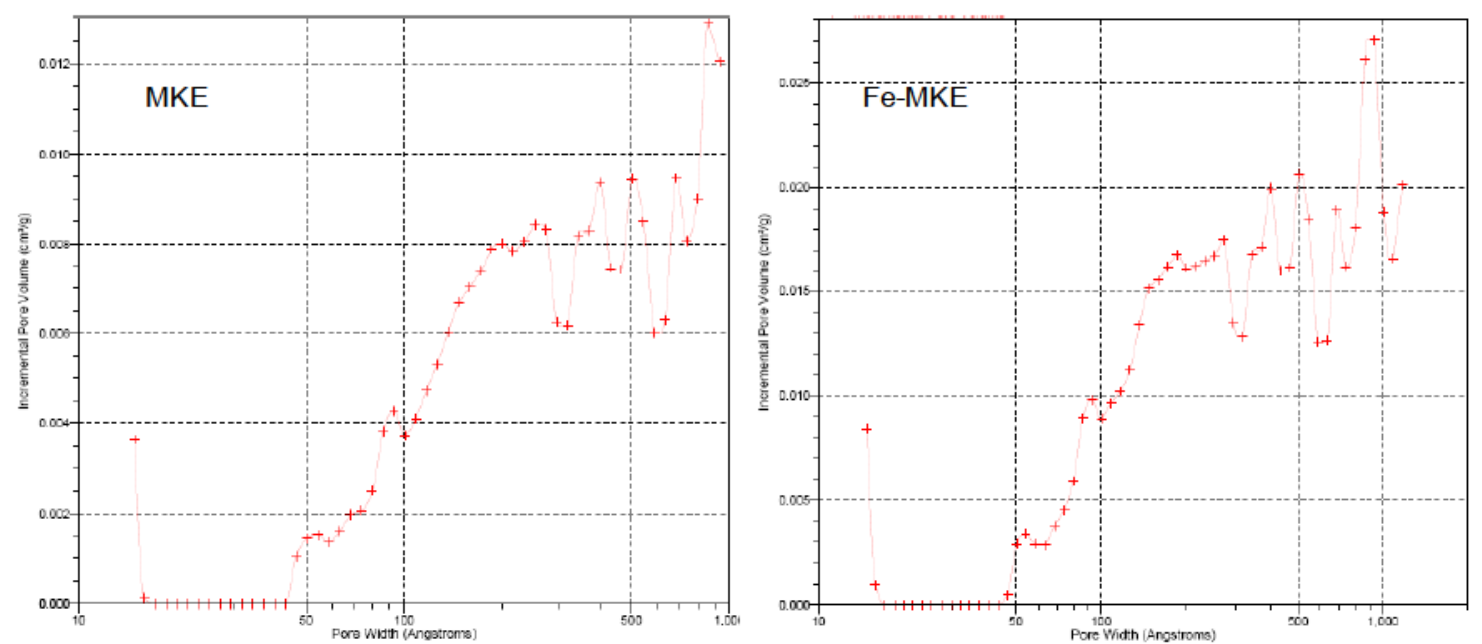

Figura 9.17. Comparación de la distribución de tamaño de poro (DFT) para MKE y Fe-MKE.

\subsubsection{Evaluación de la remoción de As a nivel laboratorio}

La muestra activada fue probada con el fin de determinar la efectividad del sólido como adsorbente, utilizando como referencia las condiciones experimentales determinadas como óptimas en el Capítulo 6 para la arcilla ferruginosa. A tal efecto se utilizó una solución de $1000 \mu \mathrm{g} \mathrm{L}^{-1}$ de As. Los ensayos se realizaron en simultáneo en el equipo Jar test empleando una relación sólido/líquido de $20 \mathrm{~g}$ en $200 \mathrm{ml}$. El sólido suspendido se decantó con la ayuda de la dosis óptima de PAC $(0,193 \mathrm{mg}$ de Al por litro de agua). La eficacia del material se estableció a través del número de ciclos útiles de tratamientos consecutivos. El adsorbente se considera saturado cuando la concentración de arsénico en la solución excede el límite permitido de $10 \mu \mathrm{g} \mathrm{L}^{-1}$.

Como control, en el primer ciclo se trabajó con la muestra activada con y sin PAC. El monitoreo de cada jarra se realizó tomando muestras transcurridas las 24 hs de sedimentación, determinando turbidez y concentración de As. Para este último se hizo uso del kit de As Merck.

En la Tabla 9.12 se observan los valores determinados a 24 hs en los distintos ciclos de adsorción realizados. En relación a los valores de turbidez determinados, se 
destaca que con la muestra sin coagulante no se logra alcanzar el valor indicado en la legislación mientras que el agregado de PAC asegura un valor de turbidez adecuado a las $24 \mathrm{hs}$.

En relación a los valores de As, la muestra sin PAC no logra disminuir el valor del mismo al estipulado por la legislación, posiblemente debido a la presencia de sólidos en suspensión. La muestra con PAC logra disminuir el valor de As a los recomendados durante 12 ciclos, demostrando que puede realizarse un aprovechamiento integral del mineral extraído.

Tabla. 9.12. Resultados de NTU y As $\left(\mu \mathrm{g} \mathrm{L}^{-1}\right)$ durante los distintos ciclos de tratamiento realizados con Fe-MKE con y sin coagulante.

\begin{tabular}{|c|c|c|c|c|}
\cline { 2 - 5 } \multicolumn{1}{c|}{} & \multicolumn{2}{c|}{ Fe-MKE } & \multicolumn{2}{c|}{ Fe-ZKEFe + PAC } \\
\hline Ciclo & NTU & As & NTU & As \\
\hline 1 & 197 & 100 & 0,56 & $<10$ \\
\hline 2 & - & - & 1,02 & $<10$ \\
\hline 3 & - & - & 1,45 & $<10$ \\
\hline 4 & - & - & 0,98 & $<10$ \\
\hline 5 & - & - & 1,04 & $<10$ \\
\hline 6 & - & - & 1,23 & $<10$ \\
\hline 7 & - & - & 1,76 & $<10$ \\
\hline 8 & - & - & 1,52 & $<10$ \\
\hline 9 & - & - & 0,95 & $<10$ \\
\hline 10 & - & - & 1,24 & 10 \\
\hline 11 & - & - & 1,89 & 10 \\
\hline 12 & - & - & 2,34 & 10 \\
\hline 13 & - & - & 0,31 & 25 \\
\hline
\end{tabular}




\section{CAPITULO 10}

\section{Inmovilización del residuo del proceso de remoción de As. Tratamiento de la} arcilla agotada

De lo expuesto en capítulos anteriores surge que la tecnología propuesta para la eliminación de As de aguas subterráneas ha resultado eficiente y resuelve una problemática vigente en una amplia región de nuestro país. Sin embargo, para resolver la sustentabilidad integral del método deben ajustarse con mayor precisión las alternativas de disposición del residuo del proceso.

En este capítulo se estudian las posibilidades de inmovilización del As procedente de la adsorción del contaminante en el material de arcilla, evaluando la utilización de la arcilla ferruginosa empleada en el tratamiento de As para la fabricación de morteros y hormigones. Se analiza el proceso desde dos puntos de vista:

1.- desde el impacto ambiental (minimizando o eliminando los efectos de lixiviación).

2.- desde su aplicación en el área de la construcción en las zonas de instalación de los equipos de tratamiento.

Con tal propósito la tarea se dividió en diferentes etapas que comprenden, la caracterización fisicoquímica y la evaluación de la peligrosidad del residuo para proceder posteriormente a la evaluación de procedimientos de solidificación para inmovilizar al contaminante. Con el fin de evaluar esas posibilidades, se trabajó en colaboración con los Dres. R. Zerbino y G. Giaccio, investigadores del Laboratorio de Entrenamiento Multidisciplinario para la Investigación Tecnológica (LEMIT-CICPBA), para la fabricación de morteros y hormigones, la realización de pruebas mecánicas y de ensayos de lixiviación de los productos obtenidos.

10.1. Generalidades sobre la disposición de residuos generados en el tratamiento de aguas conteniendo As

En primer lugar resulta interesante realizar un breve comentario acerca de los procedimientos de disposición de residuos procedentes de los diferentes métodos empleados en la eliminación de As, ya sea que se trate de una precipitación pura o de una adsorción en sistemas oxídicos a través de la cual el As se une a la superficie del adsorbente (Sullivan et al., 2010). En el marco general del cuidado del medio ambiente, todos los desarrollos tecnológicos a emplear deberían asegurar que el As, desde el punto de vista económico, ambiental y social, quede inmovilizado en forma efectiva a fin de evitar graves consecuencias a las futuras generaciones. 
En países asiáticos afectados por el consumo de agua con contenidos de As por encima de los establecidos por la OMS, las opciones para disponer los residuos generados en el tratamiento son, en realidad, bastante limitadas. Este hecho se origina en la situación socio-económica de las poblaciones carentes de agua de red, en general zonas rurales o de elevada pobreza. Es así que se vienen aplicando técnicas muy primitivas y poco seguras que implican un potencial retorno del tóxico al ambiente. Por otra parte, en estas regiones las técnicas empleadas para la detección del contaminante en medios naturales accesibles a la contaminación (por ej. suelos) resultan difíciles, en particular si se tiene en cuenta la complejidad del sistema. En general, los procedimientos de análisis, se han venido practicando tomando como referencia una simulación de las condiciones naturales que se encuentran lejos de representar la situación que opera en la realidad.

Entre los procesos más rudimentarios que pueden citarse para el tratamiento de los residuos ricos en As se encuentran aquellos constituidos por la mezcla de los lodos con excremento del ganado, sistema que por el carácter reductor de la materia orgánica resulta muy poco efectivo dado que facilita la reducción del arsénico a arsina, gas altamente contaminante (Sullivan et al., 2010).

Por otra parte, el enterramiento de los lodos, otro de los procesos más comúnmente empleados, no asegura la inmovilidad del tóxico, dependiendo fuertemente de las características del terreno. La aplicación de este método lleva implícita una elevada posibilidad de contaminación de los suelos e incluso de las napas.

Por último, aquellas opciones que signifiquen tratamiento a altas temperaturas, sin reacción química, no son aconsejadas, debido a la formación de volátiles con As, produciendo aerosoles de muy difícil detección y eliminación.

Existen protocolos que deben tener en cuenta la disposición de los barros conteniendo As (Mudgal, 2001; Riveros et al., 2001). En general, y en base a la afinidad de los sistemas $\mathrm{Fe}-\mathrm{O}$ con el anión $\mathrm{AsO}_{4}{ }^{3-}$ en medio acuoso, es bien conocida la formación de un arseniato férrico insoluble por lo que el empleo de las fases de hierro constituye una de las técnicas más recomendadas. Al respecto las fases de hierro amorfas o muy pobremente cristalinas resultan ser efectivos adsorbentes dejando un residuo de "ferrihidrita arsenical". La estabilidad y condiciones termodinámicas de dichas fases permiten predecir su condición de perdurable por varios años en sus entornos naturales (resistentes a los procesos de meteorización). Asimismo, se ha hecho referencia a la estabilidad de los sistemas en medios 
ligeramente ácidos y condiciones oxidantes (Riveros et al., 2001). El empleo de condiciones mas extremas (autoclave, procesos térmicos y temperaturas del orden de las de formación de refractarios) conducen a la formación de fases cristalinas como la escorodita $\left(\mathrm{FeAsO}_{4} \cdot 2 \mathrm{H}_{2} \mathrm{O}\right)$ y/o a distintos oxohidroxo arseniatos de hierro.

En vista a lo brevemente expuesto puede concluirse que existen diferentes alternativas para la disposición de los residuos oxídicos procedentes de la adsorción del As contenido en aguas. A continuación se mencionan con algún detalle dos de ellas, una muy simple pero de baja seguridad y otra, algo más compleja pero de mayor efectividad.

\section{Disposición del residuo como relleno de suelos ("Iandfill")}

El procedimiento consiste en enterrar el residuo en fosas dispuestas especialmente para tal fin. En los procesos de remoción por adsorción en los que el residuo es muy voluminoso debido al elevado contenido de agua (lodos) la dificultad en su manejo se soluciona a partir de un secado previo a la disposición final. El procedimiento no resulta muy efectivo desde el punto de vista ambiental dado que es imposible evitar la percolación y la meteorización, lo que podría conducir a la contaminación de los suelos cercanos y eventualmente al agua subterránea (Ashraf et al., 2003).

Por otra parte, en los últimos años se ha procedido al desarrollo de distintos métodos de análisis para determinar si las condiciones de enterramiento han sido efectivas según la definición de la USEPA. Usualmente se realiza la evaluación del residuo con el test TCLP (Toxicity Characteristic Leaching Procedure, Method 1311). La estabilidad del residuo está íntimamente relacionada con la gran variabilidad de los suelos (contenido de materia orgánica, $\mathrm{pH}$, sistemas buffers, $\mathrm{CO}_{2}$ disuelto, etc.). Respecto al test TCLP, al cual se hará referencia detallada mas adelante, el mismo es cinéticamente restringido y consiguientemente de aplicación limitada, en particular debido a que no atiende las características del entorno en lo que se refiere a la lixiviación natural (Sullivan et al., 2010).

Disposición del residuo por oclusión en otros materiales (sistemas S/S "stability/solidification"). Incorporación en especies inorgánicas inertes de tipo natural y/o sintético con potencialidad en la industria de la construcción

Algunos autores han sugerido la mezcla de los lodos residuales con minerales de arcilla para la fabricación de ladrillos o con cemento para producir bloques de construcción para viviendas. Esta técnica resulta particularmente interesante en algunas áreas urbanas de países asiáticos (Bangladesh y algunos estados de India) caracterizadas por su baja condición socio-económica y que paralelamente se 
encuentran severamente afectadas por la problemática del As. La posibilidad de oclusión del contaminante en una matriz de elevada integridad estructural garantiza la inmovilidad del mismo y la formación de bloques aptos en ese medio social. Se ha reportado la estabilidad de los residuos así como el rol de la temperatura sobre la calidad de los materiales y sobre las posibilidades de lixiviación (Roulf and Hossain, 2003).

En lo que respecta a las técnicas de estabilización y solidificación (S/S), las mismas implican el mezclado del residuo (en forma de lodo o en estado seco) con otros componentes, como por ejemplo cemento Pórtland. La idea está dirigida al encapsulado del contaminante mediante el empleo de un ligante que asegure la formación de un sólido de características adecuadas (integridad estructural, estabilidad a largo plazo y mínima lixiviación) que impida la restitución del contaminante al medio ambiente.

Si bien el empleo de un ligante puede significar un incremento en el costo del proceso, su agregado minimiza la exposición del residuo a los agentes ambientales, reduciendo así las posibilidades de lixiviación. Existe en la literatura información (Halim et al., 2004) respecto a la integridad del As disperso en la matriz de silicatos de calcio hidratados, principal producto de hidratación del cemento. En tal sentido, Mollah et al. (2004) demostraron la efectividad del proceso a través de estudios realizados durante largos periodos (mas de 10 años) mediante técnicas como DRX y FTIR.

Las opciones brevemente mencionadas conducen, sin duda, a determinar que la mejor alternativa la constituye el tratamiento del lodo residual mediante un proceso de estabilización por encapsulamiento y solidificación, minimizando la movilidad del As y asegurando su aislamiento definitivo del ambiente.

Uno de los procesos de solidificación más comunes, hace uso de cemento y cal como ligantes para la formación de la matriz que incorpora al As. La eficacia del procedimiento muestra una fuerte dependencia con el tipo de coagulante empleado (PAC, $\mathrm{FeSO}_{4}$, polisulfato férrico, etc.) en la etapa coagulación/sedimentación, así como con las características de las aguas. Esto es debido a la posibilidad de ataque del cemento por ciertos aniones, como por ejemplo sulfatos.

Entre otras variables y por razones de permeabilidad, es necesario que la relación agua/cemento resulte lo mas baja posible. Un exceso de agua puede contribuir a su exudado y, a través de la movilidad de la misma, a un incremento de la lixiviación. En ciertas condiciones, la expansión del material por cambios en la humedad da lugar a la formación de una matriz porosa. 
La presencia de ácidos (inorgánicos u orgánicos) así como la de aniones y la de algunos floculantes usados en la adsorción, como por ejemplo $\mathrm{Fe}(\mathrm{OH})_{3}$, afectan el proceso S/S, en estos casos particulares retardando el mismo. Contrariamente, la presencia de sales (como $\mathrm{NaCl}$ ), asociadas a la alúmina activada empleada en la remoción, puede presentar un efecto acelerador a través de la hidratación del cemento (Sullivan et al., 2010).

\subsubsection{Algunos aspectos del proceso de inmovilización por cementación}

La solidificación e inmovilización de residuos tóxicos, como proceso económico y práctico, se comenzó a estudiar en las últimas décadas. Basado en la producción de un sólido estructuralmente firme con posibilidad de estabilizar distintos productos no deseados, limita la solubilidad o movilidad de los mismos dentro de la matriz sólida, disminuyendo, con su aislamiento, la posible afectación del medio ambiente. En el proceso a base de la utilización de cemento Portland los contaminantes presentes en el residuo quedan incluidos dentro de la estructura cristalina que se forma por la hidratación del cemento, reduciendo la toxicidad al disminuir la disponibilidad del contaminante.

En ese contexto, la cementación es una técnica interesante que, a partir del uso de cemento Pórtland para formar monolitos de hormigón, permite aislar contaminantes inorgánicos que presenten características de elevada solubilidad (particularmente oxoaniones y cationes pesados). Presenta ventajas importantes para el tratamiento de residuos debido a su bajo costo, bajo requerimiento técnico de personal, estabilidad estructural del hormigón a largo plazo, relativamente baja permeabilidad del hormigón y en definitiva escasa posibilidad de re-ingreso al medio.

Es de destacar que el hormigón es uno de los materiales más empleados por el hombre para la realización de diversos elementos y estructuras civiles. Entre sus conocidas propiedades, que lo potencian respecto de otros materiales, se puede citar su resistencia a la acción del agua, su dureza y propiedades mecánicas, la posibilidad de fabricación de elementos con una gran variedad de formas y tamaños, etc. Por otra parte es un material económico y rápidamente disponible en las obras y requiere menor consumo de energía respecto a otros materiales. Finalmente, y no menos importante en el siglo XXI, ha demostrado ser un material que facilita la incorporación de grandes cantidades de desperdicios o subproductos de diferente tipo (restos de construcción y demolición, residuos industriales, cenizas de residuos patogénicos, arenas y escorias de fundición, vidrio, residuos de la industria de la madera, del papel, 
del cuero, neumáticos, etc.) asociados al crecimiento poblacional y al desarrollo del sector productivo/industrial (Hidalgo y Alonso, 2005).

En relación al tema desarrollado en esta tesis, cabe recalcar que los materiales de construcción están tradicionalmente basados en el uso de recursos naturales, como arena y arcilla. Sin embargo, en la actualidad se incorporan cada vez más otros materiales alternativos, habiendo alcanzado un importante grado de desarrollo aquellos materiales derivados del reciclado de residuos.

EI LEMIT, en particular ha estudiado las adiciones minerales desde hace más de 30 años y desde hace aproximadamente 10 años ha abordado la línea de investigación sobre la disposición de residuos en hormigones, morteros, etc. Al respecto cabe señalar el aprovechamiento de cenizas de cáscara de arroz, la disposición de cenizas de residuos patogénicos así como la incorporación en hormigones de residuos sólidos de la industria del cuero, arenas de fundición, etc.

La posibilidad de utilización de un residuo en un sistema S/S se debe evaluar desde dos puntos de vista: a) desde la lixiviación y b) desde las propiedades mecánicas.

\subsubsection{Algunos aspectos de la lixiviación de los residuos}

Una forma de evaluar la retención de contaminantes es a través de ensayos de lixiviación, entendiéndose por lixiviación al proceso de disolución, lavado y transporte del contaminante desde una fase sólida (o pieza consolidada) a la fase acuosa. Cuando un residuo sólido entra en contacto con el agua, puede suceder que algunos de sus constituyentes se disuelvan, parcial o totalmente, originándose un extracto o lixiviado que puede contener al contaminante, dependiendo de la interacción (química/física) que el mismo ha sufrido en el proceso de formación de la pieza. Si la concentración de un componente tóxico lixiviado es muy elevada puede resultar una amenaza potencial para el medio ambiente, por lo que los ensayos de lixiviación son indispensables para la caracterización de la efectividad del proceso de tratamiento de residuos, la inmovilización del contaminante e incluso el análisis de la potencialidad del material para la fabricación de piezas a emplear en la construcción.

La lixiviación de los materiales puede ocurrir en el lugar donde está aplicado, por infiltración natural de aguas, por lluvias, exposición a agua de mar, etc. (Amaral de Lima, 1999).

Existe abundante información respecto a los mecanismos de lixiviación, a largo plazo, de cenizas procedentes de residuos municipales estabilizadas en sistemas con cemento portland, no detectando la presencia de los contaminantes contenidos en el 
material original como $\mathrm{Sb}, \mathrm{As}, \mathrm{Cd}, \mathrm{Cr}, \mathrm{Hg}, \mathrm{Ni}, \mathrm{Pb}, \mathrm{Se}$, etc. los que son retenidos en la matriz cementícea, o bien forman parte de nuevas fases insolubles formadas "in situ" (Andac and Glasser, 1999; Hillier et al., 1999).

Trabajos previos realizados en el LEMIT sobre la inmovilidad de cenizas de residuos patogénicos han demostrado a partir de ensayos de lixiviación que la técnica es altamente efectiva (Genazzini et al., 2003).

La "disponibilidad" o concentración máxima lixiviable de un elemento, aun en condiciones extremas, es un dato necesario para determinar el comportamiento y efectividad de la mezcla en la que se ocluye el contaminante. Por este motivo, en muchos países se han desarrollado ensayos de lixiviación, en algunos casos a un nivel tan elevado que la legislación se basa en ellos. En Europa existen más de 40 comités técnicos de materiales de la construcción, cada uno de los cuales ha desarrollado sus propios ensayos de lixiviación (Hidalgo y Alonso, 2005).

La Figura 10.1 ilustra las diferencias entre los conceptos de concentración total de un componente en el material, cantidad potencialmente lixiviable de ese componente ó fracción movilizable, y la evolución de la lixiviación con el tiempo.

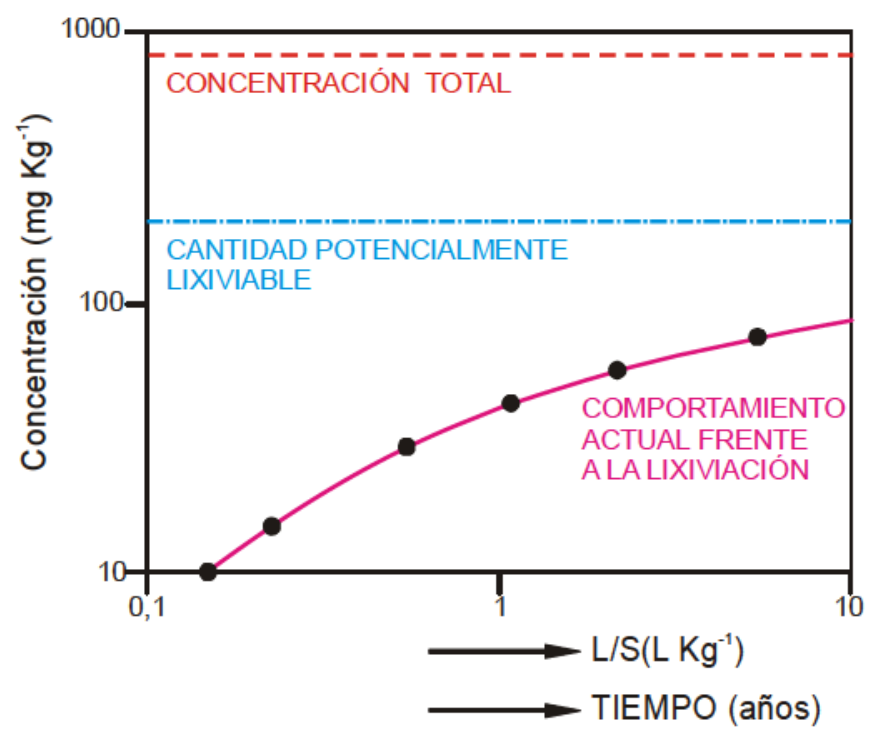

Figura 10.1. Distintas fracciones lixiviables de un componente en un material.

La concentración total de un componente no tiene una relación directa con el impacto medioambiental. La concentración potencialmente lixiviable de un componente, es la que lixiviaría en el peor de los casos, es decir en un caso extremo. La curva denominada comportamiento actual frente a la lixiviación, es función de las condiciones de exposición, será la fracción realmente lixiviable en un escenario y una aplicación determinada, bajo condiciones específicas. La diferencia entre la concentración total y la fracción movilizable debe atribuirse a la fracción de la especie 
en cuestión que se encuentra inmovilizada por la matriz mineralógica del material (Pacheco Belzunces, 2009).

Dependiendo de algunos parámetros relevantes de un escenario, como por ejemplo el $\mathrm{pH}$, la cantidad lixiviada puede estar órdenes de magnitud por debajo de la fracción potencialmente lixiviable, particularmente en los casos en los que se ha realizado un tratamiento para reducir el impacto ambiental, de modo que la concentración total y, en menor extensión, la concentración potencialmente lixiviable, no son necesariamente limitantes. Un elemento tóxico puede ser menos peligroso, desde el punto de vista ambiental, si se encuentra fijado a la matriz del material que otro que se encuentre en menor cantidad pero que tenga una gran movilidad, es decir, una gran capacidad para pasar del material al medio.

Asimismo, el comportamiento frente a la lixiviación de los diferentes tipos de materiales, está relacionado con factores críticos, como la solubilidad de cada elemento. Esta se encuentra influenciada, a su vez, por el $\mathrm{pH}$, la formación de complejos inorgánicos, la presencia de materia orgánica disuelta, las propiedades de óxido-reducción, etc. Los procesos de lixiviación pueden ocurrir para casi cualquier material aplicado en suelo, en superficie, en contacto con aguas subterráneas, etc.

Existen distintos factores que pueden influenciar la relación en la que los constituyentes son disueltos del material. Según van der Sloot et al. (1997), estos factores pueden ser divididos en físicos, químicos y biológicos (los que generalmente son considerados junto con los químicos):

- Factores físicos

- Tamaño de partícula (relacionado con la superficie expuesta a la lixiviación).

- Homogeneidad o heterogeneidad de la matriz sólida en términos de fases minerales.

- Tiempo de exposición.

- Velocidad de flujo del lixiviante.

- Temperatura.

- Porosidad de la matriz.

- Forma geométrica.

- Permeabilidad de la matriz.

- Condiciones hidrogeológicas.

- Factores químicos y biológicos:

- Equilibrio o control de salida del elemento.

- Potencial de lixiviación de los constituyentes. 
- $\mathrm{pH}$ del material o impuesto por el ambiente.

- Condiciones redox, del material o impuestas por el ambiente.

- Procesos de adsorción.

- Presencia de complejantes.

- Factores biológicos capaces de afectar el pH o condiciones redox.

En términos del comportamiento frente a la lixiviación se distinguen dos tipos de productos: materiales monolíticos y granulares. En los materiales monolíticos el mecanismo de liberación de componentes es controlado principalmente por la difusión, mientras que los materiales granulares suelen presentar un mecanismo controlado por la percolación de agua a través del producto. Los factores que influencian la liberación de contaminantes en ambos tipos de materiales se ejemplifican en las Figuras $10.2 \mathrm{y}$ 10.3 .

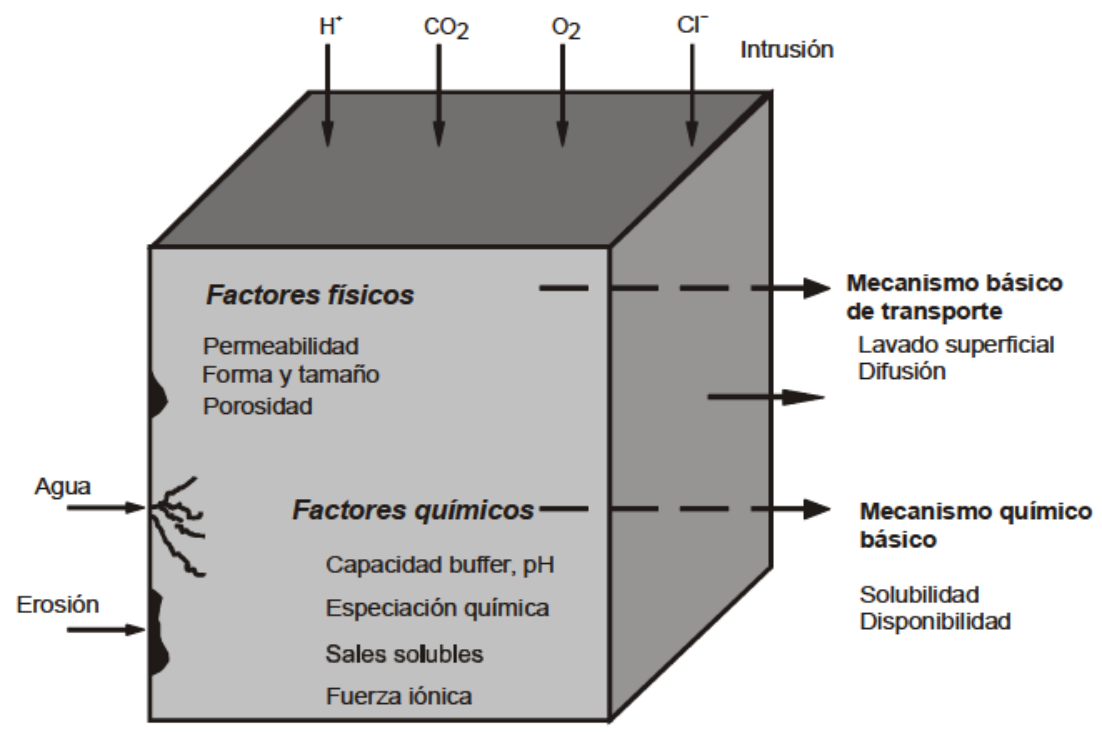

Figura 10.2. Principales factores químicos, físicos y ambientales que afectan la lixiviación en un material monolítico (modificado de van der Sloot and Dijkstra, 2004).

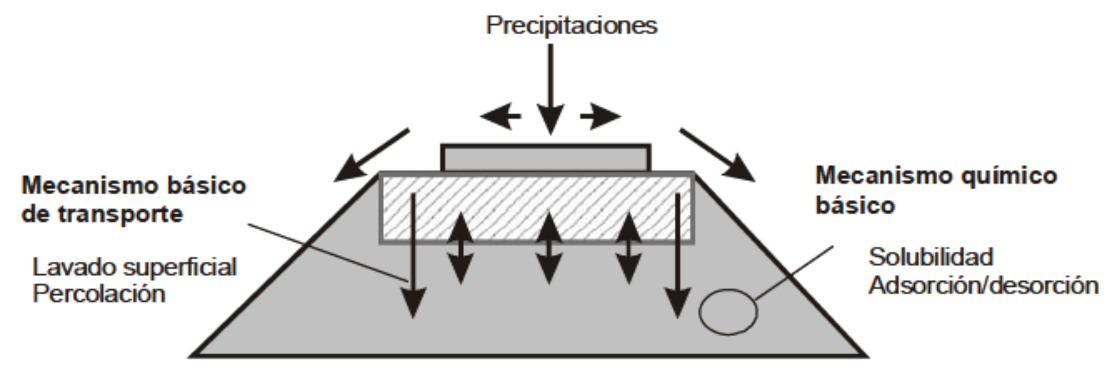
Factores fisicos
Permeabilidad
Tamaño de partícula Porosidad

Factores químicos

$\begin{array}{ll}\text { Capacidad buffer } & \mathrm{pH} \\ \text { Especiación química } & \text { Materia orgánica } \\ \text { Sales solubles } & \text { Fuerza iónica } \\ \text { Potencial redox } & \end{array}$

Figura 10.3. Principales factores químicos, físicos y ambientales que afectan la lixiviación en un material granular (modificado de van der Sloot and Dijkstra, 2004). 
En relación al valor del pH, en general el agua ácida acelera la lixiviación del hormigón, mientras que la alcalina, especialmente si contiene carbonatos, puede ser protectora (Hidalgo y Alonso, 2005). La lixiviación de metales se ha considerado dependiente del pH (Malviya and Chaudhary, 2006); se han realizado estudios de lixiviación de metales en hormigón con soluciones de extracción en el rango de pH 3 a 13 , mostrando que a valores inferiores a 5 se obtienen las concentraciones con mayor lixiviación de metales (Fernández-Olmo et al., 2003; van der Sloot, 2002).

Los ensayos de lixiviación son empleados para simular los escenarios del campo, para evaluar las propiedades específicas de los materiales, tales como, la salida de un elemento que puede ser contaminante (impacto ambiental) (van der Sloot et al., 1997). El lixiviado del ensayo refleja la emisión de contaminantes bajo las condiciones impuestas. Los parámetros que definen un ensayo de lixiviación, son (Pacheco Belzunces, 2009):

- $\quad \mathrm{pH}$ : combinación del pH del lixiviante y la capacidad neutralizadora del material.

- Tamaño de partícula o área expuesta al contacto con el lixiviante.

- Composición del lixiviante.

- Relación entre volumen del lixiviante y masa del material (L/S).

- Tiempo de contacto.

- Muestra representativa (que siga las indicaciones de cada test en cuanto a la preparación requerida y que represente el material que estará expuesto en el medio natural).

- Condiciones del test como temperatura (generalmente temperatura ambiente).

La mayoría de los ensayos de lixiviación disponibles pueden ser agrupados, de acuerdo a sus principales características, en dos categorías (Spence and Shi, 2005; Arevalo Aranda, 2008):

- Ensayos en equilibro o semiequilibrio ("extraction test")

- Se realizan en muestras de tamaño de partícula muy reducido.

- El objetivo es medir la liberación de un contaminante relacionada con condiciones químicas específicas $(\mathrm{pH}$, relación sólido/líquido, etc.) realizando extracciones en una serie.

- Utilizan un sistema de agitación.

- Dentro de esta categoría el mas comúnmente utilizado es el "single batch test", (ejemplo protocolo estandarizado de la EPA TCLP).

- Ensayos dinámicos ("dynamic test")

-Son test más complejos, llevan más tiempo y son más costosos. 
- El objetivo es la determinación de las velocidades de liberación de contaminantes considerando las propiedades físicas y químicas del material.

- Se basan en la transferencia de masa.

- Involucran restitución continua o intermitente del lixiviante, realizando extracciones en varias series de ensayos.

- Dependiendo de las especificaciones del test el material puede ser monolítico o granular.

- Dentro de esta categoría los mas usados son los ensayos denominados "tank leaching test" (ejemplo test NEN 7345) y "columna test".

En la Figura 10.4 se representan los ensayos de lixiviación citados.

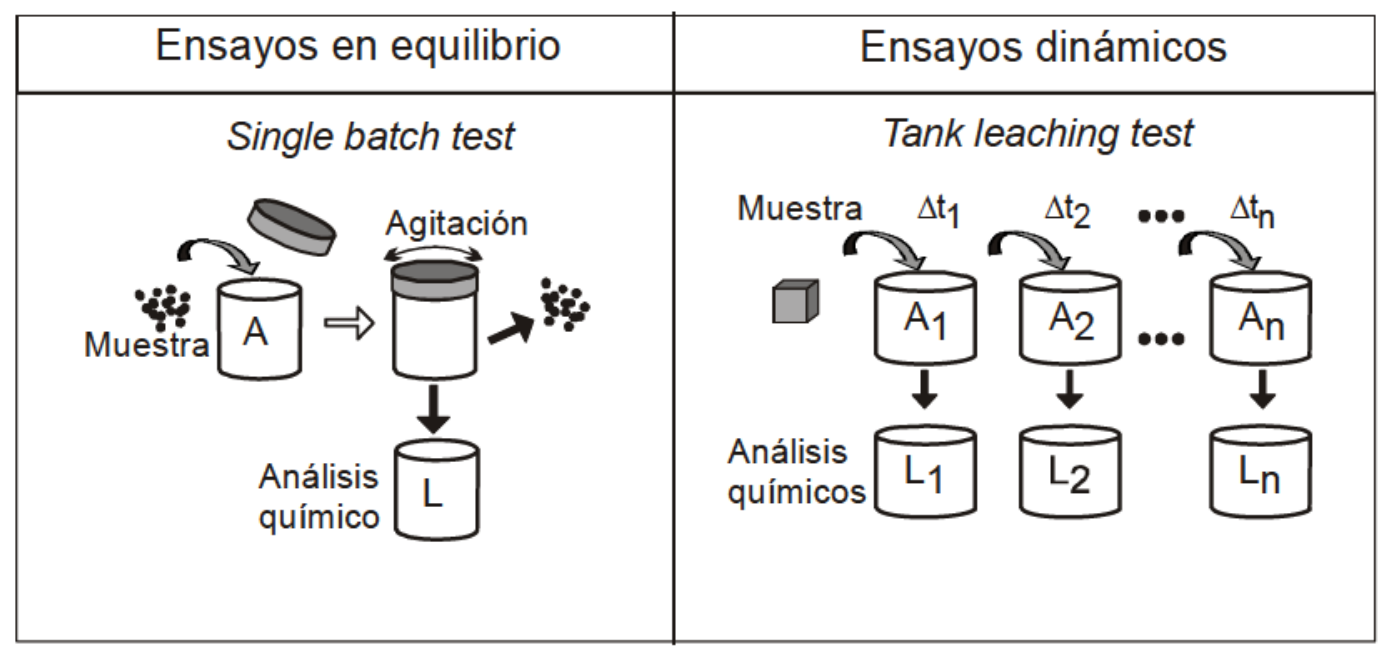

Figura 10.4. Esquema de los ensayos de lixiviación más empleados.

\section{Ensayos de lixiviación empleados en el presente trabajo}

De los numerosos test de lixiviación estandarizados, el test de la EPA TCLP (Method 1311, 1990) es uno de los mas aplicados, ya que determina la movilidad de los contaminantes orgánicos e inorgánicos en la fase en que se encuentren. Sin embargo, si el destino del residuo es el reciclaje, la tendencia actual es someter el material monolítico (bloque del material) al denominado "tank leaching test" (Norma Holandesa NEN 7345) que reproduce con mejor fidelidad el futuro comportamiento del material. Dicho test evalúa la potencialidad del material y la velocidad de lixiviación a lo largo del tiempo. En este trabajo la eficacia en la inmovilización del As en los materiales fueron valorados empleando los test TCLP y NEN 7345. Asimismo, se realizaron estudios en condiciones ácidas extremas.

\section{_ Test EPA TCLP (Toxicity Characteristic Leaching Procedure, Method 1311)}

El test de la EPA TCLP (Method 1311, 1990) es uno de los más usados en EEUU y Europa porque proporciona información sobre las características del residuo y 
constituye un procedimiento de laboratorio sencillo. El ensayo de lixiviación TCLP se ha diseñado para identificar los residuos que probablemente lixivien concentraciones de productos tóxicos al medio ambiente, es decir que determina la movilidad (disponibilidad) de analitos tóxicos orgánicos e inorgánicos en sólidos o en mezclas multifásicas. Los constituyentes son extraídos del residuo de manera tal de simular las condiciones de lixiviación que pueden ocurrir naturalmente cuando el residuo es enterrado. El extracto es luego analizado y si la concentración de un constituyente en particular excede los niveles acordados por las normas vigentes, el residuo se identifica como peligroso. Se considera un criterio internacional aceptado para determinar la no peligrosidad de un residuo.

Esta norma se aplica a suelos expuestos y no expuestos, a residuos, desechos o sedimentos, sólidos y/o líquidos provenientes de diversas industrias.

El procedimiento consiste en triturar la muestra hasta obtener partículas menores de 9,5 mm, estas partículas se mezclan con el líquido de extracción (relación S/L 20) y se agita en extractor rotativo durante $18 \mathrm{hs}$ a $30 \mathrm{rpm}$. Luego del test, sobre el líquido se determinan los elementos lixiviados y se compara el valor con lo establecido en la norma. El test TCLP determina valores guías para 40 diferentes tóxicos orgánicos e inorgánicos, si la concentración de uno de ellos excede el valor establecido, el residuo es considerado peligroso. Para el As la norma establece que el máximo permitido en el lixiviado es de $5 \mathrm{mg} \mathrm{L}^{-1}$.

Como se indicara, el test emplea dos reactivos de extracción:

_ Reactivo 1 (RE1): solución de ácido acético y NaOH de pH: 4,93 \pm 0,05.

_ Reactivo 2 (RE2): solución de acético de pH 2,88 \pm 0,05.

El ácido acético simula los ácidos orgánicos que son producidos en los rellenos de residuos. El criterio para la selección del reactivo de extracción se realiza mezclando la muestra sólida (tamaño $<1 \mathrm{~mm}$ ) con agua destilada desionizada, si el $\mathrm{pH}$ es menor a 5 se utiliza el reactivo de extracción RE1. A un pH superior a 5 , se añaden $3,5 \mathrm{ml}$ de $\mathrm{HCl} 1 \mathrm{~N}$ se calienta a $50^{\circ} \mathrm{C} 10$ minutos, se deja enfriar a temperatura ambiente si el pH es inferior a 5 se utiliza el RE1 y si es igual o superior a 5 se usa el reactivo de extracción RE2.

En el esquema de la Figura 10.5 se representan los pasos a seguir en la realización del método. 


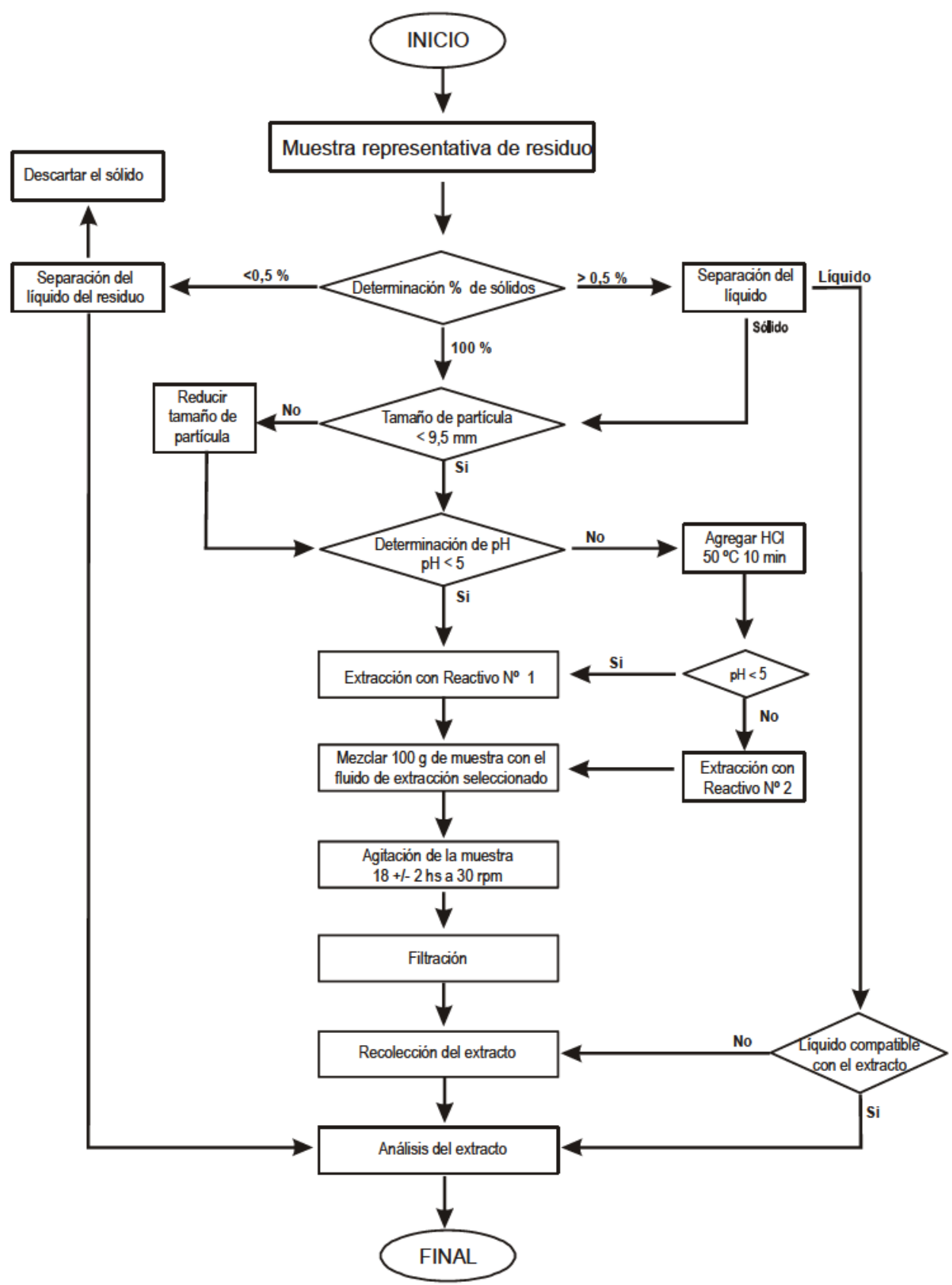

Figura 10.5. Esquema de los pasos a seguir para la realización del test TCLP.

\section{_ Notherlands Tank Leaching Test, NEN 7345}

El ensayo NEN 7345 ("Notherlands Tank Leaching Test") permite obtener información sobre los mecanismos de lixiviación de los materiales de construcción, residuos monolíticos y residuos estabilizados. Este ensayo ha sido diseñado para determinar las características de lixiviación de componentes inorgánicos en materiales de construcción. La salida de los elementos del sólido monolítico se obtiene colocando una pieza en agua acidificada y a tiempos fijados determinando la concentración de los elementos en el lixiviado. El resultado es expresado por el flujo másico acumulado de cada elemento por unidad de superficie (expresado en $\mathrm{mg} \mathrm{m}^{-2}$ ). 
La dimensión mínima de la pieza tiene que ser mayor que $40 \mathrm{~mm}$. El ensayo se realiza a temperatura ambiente, colocando la pieza en un recipiente cilíndrico de plástico cerrado y llenándolo con agua acidificada a pH 4 (con $\mathrm{HNO}_{3}$ ), de manera que la pieza quede cubierta por un volumen de lixiviante 5 veces mayor que el volumen de la pieza. El líquido lixiviante se renueva a intervalos específicos de tiempo, de acuerdo con la Tabla 10.1 (NEN 7345, 1995).

Tabla 10.1. Períodos de tiempo para la renovación del lixiviante en el test NEN 7345.

\begin{tabular}{c|c}
\hline Periodo $(\mathrm{n})$ & Tiempo (días) \\
\hline 1 & $0,25 \pm 10 \%$ \\
2 & $1 \pm 10 \%$ \\
3 & $2,25 \pm 10 \%$ \\
4 & $4 \pm 10 \%$ \\
5 & $9 \pm 10 \%$ \\
6 & $16 \pm 1$ \\
7 & $36 \pm 1$ \\
8 & $64 \pm 1$ \\
\hline
\end{tabular}

En cada extracción se toman dos muestras, una para la determinación de los elementos estudiados (en este trabajo As) y otra para la determinación de $\mathrm{pH}$ y conductividad. El pH y la conductividad se determinan para evaluar si la matriz se disuelve durante la realización del test. El valor de $\mathrm{pH}$ da idea de la alcalinidad de la pieza estudiada y los cambios de $\mathrm{pH}$ durante el test dan idea de la estabilidad del material. Grandes variaciones indican que no ha sido estabilizado.

Para la valoración ambiental del material se calcula la lixiviación de cada contaminante en cada período según la siguiente expresión:

Siendo:

$$
E_{i}=\frac{C_{i} \cdot V}{1000 \cdot A}
$$

$E_{i}$ : lixiviación medida para cada componente en el período i $\left(\mathrm{mg} \mathrm{m}^{-2}\right)$.

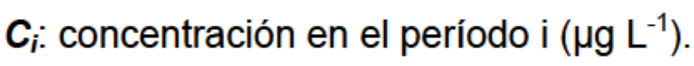

$V$ : volumen del líquido lixiviante $(\mathrm{L})$.

$\boldsymbol{A}$ : área de la pieza utilizada $\left(\mathrm{m}^{2}\right)$.

La lixiviación acumulada se calcula como la suma de las 8 extracciones realizadas, según la expresión:

$$
\varepsilon_{n}=\sum i=1^{n}\left(E_{i}\right)
$$

Siendo:

$\varepsilon_{n}$ : lixiviación acumulada de cada elemento.

$n$ : número de períodos (8). 
La legislación holandesa clasifica los materiales por medio de dos categorías según los valores de lixiviación acumulada:

- Categoría 1: materiales que presentan valores de $\varepsilon_{n}$ por debajo de los límites establecidos como U1 (umbral 1). No presentan ninguna restricción ambiental para su utilización.

- Categoría 2: materiales que presentan valores de $\varepsilon_{n}$ por encima de los límites establecidos como U2 (umbral 2). Tienen su aplicación restringida.

Los materiales que presentan $\varepsilon_{n}$ entre $\mathrm{U} 1$ y U2 no presentan restricción ambiental para su utilización pero están obligados a extraer el contaminante que supera el límite U1, cuando se acabe la vida útil del material.

Los valores límites para el As son los siguientes:

- $\mathrm{U} 1: 40 \mathrm{mg} \mathrm{m}^{-2}$

- $\mathrm{U} 2: 300 \mathrm{mg} \mathrm{m}^{-2}$

\subsubsection{Características físicas de las piezas elaboradas}

El hormigón o concreto tradicional está compuesto por cemento (aglomerante), agua y áridos, de los cuales cada uno de ellos, estará presente en la mezcla en una determinada proporción (Sánchez de Guzmán, 2001; Smith, 1998).

El cemento es el componente activo de la mezcla de hormigón; al reaccionar éste con el agua se forma la pasta de cemento, que tiene como función principal la de aglomerar los áridos, para formar una pasta homogénea y cohesiva. La pasta es la que produce el endurecimiento del hormigón, debido a la reacción química entre el cemento y el agua. Este proceso se conoce como fraguado. El cemento se hidrata en contacto con el agua, iniciándose una serie de reacciones químicas que lo convierten en un producto maleable con buenas propiedades adherentes, que en el transcurso de unas horas, derivan en el endurecimiento progresivo de la mezcla.

Por su parte, los áridos proceden de la trituración, natural o artificial de rocas. El árido cuyo tamaño es superior a $5 \mathrm{~mm}$ se llama árido grueso (grava), mientras que el inferior a $5 \mathrm{~mm}$ se llama árido fino (arena). No participan de la reacción química del agua con el cemento. Forman el esqueleto inerte de la estructura y proporcionan rigidez al hormigón; son responsables de la durabilidad y estabilidad del hormigón en el tiempo. La adición de arena a la pasta de cemento forma el mortero, material que también es de interés en este trabajo, y la adición de agregados gruesos produce el hormigón. 
El agua confiere plasticidad y trabajabilidad en estado fresco, además de hidratar al aglomerante y ayudar en el curado del hormigón. Finalmente, a estos componentes básicos se pueden añadir aditivos para mejorar algunas propiedades del hormigón.

Las características físicas de las piezas elaboradas dependen no sólo de la propia naturaleza de ésta sino, también, de su edad y de las condiciones de humedad y temperatura utilizadas en el curado. Por lo expuesto, se ha trabajado con piezas mantenidas en las mismas condiciones para poder realizar la comparación de sus propiedades.

La principal característica estructural del hormigón es que resiste muy bien los esfuerzos de compresión, pero no tiene buen comportamiento frente a otros tipos de esfuerzos (tracción, flexión, etc.). Las propiedades del hormigón y del mortero se estudian primordialmente con la finalidad de determinar el diseño de la mezcla (Sánchez de Guzmán, 2001). En este trabajo se han determinado las siguientes propiedades mecánicas de morteros y hormigones:

\section{Resistencia a compresión}

El ensayo de rotura a la compresión es el más importante que se realiza al hormigón, debido a que es un material que, generalmente, va a trabajar a compresión.

Los ensayos sobre hormigón endurecido, cuya finalidad es determinar las características mecánicas del mismo, no tienen una normativa universal, de aquí que cada país disponga de la suya propia, con lo cual, los valores obtenidos, para un mismo hormigón, pueden ser muy dispares.

En los ensayos destructivos, la resistencia a la compresión se mide fracturando probetas cilíndricas del material en una máquina de ensayos de compresión. La resistencia a la compresión se reporta en $\mathrm{kg} \mathrm{cm}^{-2} \circ \mathrm{MPa}\left(\mathrm{N} \mathrm{m}^{-2}\right)$. Las medidas generalmente se realizan a una edad de 28 días.

En hormigones (también en pastas y morteros) la resistencia depende de la porosidad, a mayor porosidad menor resistencia. A su vez, la porosidad depende directamente de la relación agua/cemento, parte del agua reacciona con el cemento para formar la pasta, las reacciones de hidratación se dan a lo largo del tiempo y los productos de la misma van llenando los espacios y reduciendo la porosidad inicial.

La resistencia del hormigón puede ser garantizada si las probetas para el ensayo por compresión son confeccionadas, protegidas y curadas siguiendo métodos normalizados. De este modo los ensayos de rotura por compresión sobre probetas normalizadas, sirven para determinar la calidad del hormigón. Si, en cambio, varían las 
condiciones de muestreo, métodos de llenado, compactación terminación y curado de las probetas no podrá determinarse si eventuales resistencias bajas son debidas a la mala calidad del hormigón o a las fallas cometidas durante las operaciones de preparación de las probetas, previas al ensayo.

Para obtener resultados adecuados se deben usar moldes indeformables, no absorbentes, estancos y de materiales que no reaccionen con el cemento. Antes de llenar los moldes, deberán ser colocados sobre una superficie horizontal, rígida y lisa. Las probetas deben dejarse almacenadas, sin desmoldar durante 24 horas, en condiciones de temperatura ambiente, evitando movimientos, golpes, vibraciones y pérdida de humedad. Una vez fraguado el hormigón, las probetas se desmoldan y transportan al laboratorio para su curado.

El hormigón de uso general tiene un valor de resistencia a compresión entre 200 a $400 \mathrm{~kg} \mathrm{~cm}^{-2}$ (20 a $40 \mathrm{MPa}$ ), mientras que un hormigón de alta resistencia, presenta un valor mayor a $700 \mathrm{~kg} \mathrm{~cm}^{-2}$ (70 MPa).

\section{Densidad}

La densidad o masa específica del hormigón endurecido depende de muchos factores, principalmente de la naturaleza de los áridos, de su granulometría y del método de compactación empleado. Será tanto mayor cuanto mayor sea la cantidad de áridos utilizados y mayor cantidad de árido grueso contenga, y tanto mayor cuanto mejor compactado esté.

En menor escala influye en la densidad la relación agua/cemento, debido a que cuanto mayor sea ésta más poroso será el hormigón por lo que contendrá mayor cantidad de huecos, de aquí el descenso de la densidad.

El grado de compactación también influye en la densidad, ya que la función de la compactación es la eliminación de las burbujas de aire y el ordenamiento de las partículas para ir juntando en la medida de lo posible la masa de hormigón, por lo que la densidad será tanto mayor cuanto mayor sea la energía consumida en la compactación.

Los aditivos aireantes influyen también de forma negativa en la densidad al incluir en la masa del hormigón burbujas de aire.

De todas formas, las variaciones de densidad del hormigón son pequeñas, los valores se encuentran en torno a los $2300-2500 \mathrm{~kg} \mathrm{~m}^{-3}\left(2,3-2,5 \mathrm{~g} \mathrm{~cm}^{-3}\right)$.

\section{Resistencia a flexión}


La resistencia a flexión es una medida de la resistencia a la tracción del hormigón. El ensayo tiene como objetivo determinar la resistencia a flexión del hormigón endurecido, mediante la aplicación uniforme de carga en una probeta prismática a través de rodillos que trasmiten la presión perpendicular a la probeta apoyada sobre otros dos rodillos (Foto 10.1).

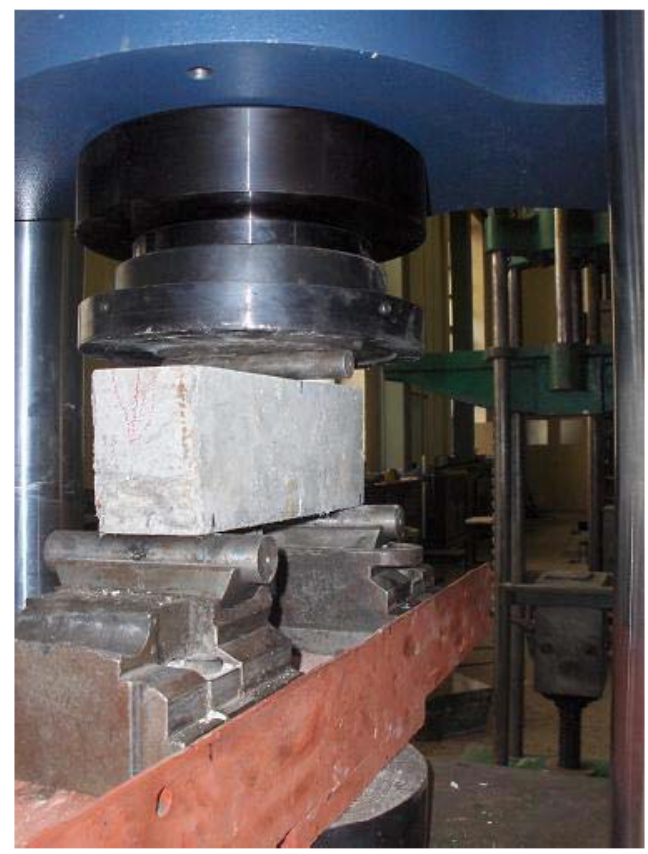

Foto 10.1. Equipo empleado en la determinación de la resistencia a flexión.

La resistencia a la flexión se expresa como el Módulo de Rotura (MR) en MPa y es determinada por métodos de ensayos normalizados. En el ensayo de carga en el punto medio, toda la carga se aplica en el centro de la probeta (Foto 10.1). El esfuerzo máximo y la deformación máxima se calculan para incrementos de carga. Los resultados se trazan en un diagrama esfuerzo-deformación y el esfuerzo máximo en el punto de ruptura es la resistencia a la flexión. El MR es cerca del 10 al $20 \%$ de la resistencia a compresión.

Los ensayos a flexión son extremadamente sensibles a la preparación, manipulación y curado de las probetas. Las medidas, al igual que los ensayos de compresión, generalmente se realizan a una edad de 28 días.

\subsection{Experimental}

\subsubsection{Preparación de las piezas}

Se exploraron diversas alternativas de disposición del residuo generado, siempre teniendo en cuenta la búsqueda de soluciones de fácil implementación en zonas rurales, que incluyen la inmovilización a través del uso de altas temperaturas o de la adición de cemento Portland. 
En una primera instancia, se analizaron las características de piezas preparadas con arcilla original a fin de determinar las condiciones óptimas de mezclado, según corresponda, con arena, cemento, grava y agua para optimizar la preparación de piezas. Posteriormente, se prepararon piezas utilizando en su composición distintas proporciones de arcilla procedente del tratamiento de remoción de arsénico.

Se consideraron como opciones de mezclas:

a) Combinaciones de arcilla + agua ( $\mathrm{y}$ eventualmente arena) para fabricar pequeñas placas (asimilables a ladrillos) y pequeñas esferas (asimilables a agregados livianos que después podrían incorporarse a hormigones) que luego fueron expuestas a distintas temperaturas.

b) Arcilla + cemento Portland + agua (y eventualmente + arena y + agregado grueso) para fabricar prismas de $40 \times 40 \times 160 \mathrm{~mm}$ (asimilables a bloques y otros elementos utilizados en la construcción), pequeñas esferas, y prismas de $75 \times 105 \times$ $430 \mathrm{~mm}$ (en el caso de los hormigones), curados con humedad a $20^{\circ} \mathrm{C}$.

\subsubsection{Materiales empleados en la preparación}

Los materiales utilizados en las mezclas fueron:

a) Arcilla original sin tratamiento con agua contaminada. Denominada 3AFO.

b) Arcillas ferruginosas tratadas procedentes del tratamiento de remoción de arsénico. Denominadas 3AFT y 7AFT. Estas arcillas proceden del tratamiento en planta piloto, según el esquema de la Figura 6.55 , utilizando $100 \mathrm{~kg}$ del material original (3AFOmolienda gruesa y 7AFO-molienda fina) y 1000 litros de agua conteniendo $1000 \mathrm{\mu g} \mathrm{L}^{-1}$ de As (preparada con agua de red y agregado de As). La arcilla 3AFT resultó útil por 23 ciclos, en tanto que la 7AFT permaneció activa durante 32 ciclos.

c) Cemento: Se usó cemento Portland normal. Se lo identifica como CP.

d) Arena: Se utilizó arena silícea natural.

e) Agua: La consolidación de la mezcla se logra mediante el empleo de agua potable obtenida de la red de abastecimiento municipal de la ciudad de La Plata.

f) Agregado grueso granítico: de $12 \mathrm{~mm}$ de tamaño máximo.

\subsubsection{Mezclas elaboradas}

En la Tabla 10.2 se muestra la identificación y proporciones (\% en peso) de las mezclas elaboradas. Se han preparado, pastas, morteros y hormigones. En la tabla se ha empleado la siguiente nomenclatura:

P: Pasta: arcilla ó arcilla y cemento + agua.

$\mathrm{P}_{\mathrm{A}}$ : pasta compuesta por arcilla + agua.

$\mathrm{P}_{\mathrm{AC}}$ : pasta compuesta por arcilla y cemento + agua. 
M: Morteros: arena, cemento y arcilla + agua.

$\mathrm{H}$ : Hormigones: arena, cemento, arcilla y grava + agua.

Las piezas denominadas $\mathrm{P}_{\mathrm{A}} 1, \mathrm{P}_{\mathrm{AC}} 2, \mathrm{M} 1$ y $\mathrm{H}_{1}$ fueron elaborados con la arcilla original $3 \mathrm{AFO}$. En la preparación de las pastas $\mathrm{P}_{\mathrm{AC}} 3$ a 5 y de los morteros $\mathrm{M} 2$ a 4 se empleó la arcilla tratada 3AFT, mientras que la arcilla tratada 7AFT fue empleada para la realización de los hormigones $\mathrm{H}_{2}$ a $\mathrm{H}_{5}$.

En el caso de las pastas $\mathrm{P}_{\mathrm{AC}} 4$ y $\mathrm{P}_{\mathrm{AC}} 5$ y los morteros $\mathrm{M} 3$ y $\mathrm{M} 4$ se utilizó la arcilla tratada luego de ser secada en estufa a $500^{\circ} \mathrm{C}$ durante 1 hora. Para la elaboración de las restantes piezas $\left(\mathrm{P}_{\mathrm{AC}} 3, \mathrm{M} 2\right.$ y H 2 a 5) se empleó directamente el barro producto del tratamiento de eliminación de As.

Tabla 10.2. Proporciones de las mezclas elaboradas y programa de ensayos.

\begin{tabular}{|c|c|c|c|c|c|c|c|c|c|c|c|c|}
\hline \multirow[t]{2}{*}{ Mezcla } & \multirow[t]{2}{*}{$\mathrm{P}_{\mathrm{A}} 1$} & \multirow[t]{2}{*}{$\mathrm{P}_{\mathrm{AC}} 2$} & \multicolumn{2}{|c|}{$\mathrm{P}_{\mathrm{AC}} 3$ a 5} & \multirow[t]{2}{*}{ M1 } & \multirow[t]{2}{*}{$\mathrm{H}_{1}$} & \multicolumn{2}{|c|}{ M2 a 4} & \multirow[t]{2}{*}{$\mathrm{H}_{2}$} & \multirow[t]{2}{*}{$\mathrm{H}_{3}$} & \multirow[t]{2}{*}{$\mathrm{H}_{4}$} & \multirow[t]{2}{*}{$\mathrm{H}_{5}$} \\
\hline & & & 34 & 5 & & & 23 & 4 & & & & \\
\hline Agua/CP & & 1,87 & 1,87 & 1 & 0,52 & 0,52 & 0,40 & 0,80 & 1,05 & 0,76 & 0,91 & 0,88 \\
\hline Agua/(CP+arcilla) & & 0,18 & 0,18 & 0,17 & 0,25 & 0,25 & 0,25 & 0,25 & 0,50 & 0,50 & 0,53 & 0,57 \\
\hline Agua & 13 & 15 & 15 & 14 & 12 & 12 & 12 & 12 & 19 & 13 & 10 & 15 \\
\hline $3 \mathrm{AFO}$ & 87 & 77 & & & 23 & 23 & & & & & & \\
\hline AFT & & & 77 & 72 & & & 25 & 35 & 18 & 10 & 7 & 10 \\
\hline $\mathrm{CP}$ & & 8 & 8 & 14 & 23 & 23 & 25 & 15 & 18 & 17 & 11 & 17 \\
\hline Arena & & & & & 42 & 23 & 38 & 38 & 18 & 26 & 23 & 16 \\
\hline Grava & & & & & & 19 & & & 27 & 34 & 49 & 42 \\
\hline
\end{tabular}

\subsubsection{Elaboración de las piezas}

En la Figura 10.6 se muestran los pasos seguidos para la elaboración de las probetas de morteros y hormigones, según las dosificaciones indicadas en la Tabla 10.2 .

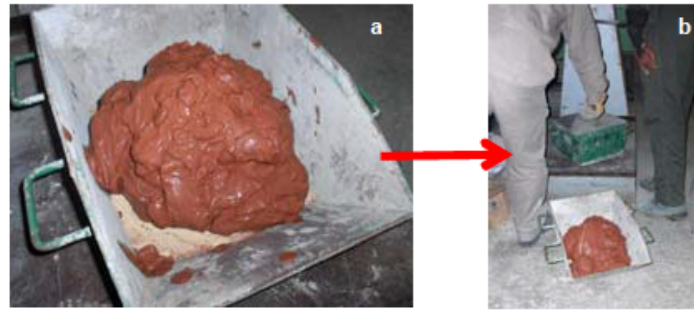

Barro de AFT

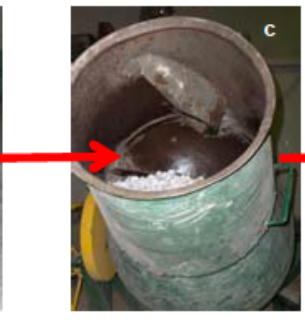

Mezclado

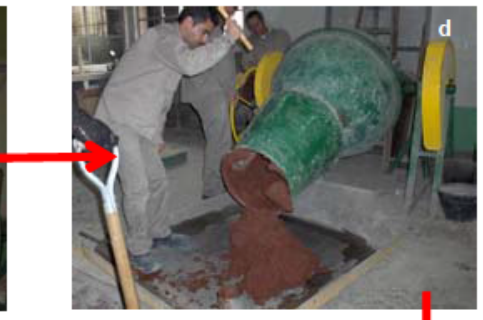

Obtención de la mezcla

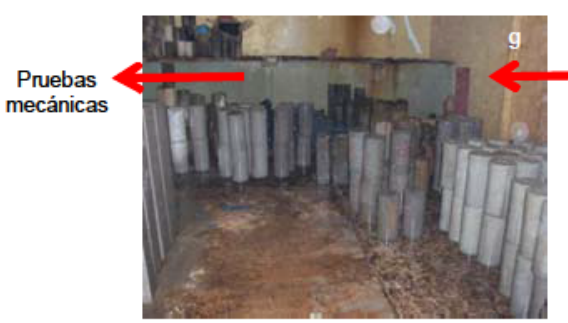

Fraguado en cámara húmeda

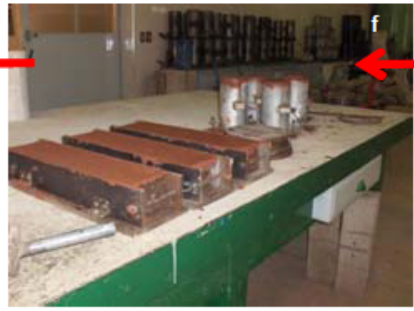

Las probetas se dejan secar $24 \mathrm{hs}$

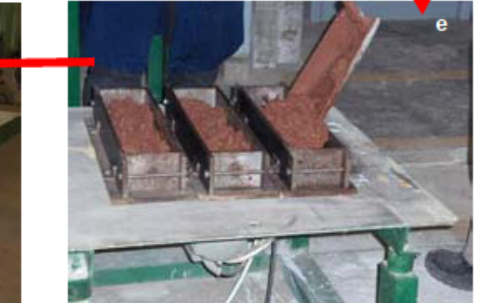

Lenado de las probetas

Figura 10.6. Esquema de preparación de las probetas. 
Para la preparación de las piezas, en el caso de las arcillas tratadas se recuperó el barro del tratamiento y se utilizó en dos condiciones: primero se consideró el empleo del barro secado al aire, que fue triturado manualmente, y en una segunda instancia se planteó la elaboración de morteros y hormigones utilizando directamente el barro que se observa en la Figura 10.6.a.

Las piezas han sido producidas en una mezcladora (Figura 10.6.c), en la que son introducidos alternativamente los distintos materiales que fueran previamente pesados (Figura 10.6.b). Los materiales han sido incorporados a medida que los que ya estaban en la mezcladora se presentaban homogéneos. El tiempo de mezclado fue aproximadamente de 15 minutos, luego el material fue volcado (Figura 10.6.d) y se llenaron las probetas (10.6.e).

Se han utilizado probetas cilíndricas y prismáticas que han sido compactadas en una máquina vibratoria y se dejaron secar durante 24 hs (Figura 10.6.f). Las probetas fueron desmoldadas a las 24 horas y llevadas a cámara húmeda (temperatura $20 \pm 2$ ${ }^{\circ} \mathrm{C}$ ) donde se dejaron fraguar hasta la edad del ensayo (Figura 10.6.g).

\subsubsection{Evaluación mecánica de las piezas}

\subsubsection{Exposición a temperatura}

Para la consolidación por exposición a alta temperatura se utilizó un horno eléctrico con control automático de temperatura y ventilación superior para permitir el escape de gases, aumentando progresivamente la temperatura a razón de $100{ }^{\circ} \mathrm{C}$ por hora. Luego de mantener el horno a la máxima temperatura deseada durante una hora, las muestras fueron enfriadas dentro del mismo.

Se prepararon placas de pasta empleando la arcilla tratada 7AFT y agua, en una proporción similar a la utilizada con $P_{A} 1$. Este nuevo material se denominó $P_{A} 2$. Las mismas fueron secadas a temperatura ambiente y luego fueron sometidas a distintas temperaturas:

$$
\begin{aligned}
& P_{A} \text { 2.1: sin tratamiento térmico } \\
& P_{A} 2.2: 900^{\circ} \mathrm{C} 1 \text { hora } \\
& P_{A} 2.3: 1000^{\circ} \mathrm{C} 1 \text { hora } \\
& P_{A} 2.4: 1100^{\circ} \mathrm{C} 1 \text { hora }
\end{aligned}
$$

Posteriormente se evaluaron la estabilidad de las piezas introduciéndolas en agua y el efecto de la temperatura sobre la estabilidad del As determinando el elemento mediante análisis químico del material. 


\subsubsection{Ensayos mecánicos}

Se realizaron evaluaciones de módulo de rotura a flexión (MR) y resistencia a compresión ( $f^{\prime} \mathrm{c}$ ) empleando prismas de $40 \times 40 \times 160 \mathrm{~mm}$ para las pastas y los morteros y de $105 \times 75 \times 430 \mathrm{~mm}$ para los morteros, siguiendo los lineamientos generales de la norma IRAM 1622 (IRAM, 1962). Además se realizaron determinaciones de absorción en agua (24 h) y densidad.

En el caso de los hormigones se aserraron pequeños prismas de $30 \times 45 \times 265$ $\mathrm{mm}$ que fueron expuestos a ciclos de mojado y secado para valorar la estabilidad dimensional.

\subsubsection{Caracterización fisicoquímica}

Los materiales de partida y algunas de las mezclas preparadas se caracterizaron por distintas técnicas fisicoquímicas de análisis como DRX y análisis químico de elementos mayoritarios por ICP-EAS y de As por ICP-MS.

\subsubsection{Ensayos de lixiviación}

En los casos donde las características fisicoquímicas y mecánicas resultaron adecuadas, se realizaron pruebas de lixiviación a fin de evaluar la cantidad de As que puede ser solubilizada.

10.2.4.1. Ensayos preliminares para determinar la estabilidad de hormigones en condiciones extremas (ácidos fuertes)

En una primera instancia, se evaluó la estabilidad del hormigón $\mathrm{H}_{1}$ realizaron ensayos de lixiviación en condiciones extremas atacando pequeños bloques $(4 \mathrm{~cm}$ de lado) con $\mathrm{H}_{2} \mathrm{SO}_{4}$ y $\mathrm{HCl} 1 \mathrm{M}$ durante 10 días. Las características del ensayo se resumen en la Tabla 10.3.

Tabla 10.3 Condiciones del ensayo de lixiviación con ácidos fuertes.

\begin{tabular}{l|c|c}
\cline { 2 - 3 } & $\mathrm{HCl}$ & $\mathrm{H}_{2} \mathrm{SO}_{4}$ \\
\hline Volumen lixiviante $(\mathrm{ml})$ & 150 & 150 \\
$\mathrm{~m}_{\text {muestra }}$ (g) & 55,97 & 59,49 \\
Tiempo (días) & 10 & 10 \\
\hline
\end{tabular}

Transcurrido el tiempo de contacto, el líquido fue filtrado con membrana de 0,45 $\mu \mathrm{m}$ y se determinó el contenido de As por el método EPA SW 846 M 7061A (límite de detección $0,003 \mathrm{mg} \mathrm{L}^{-1}$ ). Se calculó el porcentaje de retención de arsénico empleando la relación:

\% Retención As: As inicial en la muestra (mg) - As lixiviado (mg) X 100 As inicial en la muestra $(\mathbf{m g})$ 


\subsubsection{Test de lixiviación EPA 1311 (TCLP)}

Estos ensayos se realizaron para las muestras AFT (arcillas tratadas) y para todas las muestras de hormigones y las piezas que presentaron mejores características mecánicas M3, M4 y $\mathrm{P}_{\mathrm{AC}} 5$. En el procedimiento se siguieron los pasos indicados en la Figura 10.5 (ítem 10.1.2).

El test utiliza uno de los siguientes reactivos de extracción:

_ Reactivo 1 (RE1): $5,7 \mathrm{ml}$ de ácido acético glacial $+64,3 \mathrm{ml}$ de $\mathrm{NaOH} 1 \mathrm{~N}$ que se llevan a $1 \mathrm{~L}$ con $\mathrm{H}_{2} \mathrm{O}$ destilada. $\mathrm{pH}: 4,93 \pm 0,05$.

_ Reactivo 2 (RE2): 5,7 ml de ácido acético glacial llevado a $1 \mathrm{~L}$ con $\mathrm{H}_{2} \mathrm{O}$ destilada. $\mathrm{pH}: 2,88 \pm 0,05$.

Para seleccionar el reactivo a emplear se procedió según lo indicado en el ítem 10.1.2. Una vez seleccionado el reactivo de extracción se procedió al ensayo de lixiviación siguiendo los siguientes pasos:

1) Las muestras fracturadas provenientes de los ensayos de resistencia fueron molidas hasta obtener una granulometría $<9,5 \mathrm{~mm}$. Se pesaron $100 \mathrm{~g}$ y se colocaron en un recipiente de vidrio.

2) Se agregaron $2000 \mathrm{ml}$ del reactivo de extracción seleccionado. Relación S/L 1:20 (100 g de muestra y $2000 \mathrm{ml}$ de reactivo de extracción).

3) Se cerró el frasco herméticamente (tapón con cinta de teflón y parafilm).

4) Se introdujo en un equipo de agitación rotatorio a $60 \mathrm{rpm}$ durante 18 hs a T 23 $\pm 2{ }^{\circ} \mathrm{C}$. En la Foto 10.2 se observan las características del equipo empleado que fuera facilitado por la UTN Regional La Plata.

5) Se filtró la muestra. Cuando fuera necesario las muestras fueron conservadas en frascos de plástico y acidificadas a un $\mathrm{pH}<\mathrm{a} 2$ con $\mathrm{HNO}_{3}$.

6) Se determinó el contenido de As en el lixiviado por el método EPA SW 846 M $7061 \mathrm{~A}$. Se calculó el porcentaje de retención de arsénico empleando la ecuación 10.3.

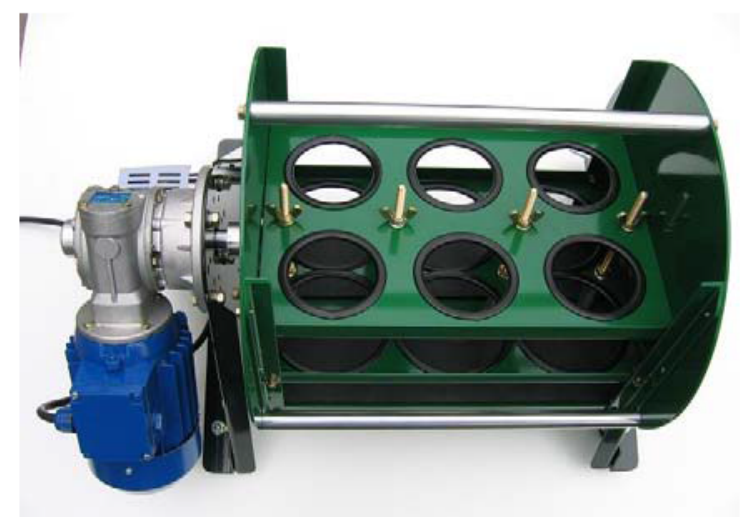

Foto 10.2. Equipo de agitación empleado en el test 1311. 


\subsubsection{Test monolítico NEN 7345}

El test se realizó para todas las muestras de hormigones. El ensayo se realizó a temperatura ambiente, colocando la pieza en un recipiente cilíndrico de plástico soportada sobre una arandela también de plástico, de forma que toda la pieza quede rodeada por el lixiviante. El volumen de líquido utilizado fue de 5 veces el volumen de la pieza, en algunos casos se utilizó un exceso para lograr que la pieza quedara completamente sumergida según las indicaciones de la norma. El recipiente se tapó con papel film y luego se cerró herméticamente. El líquido de extracción se renovó en los tiempos indicados en la Tabla 10.1. Se realizó un control con un recipiente sin muestra de hormigón.

El líquido lixiviante se preparó a partir de una solución comercial de $\mathrm{HNO}_{3}$ (c). Los valores iniciales determinados para el líquido lixiviante son: $\mathrm{pH}$ : 3,97 y Conductividad: $57,9 \mu \mathrm{S} \mathrm{cm} \mathrm{cm}^{-1}$. En la Tabla 10.4 se indican las condiciones para cada muestra analizada.

Tabla 10.4. Condiciones empleadas para la realización del test NEN7345.

\begin{tabular}{c|c|c|c|c}
\hline Hormigón & Dimensiones $(\mathrm{cm})$ & Área $\left(\mathrm{cm}^{2}\right)$ & V muestra $\left(\mathrm{cm}^{3}\right)$ & V lixiviante $(\mathrm{ml})$ \\
\hline $\mathrm{H}_{1}$ & $6 \times 5,3 \times 3,5$ & 142,7 & 111,3 & 556,5 \\
$\mathrm{H}_{2}$ & $5 \times 5 \times 5$ & 150,0 & 125,0 & 675,0 \\
$\mathrm{H}_{3}$ & $5 \times 5 \times 5$ & 150,0 & 125,0 & 675,0 \\
$\mathrm{H}_{4}$ & $5 \times 5 \times 5$ & 150,0 & 125,0 & 675,0 \\
$\mathrm{H}_{5}$ & $5 \times 5 \times 5$ & 150,0 & 125,0 & 675,0 \\
\hline
\end{tabular}

A cada tiempo se tomaron dos alícuotas:

1) Se midió el pH y la conductividad con los equipos indicados en el Capítulo 5.

2) Se filtró, se acidificó con $\mathrm{HNO}_{3}$ a pH 2 y se determinó As por el método EPA SW 846 M 7061A. Se calculó la lixiviación de As en cada período según la ecuación (10.1) y la lixiviación acumulada de As empleando la ecuación (10.2)

Adicionalmente se ha determinado el Fe por Absorción Atómica empleando un equipo Perkin Elmer 3110. El Fe no es considerado como contaminante en la norma, pero podría ser lixiviado dando idea de la unión del As a la matriz arcillosa.

\subsection{Resultados y discusión}

\subsubsection{Caracterización fisicoquímica}

En la Tabla 10.5 se presentan los datos del análisis químico de algunas de las piezas elaboradas y de los materiales de partida empleados en su preparación. Los pequeños incrementos en los porcentajes de algunos óxidos de las muestras tratadas respecto a las originales se deben a que las muestras fueron secadas luego de los ciclos de tratamiento. 


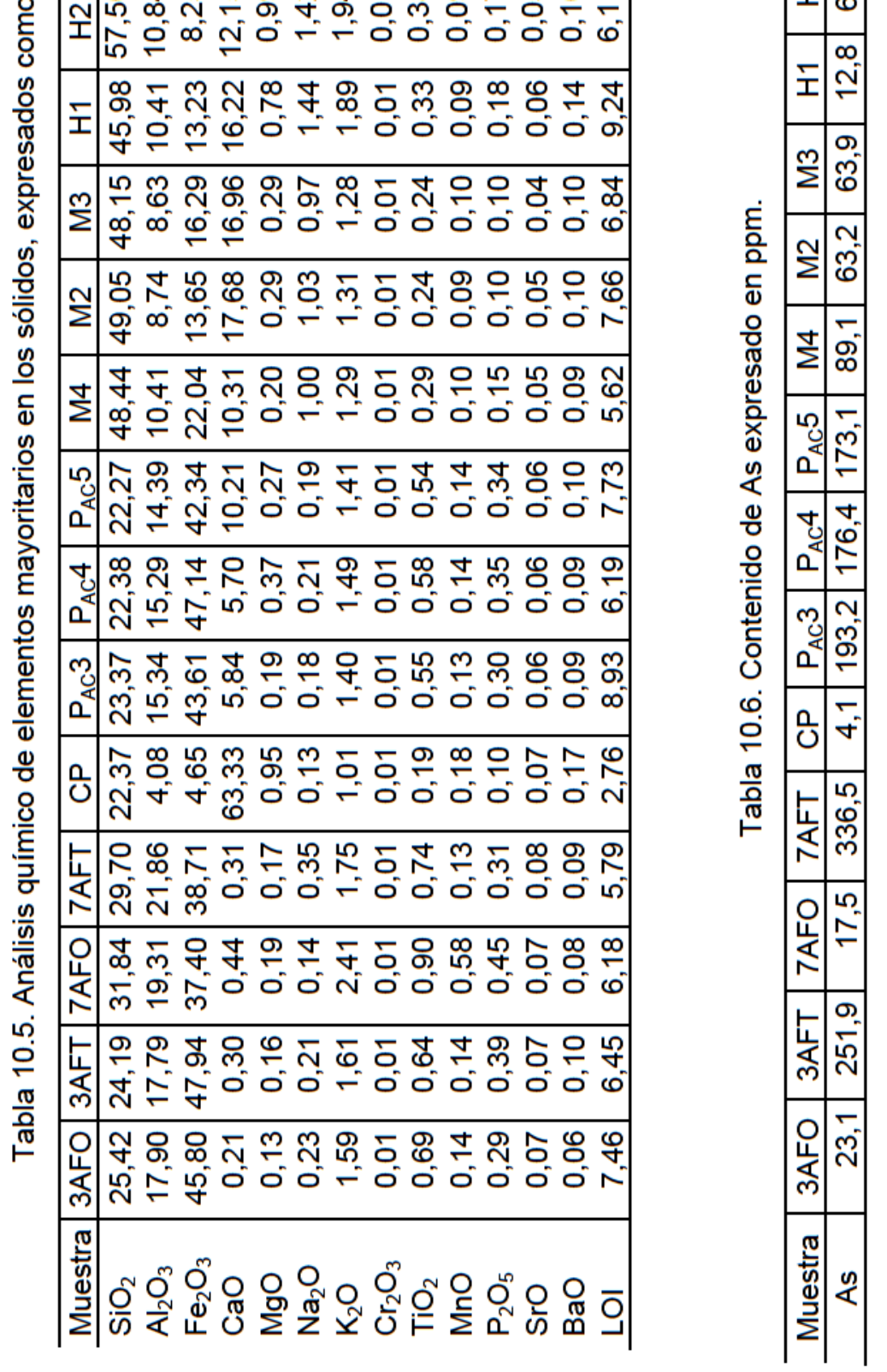


Respecto a las muestras $\mathrm{P}_{\mathrm{AC}} 3$ a 5 preparadas con arcilla $3 \mathrm{AFT}$ en mayor proporción que cemento, las pequeñas disminuciones en el contenido de $\mathrm{SiO}_{2}, \mathrm{Al}_{2} \mathrm{O}_{3}$ y $\mathrm{Fe}_{2} \mathrm{O}_{3}$ son debidas al agregado de cemento, que también es el responsable del aumento en el contenido de $\mathrm{CaO}$. Esto es más evidente en la muestra $\mathrm{P}_{\mathrm{AC}} 5$ que presenta mayor contenido de cemento en su formulación.

No se observan diferencias significativas entre las muestras $\mathrm{P}_{\mathrm{AC}} 3$ y $\mathrm{P}_{\mathrm{AC}} 4$ de igual formulación pero distinta temperatura. En relación a los morteros preparados con arcilla, cemento y arena (M4, M2 y M3), el aumento en el contenido de $\mathrm{SiO}_{2}$ y la disminución en el contenido de $\mathrm{Al}_{2} \mathrm{O}_{3}$ y de $\mathrm{Fe}_{2} \mathrm{O}_{3}$ es debido a la incorporación de arena en la formulación de las muestras. En las tres muestras el mayor contenido de $\mathrm{CaO}$ se debe a la incorporación del cemento. La muestra M4, presenta mayor proporción de $\mathrm{Fe}_{2} \mathrm{O}_{3}$ ya que es la preparada con menor cantidad de cemento y mayor contenido de arcilla. No se observan diferencias significativas entre las muestras M2 y M3 de igual formulación pero distinta temperatura.

En relación a los resultados del análisis químico de los bloques de hormigón preparados, el aumento en el contenido de $\mathrm{SiO}_{2}$ y la disminución en el contenido de $\mathrm{Al}_{2} \mathrm{O}_{3}$ y de $\mathrm{Fe}_{2} \mathrm{O}_{3}$ comparado con las arcillas empleadas en la formulación es debido a la incorporación de arena, cemento y grava, mientras que el mayor contenido de $\mathrm{CaO}$ se debe a la incorporación de cemento.

En relación al contenido de As que se muestra en la Tabla 10.6, el aumento observado en las muestras tratadas respecto a las muestras originales, es asociado al proceso de adsorción durante los ciclos de tratamiento con el agua contaminada. La diferencia en el contenido de As observada en las muestras tratadas, puede ser atribuida a la granulometría empleada en cada caso.

Es importante destacar que el cemento Portland utilizado aporta también As, si bien en una proporción menor que la arcilla. Todas las muestras preparadas presentan un contenido de As acorde a la estequeometría planteada en la formulación de la mezcla. Las muestras preparadas con arcilla, cemento y arena presentan menor contenido de As respecto a las preparadas con arcilla y cemento debido a que la arena no aporta As y a la menor proporción de arcilla empleada. Es importante destacar que la grava empleada en la formulación de los hormigones tampoco aporta As.

En general, los valores observados se corresponden con las proporciones y contenidos de las fases individuales en las mezclas, dentro de los errores que pueden observarse en materiales poco homogéneos. En efecto, las muestras minerales presentan una composición mineralógica compleja y variable dentro de ciertos límites. 
La Figura 10.7 muestra comparativamente los diagramas de difracción de rayos $\mathrm{X}$ (roca total) de la arcilla ferruginosa 3AFO original y tratada. El difractograma de la arcilla tratada no presenta diferencias apreciables con el de la arcilla sin agotar que fuera caracterizada en el Capítulo 6, presentando señales de las especies minerales pirofilita, caolinita e illita, así como hematita, caracterizada ésta última por el doblete en d 2,70 y $2,52 \AA$ y cuarzo.

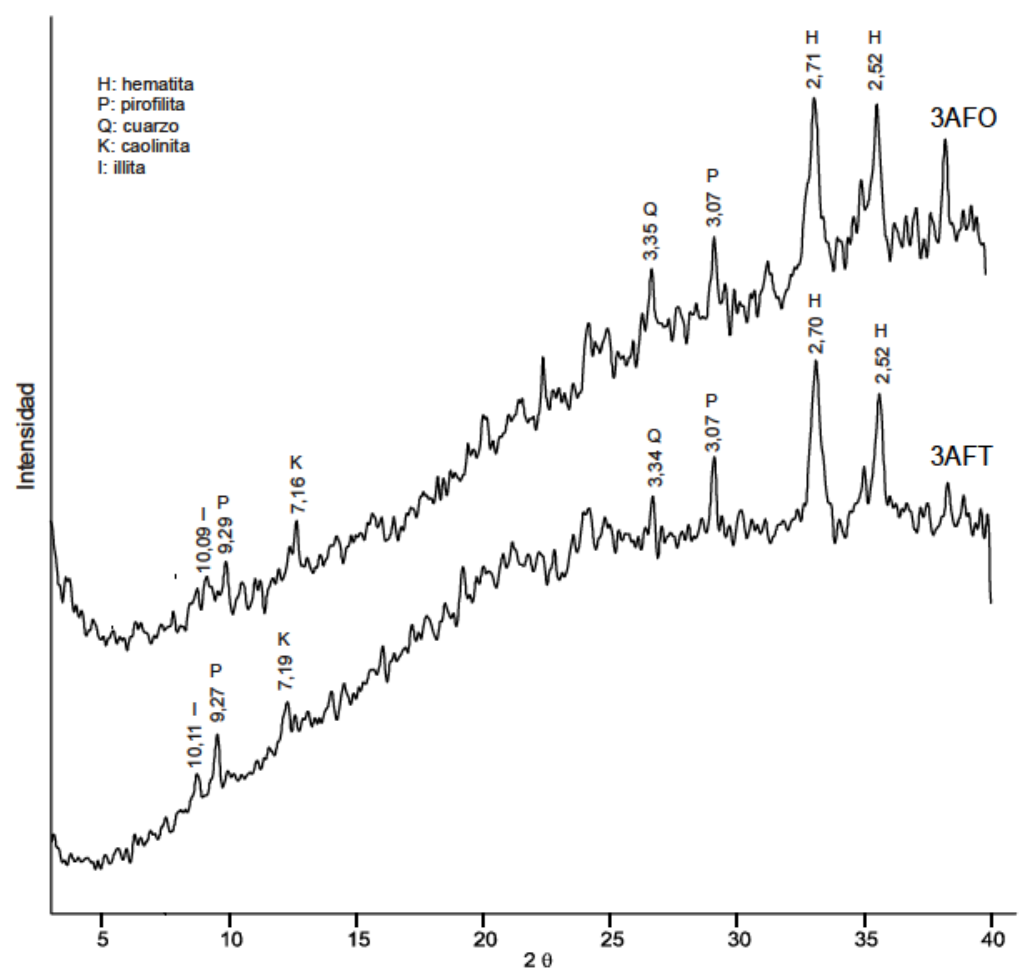

Figura 10.7. Diagramas de rayos $x$ de la arcilla ferruginosa 3 original $y$ tratada.

En la Figura 10.8 se presenta el diagrama de DRX de la muestra de cemento utilizado el que presenta las señales de los aluminosilicatos cálcicos típicos de la composición del cemento (líneas de difracción intensas entre 27 y $35^{\circ}$ de $2 \theta$ ).

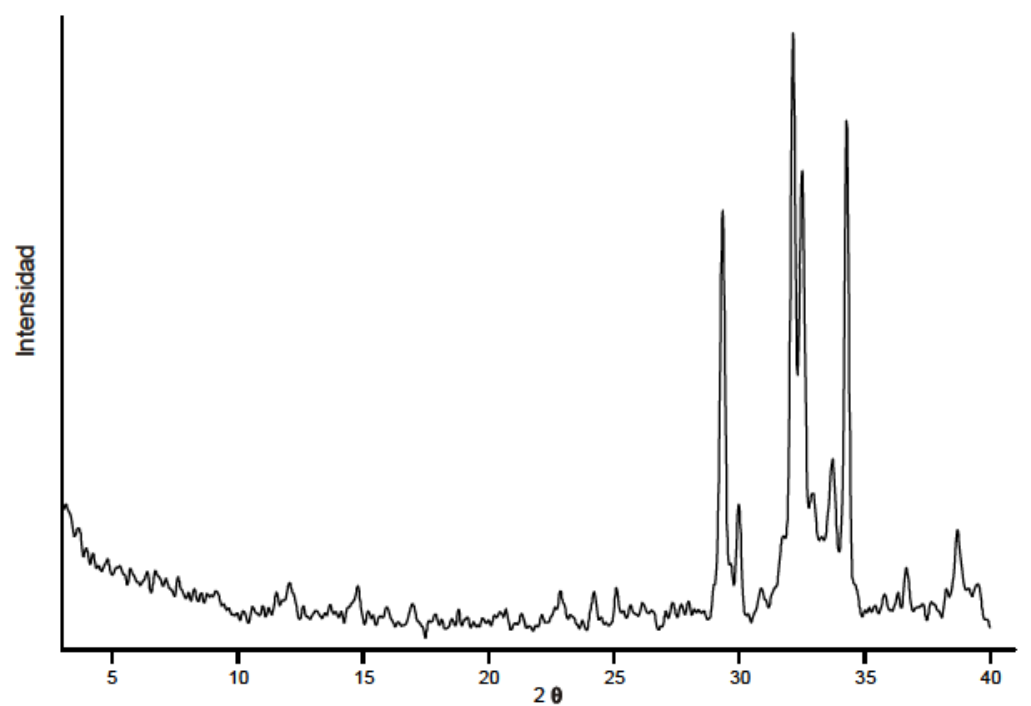

Figura 10.8. Diagrama DRX del cemento Portland. 
En las Figuras 10.9 y 10.10 se presentan los diagramas de $D R X$ de la pasta $P_{A C} 2$ preparada con arcilla y cemento y del mortero M1 con arcilla, cemento y arena respectivamente. El diagrama de la Figura 10.9 resulta similar al de la arcilla mientras que el diagrama de la Figura10.10 está dominado por la presencia de la fase cristalina cuarzo.

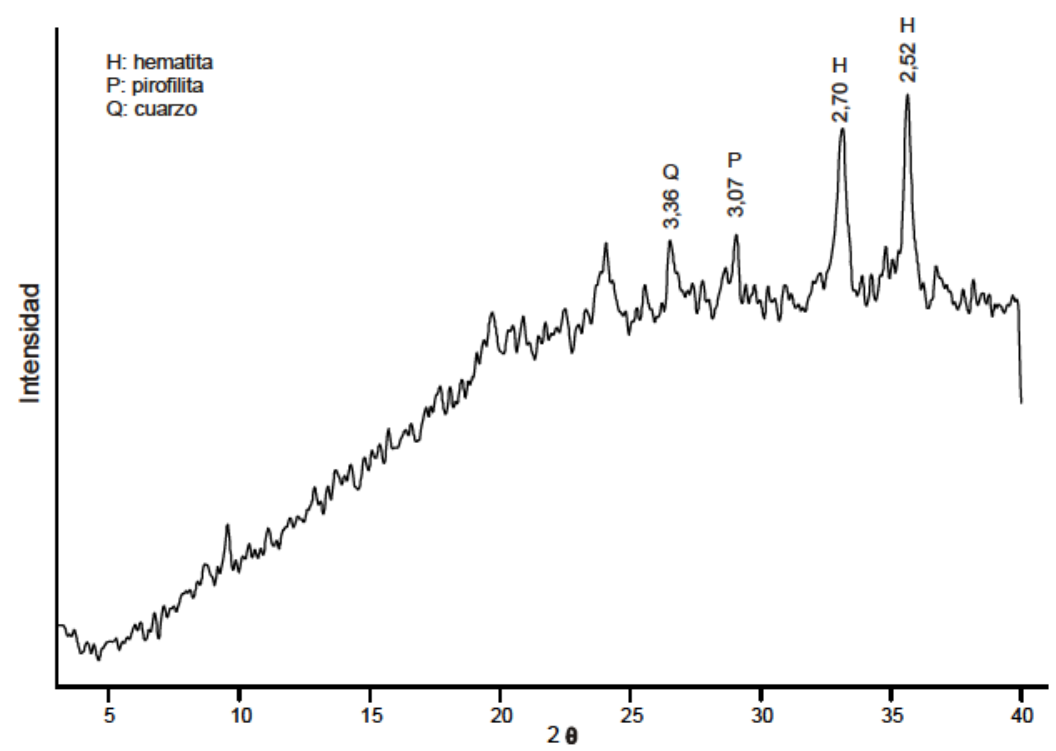

Figura 10.9. Diagrama DRX de la pasta $\mathrm{P}_{\mathrm{AC}} 2$.

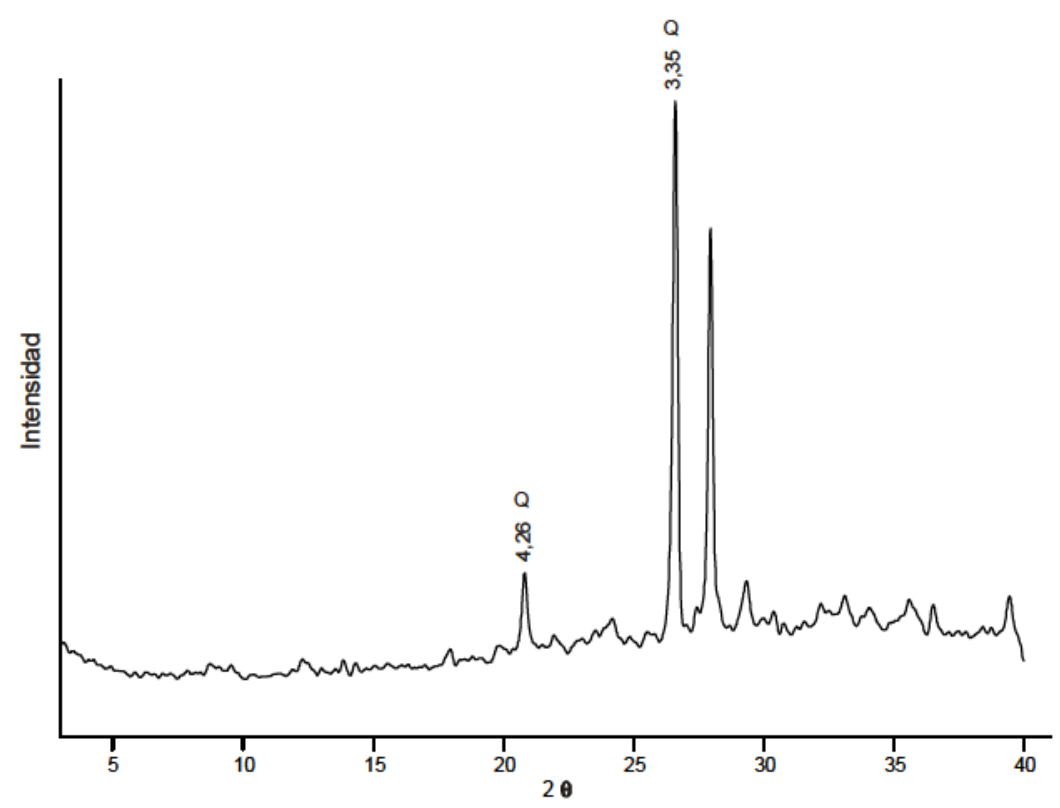

Figura 10.10. Diagrama DRX de la muestra de mortero M1.

\subsubsection{Propiedades físicas y mecánicas}

En primer lugar se evaluaron las pastas realizadas con arcilla y arcilla+cemento $(10 \%)$. A tal fin se confeccionaron placas de las pastas compactadas manualmente de aproximadamente $20 \mathrm{~mm}$ de espesor. Las mismas se expusieron a 300,500 y $700{ }^{\circ} \mathrm{C}$. Las placas que contenían arcilla no superaron los 0,2 MPa de resistencia a flexión, en 
tanto que en las placas con cemento se alcanzó un módulo de rotura en flexión igual a $1,1 \mathrm{MPa}$. Asimismo, las placas de arcilla tratadas a 300 y $500^{\circ} \mathrm{C}$ se disgregaban luego de ser sumergidas en agua en una proporción más notoria que las tratadas a $700^{\circ} \mathrm{C}$. La Foto 10.3 muestra el producto del tratamiento en agua por 72 hs de una muestra calentada a $500^{\circ} \mathrm{C}$.

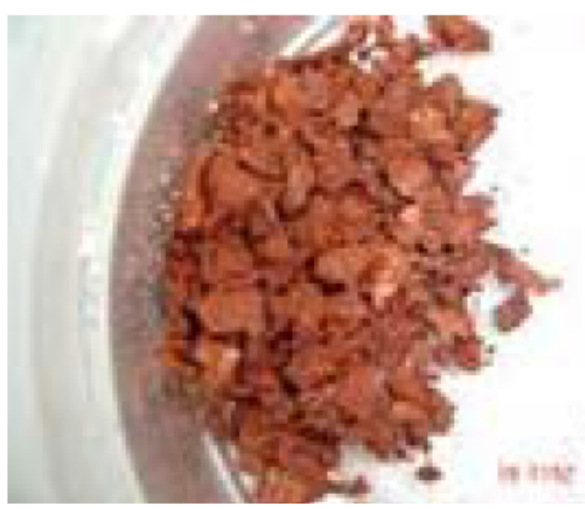

Foto. 10.3. Disgregación de la pasta calentada a $500^{\circ} \mathrm{C}$.

Debido a que se observó que al exponer las pastas de arcilla a bajas temperaturas los elementos presentaban muy baja resistencia y tendían a desintegrarse en agua, se planteó como alternativa alcanzar mayor estabilidad exponiendo las piezas a temperaturas mayores $900{ }^{\circ} \mathrm{C}$ como se indicó en el ítem 10.2.2.1. En la Tabla 10.7 se observan los contenidos de As en las pastas sometidas a 900,1000 y $1100{ }^{\circ} \mathrm{C}$.

Tabla 10.7. Contenido de As en las pastas $\mathrm{P}_{\mathrm{A}} 2$ sometidas a distintas temperaturas.

\begin{tabular}{l|l|l|l|l}
\hline Muestra & $\mathrm{P}_{\mathrm{A}} 21$ & $\mathrm{P}_{\mathrm{A}} 22$ & $\mathrm{P}_{\mathrm{A}} 23$ & $\mathrm{P}_{\mathrm{A}} 24$ \\
\hline As & 336,5 & 314,7 & 286,7 & 291,3 \\
\hline
\end{tabular}

Los resultados sugieren que la estabilidad de las especies resultantes de la interacción del As con el hierro disminuye con la consiguiente separación de los respectivos óxidos. Al respecto es sabido que la fase arseniato de hierro comienza su descomposición por encima de los $900^{\circ} \mathrm{C}$ (Ondrus et al., 1999).

Debido a estas observaciones, la alternativa de disposición en elementos tipo lajas cerámicas se descartó, optando por profundizar la alternativa de disposición de las arcillas contaminadas en productos que contengan cemento Portland.

En la Tabla 10.8 se presentan algunos resultados de resistencia mecánica y propiedades físicas de las diferentes mezclas elaboradas con cemento a diferentes edades. Si bien se toma como referencia 28 días, se han realizado algunas determinaciones a distintas edades para evaluar la evolución de la resistencia. 
Tabla 10.8.Propiedades mecánicas de pastas, morteros y hormigones.

\begin{tabular}{l|c|c|c|c|c|c|c|c|c|c|c|c|c}
\hline \multicolumn{1}{c}{ Muestra } & $\mathrm{P}_{\mathrm{AC}} 2$ & $\mathrm{P}_{\mathrm{AC}} 3$ & $\mathrm{P}_{\mathrm{AC}} 4$ & $\mathrm{P}_{\mathrm{AC}} 5$ & $\mathrm{M} 1$ & $\mathrm{M} 2$ & $\mathrm{M} 3$ & $\mathrm{M} 4$ & $\mathrm{H} 1$ & $\mathrm{H} 2$ & $\mathrm{H} 3$ & $\mathrm{H} 4$ & $\mathrm{H} 5$ \\
\hline $\mathrm{MR}(\mathrm{MPa})$ & 1,1 & 3,0 & 3,7 & 7,1 & 6,7 & 7,7 & 6,9 & 4,1 & 6,7 & 3,2 & 4,8 & 4,2 & 3,0 \\
$\mathrm{f}^{\prime} \mathrm{c}(\mathrm{MPa})$ & & 9,3 & 14,6 & 36,9 & 35,0 & 49,2 & 55,1 & 33,3 & 32,4 & 13,8 & 27,2 & 27,8 & 25,9 \\
Edad (dias) & 7 & 14 & 42 & 42 & 28 & 28 & 28 & 28 & 28 & 14 & 28 & 230 & 42 \\
Absorción (\%) & 15 & & & & & & & & 6,5 & 10,5 & 5,2 & 10,3 & 10,3 \\
Densidad $\left(\mathrm{g} \mathrm{cm}^{-3}\right.$ ) & 2,38 & & & & & & & & 2,40 & 2,10 & 2,25 & 2,28 & 2,10 \\
\hline
\end{tabular}

La Figura 10.11 muestra la variación de la resistencia a compresión con la relación agua/cemento de las mezclas a edades mayores a los 28 días. Los mayores niveles resistentes se obtuvieron en los morteros, en correspondencia con las menores relaciones agua/cemento.

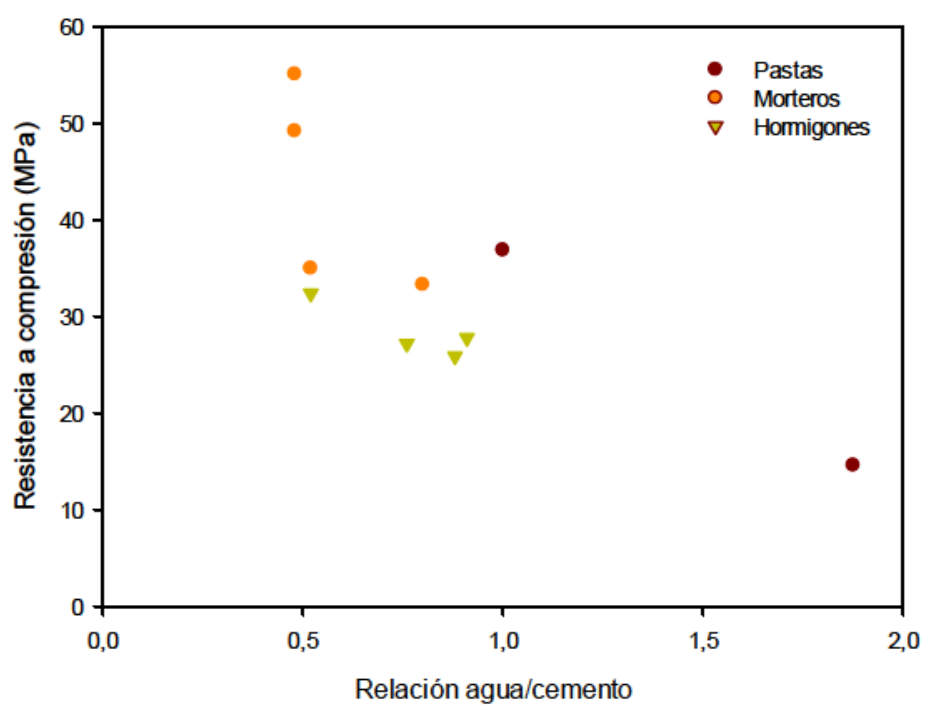

Figura 10.11. Variación de la resistencia a compresión con la relación agua/cemento de las mezclas.

Es de destacar que fue posible elaborar pastas, morteros y hormigones de diferentes trabajabilidades con niveles resistentes aptos para la elaboración de bloques portantes o incluso hormigones estructurales. Al respecto, en el caso de bloques portantes, destinados a soportar cargas menores que los hormigones, la norma indica un mínimo de resistencia igual a 6,5 $\mathrm{MPa}$ en tanto que un hormigón estructural presenta habitualmente resistencias mayores a $20 \mathrm{MPa}$ (si bien los mas empleados se encuentran entre 20 y $30 \mathrm{MPa}$ ). En obras civiles, según el reglamento nacional, se emplean hormigones entre $15 \mathrm{MPa}$ (hormigón simple) y $60 \mathrm{MPa}$ (de alta resistencia). En el rango de edades entre 28 y 42 días, las diferencias observadas en la resistencia a compresión son mínimas. El hormigón $\mathrm{H} 2$ evaluado a 14 días presentó el menor valor de resistencia a compresión. Esto puede ser atribuido a la mayor relación agua/cemento, la cual impediría que a los 28 días alcance el valor de los restantes hormigones. La evaluación de $\mathrm{H} 4$ después de 230 días, permite determinar 
que la respuesta sigue siendo satisfactoria, sin verse afectada por la presencia de arcilla. Adicionalmente, se elaboraron hormigones incorporando hasta $500 \mathrm{~kg} \mathrm{~m}^{-3} \mathrm{de}$ arcillas (en peso seco) que alcanzaron resistencias a compresión del orden de $30 \mathrm{MPa}$ a la edad de 28 días, y una absorción del $6 \%$ en peso.

La densidad relativa determinada para los hormigones es ligeramente menor a la de los hormigones convencionales y presentan una absorción, en algunos casos, ligeramente superior al límite admitido en bloques para mampostería. Al respecto, cabe mencionar que la norma IRAM 11561 (IRAM, 1997) establece un límite de absorción de 10,5\%.

La Figura 10.12 presenta los resultados del estudio de estabilidad dimensional realizado sobre las mezclas de hormigón. Se cortaron prismas de 30 × $45 \times 265 \mathrm{~mm}$ y se los sometió a ciclos de mojado y secado en cámara seca, determinando las variaciones dimensionales y de peso. El hormigón $\mathrm{H} 1$ fue estudiado durante más de seis meses. Se observa que los cambios producidos de un extremo a otro en $\mathrm{H} 1$ son del orden de $1 \mathrm{~mm} / \mathrm{m}$. Estos valores resultan significativos, algo superiores a los habituales en bloques de mampostería y este hecho deberá ser tenido en cuenta en los casos de aplicación donde la contracción revista importancia. En H2 y H3 las variaciones entre extremos de expansión-contracción, para períodos de secado equivalentes resultaron significativamente mayores que en $\mathrm{H} 1$ y la principal justificación es el menor contenido de agua. Asimismo, en la elaboración de H1 se incorporó menor contenido de arena y piedra, mayor contenido de cemento y parte de la arcilla aparece en forma de pequeños terrones a diferencia de la elaboración de H2 y H3 donde se utilizó directamente el barro, con una mejor dispersión, mayor uniformidad y coloración de las muestras (Foto 10.4). Comparando $\mathrm{H} 2$ y H3 , se aprecia que con idéntico conjunto de materiales el volumen de agregados (arena y piedra) incorporados reduce significativamente las variaciones dimensionales.
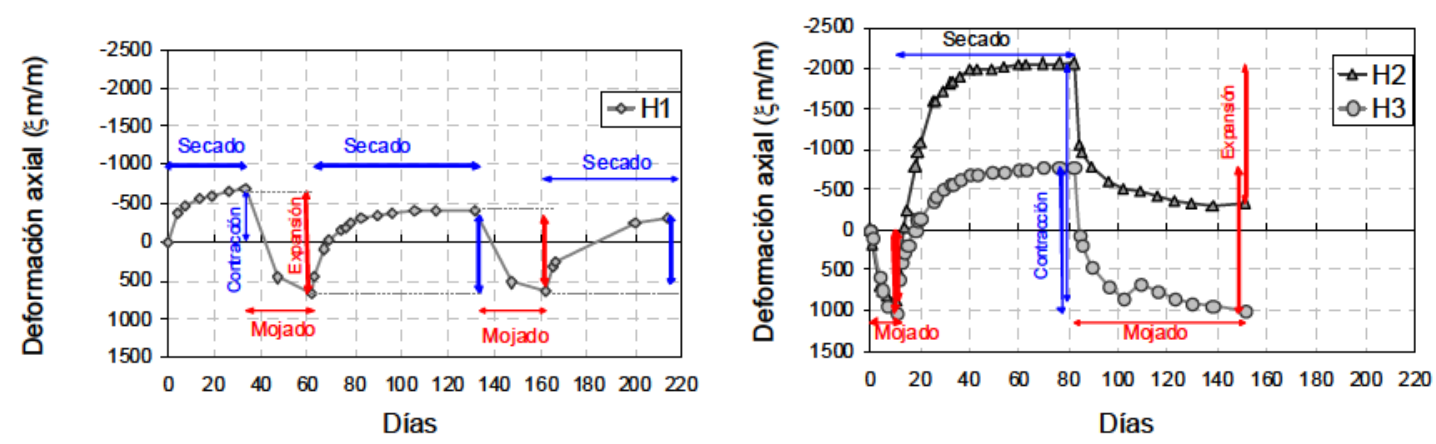

Figura 10.12. Estudio de estabilidad dimensional en placas de hormigón. 


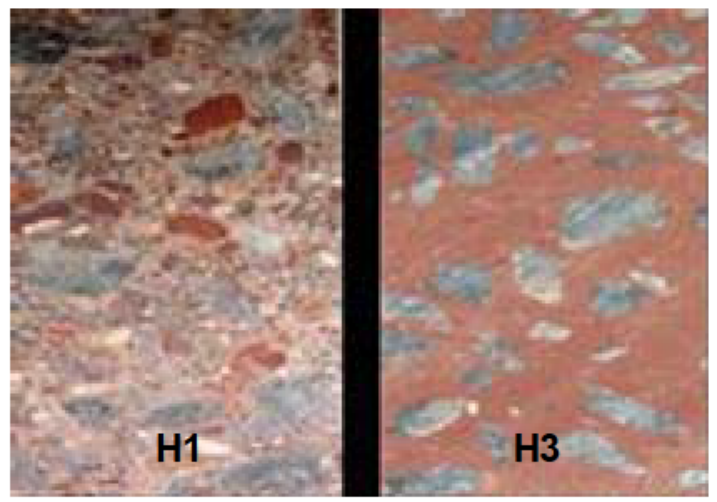

Foto 10.4. Aspecto final de algunas probetas de hormigones elaboradas.

\subsubsection{Ensayos de lixiviación}

Procedimiento 1: Ensayos preliminares para determinar la estabilidad de hormigones en condiciones extremas (ácidos fuertes)

En esta primera etapa se analizó el comportamiento de un hormigón a fin de determinar su estabilidad en medio ácido fuerte. Fue seleccionada la muestra $\mathrm{H} 1$, analizando la lixiviación del As original presente en la arcilla sin agotar.

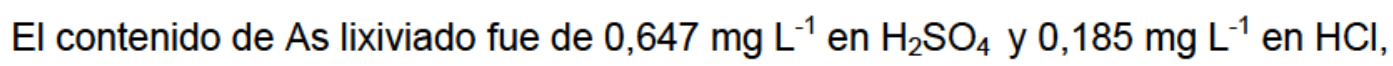
observándose que no obstante las características del tratamiento, el contenido de As en el lixiviado no supera el valor límite permisible según el ensayo de la EPA ( $5 \mathrm{mg} \mathrm{L}^{-1}$ de As en la solución lixiviante) ni el valor indicado en el Decreto 831/93, Ley Nacional No 24051/92 de Residuos Peligrosos (1993). Dicho Decreto establece como nivel máximo para As en el líquido lixiviante $1 \mathrm{mg} \mathrm{L}^{-1}$. En cuanto al porcentaje de retención de los ensayos con ácidos fuertes, puede observarse la Tabla 10.9.

Tabla 10.9. Resultados de los ensayos de lixiviación preliminares empleando ácidos fuertes.

\begin{tabular}{l|c|c|c|c}
\hline Muestra & $\begin{array}{c}\text { As inicial } \\
(\mathrm{mg})\end{array}$ & $\begin{array}{c}\text { As lixiviado } \\
(\mathrm{mg})\end{array}$ & $\begin{array}{c}\text { As retenido } \\
(\mathrm{mg})\end{array}$ & $\begin{array}{c}\text { Retención } \\
\%\end{array}$ \\
\hline $\mathrm{HCl}$ & 0,7164 & 0,0277 & 0,6887 & 96,13 \\
$\mathrm{H}_{2} \mathrm{SO}_{4}$ & 0,7615 & 0,0970 & 0,6645 & 87,26 \\
\hline
\end{tabular}

Es de destacar que el tratamiento con ácido sulfúrico ataca el hormigón, desintegrando el bloque y formando un residuo de color blanquecino, debido a la reacción química de precipitación de sulfatos de calcio, como se detallará más adelante. Los resultados del tratamiento con ácidos fuertes fueron alentadores en cuanto a la posibilidad de estimar la estabilidad del arsénico en la matriz arcillosa. Efectivamente, al no superar los valores de referencia en éstas condiciones de tratamiento, es de esperar que la posibilidad de lixiviación del residuo con el acido acético (ácido débil) indicado en el ensayo TCLP resulte aun menor, lo que es confirmado al realizar estos ensayos en los ítems que continúan. 
En la Foto 10.5 se puede observar el aspecto de los residuos de los dos ensayos de lixiviación en condiciones extremas. El bloque de hormigón es atacado con $\mathrm{H}_{2} \mathrm{SO}_{4}$ con formación de sulfatos insolubles en tanto que el $\mathrm{HCl}$ ataca al bloque sólo a nivel superficial. La coloración de la solución, en ambos casos, es debida a la solubilización del hierro contenido en el material arcilloso, observándose más claramente en el caso del $\mathrm{HCl}$.

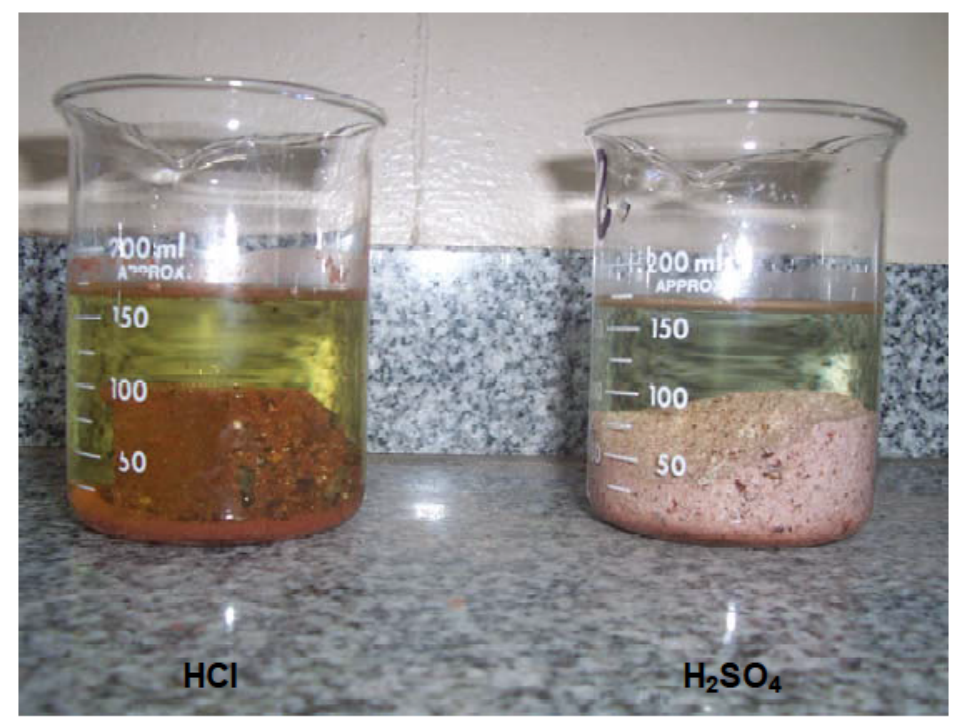

Foto 10.5. Aspecto de la lixiviación con ácidos fuertes para el hormigón $\mathrm{H} 1$.

\section{Procedimiento 2: Método EPA 1311}

Se realizó con las muestras de arcilla agotadas utilizadas en la preparación de las piezas, con una muestra de pasta y dos muestras de morteros que fueron seleccionadas por presentar las mejores propiedades mecánicas y con las cinco muestras de hormigones. En la Tabla 10.10 pueden observarse los resultados obtenidos en las distintas etapas del Test EPA 1311.

Tabla 10.10. Resultados del Test EPA 1311.

\begin{tabular}{c|r|r|c|c|c}
\hline Muestra & \multicolumn{1}{|c|}{$\mathrm{pH} 1$} & \multicolumn{1}{c|}{$\mathrm{pH} 2$} & $\mathrm{RE}$ & As lixiviado $\left(\mathrm{mg} \mathrm{L}^{-1}\right)$ & \% Retención \\
\hline 3AFT & 8,82 & 1,52 & 1 & $<0,003$ & 99,76 \\
7AFT & 8,33 & 1,91 & 1 & $<0,003$ & 99,98 \\
$\mathrm{P}_{\mathrm{AC} 5}$ & 11,85 & 2,53 & 1 & 0,010 & 99,88 \\
$\mathrm{M} 3$ & 12,31 & 10,32 & 2 & 0,006 & 99,81 \\
M4 & 12,26 & 10,23 & 2 & 0,005 & 99,88 \\
$\mathrm{H} 1$ & 11,43 & 2,11 & 1 & $<0,003$ & 99,53 \\
$\mathrm{H} 2$ & 11,80 & 11,18 & 2 & $<0,003$ & 99,90 \\
$\mathrm{H} 3$ & 11,44 & 2,27 & 1 & $<0,003$ & 99,56 \\
$\mathrm{H} 4$ & 11,70 & 5,30 & 2 & 0,003 & 99,69 \\
$\mathrm{H} 5$ & 11,60 & 5,45 & 2 & 0,003 & 99,82 \\
\hline
\end{tabular}

El análisis de los resultados permite establecer que el As lixiviado en todas las muestras analizadas, se encuentra por debajo del límite máximo establecido en el test de la EPA. Asimismo, los valores de la tabla se encuentran también por debajo de los 
límites que establece el Decreto 831/93. Es de destacar que las muestras de arcilla agotadas sin el tratamiento de cementación no son peligrosas según lo establecido por estas normativas. Para las muestras de pasta y morteros, la lixiviación también da dentro de los límites de la legislación, sin embargo los contenidos de As son levemente superiores a los de la muestra sin tratamiento, esto puede atribuirse a un ligero incremento del pH por el uso del cemento.

En el caso de los hormigones, tanto la muestra de arcilla agotada utilizada en su formulación como los hormigones elaborados dan el mismo valor de lixiviación, por lo que el procedimiento de cementación no afectó la estabilidad de la arcilla en cuanto a la lixiviación del As.

En cuanto al cálculo del porcentaje de retención incluido en la última columna de la Tabla 10.10 , en todos los casos es superior al $99 \%$, por lo que la técnica de cementación es una buena estrategia para el tratamiento de los residuos generados en la planta de remoción de As. Si bien las muestras de arcilla agotadas no son un residuo peligroso, y podrían ser utilizadas sin el tratamiento de cementación en un relleno, la fabricación de hormigones o morteros permiten dar un uso al residuo final disminuyendo los costos ambientales.

\section{Procedimiento 3: Test NEN 7345}

En las Tablas 10.11 a 10.16 se presentan los resultados obtenidos $(\mathrm{pH}$, conductividad en $\mu \mathrm{S} \mathrm{cm}^{-1}$, As en $\mathrm{mg} \mathrm{L}^{-1} \mathrm{y} \mathrm{E}_{\mathrm{i}}$ en $\mathrm{mg} \mathrm{m}^{-2}$, lixiviación de As en cada período según la ecuación 10.1), en este ensayo de lixiviación para las cinco piezas de hormigones estudiadas.

En la Tabla 10.11 se muestran los valores de $\mathrm{pH}$ y conductividad obtenidos durante el ensayo para el control (líquido lixiviante: solución de $\mathrm{HNO}_{3}$ que presenta un valor de $\mathrm{pH}$ inicial de 3,97 y una conductividad inicial de $57,9 \mu \mathrm{S} \mathrm{cm}^{-1}$ ).

Es de destacar que el control en todas las extracciones dio un valor de As inferior al límite de detección del equipo $\left(<0,003 \mathrm{mg} \mathrm{L}^{-1}\right)$.

Tabla 10.11. Resultados de $\mathrm{pH}$ y conductividad $\left(\mu \mathrm{S} \mathrm{cm}^{-1}\right)$ para el control.

\begin{tabular}{c|c|c|c}
\hline Extracción & Tiempo (días) & $\mathrm{pH}$ & conductividad \\
\hline 1 & 0,25 & 4,02 & 53,9 \\
2 & 1 & 3,99 & 54,7 \\
3 & 2,25 & 4,03 & 50,5 \\
4 & 4 & 4,00 & 48,8 \\
5 & 9 & 4,13 & 53,3 \\
6 & 16 & 4,13 & 51,4 \\
7 & 36 & 4,12 & 51,8 \\
8 & 64 & 4,12 & 50,5 \\
\hline
\end{tabular}


Tabla 10.12. Resultados ensayo NEN 7345 para la muestra de hormigón H1.

\begin{tabular}{c|c|c|c|c|c}
\hline Extracción & Tiempo (días) & $\mathrm{pH}$ & conductividad & As $\left(\mathrm{mg} \mathrm{L}^{-1}\right)$ & $\mathrm{E}_{\mathrm{i}}\left(\mathrm{mg} \mathrm{m}^{-2}\right)$ \\
\hline 1 & 0,25 & 10,70 & 162,4 & 0,004 & 0,156 \\
2 & 1 & 11,06 & 185,5 & $<0,003$ & $<0,117$ \\
3 & 2,25 & 11,19 & 295 & $<0,003$ & $<0,117$ \\
4 & 4 & 11,34 & 509 & $<0,003$ & $<0,117$ \\
5 & 9 & 11,81 & 562 & $<0,003$ & $<0,117$ \\
6 & 16 & 11,75 & 561 & 0,016 & 0,625 \\
7 & 36 & 12,25 & 807 & $<0,003$ & $<0,117$ \\
8 & 64 & 11,43 & 788 & $<0,003$ & $<0,117$ \\
\hline
\end{tabular}

Tabla 10.13. Resultados ensayo NEN 7345 para la muestra de hormigón $\mathrm{H} 2$.

\begin{tabular}{c|c|c|c|c|c}
\hline Extracción & Tiempo (días) & $\mathrm{pH}$ & conductividad & As $\left(\mathrm{mg} \mathrm{L}^{-1}\right)$ & $\mathrm{E}_{\mathrm{i}}\left(\mathrm{mg} \mathrm{m}^{-2}\right)$ \\
\hline 1 & 0,25 & 10,53 & 172,2 & 0,008 & 0,36 \\
2 & 1 & 11,03 & 243 & 0,008 & 0,36 \\
3 & 2,25 & 11,07 & 276 & 0,009 & 0,405 \\
4 & 4 & 11,25 & 353 & 0,007 & 0,315 \\
5 & 9 & 11,72 & 513 & 0,007 & 0,315 \\
6 & 16 & 11,73 & 502 & 0,005 & 0,225 \\
7 & 36 & 11,57 & 471 & 0,004 & 0,18 \\
8 & 64 & 10,94 & 500 & $<0,003$ & $<0,135$ \\
\hline
\end{tabular}

Tabla 10.14. Resultados ensayo NEN 7345 para la muestra de hormigón H3.

\begin{tabular}{c|c|c|c|c|c}
\hline Extracción & Tiempo (días) & $\mathrm{pH}$ & conductividad & As $\left(\mathrm{mg} \mathrm{L}^{-1}\right)$ & $\mathrm{E}_{\mathrm{i}}\left(\mathrm{mg} \mathrm{m}^{-2}\right)$ \\
\hline 1 & 0,25 & 11,14 & 267 & 0,005 & 0,225 \\
2 & 1 & 11,19 & 234 & 0,003 & 0,135 \\
3 & 2,25 & 11,20 & 267 & $<0,003$ & $<0,135$ \\
4 & 4 & 11,11 & 375 & $<0,003$ & $<0,135$ \\
5 & 9 & 11,60 & 395 & $<0,003$ & $<0,135$ \\
6 & 16 & 11,57 & 357 & $<0,003$ & $<0,135$ \\
7 & 36 & 12,09 & 543 & $<0,003$ & $<0,135$ \\
8 & 64 & 11,34 & 608 & $<0,003$ & $<0,135$ \\
\hline
\end{tabular}

Tabla 10.15. Resultados ensayo NEN 7345 para la muestra de hormigón H4.

\begin{tabular}{c|c|c|c|c|c}
\hline Extracción & Tiempo (días) & $\mathrm{pH}$ & conductividad & As $\left(\mathrm{mg} \mathrm{L}^{-1}\right)$ & $\mathrm{E}_{\mathrm{i}}\left(\mathrm{mg} \mathrm{m}^{-2}\right)$ \\
\hline 1 & 0,25 & 11,54 & 274 & $<0,003$ & $<0,135$ \\
2 & 1 & 11,70 & 314 & $<0,003$ & $<0,135$ \\
3 & 2,25 & 11,68 & 320 & $<0,003$ & $<0,135$ \\
4 & 4 & 11,94 & 373 & $<0,003$ & $<0,135$ \\
5 & 9 & 12,26 & 671 & $<0,003$ & $<0,135$ \\
6 & 16 & 12,14 & 714 & $<0,003$ & $<0,135$ \\
7 & 36 & 11,84 & 680 & $<0,003$ & $<0,135$ \\
8 & 64 & 11,64 & 664 & $<0,003$ & $<0,135$ \\
\hline
\end{tabular}

Tabla 10.16. Resultados ensayo NEN 7345 para la muestra de hormigón H5.

\begin{tabular}{c|c|c|c|c|c}
\hline Extracción & Tiempo (días) & $\mathrm{pH}$ & conductividad & As $\left(\mathrm{mg} \mathrm{L}^{-1}\right)$ & $\mathrm{E}_{\mathrm{i}}\left(\mathrm{mg} \mathrm{m}^{-2}\right)$ \\
\hline 1 & 0,25 & 11,72 & 367 & $<0,003$ & $<0,135$ \\
2 & 1 & 11,97 & 408 & $<0,003$ & $<0,135$ \\
3 & 2,25 & 11,88 & 495 & $<0,003$ & $<0,135$ \\
4 & 4 & 12,14 & 548 & $<0,003$ & $<0,135$ \\
5 & 9 & 12,41 & 751 & $<0,003$ & $<0,135$ \\
6 & 16 & 12,24 & 841 & $<0,003$ & $<0,135$ \\
7 & 36 & 11,89 & 894 & $<0,003$ & $<0,135$ \\
8 & 64 & 11,69 & 747 & 0,005 & 0,225 \\
\hline
\end{tabular}


En la Tabla 10.17 se muestran los resultados de la lixiviación acumulada $\left(\varepsilon_{n}\right)$ del elemento As calculados según la ecuación (10.2). En todos los casos los valores se encuentran por debajo de los límites establecidos como U1 por la legislación holandesa (40 $\mathrm{mg} \mathrm{m}^{-2}$ ) para el elemento As. Por lo expuesto los hormigones estudiados, se clasifican dentro de la categoría 1 no presentando ninguna restricción ambiental para su utilización, sugiriendo la estabilización del As en el hormigón. La muestra que presenta mayor lixiviación acumulada es la muestra de hormigón que inicialmente presenta mayor contenido de $\mathrm{As}(\mathrm{H} 2$, preparada con $18 \%$ de arcilla agotada).

Tabla 10.17. Lixiviación acumulada de las muestras de hormigón.

\begin{tabular}{c|c|c|c|c|c}
\hline Muestra & $\mathrm{H} 1$ & $\mathrm{H} 2$ & $\mathrm{H} 3$ & $\mathrm{H} 4$ & $\mathrm{H} 5$ \\
\hline$\varepsilon_{\mathrm{n}}\left(\mathrm{mg} / \mathrm{m}^{2}\right)$ & 1,483 & 2,295 & 1,170 & 1,080 & 1,170 \\
\hline
\end{tabular}

En las Figuras 10.13 y 10.14 se observa el comportamiento del $\mathrm{pH}$ y de la conductividad a lo largo del ensayo. Para ambos parámetros el control se mantiene constante indicando que las modificaciones vistas en las muestras se deben a la matriz estudiada. En todos los hormigones se observa un aumento del $\mathrm{pH}$ en los líquidos lixiviantes, indicando solubilidad de fases alcalinas. Las 5 muestras de hormigones presentan un comportamiento similar, con pequeñas variaciones en el pH durante la realización del test dando idea de la estabilidad de las piezas analizadas. La conductividad se mantiene baja aunque crece a lo largo del ensayo, indicando una escasa presencia iónica.

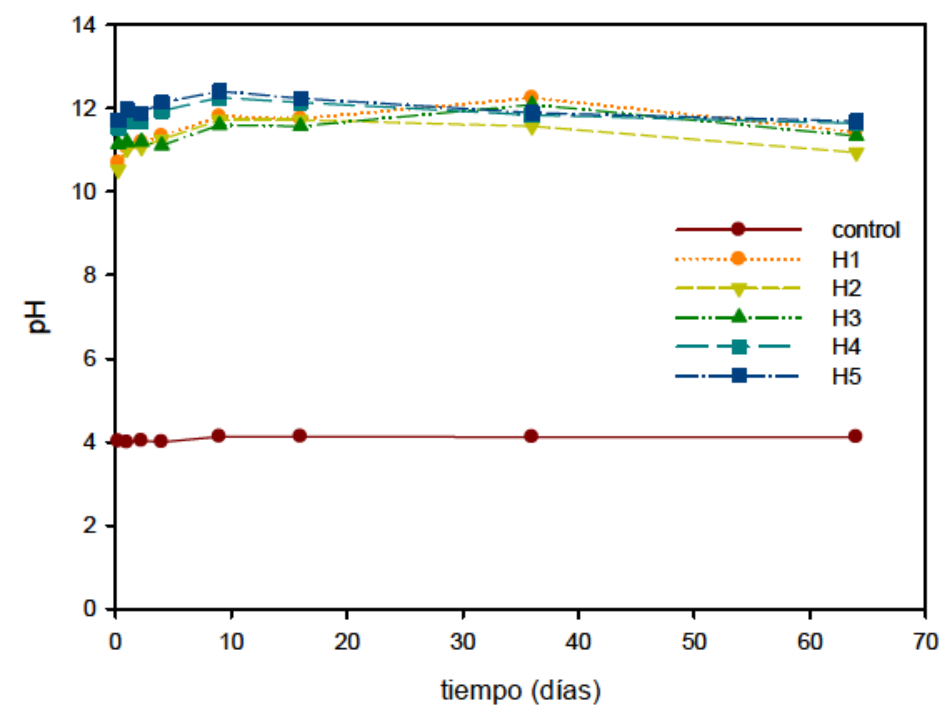

Figura 10.13. pH del líquido lixiviante de cada período del test monolítico para el control y las 5 muestras de hormigones analizadas. 


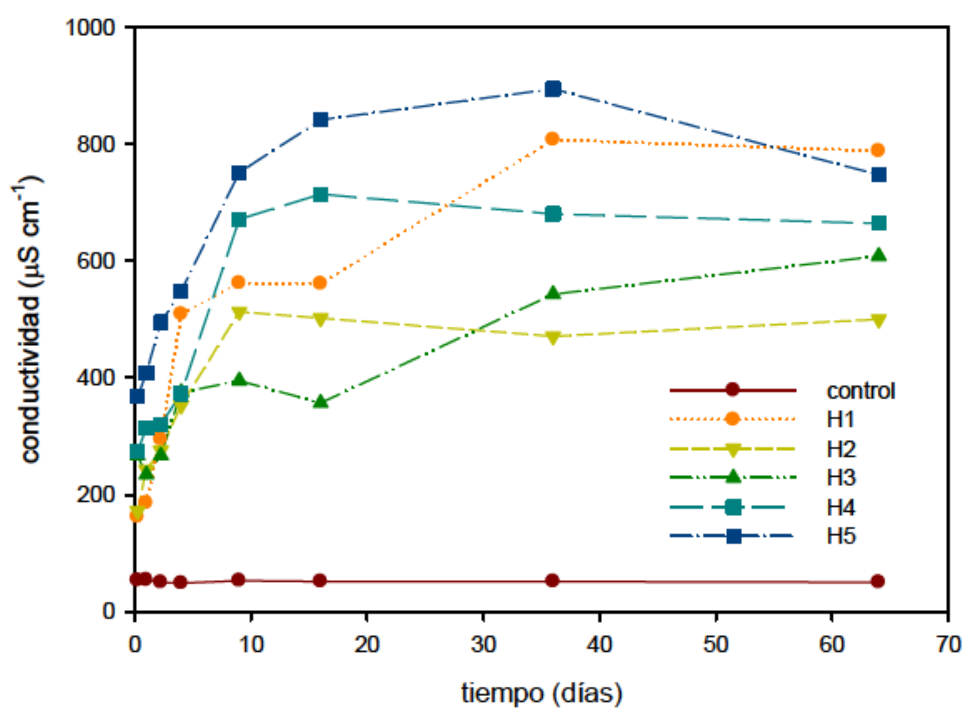

Figura 10.14. Conductividad del líquido lixiviante de cada período del test monolítico para el control y las 5 muestras de hormigones analizadas.

En relación a la determinación de Fe todas las mediciones, tanto en el control como en las muestras de hormigones, dieron por debajo del límite de detección de la técnica $\left(<0,029 \mathrm{mg} \mathrm{L}^{-1}\right)$.

\section{Conclusiones}

_ Los lodos generados en el tratamiento de remoción de As representan un pasivo ambiental debido a la necesidad de tratamiento, manejo y disposición de los materiales de desecho que se generan. El uso del residuo es muy factible ya que puede ser utilizado como materia prima para la fabricación de distintas piezas, principalmente hormigones, redundando positivamente en el impacto económico que representa la reutilización del residuo.

_ De los ensayos realizados con piezas conformadas con arcillas conteniendo cantidades variables de arsénico surge que la preparación de hormigones se presenta como la alternativa más simple, económica y efectiva para aislar en forma definitiva el contaminante del medio ambiente, posibilitando la preparación de piezas aptas para su aplicación en la construcción. 


\section{CAPÍTULO 11}

\section{Conclusiones generales}

El presente trabajo de Tesis, dirigido al estudio de las posibilidades de empleo de materias primas naturales para su uso en la adsorción del arsénico en aguas subterráneas, se ha focalizado en aspectos químicos básicos que faciliten el diseño tecnológico de una estrategia de remediación. La tarea de índole interdisciplinaria ha comprendido la realización de actividades de campo y gabinete, así como el uso de técnicas fisicoquímicas de análisis para la selección del adsorbente apropiado y la evaluación de su potencialidad a nivel laboratorio, banco y a escala piloto.

El empleo de especies minerales de la familia de los aluminosilicatos, estructural y composicionalmente muy variadas, ha permitido realizar modificaciones químicas sencillas para incrementar su capacidad de adsorción, proceso que se ha denominado activación. El mismo amplía el panorama de uso de especies abundantes y de bajo costo y ayuda a la resolución del grave problema socio-sanitario asociado al consumo de agua conteniendo valores de As superiores a los permitidos. Asimismo, la selección de un método adecuado de disposición del adsorbente agotado, determinó que la cementación constituye una alternativa simple, económica y efectiva que evita el retorno del contaminante al medio ambiente contribuyendo a la sustentabilidad del tratamiento propuesto.

En función de lo brevemente comentado, los resultados han permitido arribar a conclusiones fundadas en el empleo de dos categorías de aluminosilicatos según su contenido en hierro: aquellos naturalmente ricos en hierro y especies con contenidos muy bajos (menores al $5 \%$ como $\mathrm{Fe}_{2} \mathrm{O}_{3}$ ) susceptibles de ser enriquecidos mediante activación con sales de hierro(III).

La actividad inicial estuvo dirigida a la obtención de especies minerales cuyos aspectos geológicos más relevantes se mencionaron en el Capítulo 4. En relación a las especies ricas en hierro se estudiaron arcillas ferruginosas procedentes de las Sierras Septentrionales de la provincia de Buenos Aires y materiales de hierro oolítico del yacimiento Unchimé (provincia de Salta). Entre las especies minerales sujetas a modificación química se trabajó con minerales de arcilla 1:1 y 2:1 así como con otras especies como zeolitas y diatomitas.

Las muestras minerales originales y modificadas fueron caracterizadas mineralógicamente y estudiadas mediante la aplicación de técnicas fisicoquímicas como análisis químico másico de elementos mayoritarios, minoritarios y traza (ICPAES-MS), difracción por RX (DRX), microscopía electrónica de barrido (SEM-EDS), 
estudios de superficie (BET), espectroscópicos (FTIR-Raman), térmicos (DTG-TG, TPR) y granulométricos.

En el ámbito de la PBA, se procedió a la caracterización de doce muestras de arcillas ferruginosas procedentes de tres zonas muestreadas, seleccionando por sus propiedades físicas y químicas, accesibilidad y potencialidad del depósito, el material procedente del área identificada como Zona 3, particularmente aquel cuyo contenido en óxido férrico es del orden del $50 \%$. La mineralogía se basa en la presencia de aluminosilicatos (pirofilita, caolinita e illita) como soporte de la especie de hierro hematita, geoquímicamente depositada y químicamente activa en el proceso de remoción de As. Los resultados por microscopía electrónica revelan la morfología laminar típica de los minerales de arcilla, tapizada por un proceso de depositación natural por especies de hierro. Este hecho sustenta el incremento superficial del contenido de hierro respecto al dato másico obtenido por ICP. El material seleccionado resulta mesoporoso, con una baja superficie específica, del orden de $10 \mathrm{~m}^{2} \mathrm{~g}^{-1}$. Si bien la espectroscopía FTIR resultó poco efectiva en la caracterización del material, por espectroscopía micro-Raman se ha revelado claramente la presencia de hematita. El comportamiento térmico en atmósfera oxidante e inerte (TG-DTG) resulta típico de las especies arcillosas, en tanto que en ambiente reductor las señales de TPR observadas se corresponden a la especie hematita con una muy pequeña proporción de óxidos de hierro hidratados-amorfos. Las ligeras diferencias observadas entre la reducibilidad de la fase hematita pura y las especies de hierro de la arcilla ferruginosa, sugieren cierto grado de interacción superficial y un retraso en la última etapa de reducción del hierro debido a la cobertura de los sitios activos soportados en la matriz arcillosa.

La evaluación de la performance del material arcilloso seleccionado para la remoción de As en aguas a nivel laboratorio se efectuó en un equipo Jar test. La isoterma de adsorción que mejor ajusta los resultados obtenidos con la arcilla ferruginosa es la de Langmuir. El ajuste de las variables operativas estuvo orientado a la optimización de las siguientes condiciones:

a) Tamaño de partícula: identificado como "molienda fina".

b) Relación sólido/líquido: 1/10 (dosis de adsorbente: $100 \mathrm{~g}$ por $\mathrm{L}$ de agua a tratar).

c) Tiempo de agitación: 60 minutos a 200 rpm.

d) Empleo de un coagulante: para obtener valores de turbidez dentro de lo permitido por el CAA. Se seleccionó el policloruro de aluminio determinando una dosis óptima de $0,193 \mathrm{mg}$ Al por litro de agua a tratar. La turbidez adecuada se logra transcurridas 24 hs de sedimentación. 
e) $\mathrm{pH}$ : no se han observado variaciones apreciables en la remoción de As en el rango estudiado.

El conjunto de variables optimizadas permite definir el siguiente esquema operativo:

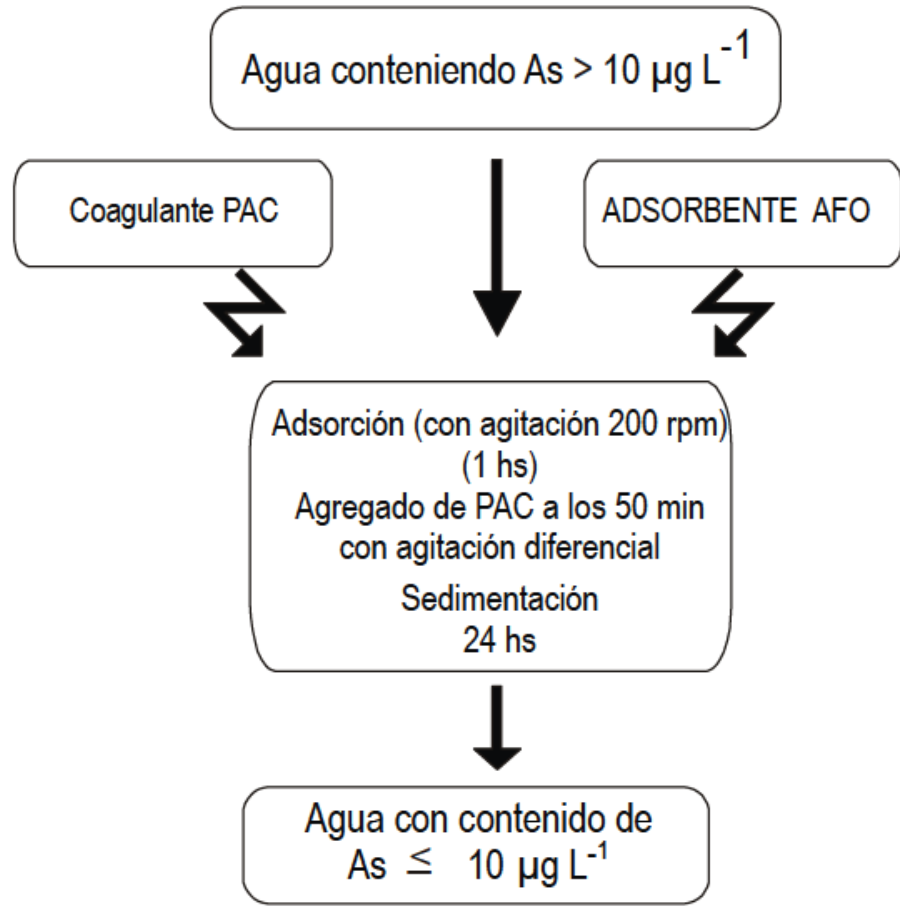

Siguiendo el esquema precedente, la efectividad del adsorbente, definida como el número de ciclos consecutivos útiles en los que la concentración de As en el agua tratada no supera los $10 \mu \mathrm{g} \mathrm{L}^{-1}$, fue determinada para distintas concentraciones iniciales de As (entre 200 y $2000 \mu \mathrm{g} \mathrm{L}^{-1}$ ). Se observó que la máxima retención se logra con la solución más diluida, alcanzando 336 ciclos efectivos de tratamiento que se corresponden a 651,20 $\mu \mathrm{g}$ de As retenidos por gramo de arcilla.

Si bien el proceso de escalado a nivel banco, empleando el esquema optimizado a escala laboratorio, permitió llegar a valores de As de acuerdo a la normativa de la OMS, la turbidez resulta superior a la requerida, situación que determinó la necesidad de introducir un segundo reactor en el sistema "batch" para finalizar la sedimentación obteniendo así los valores de turbidez apropiados. De esta forma, el agua tratada en el primer reactor, es transferida al segundo reactor donde se completa la sedimentación dejando al líquido en reposo durante 24 hs.

En el escalado a nivel planta piloto, realizado en PlaPiMu, se tuvieron en cuenta las variables optimizadas a nivel laboratorio y banco. El escalado permitió el diseño de un equipo de remoción de As que logra el tratamiento de un volumen de hasta $2000 \mathrm{~L}$ de agua. El equipo, se compone de tres tanques. En el primer tanque se produce el 
proceso de contacto adsorbente-agua. En el segundo tanque se completa la sedimentación, y en el tercer tanque se almacena el agua en condiciones aptas para su consumo. El diseño del equipo, de tipo discontinuo, resulta de simple construcción y facilidad operativa, constituye una contribución interesante y sencilla para la remediación de la problemática en zonas rurales carentes de aguas de red. El tratamiento conduce a valores de As adecuados para su consumo, evitando serios riesgos para la salud de la población.

En relación al empleo de los minerales ricos en hierro del yacimiento Unchimé (Salta), las muestras presentaron un contenido de hierro entre 34 y $66 \%$ expresado como $\mathrm{Fe}_{2} \mathrm{O}_{3}$. En las cuatro muestras la mineralogía está basada en la presencia de la especie de hierro hematita, acompañada de cuarzo como especie accesoria, observándose por DRX débiles reflexiones de especies arcillosas (caolinita e illita). Al igual que las arcillas ferruginosas el material seleccionado resulta mesoporoso, con una superficie específica del orden de $15 \mathrm{~m}^{2} \mathrm{~g}^{-1}$. Utilizando los parámetros optimizados para las arcillas ferruginosas de la PBA, las muestras se emplearon en el proceso de remoción de As para evaluar su efectividad. Para una concentración inicial de As de $1000 \mu \mathrm{g} \mathrm{L}^{-1}$, la arcilla ferruginosa de la PBA resultó efectiva durante 45 ciclos, mientras que los minerales de Unchimé fueron útiles un número menor de ciclos (entre 22 y 42 ciclos dependiendo del contenido de hierro).

Resulta evidente que, tanto el contenido en hierro como las características mineralógicas del material determinan la efectividad del proceso de remoción. Al respecto, para valores de hierro comparables, la menor eficiencia de las muestras del yacimiento de Unchimé, puede relacionarse con las dificultades que se presentaron para disminuir la turbidez a los valores recomendados por el CAA. El comportamiento observado se podría atribuir al valor excesivo de la relación hierro/arcilla, sugiriendo una deficiente interacción entre ambas especies y la imposibilidad de sedimentación de la especie de hierro en suspensión mediante el agregado del coagulante de aluminio. Es de señalar que un ajuste de las variables operativas para las muestras con mayor contenido de hierro, podría conducir a un aumento del número de ciclos efectivos.

La modificación química de los minerales con bajos contenidos de hierro $(<5 \%$ como $\mathrm{Fe}_{2} \mathrm{O}_{3}$ ), se realizó a escala de laboratorio mediante la precipitación "in situ" de oxi/hidróxidos de Fe empleando sales de hierro(III) y ajustando el pH mediante un hidróxido alcalino. Como resultado de la activación se observó un incremento en el contenido de hierro (expresado como $\mathrm{Fe}_{2} \mathrm{O}_{3} \%$ ), ligeramente inferior al $5 \%$ (entre $3,31 \mathrm{y}$ 4,11), manteniendo constante la relación $\mathrm{SiO}_{2} / \mathrm{Al}_{2} \mathrm{O}_{3}$. Los diagramas $\mathrm{DRX}$ de las 
muestras luego de la activación, no han revelado cambios estructurales significativos en comparación con los de las especies minerales originales, sin observarse las líneas de difracción correspondientes a formas cristalinas de óxidos de $\mathrm{Fe}$. El análisis químico de superficie para las muestras activadas ha revelado, en todos los casos de activación, un aumento superficial de hierro. Asimismo, y como consecuencia de la activación química, se produce un incremento de la superficie específica que se acompaña de una disminución del diámetro medio de poro, asociado a las fases de $\mathrm{Fe}$ (III) que se depositan sobre los meso y macro poros de las muestras originales, disminuyendo su diámetro y aumentando la superficie específica.

En relación a la remoción de As empleando minerales pobres en hierro, las muestras sin activar no resultan efectivas, lixiviando el As originalmente presente en las mismas. La activación conduce a geomateriales efectivos empleando la estrategia de eliminación de As que fuera optimizada para las arcillas ferruginosas. Para una concentración inicial de As de $1000 \mu \mathrm{g} \mathrm{L}^{-1}$, las arcillas activadas resultaron efectivas un número de ciclos comprendidos entre 5 y 27 dependiendo de las características estructurales. La asociación fase amorfa de hierro-aluminosilicato mineral, incrementa notablemente la potencialidad del sistema para la eliminación de As en aguas. Pequeños incrementos en el contenido de hierro son suficientes para aumentar el rendimiento operacional del adsorbente.

Sin embargo, se observaron diferencias entre las distintas muestras activadas, que pueden ser atribuidas a las características estructurales y de composición mineralógica. La depositación de un contenido similar de fase de hierro(III) es comparativamente más eficaz en las arcillas 2:1 (illita y pirofilita) que en la caolinita (1:1). Por otra parte, la menor efectividad mostrada en la diatomita D2 puede asociarse a la presencia de carbonato de calcio. Es de destacar que la muestra de bentonita no pudo ser evaluada por presentar un efecto de hinchamiento que imposibilitó el tratamiento en igualdad de condiciones.

Los ensayos realizados para la activación de la arcilla ferruginosa han permitido incorporar contenidos de hierro (expresados como óxido férrico) entre 1,90 y 5,28 \%. En forma similar a la observada en los minerales pobres en hierro, los difractogramas de las muestras activadas no presentaron variaciones ni en la intensidad ni en la posición de las líneas respecto a la muestra original. Los resultados EDS revelaron un incremento apreciable de hierro superficial producto de la modificación química que cubre el mineral de arcilla. Asimismo, se ha observado un incremento progresivo de la superficie específica con el agregado de los oxi/hidróxidos de hierro amorfos, que contribuyen a la reducción del diámetro medio de poro. Se observó que la activación 
incrementa la vida útil del adsorbente, aumentando para una concentración inicial de As de $1000 \mu \mathrm{g} \mathrm{L}^{-1}$ el número de ciclos efectivos de 45 hasta 70 (dependiendo del contenido de hierro agregado). Sin embargo, es de señalar que se presentaron dificultades para sedimentar las muestras y los resultados de la efectividad fueron obtenidos a partir de un tratamiento adicional de filtración. Es evidente que para evitar este último deberían analizarse distintas estrategias para mejorar la coagulación.

En relación a la necesidad de empleo de un coagulante para ayudar la sedimentación, se procedió a la obtención de coagulantes aptos en el proceso de remoción de As a partir de materias primas de bajo costo. A nivel de laboratorio fue obtenido un coagulante a base de $\mathrm{Al}(\mathrm{III})$ mediante el tratamiento de metacaolinita con $\mathrm{H}_{2} \mathrm{SO}_{4} 1: 1$ a $80^{\circ} \mathrm{C}$. En la solución obtenida la concentración de Al fue de $8823,16 \mathrm{mg}$ $\mathrm{L}^{-1}$. El empleo de $1 \mathrm{ml}$ de esta solución en el procedimiento de remoción de As fue suficiente para obtener valores adecuados de turbidez y de As. Por otra parte, a partir de la arcilla ferruginosa de la PBA se obtuvo un coagulante a base de $\mathrm{Fe}$ (III) mediante extracción con $\mathrm{HCl} 4 \mathrm{M}$ a $80{ }^{\circ} \mathrm{C}$. En la solución extraída se determinó una concentración de hierro de 1235,25 $\mathrm{mg} \mathrm{L}^{-1}$. El agregado de $16,75 \mathrm{ml}$ de esta solución resultó suficiente para obtener valores adecuados de As y de turbidez en el procedimiento de remoción. Asimismo y con el propósito de un aprovechamiento integral de los materiales naturales, el residuo sólido producto de la extracción de la metacaolinita con ácido fue activado con sales de hierro(III) obteniéndose un adsorbente con un marcado incremento de la superficie específica $\left(437,67 \mathrm{~m}^{2} \mathrm{~g}^{-1}\right)$ y un aumento en el contenido de $\mathrm{Fe}_{2} \mathrm{O}_{3}$ de 2,63\%, que resultó efectivo durante 12 ciclos en el procedimiento de remoción de As, empleando una concentración inicial de $1000 \mu \mathrm{g}$ $\mathrm{L}^{-1}$.

En lo que respecta a la disposición de los residuos del tratamiento, se realizaron ensayos tendientes a la elaboración de distintas piezas conformadas con diferentes proporciones de arcilla, conteniendo cantidades variables de arsénico. Fue posible elaborar pastas, morteros y hormigones de diferentes trabajabilidades con niveles resistentes aptos para la elaboración de bloques portantes o incluso hormigones estructurales. Por otro lado, la lixiviación del As en muestras de arcillas agotadas así como en las piezas elaboradas empleando el test EPA TCLP, se encontró por debajo del límite establecido. Los porcentajes de retención de As fueron superiores al 99\%, por lo que la técnica de cementación resultó una buena estrategia para el tratamiento de los residuos generados en la planta de remoción de As. Si bien las muestras de arcilla agotadas no son un residuo peligroso y podrían ser dispuestas sin el tratamiento de cementación en un relleno, la fabricación de hormigones o morteros permite dar un 
uso al residuo final disminuyendo los costos ambientales. Por otra parte la espectroscopía micro-Raman permitió sugerir que el arsénico interacciona químicamente con el material natural, indicando así su estabilidad. En relación al ensayo monolítico NEN 7345, los resultados de la lixiviación acumulada del elemento As para todos los hormigones, se encontraron por debajo de los límites establecidos por la normativa, determinando la estabilización del As en los mismos.

De los resultados surge que la preparación de hormigones se presentó como la alternativa más simple, económica y efectiva para aislar en forma definitiva el contaminante del medio ambiente, posibilitando la preparación de piezas aptas para su aplicación en la construcción.

Los resultados reportados en el presente trabajo de Tesis permiten demostrar que la remediación de arsénico en base al empleo de especies naturales constituye la base de una alternativa tecnológica simple y sustentable que se destaca por su sencillez operativa y el bajo costo del adsorbente y los aditivos, significando una propuesta viable de solución a un problema socio-sanitario vigente en nuestro país. 


\section{REFERENCIAS BIBLIOGRÁFICAS}

Agosto, M.F.; Canafoglia, M.E.; de Barrio, R.; Cabello, C.; Schalamuk, I.; Minelli, G. y Botto, I.L., 2005. Depósitos tobáceos terciarios zeolitizados del área de Paganzo (provincia de La Rioja). Su potencialidad tecnológica. XVI Congreso Geológico Argentino. Actas II: 847-854.

Agosto, M.F., 2012. Estudio Tecnológico de zeolitas de depósitos argentinos: su aplicación en agroindustria y protección ambiental. Tesis Doctoral FCE, UNLP.

Altundogan, H.; Altundogan, S.; Tuemen, F. and Bildik, M., 2000. Arsenic removal from aqueous solutions by adsorption on red mud. Waste Management, 20: 761-767.

Amaral de Lima, L., 1999. Hormigones con escorias de horno eléctrico como áridos: propiedades, durabilidad y comportamiento ambiental. Tesis Doctoral. Universitat Politécnica de Catalunya. Barcelona, España.

American Public Health Association (APHA), 2005. Standard Methods for the Examination of Water and Wastewater. 21th Edition. Washington, APHA, 2005.

Amiri, H.; Jaafarzadeh, N.; Ahmadi, M. and Silva Martínez, S., 2011. Application of LECA modified with Fenton in arsenite and arsenate removal as an adsorbent. Desalination, 272: 212-217.

Andac, M. and Glasser F., 1999. Long-term leaching mechanisms of Portland cement-stabilized municipal solid waste fly ash in carbonated water. Cement and Concrete Research, 29: 179186.

Anderson, R. and Dawson P., 1976. Experimental Methods in Catalytic Research. Vol. II: 44-67.

Angelelli, V., 1984. Yacimientos Metalíferos de la República Argentina. Tomo I. Comisión de Investigaciones de la provincia de Buenos Aires. Publicación Especial. 1-391.

Aredes, S.; Klein, B. and Pawlik, M., 2012. The removal of arsenic from water using natural iron oxide minerals. Journal of Cleaner Production 29-30: 208-213.

Arevalo Aranda, C., 2008. Leaching tests comparison for solidified and stabilized contaminated sediments. Assessment of selected inorganic contaminants. Master Thesis in Geosciences. University of Oslo.

Armienta, M., Castro de Esparza, M., López, C., Piñeiro, A. y Sassone, A., 2009. Determinación de arsénico por el método: absorción atómica-generación de hidruros-FIAS. En: Metodologías analíticas para la determinación y especiación de As en aguas y suelos. Editores: CYTED. Buenos Aires, Argentina. Capítulo 4: 65-78.

Arora, M., Megharaj, M. and Naidu, R., 2009. Arsenic testing field kits: some considerations and recommendations. Environmental Geochemistry and Health, 31: 45-48.

Ashraf, A.; Badruzzaman, A.; Jalil, M.; Feroze, A., Kamruzzaman, M. and Azizur Rahman, M., 2003. Fate of arsenic in wastes generated from arsenic removal units. Department of Civil 
Engineering, BangladeshUniversity of Engineering and Technology, Dhaka; 2003. http://www.unu.edu/env/Arsenic/Dhaka2003.

Auge, M., 2004. Regiones hidrogeológicas. República Argentina, 2004. En www.gl.fcen.uba.ar/investigacion/grupos/hidrogeologia/auge/Reg-Hidrogeo.pdf. Acceso el $11 / 10 / 2013$.

Auge, M., 2009. Arsénico en el agua subterránea. Federación Médica de la Provincia de Buenos Aires. Inédito. 1-15. La Plata.

Auge, M.; Espinosa Viale, G. y Sierra, L., 2013. Arsénico en el agua subterránea de la Provincia de Buenos Aires. En: Agua Subterránea recurso estratégico. Ed. N. González, E. Kruse, M.M. Trovato y P. Laurencena. Tomo II: 58-63.

Ayerza, A., 1917. Arsenicismo regional endémico (keratodermia y melanodermia combinadas). Boletín Academia Medicina, 2-3: 11-24.

Bang, S.; Patel, M.; Lippincott, L. and Meng, X., 2005. Removal of arsenic from groundwater by granular titanium dioxide adsorbent. Chemosphere, 60: 389-397.

Blaha, J. and Rosasco, G., 1978. Raman microprobe spectra of individual microcrystals and fibers of talc, tremolite, and related silicate minerals. Analytical Chemistry, 50: 892-896).

Belver, C.; Bañares, M. y Vicente, M., 2004. Materiales con propiedades tecnológicas obtenidos por modificación química de un caolín natural. Boletín de la Sociedad Española de Cerámica y Vidrio, 43: 148-154.

Bergaya, F. and Lagaly, G., 2006. General introduction: Clays, Clay Minerals and clay science. In: Handbook of Clay Science. Edited by F. Bergaya, B.K.G. Theng and G. Lagaly. Developments in Clay Science, Vol. 1. Chapter 1: 1-18.

Bhattacharya, R.; Jand, J.; Nath, B.; Sahu, S.; Chatterjee, D. and Jacks, G, 2003. Groundwater arsenic mobilization in the Bengal Delta Plain, the use of ferralite as a possible remedial measure-a case a study. Applied Geochemestry, 18: 1435-1451.

Bhattacharya, A.; Naiya, T.; Mandal, S. and Das, S., 2008. Adsorption, kinetics and equilibrium studies on removal of $\mathrm{Cr}(\mathrm{VI})$ from aqueous solutions using different low-cost adsorbents. Chemical Engineering Journal, 137: 529-541.

Bobos, I.; Duplay, J.; Rocha J. and Gomes, C., 2001. Kaolinite to halloysite-7A transformation in the kaolin deposit of Sao Vicente de Pereira, Portugal. Clays and Clay Minerals, 49: 596607.

Bordeepong, S.; Bhongsuwan, D.; Pungrassami, T. and Bhongsuwan, T., 2011. Characterization of halloysite from Thung Yai District, Nakhon Si Thammarat Province, in Southern Thailand. Songklanakarin. Journal Science and Technology, 33: 599-607. 
Botto, I.; Barone, V.; Sanchez, M. y Schalamuk, I. 2000. Correlation between reducibility and composition of natural wolframite in Argentinian ore deposits. Mineralogical Magazine, 64: 497-505.

Bradl, H., 2004. Adsorption of heavy metal ions on soils and soils constituents. Journal of Colloid and Interface Science, 277: 1-18.

Brigatti, M.; Galan, E. and Theng, B., 2006. Structures and Mineralogy of Clay Minerals. In: Handbook of Clay Science. Edited by F. Bergaya, B.K.G. Theng and G. Lagaly. Developments in Clay Science, Vol. 1. Chapter 2: 19-86.

Brown, G. and Brindley, G., 1980. X-ray diffraction procedures for clay mineral identification. In Crystal Structures of Clay Minerals and Their X-Ray Identification. Brindley, G. and Brown, G., edit. Mineralogical Society: 305-359.

Brunauer, S.; Emmett, P. and Teller, E., 1938. Adsorption of gases in multimolecular layers. Journal of the American Chemical. Society, 60: 309-319.

Bundschuh, J., Bhattacharya, P. and Chandrasekharam, D., 2005. Remediation of arsenic-rich groundwater. En: Natural Arsenic in Grounwater: occurrence, remediation and management. Section 4. Taylor \& Francis Group, London.

Bundschuh, J.; Bhattacharya, P.; Sracek, O.; Mellano, M.; Ramírez, A.; Storniolo, A.; Martín, R.; Cortés, J.; Litter, M. and Jean, J., 2011. Arsenic removal from groundwater of the ChacoPampean Plain (Argentina) using natural geological materials as adsorbents. Journal of Environmental Science and Health Part A, 46: 1297-1310.

Bundschuh, J.; Litter, M.; Parvez, F.; Román-Ross, G.; Nicolli, H.; Jean, J.; Liu, J.; López, D.; Armienta, M.; Guilherme, L.; Gomez Cuevas, A; Cornejo, L.; Cumbal, L. and Toujaguez, R., 2012. One century of arsenic exposure in Latin America: A review of history and occurrence from 14 countries. Science of the Total Environment, 429: 2-35.

Candal, R., 1995. Estudio fisicoquímico de la síntesis por precipitación homogénea de precursores de óxidos metálicos pulvurulentos. Tesis Doctoral FCEyN UBA.

Castro de Esparza, M.L., 2006. Remoción del arsénico en el agua para bebida y biorremediación de suelos. International Congress Mexico City, 20-24 June 2006 Natural Arsenic in Groundwaters of Latin America.

Castro de Esparza, M.L. y Wong de Medina, M., 1998. Abatimiento de arsénico en aguas subterráneas para zonas rurales. XXVI Congreso Interamericano de Ingeniería Sanitaria y Ambiental. AIDIS. www.bvsde.paho.org/acrobat/percca02.pdf.

Castro de Esparza, M.; Litter, M.; Wong, M. y Mori, V., 2009. Métodos espectrofotométricos UVVis. En: Metodologías analíticas para la determinación y especiación de As en aguas y suelos. Editores: CYTED. Buenos Aires, Argentina. Capítulo 3: 43-64. 
Celis, R.; Cornejo J. and Hermosin, M., 1998. Textural properties of synthetic clay-ferrihydrite associations. Clay Minerals, 33: 395-407

Código Alimentario Argentino (CAA), 2012. Capítulo XII. Bebidas hídricas, agua y agua gasificada. En: http://www.anmat.gov.ar/alimentos/codigoa/CapituloXII.pdf. Acceso el $11 / 11 / 13$

CONAPRIS (Comisión Nacional de Programas de Investigación Sanitaria. Ministerio de Salud de la Nación). UNIDA (Unidad de Investigación y Desarrollo Ambiental. Secretaría de Ambiente y Desarrollo Sustentable de la Nación). ATA (Asociación Toxicológica Argentina), 2006. Epidemiología del Hidroarsenicismo Crónico Regional Endémico (HACRE) en la República Argentina: Estudio colaborativo multicéntrico. Buenos Aires. 200 pp.

Cornell R.; Giovanoli, R. and Schindler, P., 1987. Effect of silicate species on the transformation of ferrihydrite into goethite and hematite in alkaline media. Clays and Clay Minerals, 35: 2128.

Cornell, R.; Giovanoli, R. and Schneider, W., 1989. Review of the hydrolysis of Fe(III) and the crystallization of amorphous $\mathrm{Fe}$ (III) hydroxide hydrate. Journal of Chemical and Technology and Biotechnology, 46: 115-134.

Cornell R. and Schwertmann, U., 2003. The iron oxides. Structure, Properties, Reactions, Occurrences and Uses. Second, completely revised and extended Edition. Wiley-VCH edi. $664 \mathrm{pp}$.

Cravero, F.; Martínez, G. y Pestalardo, F., 2009. Yacimientos de Halloysita en Mamil Choique, provincia de Río Negro, Patagonia. Revista de la Asociación Geológica Argentina, 65: 586592.

Cogollo Flórez, J., 2011. Clarificación de aguas usando coagulantes polimerizados: caso del hidroxicloruro de aluminio. Dyna, 165: 18-27.

Cortina, J.; Fiúza, A.; Silva, A. y Litter, M., 2010. Tecnologías de tratamiento in-situ de aguas subterráneas. En: Tecnologías económicas para el abatimiento de arsénico en aguas. Ed.: M. Litter, A.M. Sancha y A.M. Ingallinella. Argentina. 111-144.

Cullity, B., 1967. Elements of X-Ray Diffraction. Addison-Wesley Pub. Co. New York.

Chen, W.; Parette, R.; Zou, J.; Cannon, F. and Dempsey, B., 2007. Arsenic removal by ironmodified activated carbon. Water Research, 41: 1851-1858.

Chukanov, N., 2014. Infrared spectraof mineral species. Springer Dordrecht Heidelberg New York London.

Churchman, G.; Gates, W.; Theng, B. and Yuan, G., 2006. Clays and Clay Minerals for Pollution Control. In: Handbook of Clay Science. Edited by F. Bergaya, B.K.G. Theng and G. Lagaly. Developments in Clay Science, Vol. 1. Chapter 11.1: 625-675. 
D’Ambrosio, M. C, 2005. Evaluación y selección de tecnologías disponibles para remoción de arsénico. En: Arsénico en aguas: origen, movilidad y tratamiento. Ed.: G. Galindo, Fernández Turiel, M. Parada y D. Torrente. IV Congreso Hidrogeológico Argentino. Río Cuarto, Argentina. 123-136.

Danieli, J.; Franchini, M.; Impiccini, A.; Casé, A.; Schalamuk, I. y Deza, M., 2002. Presencia de Pirofilita del Arroyo Auquén, Varvarcó, Neuquén. XV Congreso Geológico Argentino, Actas: 406-411.

Das, S. and Hendry, M., 2011. Application of Raman spectroscopy to identify iron minerals commonly found in mine wastes. Chemical Geology, 290: 101-108.

Davis, F.; Fuller, C.; Rea, B. and Waychunas, G., 1993. Surface chemistry of ferrihydrite: Part 1. EXAFS studies of the geometry of coprecipitated and adsorbed arsenate. Geochimica et Cosmochimica Acta, 57: 2251-2269.

Decreto 831/93, Ley Nacional № 24051/92 de Residuos Peligrosos, Boletín Oficial, Argentina, 1993.

de Faria, D.; Silva, S. and de Oliveira, M., 1997. Raman microspectroscopy of some iron oxides and oxyhydroxides. Journal of Raman Spectroscopy, 28. 873-878.

Dirección de Minería de la Nación, 2012. Estadística Minera de Argentina. Informe Interno.

Dixit, S. and Hering J., 2003. Comparison of arsenic(V) and arsenic(III) sorption onto iron oxide minerals: implications for arsenic mobility. Environmental Science and Technology, 37: 4182-4189.

Djomgoue, P and Njopwouo D, 2013. FT-IR Spectroscopy applied for surface clays characterization. Journal of Surface Engineered Materials and Advanced Technology, 3: 275-282.

Domínguez, E. y Schalamuk, I., 1999. Recursos Minerales de las Sierras Septentrionales de la provincia de Buenos Aires. En Recursos Minerales de la República Argentina (ed. E.O. Zappettini, Instituto de Geología y Recursos Minerales SEGEMAR, Anales 35: 183-190.

Doušová, B.; Grygar, T.; Martaus, A.; Fuitová, L.; Koloušek, D. and Machovic, V., 2006. Sorption of $A s(V)$ on aluminosilicates treated with $\mathrm{Fe}(\mathrm{II})$ nanoparticles. Journal of Colloid and Interface Science, 302: 424-431.

Doušová, B.; Fuitová, L.; Grygar, T.; Machovic, V.; Koloušek, D.; Herzogová, L. and lhotka, M., 2009. Modified aluminosilicates as low-cost sorbents of As(III) from anoxic groundwater. Journal of Hazardous Materials, 165: 134-140.

Elizalde González, M.; Mattusch, J.; Wennrich, R. and Morgenstern, P, 2001. Uptake of arsenite and arsenate by clinoptilolite rich tufos. Microporous and Mesoporous Mater, 46: 277-286. 
EPA, 1992. Method 3020A: Acid digestion of aqueous samples and extracts for total metals for analysis by GFAA Disponible en: http://www.epa.gov/wastes/hazard/testmethods/sw846/pdfs/3020a.pdf.

EPA, 1992. Method 7061A: Arsenic (atomic absorption, gaseous hydride). Disponible en: http://www.epa.gov/wastes/hazard/testmethods/sw846/pdfs/7061a.pdf.

EPA, 1999. Analytical Methods Support Document for Arsenic In Drinking Water. EPA -815-R00-010.

EPA, 2007. Method 7010: Graphite furnace atomic absortion spectrophotometry. Disponible en: http://www.epa.gov/osw/hazard/testmethods/sw846/pdfs/7010.pdf

EPA, 2007. Method 7020: Aluminium atomic absortion. Disponible en: http://epa.gov/wastes/hazard/testmethods/sw846/pdfs/7020.pdf.

EPA, 2007. Method 7380: Iron atomic absortion. Disponible en: http://epa.gov/wastes/hazard/testmethods/sw846/pdfs/7380.pdf.

Eslinger, E. and Pevear, D. 1988. Clay minerals and log analysis, chapter 9. In Clay minerals for petroleum geologists and engineers. Society of Economic Mineralogists and Paleontologists, Short Course Notes $\mathrm{N}^{\circ}$. 22: 2-12.

Farmer, V., 1974. Infrared Spectra of Minerals. Mineralogical Society. London. Chapter 15: 331363.

Fernández, R.; Tessone, M.; Etcheverry, R.; Echeveste, H.; Coriale, N. y Caballé, M., 2010. Interpretación de la distribución de elementos de las tierras raras en el basamento alterado de la zona de San Manuel, provincia de Buenos Aires. Revista de la Asociación Geológica Argentina, 67: 216-230.

Fernández-Olmo, I.; Chacón, E. y Irabien, A., 2003. Leaching Behavior of Lead, Chromium (III) and Zinc in Cement/Metal Oxide Systems. Journal of Environmental Engineering, 129: 532538.

Fernández-Turiel, J.L.; Galindo, G.; Parada, M.A.; Gimeno, D.; García-Vallés, M. y Saavedra, J., 2005. Estado actual del conocimiento sobre el arsénico en el agua de Argentina y Chile: origen, movilidad y tratamiento. En: Arsénico en aguas: origen, movilidad y tratamiento. Ed.: G. Galindo, Fernández Turiel, M. Parada y D. Torrente. IV Congreso Hidrogeológico Argentino. Río Cuarto, Argentina. 1-22.

Filippi, M.; Machovič, V.; Drahota, P. and Böhmová, V., 2009. Raman microspectroscopy as a valuable additional method to X-ray diffraction and electron microscope/microprobe analysis in the study of iron arsenates in environmental samples. Applied Spectroscopy, 63: 621-626.

Foo, C.; Mahmood, C. and Mohd Salleh, M., 2011. The study of aluminum loss and consequent phase transformation in heat-treated acid-leached kaolin. Materials Characterization, 62: 373-377. 
Frost, R., 1995. Fourier Transform Raman Spectroscopy of Kaolinite, Dickite and Halloysite. Clays and Clay Minerals, 43: 191-195.

Frost, R. and Griffin, R., 1977. Effect of $\mathrm{pH}$ on adsorption of arsenic and selenium from landfill leachate by clay minerals. Soil Science Society of America Journal, 41: 53-57.

Fu, F. and Wang, Q., 2011. Removal of heavy metal ions from wastewaters: A review. Journal of Environmental Management, 92: 407-418.

García, S., 2012. Hidroarsenicismo crónico regional endémico argentino. A 100 años de su descubrimiento. Ciencia e Investigación, 62 (3): 5-26.

Ghafari, S.; Abdul, H.; Hasnain, M. and Akbar, A. 2008. Application of response surface methodology (RSM) to optimize coagulation-flocculation treatment of leachate using polyaluminum chloride (PAC) and alum. Journal of Hazardous Materials, 163: 650-656.

Genazzini, C.; Zerbino, R.; Ronco, A.; Batic, O. and Giaccio, G., 2003. Hospital waste ashes in Portland cement mortars. Cement and Concrete Research, 33: 1643-1650.

Giles, D.; Mohapatra, M.; Issa, T.; Anand, S. and Singh, P., 2011. Iron and aluminium based adsorption strategies for removing arsenic from water. Journal of Environmental Management, 92: 3011-3022.

Goldberg, S., 2002. Competitive Adsorption of Arsenate and Arsenite on Oxides and Clay Minerals. Soil Science Society of American Journal, 66:413-421.

Goldberg, S. and Johnston, C., 2001. Mechanisms of Arsenic Adsorption on Amorphous Oxides Evaluated Using Macroscopic Measurements, Vibrational Spectroscopy and Surface Complexation Modeling. Journal Colloid and Interface Science, 234: 204-216.

Gonsebatt, M. E., 2012. Arsénico y salud. Ciencia e Investigación, 62 (3): 27-37.

Goyenechea, M., 1917. Sobre la nueva enfermedad descubierta en Bell-Ville. Revista Médica de Rosario, 7: 485.

Guo, H.; Stüben, D. and Berner, Z., 2007. Removal of arsenic from aqueous solution by natural siderite and hematite. Applied Geochemistry, 22: 1039-1051.

Guo, H.; Stüben, D., Berner, Z. and Yu, Q., 2009. Characteristics of arsenic adsorption from aqueous solution: effect of arsenic species and natural adsorbents. Applied Geochemistry, 24: 657-663.

Gutzeit, H., 1891. Pharmazeutische Zeitung 36: 748-756.

Halim, C.; Amal, R.; Beydoun, D.; Scott, J. and Low, G., 2004. Implications of the structure of cementitious wastes containing $\mathrm{Pb}(\mathrm{II}), \mathrm{Cd}(\mathrm{II}), \mathrm{As}(\mathrm{V})$, and $\mathrm{Cr}(\mathrm{VI})$ on the leaching of metals. Cement and Concrete Research, 34:1093-102. 
Hanesch, M., 2009. Raman spectroscopy of iron oxides and oxy(hydroxides) at lower laser power and possible application in environmental magnetic studies. Geophysical Journal International, 177: 941-948.

Harper, T. and Kingham, N., 1992. Removal of arsenic from wastewater using chemical precipitation methods. Water Environmental Research, 64: 200-203.

Haque, N.; Morrison, G.; Cano-Aguilera, I. and Gardea-Torresdey, J., 2008. Iron-modified light expanded clay aggregates for the removal of arsenic(V) from groundwater. Microchemical Journal, 88: 7-13.

Hernández, M.; González, N.; Trovatto, M.; Ceci, H. y Hernández, L., 2005. Sobre los criterios para el establecimiento de umbrales de tolerancia de Arsénico en aguas de bebida. En: Arsénico en aguas: origen, movilidad y tratamiento. Ed.: G. Galindo, Fernández Turiel, M. Parada y D. Torrente. IV Congreso Hidrogeológico Argentino. Río Cuarto, Argentina. 167172.

Hidalgo, A. y Alonso, C., 2005. Evaluación del impacto medioambiental debido a la lixiviación de productos de base cemento. 1as Jornadas de Investigación en Construcción. Instituto de Ciencias de la Construcción Eduardo Torroja (CSIC), Madrid, España.

Hillier, S.; Sangha, C.; Plunkett, B. and Walden, P., 1999. Long-term leaching of toxic trace metals from Portland cement concrete. Cement and Concrete Research, 29: 515-521.

Hingston, F.; Posner, A. and Quirk, J., 1972. Anion adsorption by goethite and gibbsite. I. The role of the proton in determining adsorption envelopes. Journal of Soil Science 23: 177-192.

Höll, W. y Litter, M., 2010. Ocurrencia y química del arsénico en aguas. Sumario de tecnologías de remoción de arsénico en aguas. En: Tecnologías económicas para el abatimiento de arsénico en aguas. Ed.: M. Litter, A.M. Sancha y A.M. Ingallinella. Argentina. 17-32.

Hsia, T.; Lo, S. and Lin, C., 1994. Characterization of arsenate adsorption on hydrous Fe oxide using chemical and physical methods. Colloids Surface A: Physicochemical and Engineering Aspects, 5: 1-7.

International Agency for Research on Cancer, 1987. Overall evaluations of carcinogenicity: an updating of IARC Monographs volumes 1-42. Lyon, 100-106. (IARC Monographs on the evaluation of carcinogenic risks to humans, Suppl. 7).

Iñiguez, M.; del Valle, A.; Poiré, D.; Spalletti, L. y Zalva, P., 1989. Cuenca precambrica/paleozoica inferior de Tandilla. Provincia de Buenos Aires. En: Chebli G y L Spalleti (Eds). Cuencas sedimentarias Argentinas, 1989. Serie Correlación Geológica, 6: 245-263.

IRAM, 1962. Norma IRAM 1622. Cemento Portland. Método de determinación de las resistencias a compresión y a la flexión. Instituto Argentino de Racionalización de Materiales. 
IRAM, 1997. Norma IRAM 11561. Bloques de hormigón. Absorción de agua y densidad. Instituto Argentino de Racionalización de Materiales.

Jain, A.; Raven, K. and Loeppert, R., 1999. Arsenite and arsenate adsorption on ferrihydrite: surface charge reduction and net $\mathrm{OH}$ Release stoichiometry. Environmental Science and Technology, 33: 1179-1184.

Jesen, S.; Larsen, F.; Bender Koch, C. and Arvin, E., 2005. Sorption and desorption of arsenic to ferrihydrite in a sand filter. Environmental Science and Technology, 39: 8045-8051.

Jeon, C.; Baek, K.; Park, J.; Oh, Y. and Lee, S., 2009. Adsorption characteristics of As(V) on iron-coated zeolite. Journal of Hazardous Materials, 163: 804-808.

Jeong, Y.; Fan, M.; Singh, S.; Chuang, C.; Saha, B. and Hans van Leeuwen, J., 2007. Evaluation of iron oxide and aluminum oxide as potential arsenic(V) adsorbents. Chemical Engineering and Processing 46: 1030-1039.

Jessen, S.; Larsen, F.; Bender Koch, Ch. and Arvin, E., 2005. Sorption and desorption of arsenic to ferrihydrite in a sand filter. Environmental Science and Technology, 39: 80458051.

Jia, Y.; Xu, L.; Fang, Z. and Demopoulos, G., 2006. Observation of Surface Precipitation of Arsenate on Ferrihydrite. Environmental Science and Technology, 40: 3248-3253.

Jochum, K.; Seufer, H. and Thirwall, M., 1990. Hight-sensitivity Nb analysis by spark source mass spectrometry (SSMS) and calibration of XRF Nb and Zr. Chemical Geology, 81: 1-16.

Jones, A. and McNicol, B. 1986. Temperature Programmed reduction of Solid Materials Characterization. Marcel Dekker Inc., New York, USA.

Jones F. T., 2007. A Broad View of Arsenic. Poultry Science, 86: 2-14.

Joshi, A. and Chaudhuri, M., 1996. Removal of Arsenic from Ground Water by Iron OxideCoated Sand. Journal of Environmental Engineering, 122: 769-771.

Klein, C. and Hurlbut, C., 1997. Manual de Mineralogía. Cuarta Edición. Capítulo 13: Parte IV: Silicatos. Editorial Reverté. Barcelona, 1997.

Lantenois, S.; Bény, J.; Muller, F. and Champallier, R., 2007. Integration of iron in natural and synthetic Al-pyrophyllites: An infrared spectroscopic study. Clay Minerals 42: 129-143.

Legodi, M. and de Waal, D., 2007. The preparation of magnetite, goethite, hematite and maghemite of pigment quality from mill scale iron waste. Dyes and Pigments, 74: 161-168.

Letterman, R. and Asolekar, S., 1990. Surface ionization of polynuclear species in Al(III) hydrolysisII. A conditional equilibrium model. Water Research, 24: 941-948.

Leyva Ramos, R., 2010. Fundamentos de adsorción en sistemas líquido-sólido. En: Tecnologías económicas para el abatimiento de arsénico en aguas. Ed.: M. Litter, A.M. Sancha y A.M. Ingallinella. Argentina. 43-58. 
Litter, M. y Morgada, M., 2009. Formas arsenicales en agua y suelos. En: Metodologías analíticas para la determinación y especiación de arsénico en aguas y suelos. Capítulo 1: 19-28.

Loh, E., 1973. Optical vibrations in sheet silicates. Journal of Physics C: Solid State Physics, 6: 1091-1104.

López Escobar, K., 2006. Geología y mineralogía de los depósitos de arcilla "Don Camilo", "La Elvira", "Los Cardales" y "El Ceferino", Sierras Septentrionales de la provincia de Buenos Aires, Argentina. Tesis Doctoral FCNyM, UNLP.

Maji, S.; Pal, A. and Pal, T., 2008. Arsenic removal from real-life groundwater by adsorption on laterite soil. Journal of Hazardous Materials, 151: 811-820.

Malviya, R. and Chaudhary, R., 2006. Leaching behaviour and immobilization of heavy metals in solidified/stabilized products. Journal of Hazardous Materials, 137: 207-217.

Mamindy-Pajany, Y.; Hurel, Ch.; Marmier, N. and Roméo, M., 2009. Arsenic adsorption onto hematite and goethite. Comptes Rendus Chimie, 12: 876-881.

Mamindy-Pajany, Y; Hurel, Ch.; Marmier, N. and Roméo, M., 2011. Arsenic(V) adsorption from aqueous solution onto goethite, hematite, magnetite and zero-valent iron: Effects of $\mathrm{pH}$, concentration and reversibility. Desalination, 281: 93-99.

Mandal, B and Suzuki, K., 2002. Arsenic round the world: a review. Talanta, 58: 201-235.

Manning T. and Grow W., 1997. The chemical Educator 1. Volume 2, $\mathrm{N}^{\circ} 1$ (http://journals.springer-ny.com/chedr), Springer-Verlag, New York.

Mañay, N.; Clavijo, G. y Díaz, L., 2009. Absorción atómica con horno de grafito. En: Metodologías analíticas para la determinación y especiación de As en aguas y suelos. Editores: CYTED. Buenos Aires, Argentina. Capítulo 5: 79-92.

Method EPA1311, Toxicity Characteristic Leaching Procedure (TCLP), USEPA, 1990. Test methods for evaluating solid waste. SW-846, Office of Solid Waste and Emergency Response, Washington DC, United States Environmental Protection Agency.

Michel ,F.; Ehm, L.; Antao, S.; Lee, P.; Chupas, P.; Liu, G.; Strongin, D.; Schoonen, M.; Phillips, B. and Parise, J., 2007. The structure of ferrihydrite, a nanocrystalline material. Science, 316: 1726-1729.

Ministerio de Educación, 2011. Programa Nacional Mapa Educativo. En: http://www.mapaeducativo.edu.ar/images/stories/men/mapa riesgo arsenico.jpg. Acceso el: 13/02/13.

Minning, B. and Goldberg, S., 1996. Modeling arsenate competitive adsorption on kaolinite, montmorillonite and illite. Clays and Clay Minerals, 44: 609-623. 
Mollah, Y.; Kesmez, M. and Cocke, D., 2004. An X-ray diffraction and Fourier transform infrared spectroscopic investigation of the long-term effect on solidification/stabilisation of arsenic(V) in Portland cement type-V. Science of the Total Environmental, 325: 255-262.

Morgada, M. y Litter, M., 2010. Tecnologías fotoquímicas y solares para la remoción de arsénico de soluciones acuosas. Estado del arte. En: Tecnologías económicas para el abatimiento de arsénico en aguas. Ed.: M. Litter, A.M. Sancha y A.M. Ingallinella. Argentina. 73-90.

Mudgal, A., 2001. A draft review of the household arsenic removal technology options. Rural Water Supply Network; 2001. http://www.htnweb.com.

Mulvihill, M.; Tao, A.; Benjauthrit, K.; Arnold, J. and Yang, P., 2008. Surface-enhanced Raman spectroscopy for trace Arsenic detection in contaminated water. Angewandte Chemie, 47: 6456-6460.

Müller, K.; Ciminelli, V., Dantas, M. and Willscher, S., 2010. A comparative study of As(III) and As $(V)$ in aqueous solutions and adsorbed on iron oxy-hydroxides by Raman spectroscopy. Water Research, 44: 5660-5672.

Myneni, S.; Traina, S.; Waychunas, G. and Logan, T., 1998. Experimental and theorethical vibrational spectroscopic evaluation of arsenate coordination in aqueous solutions, solids and at mineral-water interfaces. Geochimica et Cosmochimica Acta, 62: 3285-3300.

Nagano, T.; Mitamura, H.; Nakayama, S. and Nakashima, S., 1999. Formation of goethite and hematite from neodymium-containing ferrihydrite suspensions. Clays and Clay Minerals, 47: 748-754.

Nakamoto, K., 1986. Infrared and Raman Spectra of Inorganic and Coordination Compounds, John Wiley \& Sons.

Naranjo-Merchán, W.; Gaviria-Melo, S. y Manosalva-Sánchez, S., 2007. Mineralogía y Geoquímica de Diatomitas (Boyacá, Colombia). Geología Colombiana № 32: 77-88.

Navoni, J.; De Pietri, D.; García, S. y Villamil Lepori, E., 2012. Riesgo sanitario de la población vulnerable expuesta al arsénico en la provincia de Buenos Aires, Argentina. Revista Panam Salud Pública, 31:1-8.

Navrotsky, A.; Mazeina, L. and Majzlan, J., 2008. Size-driven structural and thermodynamic complexity in iron oxides. Science, 319: 1635-1638.

NEN 7345. 1995. Leaching characteristics of builfing and solid waste materials Leaching tests: Determination of the leaching behaviour of inorganic components from shaped building materials, monolithic and stabilized waste materials. Netherlands Standardization Institute (NNI). 
Nicolli, H.; Tineo, A.; García, J.; Falcón, C.; Merino, M., 2001. Trace-element quality problems in groundwater from Tucumán, Argentina. In: Cidu, R. (Ed.), Water-Rock Interaction 2001. Swets \& Zeitlinger, Lisse. Vol. 2: 993-996.

Nicolli, H.; Bundschuh, J.; Blanco, M.; Tujchneider, O.; Panarello, H.; Dapeña, C. and Rusansky, J., 2012. Arsenic and associated trace-elements in groundwater from the ChacoPampean plain, Argentina: Results from 100 years of research. Science of the Total Environment 429: 36-56.

Nigro, J.; Delgado, M.; Tessone, M.; Fernández, R.; Etcheverry, R. y Carlini, M., 2013. Correlación mineralógica y geoquímica de la formación Las Águilas entre Sierra de La Juanita y Cuchilla Las Águilas, Barker, Buenos Aires. X Congreso Argentino de Geología Económica: 119-125.

Oh, S., Cook, D. and Townsend, H., 1998. Characterization of iron-oxides commonly formed as corrosion products on steel. Hyperfine Interactions, 112: 59-65.

OMS, 1958. International Standards for Drinking-water. Geneva.

OMS, 1971. International Standards for Drinking-water. Third Edition. Geneva.

OMS, 1993. Guidelines for Drinking-water Quality. Geneva, Vol. 1. Recommendations.

OMS, 2003. Arsenic in drinking water. Background document for preparation of OMS Guidelines for Drinking-water Quality (OMS/SDE/WSH/03.04/75).

OMS, 2012. Nota descriptiva No 372: Arsénico. En: www.who.int/mediacentre/factsheets/fs372/es. Acceso el: 07/11/13.

Ondrus, P.; Skala, R.; Viti, C.; Veselovsky, F.; Novak, F. and Jansa, J., 1999. Parascorodite, $\mathrm{FeAsO}_{4} \cdot 2 \mathrm{H}_{2} \mathrm{O}-\mathrm{a}$ new mineral from Kank near Kutná Hora, Czech Republic. American Mineralogist, 84: 1439-1444.

O'Reilly, S.; Strawn, D. and Sparks, D., 2001. Residence Time Effects on Arsenate Adsorption/Desorption Mechanisms on Goethite. Soil Science Society of American Journal, 65: 67-77.

Pacheco Belzunces, A., 2009. Normativa ambiental aplicable a productos de la construcción. Estado del arte. Codi: 706-TRE-OP-4308. Universitat Politécnica de Catalunya. Barcelona, España.

Paglia, G.; Bozin, E. and Billinge, S., 2006. Fine-Scale Nanostructure in $\mathrm{y}-\mathrm{Al} \mathrm{I}_{2} \mathrm{O}_{3}$. Chemistry of Materials, 18: 3242-3248.

Pankhurst, Q. and Pollard, R., 1992. Structural and magnetic properties of ferrihydrite. Clays and Clay Minerals, 40: 268-272.

Payne, K. and Abdel-Fattah, T., 2005. Adsorption of arsenate and arsenite by Fe-treated activated carbon and zeolites: effects of $\mathrm{pH}$, temperature, and ionic strength. Journal Environmental Science and Health A, 40: 723-749. 
Pierce, M. and Moore, C., 1980. Adsorption of arsenite on amorphous iron hydroxide from dilute aqueous solution. Environmental Science and Technology, 14: 214-216.

Pierce, M. and Moore, C., 1982. Adsorption of arsenite and arsenate on amorphous iron hydroxide. Water Research, 16: 1247-1253.

Rahman, M.; Ng, J. and Naidu, R., 2009. Chronic exposure of arsenic via drinking water and its adverse health impacts on humans. Environ Geochem Health, 31:189-200.

Raven, K.; Jain, A. and Loeppert, R., 1998. Arsenite and arsenate adsorption on ferrihydrite: kinetics, equilibrium, and adsorption envelopes. Environmental Science and Technology, 32 : 344-349.

Riveros, P.; Dutrizac, J. and Spencer, P., 2001. Arsenic disposal practices in the metallurgical industry. Canadian Metallurgical Quarterly, 40: 395-420.

Rouf, A. and Hossain D., 2003. Effects of using arsenic-iron sludge in brick making. Bangladesh University of Engineering and Technology. Archive.unu.edu/env/Arsenic/Dhaka2003/15Rouf.pdf.

Ryczel, M., 2011. Epidemiología del Hidroarsenicismo Crónico Regional Endémico en Argentina. $1^{\circ}$ Taller "El arsénico como factor limitante en la producción agrícola-ganadera". 2 de Septiembre de 2011. Conferencia.

Sadiq, M., 1997. Arsenic chemistry in soils: an overview of thermodynamic prediction and field observations. Water, Air \& Soil Pollution 93: 117-136.

Sancha, A., 2010. Remoción de arsénico por coagulación y precipitación. En: Tecnologías económicas para el abatimiento de arsénico en aguas. Ed.: M. Litter, A.M. Sancha y A.M. Ingallinella. Argentina. 33-42.

Sánchez de Guzmán, D., 2001. Tecnología del concreto y del mortero. Bhandar Editores Ltda. Bogotá, Colombia.

Schalamuk, I.; Fernández, R. y Arrospide, A., 1989. Yacimientos Metalíferos. Principales Ciclos y provincias metalogenéticas. Geología de América del Sur. Serie Correlación Geológica n'2. Tomo V: 151-212.

Schalamuk, I.; Azarevich, M. y López, V., 2004. Estudio de diatomitas del área Salar del Rincón, provincia de Salta. Informe Inédito. Trabajo a Terceros FCNyM-UNLP.

Schalamuk, I.; Azarevich, M. y López, V., 2011. Yacimientos Ooliticos de Hierro. Provincia de Jujuy y Salta. Informe Inédito. Trabajo a Terceros FCNyM-UNLP.

Schoonheydt, R. and Johnston, C., 2006. Surface and Interface Chemistry of Clay Minerals. In: Handbook of Clay Science. Edited by F. Bergaya, B.K.G. Theng and G. Lagaly. Developments in Clay Science, Vol. 1.Chapter 3: 87-114.

Schwertmann, U. and Cornell, R., 2000. Iron oxides in the laboratory. Preparation and Characterization. Second, completely revised and extended Edition. Wiley VCH. 188 pp. 
Senado y Cámara de Diputados de la provincia de Buenos Aires, 2012. Ley Provincial 11.820. En: www.ms.gba.gov.ar/sitios/laboratorio/files/2012/06/Ley11820.pdf. Acceso el: $11 / 11 / 2013$.

Shannon, R., 1979. Effective ionic radie. Acta Crystallographica. A, 32: 1957-1968.

Sidorov, T., 2007. Raman spectra and molecular structure of silicates. Russian Journal of Inorganic Chemistry, 52: 1586-1594.

Silva, J. y Ciminelli, V., 2009. Tratamiento de las muestras de agua, suelos y sedimentos para determinación de As. En: Metodologías analíticas para la determinación y especiación de As en aguas y suelos. Editores: CYTED. Buenos Aires, Argentina. Capítulo 2: 29-42.

Skoog, D.; Holler, J. and Nieman, T., 2001 .Principios de análisis instrumental. $5^{\text {ta }}$ Edición. Mc Graw Hill.

Smedley P. and Kinninburgh, D., 2002. A review of the source, distribution and behavior of arsenic in natural waters. Applied Geochemistry 17: 517-568.

Smedley, P.; Nicolli, H.; Macdonald, D.; Barros, A. and Tullio, J., 2002. Hydrogeochemistry of arsenic and other inorganic constituents in groundwaters from La Pampa, Argentina. Applied Geochemistry, 17: 259-284.

Smith, W., 1998. Fundamentos de la ciencia e ingeniería de los materiales. $3^{\circ}$ Edición. Ed. McGrawttill. Capítulo 14: 660-669.

Spence, R. and Shi, C. 2005. Stabilization and solidification of hazardous, radioactive, and mixed wastes. Boca Raton, FL: CRC Press. 378 pp.

Stol, R.; Helden, A. and de Bruyn P., 1976. Hydrolysis-precipitation studies of aluminum (III) solutions. 2. A kinetic study and model. Journal of Colloid and Interface, 57: 115-131.

Stollenwerk, K., 2003. Geochemical Processes Controlling Transport of Arsenic in Groundwater: A Review of Adsorption. En: Arsenic in groundwater: geochemistry and occurrence. Chapter 3: $67-100$.

Stumm, W. and O'Melia, C., 1968. Stoichiometry of coagulation. Journal American Water Works Association, 60: 514-539.

Suarez, D.; Goldberg, S. and Su, C., 1998. Evaluation of oxyanion adsorption mechanisms on oxides using FTIR spectroscopy and electrophoretic mobility. American Chemical Society Symposium Series, 715:136-178.

Sullivan, C.; Tyrer, M.; Cheeseman, C. and Graham, N., 2010. Disposal of water treatment wastes containing arsenic-A review. Science of the Total Environment, 408: 1770-1778.

Sun, S. and McDonough, W., 1989. Chemical and isotopic systematics of oceanic basalts: implications for mantle composition and processes. In: Saunders A.D. and Norry M.J. (eds.), Magmatism in ocean basins. Geol. Soc. London. Spec. Pub. 42: 313-345. 
Sun, X. and Doner, H., 1998. Adsorption and oxidation of arsenite on goethite. Soil Science, 163: 278-287.

Tarquini, G., 2010. Tecnologías de membranas aplicadas al tratamiento de aguas con elevado contenido de arsénico. En: Tecnologías económicas para el abatimiento de arsénico en aguas. Ed.: M. Litter, A.M. Sancha y A.M. Ingallinella. Argentina. 59-72.

Tello, E., 1951. Hidroarsenicismo Crónico Regional Endémico (HACRE), sus manifestaciones clínicas. Córdoba: Imprenta de la Universidad Nacional de Córdoba; 1951.

Thibeau, R.; Brown, C. and Heidersbach, W., 1978. Raman spectra of possible corrosión products of iron. Applied Spectroscopy, 32: 532-535.

Thirunavukkarasu, O.; Viraraghavan, T. and Subramanian, K., 2003. Arsenic Removal from Drinking Water using Iron Oxide-Coated Sand. Water Air and Soil Pollution, 142: 95-111.

Thompson, D. and Mitchell C., 1993. The hydrolitic precipitation of iron in aqueous dispersions of mineral particles. Physicochemical and Engineering Aspects, 73: 103-115.

Torra, A.; Valero, F.; Bisbal, J. y Tous, J., 1998. Policloruro de aluminio en el proceso de potabilización de aguas superficiales. Tecnología del Agua, Junio 1998.

Tripathi, J. and Rajamani, V., 2007. Geochemistry and origin of ferruginous nodules in weathered granodioritic gneisses, Mysore Plateau, Southern India. Geochimica et Cosmochimica Acta, 71: 1674-1688.

Van Benschoten, J. and Edzwald, J., 1990. Chemical aspects of coagulation using aluminum salts: Hydrolytic reaction of alum and polyaluminum chloride. Water Research, 24: 15191526.

Van der Sloot, H., 2002. Methodologies for soil and sediment fractionation studies. In: P. Quevauviller (Ed.), Harmonisation of Leaching/Extraction Procedures for Sludge, Compost, Soil and Sediment Analyses, Royal Society of Chemistry: 142-170.

Van der Sloot, H. and Dijkstra, J., 2004. Development of horizontally standardized leaching tests for construction materials: a material based or released based approach? ECN-C-04060 Energy Research Centre of the Netherlands (ECN), Petten, The Netherlands, 43 pp.

Van der Sloot, H.; Heasman, L. and Quevauviller, P., 1997. Harmonisation of leaching/extraction tests. Elsevier Science B. V. Amsterdam. 1 edición.

Wan Ngah, W. and Hanafiah, M., 2008. Removal of heavy metal ions from wastewater by chemically modified plant wastes as adsorbents: A review. Bioresource Technology, 99: 39353948.

Wang, A.; Freeman, J. and Kuebler, K., 2002. Raman Spectroscopic Characterization of Phyllosilicates. Lunar and Planetary Science XXXIII, 1374.pdf.

Wilkie, J. and Hering, J., 1996. Adsorption of arsenic onto hydrous ferric oxide: effects of adsorbate/adsorbent ratios and co-occurring solutes. Colloids and Surfaces A, 107: 97-110. 
Wilson, M., 1994. Clay Mineralogy Spectroscopic and Chemical Determinative Methods. Chapman y Hall London.

Ye, C.; Wang, D.; Shi, B.; Yu, J.; Qu, J.; Edwards, M. and Tang, H., 2007. Alkalinity effect of coagulation with polyaluminum chlorides: Role of electrostatic patch. Colloids and Surfaces A: Physicochemical and Engineering Aspects, 294: 163-173.

Zalba, P., Andreis, R. e Iñiguez, A., 1988. Formación Las Águilas, Barker, Sierras Septentrionales de la provincia de Buenos Aires. Nueva propuesta estratigráfica. Revista Asociación Geológica Argentina, 43: 198-210.

Zhang, H. y Selim, H., 2008. Reaction and transport of arsenic in soils: equilibrium and kinetic modeling. Advances in Agronomy, 98: 45-115.

Zhang, S.; Liu, C.; Luan, Z.; Peng, X.; Ren, H. and Wang, J., 2008. Arsenate removal from aqueous solutions using modified red mud. Journal of Hazardous Materials, 152: 486-492. 


\section{ANEXO 1 \\ CODIGO ALIMENTARIO ARGENTINO \\ CAPÍTULO XII \\ BEBIDAS HÍDRICAS, AGUA Y AGUA GASIFICADA}

\section{AGUA POTABLE}

\section{Artículo 982 - (Resolución Conjunta SPRyRS y SAGPyA N 68/2007 y $\mathrm{N}^{\circ}$ 196/2007)}

"Con las denominaciones de Agua potable de suministro público y Agua potable de uso domiciliario, se entiende la que es apta para la alimentación y uso doméstico: no deberá contener substancias o cuerpos extraños de origen biológico, orgánico, inorgánico o radiactivo en tenores tales que la hagan peligrosa para la salud. Deberá presentar sabor agradable y ser prácticamente incolora, inodora, límpida y transparente. El agua potable de uso domiciliario es el agua proveniente de un suministro público, de un pozo o de otra fuente, ubicada en los reservorios o depósitos domiciliarios. Ambas deberán cumplir con las características físicas, químicas y microbiológicas siguientes:

\section{Características físicas}

Turbiedad: máx. 3 NTU

Color: máx. 5 escala Pt-Co

Olor: sin olores extraños

\section{Características químicas}

$\mathrm{pH}: 6,5-8,5$

pH sat.: $\mathrm{pH} \pm 0,2$

\section{Substancias inorgánicas}

Amoníaco $\left(\mathrm{NH}^{+}\right)$máx.: $0,20 \mathrm{mg} \mathrm{L}^{-1}$

Antimonio máx: : $0,02 \mathrm{mg} \mathrm{L}^{-1}$

Aluminio residual (AI) máx:: $0,20 \mathrm{mg} \mathrm{L}^{-1}$

Arsénico (As) máx.: $0,01 \mathrm{mg} \mathrm{L}^{-1}$

Boro (B) máx.: $0,5 \mathrm{mg} \mathrm{L}^{-1}$

Bromato máx:: $0,01 \mathrm{mg} \mathrm{L}^{-1}$

Cadmio (Cd) máx.: 0,005 mg L-1

Cianuro $\left(\mathrm{CN}^{-}\right)$máx.: $0,10 \mathrm{mg} \mathrm{L}^{-1}$

Cinc (Zn) máx.: $5,0 \mathrm{mg} \mathrm{L}^{-1}$

Cloruro $\left(\mathrm{Cl}^{-}\right)$máx:: $350 \mathrm{mg} \mathrm{L}^{-1}$

Cobre (Cu) máx.: 1,00 $\mathrm{mg} \mathrm{L}^{-1}$

Cromo (Cr) máx.: 0,05 mg L-1

Dureza total $\left(\mathrm{CaCO}_{3}\right)$ máx.: $400 \mathrm{mg} \mathrm{L}^{-1}$

Fluoruro $\left(\mathrm{F}^{-}\right)$: para los fluoruros la cantidad máxima se da en función de la temperatura promedio de la zona, teniendo en cuenta el consumo diario del agua de bebida:

- Temperatura media y máxima del año $\left({ }^{\circ} \mathrm{C}\right) 10,0$ - 12,0, contenido límite recomendado de Flúor $\left(\mathrm{mg} \mathrm{L}^{-1}\right)$, límite inferior: 0,9: límite superior: 1,7

- Temperatura media y máxima del año $\left({ }^{\circ} \mathrm{C}\right) 12,1$ - 14,6 , contenido límite recomendado de Flúor $\left(\mathrm{mg} \mathrm{L}^{-1}\right)$, límite inferior: 0,8: límite superior: 1,5

- Temperatura media y máxima del año $\left({ }^{\circ} \mathrm{C}\right) 14,7-17,6$, contenido límite recomendado de Flúor ( $\left.\mathrm{m} \mathrm{L} \mathrm{L}^{-1}\right)$, límite inferior: 0,8: límite superior: 1,3

- Temperatura media y máxima del año $\left({ }^{\circ} \mathrm{C}\right) 17,7$ - 21,4, contenido límite recomendado de Flúor $\left(\mathrm{mg} \mathrm{L}^{-1}\right)$, Límite inferior: 0,7: límite superior: 1,2 
- Temperatura media y máxima del año $\left({ }^{\circ} \mathrm{C}\right) 21,5$ - 26,2 , contenido límite recomendado de Flúor ( $\left.\mathrm{mg} \mathrm{L}^{-1}\right)$, límite inferior: 0,7: límite superior: 1,0

- Temperatura media y máxima del año $\left({ }^{\circ} \mathrm{C}\right) 26,3$ - 32,6, contenido límite recomendado de Flúor ( $\left.\mathrm{mg} \mathrm{L}^{-1}\right)$, límite inferior: 0,6 ; límite superior: 0,8

Hierro total (Fe) máx:: $0,30 \mathrm{mg} \mathrm{L}^{-1}$

Manganeso (Mn) máx.: 0,10 $\mathrm{mg} \mathrm{L}^{-1}$

Mercurio $(\mathrm{Hg})$ máx:: $0,001 \mathrm{mg} \mathrm{L}^{-1}$

Niquel (Ni) máx.: $0,02 \mathrm{mg} \mathrm{L}^{-1}$

Nitrato (NO3-) máx.: $45 \mathrm{mg} \mathrm{L}^{-1}$

Nitrito (NO2-) máx.: $0,10 \mathrm{mg} \mathrm{L}^{-1}$

Plata (Ag) máx.: 0,05 $\mathrm{mg} \mathrm{L}^{-1}$

Plomo $(\mathrm{Pb})$ máx.: $0,05 \mathrm{mg} \mathrm{L}^{-1}$

Selenio (Se) máx.: $0,01 \mathrm{mg} \mathrm{L}^{-1}$

Sólidos disueltos totales, máx.: $1500 \mathrm{mg} \mathrm{L}^{-1}$

Sulfatos (SO4 ${ }^{=}$) máx.: $400 \mathrm{mg} \mathrm{L}^{-1}$

Cloro activo residual $(\mathrm{Cl})$ mín.: $0,2 \mathrm{mg} \mathrm{L}^{-1}$

La autoridad sanitaria competente podrá admitir valores distintos si la composición normal del agua de la zona y la imposibilidad de aplicar tecnologías de corrección lo hicieran necesario. Para aquellas regiones del país con suelos de alto contenido de arsénico, se establece un plazo de hasta 5 años para adecuarse al valor de $0,01 \mathrm{mg} \mathrm{L}^{-}$ 1.

(Modificado por Resolución Conjunta SPRel № 34/2012 y SAGyP N ${ }^{\circ}$ 50/2012): Prorrógase el plazo de cinco (5) años previsto para alcanzar el valor de $0,01 \mathrm{mg} \mathrm{L}^{-1} \mathrm{de}$ arsénico hasta contar con los resultados del estudio "Hidroarsenicismo y Saneamiento Básico en la República Argentina - Estudios básicos para el establecimiento de criterios y prioridades sanitarias en cobertura y calidad de aguas" cuyos términos fueron elaborados por la Subsecretaría de Recursos Hídricos del Ministerio de Planificación Federal.

Los tratamientos de potabilización que sea necesario realizar deberán ser puestos en conocimiento de la autoridad sanitaria competente. 


\section{ANEXO 2}

Resultados obtenidos para turbidez y As en los diferentes ciclos realizados para determinar la efectividad del adsorbente (ítem 6.2.5) empleando 6 concentraciones iniciales de As.

\begin{tabular}{|c|c|c|c|c|c|c|c|c|c|c|c|c|}
\hline & \multicolumn{2}{|c|}{$200 \mu \mathrm{g} \mathrm{L}^{-1}$} & \multicolumn{2}{|c|}{$400 \mu \mathrm{g} \mathrm{L}^{-1}$} & \multicolumn{2}{|c|}{$600 \mu \mathrm{g} \mathrm{L}^{-1}$} & \multicolumn{2}{|c|}{$800 \mu \mathrm{g} \mathrm{L}^{-1}$} & \multicolumn{2}{|c|}{$1000 \mu \mathrm{g} \mathrm{L}^{-1}$} & \multicolumn{2}{|c|}{$2000 \mu \mathrm{g} \mathrm{L}^{-1}$} \\
\hline Ciclo & NTU & As & NTU & As & NTU & As & NTU & As & NTU & As & NTU & As \\
\hline 1 & 1,58 & $<5$ & 1,24 & $<5$ & 2,21 & $<5$ & 1,42 & $<5$ & 1,73 & 5 & 1,94 & $<5$ \\
\hline 2 & 0,70 & $<5$ & 0,92 & $<5$ & 1,49 & $<5$ & 0,99 & $<5$ & 1,11 & 5 & 1,03 & $<5$ \\
\hline 3 & 1,09 & $<5$ & 0,73 & $<5$ & 0,74 & $<5$ & 1,13 & 5 & 0,84 & 5 & 0,78 & $<5$ \\
\hline 4 & 0,89 & $<5$ & 1,62 & $<5$ & 0,88 & $<5$ & 0,83 & 5 & 1,28 & $<5$ & 1,34 & 5 \\
\hline 5 & 1,65 & $<5$ & 1,13 & $<5$ & 1,22 & 5 & 1,10 & 5 & 1,69 & 5 & 2,12 & 10 \\
\hline 6 & 1,70 & $<5$ & 1,28 & 5 & 1,03 & 5 & 1,46 & 5 & 0,84 & $<5$ & 1,67 & 10 \\
\hline 7 & 1,94 & $<5$ & 2,72 & $<5$ & 1,95 & $<5$ & 1,98 & $<5$ & 1,24 & 5 & 2,34 & 10 \\
\hline 8 & 1,43 & 5 & 2,98 & 5 & 1,31 & $<5$ & 1,37 & $<5$ & 1,16 & 5 & 2,14 & 10 \\
\hline 9 & 1,72 & 5 & 1,78 & 5 & 1,91 & $<5$ & 1,40 & 5 & 0,98 & 5 & 2,43 & 10 \\
\hline 10 & 1,49 & $<5$ & 1,81 & $<5$ & 1,71 & $<5$ & 1,24 & 5 & 1,34 & 5 & 2,76 & 10 \\
\hline 11 & 2,13 & $<5$ & 2,35 & $<5$ & 2,63 & 5 & 2,53 & 5 & 1,36 & $<5$ & 1,98 & 10 \\
\hline 12 & 2,44 & $<5$ & 1,98 & $<5$ & 2,14 & 5 & 1,96 & $<5$ & 2,09 & 5 & 1,77 & 10 \\
\hline 13 & 2,28 & $<5$ & 2,52 & 5 & 2,62 & $<5$ & 2,97 & 5 & 2,56 & $<5$ & 1,34 & 10 \\
\hline 14 & 1,32 & $<5$ & 1,52 & $<5$ & 1,67 & $<5$ & 2,79 & $<5$ & 1,42 & 5 & 2,45 & 10 \\
\hline 15 & 2,46 & $<5$ & 2,79 & 5 & 3,01 & 5 & 3 & 5 & 1,98 & 5 & 2,69 & 10 \\
\hline 16 & 2,30 & $<5$ & 2,39 & 5 & 2,38 & 5 & 3,65 & 5 & 1,23 & 5 & 2,54 & 10 \\
\hline 17 & 2,63 & $<5$ & 2,83 & $<5$ & 2,60 & $<5$ & 2,84 & 5 & 1,55 & 5 & 1,26 & 10 \\
\hline 18 & 2,13 & 5 & 1,75 & 5 & 2,13 & 5 & 2,36 & 5 & 2,09 & 5 & 1,87 & 10 \\
\hline 19 & 1,13 & $<5$ & 0,87 & 5 & 1,10 & 5 & 3,62 & $<5$ & 2,78 & 5 & 2,98 & 10 \\
\hline 20 & 1,89 & $<5$ & 2,08 & 5 & 2,37 & 5 & 5,06 & 5 & 2,94 & 5 & 1,23 & 10 \\
\hline 21 & 2,01 & $<5$ & 1,71 & 5 & 1,82 & 5 & 1,36 & $<5$ & 1,26 & 5 & 0,85 & 50 \\
\hline 22 & 2,14 & $<5$ & 2,86 & $<5$ & 2,92 & 5 & 1,64 & 5 & 1,98 & 5 & \multicolumn{2}{|c|}{ Agotada } \\
\hline 23 & 1,52 & $<5$ & 2,22 & $<5$ & 3,03 & 5 & 1,66 & 5 & 2,34 & 5 & & \\
\hline 24 & 2,62 & $<5$ & 2,56 & $<5$ & 2,98 & 5 & 1,75 & 5 & 2,65 & 5 & & \\
\hline 25 & 2,96 & $<5$ & 2,83 & $<5$ & 3,31 & 5 & 1,51 & 5 & 1,27 & 5 & & \\
\hline 26 & 1,24 & $<5$ & 1,44 & $<5$ & 1,27 & 5 & 1,60 & 5 & 1,48 & 5 & & \\
\hline 27 & 2,98 & $<5$ & 2,80 & $<5$ & 3 & 5 & 0,98 & 5 & 2,34 & 5 & & \\
\hline 28 & 2,49 & $<5$ & 2,54 & $<5$ & 3,35 & 5 & 2,97 & 5 & 2,63 & 5 & & \\
\hline 29 & 2,77 & $<5$ & 2,53 & $<5$ & 3,16 & 5 & 2,28 & $<5$ & 2,89 & 5 & & \\
\hline 30 & 2,88 & $<5$ & 3,40 & $<5$ & 3,25 & 10 & 3,38 & 5 & 2,78 & 5 & & \\
\hline 31 & 1,95 & 5 & 1,30 & 5 & 1,25 & 10 & 1,98 & 5 & 2,31 & 5 & & \\
\hline 32 & 2,71 & $<5$ & 2,81 & 5 & 3,68 & 10 & 2,56 & 5 & 1,75 & 5 & & \\
\hline 33 & 2,71 & $<5$ & 2,70 & $<5$ & 2,64 & 10 & 2,23 & 5 & 1,98 & 5 & & \\
\hline 34 & 2,73 & $<5$ & 2,82 & $<5$ & 3,04 & 10 & 1,07 & 5 & 2,76 & 5 & & \\
\hline 35 & 2,52 & $<5$ & 3,17 & $<5$ & 3,22 & 10 & 1,27 & 5 & 2,37 & 5 & & \\
\hline 36 & 2,61 & $<5$ & 3,16 & $<5$ & 2,49 & 10 & 1,24 & 5 & 1,26 & 5 & & \\
\hline 37 & 1,26 & $<5$ & 1,65 & $<5$ & 1,39 & 10 & 1,95 & 5 & 2,66 & 5 & & \\
\hline 38 & 3,77 & $<5$ & 3,97 & $<5$ & 3,58 & 10 & 2,67 & 10 & 2,07 & 5 & & \\
\hline 39 & 3,95 & $<5$ & 3,74 & $<5$ & 3,78 & 10 & 3,04 & 10 & 1,04 & 5 & & \\
\hline 40 & 3,43 & $<5$ & 4,24 & $<5$ & 5,08 & 10 & 3,08 & 10 & 1,27 & 10 & & \\
\hline 41 & 4,13 & $<5$ & 4,23 & $<5$ & 4,18 & 10 & 2,83 & 10 & 1,34 & 10 & & \\
\hline 42 & 1,32 & $<5$ & 1,49 & $<5$ & 2 & 10 & 2,53 & 10 & 2,93 & 10 & & \\
\hline 43 & 4,10 & $<5$ & 3,72 & 5 & 3,56 & 10 & 1,43 & 10 & 2,67 & 10 & & \\
\hline 44 & 3,77 & $<5$ & 5,11 & $<5$ & 3,96 & 10 & 3,06 & 10 & 2,55 & 10 & & \\
\hline 45 & 3,16 & $<5$ & 4,39 & 5 & 3,73 & 10 & 0,96 & 10 & 2,84 & 10 & & \\
\hline 46 & 3,72 & $<5$ & 4,21 & $<5$ & 3,37 & 10 & 2,53 & 10 & 1,26 & 25 & & \\
\hline 47 & 1,33 & $<5$ & 1,56 & $<5$ & 2,33 & 10 & 1,54 & 10 & \multicolumn{2}{|c|}{ Agotada } & & \\
\hline 48 & 3,77 & $<5$ & 5,85 & $<5$ & 4,04 & 10 & 1,58 & 10 & & & & \\
\hline 49 & 2,58 & $<5$ & 2,54 & $<5$ & 3,33 & 10 & 2,87 & 10 & & & & \\
\hline 50 & 4,18 & $<5$ & 4,90 & $<5$ & 3,99 & 10 & 2,82 & 10 & & & & \\
\hline 51 & 1,85 & $<5$ & 1,61 & $<5$ & 1,89 & 10 & 2,23 & 10 & & & & \\
\hline 52 & 4,71 & $<5$ & 5,37 & $<5$ & 4,61 & 10 & 0,90 & 10 & & & & \\
\hline 53 & 4,61 & $<5$ & 4,91 & $<5$ & 4,02 & 10 & 3,16 & 10 & & & & \\
\hline 54 & 4,92 & $<5$ & 4,22 & $<5$ & 4,78 & 10 & 2,97 & 10 & & & & \\
\hline 55 & 3,42 & $<5$ & 4 & $<5$ & 3,68 & 10 & 2,79 & 10 & & & & \\
\hline 56 & 1,86 & $<5$ & 2,38 & $<5$ & 2,43 & 10 & 3 & 10 & & & & \\
\hline 57 & 2,41 & $<5$ & 2,86 & $<5$ & 2,80 & 10 & 2,65 & 10 & & & & \\
\hline 58 & 1,68 & $<5$ & 2,38 & $<5$ & 2,97 & 10 & 2,84 & 10 & & & & \\
\hline 59 & 2,73 & $<5$ & 2,89 & 5 & 2,68 & 10 & 2,54 & 25 & & & & \\
\hline 60 & 2,53 & $<5$ & 4,99 & $<5$ & 2,92 & 10 & \multicolumn{2}{|c|}{ Agotada } & & & & \\
\hline 61 & 2,38 & $<5$ & 1,79 & $<5$ & 1,69 & 10 & & & & & & \\
\hline 62 & 4,27 & $<5$ & 2,85 & $<5$ & 3,10 & 10 & & & & & & \\
\hline
\end{tabular}




\begin{tabular}{|c|c|c|c|c|c|c|}
\hline 63 & 2,42 & $<5$ & 2,70 & $<5$ & 2,71 & 10 \\
\hline 64 & 2,05 & $<5$ & 1,93 & $<5$ & 1,79 & 10 \\
\hline 65 & 3,27 & $<5$ & 3,67 & $<5$ & 3,95 & 10 \\
\hline 66 & 3,70 & $<5$ & 3,84 & $<5$ & 3,62 & 10 \\
\hline 67 & 1,88 & $<5$ & 2,05 & $<5$ & 2,33 & 10 \\
\hline 68 & 2,30 & $<5$ & 1,42 & $<5$ & 1,76 & 10 \\
\hline 69 & 4,78 & $<5$ & 5,61 & $<5$ & 5,40 & 10 \\
\hline 70 & 3,16 & $<5$ & 3,52 & $<5$ & 5,48 & 10 \\
\hline 71 & 3,93 & $<5$ & 4,17 & $<5$ & 4,76 & 10 \\
\hline 72 & 3,97 & $<5$ & 4,78 & 5 & 5,14 & 10 \\
\hline 73 & 2,58 & $<5$ & 1,71 & $<5$ & 1,77 & 10 \\
\hline 74 & 6,83 & $<5$ & 6,61 & $<5$ & 5,75 & 10 \\
\hline 75 & 4,32 & $<5$ & 4,54 & $<5$ & 4,53 & 10 \\
\hline 76 & 2,36 & $<5$ & 2,51 & $<5$ & 2,83 & 10 \\
\hline 77 & 2,07 & $<5$ & 2 & $<5$ & 2,08 & 10 \\
\hline 78 & 4,99 & $<5$ & 2,19 & $<5$ & 5,07 & 10 \\
\hline 79 & 3,76 & $<5$ & 3,81 & $<5$ & 3,68 & 10 \\
\hline 80 & 1,96 & $<5$ & 3,01 & 5 & 2,25 & 10 \\
\hline 81 & 2,51 & $<5$ & 1,98 & 5 & 1,61 & 10 \\
\hline 82 & 5,39 & $<5$ & 4,78 & 10 & 4,15 & 10 \\
\hline 83 & 6,08 & $<5$ & 5,03 & 10 & 4,57 & 10 \\
\hline 84 & 2,18 & $<5$ & 2,98 & 10 & 2,78 & 10 \\
\hline 85 & 4,30 & $<5$ & 2,97 & 10 & 1,41 & 10 \\
\hline 86 & 6,96 & 5 & 4,69 & 10 & 5,13 & 10 \\
\hline 87 & 3,70 & 5 & 3,57 & 10 & 2,80 & 10 \\
\hline 88 & 6,85 & 5 & 11,3 & 10 & 8,42 & 25 \\
\hline 89 & 8,28 & $<5$ & 7,87 & 10 & \multicolumn{2}{|c|}{ Agotada } \\
\hline 90 & 6,96 & $<5$ & 5,68 & 10 & & \\
\hline 91 & 5,03 & $<5$ & 7,00 & 10 & & \\
\hline 92 & 3,68 & $<5$ & 4,30 & 10 & & \\
\hline 93 & 1,61 & $<5$ & 2,40 & 10 & & \\
\hline 94 & 1,37 & $<5$ & 2,23 & 10 & & \\
\hline 95 & 1,49 & $<5$ & 2,17 & 10 & & \\
\hline 96 & 2,52 & $<5$ & 1,98 & 10 & & \\
\hline 97 & 3,91 & $<5$ & 7,47 & 10 & & \\
\hline 98 & 8,77 & $<5$ & 11,60 & 10 & & \\
\hline 99 & 3,50 & $<5$ & 4,31 & 10 & & \\
\hline 100 & 2,36 & $<5$ & 3,54 & 10 & & \\
\hline 101 & 6,13 & $<5$ & 7,96 & 10 & & \\
\hline 102 & 3,22 & $<5$ & 4,34 & 10 & & \\
\hline 103 & 1,84 & $<5$ & 2,04 & 10 & & \\
\hline 104 & 3,39 & $<5$ & 3,32 & 10 & & \\
\hline 105 & 1,86 & $<5$ & 2,74 & 10 & & \\
\hline 106 & 5,17 & $<5$ & 3,84 & 10 & & \\
\hline 107 & 5,69 & 5 & 4,63 & 10 & & \\
\hline 108 & 4,61 & $<5$ & 4,29 & 10 & & \\
\hline 109 & 4,38 & $<5$ & 2,79 & 10 & & \\
\hline 110 & 7,62 & $<5$ & 7,34 & 10 & & \\
\hline 111 & 3,15 & $<5$ & 2,69 & 10 & & \\
\hline 112 & 1,37 & $<5$ & 1,17 & 10 & & \\
\hline 113 & 5,14 & $<5$ & 4,46 & 10 & & \\
\hline 114 & 3,20 & $<5$ & 3,32 & 10 & & \\
\hline 115 & 4,26 & $<5$ & 4 & 10 & & \\
\hline 116 & 5,43 & $<5$ & 4,78 & 10 & & \\
\hline 117 & 3,99 & $<5$ & 7,42 & 10 & & \\
\hline 118 & 2,04 & $<5$ & 1,82 & 10 & & \\
\hline 119 & 1,36 & $<5$ & 1,20 & 10 & & \\
\hline 120 & 2,36 & $<5$ & 3,38 & 10 & & \\
\hline 121 & 4,71 & $<5$ & 4,87 & 10 & & \\
\hline 122 & 4,54 & $<5$ & 3,02 & 10 & & \\
\hline 123 & 2,04 & $<5$ & 2 & 10 & & \\
\hline 124 & 2,84 & $<5$ & 3,41 & 10 & & \\
\hline 125 & 2,63 & $<5$ & 2,34 & 10 & & \\
\hline 126 & 2,86 & $<5$ & 2,47 & 10 & & \\
\hline 127 & 1,82 & $<5$ & 1,72 & 10 & & \\
\hline 128 & 3,07 & $<5$ & 4 & 10 & & \\
\hline 129 & 1,86 & $<5$ & 2,52 & 10 & & \\
\hline 130 & 1,53 & $<5$ & 3,17 & 10 & & \\
\hline 131 & 2,17 & $<5$ & 2,73 & 10 & & \\
\hline 132 & 1,63 & $<5$ & 3 & 10 & & \\
\hline 133 & 1,41 & $<5$ & 3,31 & 10 & & \\
\hline 134 & 0,93 & $<5$ & 2,52 & 10 & & \\
\hline
\end{tabular}




\begin{tabular}{|c|c|c|c|c|}
\hline 135 & 0,96 & $<5$ & 1,32 & 10 \\
\hline 136 & 2,27 & $<5$ & 4,14 & 10 \\
\hline 137 & 2,62 & $<5$ & 4,47 & 10 \\
\hline 138 & 1,99 & $<5$ & 3,91 & 10 \\
\hline 139 & 1,15 & $<5$ & 2,13 & 10 \\
\hline 140 & 0,84 & $<5$ & 1,49 & 10 \\
\hline 141 & 2,50 & 5 & 4,20 & 10 \\
\hline 142 & 2,93 & 5 & 3,09 & 10 \\
\hline 143 & 1,72 & 5 & 4,06 & 10 \\
\hline 144 & 1,22 & 5 & 3,54 & 10 \\
\hline 145 & 3,52 & 5 & 3,43 & 10 \\
\hline 146 & 2,54 & 5 & 2,12 & 10 \\
\hline 147 & 4 & 5 & 3,48 & 10 \\
\hline 148 & 2,27 & 5 & 1,92 & 10 \\
\hline 149 & 2,54 & 5 & 3,91 & 25 \\
\hline 150 & 0,63 & 5 & Agotada \\
\hline
\end{tabular}

Continuación de los resultados de los ciclos de la muestra de concentración inicial de As de $200 \mu \mathrm{g} \mathrm{L}^{-1}$

\begin{tabular}{|c|c|c|c|c|c|c|c|c|c|c|c|}
\hline Ciclo & NTU & As & Ciclo & NTU & $\mathrm{As}$ & Ciclo & NTU & As & Ciclo & NTU & As \\
\hline 151 & 1,78 & 5 & 201 & 1,04 & 5 & 251 & 2,92 & 5 & 301 & 2,74 & 10 \\
\hline 152 & 2,02 & 5 & 202 & 2,93 & 5 & 252 & 3,17 & 5 & 302 & 1,65 & 10 \\
\hline 153 & 4,87 & 5 & 203 & 2,75 & 5 & 253 & 3,26 & 5 & 303 & 1,53 & 10 \\
\hline 154 & 3,56 & 5 & 204 & 1,38 & 5 & 254 & 2,44 & 5 & 304 & 2,37 & 10 \\
\hline 155 & 2,68 & 5 & 205 & 0,68 & 5 & 255 & 5,38 & 5 & 305 & 2,92 & 10 \\
\hline 156 & 2,55 & 5 & 206 & 2,85 & 5 & 256 & 11,47 & 5 & 306 & 2,24 & 10 \\
\hline 157 & 3,12 & 5 & 207 & 1,36 & 5 & 257 & 2,96 & 10 & 307 & 2,17 & 10 \\
\hline 158 & 3,34 & 5 & 208 & 3,86 & 5 & 258 & 4,17 & 10 & 308 & 1,26 & 10 \\
\hline 159 & 2,86 & 5 & 209 & 1,50 & 5 & 259 & 1,17 & 10 & 309 & 2,38 & 10 \\
\hline 160 & 3,06 & 5 & 210 & 3,88 & 5 & 260 & 3,75 & 10 & 310 & 2,49 & 10 \\
\hline 161 & 2,65 & 5 & 211 & 6,08 & 5 & 261 & 2,38 & 10 & 311 & 2,52 & 10 \\
\hline 162 & 2,31 & 5 & 212 & 2,78 & 5 & 262 & 3,28 & 10 & 312 & 1,63 & 10 \\
\hline 163 & 3,63 & 5 & 213 & 0,76 & 5 & 263 & 1,93 & 10 & 313 & 2,56 & 10 \\
\hline 164 & 2,79 & 5 & 214 & 0,99 & 5 & 264 & 4,51 & 10 & 314 & 2,67 & 10 \\
\hline 165 & 1,60 & 5 & 215 & 3,34 & 5 & 265 & 1,96 & 10 & 315 & 2,59 & 10 \\
\hline 166 & 2,94 & 5 & 216 & 3,19 & 5 & 266 & 3,86 & 10 & 316 & 3,03 & 10 \\
\hline 167 & 1,48 & 5 & 217 & 1,41 & 5 & 267 & 2,26 & 10 & 317 & 1,90 & 10 \\
\hline 168 & 1,54 & 5 & 218 & 3,92 & 5 & 268 & 2,72 & 10 & 318 & 1,67 & 10 \\
\hline 169 & 1,80 & 5 & 219 & 2,50 & 5 & 269 & 2,02 & 10 & 319 & 2,14 & 10 \\
\hline 170 & 1,75 & 5 & 220 & 3,13 & 5 & 270 & 2,52 & 10 & 320 & 1,16 & 10 \\
\hline 171 & 1,61 & 5 & 221 & 2,88 & 5 & 271 & 3,37 & 10 & 321 & 1,89 & 10 \\
\hline 172 & 0,67 & 5 & 222 & 1,53 & 5 & 272 & 2,76 & 10 & 322 & 1,77 & 10 \\
\hline 173 & 2,17 & 5 & 223 & 4,59 & 5 & 273 & 2,21 & 10 & 323 & 2,39 & 10 \\
\hline 174 & 2,36 & 5 & 224 & 2,85 & 5 & 274 & 2,05 & 10 & 324 & 2,48 & 10 \\
\hline 175 & 2,33 & 5 & 225 & 9,27 & 5 & 275 & 2,90 & 10 & 325 & 2,67 & 10 \\
\hline 176 & 2,03 & 5 & 226 & 2,36 & 5 & 276 & 1,54 & 10 & 326 & 2,35 & 10 \\
\hline 177 & 2,16 & 5 & 227 & 4,37 & 5 & 277 & 3,01 & 10 & 327 & 1,47 & 10 \\
\hline 178 & 2,73 & 5 & 228 & 3,54 & 5 & 278 & 2,56 & 10 & 328 & 1,97 & 10 \\
\hline 179 & 0,89 & 5 & 229 & 3,42 & 5 & 279 & 1,63 & 10 & 329 & 2,70 & 10 \\
\hline 180 & 2,45 & 5 & 230 & 1,46 & 5 & 280 & 1,89 & 10 & 330 & 1,71 & 10 \\
\hline 181 & 0,81 & 5 & 231 & 4,57 & 5 & 281 & 2,95 & 10 & 331 & 1,57 & 10 \\
\hline 182 & 1,41 & 5 & 232 & 4,47 & 5 & 282 & 2,87 & 10 & 332 & 2,29 & 10 \\
\hline 183 & 2,10 & 5 & 233 & 3,01 & 5 & 283 & 1,94 & 10 & 333 & 1,39 & 10 \\
\hline 184 & 3,50 & 5 & 234 & 2,80 & 5 & 284 & 2,46 & 10 & 334 & 2,86 & 10 \\
\hline 185 & 2,95 & 5 & 235 & 5,42 & 5 & 285 & 0,96 & 10 & 335 & 2,99 & 10 \\
\hline 186 & 2,73 & 5 & 236 & 4,45 & 5 & 286 & 3,01 & 10 & 336 & 2,74 & 10 \\
\hline 187 & 3,01 & 5 & 237 & 8,59 & 5 & 287 & 2,92 & 10 & 337 & 2,77 & 25 \\
\hline 188 & 1,38 & 5 & 238 & 3,16 & 5 & 288 & 2,47 & 10 & & \multicolumn{2}{|c|}{ Agotada } \\
\hline 189 & 2,22 & 5 & 239 & 1,59 & 5 & 289 & 2,33 & 10 & & & \\
\hline 190 & 0,95 & 5 & 240 & 2,35 & 5 & 290 & 1,65 & 10 & & & \\
\hline 191 & 3,72 & 5 & 241 & 1,86 & 5 & 291 & 2,38 & 10 & & & \\
\hline 192 & 1,81 & 5 & 242 & 5,71 & 5 & 292 & 2,84 & 10 & & & \\
\hline 193 & 0,55 & 5 & 243 & 4,78 & 5 & 293 & 2,44 & 10 & & & \\
\hline 194 & 3,14 & 5 & 244 & 5,24 & 5 & 294 & 2,57 & 10 & & & \\
\hline 195 & 2,32 & 5 & 245 & 3,43 & 5 & 295 & 1,86 & 10 & & & \\
\hline 196 & 1,14 & 5 & 246 & 4,27 & 5 & 296 & 0,94 & 10 & & & \\
\hline 197 & 0,45 & 5 & 247 & 4,59 & 5 & 297 & 1,37 & 10 & & & \\
\hline 198 & 2,33 & 5 & 248 & 2,39 & 5 & 298 & 2,92 & 10 & & & \\
\hline 199 & 1,89 & 5 & 249 & 2,44 & 5 & 299 & 2,87 & 10 & & & \\
\hline 200 & 1,36 & 5 & 250 & 3,64 & 5 & 300 & 2,68 & 10 & & & \\
\hline
\end{tabular}




\section{Cálculos}

Concentración inicial de As $200 \mu \mathrm{g} \mathrm{L}^{-1}$ : en cada ciclo hay $150 \mu \mathrm{g}$ de As $(750 \mathrm{ml}$ por vaso reactor)

336 ciclos efectivos: 256 ciclos de $5 \mu \mathrm{g} \mathrm{L}^{-1}$ y 80 de $10 \mu \mathrm{g} \mathrm{L}^{-1}$.

As retenido en los 256 ciclos: $256 \times 146,25 \mu \mathrm{g}=37.440 \mu \mathrm{g}$

As retenido en los 80 ciclos: $80 \times 142,50 \mu \mathrm{g}=11.400 \mu \mathrm{g}$

As total retenido en los 336 ciclos: $48.840 \mu \mathrm{g}$

As retenido por gramo de mineral: $48.840 \mu \mathrm{g} / 75 \mathrm{~g}$ de 5 AFO: $651,20 \mu \mathrm{g} / \mathrm{g}$ de 5 AFO

_ Concentración inicial de As $400 \mu \mathrm{g} \mathrm{L}^{-1}$ : en cada ciclo hay $300 \mu \mathrm{g}$ de As $(750 \mathrm{ml}$ por vaso reactor)

148 ciclos efectivos: 81 ciclos de $5 \mu \mathrm{g} \mathrm{L}^{-1}$ y 67 de $10 \mu \mathrm{g} \mathrm{L}^{-1}$.

As retenido en los 81 ciclos: $81 \times 296,25 \mu \mathrm{g}=23.996,25 \mu \mathrm{g}$

As retenido en los 67 ciclos: $67 \times 292,50 \mu \mathrm{g}=19.597,50 \mu \mathrm{g}$

As total retenido en los 148 ciclos: $43.593,75 \mu \mathrm{g}$

As retenido por gramo de mineral: $43.593,75 \mu \mathrm{g} / 75 \mathrm{~g}$ de 5 AFO: $581,25 \mu \mathrm{g} / \mathrm{g}$ de 5 AFO

_ Concentración inicial de As $600 \mu \mathrm{g} \mathrm{L}^{-1}$ : en cada ciclo hay $450 \mu \mathrm{g}$ de As (750 ml por vaso reactor)

87 ciclos efectivos: 29 ciclos de $5 \mu \mathrm{g} \mathrm{L}^{-1}$ y 58 de $10 \mu \mathrm{g} \mathrm{L}^{-1}$.

As retenido en los 29 ciclos: 29 x 446,25 $\mu \mathrm{g}=12.941,25 \mu \mathrm{g}$

As retenido en los 58 ciclos: $58 \times 442,50 \mu \mathrm{g}=25.665,50 \mu \mathrm{g}$

As total retenido en los 87 ciclos: $38.606,25 \mu \mathrm{g}$

As retenido por gramo de mineral: $38.606,25 \mu \mathrm{g} / 75 \mathrm{~g}$ de 5 AFO: $514,75 \mu \mathrm{g} / \mathrm{g}$ de 5 AFO

Concentración inicial de As $800 \mu \mathrm{g} \mathrm{L}^{-1}$ : en cada ciclo hay $600 \mu \mathrm{g}$ de As $(750 \mathrm{ml}$ por vaso reactor)

58 ciclos efectivos: 37 ciclos de $5 \mu \mathrm{g} \mathrm{L}^{-1}$ y 21 de $10 \mu \mathrm{g} \mathrm{L}^{-1}$.

As retenido en los 37 ciclos: $37 \times 596,25 \mu \mathrm{g}=22.061,25 \mu \mathrm{g}$

As retenido en los 21 ciclos: $21 \times 592,50 \mu \mathrm{g}=12.442,50 \mu \mathrm{g}$

As total retenido en los 58 ciclos: $34.503,75 \mu \mathrm{g}$

As retenido por gramo de mineral: $34.503,75 \mu \mathrm{g} / 75 \mathrm{~g}$ de $5 \mathrm{AFO}: 460,05 \mu \mathrm{g} / \mathrm{g}$ de $5 \mathrm{AFO}$

_ Concentración inicial de As $1000 \mu \mathrm{g} \mathrm{L}^{-1}$ : en cada ciclo hay $750 \mu \mathrm{g}$ de As $(750 \mathrm{ml}$ por vaso reactor)

45 ciclos efectivos: 39 ciclos de $5 \mu \mathrm{g} \mathrm{L}^{-1}$ y 6 de $10 \mu \mathrm{g} \mathrm{L}^{-1}$.

As retenido en los 39 ciclos: $39 \times 746,25 \mu \mathrm{g}=29.103,75 \mu \mathrm{g}$

As retenido en los 6 ciclos: 6 x 742,50 $\mu \mathrm{g}=4.455,00 \mu \mathrm{g}$

As total retenido en los 45 ciclos: $33.558,75 \mu \mathrm{g}$

As retenido por gramo de mineral: $33.558,75 \mu \mathrm{g} / 75 \mathrm{~g}$ de $5 \mathrm{AFO}: 447,45 \mu \mathrm{g} / \mathrm{g}$ de $5 \mathrm{AFO}$

Concentración inicial de As $2000 \mu \mathrm{g} \mathrm{L}^{-1}$ : en cada ciclo hay $1500 \mu \mathrm{g}$ de As $(750 \mathrm{ml}$ por vaso reactor)

20 ciclos efectivos: 4 ciclos de $5 \mu \mathrm{g} \mathrm{L}^{-1}$ y 16 de $10 \mu \mathrm{g} \mathrm{L}^{-1}$.

As retenido en los 4 ciclos: $4 \times 1.496,25 \mu \mathrm{g}=5.985,00 \mu \mathrm{g}$

As retenido en los 16 ciclos: $16 \times 1.492,50 \mu \mathrm{g}=23.880,00 \mu \mathrm{g}$

As total retenido en los 20 ciclos: $29.865,00 \mu \mathrm{g}$

As retenido por gramo de mineral: $29.865,00 \mu \mathrm{g} / 75 \mathrm{~g}$ de $5 \mathrm{AFO}: 398,00 \mu \mathrm{g} / \mathrm{g}$ de $5 \mathrm{AFO}$ 